\title{
PANDAEMONIUM : Ken Russell's artist biographies as baroque performance
}

Citation for published version (APA):

van Eecke, C. C. J. (2015). PANDAEMONIUM : Ken Russell's artist biographies as baroque performance. [Doctoral Thesis, Maastricht University]. Datawyse / Universitaire Pers Maastricht. https://doi.org/10.26481/dis.20151105ce

Document status and date:

Published: 01/01/2015

DOI:

10.26481/dis.20151105ce

Document Version:

Publisher's PDF, also known as Version of record

\section{Please check the document version of this publication:}

- A submitted manuscript is the version of the article upon submission and before peer-review. There can be important differences between the submitted version and the official published version of record.

People interested in the research are advised to contact the author for the final version of the publication, or visit the DOI to the publisher's website.

- The final author version and the galley proof are versions of the publication after peer review.

- The final published version features the final layout of the paper including the volume, issue and page numbers.

Link to publication

\footnotetext{
General rights rights.

- You may freely distribute the URL identifying the publication in the public portal. please follow below link for the End User Agreement:

www.umlib.nl/taverne-license

Take down policy

If you believe that this document breaches copyright please contact us at:

repository@maastrichtuniversity.nl

providing details and we will investigate your claim.
}

Copyright and moral rights for the publications made accessible in the public portal are retained by the authors and/or other copyright owners and it is a condition of accessing publications that users recognise and abide by the legal requirements associated with these

- Users may download and print one copy of any publication from the public portal for the purpose of private study or research.

- You may not further distribute the material or use it for any profit-making activity or commercial gain

If the publication is distributed under the terms of Article $25 \mathrm{fa}$ of the Dutch Copyright Act, indicated by the "Taverne" license above, 


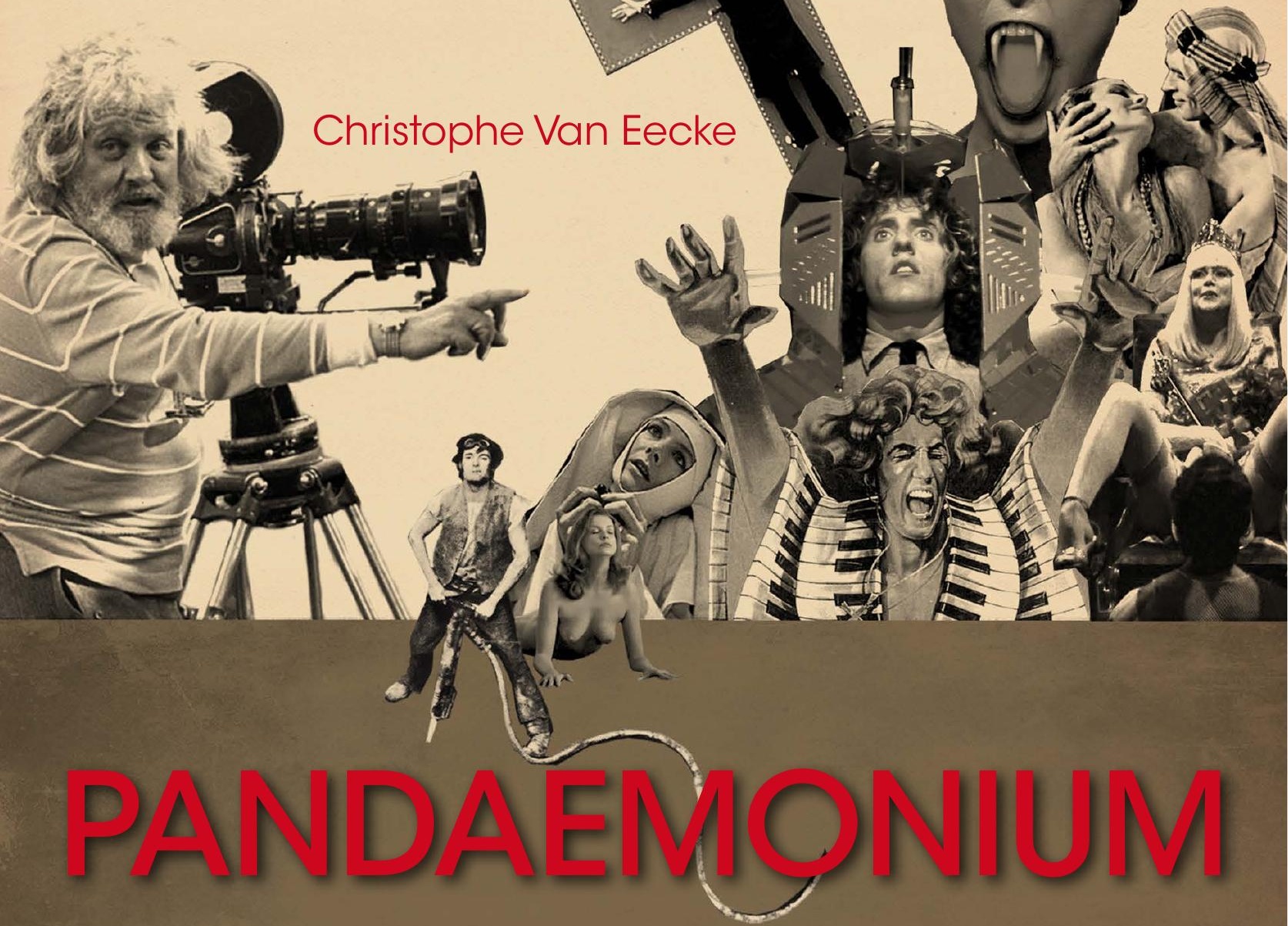

Ken Russell's Artist Biographies as Baroque Performance 
Copyright $\odot$ 2015, Christophe Van Eecke

Cover illustration designed by Gilles Vranckx and used with permission.

Lay-out and printing by DataWyse, Maastricht.

ISBN 9789461594884 


\section{Maastricht University}

\section{PANDAEMONIUM}

Ken Russell's Artist Biographies as Baroque Performance

\section{DISSERTATION}

to obtain the degree of Doctor at Maastricht University and the degree of Docteur en Histoire, Art et Archéologie at the Université Libre de Bruxelles,

on the authority of the Rector Magnificus of Maastricht University and the Rector of the Université Libre de Bruxelles, prof. dr. L.L.G. Soete and prof. dr. Didier Viviers in accordance with the decision of the Board of Deans, to be defended in public on Thursday, 5 November 2015 at 10:00 hours

Christophe Camiel Josephine Van Eecke

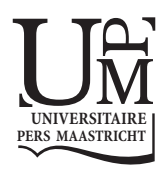




\section{Supervisors:}

Prof. dr. Maaike Meijer (UM)

Prof. dr. Karel Vanhaesebrouck (ULB)

\section{Co-supervisor:}

Dr. Jack Post (UM)

\section{Assessment committee:}

Prof. dr. Lies Wesseling (UM) (Chair)

Prof. dr. John Hill (Royal Holloway, University of London)

Prof. dr. Muriel Andrin (ULB)

Prof. dr. Isabelle Meuret (ULB) 


\section{CONTENTS}

Introduction MAD, BAD, AND DANGEROUS TO SHOW Ken Russell,

Biography, and Baroque Excess....................................................................

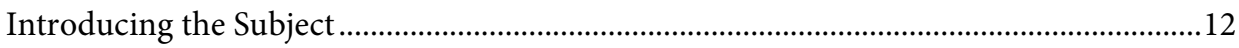

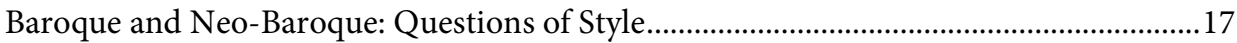

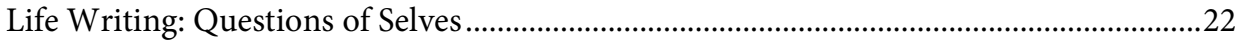

How To Do Things With Film: The Gap Between Performance and Performativity......26

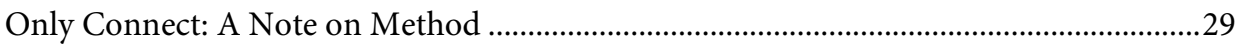

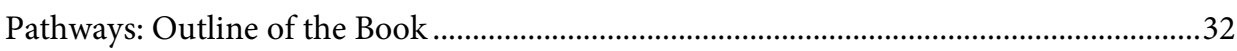

Chapter One I SEARCHED FOR THE SOUL OF THE MAN Ken Russell's

Autobiography as Baroque Performance ...................................................37

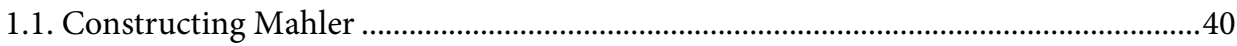

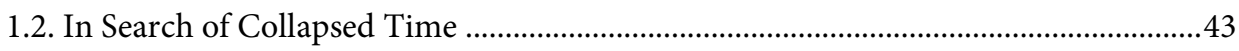

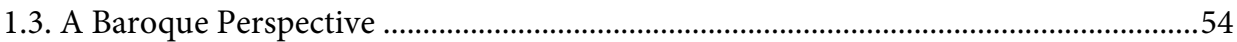

1.4. The Gap Between Reality and Representation..............................................................

Chapter Two WE NEED A LARGER THEATRE The Devils (1971) as

theatrum mundi ................................................................................................79

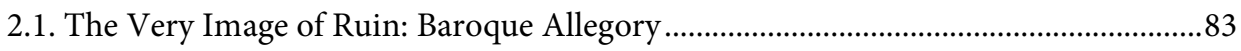

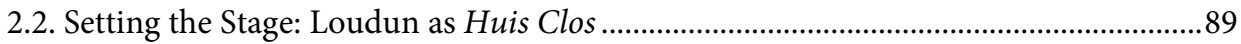

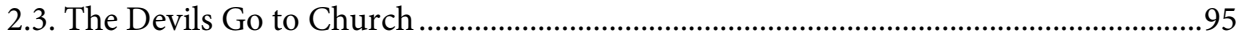

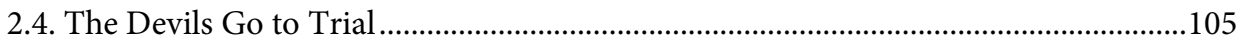

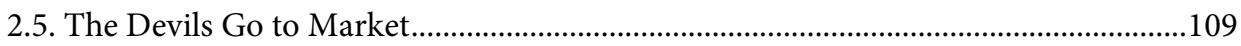

2.6. The World Made Flesh: A Mystery Play in Secular Time ..........................................124

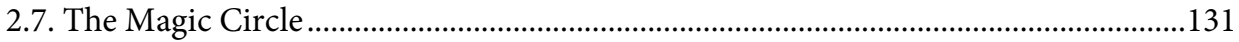

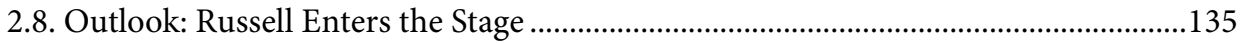


Chapter Three WITH BIG STROKES, BOLDLY Fashioning the Artist as a Savage Messiah (1972) .........................................................................137

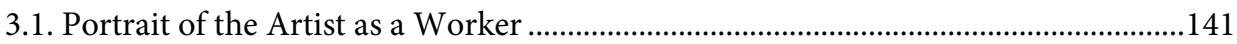

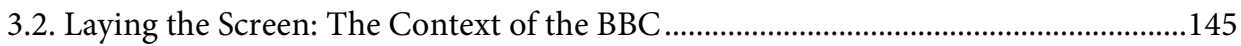

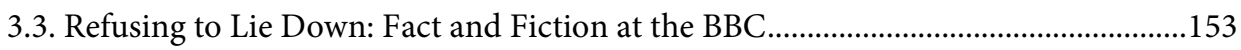

3.4. See Me, Feel Me: Truth, Vulgarity, and Art ..............................................................173

3.5. Performing Influence: Russell's Poetics of the Swerve .................................................183

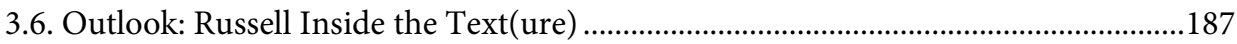

Chapter Four WE ARE THE GODS NOW Performing Genius in Salome's Last Dance (1988) and Gothic (1986) .......................................................189

4.1. Moonstruck Follies: Staging Salome's Last Dance ........................................................194

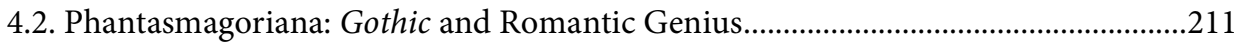

4.3. Building Narratives: Russell's Art of Montage...........................................................225

4.4. Perchance to Dream: Portrait of the Artist as Genius .................................................248

Conclusion MOY QUI ME VOY An Essay on the Self in a Time of Baroque......255

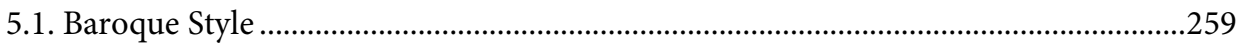

5.2. Baroque Lives: The Art of Performing .....................................................................262

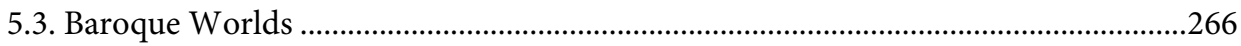

5.4. No Exits and No Entrances: Life Beyond Performance and Performativity ............271

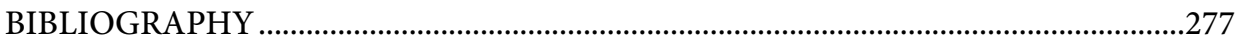

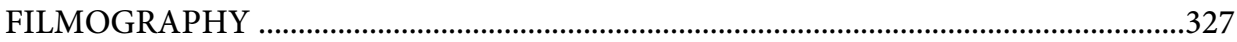

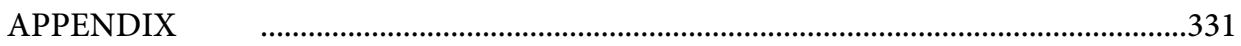

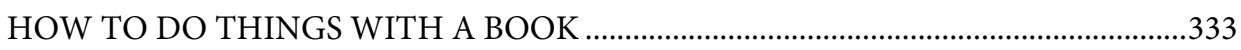

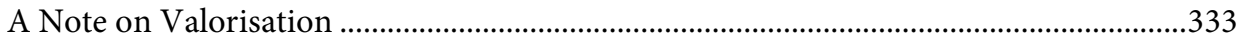

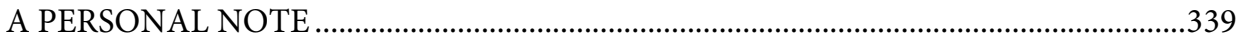

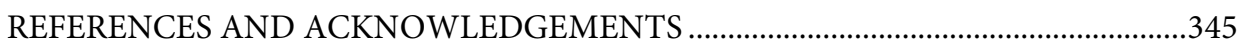

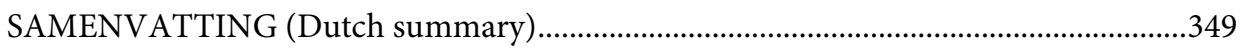

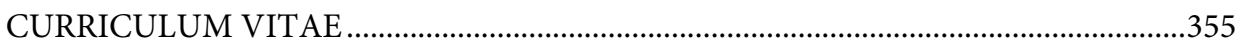


'the history of a Poet's mind Is labour not unworthy of regard'

- William Wordsworth, The Prelude (1850: XIV, 412-413) 



\section{Introduction}

\section{MAD, BAD, AND DANGEROUS TO SHOW Ken Russell, Biography, and Baroque Excess}

'The highest as the lowest form of criticism is a mode of autobiography.'

Oscar Wilde, The Picture of Dorian Gray (1891 [2007: 3]) 

This is a study of representation. It investigates how works of art can be used to perform the self. Its subject is the work of film-maker Ken Russell (1927-2011), who is mainly remembered for a long series of films on the lives of artists made both for television and for theatrical release. However, Russell's approach to artist biography was highly unorthodox: rather than reconstruct a factual account he consistently offered a deeply personal interpretation of artists' lives based on his own understanding of their work. Elaborating on his method in a programmatic text for his film on Mahler (1974), Russell explained that 'most of my films on composers evolve through a stream of consciousness in which the man and the myth, the music and its meaning, time, place, dream and fact all flow and blend into the mainstream of the film itself. [...] My film is simply about some of the things I feel when I think of Mahler's life and listen to his music' (1974: 6). This statement, to which I will return again and again throughout the book, is the point of departure for my investigation. In many ways this book is an attempt to explain, in the greatest possible detail, what that statement means and to unpack all its implications for the practice of life writing. The investigation was triggered by the suggestion, contained within the statement, that Russell's films, including the one on Mahler, are really a form of oblique self-portrait by Russell. After all, what we get in Russell's film(s) is his stream of consciousness and his interpretation of the life through his experience of the work. This is articulated in a new work of art: Russell's film(s). If we sustain the logic, we should in turn be able to read Russell himself out of his own work, too, just the way that he reads Mahler out of Mahler's work. But such an approach to art, where the work comes to perform the self, is also deeply Baroque. That is the analytical angle of this book: to show that the form of Russell's performance, from its narrative structure to the way Russell creates his imagery, is indebted to theatrical and allegorical conceits that flourished in the seventeenth century, when they were used for similar purposes, namely to shape, in art, an idea of one's self and of the world. This also means that the import of the present analysis extends well beyond the Russell corpus: the book's ultimate aim is to understand Russell's performance of self through art as part of the Nachleben of the Baroque and therefore also as an important point of reference if we would seek to understand more about the way we conceive of and create our selves today. 


\section{INTRODUCING THE SUBJECT}

Ken Russell was a late bloomer. ${ }^{1}$ After several abortive careers (including as a ballet dancer and stage actor) Russell took up photography in the 1950s and also started making amateur films. One of these, Amelia and the Angel (1957), drew critical acclaim. ${ }^{2}$ On the strength of it he was offered a position as freelance director of documentaries for the BBC arts programme Monitor in 1959. For the next decade Russell would direct more than thirty innovative films for the BBC. The 1960s were a period of profound cultural change, also in television, and Russell's BBC films were at the vanguard of developments in ideas about what arts documentaries could or should look like. By the end of the decade, however, and especially after the scandal over his film Dance of the Seven Veils (1970), which used grotesque camp imagery to portray Richard Strauss as a Nazi sympathiser, Russell and the BBC went their separate ways. But by that time Russell had already established himself as a director of feature films with Women in Love (1969), based on the D.H. Lawrence novel. The following decade saw Russell at the helm of a series of highly innovative (and commercially successful) feature films. The bulk of these were artist biographies: The Music Lovers (1970) on Tchaikovsky, Savage Messiah (1972) on the sculptor Henri Gaudier-Brzeska, Mahler (1974), Lisztomania (1975), and Valentino (1976) about the actor Rudolph Valentino. His most notorious film of the decade, however, was The Devils (1971), while the rock opera Tommy (1975) proved to be a commercial high-point. By the end of the decade, and following the commercial (and, some would argue, artistic) disasters of Lisztomania and Valentino, Russell's career came to a temporary stand-still, which was broken by Altered States (1980) and the startling Crimes of Passion (1984). After the video rental success of Gothic (1986) video distributor Vestron put up the money for three low-budget films: Salome's Last Dance (1988), The Lair of the White Worm (1988), and The Rainbow (1988), which was a prequel to Women in Love. Not one of these films was commercially very successful, and after the box office failure of Whore (1991) Russell's career as a feature film director was over. New television work followed, mainly for Melvyn Bragg's arts programme The South Bank Show, but at the dawn of the new millennium Russell had effectively become unbankable. He spent the last decade of his life making underground video films in his home and garden.

\footnotetext{
${ }^{1}$ Detailed biographical information of a more or less conventional kind (and as will become clear, in relation to Russell "more or less" is really the closest to "conventional" one can ever get) can be found in Baxter (1973) and Sutton (2012), and of course in Russell's (2008) autobiography. Much information can also be culled from Russell's two volumes of memoirs and criticism (Russell 1993 and 2000).

${ }^{2}$ See Hoyle (2013), Sutton (2012: 99-107 and 127-147), and Phillips (1976) on Russell's early amateur films.
} 
Russell's films have always generated a lot of commentary, much of it adverse ${ }^{3}$, but his work seems not to have benefited from the explosion of writing on British cinema over the last three decades: there are a number of books on Russell, but these were mainly published during the heyday of his career in the 1970s and there has been no serious critical assessment of his complete work and achievement. The best books on Russell are still the earliest. John Baxter's An Appalling Talent (1973; henceforth AT) remains an invaluable source of information, especially because every other chapter is a first-person account by Russell himself, based on extensive interview material. This means that the book is in many ways a thinly disguised autobiography. The Adaptor as Creator (1976) by Joseph Gomez was the first attempt at systematic analysis of Russell's work. The author finds a 'tripartite perspective' (o.c. 51) in Russell's biopics which incorporates the protagonist's own romantic self-image, a more objective view revealed by the perspective of time, and finally Russell's personal vision of his subject' (o.c. 35). This model works quite well with a number of Russell's biopics, but not with others, and on the whole it is difficult to keep the several categories neatly separated. As an interpretative model this approach quickly reaches its limits. In the same year Thomas R. Atkins published an edited volume of essays, Ken Russell (1976). Next, Gene D. Phillips's Ken Russell (1979) and Ken Hanke's Ken Russell's Films (1984) provided helpful surveys, although the latter, while often insightful in its detailed analyses, suffers from an attempt to impose a developmental model on Russell's work that culminates in the last film that Russell happened to have completed before the book went to press. There followed a long gap until Joseph Lanza's largely journalistic Phallic Frenzy (2007), which is especially sketchy on the later part of Russell's career, and Kevin Flanagan's edited volume Ken Russell: Re-Viewing England's Last Mannerist (2009), which collects notable earlier contributions with new work. Most recently, Paul Sutton's Becoming Ken Russell (2012) is the first part of a projected five-volume authorised biography. This means that there has been no attempt at systematic and sustained analysis of Russell's work since Hanke's 1984 monograph, which predates several of Russell's most significant films. ${ }^{4}$

The relative neglect of Russell's work in recent scholarship suggests that his position in the canon of British cinema remains contested. It is tempting to speculate on the

\footnotetext{
${ }^{3}$ In their discussion of British film criticism of the 1970s, Harper and Smith point out that the journal Films and Filming was 'rare in the praise it gave to Ken Russell' (2012: 218-225, here 219). See Wakeman (1988) for a survey of the Russell reception.

${ }^{4}$ There have also been some minor journalistic monographs that might be mentioned here, such as Wilson's (1974) brief observations; Barnes's (1977) tie-in book on Tommy, which includes a valuable Russell interview (Litchfield 1977); Bland's (1977) engaging tie-in book for Valentino, which is one of the best introductory texts on Russell; and Crouse's (2012) account of the making and reception of The Devils, which contains some interesting new interview material.
} 
reasons for Russell's marginality. For one thing, it is remarkable that many critics, and especially those who do not very much like his work, subscribe to a compromise view that hails Russell's early television work, and especially Elgar (1962) and Song of Summer (1968), as powerful yet tastefully restrained, while dismissing his later features for being tastelessly excessive. ${ }^{5}$ This reflects what was for a very long time a deeply ingrained critical attitude in British film criticism, which used to be dominated by a very powerful 'set of commonly perceived tendencies in British cinema which could be summed up as follows: a hostility towards stylisation, the hegemony of the "documentary spirit", the elevation of "contents" over "forms", isolation from wider European artistic trends [...], the conflation of moral prescriptions with aesthetic criteria' (Petley 1986: 99-100). In short, British cinema was considered to be a cinema of realism and restraint. This critical shibboleth has made it possible to continuously and systematically neglect what Julian Petley has called 'the lost continent' of 'an other, repressed side of British cinema, a dark, disdained thread' (o.c. 98) that Jim Leach labels the "expressionist tradition" of British cinema. This includes the Gainsborough melodramas of the 1940s, featuring Margaret Lockwood's heaving bosoms; the films of Michael Powell and Emeric Pressburger; and the Hammer horrors of the 1960s. More recently, the films of Nicolas Roeg, Derek Jarman, Peter Greenaway, Donald Cammell, and, indeed, Russell have been included in this tradition. ${ }^{6}$ Although this line of film-making contains much of what many critics and viewers would now consider to be the best or the most exciting in British film-making, this shift in focus is a relatively recent phenomenon. Raymond Durgnat's seminal book A Mirror for England (1970) was one of the first major critical statements to argue for the importance and value of this strand of British film. Since then there has

\footnotetext{
${ }^{5}$ Alexander Walker's Hollywood, England, originally published in 1974, probably provides the classic articulation of this point of view when he writes that 'one had better try to enumerate [Russell's] considerable gifts when they are most in evidence in his early work; later on, they are harder to discern so confidently, as he lets his temperament ride roughshod over his talent' (2005: 387). McFarlane's (1997: 505-506) brief entry on Russell, half of which is filled with Russell quotes, bizarrely suggests that Russell became less iconoclastic after Women in Love (1969).

${ }^{6}$ Petley (1986) is excellent on the causes of the "realist and restrained" bias while Leach (2004: 66-85) provides a good survey of the "expressionist" tradition. That this tradition is still not fully accepted as a major line in British film must be the implication of Geoff Brown's observation that 'only in the 70s and 80s did the pendulum decisively swing the other way, against realism' (2009: 29). See also Gibson and Hill (2009) on the "excessive" cinema of Roeg and Russell, O'Pray's (2009) discussion of the "Romantic" school of the 1980s, and Harper and Smith (2012: 132-134) on Russell as one of a number of directors working in a 'fantasy mode' (o.c. 132 ) in the 1970s. Allen (2012: 42) has even associated this "Romantic" school in British 1970s cinema with the avant-garde art film of the period.
} 
developed a revisionist scholarship. Even in this literature, however, Russell is often neglected or mentioned merely in passing. ${ }^{7}$

But Russell is missing from other discussions as well. Since the 1990s there has been a lively (and voluminous) debate in British film studies about the so-called "heritage" film. First identified as a strand of "quality drama" in British films of the 1980s, epitomised by the Merchant/Ivory productions based on a number of E.M. Forster novels, the heritage film was a form of costume drama situated in the Victorian or Edwardian era which focused on the lives of the privileged English classes and would often be adapted from canonical but popular literary sources from the same period. ${ }^{8}$ Although one could argue that all of Russell's British films of the 1980s fall under the heritage label (Gothic is a film on Romantic poets; Salome's Last Dance is an adaptation of an Oscar Wilde play from the 1890s; The Lair of the White Worm is an adaptation of a 1911 Bram Stoker novel; The Rainbow is based on D.H. Lawrence) the literature on heritage film appears mute on Russell. ${ }^{9}$ But perhaps most remarkable of all is his absence in the literature on the genre of the biopic or biographical film. Biographical films are almost as old as cinema itself, and while an academic literature on this genre began to emerge in the 1970s, systematic scholarly interest in the biopic seems to have gained prominence par-

\footnotetext{
${ }^{7}$ For example, Hill's (1999) outstanding book on 1980s British cinema mentions Russell only in passing, despite Russell's four British features (and two major American films) in this decade, when British cinema was moribund. Sargeant's (2005) critical history of British film, which aims to re-evaluate neglected figures and films, has little space for Russell beyond Tommy, which is probably his least neglected and most widely known film.

${ }^{8}$ Of course, films addressing the national past or heritage were not a new invention of the 1980s. The "heritage" label was introduced in the 1980s by a number of critics who saw these films as part of a larger "heritage industry: a potent marketing of the past as part of the new enterprise culture, a commodification of museum culture' (Higson 2003: 1) that was associated with the conservative politics of Margaret Thatcher. This assessment of heritage films has since been revised: where heritage films were previously derided as 'decorous palliatives' (Medhurst 1996: 29) recent critics have found in these films a number of progressive subtexts, including 'overt concern with sexuality and gender, particularly non-dominant gender and sexual identities' (Monk 1995: 33), and an 'ambivalence [...] to both the past and to the Thatcherite present' (Higson 2006: 108). The evolution of the heritage film (including the gradual broadening of the label itself to take in all manner of historical drama) is discussed by Hill (1999: 73-98), Gibson (2000), Monk (2002), Sadoff (2010), and Vidal (2012a: 91-120), while Vincendeau (2001) collects many key articles from the 1990s. Finally, Vidal has discussed the heritage film in terms of a "mannerist" aesthetic, although the term is used here to refer to 'an aesthetic of figures, a term that is redolent of the rhetorical function of language' (2012b: 22) rather than to the period in art history (see also Post [2012] for a similar approach to melodrama). Interestingly, Flanagan's (2009a) edited volume identifies Russell as a "mannerist" without engaging with the term on a theoretical or interpretative level, suggesting that he is using it simply to refer to the fact that Russell, as an auteur, has a highly distinctive maniera.

${ }^{9}$ There are exceptions, such as Flanagan (2009c) on Russell's BBC mini-series Lady Chatterly (1993), and Sadoff's (2010: ix-xi) thoughts on Gothic, but they are rare (and in any case, Flanagan's article was written from the perspective of Russell studies and did not emerge from inside the heritage film debate). Vincendeau's (2001) important collection of critical writing on heritage film mentions Russell only once.
} 
allel to an interest in the problems pertaining to historical films in general. Both genres not only often overlap (many historical films portray the lives of historical personages; many biopics are set in the past), they also raise similar questions about what a reliable and truthful representation of the past on film should be. The first systematic enquiry into the biopic, and still the most important monograph, was George Custen's Bio/Pics (1992), which focused exclusively on classical Hollywood cinema. Scholarly inquiry into the historical film was galvanised by Robert Rosenstone's Visions of the Past (1995). Since then there has been a flood of publications on biopics, and the release of a major new biopic is almost inevitably accompanied by the publication of a number of academic articles. Dennis Bingham's voluminous Whose Lives Are They Anyway? (2010) takes stock of the field and covers several of the sub-categories of the biopic through casestudies of individual films. Incredibly, Russell is virtually absent from the biopic literature, despite the fact that there is no other major film-maker who has made more biopics or made them so consistently as the major part of his output throughout his career. An exception is the chapter devoted to Russell's composer biopics in Tibbetts's Composers in the Movies (2005).

It is not possible to restore Russell to all these debates in the scope of one book. Instead, I will cut right through all these fields, and others, to pursue my own goal: an understanding of Russell's performance of himself through his films. To do that I will investigate Russell's work along three axes that are intricately intertwined. The following sections of the Introduction will sketch each of these axes and suggest how they will connect with each other in the course of my argument. First, I will situate Russell's work in relation to critical discourses on the Baroque. There is a large literature on neobaroque tendencies in contemporary culture and Russell's work can be used, I will argue, to unsettle some of the approaches in that field. But since Russell's main activity has always been concerned with biographical films, any discussion of his work inevitably ventures into the field of life writing, which studies how life narratives are created. The two main ways in which this happens, are biography and autobiography, and both are deeply entangled in Russell's work. Finally, I will say something about the term performance, which is central to my discussion and therefore needs to be clearly defined before the inquiry can begin. As such, the rest of the Introduction will sketch the three main lines that run through this book: the baroque, life writing, and the performance of self. They must be clearly grasped in isolation here so that we can comfortably connect them in the course of the argument. The Introduction ends with a discussion of the main method that I will follow in bringing about these connections. My approach will be iconological. Specifically, I am taking my cue from the work of Aby Warburg, who has tracked motifs, themes, and ideas from context to context on historical Wander- 
strassen. This is an approach that pays dividends with Russell because his work constantly forces us to enter into new fields and areas: every film tackles different historical figures in different contexts, all of which has to enter into the mix of an analysis. To prevent such an interdisciplinary approach from becoming a soup of pointless references and pedantic erudition one needs a sense of how it all holds together. Warburg's outlook provides this, and more.

\section{BAROQUE AND NEO-BAROQUE: QUESTIONS OF STYLE}

By discussing Russell as "baroque" I am first of all engaging the field of neo-baroque studies, which inquires about the way that many elements in our (visual) culture seem to hark back to forms typical for the historical Baroque. As I will show, Russell's work invites us to re-think parts of the discussion about "neo-baroque" in a fruitful way. But there is also a more prosaic connection between Russell and the baroque. Critics who dislike Russell's work have tended to call his films "baroque" in style, and they usually do not mean that as a compliment. Over the years Russell's work tended to inspire ever greater heights of hysteria in a number of critics who were chronically outraged by what Pauline Kael, who never did get to like Russell's work, called 'Russell's baroque vulgarity' (1973: 241). The "baroque” label has stuck and runs like a mantra through Russell criticism. Joseph Gomez, while admiring Russell's work, did agree that Russell's films 'seek the baroque, or what could be called an operatic style' (1976: 39), while a recent student of British cult film has found in Russell 'a very English style of baroque high camp' (Hunter 2013: 152). Stephen Calloway, although writing appreciatively on baroque trends in the twentieth century, nevertheless deplores that Russell seemed 'to use baroque excess as an end in itself (1994: 181). Director Lindsay Anderson felt that 'British cinema lost its way with the romantic neo-baroque of [Nicolas] Roeg and Ken Russell' (quoted in Hacker and Price 1991: 55), while New York Times critic Richard Eder took things a step further, at least in terms of art-historical chronology, and diagnosed Russell with 'post-Beatles Rococo,' arguing that for Russell 'the shortest line between two points is a pretzel, preferably painted gold and doped' (quoted in Lanza 2007: 191). But besides being fun to read, such criticism seems to suffer from considerable confusion as to what actually constitutes "baroque" in this case. The baroque is associated with vulgarity, with opera, with camp, and with excess. Beyond the common denominator of a rather broad visual flair, or what one critic called the films' 'exuberant vitality and visual panache' (Williams 2007: 29), the underlying concepts of baroque seem to be all over the place, borrowed not from history or art history but from the realm of every- 
day language, where "baroque" equals the overwrought and the loud, as in Susan Rice's one-sentence Blitzkritik review of Tommy (1975) which read: 'Ken Russell's rendering of The Who's rock opera is loud, really loud' (quoted in Rosenfeldt 1978: 109).

Lurking behind these critical observations we can find one of the most widespread and clichéd preconceptions about the baroque. It treats the baroque as what Panofsky once endearingly called 'a lordly racket' (1995: 20): an overwhelming art that is calculated to achieve spectacular visual effects. Interestingly, especially since the 1970s there has developed a literature on what is called the "neo-baroque". Many authors within this field argue that the arts and visual media in our post-modern culture take a form that is in some ways a "return" of the baroque in the present. Important contributions to this endeavour were Sarduy's monograph on the baroque, published in 1975, Deleuze's book on the fold in Leibniz, and Buci-Glucksmann's reflections on baroque allegory and what she called the 'folie $d u$ voir' (1986: 9). ${ }^{10}$ This latter term has proved fateful, for a lot of literature exploring so-called "neo-baroque" elements in contemporary culture, and especially in popular culture and the entertainment industry, has indeed focused on a conception of the baroque as visual spectacle. ${ }^{11}$ In a book that proved widely influential, Omar Calabrese defined the neo-baroque as 'a search for, and valorisation of, forms that display a loss of entirety, totality and system in favour of instability, polydimensionality, and change' (1992: xii), adding that 'variation on a theme or style: this is the first principle of the neo-baroque aesthetic, since it is based on the general baroque principle of virtuosity' (o.c. 40). Among neo-baroque's other features he counts 'organised variation, polycentrism and regulated irregularity, and frantic rhythm' (o.c. 43), a list he seems to have tacitly borrowed from Umberto Eco's observation that 'organised differentiations, polycentrism, regulated irregularity - such would be the fundamental aspects of this neo-baroque aesthetic, the principal example of which is musical variations à la Bach' (1985: 180). In another major contribution, Angela Ndalianis put theme parks and video games to the baroque test and found that they shared 'a baroque delight in spectacle and sensory experience' (2004: 5). Such spectacle is described as "immersive" on account of its overwhelming the senses in the way that a virtual reality environment, a theme park

\footnotetext{
${ }^{10}$ The books referred to are Sarduy (1975), Deleuze (1988), and Buci-Glucksmann (1984 and 1986). Deleuze's fold is mainly a metaphor, which makes it difficult to use for practical criticism about anything other than Leibniz. This already comes out in Deleuze's own discussion, for when he turns to a treatment of the fold in the visual arts his approach is surprisingly literal and makes much of painted depictions of folds in clothes and textiles (1988: 164-170). As an approach to baroque visual art this must count as one of the poorest on record. ${ }^{11}$ An important line of inquiry into the neo-baroque, but one which cannot be pursued in these pages, investigates the rediscovery and re-use of baroque forms in (post-colonial) Latin-American and Carribean literature and culture. See, for example, the discussions by Malcuzynski (2009), Egginton (2010: 69-84), and especially the many selections and contributions in Zamora and Kaup (2010).
} 
ride or, indeed, the spectacular interior of a Counter-Reformation church are intended to "envelop" the spectator in an all-over experience (that also moulds their response to the experience). ${ }^{12}$ However, when yet another critic contributes that in addition to a great amount of self-conscious artifice, the aesthetic figurae of the baroque manner include many scopic/observational devices such as the conceit, repetition, parody, the menippean satire, carnivalisation, metamorphoses, metalepses, intertextuality, the encyclopedia, cataloging, mirroring, trompe l'oeil, the labyrinth, staging, distortion, instability, disorder, chaos, detail, and fragment' (Degli-Esposti 1996b: 76-77) it is clear that we have entered the realm of definition as pointless inventory and that none of this is very helpful. ${ }^{13}$

If such inventories seem to lack critical focus, then this is probably symptomatic for the basic problem with the baroque. After all, the term "baroque" did not really enter critical or art-historical discourse until the late nineteenth century, and it was Wölfflin's work, which opposed the open and dynamic forms of the baroque to the closed and harmonic forms of classicism, which did most to establish the term as an important tool for making sense of the forms of art of the late sixteenth and the first half of the seventeenth centuries. ${ }^{14}$ Almost from the start, however, there was a tension between two uses

\footnotetext{
${ }^{12}$ In her discussion of virtual reality and interactivity Marie-Laure Ryan points out that 'the term immersion has become so popular in contemporary culture that people tend to use it to describe any kind of intensely pleasurable artistic experience or any absorbing activity. In this usage, we can be immersed in a crossword puzzle as well as in a novel' (2001: 14). This argument is well taken in the context of the neo-baroque, where forms of immersive experience have been ascribed to anything from film to comics (Ndalianis 2009).

${ }^{13}$ Countless books and articles on the neo-baroque inevitably also address the neo-baroque in cinema. Among the directors who have been especially singled out as "neo-baroque" we find Federico Fellini (Degli-Esposti 1996a), Sally Potter (Degli-Esposti 1996b), Peter Greenaway (Degli-Esposti 2008), and Pedro Almodovar (Egginton 2010: 107-126), although the entire blockbuster type of film (from the Alien and Terminator franchises through Spielberg) has been drawn into the debate (Ndalianis 2004), as has the Matrix trilogy of films (Burningham 2008: 147-170). An interesting contribution to the neo-baroque film debate is Plasseraud's monograph investigating whether 'the cinema can induce a vision of the world that connects with the one elaborated in the baroque era, but which incarnates itself in a particular aesthetic that is specific for the cinema' (2007: 251). Although his outlook is interesting, Plasseraud's discussion remains structured around a number of formal and thematic elements rather than offering an integrated view of what a baroque cinema could be.

${ }^{14}$ On Wölfflin, see Zamora and Kaup (2010: 46-54). Payne (2011) discusses the intellectual context in which Wölfflin's ideas developed. Already in his classic study of French literature of the Baroque, Jean Rousset pointed out that Baroque and Classicism, as supposedly opposed trends in seventeenth-century culture, really existed in a much closer relationship of sibling rivalry: 'they oppose each other in a fraternal way' (1953: 243). In his classic handbook on Baroque (1991; orig. 1977), published a quarter of a century later, John Rupert Martin equally argued that classicist elements are among the central characteristics of the Baroque, for example in the work of Poussin. When Rousset, reflecting on the pluriformity of the Baroque and its resistance to unequivocal definition, ponders whether one could 'admettre à côté du baroque berninien et rubénien, qui tourbillonne et explose au dehors, un baroque rembranesque, plus replié sur l'intérieur, plus méditatif et assour$d i$ (1953: 240) one can already see a prefiguration, in the question itself, of some of the categories and lines of
} 
of the term. On the one hand "baroque" refers to the arts of the period just mentioned, but on the other hand it also refers to a certain visual style that, while strongly connected to the dominant trends of this period, is also found to be timeless and can be seen to manifest itself again and again in subsequent centuries, for example in elements of Romanticism or fin-de-siècle decadence or, most recently, "post-modern" culture. The latter, trans-historical interpretation of the baroque has descended from Eugenio d'Ors's Lo Barrocco (1935), which was immediately translated into French and became the source from which the contemporary concept of the neo-baroque has sprung. As one critic points out, in a survey of the history of the term "baroque", with d'Ors's book 'the baroque has become a timeless aesthetic category, identified by a mixture of genres and styles, and by a rhetoric of the superlative' (Levillain 2003: 11). One of the aims of the present book is to show that re-establishing the connection to the historical context in which they first emerged, can actually help to clarify what it means for baroque forms to re-emerge in the present, and that Russell's work is an ideal site for establishing such a connection. ${ }^{15}$ To do that, however, a practical intervention is needed right from the start. I will use the capitalised term "Baroque" to refer to what is conventionally understood as the cultural period of that name, covering more or less the last third of the sixteenth century and most of the seventeenth. ${ }^{16}$ When I use "baroque" in a noncapitalised way it refers to the formal matrix, also with its conventionally understood properties (such as curves, movement, colour, excess, and so on). Obviously, this distinction does not solve all problems and there is some very clear overlap between the two terms (otherwise it would be hard to argue that the culture of the seventeenth century is the background against which baroque forms were developed), but the consistent use of capitalisation at least makes some cumbersome qualification at every mention of

argument in Martin's masterly discussion, which has much to say about the non-spectacular side of the Baroque. The opposition of baroque and classicist formal principles explains very little about the Baroque. This is not to deny either the reality or the importance of Classicism in French art and culture of the second half of the seventeenth century. It is simply to say that, within these two periods (Baroque and Classicism), the two formal matrixes of baroque and classicism only exist in constant contamination.

${ }^{15}$ It should be clear that, for my purposes, it matters little whether the term "baroque" derives from late Scholastic logic (where "Baroco" referred to a form of syllogism) or from the Portuguese word for an irregular pearl. Most longer studies of the Baroque discuss the origins of the term, often in connection with a survey of the historiography of the Baroque. Mérot (2007) is particularly clear and helpful on these issues, but see also Wellek (1963: 69-127, and especially 69-88 for the dissemination of the term), Bialostocki (1981: 106-141), Levillain (2003: 11-53), and Hills (2011).

${ }^{16}$ Inevitably, the chronology varies from author to author, although I like Jean Rousset's demarcation of the Baroque as a period that 'runs approximately from 1580 to 1670, from Montaigne to Bernini' (1953: 8). Many critics limit the Baroque to the first half of the seventeenth century, often because the classicist tendencies of the century's second half conflict with their concept of the baroque as an open and dynamic style along Wölfflinian lines. Again, I refer to Rousset (1953) and Martin (1991), who argue for the co-existence of baroque and classicist qualities in the Baroque. 
the term superfluous. I will, however, provide such qualification when the context requires it or when I deem it necessary or helpful to stress a critical point. ${ }^{17}$

Russell's work is interesting exactly because it is positioned on the neuralgic intersection of the several uses of the term "baroque" as either a historical/cultural/epochal or a formal concept. Careful analysis of Russell's work will show that his films can indeed be called baroque, but that their visual flair is the least of it. On a deeper level one can see that the narrative structure of his films, but also (and crucially) of his autobiography, uses representational devices such as embedded narratives, the mise-en-abyme (a selfreflexive embedded narrative), and allegory, which, while certainly not exclusive to the literature and theatre of the Baroque period, are nevertheless very typical for it. These baroque elements in Russell's work will be analysed in Chapter One and will provide the backbone for the entire book. But they also provide an interesting angle on the question of the trans-historical (or timeless) nature of the baroque. I will argue that, in their historical context, these representational devices were used in ways that expressed a deep anxiety about man's relation to the world and to himself. The humanism of the Renaissance had not simply, and benignly, occasioned a flourishing in the arts, it had also delivered a number of concussive shocks to man's sense of self. The recovery of atomist theory, especially through the work of Lucretius, and the revolutions of Copernicus and Galilei, who uprooted the cosmological order that was based on centuries of religious tradition (and Aristotle), are only two developments that contributed to the shattering of what had seemed like absolute (and divinely decreed) certainties about the nature of the world and man's place in it. The sometimes painful soul-searching that this decentering of mankind entailed, but also the exciting new sense of autonomy and selfdetermination, found expression, among other things, in a certain self-reflexiveness that we find in the extensive use of the very same representational devices that Russell also uses to construct his performance of self. The fact that Russell is putting baroque modes

\footnotetext{
${ }^{17}$ Similarly, Classicism and classicism refer to the period and to the trans-historical formal matrix, respectively. I will use the term Romanticism/Romantic exclusively in a capitalised form because, in the context of my discussion (mainly in Chapter Four), I am especially interested in Romanticism as a world-view and philosophical outlook that is associated with the historical period conventionally covered by that name. The term realism/realistic also suffers from a duality in meaning, referring either to a period in the history of nineteenth-century art and literature or to a stylistic convention based on what may be called "representational fidelity". This latter meaning, however, raises many questions, if only because what such "fidelity" would be very much depends on who is doing the representing and with what kind of presuppositions about what the world and our perception of it are like. As Daston and Galison point out, reflecting on "objective" scientific representation, 'objectivity is related to subjectivity as wax to seal' (1992: 82). The complex issues that this raises cannot be addressed here, but see Hill (1986: 57-61) on the question of realism in British cinema of the period 1956-1963 and Petley (1986) on the unspoken assumptions behind the "realism and constraint" bias in discourses on British film. In the present book I will use the term "realism" in non-capitalised form throughout because it never refers to the art-historical period.
} 
of representation to a use that is, at the very least, similar in purpose and function to the uses made of them in the historical Baroque, should give us pause if we want to understand how and why the baroque re-emerges today or, indeed, has re-emerged occasionally throughout history. This means that I am exploiting the baroque for double gain in these pages. First, a number of important baroque forms are the tools with which I analyse Russell's work. But when it next transpires that Russell's use for these forms is similar in purpose to their use in the historical Baroque the analysis suggests that Russell's work can and should be seen as part of the Nachleben of the Baroque. Reading Russell may then contribute to a better understanding of our own culture, of which he is a part.

\section{LIFE WRITING: QUESTIONS OF SELVES}

But my investigation into Russell does not only engage the baroque. It is also an intervention into life writing. This is a vast field (rather than a discipline or method) that involves (the study of) all conceivable ways in which lives are told, constructed, deconstructed, reconstructed, shared. As such it encompasses first and foremost the traditional genres of biography and autobiography, but also hagiography, diaries, biographical films or biopics, painted portraits or self-portraits, epithets, tomb inscriptions, personal ads, forms of reality television, testimonies of all kinds, civil records, medical files, legal documents ${ }^{18}$, and much besides. It encompasses all such documents both when people produce them to tell (part of) their own lives or when people produce them to write (part of) the lives of others. Any cultural artefact, document, or practice that contributes to the construction or reconstruction of a self, its life, or its identity can be considered (an act of) life writing. But even in the most seemingly self-evident cases of biography and autobiography a doubling of the subject occurs. For the term life writing covers both the production of such documents and the study of their production and outcomes. When a biographer writes the life of an artist she engages in an act of life writing.

\footnotetext{
${ }^{18}$ Legal documents are an especially relevant source of life writing for the early modern period. In Fiction in the Archives (1987) Natalie Zemon Davis shows how people on trial for or convicted of capital crimes would shape their life stories according to certain genre conventions in the writing of letters of remission which would obtain them a pardon from the King. In The Return of Martin Guerre (1983) Davis had previously reconstructed the life and self-fashioning of the impostor Jean du Tilh who famously assumed the identity of Martin Guerre. One of her main sources was judge Jean de Coras's Arrest Memorable (1561) documenting the case, which Davis identifies as a new genre in life writing (o.c. 104-113). For our contemporary context, Martha Nussbaum has suggested, in Poetic Justice (1995), that judges ruling on court cases should approach the life narratives of the accused who are presented before them with the same generous humanity with which we read the lives of fictional characters in novels. These intersections of legal discourse, fiction, and life writing (addressing cases centuries apart) show just how wide and diverse the field of life writing can be.
} 
But a life writing scholar who studies the practice of writing biographies also ventures into the field of life writing. In fact, the scholar's ideas on how lives should be written may influence the way subsequent biographers write biographies. When that happens, the scholar has influenced shared ideas about what is a life, what it might look like, or how an account of it should read. But even the biographer herself may "disturb" the site of the life she is writing and thereby change the life upon which she is supposedly only reporting. Very often the interpretative work of the biographer is experienced, by the biography's subject or their surviving relatives, as a retrospective re-writing and refashioning of the life. Which is why biographers are often regarded with tremendous hostility: the work of the biographer can be experienced as intrusive, voyeuristic, disrespectful, sensational, invasive, even a violation. ${ }^{19}$ This is an important concern because biographers are powerful: a successful or highly publicised biography or biopic can shape people's ideas of a certain person for a long time to come.

The work of Ken Russell complicates such issues even further because it exists in an area of overlap between biography and autobiography. Although Russell did write his own autobiography, I will argue that an important part of his performance of self (which is a form of autobiographical work) actually happened through his works of art, which were themselves biographical films on the lives of other artists. This rather vertiginous construction is the subject of the present book. I will study the use of art in Russell's performance of self. Although that sounds relatively straightforward it is a complicated topic, for it means that my investigation does not address art based on the biography of a person (in this case Russell), whether this is the artist themselves or another person. Many artists have used elements of their own autobiography or others' lives as themes or motifs in their art, from the roman à clef to forms of identity-based art and the popular film genre of the biopic, which dramatises the lives of notable people past and present. In these cases one could say that the self comes before the art: first there is a self, which has life experiences, and these are next used in a work of art (which may or may not acknowledge the biographical source). The present book, however, is concerned with the way works of art can be used to perform the self in the sense that the self is constituted in, through, or by the work. Of course, this does not mean that there is no private person with a life story behind the work of art. The point is that this person is very consciously using their art to construct the (public) image that we have of them. Who they are, is something we (are allowed to) know primarily through their art. I say "primarily" because very few people are capable of shielding off their private life to such

\footnotetext{
${ }^{19}$ See the discussion by Lee (2009: 93-100). As an example of the counter-force to the perceived intrusion of biographers, Hebron and Durlinger (2010) provide an intriguing account of how Percy Shelley's descendants have tried to shape and control the posthumous image of and narratives about the poet.
} 
an extent that there is absolutely no seepage to public eyes. In art, as in life, there are no absolutes. But this does not mean that it is not possible to make valid and important critical distinctions. In this case, the distinction is between art about a person (because it takes that person's life as its main subject or because it uses biographical elements as motifs in the art) and art that constitutes a person. The latter is my subject. Who Russell is (and that means: the image that we have of him, the way his presence in the public sphere was experienced, and how he himself performed that self in the public eye) is something that Russell to a considerable extent created in and through his work. Russell's performance as himself in his own public appearances was modelled on the image of himself that he created through his art and vice versa. What we have here, then, is a remarkable case of what one might call a performative co-dependency between the artist's art and the artist's person, where one endlessly reflects the other. Almost as if the person and the work formed an endless tautology, with the one always implying the other. How this process works, and how Russell achieved it, is the purpose of this book to analyse in as great detail as possible. ${ }^{20}$

This means that the subject of Ken Russell falls somewhat outside the established categories for thinking about biography and autobiography. Ken Russell certainly made biographies: the overwhelming majority of his films are biopics about other artists. However, my main concern is with the way these biopics next came to function in a larger and more encompassing project, which is Russell's own performance of self, which happens partly through those films. In the Introduction to a book on the relationship between life writing and fiction in modernist literature Max Saunders lists a number of critical categories from the field of (auto)biography studies that would seem to touch upon Russell's practice. Saunders argues that scholars have become deeply aware of the fact that 'biography and autobiography [...] cannot be kept entirely separate from each other' (2011: 6). The term “auto/biography” (marked by a forward slash) has been introduced to 'condense their interrelations' (ibid.). But this pertains to the way that, on the one hand, writing an autobiography is always also an encroachment upon the biography of others because one ends up writing part of the life of the people who are part of

\footnotetext{
${ }^{20}$ Russell has always been keenly aware of the implications of what he was doing for his performance of self. In an interview near the end of his life he acknowledged that 'I guess it's fair to say the obvious, that these portraits of composers are in a way self-portraits. [...] And didn't Tchaikovsky and Mahler say that their music is autobiographical, too? Anything happens to me, I find a way of putting it into my films. I can't just depend on historical truth, whatever that is. History is bunk' (quoted in Tibbetts 2005b: 45). Three decades earlier he had said that 'I'm suspicious of facts because nobody really knows all the facts. So a book on a composer which just gives you the facts is very useful up to a point, but you've really got to listen to the music. The music tells you if he's lying.' He further added, about Mahler, that 'although it's a film about Mahler, it's also about me. [...] I suppose in every film one does a different part of one's personality comes out' (quoted in Litchfield 1977: 88 and 97).
} 
one's own life; while, on the other hand, writing a biography also involves the person who is writing the life, so that there is always an element of oblique autobiography in the writing of someone else's biography. The mutual involvement of these two processes is indicated by "auto/biography", and it certainly has some relevance for the way Russell made his biographical films on other artists. Other possibly helpful terms are "autobiografiction" and "autofaction": both indicate that 'auto/biography can be read as fiction, and that fiction can be read as auto/biographical' (o.c. 7). The latter is the case when we are dealing with a roman à clef where the main character is a barely concealed selfportrait of the author while we can see the shadows of other real historical personages through the contours of certain fictional characters. In such cases the author achieves 'the transmutation of life facts into art works' (o.c. 76). Saunders further adds, with some irony, that the term "autobiografiction" in turn 'seems to require the invention of biografiction to accompany it, and, alas, auto/biografiction, for the sake of exhaustiveness as well as symmetry' (o.c. 7). Apart from the fact that such a proliferation of terms, especially when they look so similar and refer to phenomena that are sometimes difficult to distinguish clearly in practice, may not be very helpful, none of these terms covers exactly what Russell does in his work. And that is really a very particular form of autobiography that feeds on a series of auto/biografictions (Russell's biopics) for the performance of Russell's self. I will therefore continue to speak simply of Russell's performance of self through art, since this is not only an elegant phrase, but also an accurate description of what he is actually doing.

This performance of self through art, however, must be differentiated, not simply from identity-based and (auto)biographical art, but also from the work of artists whose public image is very obviously an artistic performance without being a creation of self in the performative sense that I find it in Russell. The two most obvious cases of such engagement with public image are David Bowie, who invented a new artistic persona for almost every album he released in the $1970 \mathrm{~s}^{21}$, and Madonna, whose career has been marked by a 'flood of inner sexual personae, which appear and disappear like the painted creatures of masque' (Paglia 1993: 9). The ease with which these artists shift their personae and change their look is in many ways the opposite of what I am investigating in Russell. The constantly shifting image of Madonna suggests not that any of these images "is" Madonna, but that the shifting of image itself is her identity as an artist: changing masks is something she does, next to the other things she does, such as writing and recording songs and performing as a dancer. Madonna is chameleonic, constantly

\footnotetext{
${ }^{21}$ Paglia (2013) provides a detailed analysis of Bowie's several personae. See also Burningham's (2008: 31-53) account of how the autobiographies of Johnny Rotten and Marilyn Manson function as a form of picaresque performance.
} 
appropriating past and present styles. Each incarnation is also an artistic statement. But they are closer to the kinds of roles that an actor creates than to a performance of identity. ${ }^{22}$ In contrast, Russell's performance of self has been remarkably stable over the years. There is an identification between the artist Ken Russell and the public persona Ken Russell that does not exist between the artist Madonna and any one of her many manifestations. This suggests that Russell's is an entirely different kind of performance, marked by the performative tautology mentioned before, and which seems to be absent in the many personae that either Madonna or David Bowie have moved through. ${ }^{23}$

\section{HOW TO DO THINGS WITH FILM: THE GAP BETWEEN PERFORMANCE AND PERFORMATIVITY}

The pivotal term throughout my analysis is "performance": how Russell performs himself, how he does this (partly) through his work, and what this means. Something must therefore be said about the way this term will function in the following chapters, especially because "performance" is widely used to cover a number of practices that need to be kept separate in the analysis although, inevitably, there is no ready alternative for the word itself to clearly distinguish the several uses. In the course of this book the term performance will appear in three distinct ways: first, to refer to theatrical presentations (actors playing a part in a play, a film, or another fiction); second, to refer to what Erving Goffman has called the presentation of self in everyday life, or the playing of social roles; and third, to refer to the creation or performance of self through a work of art. The third form is the subject of this study. We need the first two uses of the term, however, to make sense of the third, not in the least because the third seems to hover somewhere between the first and the second and we should like to know exactly where and how it hovers there, and to what effect. Sociologists have shown great interest in the way that theatrical performance and social performance seem to mirror each other's conven-

\footnotetext{
${ }^{22}$ In the visual arts, the photography of Cindy Sherman, in which the artist constantly uses herself as a model to reflect upon the masquerade of gender, would seem to present a similar case: see Jones (1997 and 2002).

${ }^{23}$ With the inevitable proviso that extensive research into their performances would be required before we can come to any definite conclusions, I would suggest that the performative co-dependency between artist and work is very much present in the cases of Siouxsie Sioux and Grace Jones: both their public images are so tightly constructed and performed through their work, and are so consistently performed as to allow no glimpse of the private person behind the persona, that I would suggest their performance of self is significantly similar to Russell's. In the visual arts, the life and work of Andy Warhol strike me as a paradigmatic case. I hope to explore these artists' performance of self on a later occasion.
} 
tions $^{24}$ and their work has a clear bearing on Russell's performance of self. After all, Russell has often made a spectacle of himself in the literal sense through his highly eccentric, inflammatory, or "wild" public performances, which seemed to dutifully indulge his received (and, I will argue, consciously cultivated) image as the enfant terrible of British film. The study of Russell's public behaviour, however, is not my main focus because it might not necessarily reveal much that we do not already know: the notion that Russell's excessive public persona was a role he played, is hardly news.

My focus is obviously on the way Russell performed himself through his work. If a work of art, which exists independently of its maker, can actively perform the artist's identity we are looking at a performance of self that is, while artistic, not a performance entirely in the first, theatrical sense. It is not part of the second kind of performance, either, because the social performance of self requires the physical presence of real people in an interaction. Performance of self through art would seem to be a kind of performance by proxy, and a paradoxical one: a way of performing oneself from a distance. The performance even continues to perform oneself when one is not physically present on the site of the performance: if Russell's films help to perform him, then we must assume that they also do this when the film is being shown in a place far away from where Russell is at that time residing. Another way of describing this effect would be to say that the performance of self is somehow externalised and objectified in the work of art, which captures it like an insect preserved in amber. It could then be realised every time that the work is shown to an audience. The performance of self has become part of the meaning that the work of art conveys (or is intended to convey by the artist: there is no escaping intentionality in the present discussion) and every time that this meaning is realised the work in some sense achieves the performance of self of its creator. In other words, when a work of art is supposed to be capable of performing its author independently of the author as a physical person it seems to acquire a family resemblance to the process of meaning-production that Judith Butler, in her work on the performance of gender roles, calls (re)iteration. Butler argues that gender is performed by the largely unconscious repetition of conventional scripts: it is through the repetition that the ways of performing gender become established as normal and accepted. This process of making-real through repetition is what she refers to as (re)iteration. ${ }^{25}$ The difference with

\footnotetext{
${ }^{24}$ See Goffman (1990; orig. 1959) and Burns (1973); Sennett (1992; orig. 1977) from the perspective of the social historian; and Butler (2006 [orig. 1990] and 2011 [orig. 1993]) from the perspective of gender studies. See Jackson (2004) for a detailed survey of the shifting academic uses and meanings of the term "performance" in the twentieth century.

${ }^{25}$ See Butler (2006: 198-200 and 2011: 70). Iteration is so efficient in perpetuating gender models because most social activities (i.e. almost all activities in which people interact with other people) are somehow marked by sex difference. As West and Zimmerman point out, 'insofar as sex category is used as a fundamental criterion
} 
what I find in Russell, however, is that the work of art cannot really be said to (re)iterate again and again: at best, it can be said to be re-displayed, which is something else. Every (re)iterated performance of a gender script is itself a unique and original act happening in the real time of lived life. Every repeated screening of a Russell film does not constitute a unique and original creative act: it simply displays, again and again, the final product of a creative act. This display, however, seems to contain and represent something of the creative act, and this in turn reflects back upon the person who performed that act. This is the artist, reflected in the work he made.

Performance of self through art seems to lack the never-ending process of performativity. Even more importantly, the processes of performativity and (re)iteration are to a considerable extent unconscious or involuntary: it is because we perform behavioural models so effectively despite ourselves that they are so tenacious and manage to be reproduced and survive even despite our deliberate attempts to subvert them. ${ }^{26} \mathrm{~A}$ work of art, however, is entirely a conscious construct. This is not to deny that a work of art may articulate or express certain sensibilities or subtexts that the artist is not wholly aware of: every human act necessarily resonates with unintended meanings (and we should not forget that such meanings can also be read into the work by the perceiver, who then ascribes them to the artist). Nor is it to deny that the artist and his work are to a considerable extent shaped by cultural presuppositions that they neither control nor are aware of. I am saying, however, that within this cultural context the creation and completion of a work of art is still a highly conscious, deliberate, and usually intensely reflected and premeditated act that can therefore have nowhere near the involuntary features that attend to, for example, the (re)iteration of behavioural scripts for gender performance in the raising of one's children or the performance of one's own gender role in everyday situations. The fact that artists cannot account for everything that shapes their work does not diminish the intentionality of their work: it merely means that their work is made by a human being, and not by an abstract disembodied intellect. Similarly, the fact that Judith Butler is a scholar of gender will not prevent her own performance of her own gender in everyday life to elude her conscious control at many times. Nor does the latter fact in any way diminish the importance of her insights into performativity. How-

for differentiation, doing gender is unavoidable. [...] In virtually any situation, one's sex category can be relevant' (1987: 145).

${ }^{26}$ Butler has repeatedly shown herself to be sceptical about the possibility of subversive gender performances. In Gender Trouble (2006: 186-188; orig. 1990) she argued that drag, for example, reveals the constructedness of gender roles and may therefore have subversive potential, but she later qualified this with the observation that 'there is no necessary relation between drag and subversion' (2011: 85; orig. 1993; my emphasis). Butler argues that, for drag or other gender performances to be subversive, they would need to actively displace gender norms (2006: 202-203). 
ever, if the performance of self through art is indeed possible and successful, and my preliminary sketch of Russell's work certainly suggests that it is, it does invite us to think about the gap between performance and performativity. For here we have a form of "halted" or objectified performance that seems to have performative effects (it helps to perform Russell's self) despite the obvious lack of meaningful (re)iteration (because each showing of the films is a new display and not a new act). Furthermore, the objectified performance must be assumed to be very considerably intentional and deliberate rather than involuntary. The performance of self through art thus emerges as a deeply hybrid process, and one which we should like to understand more fully.

\section{ONLY CONNECT: A NOTE ON METHOD}

My analysis of Russell's work is built on elements of narratology, the study of film rhetoric (specifically the study of mise-en-scène and montage), and iconology. These are all used in a comparative perspective to connect Russell's work to a baroque framework. The narratological elements pertain to the structure of Russell's work. Following Georges Forestier's masterful discussion of the play-within-the-play and the mise-enabyme in seventeenth-century French theatre ${ }^{27} \mathrm{I}$ will show that these are also the structural devices that Russell uses to build his narratives, both in his films on artists and, importantly, in writing his own autobiography. Although this is done systematically in Chapter One, the rest of the book will constantly apply these structures to a wide range of Russell's films. But film is of course primarily a visual medium. This means that a substantial discussion of Russell's cinematic poetics is also in order. To analyse his films' rhetoric I will look at Russell's approach to montage. But the word "montage" extends well beyond the technical process of film editing: although editing is part of it, montage looks at the way the entire artistic texture of a film, which includes its use of recurrent visual motifs, colour, sound, and the structuring of the image in the frame (what we call mise-en-scène), holds together. In that sense the study of montage is the study of film as a unified work of art, seeing how all its elements contribute to its overall effect. That is why the discussion of montage in Russell will be introduced only in Chapter Four, when all the other elements of the analysis are in place and can be put into play to provide the fullest possible canvas for a representation of Russell's poetics. In my study of montage in Russell I will use the terminology and models of Sergei Eisenstein, whose work on montage was foundational, both in theory and in practice. Eisenstein has added rele-

\footnotetext{
${ }^{27}$ The reference is to Forestier (1996): see the discussion in Chapter One.
} 
vance here because his influence on Russell can be very easily established. Both these devices, the embedded narrative and Eisensteinian montage, are the most consistently used creative techniques throughout Russell's work and any sustained analysis of his oeuvre should therefore require their application. More importantly, they are also the ones that work best on Russell. One of the common criticisms of Russell's work is its supposed lack of focus, its messy excessiveness, its barrage of ill-sorted imagery, - in short: its "baroqueness". The tools from narratology and film studies outlined here will establish that, rather than a mess, Russell's work is deeply and consistently structured throughout, and that everything he puts into his work is brought in with an articulated sense of purpose. This will be nowhere more clear that in the discussion, in Chapter Four, of Russell's cinematic allegorical hyperboles, a stylistic device that he has made into his trademark.

Narratology and montage are the tools that allow us to see the structure of Russell's work. But iconology helps us to see how everything is kept together on the level of the works' meaning. Iconologists not only try to understand works of art within the broad background of the culture in which they are at home, but also trace how these works (and particularly their iconographical motifs) travel from context to context on what Aby Warburg has called, in his discussion of astrological imagery in the Italian Renaissance, a 'Wanderstrasse' (2010: 480). A Wanderstrasse is an 'exegetic journey' ('exegetische Rundreise'; o.c. 484): a map connecting thematic or iconographical dots through diverse territories. This means that Warburgian iconology is not merely concerned with restoring a work of art to its broader original setting: it also seeks to show how the position of the work in that setting is only one point in the historical Nachleben of older motifs. ${ }^{28}$ Meaning and expressive forms are rarely created ex nihilo: they have a history. Often, the forms and ideas we use are conglomerates of motifs that have a long history that can be traced (like so many dots on a trans-historical map) through widely different times and places. This history also continues (if the object under scrutiny belongs to the past) beyond that specific point in time and space. In researching Wanderstrassen Warburg engages a view of history in which strict demarcations between periods (something that has increased with the professionalisation of the humanities, which requires subjects and chairs to be neatly packaged in marketable "slots") seems rather futile. History is always lived in the present and it is only retrospectively that periods and movements

\footnotetext{
${ }^{28}$ The fact that Nachleben is the central idea in Warburg's work is articulated by Rampley (1997) and McEwan (2006). Didi-Huberman (2002: 91-102) has effectively argued that a number of important texts by Panofsky, such as 'Iconography and Iconology: An Introduction to the Study of Renaissance Art' (1970: 51-81) and 'Renaisance and Renascences' (1972: 42-113), were expressly written in opposition to Warburg's notion of Nachleben: his discussion illuminates Warburg's point.
} 
are inscribed upon the willing (and defencelessly passive) palimpsest of times past. From day to day, time goes on and life goes on. That is the real movement of history, and it is in this real context that meanings, ideas, and motifs journey, disappear, re-appear, and mutate. On this view, history is more appropriately seen as a mighty river, with neither beginning nor end, and in which currents, rivulets, but also the debris of artefacts, motifs, and ideas that have been swept along in the stream sometimes surface, then disappear, only to turn up again in unexpected places. Chance and coincidence have more to do with this than we sometimes care to think. It is sufficient to consider how the discovery of the cultural treasures of Antiquity changed the culture of what we now call the Renaissance, or how Aristotle survived into medieval European philosophy via Arab libraries: these were unplanned developments which are in a very real sense coincidental and could just as well not have happened. On a Wanderstrasse things therefore sometimes go underground or follow eccentric trajectories.

The aim of the present book is therefore not merely to understand the internal logic and poetics of Russell's work and to understand these in the setting of the times in which he lived and worked. The aim is to show that what makes Russell relevant for our own time is the way he exemplifies the Nachleben of an attitude to life that has long historical roots but which has become primarily associated with the historical Baroque. This is why Russell's body of work is important for the discussion of the neo-baroque: not because of his "excessive" formal strategies (a reading that takes its cue from the impoverished understanding of the historical Baroque as "the art of the CounterReformation" or Panofsky's "lordly racket") but because his work expresses attitudes to the self, the performance of the self, and the role of art in that performance which can be read as dots on a continuing history of motifs and ideas that can be traced back to the historical Baroque. They can also be traced back beyond that, but what interests us is the fact that the historical Baroque is a moment in modern history when these elements crystallised into a cultural form whose long shadow is clearly cast into our own time. The present book therefore treats Russell's work as an archaeological site where we can dig up the history of the present. This archaeology of the present, however, is at the same time synchronic and diachronic and cannot be the one without the other: it is synchronic because it attempts to establish the structure of contemporary pressures and tensions that go into shaping the work, but it is diachronic because it also seeks to show how these pressures and tensions, and the motifs and ideas they occasion, are always already carried over from past times and places. This is the key point: what shapes the present is always carried over and revivified, not simply from "the" past, but from many pasts and many histories, each of which are themselves carried over from other pasts and other histories. 


\section{INTRODUCTION}

For the genre of the artist biography such a map of thematic dots was already established many decades ago in Ernst Kris and Otto Kurz's book on Die Legende vom Künstler (1934; new edition 1980) and in Margot and Rudolf Wittkower's Born Under Saturn (1963), to name only the two most widely known titles in the literature. These books, whose methodology is deeply indebted to Warburg's, trace a number of typical anecdotes and stereotypes about artists to their sources in mythological or religious lore. They pay special attention to the way such stories were re-used in the Renaissance, when they appear in the lives of artists published by authors such as Vasari and Van Mander and also became part of the cult of the artist as troubled genius. As I will show in Chapters Three and Four, Russell's work and his performance of self form a very idiosyncratic addition to this Wanderstrasse of biographical motifs in the lives of artists. On the one hand Russell explicitly presents his artist biographies as a counter-force to the "Hollywood version" of artist's lives, which is deeply informed by such traditional views and also tended to be highly sanitised, embellished, and sometimes even completely divorced from the historical record. Russell wants to debunk the myth of the artist as isolated genius and bring the dirty laundry which has been spirited away (and this usually means the unseemly side of an artist's private sexual affairs) back into the limelight. At the same time, however, he identifies himself as a myth-maker, - but of a different kind. In analysing how Russell developed his own views on the artist and put them into practice in the creation of his own work I will show that Russell on the one hand debunks the Romantic myth of the artist (which was in reality already a Platonic myth which later became a Renaissance myth), but on the other hand introduces a new myth in its stead. The interesting twist, however, is that Russell's alternative myth actually takes its inspiration and to a considerable extent even its creative method from the work of Romantic artists, and especially William Wordsworth. This suggests that Russell has managed to subvert the Romantic myth of the artist from within. By the end of Chapter Four it should be clear how exactly he has achieved that.

\section{PATHWAYS: OUTLINE OF THE BOOK}

The book is divided into four main chapters and a concluding essay. Chapter One begins by showing how the narrative devices that Russell uses in his autobiography are similar to those used in his films on the lives of other artists. This is demonstrated by putting Russell's autobiography next to his film Mahler. I also show that the narrative structure that Russell has most consistently used throughout his career is that of the embedded narrative, including its particular form of the mise-en-abyme, which is a self- 
reflexive embedded narrative. I will argue that these narrative devices are very typical (though not exclusive) of the historical Baroque, where they were frequently used in the theatre. This is demonstrated with key plays by Corneille and Molière. The chapter ends with the suggestion that these narrative structures, rather than the perceived "excess" of Russell's style, are the most promising way of exploring what is "baroque" about Russell, especially because these structures are connected, in the context of the Baroque, to a world-view that sees the entire world as a stage. This idea, which is crucial to my analysis, is further developed in Chapter Two, where an extensive analysis of The Devils will show that this film is completely constructed as an allegorical theatrum mundi: a theatre stage that represents the world. This is a popular Baroque trope and one that is of key importance for understanding how Russell performs himself through art. In that sense the first two chapters provide the bedrock of the analysis by elaborating, respectively, the fundamental narrative structure of Russell's work (embedded narratives) and how this structure is connected to the Baroque world-view. From this basis I will argue that Russell's work, and specifically his performance of self through art, is part of the $\mathrm{Na}$ chleben of the Baroque in the present.

Chapters Three and Four are also connected because they look more closely at how Russell performs himself on the stage of the world and what kind of idea of the artist guides that performance. In Chapter Three I first establish that Russell wants to break with a traditional Romantic view of the artist as pristine genius. He sees the artist as a worker. Most of the chapter reconstructs how Russell came to hold this view of the artist and shows that it developed throughout the 1960s, when he was working for the BBC. I show how his ideas on art and artists, and on how one should make biographical films about artists, developed in response to institutional pressures and conventions which Russell increasingly sought to subvert. Interestingly, this subversion and the evolution of his ideas on art and artists are not only part of the narrative content of his films: Russell also applies these developing ideas and principles in the way he makes his own films. Russell's work at the BBC can therefore be read as a record of his own changing attitudes as a creative artist. In the second part of Chapter Three I take a close look at several of Russell's BBC films, and especially his film on Isadora Duncan (1966), to show in detail how Russell's ideas on art and artists translate into a highly individual way of making films. I will argue that it is at this point that the films begin to function as a performance of self: who Russell is, and how he conceives of himself as an artist, is something that he performs in the way he makes his films. While Russell has also talked about this in interviews and has often played his chosen role (as a Romantic and selfproclaimed enfant terrible of British cinema) in public, it is in the texture and structure of his films that the performance is most interestingly achieved. 


\section{INTRODUCTION}

In Chapter Four I look in more detail at how Russell performs himself through his art by looking at both the kind of artist he wants to be (perceived as) and how this translates into the texture of his films. The chapter has two main parts. First, I perform a detailed analysis on Russell's film Salome's Last Dance to show how the film re-engages with the trope of the world as a stage from The Devils, except that this time Russell has introduced himself into the performance to make an elaborate comment on his own work as director. The film, and Oscar Wilde's play Salomé (1893) upon which it is based, are both about the way artists create a world. This makes it possible for the film to be read as a comment on Russell's own work as an artist. In the second part of the chapter I argue that Russell's film Gothic goes a step further and can be read as a poetical statement on some of the cardinal principles in the Romantic theory of artistic creation as articulated in Wordsworth's Preface to the Lyrical Ballads (1802), which is a key text in Romantic poetics. Russell applies these principles to film through the use of montage, and especially along the lines of Eisenstein's theory of montage. This means that with Gothic Russell has made a film about the principles of creation that inform his work, but which at the same time puts these principles into practice. This is a point where his work can clearly be seen to be performative: the narrative about Romantic creation is constructed along the principles of Romantic creation. This means that Gothic performs Russell as a Romantic artist because the film actually shows him making a film like a Romantic artist. This is the point at which all the strands that run through this book come together. Some of the implications of the performative quality of Russell's work will be elaborated in the concluding essay, which reconsiders the issues and questions from this Introduction in the light of the results of my analysis.

Throughout the book I have tried to let Russell's work do most of the talking and have kept the theoretical baggage to a minimum. There is always the risk of turning a work of art, or an entire oeuvre, into an illustration of a theory, while in this case it is clearly the artist and his work who challenge us to rethink some of our theories about art and artists, about biography, and about the baroque. In that sense I have heeded the advice of A.E. Kolve, whose discussion of medieval Corpus Christi plays (which will be central to my analysis in Chapter Two) introduces much theological and philosophical evidence of which Kolve openly acknowledges that the authors of the Corpus Christi plays could and would not have been aware. In fact, he says, 'the machinery of learning is little evident in these plays, though subtleties of theological understanding are apparent everywhere, determining the choice of an episode, the manner of its staging, the shaping of its action, the textures of its language, and even the invention of new action. Though I have had to support my readings with a burden of learned reference, the purpose of all this material has been simply to alert our eyes and ears: it is meant to be re- 
membered in substance, not in scholarly detail; it should be kept at the back of the mind, not the front. Once the play has begun, or we have opened a text to begin reading, we must put ourselves entirely into the dramatist's hands. He will make such demands upon our knowledge of these traditions as serves his specific end; our duty and privilege is to attend to the immediate address of the work of art' (1966: 265-266). To alert our eyes and ears to the immediate address of the work of art: this is my intention throughout this book. And I can think of no nobler or higher mission for any serious work of criticism. 



\section{Chapter One}

\section{SEARCHED FOR THE SOUL OF THE}

MAN

Ken Russell's Autobiography as Baroque Performance

'Cette histoire ne me paraît guère vraisemblable.' 

After three decades of making films about other artists, Ken Russell finally came around to making his own autobiography. A British Picture: Portrait of an Enfant Terrible (1989) exists in two versions: an autobiographical book ${ }^{29}$ and a television film of the same title made for Melvyn Bragg's South Bank Show and first broadcast on 15 October $1989 .{ }^{30}$ Although the film version is a very ingenious piece of work, with Russell's young son Rupert playing the part of his father, my discussion will focus on the book version, which is a major contribution to the Russell canon, on equal footing with his biopics on the lives of other artists. In fact, if we look at the autobiography against the background of Russell's biographical films on artists it is striking how he has appropriated many of the structural features and tropes of his biopics in the presentation of his own story. In a sense, Russell gives Russell the Russell treatment in his autobiography: the way he approaches his own life story is quite similar to the way he would tell the lives of other artists. To illustrate the many parallels between Russell's autobiography and his work on other artists I will perform a comparative analysis of the narrative structure of the autobiography and Russell's film Mahler (1974), which is one of his most accomplished artist biographies. Since I am exploring Russell's narrative tropes my main concern is not with the accuracy or veracity of the biographical and historical facts Russell presents. I am interested in the narrative structures deployed for the purpose of constructing the autobiography. Specifically, I want to argue that the methods Russell uses in his work have striking structural similarities to narrative tropes that are typical for Baroque theatre. But even more importantly, I want to show how such a triangulation of Russell's biopics, his autobiography, and Baroque theatre opens up a new and very promising perspective on treating Russell as baroque. To do that I will first look at the way his film on Mahler is constructed. In the second part of the chapter I show how a similar structure informs key passages of Russell's autobiography, and often to similar effect. Finally, the last sec-

\footnotetext{
29 Three editions of the book version of Russell's autobiography exist. The original, A British Picture, was published by Heinemann in 1989. Next came Altered States, an American edition of the book published by Bantam in 1991. The American version contains a short new chapter covering events since the publication of the British edition. There is also a Foreword by Twiggy Lawson, star of Russell's film The Boy Friend (1971), and the American edition features a modest number of black-and-white illustrations. Finally, in 2008 Southbank Publishing issued a new edition of the book that returns to the original 1989 text. It does not retain the new chapter written for the American edition, features no illustrations, and substitutes a Foreword by Melvyn Bragg for the Twiggy Foreword. It does offer a new brief final chapter by Russell (covering a number of events between 1989 and 2008) and there is a Postscript by Russell's fourth wife, Lisi Tribble. There is also and inadequate Filmography at the back which is copy-pasted from the Internet Movie Database. However, since this was the last edition authorised by Russell himself, and since the supplementary chapter of the 1991 American edition offers no substantial content, I use the 2008 edition throughout. References in the text are preceded by the abbreviation BP.

${ }^{30}$ Date given by Kermode (2002: 30), who lists first broadcast dates for all of Russell's television films.
} 
tion of the chapter will argue that these narrative conceits are best understood from a baroque perspective.

\subsection{CONSTRUCTING MAHLER}

Russell's autobiography A British Picture is written from the point of view of 1989. Russell looks back on his life and reconstructs his life story. He uses several framing devices to achieve this. The first sentences of the first chapter immediately propel us back in time: 'It was 1976. Valentino was in post-production. My marriage was on the rocks' (BP 1). Russell remembers how 'one of the regional TV stations wanted to know if their local lad would be interested in making a documentary on childhood memories of his home town' (ibid.). Russell accepts the project as an excuse to get out of the house, where the atmosphere between him and his wife has become 'electric' (ibid.). In the event this proposed documentary, titled Ken the Kid (which is also the title of the first chapter of the autobiography), would never be made, but in the first three chapters of the book Russell recounts his visits to sites from his childhood doing research for the film. These visits are developed into extended embedded flashback narratives that are intertwined with his account of finalising the film Valentino and the disintegration of his marriage (to Shirley Kingdon, the celebrated costume designer for many films both by her husband and by other directors). By the end of the third chapter most of Russell's childhood memories have been presented and Russell spends the following chapters developing his romance with his future second wife Vivian 'Viv' Jolly and his inability to find new work after the commercial failure of Valentino. In chapter four he uses a boat journey to the United States, where he will be greeted by Vivian, as another framing device for memories. After that, the journey-as-memory trope is abandoned for a more conventional narrative where the events of 1976 through 1989 are the frame in which further memories are embedded. Several of the subsequent chapters focus on a particular aspect of Russell's life, sometimes with extensive biographical flashbacks embedded into the narrative. In chapter twelve, for example, Russell's conversion experiences have pride of place. Chapter fourteen deals primarily with his direction of opera for the stage. The final chapters sixteen and seventeen bring the story up to 1989 , when his marriage to Vivian is also disintegrating (by the time the American edition of the book appeared in 1991 they were divorced).

Throughout the book Russell is not very strict with chronology. Many events are only vaguely dated. Russell's narration is often associative. As such, the book's narrative structure has many striking similarities to Russell's films, which tend to use analeptic 
framing devices to construct life stories, telescope different events into one event, or even alter chronology for dramatic effect. To understand what kind of autobiographical narrative Russell aims at presenting it is therefore necessary to establish his general method and its underlying concept of biography and biographical narration. Russell has made his most programmatic statement on his method in the production notes for Mahler, where he explains that 'most of my films on composers evolve through a stream of consciousness in which the man and the myth, the music and its meaning, time, place, dream and fact all flow and blend into the mainstream of the film itself. The lifespan of a man is measured in years, the screen-time of a film on him is measured in minutes.' Russell believes that, in order to achieve such condensation, 'the impressionistic technique works best. When every second counts it is often necessary to say two things at once which is why I frequently introduce symbolism into scenes of reality' (Russell 1974: 6). It is clear that "impressionistic" in this statement refers not to the arthistorical movement but to the presentation of a subjective view, a subjective impression. As Russell himself explains, 'my film is simply about some of the things I feel when I think of Mahler's life and listen to his music. It is by no means a definitive view, there are as many facets to the mystery of Mahler's music as there are lovers of it' (ibid.). However, this subjective impression of the artist as experienced through his work is not entirely disconnected from traditional biography: it is informed by historical fact. 'As is my custom when approaching a film or a composer, I [...] searched for the soul of the man in his music, while also keeping the facts of his life in mind' (BP 141). Furthermore, in Mahler this subjective experience also provides the basis for the film's structure. Or, as Russell himself puts it, 'Mahler himself really dictated the content of my film and in a sense the musical shape as well - that of a Rondo. Rondo form is A B A C A D A E etc. In this case $\mathrm{A}$, the recurring theme, is love - the love of Mahler for his wife - B, C, D, E etc are all variations on the theme of death including the death of innocence, responsibility, aspiration, trust, understanding, etc. Some of the death themes are also connected with the main theme and one of these is developed at some length. It is probably the most important of all - the death of love' (1974: 4). The strong focus on death is justified with reference to Mahler's symphonies, for Russell argues that at least five of the symphonies, with the addition of Das Lied von der Erde and the Kindertötenlieder, have death as one of their main themes. Russell also suggests several connections between the music and the life and claims that, of the symphonies, 'the sixth is autobiographical' (ibid.).

But the rondo structure of Mahler is not merely a thematic device, it also structures the narrative framework of the film. Mahler is set at the very end of the composer's life, in early 1911, and it takes place entirely during a train ride home to Vienna after an 
exhausting period of conducting in New York. During the journey Mahler, who is critically ill, regularly sinks into reverie, which cues several flashbacks to key moments in the composer's life. In rondo terms, $\mathrm{A}$ is the framing device of the train journey, and $\mathrm{B}, \mathrm{C}$, $\mathrm{D}$, and all the other movements are embedded flashback fugues that Russell has interwoven with the journey. The most famous, and also the most infamous, of these fugues is the fantasy on Mahler's conversion to Catholicism in order to obtain his position as conductor at Bayreuth, where the anti-Semitic Cosima Wagner pulled all the strings. This fantasy, which is probably 'the most universally disliked scene' (Hanke 1984: 245) in the whole of Russell's output, is presented as a film-within-the-film, "The Convert, starring Cosima Wagner with Gustav Mahler", which is embedded in Mahler's own flashback of the events leading up to his conversion. This outrageous fantasy shows Cosima Wagner (Antonia Ellis) dressed in a Nazi stormtrooper outfit cracking a whip to make Mahler jump through burning hoops and climaxes with the two of them sitting on the hilt of a giant sword singing, to the tune of Wagner's Ride of the Walkyries, that Mahler is 'no longer a Jew-boy, you're one of us now, now you're a goy'. To confirm his conversion Mahler takes a bite out of a pig's head and gulps down a glass of milk. ${ }^{31}$ As a film-within-the-flashback this fantasy is twice embedded. It is also a good example of the way Russell imposes his vision on his subject, for it is obvious that he is here presenting his own metaphorical interpretation of Mahler's memories of his conversion and not offering a representation of Mahler's actual memories. It is unlikely that Mahler, even as represented in Russell's film, would actually have had a memory in the shape of a film in high camp mode. At this point, Russell simply invades the narration to impose his own interpretation on (the memory of) events. This interpretation has to do with "selling out": Mahler betrays his beliefs and his art to further his career. Russell was always severely critical of artists who compromised their integrity in such a way. ${ }^{32}$ In

\footnotetext{
${ }^{31}$ Russell's camp use of Nazi iconography in this embedded film is a continuation of his grotesque approach to Nazism in Dance of the Seven Veils (1970) on Richard Strauss. The latter film ended his collaboration with the $\mathrm{BBC}$ and proved highly controversial. Hill (2015) has reconstructed the film's tumultuous reception and the extensive support that Russell received from within the BBC. Russell himself acknowledged that 'Huw Wheldon made a speech in the Houses of Parliament defending the film and my right to say what I felt. That was a great moment. I have no bitterness about that - if it rains you get wet' (quoted in Tibbetts 2005b: 44). The whole play with Nazi-paraphernalia should perhaps also be seen in the context of the dubious wave of "Nazi chic" of the 1970s, extending from auteur films such as The Night Porter (Liliana Cavani, 1973) to a miniature industry of unsavoury European sex films set in Nazi death camps.

${ }^{32}$ Russell's dislike of "selling out" to commercialism is a constant concern throughout his career. In The Music Lovers, for example, Tchaikovsky's pursuit of financial success (under the watchful eye of his brother Modeste) is sarcastically represented in the "Ouverture 1812" segment (see the discussion below, section 4.3.3.). In this respect, Dickinson has argued that Russell's composer biopics of the 1970s can be read as responses to the difficult working conditions for artists at that time, and that Russell portrays his composers as 'victims of job insecurity. None are working for guaranteed salaries, and each makes enormous sacrifices in order to stay
} 
Mahler it is the composer himself who, facing death, comes to regret this compromise and urges Alma never to do anything out of a sense of duty, and only to act out of love, for 'duty destroys. Duty always destroys.'

\subsection{IN SEARCH OF COLLAPSED TIME}

A close reading of A British Picture reveals many of the structural features that I have identified in Mahler. The first three chapters of the book provide a framing device quite similar to the train journey in the film: as Russell is completing Valentino he goes on a journey of remembrance to the sites and places of his youth. This journey triggers many of the most important flashbacks in the book, covering the key events of his youth, many of which are already familiar to the reader of John Baxter's An Appalling Talent (1973), for which Russell allowed extensive interviews that were developed into chapters that offer a first-person autobiographical account (and which were heavily edited by Russell himself ${ }^{33}$ ). But the parallel goes further, for one of the reasons Russell agreed to go on this journey of remembrance is to avoid confrontation with his wife during the break-up of their marriage. This provides an analogue to the unravelling of the Mahlers' marriage in the film, for although the train journey ends with Alma Mahler choosing her husband over her lover Max (a symbolic figure in whom Russell, in a common biopic device, 'distilled all the men interested in Alma'; Russell 1974: 5), we know that Mahler will be dead within weeks. As pointed out before, the framing device of the location scouting for the autobiographical film is effectively abandoned at the beginning of chap-

afloat: Tchaikovsky denies his homosexuality in order to curry favour with patrons; Mahler converts from Judaism to Catholicism to secure a post at the Vienna Opera; and Liszt's career is based more on populist cash-generating concerts than intellectually taxing composition. Under harsh conditions, work is inevitably compromised' (2008: 89). Russell himself directed a number of commercials in the 1960s and his very unpleasant experiences in this area informed the vigorous attacks on commercialism in Tommy (AT 131-132 on the commercials; Wallis 2009 on Tommy). Regarding this rejection of the commercial side of film-making, Hoyle has argued that Russell's cinema is very much a cinema of the "amateur", but in 'the "correct" definition of the term, which means simply "one who loves" and refers to anyone who is involved in any activity, such as art, for pleasure rather than for material gain,' and that Russell himself has always remained an artist who 'creates art for the love of it and works with and for family and friends' (2009: 40 and 60).

${ }^{33}$ Gomez regularly quotes from the typescript of Baxter's book, which contains much material that was dropped in the version that ultimately went to press. He explains that 'Russell also changed many of his comments and deleted larger sections of the manuscript dealing with The Boy Friend. In view of the legal difficulties surrounding the publication of the book, perhaps it was a wise decision to cut out many of the very personal and often extremely candid comments found in this version of the book' (1976: 31-32). Interestingly, Hanke also reports that Russell showed 'great kindness' in helping out with his book, 'going so far as to virtually perform the function of proof-reader, catching several errors and making helpful suggestions all round. He never took issue with any value judgements or interpretations' (1984: v). 
ter four, which reconnects with the events during production of Valentino. After that the structure of the book becomes less dense, but Russell compensates by including a number of highly effective narrative fugues which collapse the events of several days, or events that took place some time apart, into one day. It is interesting to look at three of these fugues in detail. The first, in chapter seven, is what I will call Russell's "false gay memory". The second, in chapter ten, concerns a nervous breakdown in the late 1970s, culminating in an embarrassing black-out during a live television interview. The third, and also the most impressively accomplished, is what I will call the "fell-walking fugue" in chapter nine. In the next three sections I will analyse these fugues to introduce a number of narrative tropes Russell regularly uses and suggest that these are also the most fruitful way of exploring how Russell's work could be considered baroque.

\subsubsection{The False Gay Memory Fugue: Embedded Narratives}

The "false gay memory" is most interesting, for our present purposes, as an exemplary case of the way Russell generates embedded narratives with great cinematic vividness. The sequence, which runs for the better part of chapter seven (BP 105-115) recounts a day spent with one Denny, a gay Russell groupie who has a Russell shrine in his backyard where he keeps memorabilia from Russell's films. For a considerable part of the fugue Russell entertains and teases Denny with stories of gay adventures from his life as a bohemian artist in the early 1950s. At the end of the story Denny wonders why none of these stories were included in the autobiographical sections of An Appalling Talent, which was 'supposed to be your authorised autobiography' (BP 114). To which Russell replies that these stories are merely stories and leaves both Denny and us in the dark as to the veracity of the narrated events. Structurally, however, most of Russell's own reported dialogue in this long section is double-layered. The Denny fugue contains several pages of direct dialogue between Russell and Denny, as if it were quoted from memory. Obviously, this encounter with Denny is a construct. Even if both men did spend such a day together, nobody could recall their dialogue in such verbatim detail. Furthermore, many of Russell's supposed (but possibly invented) memories of his bohemian life are also full of direct dialogue. This makes for many quotations-within-quotations, with Russell reporting reams of direct dialogue from the 1950s embedded in an extended framing dialogue that is supposedly quoted from memory. This leads to complex constructions, where several lines of dialogue between Russell and an artist friend in the 1950s are actually reported by Russell to Denny, with Denny's questions and Russell's answers to Denny inserted between. 
Similar constructions occur elsewhere in Russell's autobiography, for instance when an infamous incident on the set of Valentino, where Russell had to adjust a hose in Rudolf Nureyev's pants for the filming of a scene in which Valentino wets his pants in prison, is told to Viv in New York. This 1976 conversation between Russell and Viv contains the embedded narrative of Russell's report of the event, including direct quotations from many parties involved. The result of this approach is a heightened vividness quite similar to the effect of watching a film. Instead of reporting events in Mahler, for example, Russell simply uses flashbacks to give us the actual event, cutting back and forth between time-frames at an often bewildering pace, especially when he also includes fantasies or further memories within the flashback. The result for the viewer, however, is always the same: it is as if we are experiencing events at first hand. The same holds for Russell's autobiography. When Russell reports on his 1976 self reporting on the events with the hose on the Valentino set, the effect for the reader is an impression of simple direct reporting, including extended dialogue, from the Valentino set. Similarly, when Russell (the 1989 autobiographer) reports on his 1976 self reporting events and dialogue from the 1950s to Denny, the dramatic effect for the reader is a straightforward account of the 1950s events. In this respect the embedded narratives in the book and in the films are structurally analogous. The analogy is accomplished in the book through the use of (embedded) direct speech, which lends a sense of immediacy. In cinema such immediacy is inevitably achieved whenever actors appear on the screen and (do or do not) speak, even in embedded flashback scenes. In film everything, even a flashback, is always present here and now in front of our eyes. ${ }^{34}$ In the book Russell uses the structure of reported dialogue to achieve a similar effect.

Although it is always tricky to speculate about an artist's sources, there is some tantalising evidence that suggests a biographical source for Russell's extensive use of embedded direct speech and dialogue-within-dialogue. Russell's BBC film on the life of Delius, Song of Summer (1968), relies extensively on the memoirs of Eric Fenby, the young composer who spent four years with the declining Delius to take down his compositions in dictation (Delius had become paralysed and Russell's film was in fact the first biography of Delius to acknowledge that this was due to syphilis). Fenby often gave public lectures on his life with Delius, during which he acted out his discussions with the composer. He also became involved in the preparations for the film and visited the composer's former house together with Russell. During this visit Russell was struck by Fenby's 'remarkable ability to dramatise vividly his life with Delius' and by Fenby's re-

\footnotetext{
${ }^{34}$ This is what one could call the "emergent" nature of film. I will return to this when I discuss Susanne Langer's ideas on film in Chapter Four: see section 4.4.
} 
markable memory: 'I'd ask Fenby about a particular event and he'd just tell me the dialogue for it. It was the most immediate impression I've ever had of any person I've filmed. We changed a few lines but most of the script was taken from his recollections of their own words' (quoted in Gomez 1976: 60). In his detailed analysis of several of Russell's films Gomez has also established that the films' dialogue is often taken directly from the sources Russell used. He explains that 'Russell likes to use the exact words of the actual personages even if the context may be totally different from the original use' (o.c. 100). Russell himself has acknowledged that 'there are more quotes than most people think in my films. Whole scenes are often made up from things the people said at various times' (quoted in o.c. 112). Gomez shows that Russell often makes very free use of such quotes. He changes the occasion or context, sometimes he gives a quote taken from one person to another person, or he collapses the words of several historical characters into text spoken by one character who represents these several historical personages. But whatever the doctoring or collage involved, Russell would often take his basic material from external sources rather than invent new dialogue. Russell's main concern in borrowing texts and events from historical sources and using them in his own way, is that 'I believe you've always got to be accurate to the spirit or the word all the time when you're doing a biography or an adaptation' (quoted in ibid.).

However, such strategies of adaptation also harbour dangers. The complex approach of remembering or reporting on past events sometimes leads to constructions that are logically and structurally impossible, as when a memory belonging to one character suddenly leads into an embedded memory belonging to another character. We are then faced with the factual impossibility of one person remembering another person's memories as remembered at the event remembered by the first person. Two examples from Russell's films will make clear how such incongruity comes about. The first example is taken from Valentino (1976), Russell's film on the life of film star Rudolph Valentino. In this film the framing device is the star's funeral. As his body is laid out, mourners come to pay their respects or make a spectacle of their mourning for the press. Their memories of Valentino, or their answers to questions by eager journalists, are the cues for a number of flashbacks that reconstruct the actor's life. Gene D. Phillips has identified one 'serious failure in narrative logic' (1979: 139) in this film, when June Mathis's fantasies about Valentino are embedded in a sequence that is narrated by actress Natasha Rambova, Valentino's wife. As Phillips points out, 'June Mathis's private fantasies about Valentino simply have no place in a flashback presented from Natasha's point of view' (ibid.). There is a similar incongruity in Mahler. After the composer has collapsed with a heart attack on the train (which triggers a nightmare about his own funeral), he is resting with his head on Alma's lap. We are then taken into Alma's memory of the meta- 
phorical death of her music as she remembers an occasion when Mahler played one of her songs on the piano. His mistress Anna sings the words. After the performance Mahler and Anna mock Alma's composition and Mahler advises her to give up composing on the grounds that 'I don't want to see you get hurt, I've seen it too often'. The camera then briefly stays on Mahler's face, which cues an embedded memory of a visit by Mahler and his sister Justine to the composer Hugo Wolff, who is living in an insane asylum, driven mad by lack of recognition. After this embedded memory Mahler repeats his concern for Alma, after which she leaves the room and literally buries her music. In this reading Mahler's memories of his visit to Hugo Wolff (at which Alma was not present) are structurally part of (embedded in) Alma's memory of Mahler's and Anna's hurtful performance of her song. But how could Alma remember what Mahler was privately thinking when he gave her the advise to give up composing?

Perhaps there is a satisfactory answer to this puzzle. In Valentino Russell does seem to violate narrative logic, but the sequence in Mahler opens up a more interesting structural perspective. A possible explanation for the introduction of Mahler's memory could be that the embedded memory of the visit to Hugo Wolff, which contains several brief touches of fantasy (notably images of Mahler and his sister waltzing through the gardens of the asylum because Wolff, who believes he is the emperor Franz Ferdinand, wants to test the couple's social skills for life at court), was a memory that Mahler told Alma about to explain why he did not want to see her get hurt (the way Wolff was). In that case the introduction of Mahler's memory in this sequence would be the cinematic equivalent of free indirect speech in literature. Instead of Alma's memory of Mahler telling her about unfortunate Hugo Wolff, Russell substitutes his own brief fugue on the story. If we accept the sequence as visual free indirect speech, we would no longer have to explain how Alma could, within her memory, envision how Mahler remembered his visit to Wolff: the sequence would then be an authorial intervention by Russell. Just as Russell invades the narrative to present the film-within-the-film "The Convert" to comment on Mahler's conversion, he also invades the narrative to paraphrase Mahler's narrative, which is then told from Russell's point of view rather than from the point of view of any of the characters in the film (Mahler's memory of the visit or Alma's memory of Mahler telling the story). Free indirect speech achieves two things at once: it explains how Alma knows about Mahler's memory (he told her about it, rather than simply think about it while talking to her), and it substitutes a cinematically more interesting representation of the narrative for a scene in which Mahler simply tells the story. We, as viewers, are not privy to this dialogue but are treated to a paraphrase of the story. 


\subsubsection{The Blackout Fugue: Telescoping Events}

The blackout fugue is another extended sequence that rewards close scrutiny. It takes up about half of chapter ten and brings together a number of possibly disparate events within the scope of one day. The central feature of the day is Russell's appearance on a television programme at a local television station in Southampton. On his way there Russell first makes a stop in London, where he is to be interviewed by an editor for 'a famous publishing house' (BP 154) who would like him to write a book on the wild side of the 1960s. The interview is a failure because Russell has no wild stories to tell. After that disappointment he continues to Southampton and visits his mother 'who was now undergoing treatment at Fareham, the local lunatic asylum' (BP 157). The dispiriting sight of his mother mindlessly clapping her hands triggers a series of embedded memories of his mother as his biggest fan, applauding a number of his ill-fated performances as a stage actor in the early 1950s. After this visit, Russell stops for drinks and then takes a cab to the television station. To his astonishment, 'they weren't expecting me. Fortunately I realised my mistake before making an even bigger fool of myself. I'd confused the stations. STV were the people who'd commissioned the autobiographical film script. God knows when they'd get it' (BP 162). When he finally makes it to the correct television station he has another drink, is put through make-up, and the interview starts. 'The very next thing I remember was the interviewer saying, "And thanks again, Ken Russell, for joining us on Viewpoint"' (ibid.). He is whisked off the set, oblivious to what has happened, and is informed that he has made an obnoxious spectacle of himself, talking nonsense and offending the interviewer and the crew. 'Nausea was sweeping over me in waves. I excused myself and made for the loo, where I arrived just in time to throw up.' After this debacle Russell takes refuge in his hotel room and crashes in bed. But he wakes up in the middle of the night to go to the bathroom. Half asleep and stark naked, he walks into the corridor rather than the bathroom and the door of his room closes automatically behind him. He makes his way to the front desk and manages to draw the attention of the night porter, who lets him back into his room. After this humiliating trial, 'I stepped into the room, stone-cold sober, and noticed an envelope on the floor that I must have overlooked before' (BP 165). It contains a telephone message: he has been offered a development deal for a film adaptation of Dracula (which never made it into production ${ }^{35}$ ).

This fugue is a fine example of Russell's "telescoping of events": representing events that are not actually or factually connected as if they were, for example by presenting

\footnotetext{
${ }^{35}$ The Dracula script has now been published with an introduction by Paul Sutton (Russell 2012).
} 
them as the interconnected events of a single day. It is unlikely (although not impossible) that all of the events described above took place within the span of one day. There is, for example, a dramatic build-up to an emotional and physical nadir, the blackout and the humiliation of being locked out of his room, followed by the release of good news in the form of a development deal, which will ensure Russell an income for some time. It would be highly unlikely for real life to imitate the dramatic requirements of narrative art so dutifully. The fugue also allows Russell to embed a number of memories. The interview with the publishers allows him to recall a comical incident with Twiggy. Just like the Denny sequence, this interview is recounted in direct dialogue, as if Russell can still remember verbatim everything that was said at the meeting, enhancing the vividness of events and allowing him to tell two memories (the memory of the interview with the publisher and the embedded memory of Twiggy) at the same time. He also embeds memories of his mother, which further allows him to present several of the key moments in his brief career as a stage actor. Finally, this narrative build-up also moves the framing story along by taking us from a situation of crisis (at the beginning of the chapter Russell had become unbankable after the failure of Valentino) to a situation of renewed hope (there is a development deal, meaning his career might recover after all). By collapsing time-frames and events in this way, and by structuring the events as a build-up to resolution, Russell achieves dramatic intensity and a compelling narrative drive. All elements in the chapter are focused on the same outcome: the development deal that offers relief at the end of a bad trip.

Russell uses this structure again in chapter twelve, where he offers a further number of childhood experiences. These memories are framed by a boat journey from the United States to the United Kingdom after work on Altered States (1980) has been completed. The journey takes place on the Queen Elisabeth 2. This is interesting because Russell several times mentions that, when he was a child, the captain of the QE1 was their neighbour. The first embedded narrative of the chapter relates Russell's conversion to Catholicism, which he presents in terms of becoming 'a Catholic space cadet' (BP 190) for 'the Great Spaceman in the Sky' (BP 191). The main embedded memory, however, relates a family trip on a boat. Russell's father had obtained a lifeboat from an oceanliner that had been demolished and had transformed it into a motorised yacht. It was used for mandatory family boating trips. Russell remembers one such outing during which his father first unwittingly manoeuvred the boat onto a maritime landing strip, which causes the boat to almost be toppled by a landing aircraft. Next, Russell describes the horror of all concerned when his father urges them to use a species of 'thick-ribbed worms a foot long with hundreds of flailing legs' (BP 197) as bait for fishing. Finally, as Russell, his father, and his uncle are wrestling with a giant conger eel that Russell's fa- 
ther has caught, there is suddenly 'the sound of an almighty fart' and 'a black and white city the size of New York was bearing down on us' (BP 198). This huge ship, which misses the Russells' boat by inches and nearly capsizes it with its bow wave, is the QE1, connecting the embedded memory to the QE2 of the framing narrative (there is also the possible humiliation of their neighbour, the captain of the $Q E 1$, having seen them from his ship). Finally, there is a final childhood recollection of Russell running away from home during the night after a humiliating incident in the car with his father (Russell mistakes the hiss of a battery that is short-circuiting for the hiss of snakes and panics) and seeking refuge on a bridge over the railway line to London at St Denys station. After disembarking the QE2 in the framing narrative, Russell again visits his mother and then catches the last train to London, riding under the very bridge on which he had taken refuge in the embedded memory. Again, the many resonances between the framing story and the embedded narratives suggest that Russell has rearranged the facts to fit the narrative and dramatic demands. Furthermore, the childhood memory of the sailing trip itself is possibly a composite of several events and might even contain some fictional elements.

\subsubsection{The Fell-Walking Fugue: Self-Reflection}

The most accomplished of all the fugues under discussion is the fell-walking fugue in chapter nine of A British Picture. This fugue is remarkable for several reasons. It is set in the late 1970s, after Russell has finished making the two Clouds of Glory (1978) films on the British romantic poets Wordsworth and Coleridge for Granada Television. He is describing his new life with Viv after the divorce from Shirley. The new couple is living in a cottage ('something I'd won in the divorce lottery'; BP 133) on the shores of Lake Derwentwater. Since Russell has become unbankable as a director, he and Viv have a lot of spare time and they like to spend at least some of it hiking on the surrounding mountains, of which Skiddaw is the most commanding. In an impressive fugue Russell describes how they decide to climb Red Pike mountain and set out by car. As they drive along the winding roads, Russell starts speeding until 'we're airborne' (BP 136). Russell and Viv fly over the landscape in a fantasy that recalls a similar shot in Mahler where the camera races over Derwentwater towards Skiddaw, which poses for the Alps. It also prefigures the very last paragraph of A British Picture, in which Russell is in a helicopter filming an aerial shot for The Rainbow (1989) and describes racing over Derwentwater towards Viv and the children, 'all waving, waving up at me' (BP 293). But when Russell and Viv after much exertion finally reach the top of Red Pike the trip becomes an inferno. First a fog sets in, then a snow blizzard, the Russells get lost, they are nearly hit by a 
body-bag that is dropped down the mountain (apparently the local way of recovering mountaineering casualties), and almost fall down a mine-shaft and over the mountain's edge. After they have finally made it home again, a thunderstorm cuts the electricity, ending the fugue. The first thing that is remarkable about this fugue is that it is framed from the surrounding text not by a shift in perspective but by a shift in tense. The book is written in the simple past, but the fugue opens with an abrupt shift to the present tense: 'On fine days we go fell-walking' (BP 134). This creates a sense of immediacy. The second remarkable thing about it is that it ends with a self-reflexive comment by Russell, who explains that while he and Viv spent much of their free time writing a new film script, they 'did get out for some walks - the highlights of which you've just read about. Well, you don't think they all happened in one single outing, do you? Just as I pack a person's life into ninety minutes of celluloid, so I've just packed the activities of several months into a few minutes. You don't want a second-by-second account of my life, surely? You'd be sitting there for sixty years and, heaven knows, we're all pushed for time' (BP 140-141).

With this self-reflexive comment Russell not only reveals his narrative method (collapsing time, telescoping events) to his readers, telling them how he wrote the book, he also refers, almost verbatim, to his statement in the production notes for Mahler that 'the lifespan of a man is measured in years, the screen-time of a film on him is measured in minutes. [...] When every second counts it is often necessary to say two things at once' (1974: 6). A similar desire to make a programmatic declaration seems to be the motivation behind another, shorter memory presented in chapter four, where Russell inserts a brief description of his visit to the house where Tchaikovsky spent his last years, and which is now a museum. As Russell gets more and more irritated with the Soviet guide's omission of all the undesirable aspects of Tchaikovsky's life, and especially his homosexuality, he angrily attacks the man for censoring history. This leads to a heated argument in which most of the attacks of the guide (who knows very well that Russell is the notorious director of the scandalous biopic The Music Lovers, which was all about the composer's sexuality) are simply the stock criticisms that Russell's films have had to face in the press. The guide shouts that Russell hates Tchaikovsky, Russell shouts back that 'I love him, but my love isn't blind'. The guide further claims that 'you telescope events and characters' and that Russell turned Tchaikovsky's life into 'a frenzied carnival'. Russell in turn repeats several of the arguments he had used in interviews, for example that Tchaikovsky himself claimed that his music was autobiographical, and that 'every bar of his music is open to a different interpretation', implying that the life itself is therefore also open to many different interpretations, including Russell's. Finally, Russell thunders that 'great heroes are the stuff of myth and legend, not facts. Facts 
are for computers. I'm a myth-maker' (BP 57). It is the purpose of this book to show how exactly Russell creates his myths, both about himself and about other artists. Clearly, the narrative devices which I have been analysing play an important part in the fabric of Russell's mythography.

But the fell-walking fugue is more than merely self-reflexive. I would argue that it is also Russell's creative revisioning of the famous Mount Snowdon section at the end of Wordsworth's The Prelude (1805: XIII, 1-84/1850: XIV, 1-129). On Russell's own account, The Prelude became his new Bible after he fell from the Catholic faith towards the end of the 1960s, so there is no doubt that Russell knew the poem very well. ${ }^{36}$ His text contains several elements that seem too close to Wordsworth's account to be mere coincidence. At the beginning of their ascent, Wordsworth and his companions 'roused the shepherd who attends / The adventurous stranger's steps, a trusty guide' (1850: XIV, 89). Russell also introduces a shepherd. As the Russells drive off in their car, they 'wave to our neighbour, the blond, bronzed, bare-chested Farmer Weir, herding a flock of sheep past our front gate' (BP 135). Although the pin-up shepherd neighbour is apparently real (and features in several episodes of the autobiography as an emblem of traditional Lake District masculinity, including a major intervention when he drives Viv to hospital in his tractor after she has gone into labour during a snow storm), the shepherd is also a favourite Arcadian motif in Victorian painting and could be counted here as an element of mock-Victoriana. But there are further parallels. In Wordsworth's account 'It was a summer's night, a close warm night / Wan, dull and glaring, with a dripping mist / Lowhung and thick that covered all the sky' (1805: XIII, 10-12). Wordsworth's mist imagery continues as he reaches the top of the mountain, where he finds himself 'on the shore [...] of a huge sea of mist' (1805: XIII, 42-43), a 'still ocean' (1805: XIII, 46) that calls to mind Caspar David Friedrich's slightly later painting Der Wanderer über dem Nebelmeer (ca. 1818). Although the Russells climb by day (in May), 'the sun climbs with us and soon we are hot and sweating' (BP 136). As the Russells reach the summit, night and day switch places as 'the sun has gone and the mist is cold and clammy'. Most startlingly, 'giant doppelgangers rise before us,' which are 'a pretty rare optical phenomenon called Brocken spectres caused by tricks of sun and mist' (BP 137).

With this added layer of inter-textuality the fell-walking fugue is clearly the most complex of the three fugues discussed. The homage to Wordsworth, however, is not innocent. It is an important clue about Russell's approach to the art of biography. As I pointed out at the beginning of this chapter, I am not especially interested in whether Russell's account is factually accurate. In other words, I am not concerned with estab-

\footnotetext{
${ }^{36}$ The importance of Wordsworth for Russell will be addressed in Chapter Four.
} 
lishing whether Russell sticks to what Philippe Lejeune calls the 'autobiographical pact' (1996: 26), which stipulates that the author of a text presented as autobiography assumes moral responsibility to ensure the identity of himself, as author of the text, with the subject whose life is being narrated. Within this pact, however, authors have considerable leeway. Although, as John Paul Eakin points out, 'telling the truth is the cardinal rule' (2008: 21) we nevertheless 'tolerate a huge amount of fiction these days in works we accept nonetheless as somehow factual accounts of their authors' lives' (o.c. 63). But while the reader might quibble about the resemblance of the text to reality, there may never be doubt about the identity of author and subject. ${ }^{37}$ Eakin argues that the allegiance to truth that is the central, defining characteristic of memoir is less an allegiance to a factual record that biographers and historians could check than an allegiance to remembered consciousness and its unending succession of identity states, an allegiance to the history of one's self (o.c. 64). In this respect, Thomas McFarland has argued that fidelity to chronology is much less important in autobiography than we like to think. In fact, 'the more rigorously a biography begins at the beginning and proceeds by chronological steps to the end, the less vital it tends to be [...]. Chronological markings impose a Procrustean evenness upon the varying contours of actual experience' (1987: 157). He illustrates this point with Wordsworth's famous "spots of time", which are evocative and emotionally charged 'units of experience free from chronological sequence' (o.c. 159). Wordsworth introduced this notion in The Prelude, a long autobiographical poem in which such spots of time function 'in terms of an emphasis of feeling, not an emphasis of chronology. Wordsworth uses his temporal schematism of progression from childhood to adulthood merely as a wire upon which to string his timeless globules of recollection' (o.c. 159). This, I would argue, is also the logic underlying, not just the general structure of Russell's autobiography, but especially the fugue-like combination of disparate events into one extended movement where they are grouped together on the basis of emotional resonance. This was clearly the case with the black-out fugue.

Throughout the three fugues we have found increasingly complicated structures. If the false gay memory fugue was still a more or less conventional embedded narrative (a case of extended reported speech), then the blackout fugue introduced a crucial new element, namely the collapsing of several events into one event. I have suggested Wordsworth's spots of time may be a model for this approach. But there is another model which is complementary to it. Collapsing or telescoping events is really a form of narrative collage: Russell takes pieces of (presumably true) events that happened at dif-

\footnotetext{
${ }^{37}$ I am here paraphrasing Lejeune's remark that 'les formes $d u$ pacte autobiographique sont très diverses: mais, toutes, elles manifestent l'intention d'honorer sa signature. Le lecteur pourra chicaner sur la resemblance, mais jamais sur l'identité; 1996: 26).
} 
ferent times and glues them together in a single narrative of great dramatic sweep. It is a cut-and-paste narrative with the seams neatly smoothed over. The fell-walking fugue is a similar collage of disparate events, as Russell's self-reflexive comment explicitly makes clear (but modelled on a passage in Wordsworth's poem). This kind of collage, however, is one of the most essential stylistic devices in Russell's work, and especially in his films, where he uses the technique to create, not just collages of collapsed events, but allegorical streams of images that symbolically represent events. It is these allegorical fugues with which Russell is most readily identified, and they were also one of the main sources of criticism of his work. In Chapter Four I will discuss this technique in detail and argue that it more appropriately be called montage. ${ }^{38}$ This term has a long history in film studies, stretching back to the work of Sergei Eisenstein, where it covers not just collage techniques in literature, but also in film and in the visual arts. I will show that Eisensteinian montage is an excellent analytical tool to make sense of Russell's cinematic allegories. The fell-walking fugue is the closest Russell comes to creating a similar montage in his autobiography. In that sense, the discussion of these three fugues has not only yielded insight into the narrative structure of Russell's work, it also already points forward to the techniques used in his most ambitious cinematic experiments, which are his essays in cinematic allegory. As I will show, however, the spirit of Wordsworth informs this most central part of Russell's poetics just as much as does Eisenstein. In that sense, too, the homage to one of the most famous passages in Wordsworth's work is anything but a coincidence. It is a knowing wink from Russell to his informed reader. But before we can discuss the triangulation of Wordsworth, Eisenstein, and Russell in detail (in Chapter Four) there are many other aspects of Russell's work that we need to get into focus. The first of these is the connection between his narrative methods and the conventions of Baroque theatre.

\subsection{A BAROQUE PERSPECTIVE}

A useful way of making sense of Russell's method is to look at it from a narratological point of view and examine his approach to narrative structure, as I have been doing. I have shown that one of the defining features of Russell's narratives is their extensive use of embedded narratives. Although embedded narratives can be identified in the narrative arts of all times, they are very closely associated with the seventeenth century, and especially with Baroque theatre, where embedded narrative finds its clearest articulation

\footnotetext{
${ }^{38}$ See Chapter Four, especially section 4.3.3. on allegorical hyperboles.
} 
in the practice of the play-within-the-play. If we want to address Russell in terms of baroque we cannot ignore this connection. In fact, I will show that establishing the link between Russell and Baroque theatre opens up interesting perspectives on both Russell and the return of the baroque in the present. To do that, however, we must first establish how the play-within-the-play functioned in the context of the historical Baroque and explore the analogies with Russell's embedded narratives. It is obvious that establishing embedded narratives and even direct analogies to the play-within-the-play in Russell in itself hardly constitutes sufficient grounds to claim Russell as a contemporary baroque artist. If it did, we would be repeating the error of reducing the baroque to a formal matrix, albeit a narrative formal matrix rather than a visual one. In the course of my analysis, however, it will become clear that the analogy is more than merely structural or narratological: there is a parallel in the way both Baroque authors and Russell use embedded narratives and the play-within-the-play. There is, if you will, an ontological connection. Establishing this connection is my main aim. This means that it is not my intention, nor is it even necessary, to establish a full coincidence between the structure of Russell's films and the structure of Baroque theatre. This would only prove that Russell was very good at using a specific narrative method, which is hardly exciting news: all good artists who work in the narrative arts are good at using some such method. What I do want to establish is a close parallel in the uses to which certain narrative structures are put in Baroque theatre (and, by extension, Baroque art in general) and in Russell's narratives. These uses, I will argue, have to do with the performance of self. It is my aim to establish this connection through a comparative analysis of Baroque texts and Russell's work. The implications of this baroque perspective will be elaborated in the subsequent chapters of this investigation.

\subsubsection{Curtains Up and Up and Up: Play-Within-the-Play and Mise-en-Abyme}

In his authoritative study of the play-within-the-play in French theatre of the seventeenth century Georges Forestier distinguishes between the play-within-the-play and the mise-en-abyme. More specifically, he identifies the play-within-the-play as a core structure of Baroque theatre and argues that the mise-en-abyme is its most intricate elaboration. The play-within-the-play and the mise-en-abyme are therefore not different in kind; what distinguishes them is a level of intensity. The latter is the most complex form of the former. The play-within-the-play occurs every time at least one character in a play becomes a spectator of an interior play. The presence of an internal spectator is therefore structurally important. It distinguishes the play-within-the-play from instances of roleplaying or an intermission, both of which could also be perceived as forms of theatre 
within the framework of a play. ${ }^{39}$ Role-playing occurs every time characters dress up as someone else to dupe another character. But in role-playing there is no shift in narrative level, which distinguishes it from the play-within-the-play. The presence of an interior spectator assures that the play performed within the play takes place on an embedded narrative plane. It is clear, for example, that the performance of The Murder of Gonzago in Hamlet introduces a deeper narrative level. It takes place on a stage within the fictional world of the play and thus introduces a new narrative level. This does not happen in role-playing, where the duping of a character is simply part of the ongoing dramatic action. The interior spectator of a play-within-the-play is aware of the fact that he or she is watching a play that is not co-extensive with his own world. For role-playing to be effective, the duped character(s) must not be aware of the role-playing. Similarly, there is a distinction between the play-within-the-play and an intermission. The interior spectator of the play-within-the-play ensures that there is dramatic continuity in the framing narrative. While the embedded play is performed, the framing narrative simply continues, but in a minimal way: the characters' dramatic action is temporarily reduced to watching another narrative. But for the real audience watching the play, the characters are still on the stage, engaged in watching a play. In an intermission, which might be quite elaborate, there is no such narrative continuity: the intermission is literally a performance that comes between two sections of the actual play. In modern terms, we might compare an intermission to a commercial break during the television broadcast of a film: although the commercials might be very elaborate and even cinematic, they have no dramatic connection to the film, which they are effectively putting on hold. ${ }^{40}$

The mise-en-abyme is a highly specific form of play-within-the-play. Forestier argues that it is a form of functional embeddedness, as opposed to the merely structural embeddedness of the play-within-the-play. The play-within-the-play is essentially a formal or structural conceit: it simply designates that a play is being mounted within the narrative framework of another play. It suggests the creation of a second (or third, for there are also plays-within-the-play-within-the-play) narrative level. The mise-en-abyme is structurally a play-within-the-play: it introduces a new narrative level. But it also fulfils a functional role: the mise-en-abyme is a play-within-the-play that mirrors or reflects back

\footnotetext{
${ }^{39}$ See Forestier (1996: 11). See also Genette (1969: 195-222) for a discussion of embedded narrative in Baroque narrative poetry and his more systematic discussion in Discours du récit (2007: 236-247).

${ }^{40}$ Pace, of course, Raymond Williams's (2003: 86-96) argument about television as flow, which I do not want (or need) to dispute: the fact that programmes, previews of other programmes, and commercials seem to become a solid stream of visual stimuli does not alter the fact that, structurally and from a narrative point of view, commercials effectively interrupt the broadcast of a film and do not contribute to the film's content or narrative. See also Corner (1999: 60-69) for a critical discussion of the concept of flow.
} 
upon the dramatic action of the framing narrative. ${ }^{41}$ The classic example is The Murder of Gonzago, also known as The Mousetrap, from Hamlet, where the embedded performance of the play reveals something about the framing narrative (it alerts the spectators in the framing narrative to the fact that Hamlet knows who killed his father ${ }^{42}$ ). However, as a functional feature the mise-en-abyme is not limited to the theatre: we find it in many of the arts, and it occurs every time an embedded representation (narrative, image, film,...) reflects back upon its frame (the framing narrative, image, film,...), regardless of the kind of art in which this happens (theatre, film, literature, painting,...). In Russell's work we will encounter examples of (self-)reflexive film-within-the-film, ballet-withinthe-film, play-within-the-film, and painting-within-the-film. ${ }^{43}$ In each of these cases a representation has been embedded into the film (structural embeddedness) with the purpose of reflecting back upon the framing narrative (functional embeddedness). ${ }^{44}$

Forestier discusses several instances of the mise-en-abyme in French theatre of the seventeenth century, the most well-known of which are probably Molière's L'Impromptu de Versailles (1663) and Corneille's L'Illusion comique (1635). Molière's

\footnotetext{
${ }^{41}$ See Forestier (1996: 87) and Genette (2007: 242), who calls it a form of thematic embeddedness because of its function as commentary on the framing narrative. The term mise-en-abyme itself originates in an 1893 journal entry by André Gide (see Dällenbach 1989: 7-38), where it refers to a coat of arms that contains, within itself, a smaller shield that is an exact miniaturised replica of it. However, some of the other examples that Gide introduces are from art history, including interior scenes containing convex mirrors that reflect part of the scene, but also things that are not in the painting (Van Eyck, Velazquez). Clearly, this is not the mise-enabyme as Gide finds it in heraldics. Such confusion permeates many discussions of the mise-en-abyme and has helped to perpetuate the misconception of the mise-en-abyme as a literal mirroring effect (as in endlessly reflecting mirrors).

${ }^{42}$ Green (1953) discusses the Mousetrap stratagem and its importance in performance of the play. Doebler (1972) elaborates on the mousetrap as a common Renaissance metaphor in relation to Hamlet.

${ }^{43}$ Without seeking to be exhaustive here, I will identify (self-)reflexive film-within-the-film in The Debussy Film (section 1.3.2.1.); ballet-within-the-film in The Music Lovers (section 1.3.2.2.); play-within-the-film in The Devils (section 2.5.1.), Salome's Last Dance (section 4.1.), and, in the specific form of musical-within-thefilm, in The Boy Friend (section 1.3.2.2.); and painting-within-the-film in Gothic (section 4.3.1.).

${ }^{44}$ The literature on embedded representations and on the specific form of the mise-en-abyme is large, but there are a few systematic inquiries. As already pointed out, Dällenbach (1989; orig. 1977) was an important work addressing embedded narrative fiction, and Forestier (1996) is the classic text on embedded plays in seventeenth-century French theatre. Golder (2007) illuminates the professional context in which self-reflexive theatre emerged. Embedded representations in painting have received a very clear, systematic, and exhaustive treatment in Stoichita's (1999, esp. 162-163 and 172-176 for the mise-en-abyme) classic study of the frame in painting. Metz (1991: 93-111) extensively discusses the film-within-the-film, but his category is far too broad, including even flashbacks because it 'a quelque chose à voir avec le film dans le film, du moins pour ce qui est de son effet de "coupe" au sein du récit' (o.c. 107). Similarly, his discussion of the mise-en-abyme (o.c. 73-76) is not clearly distinguished from the film-within-the-film, as when he writes that 'l'écran secondaire (et a fortiori le film dans le film) évoquent [sic] avec insistance la "mise en abyme" (o.c. 73). Metz's categories are a muddle and this is not the place to disentangle them, but some of Stoichita's categories could certainly help to sort them out.
} 
play was written in response to criticism of his plays. In it the author dramatises himself as the director of a theatre company who is trying to get his actors to rehearse a play he has written. This company is in fact Molière's own theatre company and all the characters in the play are the actual actors belonging to the company, including Molière. When the play was first performed before the King (obviously by Molière's company) all the actors would effectively play themselves, and Molière took his own part. Most of the play is given to an attempt to get the rehearsal underway, with Molière (the character) giving elaborate instructions to the actors about how his play is to be performed (as in Hamlet's instructions to the players). Finally, the rehearsal itself takes off, establishing the embedded level of the play-within-the-play. In this embedded play the actors perform the parts of disgruntled aristocrats who criticise the plays of Molière, in which they are remorselessly sent up and criticised, and rejoice in the prospect of a new play that has apparently been written and which entails a critique of Molière's theatrical practices. This rehearsal is in turn occasionally interrupted by Molière (the character) to correct his actors' performance. The conceit of the play-within-the-play effectively allows Molière to blur the boundaries between fact and fiction, becoming at once the author of, character in, and dramatised critic of his own play. In response to his critics Molière has written a play that is fashioned as a rehearsal of a play by Molière (the character), under the direction of Molière (the same character), and in which both narrative levels (the framing narrative and the play-within-the-play) perform a commentary on the work of Molière (the character, but in this respect most obviously also the actual person). Furthermore, since the character of Molière also plays one of the artistocrats in the embedded play, during performance the historical Molière would effectively play both himself in the framing narrative and a character criticising himself in the embedded play.

Molière's play is a considerable technical feat, creating a wickedly funny air of huis clos, especially in the very short final scenes that show Molière desperately trying to stall the King who awaits a performance of the as yet not fully rehearsed play. Corneille's L'Illusion comique is less complicated. It is also an uproariously funny play, with some hilariously overblown speeching by the buffoon character Matamore in the second act, which is riotously funny. L'Illusion comique is remarkable because it operates on three narrative levels, establishing a play-within-the-play-within-the-play. The story is seemingly straightforward. Pridamant is taken by his friend Dorante to visit Alcandre, a magician. Pridamant has not seen his son Clindor for a decade and is very eager to learn about his whereabouts. Alcandre invites Pridamant into his magic cave where he will conjure a number of visions showing the adventures of Clindor over the past few years. These visions, which take up most of acts two, three, and four, are the play-within-theplay. This embedded narrative, relating the adventures of Clindor, is seemingly contin- 
ued in the fifth act, at the end of which Clindor dies, much to Pridamant's despair. It is then revealed by Alcandre that Clindor has taken up the profession of actor and that the tragic events shown in the vision of the fifth act were actually a performance of a play by Clindor and his fellow actors. The vision is then briefly conjured anew to show Clindor and the other actors counting their money after the performance. This means that Clindor is not dead after all. The vision of the fifth act therefore introduces a third narrative level, a play-within-the-play-within-the-play, but it only identifies this level as such after the fact. At this point, however, the mirroring effect of the mise-en-abyme performs some of its own magic, for if the events of the vision of the fifth act were merely a play, who can guarantee that the events shown in the earlier acts were not also a play performed by Clindor and his fellow actors? It looks as if Pridamant might have been duped and that he has been lured into Alcandre's cave to see his long-lost son actually perform a number of scenes from his own life. This would also mean that Alcandre is no magician at all, but simply someone who is part of a conspiracy to dupe Pridamant.

In retrospect there are several elements in the first act of the play to suggest that the visions conjured by Alcandre have been a play all along. When Alcandre first conjures Clindor the curtain of the vision-within-the-play rises to show, as Corneille's instruction reads, a parade of 'les plus beaux habits des comédiens'. Pridamant is amazed at his son's garments and observes that 'Mon fils n'est point du rang à porter ces richesses, / Et sa condition ne saurait endurer / Qu'avecque tant de pompe il ose se parer' (I, ii, 138-140). Alcandre counters that Clindor has made his way in the world quite successfully and that 'Personne maintenant n'a de quoi murmurer / Qu'en public de la sorte il ose se parer' (I, ii, 143-144). This almost gives the play away, and it is certainly a knowing wink to the spectator, for 'en public' can refer to the fact that Clindor walks around publicly in such garments, but also to the fact that he is showing himself thus attired in front of an audience (on a stage). When Alcandre next describes the ghosts he conjures as 'des spectres pareils à des corps animés' (I, ii, 152) the viewer is given another clue about the possible true nature of the visions he is about to witness, for ghosts tend to be fog-like appearances. One can see through them. Ghosts do not, as a rule, look like solid animate bodies. Unless, of course, they are real people pretending to be a vision. But the title of the play also provides a clue that what Pridamant is seeing is always already a play by Clindor and his friends, for in seventeenth-century French an illusion meant a fausse apparance, a conceit to make things seem other than what they really are (Corneille 2008: 47n4). Furthermore, in the seventeenth century comique did not yet have its narrow meaning referring to comedy, but designated theatre in general (o.c. $35 \mathrm{n} 1$ ). So the title of the play refers to a theatrical illusion (Alcandre in fact also tells Pridamant that he will show him his son 'Sous une illusion'; I, ii, 150), all of which retrospectively reinforces the 
point that the revelation of the embedded narrative of the fifth act as a play-within-thevision-within-the-play reflects back upon the whole embedded narrative of the earlier acts and its actual relation to the framing narrative. The very title of the play, signalling the theatre's ability to show things that are not really what they seem, announces this reflective revelation as the theme of the play itself. It would seem, then, that the conceit of Alcandre's conjuring of visions in his cave is itself an illusion. He is not a magician. The joke is on Pridamant and everybody in the fictional world of L'Illusion comique is in on the joke.

\subsubsection{Staging in Depth}

I have discussed both the Molière and the Corneille plays at considerable length because they offer particularly clear illustrations of the principle of the mise-en-abyme and the way it creates mirroring effects. Now we must turn to Russell's work and vet it for instances of the mise-en-abyme. An exact counterpart to the mise-en-abyme in Russell's films would have to meet two requirements: first, they must be scenes or sections of the film in which works of art (plays, but also musical pieces or a ballet) are performed as part of the diegesis; and second, these performances must reflect back upon the framing narrative. ${ }^{45}$ Several such instances can be found in Russell's films, and among the most remarkable are sections of The Debussy Film, The Boy Friend, and The Music Lovers. There are also instances in other Russell films such as The Devils, which I will discuss in the next chapter. I will first look at The Debussy Film, which in many ways provides the blueprint for future embedded narratives in Russell's work (and especially for The Boy Friend). Second, I will address an embedded performance of Swan Lake in The Music Lovers, which is structurally the clearest and most straightforward example of the miseen-abyme in Russell's oeuvre. Finally, I will briefly say something about Russell's entanglement of the several self-reflexive narrative levels of The Boy Friend. ${ }^{46}$

\footnotetext{
${ }^{45}$ I suppose one could argue that any memory, flashback, or dream sequence is an embedded narrative (and therefore a structure parallel to the play-within-the-play) that reflects back upon the framing narrative to the extent that such sequences are instrumental for character or plot development, and that they therefore also constitute a mise-en-abyme. A memory or dream is always likely to reveal something about the framing narrative and its characters. However, such a broad interpretation would seem to me to render the analysis specious. Revelations or character development in themselves do not a mise-en-abyme make; there must be a structural mirroring effect encapsulated in an embedded narrative that has an (implied) internal spectator.

${ }^{46}$ There is a specific and very small category of embedded narratives in Russell's work that I will totally disregard in this analysis, and these are the recreations of scenes from actual fictional films. For example, the film Valentino contains several recreations of scenes from films in which Rudolph Valentino starred. Since these recreations have no dramatic or narrative connection to the framing story (the adventures of the fictional characters that Rudolph Valentino played have no bearing on the life of Valentino) there is nothing to be
} 


\subsubsection{Performing Debussy}

The Debussy Film (1965) opens with a scene of trucks and cars arriving in front of a stately mansion. A film crew is setting up to film a scene. Actors are lounging about in costume and somewhere in the buzz of activity the director (Vladek Sheybal) is instructing a young boy to play his one-line part. In the scene they are about to film Debussy is being buried and his coffin is taken away on a horse-drawn hearse. The boy is supposed to remark that 'It seems he was a musician'. The director shouts 'action', some firemen conjure rain with a firehose, and as the scene unfolds we hear the director giving directions through a megaphone ('Start the zoom!'). Then the title card comes up: The Debussy Film; followed by a second card: Impressions of the French Composer. Next is a collage of historical photographs of Debussy and his friends and lovers as a voice-over explains that this will be 'a film based on incidents in his life, his own words, and his relationships' with a number of women and with his friend, the pornographer Pierre Louÿs. It is clear from the start that the entire film is conceived as a report on the filming of a film on Debussy. ${ }^{47}$ As I will discuss more fully in Chapter Three, this conceit was developed to circumvent some of the BBC's restrictions on historical documentaries. The film, which was written by Russell and Melvyn Bragg, explores the ways in which the boundaries between fact and fiction become blurred in art, and especially in a biographical film. As the film progresses, the actors playing Debussy and his lovers become increasingly entangled in their roles, up to the point that their real lives (the framing story of the filming of the film) reflect the events they are portraying (the story of Debussy as it is enacted in the film-within-the-film). This blurring of fact and fiction is established right from the start, for the historical characters of Debussy and his friends are introduced in voice-over while we are actually seeing seemingly documentary footage of the actors between takes on the outdoor set. As such, the Debussy actor (Oliver Reed), who is seen talking to an actress, is simply introduced as Debussy. At no point in the film, not even in the framing narrative, will it ever be revealed what the name of the actor playing Debussy is. The end titles also simply identify him as 'Debussy'. This holds for all the main characters. The actresses (in the framing story) who play Debussy's lovers Gaby, Lily, and Madame Bardac are never identified in any other way than by the names of the characters they play in the film-within-the-film. The only exception is the

gained from analysing them from the perspective of the mise-en-abyme. The obvious exception would be a reconstructed scene from a film- $\grave{a}$-clef or the intentional selection and use of a reconstructed scene as a comment on the framing narrative by Russell. Neither case would seem to apply to Russell's film.

${ }^{47}$ Interestingly, the previous year Charles Jarrott had directed a production of Bertolt Brecht's The Life of Galileo (BBC, 1964) which is unique among BBC television adaptations of Brecht in not disguising that it is a television production. This is achieved through bookending the production with "documentary" scenes set in the television studio. The adaptation starts by showing the studio gallery at work' (Smart 2012: 41-47, here 45). 
director, who also plays the part of Pierre Louÿs in the film-within-the-film, and whom the end titles list as 'Director and Pierre Louÿs'.

The structure of the film-within-the-film is exploited to the full by Russell and Bragg to achieve effects that are a perfect illustration of the mise-en-abyme. For example, quite early in the film the director invites the cast to his hotel room to watch a rough cut of a scene they have just filmed. As the actors settle on the floor and on the bed the director explains to his girlfriend what the narrative context is of the scene they are about to see (for Bragg and Russell such explanations are obviously vehicles for conveying biographical information on Debussy to us, the actual audience). The scene is next shown without sound (it is only a rough cut shown on a portable projector) but Debussy's Prélude à l'après-midi d'un faune is played on the soundtrack. This is non-diegetic music. The scene itself shows Debussy and his lover Gaby (Annette Robertson) frolicking in the woods. Their tryst is intercut with shots of the actors playing Debussy and Gaby sitting on the floor, watching themselves in the film, and also kissing. This introduces the mirroring conceit of the film, for as the relationships between Debussy and his friends and lovers turn sour, so, too, will the real-life relationships between the actors take a turn for the worse. In fact, the scene immediately following the projection of the rough cut takes us into a café where the director and his cast have gone for drinks. As the director explains the background to 'La Gigue' from Debussy's Images to the Debussy actor, they both watch the Gaby actress dancing. The director slyly suggests that Gaby knew very well how to make her lovers desperate through her capricious behaviour, and it becomes clear that he himself is having an affair with the Gaby actress, which will eventually lead to grief between the Gaby actress and the Debussy actor. The relationships behind the scenes of the film mirror the relationships that they are creating in the film-within-thefilm. Throughout the cafe scene the non-diegetic music of 'La Gigue' is heard. Although it is clear that the actors are dancing to pop tunes, we only hear Debussy's music.

There immediately follows an even more intricate sequence that is framed by the preparations for the filming of a domestic quarrel between Debussy and Gaby. As the Gaby actress moves through the set of the couple's Paris apartment, the director is heard explaining her character's motivation. This is interrupted to show the director and the Debussy and Gaby actors visiting a very eccentric man, who is only identified (also in the end credits) as The Actor. This Actor is first seen using a toy gun on a black cat in his house, swearing he will next use the real thing on Debussy. At that point, however, the director and his actors have already walked in and the Debussy actor confronts the Actor as if he (the Debussy actor) actually were Debussy. In fact, it becomes clear that the Actor is set to play the character of Maeterlinck in the film-within-the-film, and throughout the discussion that ensues both the Debussy actor and the anonymous Actor 
move back and forth between themselves and their characters, using the personal pronouns 'I' and 'me' to make statements that refer to Debussy and Maeterlinck and their relationship. In fact, they seem to be speaking the lines of their roles as part of a real-life conversation, as if they fully identified with their assigned roles. The friction between Debussy and Maeterlinck next explodes into a fight on the grand staircase of the Actor's house, where the Debussy actor and the anonymous Actor battle it out with, respectively, a walking cane and a broomstick to the sound of Wagner's Ride of the Valkyries on the (non-diegetic) soundtrack. Meanwhile the director and the Gaby actress are seen dancing to a pop tune (not to Wagner, whom we are hearing) as small plastic balls rain down on them. To complicate matters even further there is a voice-over from the director telling the story of Maeterlinck while this whole vivid scene is intercut with images of the Gaby actress and the director's secretary having fun on a fairground. Finally, rather than leading to a resolution of this complicated tangle of fact and fantasy across several narrative levels, the scene cuts abruptly back to the domestic quarrel between Debussy and Gaby as it was actually filmed for the film-within-the-film.

Obviously, this domestic row signals the break-up of the relationship between Debussy and Gaby, and to further enforce the parallel between the framing narrative and the embedded narrative, Russell now cuts straight to a party scene. The Debussy actor is by now beginning to identify with his character and stops the music (as the party starts, the Kinks' 'You Really Got Me' is playing on the turntable) to put on a record of Debussy's Danse profane. His girlfriend, the Gaby actress, does not like this, accuses him of spoiling everybody's fun, and taunts him by stripping to the music. The Debussy actor does not respond but simply stands and broods as we cut back to the embedded scene of the domestic quarrel between Debussy and Gaby, which now explodes with full force. Gaby assaults Debussy, cursing and hitting him, until Louÿs walks in on the scene. Louÿs, who is obviously also the director, shouts 'cut' and the actors all sit down with him on the bed to discuss the scene they've just played. It is clear, however, that the relationship between the Debussy actor and the Gaby actress is now over, for the Debussy actor is kissing the actress who will play Lily, Debussy's next lover. Real-life relationships mirror fictional relationships. As the director gives more voice-over commentary we are witness to domestic scenes from the life of Debussy and Lily. As she irons, Debussy is lost in reverie on the bed. He imagines himself on the coast, listening to the sea as La Mer plays on the (non-diegetic) soundtrack. Some distance away a woman is sitting and reading a book. The director shouts 'cut' and steps into the image to talk to the Debussy actor. During this conversation it becomes clear that the woman who is reading is Madame Bardac (Isa Teller), whom Debussy will marry and have a child with. At this point, Russell achieves an effect that is similar to the disclosure of the illusion comique at 
the end of Corneille's play. As Debussy was lying on the bed, he was dreaming/imagining himself on the beach (ill. 1). This is a third narrative level, a dreamwithin-the-film-within-the-film. But without informing us Russell simply develops this scene into a second-level scene by introducing Madame Bardac into it. Suddenly we are once again on the second narrative level of the film-within-the-film and have leapt forward in time to Debussy's relationship with Bardac (ill. 2). This is achieved simply by introducing Bardac into the third-level dream image of Debussy by the sea (because Debussy could obviously not be daydreaming future events from his life). And by having the director shout 'cut' we come crashing back to the framing narrative of the filming of the film (ill.3). Here, a number of simple cuts allow Russell to move from a third-level embedded narrative (the daydream-within-the-film-within-the-film) through the second level (Debussy and Bardac on the beach: film-within-the-film) back to the framing narrative (the director intervenes).

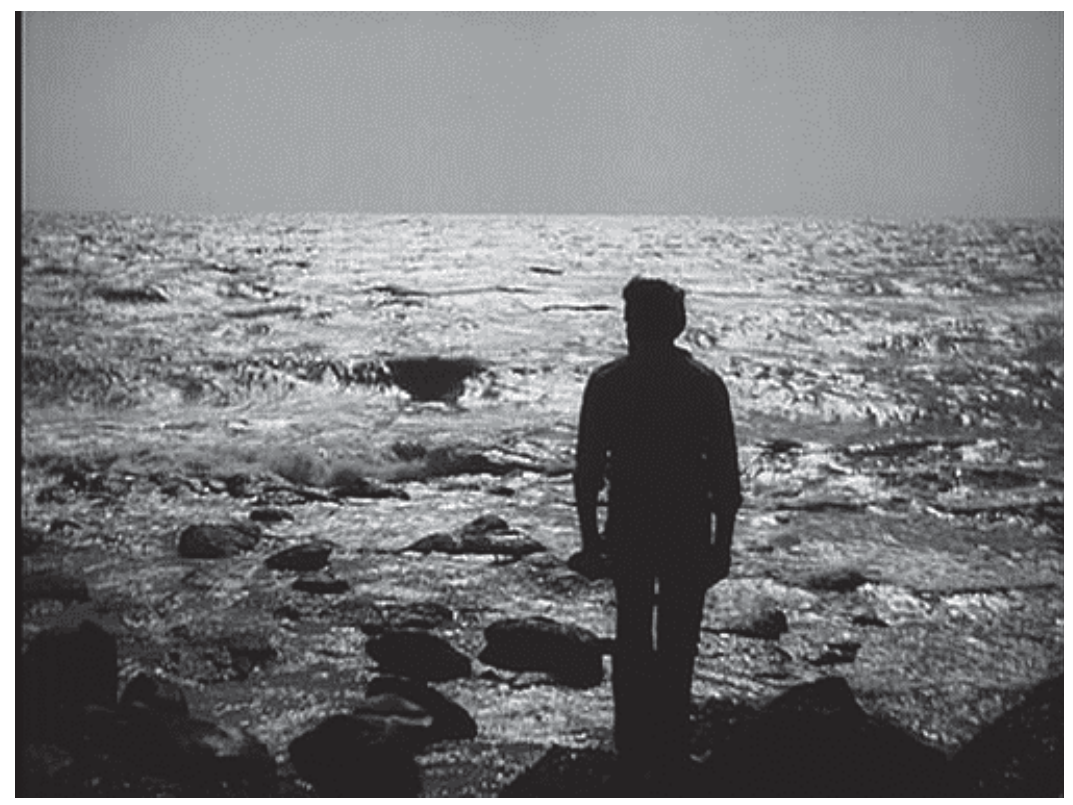

Illustration 1 Debussy dreams himself upon a beach... 


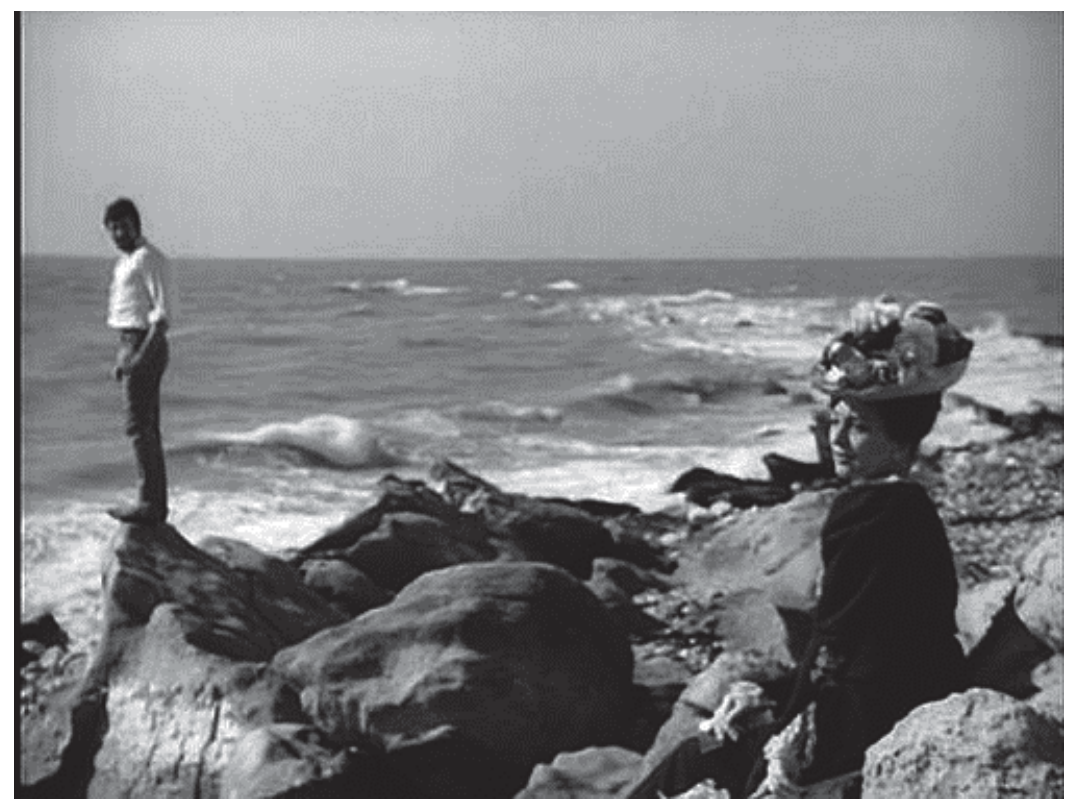

Illustration 2 ...until Madame Bardac appears...

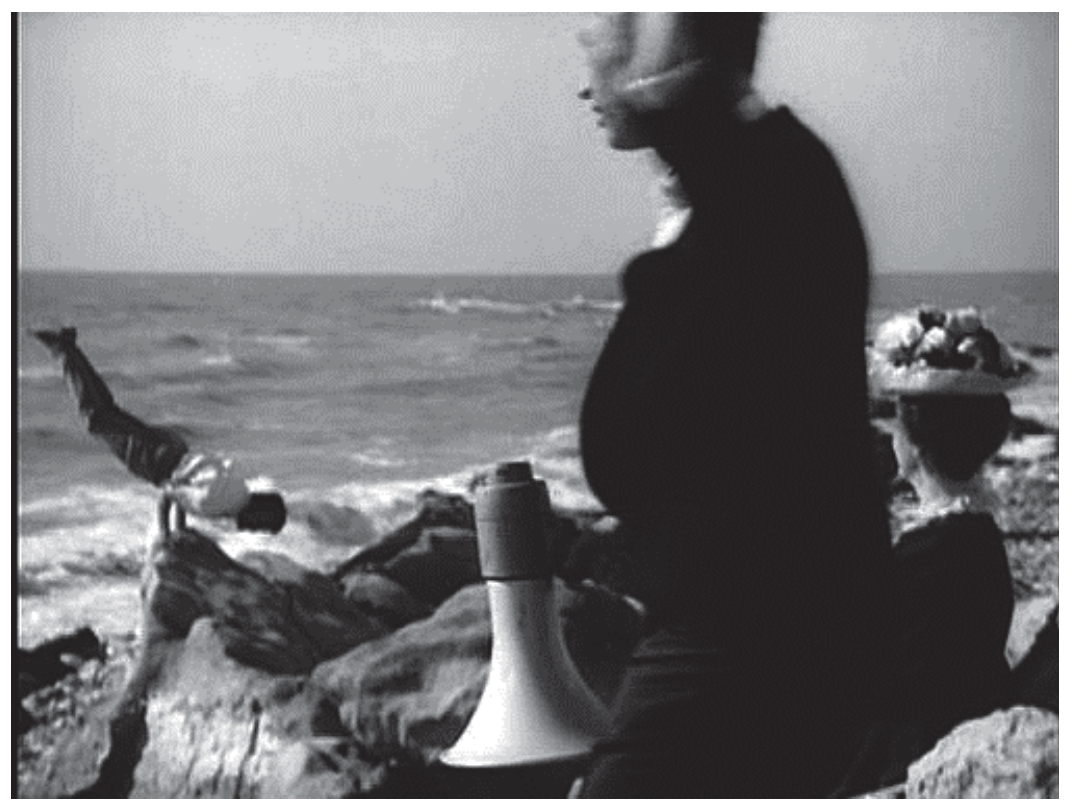

Illustration 3 ...and the director steps in to stop the performance... 
Finally, there is the pièce de résistance of Russell's theatrical fireworks. Obviously, for Debussy to marry Madame Bardac, Lily must first discover the affair and a break-up must ensue. As Lily walks in on the clandestine couple in a hotel room, we are suddenly confused: the actress playing Lily looks nothing like the Lily actress in the rest of the film(-within-the-film). A brief cut to the director and cast standing in front of a theatre stage in a park informs us that we are now watching a scene from Henri Bataille's play The Naked Lady, which is a play à clef about Debussy, and which is being performed especially for the benefit of the film's actors, who are watching a performance of a scene that they themselves will have to play in the film-within-the-film (ill. 4). This allows Russell to achieve his most complex mirroring effect, a three-way mirror in fact. As the scene is being played on the theatre stage, it suddenly appears that the Debussy actor (bored with the performance on stage) has disappeared into a cabin where he is making love to the director's secretary. The Lily actress (with whom the Debussy actor is now having a relationship) notices he is gone, enters the cabin, and catches the trysting lovers in flagrante. There follows a brilliantly conceived parallel montage of, first, the on-stage Lily fleeing the room with Debussy and Madame Bardac; second, a scene from the filmwithin-the-film in which Lily (played by the Lily actress) rushes home through the woods after discovering the affair, throwing herself on her bed, and shooting herself; and, third, the Lily actress in the park fleeing the cabin as she discovers the Debussy actor with another woman. With its three intertwined narratives, combining a framing narrative with two embedded narratives (the play as performed in the park and the scene from the film-within-the-film, neither of which, however, is embedded in the other: there is no third narrative level here) this climactic sequence is emblematic for the project of The Debussy Film, which is to show how it is nearly impossible to draw the line between fact and fiction, between fact and interpretation, when one is doing biography. This concept is brought to a solemn close in the final section of the film, which abandons the framing narrative for the concluding sequence of the film-within-the-film showing Debussy in the last years of his life, retreating into solitude to compose La chute de la maison de Usher. As he slowly closes all the windows of his house, Debussy's voiceover several times repeats that 'I am Roderick Usher'. But since the Debussy actor is obviously still playing the Debussy part, this final sequence is again a comment on the entire film. The Debussy actor has identified with the role of Debussy to the point that his real personal relationships have begun to mirror the personal relationships and betrayals between Debussy and his lovers. He has identified with his creation (the role of Debussy) in the same way that Debussy (as played by the Debussy actor) is now identifying with his own (and, of course, Poe's) creation, Roderick Usher. As Debussy dies, 
Russell cuts back to the image with which he started the film: the funeral coach carrying the coffin with Debussy's body.

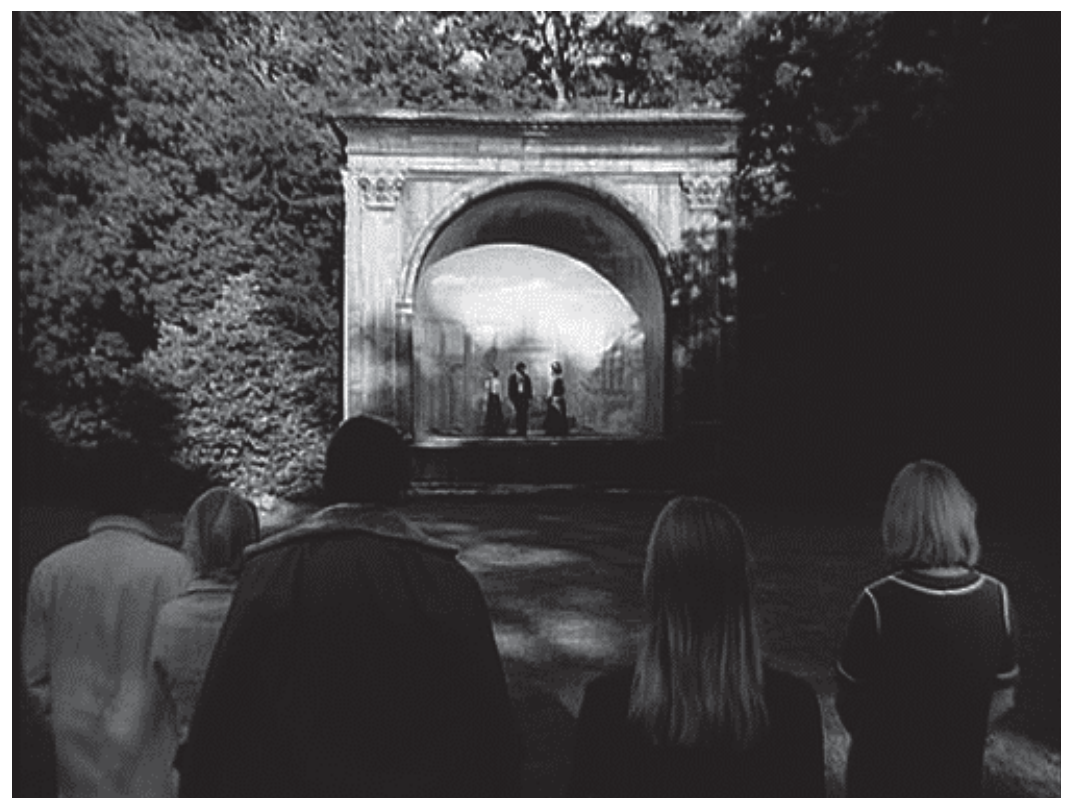

Illustration 4 An embedded stage for the benefit of the actors

In The Debussy Film Russell performs a virtuoso juggling act that keeps us constantly suspended between two narrative levels that seem to melt and flow into each other. He uses several deceptively simple devices to achieve this. One of them is his use of music. Rather than using snippets of Debussy as incidental music, full pieces or longer extracts are played while the images are composed to the music. As such, the music is often allowed to cut through the several narrative planes, as is the case with 'La Gigue' from Images, which floats along as the accompanying images almost carelessly drift in and out of the first and second narrative levels in a highly associative way. This, along with the subtitle of the film, which identifies its narrative as a number of 'impressions', takes us back to Russell's claim, quoted at the beginning of this chapter, that he uses an 'impressionistic technique' (1974: 6). Another device connects back to L'Impromptu de Versailles, for the character of the director repeatedly instructs his actors on the background story behind the film and explains their characters' motivation and how they must play their scenes, quite like Molière does in L'Impromptu. Furthermore, the director also plays the role of Louÿs in the film-within-the-film, providing another analogue with Molière (with the obvious difference that actor Vladek Sheybal is neither the screenwrit- 
er nor the director of The Debussy Film itself). The interventions of the director, who also provides most of the voice-over commentary in the film-within-the-film (but like the music, this commentary tends to continue quite naturally into scenes that follow the actors in the framing narrative, continuing the conflation of actor and character that is already established by not giving the actors any names beyond those of their characters), function as a number of punctuations. Every time he shouts 'cut' or engages the actors in a discussion of their character, the director character achieves two things: he briefly grounds the film again in the framing narrative, establishing for a moment the solid ground of narrative reference, but at the same time he reveals how everything we see is always already a performance (a point that is made already in the very first scene of the film when the film crew arrives). Since the two narrative levels flow into each other through the mirroring of fictional relationships and real relationships, whatever directorial commentary is given about the embedded narrative of the film-within-the-film almost necessarily also pertains to the framing narrative. Especially in the cafe scene where the director seems to taunt the Debussy actor with his sly revelation of his affair with the Gaby actress one clearly gets the impression that the director is directing reallife events as much as he is directing the film on Debussy. Amorous intrigue drives everything that happens on the film set of the Debussy film in The Debussy Film.

\subsubsection{All-Singing, All-Dancing: Life on Stage}

The Debussy Film achieves the mise-en-abyme in two ways. First, there is the embedded narrative of the film-within-the-film that reflects back on and comes to mirror the framing narrative. But there is also a second instance in the remarkable three-way mirroring effect achieved through the introduction of an actual play-within-the-film near the end. Russell would later use the play-within-the-film conceit again, first and foremost in The Music Lovers (1970), his film on the life of Tchaikovsky. It is interesting, in this respect, that both The Debussy Film and The Music Lovers were scripted by Melvyn Bragg, who must share the credit for Russell's use of such mirroring effects. ${ }^{48}$ The scene in The Music Lovers, however, is much less intricate than the earlier example; in fact, it is a straightforward example of a mise-en-abyme. During their honeymoon Tchaikovsky (Richard Chamberlain) and his wife Nina (Glenda Jackson) attend an open-air performance of Tchaikovsky's ballet Swan Lake. Tchaikovsky's homosexual lover, Count Chi-

\footnotetext{
${ }^{48}$ Bragg suggests that the device of the embedded narrative was something he contributed to the films. He told Paul Sutton that 'the idea of looking inside a frame is something which must have been around for centuries. I can't claim originality for it, but I can't consciously remember nicking it from anybody. I'm sure there were many influences around and it didn't just come wonderfully out of the blue. I just saw it as a way to tell the audience that what they were seeing was artificial, an artifice, people pretending' (quoted in Sutton 2002a: 6).
} 
luvsky (Christopher Gable), is also at the performance and takes the seat next to Nina, who does not yet know who he is (ill. 5). Nina has already been rebuked by an irritated Tchaikovsky when she asked him what was happening on the stage and now she turns to the stranger next to her to ask whether he has a programme. Chiluvsky laughs and says there is no programme: 'They expect everyone to know the story'. As the ballet unfolds and the Prince dances with the Black Swan, Chiluvsky informs Nina that 'the man is the Prince. The woman is called Odile. He thinks she is the pure beautiful swan woman he dreams of marrying. But she's a cheat. She'll destroy him. You'll see it happen in a few moments.' These words already achieve the mise-en-abyme, for Nina is Tchaikovsky's black swan: she tricked him into marrying her by posing as someone other than she is. He has no idea that Nina is a mentally unstable nymphomaniac. And although it would be unfair to Nina to say that she knowingly destroys Tchaikovsky, together they do quite a good job of destroying each other. That she will see it happen in a few moments is a remark directed as much to Nina as to us, the viewers of the film, who will presently see the undoing of Tchaikovsky in the second part of the film.

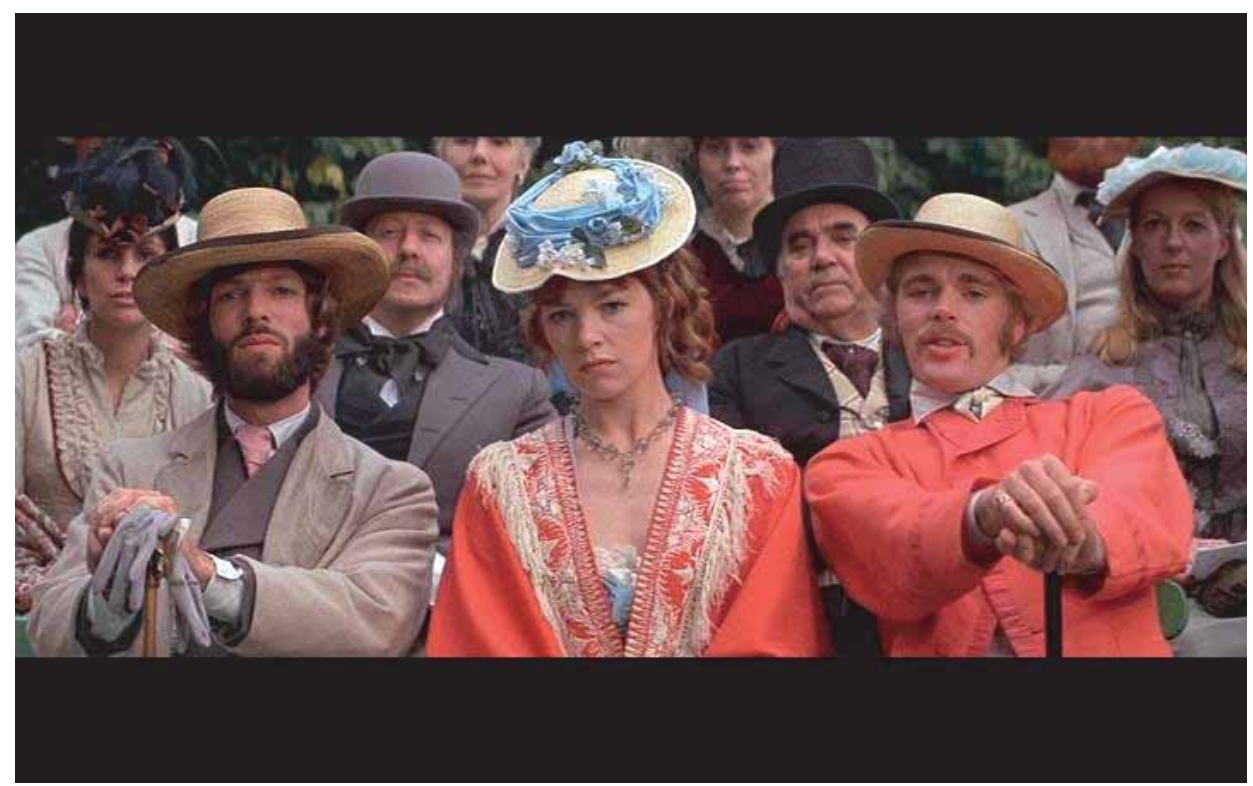

Illustration 5 Count Chiluvsky (right) tells Nina exactly what she is about to see

When the White Swan appears in the ballet Nina again enquires about this figure's identity. 'That is True Love,' Chiluvsky smugly replies. And as the King appears, who wants to come between the Prince and True Love, Chiluvsky remarks: 'And that's the wicked 
Uncle'. This revelation is keyed to a brief musical explosion that is accompanied by a short vigorous montage of the characters' faces. In quick succession Russell cuts from Tchaikovsky's face to the Prince's face, to Nina, to the Black Swan, to Chiluvsky, to the Wicked Uncle, and back to Tchaikovsky. Again, this achieves the mise-en-abyme, for the real-life persons are coupled with the fictional characters who mirror them. Tchaikovsky is the hapless Prince who has been fooled into a union with Nina, his Black Swan. Interestingly, Chiluvsky, who fashions himself Tchaikovsky's True Love, is coupled with the Wicked Uncle. This achieves a double effect. First, it makes clear that this montage is an authorial intervention by Russell. Although it is Chiluvksy who, as a perverse master of ceremonies, comments on the mirroring effects of the ballet (Chiluvsky's smug replies to Nina clearly suggest that he, like us, is aware of the parallels between reality and the ballet), Russell intervenes to adjust at least one aspect of Chiluvsky's analysis: Chiluvsky is no True Love. He is a Wicked Uncle. But second, connecting Chiluvsky to the Wicked Uncle also points forward to a later scene in the film, where it is Chiluvsky who will try to destroy Tchaikovsky by revealing his homosexuality to the composer's benefactress, Madame von Meck (Isa Teller). Finally, the mise-en-abyme is closed by Chiluvsky with an ominously foreboding remark to Nina about the dance of the Black Swan: 'Do you know what she's saying? She's saying you and your ideal love will die.' And so they will.

The mirroring effect of a play-within-the-film was taken up again by Russell in The Boy Friend (1971), his adaptation of Sandy Wilson's stage musical. The film documents the goings-on among a run-down theatre company who are staging a very low-grade performance of Wilson's musical. When it is announced that the major Hollywood director De Thrill (Vladek Sheybal, again performing as a film director) will attend a rehearsal in search of new talent, all the performers try to upstage each other. Meanwhile, the star of the show (Glenda Jackson) sprains her ankle, so that her stand-in Polly, a flustered ingenue played by fashion model Twiggy, has to step in at the last moment. She is in love with the star of the show, Tony (Christopher Gable). As the rehearsal progresses and everybody is competing to capture De Thrill's attention, Russell constantly contrasts the very cheap staging of the musical in the theatre with the way the several characters imagine the staging in their heads. Especially De Thrill conjures up grand images of The Boy Friend as a big Hollywood musical in Busby Berkeley style. As a result, life backstage mirrors life on-stage as we weave in and out of the framing narrative and the several protagonists' re-imaginings of it. The interesting twist of the film is that all the embedded narratives are private fantasies belonging to the point of view of one of the characters. A particularly fine example of this conceit is a sweet scene in which Polly and Tony, who are beginning to fall in love (both on stage and behind), sing a duet to an old gramophone record. They begin by hesitatingly playbacking the singers' voices on 
the old record. As their self-assurance grows, the real singing voices of Twiggy and Gable take over the song on the soundtrack until the gramophone gets stuck and repeats the same word over and over. Suddenly, the illusion is broken. At that point an amused De Thrill leans in from his box and imagines a lush Busby Berkeley treatment of the scene with the two stars dancing on a giant revolving gramophone set. The most remarkable thing about the playback duet, however, is that the shift in narrative level only takes place on the soundtrack. As the actors' voices take over we keep seeing them on the stage in the rundown theatre, but we hear their fantasy of the song in which they are no longer singing the song for each other's character but for each other. This is really very sophisticated: Russell achieves half a narrative shift because the actors sing the same song in a different reality than the reality shown. But by having the soundtrack warp into another level Russell also makes a wonderful meta-comment on how actors give voice to their characters: the actor is always a persona, a mask through which another's words are spoken (or, in this case, sung). But because the words are a love-song articulating the actors' real feelings for each other this warping also becomes a comment on how we so often give voice to our own feelings through the words written (or dramatic realities devised) by others.

\subsection{THE GAP BETWEEN REALITY AND REPRESENTATION}

Forestier has argued that embedded narratives bestow reality upon the framing narrative. He suggests that when actors sit down to watch a play-within-the-play, fiction moves up a level to the embedded narrative, and the audience can identify with the framing narrative as the level of reality. It then seems as if the internal spectators in the framing narrative come to inhabit a space that is a natural extension of the space of the real audience. The line between fact and fiction, demarcated by the proscenium arch, seems to move up to the line of the fictional proscenium arch framing the play-withinthe-play off from the fictional audience (obviously, this effect would also obtain when there is no actual fictional proscenium arch). The effect might even be reinforced by the practice, which was not uncommon in the seventeenth century, of allowing members of the real audience to sit on the stage during the performance. So if an actor playing the part of a character watching an embedded play quietly disappeared into the wings to reemerge as a character in the embedded play, he would not necessarily be missed in the framing narrative since there were plenty of real spectators on stage to take the place of 
the fictional spectators. ${ }^{49}$ If Forestier is correct, then embedding narratives allows the framing narrative to acquire a sense of reality. But that is problematic. Forestier is arguing that embedding narratives, and allowing fiction to "move up" a stage, achieves a breaking of the fourth wall: once the fictional and the real audiences begin to mingle the line between fact and fiction is cancelled. Fiction spills into reality and vice versa. The question, however, is whether the members of the fictional audience really become (or come to be perceived as) part of the "real" audience, or whether members of the "real" audience suddenly think of themselves (and are perceived by others) as actors or as characters in the fictional world of the play. This seems unlikely. Even when actors mingle with real people, or vice versa, we don't really believe that the fictional spectators have suddenly become real spectators or that the real spectators have suddenly become characters in the play.

This is a significant point. In more general terms, Forestier seems to suggest that the breaking of the fourth wall in a work of fiction, or the spillage of narrative frames into each other and of the fictional world into the real world, can actually compromise the dividing line between fact and fiction. At that point the theatrical performance ceases to be a representation of life and becomes (part of) life itself. This effect has been called the 'literalism of theatrical performance' (Jackson 2004: 127): its inability to maintain the illusion of self-enclosed artifice. ${ }^{50}$ In his discussion of L'Impromptu de Versailles Forestier certainly suggests this when he claims that the character of Molière, as played (in the framing narrative) by the real-life Molière, is 'transformed' into 'a non-fictional theatrical presence' (1996: 270) at the moment that he begins to play another character in the play-within-the-play. But this seems highly questionable. I suggest that one of the reasons that breaking the fourth wall is such an effective and popular tool in the theatre is

\footnotetext{
${ }^{49}$ For the real audience on stage, see Forestier (1996: 68-69, but also 101 and 180-181) and Lawrenson (1986: 168), but especially the extensive discussion by Biet (2002: 177-184), who argues that, following the huge success of Corneille's Le Cid, the practice of putting chairs on the stage was institutionalised at the Hôtel du Marais in 1637. Initially these seats were meant for the pages and valets of privileged citizens, but since the seats on stage also created great visibility they were soon occupied by the aristocratic citizens themselves because, 'despite the reprobation of theoreticians, a number of authors and connaisseurs, it becomes important to be seen there, to appear on the stage itself, to show that one is attending the performance and that one is paying good money to do so [...]. One buys one's place at the "theatre" to be seen watching the spectacle and, if required, to ostentatiously demonstrate one's opinion on one or the other passage' (o.c. 180). As a consequence, the spectators become 'character-spectators' (ibid.): both spectators of the spectacle and part of the spectacle (i.e. part of what other spectators come to see). Citizens went to the theatre to look at each other looking at each other, turning the theatre into an important social event where the city (and the citizens) represented (or staged) itself in 'a moving assembly organised around multiple gazes' (o.c. 187).

${ }^{50}$ Jackson (2004: 115-132) discusses the literalism of theatre alongside criticisms of similar phenomena in post-modern art forms by critics such as Michael Fried, who had deplored 'the intolerable incorporation of the audience' in certain forms of minimalist and performance art and 'the way that the art object and its receiving context blurred' into each other in such works (o.c. 123 and 122).
} 
the fact that it always remains part of the performance. If it did not, it would simply not be useful. In many plays or performances the breaking of the fourth wall is even scripted, with instructions for actors/characters to address the audience directly. But this never confuses audiences into mistaking that actor/character for a real person in the pragmatic world of everyday events or into thinking that the act of involving the audience is no longer part of the performance but something "real" that interrupts it. In other words, breaking through the fourth wall does not cancel or destabilise the performance or the play, it is simply one of the many devices used as part of the performance or play. It is a dramatic device that is used to trigger a moment of reflection in the audience. Rather than blur the line between fact and fiction, the breaking of the fourth wall occasions a (self-)reflexive awareness of that line. There is no question of what Egginton calls an actual 'overflow of theatrical into real space' (2003: 79). Because the breaking of the fourth wall always occurs within a fictional context (it is part of the content or set-up of the play) this breakage itself remains part of the fictional world. Rather than turning reality into fiction, or fiction into reality, it simply invites us to think about the possibility that reality might be like fiction. The breaking of the fourth wall in art allows us a brief moment of exhilaration in which we can act as if the line between fact and fiction were broken. But it is an as if-experience and we never actually believe that it is really (ontologically) so. In fact, as audiences we have become so familiar with the trope that it has by now largely lost its effect of Verfremdung and has become a steady fixture even of mainstream entertainment. ${ }^{51}$

This means quite simply that works of art are always fictional. They create what Susanne Langer calls a 'virtual' (FF 48-51) or imaginary realm that is cut off, but virtue of its fictionality, from the "real" world of everyday affairs. In the theatre the proscenium arch represents the line that separates the real from the virtual although, in practice, an actual physical proscenium arch is not always required: the sheer fact that something is presented as a work of art will suffice to make us experience it as something altogether

\footnotetext{
${ }^{51}$ In its complete form Forestier's claim about Molière holds that 'Molière se jouant lui-même, les spectateurs croient à son personnage, tout en sachant bien que ce n'est qu'un personnage, jusqu'au moment où il représente un autre personnage, ce qui transforme son rôle précédent en présence scénique non-fictionelle' (1996: 270). I maintain that Molière's presence does not suddenly become non-fictional for the audience, but that the audience is simply made aware of the fact that Molière is playing a clever game with the line between fact and fiction. But whatever is represented on stage, by virtue of its being represented on stage, is never real. That is also why an actor playing him- or herself in a film is never really him- or herself in that film. The sheer fact of being in front of a camera or on a stage (not to mention the presence of a script!) necessarily entails an amount of self-consciousness that makes it impossible to say that the person playing themselves really are themselves. Their self has simply become another character in the performance.
} 
different from the everyday. ${ }^{52}$ The important point in the present discussion, however, is that works of art, including theatrical performances, remain fictional even when they become self-reflexive. ${ }^{53}$ Incidentally, this point also helps to clear up the traditional misconception that, as it was formulated by Coleridge in Chapter Fourteen of his $\mathrm{Bi}$ ographia Literaria, the enjoyment of (narrative) art requires the 'willing suspension of disbelief for the moment' (Coleridge 2000: 314). The positive formulation of this principle holds that the enjoyment of fiction requires belief in its content, although a conscious effort (a suspension of disbelief) is required to achieve this. But the opposition between belief or disbelief is inappropriate to works of art. When we read a novel, or watch a play or a film, we do not need to believe in what we see in order to enjoy it. We do not even have to consciously pretend that what we are seeing is real. No belief, no pretence, and no suspension of disbelief are required because belief simply does not figure into the enjoyment of art. We don't believe in the reality of a work of fiction, we engage with it as a representation. In fact, our enjoyment of the work is all the greater for our not believing in it. Suppose one were to (need to) believe in the reality of a play in which a murder occurs in order to enjoy it. The moment of the murder would then fill us with alarm rather than with suspense or excitement and should occasion us to either rush to the rescue of the victim or run out of the theatre in search of the police. Our enjoyment of the play would be rather short-lived! But surely, any person who calls the police after a murder has occurred in a play on stage would be in a somewhat unfortunate state of mind (and we can only hope that this person would not be attending a performance of Hamlet, considering the alarming body-count in that particular entertainment). We enjoy fiction, not despite the fact that it is fiction, but because we know that it is fiction and are therefore free to surrender to its illusion. Since works of art formulate no claims about a state of affairs, true or false, in the real world there is no need to make ourselves believe anything. Hence, no suspension of disbelief is required,

\footnotetext{
${ }^{52}$ Langer's use of the term "virtual" obviously predates the development of "virtual reality" technologies. In modern philosophy the argument that works of art inhabit an independent fictional realm is indebted to Kant's claim, in his Kritik der Urteilskraft (1790), that aesthetic judgements should always be 'disinterested' ('ohne alles Interesse'; $\$ 2$ ), which means: free from the influence of practical or utilitarian concerns. See, in this respect, also Polanyi on the work of art as "framed" (Polanyi and Prasch 1975: 85-87).

${ }^{53}$ Specifically for film this point was also made by Christian Metz, who argues that no amount of selfreflexiveness can make a film break out of itself because this self-reflexiveness must always be shown as part of the projected film. Hence, he argues, 'on pourrait dire que la caméra, sans l'aide d'un miroir, ne peut jamais se filmer elle-même - elle est comme nos yeux, que nous ne voyons pas -, et que le hors-texte prétendu ne peut donc être que du texte, du texte redoublé, du métatexte' (1991: 31). Put more succinctly, and with a nice image, Metz says that any moment of cinematic self-reflection is 'comme un agent double: elle dénonce le leurre filmique, mais elle en fait partie' (o.c. 43). In fact, even if the camera does film itself in a mirror, this still results in a strip of film showing that image which will still be part of the film, albeit a self-reflexive part.
} 
either. ${ }^{54}$ Forestier seems to assume that we actually come to believe in the rupture of the fourth wall and its implications. In reality, the breaking of the fourth wall is merely represented for our entertainment and our consideration. It is part of the performance and therefore something we (need) neither believe nor disbelieve. Its aim is not to undermine reality but to trigger reflection: it promotes awareness of what is happening, both in the play and in the real world.

Audiences in the seventeenth century certainly seem to have taken this playing with the fourth wall, or the representation of a blurred line between fact and fiction, in their stride. Audiences, and especially the sophisticated audiences at court, had little trouble "reading" self-reflexive plays such as L'impromptu de Versailles appropriately without becoming confused about the reality of the world around them or the several versions of Molière in it. This suggests that plays with such effects were not the cause of a selfreflexive (or even de-realising) awareness in the audience; rather, they must have been the expression of a pre-existing and widely shared understanding of the world. The audience enjoyed such representations because they recognised the conceit. After all, as courtiers in Versailles, they were living this reality every day: life at court was a theatre of power, and under Louis XIV the palace of Versailles became the theatre set on which this play was performed for the world. ${ }^{55}$ Apostolidès has argued that, on this public stage, 'the courtier constructs himself like a château, as a complete front; his full effect is only gauged if seen from a certain distance' (1981: 53): the courtier's appearance becomes a theatrical display, dominated by elaborate wigs and make-up, while the ladies move around in huge dresses with many layers 'similar to the curtains of the stage' (ibid.). This masquerade caused the courtier Primi Visconti to observe that 'la cour est la plus belle comédie du monde' (quoted in Cornette 2009: 86). ${ }^{56}$ In fact, the very decor of

\footnotetext{
${ }^{54}$ My argument in this paragraph is indebted to Michael Polanyi's critique of Coleridge's famous phrase (Polanyi and Prasch 1975: 92).

${ }^{55}$ See Apostolidès (1981) and Burke (1992) on the symbolic functioning of Versailles, but also many of the arts in general, as part of what Burke has called "the fabrication of the King". Ranum (1980) shows how even official historiography was used to create the image of the King in what Apostolidès calls a mythistoire rather than factual history. Maral (2013a) paints a vivid picture of the many aspects of life at Versailles throughout the Ancien Régime.

${ }^{56}$ This theatre was also cause for concern among moralist writers of the seventeenth century. Jean Rousset points out that 'les théoriciens de l'honnêteté construisent l'homme comme un édifice baroque: les vertus d'apparence prennent le pas sur les vertus intérieures; toutes les formes de décoration morale sont recommandeés ou même exaltées; le paraître l'emporte sur l'être, qui n'est plus que le support ou le prétexte' (1953: 219). He follows this with an eloquently lucid discussion of Baltasar Gracian's manuals for survival at court, where 'l'ostentation se lie à la dissimulation, qui est chez Gracian une autre vertu majeure: se rendre impénétrable, cacher son coeur, donner le change, c'est un des thèmes centraux de son honnêteté. Cette honnêteté est une stratégie: car la vie de l'homme est un combat contre l'homme; un combat de masques; il faut se masquer et cacher son jeu pour mieux lever le masque d'autrui [...]. Voilà donc constituée une véritable morale "décorative"
} 
Versailles and its gardens were designed by Colbert and his collaborators to be 'one vast allegory' (Jeanneret 2012: 16) propagating the image of the absolute ruler as Sun King, represented as Apollo. As such Versailles was almost literally a theatre stage designed to represent the order of power in the world. The central theme of the programme was the triumph of Apollo, representing Louis XIV, over the primeval swamp with its monsters: a triumph of order (the light of Apollo) over chaos. ${ }^{57}$ This programme self-reflexively repeated the construction of Versailles itself, which was built on a terrain that used to be marshland. On the central east-west axis of the garden (the so-called Grande Perspective), dominated by the Allée Royale and the Grand Canal (which lie perpendicular to the main facade of the palace), this programme was developed in three stages. It began with the Parterre d'eau, which was decorated with a series of sculpture groups, the socalled Grande Commande of 1674, allegorically representing the whole natural universe. ${ }^{58}$ Next down the line was the Basin of Latona, the mother of Apollo and Diana, symbolising the birth of Apollo (or Louis XIV). ${ }^{59}$ Finally, the third station of the programme was the Basin of Apollo, which shows the god of light emerging, on his chariot, from the waters to begin his journey across the sky. ${ }^{60}$ This programme was closed again in the Grotto of Thetys, located just to the north of the palace, 'where Apollo, in a symbolic rendering of the setting of the sun, ended his arduous journey by sinking into the sea. [...] The Grotto [...] was erected close to the palace so as to signify (in the words of Charles Perrault) "that the King retires at Versailles after having worked for the good of

(o.c. 221). Although his evidence comes mainly from the period 1700-1715, which is the tail end of the Baroque even by the most generous periodisation, Le Roy Ladurie (1978 and 1986) provides very entertaining analyses of the several inter-connected cabals that jostled for power and influence at the court of Louis XIV and traces the intricate webs of family relations, friendships, and 'serpentine endogamy' (1978: 295) that governed life at court. See also Saule (2007: 59-62) for a discussion of the Galerie des Glaces as a social space where courtiers met for gossip and intrigue.

${ }^{57}$ Jeanneret (2012) is very wide-ranging and illuminating in his discussion of the iconography of the domain of Versailles, but see also Hedin (1997), who is the authoritative source on the development of the programme for the gardens. The architect of the gardens was Le Notre: see the lavishly illustrated volume edited by Bouchenot-Déchin and Farhat (2013) for an assessment of his legacy.

${ }^{58}$ See Maral (2013b) for a detailed discussion of the Grande Commande, its intricate iconographical programme, and its development over time. In 1684, after Louvois succeeded the deceased Colbert as surintendant des bâtiments $d u$ Roi, the Parterre d'eau was destroyed and replaced with two new, and less elaborately decorated, basins. The sculptures were dispersed to other sites in the park while the new basins were decorated with newly commissioned sculptures that no longer had any iconographical connection to the theme of Apollo. It seems, however, that the initial decision to abandon the original project for the Parterre d'eau dates back to 1681, when Colbert was still sûrintendant.

${ }^{59}$ Gaspard and Balthasar Marsy, Latone et ses enfants (marble, 1668-1671). See Maral (2012: 29-30). The sculpture of Latona and her children may have had political connotations, allegorically representing Anne of Austria (the King's mother) protecting her son in her capacity as regent during the tumultuous years of the Fronde (a series of uprisings among all social layers of the realm during the King's minority).

${ }^{60}$ Jean-Baptiste Tuby, Apollon sur son char (guilded lead, 1668-1670). See Maral (2012: 67-68). 
the whole world"' (Martin 1991: 150). With the circle thus closed, the site (and sight) of Versailles became a scene representing the order of reality in France.

The sense that the world was a stage, and which the design of Versailles clearly brings to mind, was deeply ingrained in early modern culture, and especially in the culture of the Baroque. This was the topos of the "theatre of the world" or (in its Latin coinage) the theatrum mundi. In the next chapter I will explore this topos extensively through a close reading of Russell's film The Devils. From the present discussion I mainly want to retain the fact that the self-reflexive quality of staging embedded narratives is obviously a very helpful tool to promote an awareness of the stage-like nature of the world in a spectator. To attend plays with embedded plays was simply to be made aware again, in a moment of self-reflection, of the complexities of the (social) theatre of the real world. In plays such as L'Impromptu de Versailles the whole problem of the theatre of (social) life is crystallised in a way that clarifies it for the audience rather than confusing them. Such plays show the audience exactly how the social drama works and how one plays one's role. These plays did not confuse, nor did they baffle or alarm: they pleased the audience because they confirmed something that they knew. Such plays functioned as a mirror: not a distorting mirror, but a revealing mirror that makes clear the structure of a shared and lived reality. It is my hypothesis that it is this feature of embedded narratives that made the trope so useful to Russell. When we say that Russell is baroque, I suggest that this should not, or at least not primarily, refer to the visual extravagance or outrageousness of his films. Russell is baroque because his work is shot through with the awareness that who we are is essentially a performance: a role we play; and that we can therefore also choose to play it in a certain way. Which also means that we can change the performance (despite the fact that there are always social and historical circumstances that, to a greater or lesser extent, constrain our freedom to vary the performance). In the following chapters I want to show how this awareness informs every aspect of his work: his ideas about art and artists, the way he constructs his narratives, and the way he performed his own role as an artist.

Our first task, however, is to explore more deeply what it means to say that the world is a stage on which we perform. Is this merely a theoretical idea or something we can actually see around us in everyday life? And, perhaps most importantly within the present discussion, how can we see this notion working in and shaping Russell's narratives? Answers to these questions can be found in what is now increasingly (and perhaps not coincidentally) regarded as Russell's greatest film: The Devils. This is a film that is constructed entirely along the lines of a theatrum mundi with the purpose of showing how exactly the real world resembles a play or a theatrical performance. To understand this film and establish its importance for my interpretation of Russell's work is the business 
of the following chapter. As I argued in the Introduction, the best way of understanding Russell as "baroque" is to connect the baroque back to its historical context. The Devils dramatises a number of historical events from the Baroque era that highlight one of the central concerns of the time: the growing awareness that there was no transcendent source of meaning and that all meaning was therefore a human construct. This immediately conjures up a Machiavellian view of the world where, in the absence of absolute metaphysical authority, (groups of) people will engage in conflict over the question whose world-view (or meaning) should become dominant in the shared world. The Devils is about such a conflict. In that sense the film provides the philosophical blueprint for Russell's performance of self through art. After all, one can only perform oneself through works of art if the self is something one can construct, mould, and design, and which is therefore no longer connected to any intrinsic transcendent essence. As I will argue, it is this basic assumption about the loss of essence that allows us to think about Russell, and also about our own time, as baroque. 


\section{Chapter Two}

\section{WE NEED A LARGER THEATRE}

The Devils (1971) as theatrum mundi

'The charm of history and its enigmatic lesson consist in the fact that, from age to age, nothing changes and yet everything is completely different.' 

If you blow up the world you have to build it again. This was made painfully clear when Ken Russell accidentally blew up the set of The Devils, one of the largest ever built at England's Pinewood studios. The film is set in 1634 in the French town of Loudun, for which a large modernist set was designed by Derek Jarman. In the finale of the film the walls of Loudun are blown up. But on the day of filming Russell got his timing wrong, pressed the detonator too soon, and blasted the set away with not a single camera rolling. It took a week to rebuild the set, only to blow it up again, this time on film. ${ }^{61}$ This anecdote about the making of The Devils points to what the film is actually about. The way worlds, or more specifically world-views, are made and unmade is the central theme of Russell's film. The Devils is about a highly controversial trial for witchcraft in which a priest, Urbain Grandier, was convicted and burned at the stake. This happened against a background of complex political and religious tensions, including the explosive combination of Cardinal Richelieu's centralising policies, forcing absolutism upon the country, and the aftermath of many decades of religious wars between Catholics and Protestants. In the trial against Grandier all these tensions came together and the figure of the priest became the focal point for the mood of volatile instability that resulted from them. Russell's film dramatises this instability by taking the trial against Grandier as an emblem for the deep disruptions of the times. But Russell does more than that: he also shows that what happened in Loudun was not an isolated historical event. Rather, he sees the events in Loudun as a unique archaeological site to learn something about how power relations determine the destiny, not just of individual men and women, but of entire societies. In that sense, the story of Grandier and Loudun becomes a metaphor for the destiny of human society in general. It tells us something about how we shape our

\footnotetext{
${ }^{61}$ Different versions of this remarkable story exist. Dudley Sutton, who played the character of Laubardemont (who gives the order for blowing up the city's walls), remembers that he was supposed to step in front of the camera and nod to cue the explosion, but Russell 'blew it up before I had nodded. This is how I remember it. I was actually on the set. My memory is that people were so fed up with Ken by then, at his rages, that nobody was volunteering to press this button, so he said "All right, I'll bloody well do it," and he goes "Action," and just before I step in front of the camera - there's a big Panavision lens - and just as I'm stepping into the camera, he presses the button before I have even arrived and nodded. To my memory that's what happened. Then we had to come back a month later and shoot it again' (quoted in Crouse 2012: 117). Set designer Derek Jarman offers an account in which not Russell but someone else pushed the button: 'December 1970, Pinewood: Ken and his camera crew were tempers frayed come the end of filming in December. When the day for the great detonation of the walls of Loudun arrived, when all the charges were laid and we were ready to go, Ken, who had been very moody, said, "I'm not having this fucked up," and climbed on to the camera to film it himself. The signals that had been organised to let the explosives experts know we were rolling were primitive; and Ken, waving his arms in the argument around the camera, set the whole lot off. The camera stood idle, and as the dust and debris descended from the massive explosion everyone stood around dumbfounded. The next ten days were spent restoring the walls to get the shot' (Jarman 1991: 104). In the documentary Hell on Earth (Paul Joyce, 2002) Russell himself confirms that he pressed the button before Sutton had stepped in front of the lens and nodded.
} 
world and, by shaping the world, fashion our selves. This means that The Devils is not a straightforward historical film: it is an allegory. And it is this allegorical import of the film that makes it important for my investigation into Russell's performance of self.

In the previous chapter I discussed a number of narrative techniques that Russell used in his (auto-)biographical work. I also showed that these self-reflexive techniques were widely used in seventeenth-century theatre, where they were connected to an awareness that life is in a sense a performance on a stage. But this awareness was not without foundation: it was motivated by the fact that, throughout the sixteenth and early seventeenth centuries, European culture underwent a slow but deeply unsettling change in the course of which many traditional (theological) truths and certainties were called into question, challenged, and even overturned. The heritage of Renaissance humanism was not limited to a benign flourishing of the arts on a classical model: it also entailed the challenge of the heliocentric world-view, new scientific developments, and the impact of atomism (rediscovered through the work of Lucretius) on natural philosophy. ${ }^{62}$ Old and new models existed side by side, often struggling for prominence. Furthermore, the period witnessed brutal religious conflict, extended warfare, and the introduction of a new form of government, namely absolutism. What we now call the Baroque was a period of transition from the medieval to the modern world-view. As one historian of the period puts it, 'the baroque is [...] an artistic and political response to a diffuse feeling that people had, since the end of the [sixteenth] century, of being, paradoxically, at once abandoned and autonomous in a new world' (Levillain 2003: 55). On the one hand, the shattering of traditional truths and certainties left people feeling stranded, isolated, and abandoned in a universe they did not understand anymore (Pascal's meaningless cosmos). This is the sense of melancholy that informs important parts of Baroque culture. On the other hand, it promoted a sense of new possibilities opening up, of possibilities for determining one's own destiny. It made people aware of the fact that they could possibly fashion themselves and make or remake their lives. This awareness of the self as changeable, or as a role one could play, promoted the sense that life was a play in which we are actors with our exits and entrances. I will show that the allegorical import of

\footnotetext{
${ }^{62}$ The revival of atomist theories and the heliocentric cosmology helped remove Aristotelian final causes from physics and fundamentally altered the way the world was understood (Kraye 2007; Garber, Henry et al. 1998; Copenhaver 1998; Westfall 1977). That this process of change was slow and complicated is attested by the fact that even very late in the seventeenth century the decorations of the Grands Appartements $d u$ Roi in the palace of Versailles, executed in the 1670s, could still be organised around an astrological programme (Milovanovic 2005, 2012a, and 2012b). Scientific changes also had tremendous impact on the interpretation of Scripture and on (radical) political philosophies that developed in the seventeenth century, especially among the so-called Spinosists (Israel 2001). Panajotis Kondylis has called the long shift that took place during the period a 'Rehabilitation der Sinnlichkeit' (2002: 19 and passim): a rehabilitation of the senses, or a turn away from the theological towards a secularised world-view, out of which the Enlightenment developed.
} 
Russell's representation of the events in Loudun is constructed around this insight. What he shows us in The Devils is not simply a political trial against a suspected witch and heretic; he shows us how such a trial can become a public spectacle, a piece of theatre, in which people try to shape their world and their shared destiny. This means that The Devils is a film that comments on the very social processes that it dramatises.

My discussion begins with a clarification of the two central concepts involved in my analysis of The Devils: allegory and the theatrum mundi. For the first, I draw on Walter Benjamin's notion of allegories as ruins of thought, which is especially appropriate to Russell's film. I next introduce the trope of the theatre of the world with a brief backward glance at its history and at the way it re-emerged in Italy in the early Renaissance. These are the two key concepts underlying the further analysis, which triangulates Russell's film with its sources (Aldous Huxley's book on the Loudun possessions and John Whiting's play based on that book) and with the historical events on which they are based (especially as reported by Michel de Certeau). The first part of the analysis establishes how the set of Loudun in the film functions as an allegorical theatrum mundi. Next, each of the following sections of the chapter looks at one of a series of embedded stages within Loudun that develop both the narrative and the film's allegorical import. I will show that the exorcisms of the nuns were orchestrated as theatrical performances culminating in the public spectacle of Grandier's execution, which carries tremendous symbolic weight in the allegorical context of the film. But Russell also stages a burlesque mise-en-abyme when Louis XIII pays an incognito visit to Loudun to expose the charade of the exorcists. In the climactic scene of Grandier's burning at the stake Russell even introduces elements from early modern popular culture that further flesh out the film's allegorical import. In the concluding section of the chapter I will show that the film's allegorical dimension can be expanded to another level if we see its structure as modelled on the structure of a Corpus Christi play.

\subsection{THE VERY IMAGE OF RUIN: BAROQUE ALLEGORY}

The Devils is an allegorical film, presented as a theatrum mundi. These two notions, allegory and the theatre of the world, require some preliminary clarification, especially because they are central to the creative world of the Baroque, but also because the allegory, as expressive form, will remain prominent in the following chapters, where it will be used to flesh out a number of central elements in Russell's work. Since the theatrum mundi is itself an allegorical trope, it is best to begin with a discussion of allegory as the broader category. Walter Benjamin has argued, in his book on the German lament-play, 
that allegory is a form of expression that articulates a sense of desolation that was widespread in Baroque culture. ${ }^{63} \mathrm{He}$ makes this clear by contrasting allegory with the concept of the symbol that had become widespread since Romanticism. This concept held that in a symbol an abstract idea is materially articulated in a clear and accessible way. In a symbol there is 'an inseparable connection of form and content' ('eine unzertrennliche Verbundenheit von Form und Inhalt; Benjamin 1978: 138) resulting in an expressive clarity and unity that is associated with beauty. In comparison, allegory is literally an “"other-discourse" (allegoria), a mode that conceals its relation to its true objects' and 'shows a conviction that the truth resides elsewhere' (Cowan 2005: 59). Where a symbol makes present what it represents, allegory articulates, in its very form, the fact that the thing it represents is elsewhere, and difficult to grasp. Allegory lacks the unity of a symbol, and this is due to the fact that allegories are often composites of several elements rather than single images. In that sense one could argue that 'allegory appeared to be a feeble imitation of the symbol. Instead of brevity and beauty, allegory offered only the long-winded elaboration and excessive ornamentation of strained, commonplace associations' (Gilloch 2002: 81). In other words, allegory requires an effort from the reader or viewer to read and decipher the image, if not to know its meaning fully, then at least to try and get on its trail. ${ }^{64}$

The associative structure of allegory is perhaps nowhere more clear than in the emblem, which was a hybrid form of illustrated literature that was very popular in the historical Baroque. An emblem is essentially an image with subtitles: it consists of an image combined with an epigram and a short explanatory text or poem. The imagery in these emblems drew on a wide range of sources, including mythology, the natural world, science, alchemy, folklore, and so on. Together with their inscriptions these images functioned as a form of moral instruction. Such images were often published in collections and the emblem books of Ripa, Alciati, and, in The Netherlands, Cats and Roemer Visscher, were widely disseminated throughout Europe and informed the visual arts, where we can see the motifs and sometimes entire scenes from the emblems be adapted

\footnotetext{
${ }^{63}$ I prefer the translation lament-play over the more commonly used mourning-play for the reasons outlined by Plate (2005: 44-45). Benjamin discusses allegory in the second part of Ursprung des deutschen Trauerspiels (1928; here 1978: 138-211). The notion is also important in his writing on Baudelaire: see Lindner (2000: 70$81)$.

${ }^{64}$ Despite Benjamin's criticisms of Romanticism (which need not detain us here) it is interesting to connect his ideas on allegory with the work of Friedrich Schlegel, for whom allegory, along with the joke and the fragment, is a way of trying to overcome the limits of human knowledge and catch a glimpse of truth or the absolute, however fleeting. There is an excellent discussion of these aspects of Schlegel's work in Frank (1997: 921-944, esp. 931-933 on allegory; this text overlaps considerably with other discussions by the same author [1989: 287-306; 2007: 88-138]).
} 
into paintings. ${ }^{65}$ Especially for seventeenth-century Dutch genre painting critics have argued that seemingly innocuous everyday objects, animals, or even whole scenes are drawn directly from these emblems. ${ }^{66}$ Such details, but often also entire scenes, can then be argued to function as a form of what Panofsky has called, in a discussion of early Netherlandish painting rather than Baroque painting, "disguised symbolism" (1971: 140-144): seemingly naturalistic scenes that actually carry an allegorical meaning that needs to be "read" out of the iconography of the image by the informed viewer. John Rupert Martin has called this principle 'the transcendental view of reality' (1991: 119153) that informs much Baroque art. Perhaps the most familiar example of allegorical representations of the period is the genre of the vanitas: carefully assembled still lives, often with a skull, (wilting) flowers, soap bubbles, or other fragile objects that signify the transience of human existence. ${ }^{67}$ What all such works have in common, however, is that their images are neither singular nor straightforward: they are composites (or compositions) of elements that the viewer has to connect to achieve a sense of meaning. Often, as in Dutch genre painting, the works may seem merely descriptive of external reality if one is not aware of the fact that an allegorical meaning is or may be intended. For this reason, modern iconologists are still often in disagreement about the meaning of a given painting, or whether such a meaning is intended at all. ${ }^{68}$

It is exactly this resistance to unequivocal reading that Benjamin finds typical of Baroque allegory, where 'any person, any thing, any relationship can mean any other' ('Jede Person, jedwedes Ding, jedes Verhältnis kann ein beliebiges anderes bedeuten'; Benjamin 1978: 152). It is this random compilation or association of signifiers and (possible) meanings that expresses the turbulent world-view of the Baroque. If the meaning of the universe is in dispute and if the foundations of all knowledge and ultimate mean-

\footnotetext{
${ }^{65}$ Henkel and Schöne's Emblemata (2013; orig. 1967) is the classic reference: a massive compendium of emblems culled from all the major sources. On the structure and functioning of emblem books, see Schöne (1993: 18-26) and especially the systematic discussion of the aim and methods of Ripa's Iconologia (first published in 1593) by Werner (1977: 11-39).

${ }^{66}$ Eddy de Jongh (esp. 1967; 1976; and 1999) has shown the importance of emblem books in identifying such symbolism in seventeenth-century Dutch genre painting. But the use of symbolism in art went beyond genre painting. Even landscape painting could contain symbolic meanings in what Panofsky called the "paysage moralisé" (1962: 64; also Martin 1991: 138-140). See Bruyn (1987) for a discussion of scriptural symbolism in Dutch landscape painting of the period and Walsh (1991) for a sceptical approach to the possibility of metaphysical meanings in cloud formations, although both these topics extend to symbolism beyond the sources of emblem books. Of course, in pursuing such hidden meanings, even with the help of emblem books, there is always the risk of iconology run amok into Hineininterpretierung: see the cautionary remarks by De Jongh (1991; also 1999: 129-143) and Hecht (1986) and the methodological remarks by Sluijter (1991).

${ }^{67}$ See the excellent discussions of the vanitas motif by Stoichita (1999: 354-363) and Martin (1991: 134-138). For the motif of the soap bubbles (often a child blowing bubbles), see De Jongh (1976: 45-47).

${ }^{68}$ See De Jongh (1991) for discussions of such disagreements and examples of a number of readings of paintings that turned out to be wrong.
} 
ing are being eroded there is a very real sense that nothing is ever really what it seems to be. That is why 'in the allegorical emblem [...] the arbitrariness and unreasonableness of assigning a thing to a particular meaning' (Cowan 2005: 62) is made exceptionally clear. To compose an emblem is to (re)organise elements from the world into a new whole with a new intended meaning. The image of the allegorical emblem can literally be said to be re-writing or re-visioning the world and its meaning. In doing so, it highlights the instability of all meaning and all signification. By making explicit how any form or object can be connected to a (hidden, disguised) meaning it reveals the relativity and arbitrariness of all established meaning. The Baroque was a period of tremendous existential upheaval. After all, 'one of the momentous effects of the Renaissance, where men had turned their eyes to the things of this world, was to give new life to the idea of the decay of the world by planting mutability in the heavens' (Williamson 1935: 121). This unhinging of the heavens was accompanied by a rediscovery of the atomism of Antiquity, turning the whole of the universe into a Heraclitean river of constant change and instability. In such a context 'allegory arises from [the] apprehension of the world as no longer permanent, as passing out of being: a sense of its transitoriness, an intimation of mortality' (Cowan 2005: 57). An artistic form that articulates such an experience almost inevitably becomes 'fragmentary and enigmatic; in it the world [...] becomes an aggregation of signs' (ibid.) that can be manipulated. It is this experience of meaning unmoored and of certainties set adrift that Benjamin considers in his famous observation that 'allegories are in the realm of thought what ruins are in the realm of things. Thence the baroque cult of ruins' ('Allegorien sind im Reiche der Gedanken was Ruinen im Reiche der Dinge. Daher denn der barocke Kultus der Ruine'; Benjamin 1978: 156). A ruin, after all, is a fragment left over from a previous meaning that has now lost its wholeness. It is because allegories offer no semantic closure that they so perfectly express, even as a formal conceit, the existential experience of early modern culture, where the certainties of yesteryear were slowly turning into crumbling ruins. It is this sense of the ruin of ultimate meaning that underlies the feeling of melancholy that is often found in Baroque culture. $^{69}$

\footnotetext{
${ }^{69}$ Since Antiquity melancholy had been associated, in a complex semantic continuum, with black bile (in medical humourology), madness, artistic genius, astrology, divine inspiration (Platonic mania), or, in the Middle Ages, the sin of acedia (sloth or apathy). See Wittkower and Wittkower (2007: 102-108), Dandrey (2003: 87-128), and Starobinski (2012: 19-77) for surveys of the tradition, but also the several essays and images collected by Clair (2005), especially Demont (2005) on humourology and Hersant (2005) on acedia. Surveying sixteenth- and seventeenth-century theories of melancholy, Gowland points out that these were often a mixture of Galenic, Platonic, alchemical, astrological, and other elements brought together by 'the non-dogmatic eclecticism of the majority of learned medical theorists and practitioners' (2006: 89). The impact of the changes in astronomy, however, is not always accounted for as an important contributory factor. In this respect, Spenser's Two Cantos of Mutabilitie have received excellent commentaries in view of the
} 
As an allegory, however, Russell's film takes on a specific form. The Devils is structured as a theatrum mundi: a theatre of the world. The city of Loudun, as it is re-created in the film, is treated by Russell as a theatre stage on which an allegorical play is performed about the way people perform on the stage of the world. Since the concept of the theatrum mundi is the central tool for my analysis of The Devils something more must also be said about its meaning and background. The topos of the theatrum mundi had been widely used in Antiquity, particularly in Stoic philosophy, and was revived in the fifteenth century through Ficino's translation of Plotinos. ${ }^{70}$ But the topos of the world as a stage was developed in several ways, and two important traditions are relevant to the present discussion. The first draws on the Hermetic tradition and saw man as a kind of second creative god. It is found in the work of, among others, the humanist Pico della Mirandola. ${ }^{71}$ A well-known example of this interpretation of the topos is Prospero in Shakespeare's The Tempest, 'the magus who directs the exits and entrances of other men and is able completely to manipulate his environment' (Christian 1987: 58). ${ }^{72}$ In Corneille's L'Illusion comique the magician Alcandre, conjuring visions at will, is a similar figure. A second interpretation of the topos is indebted to the Stoic tradition coupled with Christian ideas. On this view God has assigned man a role to play on the stage of

anxieties kindled by contemporary developments in the study of the heavens (Williamson 1935; Freeman 2005; Powrie 2013). The anxiety about the mutability of the heavens is also part of a more general (and not necessarily anxious) concern with transience in the Baroque era, which is characterised by what Jeanneret calls (specifically for the sixteenth century) a 'metamorphic sensibility' (1997: 5) that can be found in the cosmology, geology, biology, and physics of the time, but obviously also in literature and the arts.

${ }^{70}$ Lynda Christian has argued that the topos disappeared in the Middle Ages, probably 'because the theatre had ceased to exist as a viable institution after the fall of Rome. Drama had ceased to be a literary genre, and theatres existed as antique ruins of a dead age' (1987: 197). However, Stevens (1973) argues that the idea can also be discerned, although less as a theatrical metaphor, in the Middle Ages, especially in the structure of the Corpus Christi plays. Finally, in the Renaissance the theatrum mundi was also an important mnemotechnic device, as in the theatre of Giulio Camillo, which is discussed in an important article by Bernheimer (1956: 225-231; also 1958). The classic discussions of this tradition are of course those by Yates (1969a and 1969b). Coldewey (2004: 22-61) discusses the eclipse of theatre in the Middle Ages and the role of liturgical drama in its re-appearance in the British context.

${ }^{71}$ The origins of the topos of the artist as a second god are discussed by Kris and Kurz (1995: 64-86), who also address the complementary image of the creative god of Genesis as an artist-creator of the world. See Cassirer (1942) for Pico della Mirandola.

${ }^{72}$ Frances A. Yates (1969b) has suggested that the ground-plan of the first British theatres, built from the 1570s on, was deeply influenced by Vitruvian elements as formulated in John Dee's Preface to Euclid. She argues that the ground plan of the Globe was structured to reflect the zodiac, thus symbolically representing the entire cosmos. Following the Hermetic tradition that saw man as a microcosm mirroring, as a theatrum mundi, the macrocosm, the ground plan could be read as 'a statement in symbolic geometry of man's relation to the cosmos, of man the Microcosm whose harmonious constitution relates him to the harmonies of the Macrocosm' (o.c. 133). As such the theatre structure (not just of the Globe but also, as in the context of the following quote, Burbage's first theatre of 1576), 'showed forth clearly that this was a "Theatre of the World", in which Man, the Microcosm, was to play his parts within the Macrocosm' (o.c. 128). 
the world and it is man's duty to play this role well. This tradition finds an almost literal expression in Calderón's play El gran teatro del mundo (ca. 1645), where allegorical figures enter the stage of the world, are dressed for their assigned part, act it out, and are finally judged by God. In these two traditions one can see the tensions between the old world-view and the new: the first, humanist, tradition has freed man to be his own creator, while the second tradition remains deeply indebted to the theological world-view, governed by God. ${ }^{73}$ The point of interest for the present discussion lies in the fact that both Shakespeare and Calderón thematised the topos of the world-stage in actual stage plays. They investigate the nature of reality (the world as a stage) through theatrical representations of the issues, whether it is Prospero conjuring visions or the allegorical character of the World in El gran teatro del mundo who, as the other actors enter the stage, inquires of each actor what his part is and then gives him the costumes and properties which befit his role, thereby incarnating each soul' (o.c. 173). This gives the plays a self-reflexive quality because what they show (their reflection on the ontological status of the world as a stage) is reflected in how they show it (they dramatise the world-stage, and man's playing of his part, in a play performed on a stage).

The argument of this chapter is that The Devils is structured throughout as such a theatrum mundi. If Shakespeare's Globe Theatre was a "wooden O" that could encompass the whole world by representing it on its stage, then Loudun is Russell's "wooden O". The film treats the city of Loudun, which is the main set on which the drama is played out, as a theatre stage on which a drama is performed about the nature of reality. To do this, it treats the trial against Grandier, with all its political implications, as an allegorical drama about how the social world is made. That is how, in a metaphorical sense, the stage of Loudun represents the whole world within its circumference. It is also why an extensive analysis of The Devils must be central to the investigation of Russell's performance of self. It is in this film that one finds what one might call the ontology behind Russell's work. If Russell invites us to think of the self as a performance, then The Devils is the film that shows us the underlying world-view that makes such a concept of the self possible. The film reveals why and how the world (and not just the world of Loudun in 1634, but human society in general) can be seen as a stage upon which we perform our selves. In that sense, everything that was said about self-reflexive theatrical

\footnotetext{
${ }^{73}$ Larue (1992: 18) argues that Calderón's theatre under the gaze of God (still) implies a geocentric world-view, a sub-lunar "closed world" with a pantheocratic God as its sole spectator. El gran teatro del mundo belongs to the Spanish genre of the auto sacramental which was performed annually as part of the Corpus Christi celebrations (see Parker 1943: 58-67). For the auto and the concept of the theatrum mundi, see Parker (o.c. 110-155, with a detailed analysis of El gran teatro del mundo), Arias (1980), and Souiller (1992). The Corpus Christi plays (especially in their English form) will be discussed later in this chapter: see section 2.6.
} 
performance in Baroque theatre and in Russell in Chapter One presupposes the worldview articulated in The Devils. Throughout this book I argue that Ken Russell's work is a representation of self through art and that this is what can most meaningfully be called "baroque" about Russell's work. My analysis of The Devils will provide the cornerstone for the argument why and how this should be so. The baroque modes of representation introduced in the previous chapter are the tool with which these insights are teased out of Russell's film. The analysis of The Devils therefore continues the approach of Chapter One: it is based on a detailed dissection of the way Russell uses structures of embeddedness and the mise-en-abyme. The mise-en-abyme will be especially relevant because it is partly through such self-reflexive embeddedness that the film can be made to function as an allegory. However, I will also take a close look at a number of other modes of representation that Russell uses, such as the conventions of burlesque theatre and ballet and the mummers' play (both of which, incidentally, are also central to early modern and Baroque drama). Finally, at several points in the discussion I will scrutinise a number of iconographical details of the film. But all these elements will be brought to bear on the development of the central hypothesis: that The Devils is a theatrum mundi that reveals how reality is structured like a play on a stage. ${ }^{74}$

\subsection{SETTING THE STAGE: LOUDUN AS HUIS CLOS}

The Devils is based on an actual case of alleged demonic possession that took place in the early 1630s in the French town of Loudun. ${ }^{75}$ It was the subject of Aldous Huxley's book The Devils of Loudun (1952), which was subsequently adapted for the stage by John Whiting as The Devils (1961). Russell's adaptation of the story is based on both these accounts. Although Russell's screenplay borrows extensively from both Huxley's book and Whiting's play Russell 'was chiefly concerned with the dominant themes of the Huxley account' (Gomez 1976: 137). ${ }^{76}$ Both the book and the film show how religious beliefs and mass hysteria can be exploited for political purposes. The story, especially in Russell's film, is deceptively simple. Cardinal Richelieu's (Christopher Logue)

\footnotetext{
${ }^{74}$ Although serious criticism of the film (and especially Gomez [1976: 114-164] and Hanke [1984: 118-150]) has always acknowledged the allegorical structure of The Devils, the full extent of how this holds the film together in one imposing vision has never been fully appreciated.

75 The Loudun possession has generated much commentary. The most important modern historical investigations are those by De Certeau (1970; now 2005), Carmona (1988), and Rapley (1998).

${ }^{76}$ Gomez (1976: 114-164) has analysed the adaptations of book to play, and of book and play to screenplay, in considerable detail. Only the shifts in adaptation that are significant to my interpretation of the film will be discussed in the present analysis.
} 
ambition to centralise political and religious power in Paris requires that all the walls around French towns be destroyed. He sends his representative Baron de Laubardemont (Dudley Sutton) to Loudun with the mission to tear down its walls. But Laubardemont faces opposition from Urbain Grandier (Oliver Reed), a libertine Jesuit priest who has secretly performed his own marriage ceremony to Madeleine de Brou (Gemma Jones), one of Loudun's most virtuous women. He has also impregnated Philippe Trincant (Georgina Hale), the daughter of one of the town's foremost citizens. Grandier blocks Laubardemont's attempt to destroy the walls on the authority of the King's promise to the city's late governor Sainte-Marthe that the walls of Loudun would not be touched. While Richelieu sets about changing the King's mind on this issue, Laubardemont tries to find a way of undermining Grandier with the help of Canon Mignon (Murray Melvin), who resents Grandier's debonair unorthodoxy. They find their tool in Sister Jeanne of the Angels (Vanessa Redgrave), the hunchbacked mother superior of the local Ursuline convent who has developed a hysterical erotic fascination with Grandier, whom she has never met. When Grandier turns down her request to become the convent's new father confessor she spitefully accuses him of witchcraft and of having violated both her and her fellow sisters in the shape of a demonic incubus. Although he clearly sees that the accusations are merely the ravings of a frustrated woman Laubardemont jumps at the opportunity to bring Grandier to trial for witchcraft. Father Barré (Michael Gothard), a notorious witch-hunter, is called in to exorcise the sisters and find damning proof against Grandier. Since the whole trial is politically rigged, its outcome is a foregone conclusion: Grandier is tortured in an (unsuccessful) attempt to extort a confession and burnt at the stake while the walls of Loudun are blown to pieces.

Michel de Certeau, whose classic discussion of the Loudun possession was published in 1970, the same year that Russell's film went into production, has pointed out that Huxley's account offers 'un matériau historique très déficient, des vues très pénétrantes' (2005: 429). For the film to work, and for my analysis of how it works, it is not especially important whether, as De Certeau claims, Huxley's book is deficient in its presentation of the facts. Whether accurate or not, the book was the main source for the philosophical outlook of Russell's film. As Joseph Gomez suggests, 'Russell's film, like Huxley's book, is really a message for the present' (1976: 137): both are concerned with ideology and power, the mechanisms of which they seek to expose. Or, as Russell himself observed, 'Grandier's case seemed to me, when I went into it, to be the first welldocumented political trial in history' (AT 205). Looking back on the film two decades later Russell commented that 'The Devils was a political statement worth making. Although the events took place over four hundred years ago [sic], corruption and mass brainwashing by Church and State and commerce is still with us, as is the insatiable 
craving for sex and violence by the general public' (BP 193). ${ }^{77}$ Throughout his account, Huxley himself regularly comments on the analogies between what happened in Loudun and what happened under Nazism and Communism, but also under McCarthyism in the United States: religious and political persecution of undesirables, show trials, mass exterminations. The following discussion is therefore primarily concerned with Russell's presentation of the case (drawing on the Huxley book and the Whiting play). While the film is very true to the spirit of the historical facts, and takes much of its detail from recorded events, the actual historical background will only be used to flesh out the 'vues très pénétrantes' that motivate Russell's film. These penetrating views extended beyond the mere evocation of a disturbing episode from history. The events in Loudun are used by Russell as an exemplum, an exemplary case representing the machinations that underlie the struggle for power at all times throughout history.

Russell has said that 'The Devils was about the self-destruction of a citadel from within' (BP 192). The image is appropriate for two reasons. First, the destruction of Loudun is not merely brought about by the oppressive centralised power of Richelieu, it is as much a consequence of the city's inner decay, which has left it vulnerable to outside attack. In the film the plague is used as a metaphor for this decay: it is a physical rot that has managed to seep into the city despite the fact of its still erect walls. On a more concrete level the inner rot of Loudun is manifested in the resentments that several influential people harbour against Grandier and which will lead them to collaborate with Laubardemont; in the festering frustrations of the secluded nuns whose sexual desires will be exploited in the exorcisms; but also in Grandier's own cavalier attitude to accepted morality and the rules and principles of the Church. Each of these internal weaknesses will be ruthlessly exploited by Laubardemont and his companions to bring about Grandier's ruin. But the metaphor of the citadel destroyed from within also refers to the extreme huis clos conditions under which the people of Loudun are living. When he warns his fellow citizens of Richelieu's intention to destroy the city's walls Grandier sarcastically points out that the central powers in Paris want to clear the view of the poor provincials who, literally and metaphorically, cannot see the wider world beyond their city

\footnotetext{
${ }^{77}$ The theme of corrupt or false religion would continue to occupy Russell over the following years, first in an unrealised project called The Angels and next in his film of The Who's rock opera Tommy (1975), in which a deaf, dumb, and blind boy turns pinball champion and becomes the messianic leader of a crassly commercial religious cult. In a key scene of the film a group of crippled people attend a mass in worship of a giant statue of Marilyn Monroe that is reputed to have healing powers. Intriguingly, after the hysteria in Loudun had died down, Jeanne had a second career travelling through France with a miraculous chemise while thousands of people flocked to touch her hand, which was also reputed to have healing powers (see De Certeau 2005: 395417). On The Angels, see Baxter (AT 96-97) and Gomez (1976: 195-196). For Tommy and its thematic connections to The Devils, see Gomez (1976: 194-200), Phillips (1979: 158-167), and Hanke (1984: 253-291).
} 
walls. This alleged shortsightedness is also political: Grandier is urging his fellow citizens not to be blind to the broader political implications of what is happening. It is not just about Loudun, not just about the city's walls, but about the kind of France that Richelieu wants to bring about. Ironically, the townspeople will indeed prove incapable of taking the broader view. Except for a few critical minds, who are severely sceptical of the exorcisms and remain very conscious of Laubardemont's political motives, most people, both citizens and tourists who have flocked to see the demonic spectacle of possessed nuns, are all too happy to surrender to the mob spirit of the exorcisms and Grandier's execution. The city of Loudun, enclosed within its pristine white-bricked walls, is like a bell jar or a pressure cooker seething with resentment, frustration, political manoeuvring, and debauched abandon. It is only at the end, when the walls are literally blown apart, that the festering pustule of the city is ripped open. In the final image of the film the camera holds still on a rupture in the wall that offers a vista of the surrounding landscape, littered with breaking wheels on which the dead bodies of Huguenots are rotting. Madeleine climbs over the rubble and stumbles into the landscape, the only person to escape the ravages of the hysterical huis clos that is Loudun.

The huis clos of Loudun, into which we, as the film's spectators, are also enclosed for most of the duration of the film, is essentially a stage on which Russell (following Huxley) presents a political allegory. The massive set of Loudun on which much of the action takes place is not simply the background against which events unfold: its look is part of the film's allegorical meaning. Russell told John Baxter that 'I wanted to make everyone realise I wasn't trying to be "true" in the sense they thought I should be true to what I was showing. I was cocking a snook at people who had preconceived ideas of what a historical film should be. I really despise period films. Anything before the eighteenth century is automatically in crumbling ruins, all grey blocks of stone. It looks like a pageant with everyone in fancy dress. We wanted to do away with the cobwebs and grey stone and get a contemporary feeling. The people of Loudun who were so crazy about their city and trying to save it certainly didn't see it as an old museum relic. For them it was something new and modern. So we had to make it modern for people today' (AT 206). To achieve a modern look for the film Russell and set designer Derek Jarman took their cue from Huxley's notorious observation that during the exorcism of Sister Jeanne, 'Barré had treated her to an experience that was the equivalent, more or less, of a rape in a public lavatory' (Huxley 1971: 117). Hence the white bricks out of which the set is constructed and which resemble the 'faux white-glazed bricks of the kind favoured by 
Victorian sanitary architects' (Ede 2012: 58).$^{78}$ Russell also explains that the arched shape of many of the interior spaces in the convent is based on a scene in Fritz Lang's Metropolis (1927) 'where the workers run along an underground passage that's a cross between the Metro and the Maginot Line, and we went for these arches because they have a timeless quality about them, especially when they're painted white' (AT 207-208). Finally, the general monumentality of the sets is indebted to epic spectacles from the silent film era. 'All detail is sacrificed to scale,' comments Jarman, 'as I want the sets as large as possible, and as forceful as the sets from an old silent' (1991: 100). ${ }^{79}$

Ultimately, the effect of using such a modern-looking set seems fruitfully paradoxical. On the one hand it makes the events look timeless, for what looks contemporary to us also looks like something not out of the past and therefore relevant to the present. But on the other hand this timeless effect also makes it possible to focus on what it actually meant back then to be part of these events. In terms of getting the viewer to understand the import of the historical events, the anti-naturalistic modern sets achieve an increase in experiential realism for the spectator, who is not distracted by period detail from the real issues at hand. As such, the modernist set is key to an analysis of the film as allegory. In his study of the possibilities and limits of historical representation in film, Robert Rosenstone argues that 'history with a "period look"' (1995: 63) very easily 'slides into what might be called false historicity. Or the myth of facticity, a mode on which Hollywood has long depended. This is the mistaken notion that mimesis is all, that history is in fact no more than a "period look," that things themselves are history, rather than become history because of what they mean to people of a particular time and place' (o.c. 60). He further argues that "to be considered "historical," rather than simply a costume drama that uses the past as an exotic setting for romance and adventure, a film must engage, directly or obliquely, the issues, ideas, data, and arguments of the ongoing discourse of history' (o.c. 72). This was exactly Russell's ambition on The Devils, which perfectly fits the ideal that Rosenstone projected: a dramatisation of historical events that avoids the period look to bring out what the depicted events mean, both to the people who lived it in history and to us who watch its drama unfold on the screen. By

\footnotetext{
${ }^{78}$ Incidentally, the historical city of Loudun actually did have white walls, and it was known at the time as ' $l a$ ville blanche' (Carmona 1988: 48).

${ }^{79}$ Jarman's sets were probably also indebted to his earlier geometric designs for John Gielgud's staging of Mozart's Don Giovanni at the London Coliseum in 1968 (images in Wollen 1996: 90-91). When Jarman later designed sets for Russell's staging of Stravinsky's The Rake's Progress in 1982, which was hugely successful both with the critics and the audience, the subway curves and tiles returned, along with crowds of bald-headed people, in the set for Angel underground station (Snow 1996: 87). Hanke points out that there is also 'more than a passing similarity' (1984: 127) to the set used in Peter Brook's Marat/Sade (1967). See also Peake (2001: 153-157) on Jarman's work on the film.
} 
doing this the film works on two levels simultaneously: as a dramatisation of historical events (based on two literary sources) and as an allegorical representation of the role of power in politics. It is in this allegorical sense that The Devils is structured as a timeless theatrum mundi: Loudun is presented to us as a stage upon which the universal drama of the human struggle for power is played out. Dramatising the events in Loudun on a timeless set allows Russell to connect the past to the present.

But if the city of Loudun is a stage, then it contains a number of embedded stages. One such stage is the chapel of the Ursuline convent which, in the course of Sister Jeanne's exorcism, is literally turned into a theatre where citizens and tourists can come to gape at uncannily flexible nuns who speak in diabolical tongues. In fact, after the exorcism of Sister Jeanne before an outraged audience of town notables, Laubardemont foresees an explosion of public attention and cynically quips that for any further proceedings 'we need a larger theatre'. Such larger theatres or stages are, in both chronological and expansive order, first, the town church where Barré stages orgiastic group exorcisms; second, the rigged trial of Grandier (where the audience is cleared out of the hall as soon as it starts to oppose the obviously prejudiced proceedings); and third, the main square of the town itself, where Grandier is placed upon a scaffolding to be burnt to death as the city's walls are razed. Each of these stages is a stage-within-the-stage, but I will argue that some of these stages also function as a mise-en-abyme because they reflect back upon the meaning of the framing stage of Loudun. As the framing stage, Loudun can almost literally be called a closed set, a hellish sans issu that becomes the stage of the world (the theatrum mundi) on which truths about power and politics are played out in allegorical miniature. I shall look in detail at how each of the embedded stages helps to support such an allegorical reading. It is important, however, to stress that these are mostly embedded stages and not embedded narratives. The Devils has one main narrative, which is remarkably (and ruthlessly) linear. There are a few brief embedded narratives in the film, but they do not affect the main narrative flow: neither the court masque at the beginning (which, as we shall see, has allegorical import) nor Sister Jeanne's two hallucinations about Grandier (in which she imagines him as a Christ-like figure who walks over water and descends from the cross to make love to her) disrupt or interfere with the main narrative of the film. The embedded stages, on the other hand, are used within the main narrative to lay bare the mechanics of the events. That is why they can be read as instances of the mise-en-abyme. The embedded stages make clear that whatever reality there is in Loudun, but by extension in the world at large, is never ontologically given: it is staged, and the staging is directed by those who have sufficient power to determine what the performance, and therefore reality itself, will be like. 


\subsection{THE DEVILS GO TO CHURCH}

The first dramatis personae to enter Loudun's allegorical stage of the world are Sister Jeanne and her exorcists. The purging of Sister Jeanne takes place in two steps. First, she is exorcised in the chapel of the convent. Second, a much more spectacular exorcism takes place in the church. ${ }^{80}$ This geographical shift is also a theatrical upgrade: from the relatively narrow chapel of the convent, where Jeanne is exorcised before a handful of the city's men (and a few women) of quality, the circus moves to the much more expansive stage of a nave-wide church orgy with the whole town and an army of sensationseeking tourists in greedy attendance. This shift follows the way the historical exorcisms were staged. These, too, moved from the seclusion of the convent to the publicity of the church, or rather to a number of churches; this move also implied an increase in theatricality; but it also implied a shift from the clerical to the legal, for the exorcisms in the convent were part of a religious investigation into the possession whereas the more public exorcisms were part of legal proceedings against Grandier (sorcery and commerce with the devil, besides obvious mortal sins, were also criminal offenses). In Russell's film, which collapses the possessions and the many phases of Grandier's persecution (which covered a period of two years from 1632 through 1634) into one linear movement towards climax, the distinction between the clerical and the legal is largely lost and both proceedings are conflated. To understand this movement's import as theatre, however, it is important to first have a look at how the historical events unfolded.

\footnotetext{
${ }^{80}$ Predictably, The Devils ran foul of the British film censor and after extensive negotiations the film was released in censored form. The orgy in the church suffered most. A whole sequence, affectively known among fans as "The Rape of Christ", in which naked nuns sexually assault a large sculpture of their crucified saviour, was completely cut from the film (in America, producer Warner Bros., who had never liked the finished film, cut out even more material). This censored version, which is the official 1971 British release version, is still the longest officially available. Much of the cut footage, notably the Rape of Christ, was deemed lost until Frank Kermode discovered it in 2002. Under Russell's supervision the material was restored and in $2004 \mathrm{a}$ 'director's cut' (with still some material missing, which is probably irretrievably lost) was shown at the National Film Theatre. Russell also recorded an audio commentary for this version. It has rarely been shown since and the version released on dvd by the BFI in 2012 is still the 1971 British release print. A documentary about the censorship issues, Hell on Earth (Paul Joyce, 2002), includes the recovered footage, although the version of it included on the BFI dvd is also shorn of some censored material. The censorship history of The Devils is very complex. Lucas (1996) offers a detailed inventory of all the material cut in several theatrical and video versions of the film, but compare Lapper (2012) for a discussion of the film's censorship history and Petley (2015) for the role of the press and local councils in the censorship troubles of the film. Simkin (2012) and Barber (2012) illuminate the context of British censorship at the time. See Kermode (2002) for an account of the search for and retrieval of the lost footage. Finally, Fentone (2000) puts The Devils in the context of the exploitation of the theme of sexually frustrated nuns in a wave of soft-core sex-films of the 1970s, for which Russell's film has been held partially responsible. I want to thank Dirk Van Extergem for making a copy of the restored version of the film available as opening film for the Russell conference Imagining the Past (Brussels, 19-20 March 2014).
} 
We will then return to the orgy sequence to show how it is both the heart of and the key to Russell's film as an allegorical theatrum mundi.

\subsubsection{Bending to Human Nature: Nuns on Stages}

One advantage of collapsing (or "telescoping") events is that it allows Russell to move very fast. Consequently, Sister Jeanne seems to plunge headlong from sexual frustration into diabolical possession. Interestingly, the historical possessions developed at a similarly swift pace. ${ }^{81}$ Everything started in the night of 21 September 1632, when Sister Jeanne and two other sisters reported seeing a ghost in the shape of the convent's late father confessor. Before long (in reports of 11 October, to be precise) the ghost was claimed by the good sisters to have assumed the shape of Urbain Grandier and was reported to be making very improper sexual overtures of a most insistent nature. From the beginning extensive notes on the events were taken by Canon Mignon and Father Barré, a priest from nearby Chinon who would soon take charge of the attempts to exorcise the assailed sisters. With hindsight we can say that at this time the outcome of the events had probably already been decided, for after the nuns identified Grandier as the ghost who was possessing them Canon Mignon (a friend and relative of Trincant, but in the film portrayed as mainly acting out of spite towards Grandier) was pointing out, on record, the parallels between the possession in Loudun and a similar case in Aix-enProvence in 1612, when a priest, Father Gaufridy, was tortured and burned alive for allegedly possessing a nun. ${ }^{82}$ The analogy (not thematised in the film) is relevant because, as Michel de Certeau has argued, the possession in Loudun followed a script. This means that the symptoms of the possession were not spontaneous eruptions but consisted of a number of actions that had become established and accepted as the "usual" symptoms suffered by possessed nuns. De Certeau suggests that the nuns at Loudun followed very closely the behaviour of possessed nuns as recorded at Aix. The fact that Mignon was the one who pointed out the analogies with the Gaufridy case suggests (but there is no proof of this) that he may have coached the nuns by steering their hysterics into a choreography that followed the Gaufridy model. In any case, De Certeau observes that in Loudun 'the characters are very rapidly put in place. Three weeks are sufficient to

\footnotetext{
${ }^{81}$ All facts and dates in the following account are taken from De Certeau (2005; orig. 1970) and Carmona (1988).

${ }^{82}$ See Carmona (1988: 40-44) on the Gaufridy case.
} 
mount the theatre that will develop according to the initial set-up ('le schéma initial')' (2005: 37). ${ }^{83}$

The events of this early stage of the possession are telescoped by Russell into the extended exorcism of Sister Jeanne in the chapel of the convent, where Father Barré is called in to rid Jeanne's innards of the hellish fiend. Barré was a notorious witch-hunter from the nearby town of Chinon. In Russell's rendering, which never allows one to forget Huxley's metaphor of the public lavatory, Jeanne's exorcism culminates in the identification of Grandier as the demonic source of the possession. By letting Laubardemont (a secular authority) supervise the exorcism in the convent (a clerical process) Russell makes clear right from the start that the whole spectacle of the exorcisms is mounted with the prime objective of incriminating and eliminating Grandier, who has become a nuisance through his opposition to the razing of Loudun's fortifications. In the film, Grandier is out of town during the exorcism. He has gone to Paris to plead the case of Loudun's walls with the King. When he returns, the exorcism has already exploded onto the larger public scene of the church, where Grandier is arrested (although not before Russell has given him the opportunity to try and clear out the revellers in a way that recalls Christ chasing the merchants from the temple $\left.{ }^{84}\right)$. The historical events did not come together quite so neatly. On 13 October, Sister Jeanne imposed order on the possession. In a bizarre exchange (which was documented on the scene) she listed the seven demons that had allegedly possessed her. In a remarkable feat of thespian prowess each of these demons manifested itself through Sister Jeanne with uniquely identifying facial grimaces, bodily contortions, and, perhaps most remarkably, a unique voice. By introducing this cast of demonic characters the exorcisms became a theatrical performance. As De Certeau explains, henceforth 'the modification of a look in the possessed signals the entrance of another demon,' effectively turning Sister Jeanne's hunchbacked body into a series of 'tableaux mouvents' that constitute 'a cosmological landscape' (o.c. 182). This observation is of major importance to understand the allegorical nature of the events as a theatrum mundi. To the seventeenth century mind there really was an elaborate order of demons that physically existed, a veritable cosmos of evil. By allowing eve-

\footnotetext{
${ }^{83}$ Implicit in De Certeau's use of the term 'schéma' one could see a reference to Warburg's notion of $P a$ thosformeln. In their survey of Les Démoniaques dans l'art (1887) Charcot and Richet similarly trace a number of typical physical postures through several centuries of representations of allegedly possessed persons. In this respect it is also interesting to consider that Didi-Huberman (2012) has revealingly demonstrated how Charcot and his fellow doctors staged the hysterical symptoms of their patients for public performance.

${ }^{84}$ In this respect it is also interesting that the scene of the group orgy in the church, which is loud and hysterical, is edited in a dialectic way with a very restrained and quiet scene of Grandier saying Mass on his own in nature on his way back from Paris: by switching back and forth between hysterical amok and pastoral calm Russell stresses the opposition between Grandier and his persecutors.
} 
ry demon to speak through her body with recognisable visual and vocal features the body of Sister Jeanne (but also the bodies of her fellow sisters, who were also each possessed by one or several individually identified demons ${ }^{85}$ ) became a sign of and a map to this demonic world. That is to say that the body could be read as a microcosm. The evil in the cosmos is something that hides behind the world of appearances. But in the body of the possessed it becomes visible because it is represented on a physical stage. ${ }^{86}$

The shift from convent to church was the shift towards legal proceedings, which were (and still are) meant to be public affairs. The exorcisms and the nuns' accusations of Grandier were now evidence against the priest that required publicity. From now on, the exorcisms were no longer private exchanges between the nuns, one or several priests, and a handful of privileged notables. When the case went public the exorcisms began to take place at fixed times. The nuns were separated and exorcised in different churches and chapels within Loudun. These exorcisms were also performed on a scaffolding and on beds that were furnished with rudimentary mattresses and cushions to prevent the good sisters from damaging themselves during their exertions. Discussing these public performances Huxley can barely contain his scorn. 'Reading [the] accounts of the nuns' performances,' he writes, 'one is forced to the conclusion that, as well as naturaliter Christiana, the feminine soul is naturaliter Drum-Majoretta. So far as the Eternal Feminine is concerned, a taste for acrobacy and exhibitionism would seem to be built-in, only awaiting a favourable opportunity to manifest itself in handsprings and back somersaults. In the case of the cloistered contemplatives, such opportunities are not of frequent occurrence. It took seven devils and Canon Mignon to create the circumstances in which, at long last, it became possible for Sister Jeanne to do the splits' (1971: 191). However, he also adds that the nuns' enthusiastic participation in these extraordinary feats of elasticity was almost certainly the hysteric's response to extreme sexual frustration. What the public was witnessing on the scaffolding was simply the unleashed sexual energy of young women who had been secluded, sometimes against their will, in a convent. And among the public flocking to see the exhibition there were at least a handful of sober-minded men who have gone on record in their disapproval of the exploitation of the frustrated women, arguing that the women needed a carnal rather than a spiritual cure. Claude Quillet, a doctor from Chinon (hometown of the zealous Father Barré),

\footnotetext{
${ }^{85}$ De Certeau (2005: 175-182) lists all the devils and the specific parts of the nuns' bodies they inhabited, based on the historical records.

${ }^{86}$ In his insightful discussion of Russell's films of the 1980s Barry Keith Grant argues that throughout these films 'social and political issues become translated into personal terms' (2009: 31) and are especially translated into "hysterical" (female) bodies. It is clear that this already applies to the hysterical bodies of the nuns in The Devils.
} 
claimed that the whole affair was due to 'Hystéromanie, ou bien Erotomanie... Ces pauvres diablesses de religieuses, se voyant enfermées entre quatre murailles, raffolent, tombent dans un délire mélancolique, travaillées par l'aiguillon de la chair, et, en réalité, c'est d'un remède charnel qu'elles ont besoin' (quoted in De Certeau 2005: 257). ${ }^{87}$

\subsubsection{Geeks Baring Gifts: The Orgy as Burlesque}

With the exorcism-turned-orgy in the church we enter the heart of The Devils, for as the exorcism reaches fever pitch Russell introduces an unexpected guest in the figure of the Duc de Condé, who is actually Louis XIII (played by Graham Armitage) travelling incognito (since we, as viewers of the film, have already seen Louis XIII in other scenes, we recognise him; obviously, the good people of Loudun and the exorcists have never seen the King before so they cannot be aware of the impersonation). Lounging on a bed as he is carried into the church, the Duc is accompanied by a group of effeminate courtiers. The Duc has brought with him a relic box containing a sample of Christ's blood which Barré uses to put the devils to flight. The Duc then opens the box to show that it is empty, unmasking the exorcism for the sham that it is. He entreats the good sisters to 'have fun' and takes his leave, after which the pandaemonium reaches new levels of hysteria. This scene is the key to the whole film: it is here that Russell most explicitly shows the extent to which we are watching a performance. And by including this unmasking of the events as a performance in the narrative he immediately also turns this scene into a mise-en-abyme: the visit of the Duc de Condé is a masque that unmasks the machinery behind the spectacle of the exorcism while itself being part of that spectacle. The visit is the staging of Loudun's blind spot: it unveils the truth that cannot be acknowledged if the reality that is created by the exorcism is not to fall apart. By lifting the veil the Duc simply opens the floodgates to more excess: exposed as frauds the exorcists can no longer control the exorcism/orgy, which becomes a veritable free-for-all of clerical gropings and Ursuline sapphistry. To understand the full import of this scene for the narrative we must look closely at the faux Duc de Condé and understand what he does, why he does it, and what this means for my reading of (Russell's rendering of) Loudun as a theatrum mundi.

\footnotetext{
${ }^{87}$ One strand of medical discourse argued that supposed witches were really the victims of melancholic visions. The Scottish physician Marc Duncan proposed an explanation of the Loudun "possession" through the theory of melancholy: see Gowland (2006: 93-96) and De Certeau (2005: 258-260).
} 


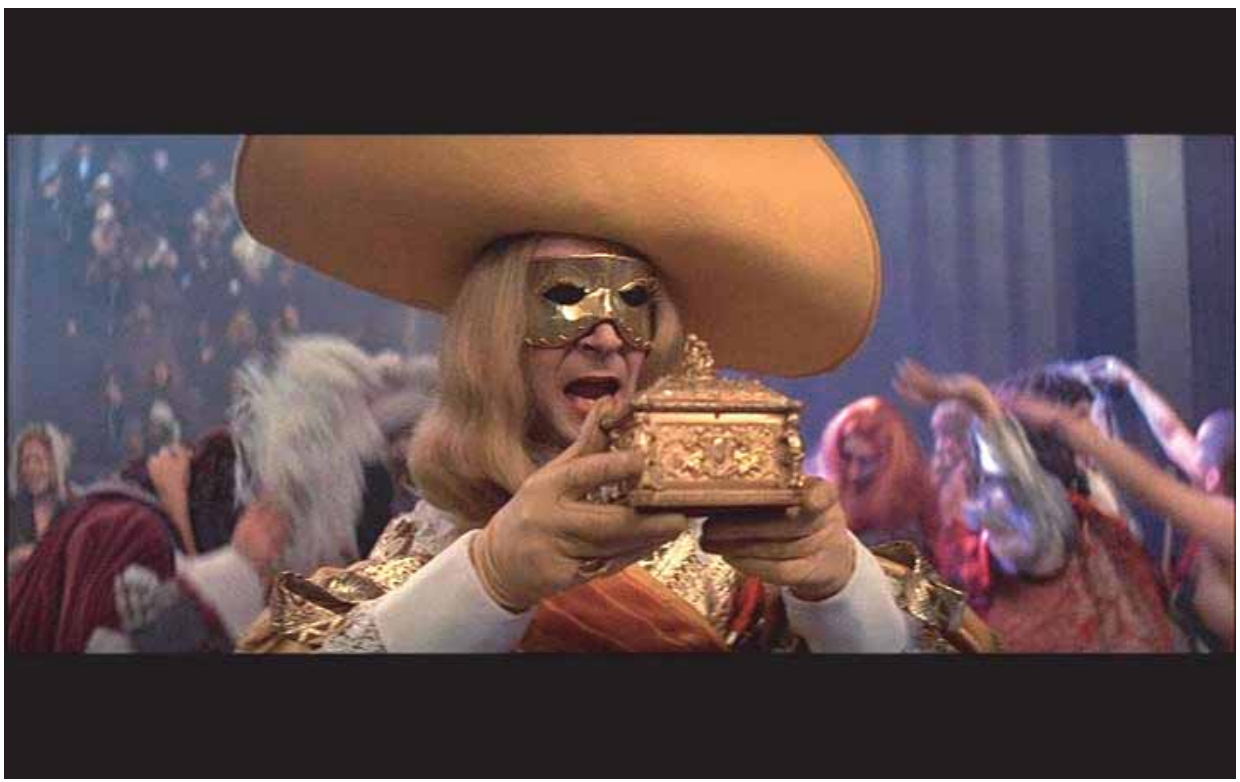

Illustration $6 \mathrm{~A}$ box with exceedingly holy relics

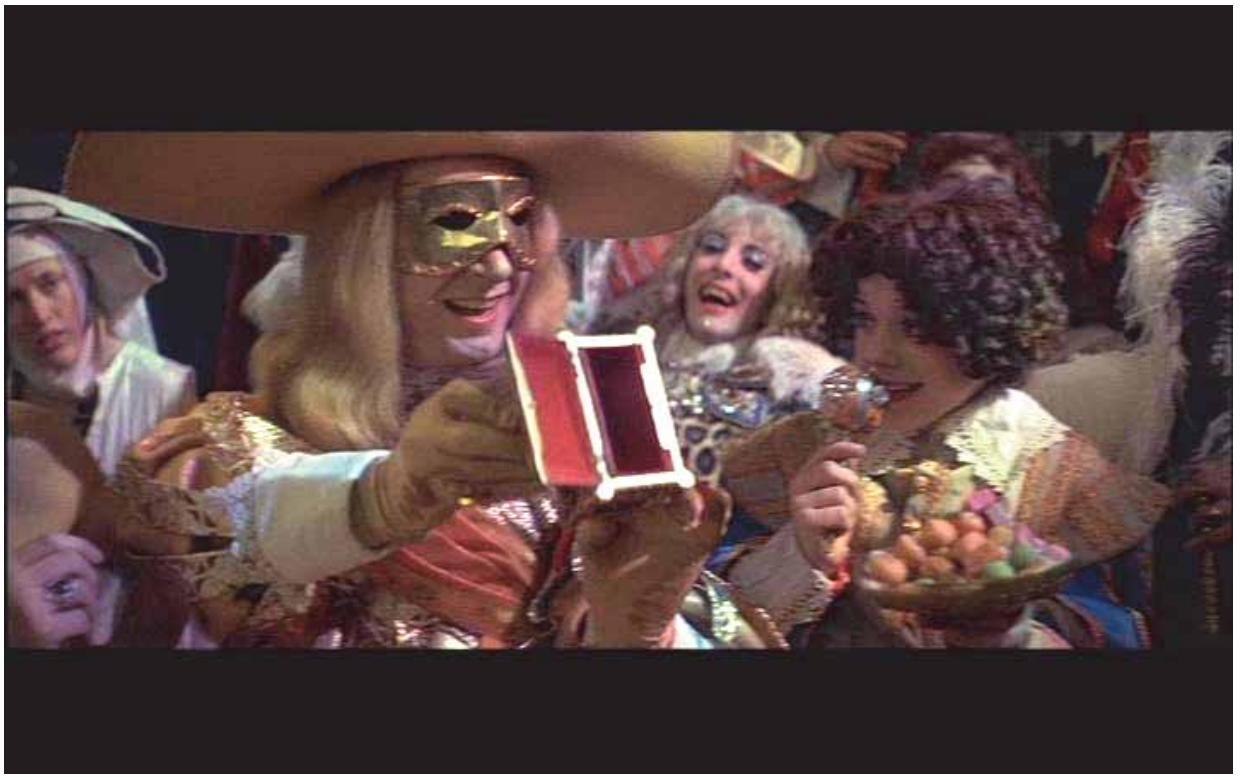

Illustration 7 "Reverend father, what sort of a trick have you been playing on $u s$ ?"

The sequence with the Duc de Condé is based on a scene in Whiting's play which in itself seems to conflate two separate events in Huxley's book. Huxley reports that while the 
exorcisms were still taking place in the convent 'Loudun was honoured by the visit of a very distinguished personage, Henri de Condé. This prince of the royal blood was a notorious sodomite, who combined the most sordid avarice with an exemplary piety. In politics he had once been an anti-Cardinalist, but now that Richelieu's position seemed impregnable, he had become the most fawning of His eminence's sycophants' (1971: 145). After visiting the convent and witnessing the exorcism of several sisters the prince is convinced of the reality of the possession and takes his leave. Later Huxley describes a number of traditional "tests" to which the sisters were subjected to ascertain the theological truth of the possession. Such tests were meant to prove that the nuns' sufferings (both psychological and balletic) really were the operations of the devil. It would be required for the sisters to levitate, speak in a language they did not know, or perform some other feat that could not be explained in a natural way (understandably, and for reasons of gravity, the avenue of levitation was barely explored: even a hysterical nun cannot hover) ${ }^{88}$ An impromptu test was coincidentally devised by 'a visiting nobleman who handed the exorcist a box in which, so he whispered, there were some exceedingly holy relics (ill. 6). The box was applied to the head of one of the nuns, who immediately exhibited all the symptoms of intense pain and threw a fit. Much delighted, the good friar returned the box to its owner, who thereupon opened it and revealed that, except for a few cinders, it was completely empty. "Ah, my lord," cried the exorcist, "what sort of a trick have you played upon us?" "Reverend father," answered the nobleman, "what sort of a trick have you been playing on us?"' (o.c. 178-179) (ill. 7) This event, including the exchange between the friar and the nobleman, has made it into Whiting's play and subsequently into Russell's film, but in The Devils the unidentified nobleman's relic is given to the Duc de Condé while Barré takes the place of the unidentified friar who is revealed to be playing tricks.

The most interesting aspect of the whole orgy sequence, and particularly the intermezzzo with the Duc, is its overall atmosphere of the carnivalesque and the exaggerated gendering of the Duc as an effeminate homosexual. On one level Russell can be said to just be following his sources. Huxley characterised Henri de Condé as a notorious sodomite and Whiting's stage instructions read that, as Henri de Condé enters, 'this exquisite and handsome sodomite is surrounded by painted boys' (1961: 83). In Russell's film, the Duc is surrounded by a bevy of transvestite characters (two of which are played, in cameo appearances, by the model Twiggy, who would star in Russell's next film The Boy Friend, and her manager Justin de Villeneuve). But in the film the Duc is also the King, and Louis XIII may have had homosexual inclinations. ${ }^{89}$ But despite such justifications it still seems remarkable

\footnotetext{
${ }^{88}$ See Carmona (1988: 191-193) for the tests to which the nuns were subjected.

${ }^{89}$ In his biography of Louis XIII, Jean-Christian Petitfils argues that it is 'fort possible' that Louis XIII had homosexual inclinations but deems it most unlikely that he ever acted upon them (2014: 301-303, here 301).
} 
that such a key scene should be presented as a camp interlude rather than as a dramatic high-point. After all, the intervention of the Duc is one of the main dramatic and narrative catalysts of the film because it is the (fake) Duc who unmasks the whole affair as a put-on. Also, both in the play and in the film we are invited to identify with the Duc's position, for to the extent that both Whiting and Russell conceive their play and film as a critical comment on a witch-hunt that has political relevance for the twentieth century, the Duc is their mouthpiece: at least part of their authorial comment on the events is voiced through the Duc's actions. In other words, it is the Duc who speaks for Whiting and Russell because it is the Duc who makes their political point by revealing the exorcism to be a sham. Why should such a crucial moment in the film be played camply for laughs rather than straight?

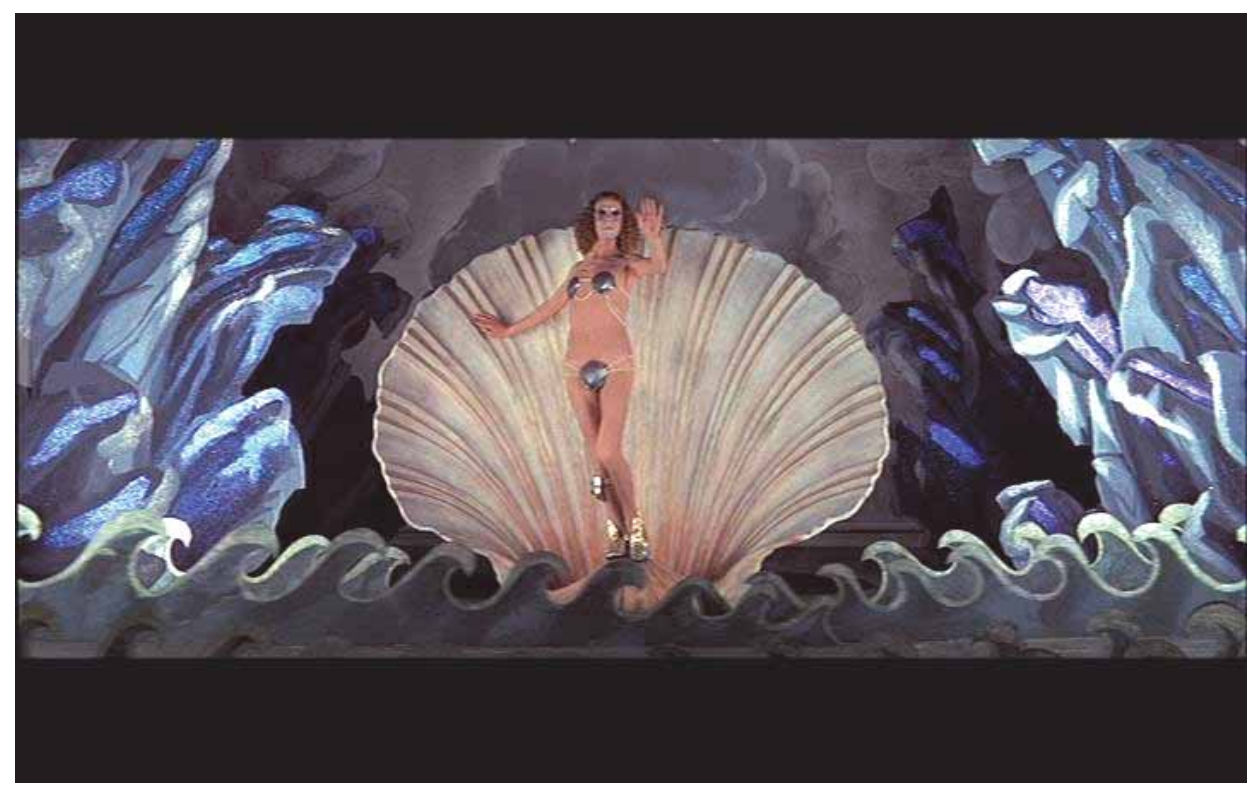

Illustration 8 Louis XIII rises like Venus from the waves

The King's carnivalesque intermezzo as the Duc de Condé should be understood as a burlesque performance. This also allows us to connect the central orgy scene to the film's

One of the key elements in this question is the close friendship between the King and the Duc de Luynes, who was the King's greatest favourite. De Luynes was more than twenty years older than the monarch. He became the King's falconer when the latter was still a child and a deep attachment developed over the years. As favourite, De Luynes became quite powerful at court. He also danced the title roles in Le Ballet de la Délivrance de Renaud (1617) and Le Ballet de Tancrède (1619). He also starred in Le Ballet d'Apollon (1621), which marked the apotheosis of his glory as the King's favourite. For the content and context of these ballets, see McGowan (1963: 105, 117-122, and 179-182 respectively). See also Muchembled (1978: 241) on Louis XIII's sexual education. 
opening sequence, where Louis XIII performs in a court ballet as Venus rising from the waves (ill. 8). In both cases, Russell uses burlesque theatre, which was a popular genre in the seventeenth century, to reveal the internal machinations of power. More specifically, in both cases Russell uses a burlesque performance to show that, behind the facade of political power, there is really nothing. This is what the empty relic box signifies: at the heart of it all, there is a void. But in the seventeenth century burlesque theatre or ballet was often put to similar subversive use. Burlesque plays or ballets usually presented grotesque buffoon-like characters with grossly exaggerated physical features. These characters were often used to mock (more or less gently) the official policy of the King (who was likely to be present in the audience), but also common vices or forms of misrule in general. During the reign of Louis XIII, and especially in the 1620s, burlesque court ballet flourished, and it was championed by the King himself, who did indeed on occasion dance transvestite roles (as he does in Russell's opening sequence). In fact, this kind of ballet was generally danced by 'the highest aristocrats and princes of the blood' (Franko 1993: 6), who could use it to express some of their frustrations with the King's policies. Burlesque ballet was an occasion 'to challenge, if only temporarily, the order of official culture' (o.c. 71). This usually required little in the form of narrative: burlesque ballets tended to consist simply of a number of entrées, which are self-contained numbers climaxing in a grand ballet. This gave them the character of 'parades of disparate figures whose identities were established by their choreography, costume, and the allusive content of their récits' (o.c. 79), which were the explanatory notes distributed among the audience. Franko describes the ballet Les Fées des forests de Saint Germain (1625) as 'a paradigm of the genre: seemingly unrelated scenes, a degree of apparent frivolity, and a predominance of erotic humour' (o.c. 87). ${ }^{90}$ Russell is following the spirit of Baroque burlesque when he presents the key scene of his film, in which the central "message for the present" is revealed, as a burlesque performance. The masks may be grotesque, but they reveal.

\footnotetext{
${ }^{90}$ See McGowan (1963: 133-153 and 169-174) and Franko (1993: 63-107) on burlesque court ballet in the 1620s; McGowan (2001) for a report on the political motives behind a burlesque ballet danced at the Paris Town Hall by the King and his courtiers in 1627; and McGowan (1986) for a rich iconography of the costumes created for such performances. Cowart (2008) discusses the further evolution of burlesque court ballet in the second part of the seventeenth century. In the 1650s, during the regency period when Louis XIV was still in his teens, ballet was relatively free of politics, although the Ballet de la Nuit (1653), in which Louis XIV for the first time appeared as Apollo (the Sun King), was 'an allegorical celebration of the end of the Fronde' (Cowart 2008: 19; see also Gruber 1994 and Christout 2005: 68-74). Cowart also shows how Molière's comédie-ballets of the 1660s, and especially Le bourgeois gentilhomme (1670), performed a similar function of symbolic contestation and places this development in the context of the libertins érudits and the salons of Paris, where an atmosphere of galanterie was cultivated. On this latter development, see also Fumaroli (1997: 41-105). The burlesque and the grotesque should also be seen in the context of the appropriation of popular culture by the elite in the early modern period: see section 2.5.1.
} 
The performance of the King as Venus at the beginning of the film can now be understood from a similar perspective, although in this case the King is using burlesque court ballet against itself. The Devils opens with a camp ballet in which Louis XIII dances the role of Venus in the throes of maritime birth for a decidedly (and ostentatiously) bored Richelieu. At the end of the performance Richelieu patronisingly "guesses" the subject of the ballet and expresses his desire to in turn assist His Majesty in the birth of a new France that will be rid of the Protestant. Richelieu then extends his be-ringed hand upwards towards the King, who bows and kisses it. This image very adequately reflects the historical relation between Louis XIII and Richelieu, who masterminded most of the King's policies. In this scene we can almost see the alliance between them taking shape: they meet each other half-way. The King has to bow down to kiss Richelieu's hand, which is a very submissive gesture for an absolute monarch. But Richelieu has to look up to the King who is on the stage to be adored as the incarnation of a new-born France in the guise of Venus. As the two men exchange knowing looks the title "The Devils" appears over their faces, literally inscribing the film's theme over the visage of its true villain: the central powers that will ruthlessly exploit the possession and use religion for political ends. But it would be wrong to see the King's cross-dressed and therefore "symbolically feminine" performance throughout this sequence as somehow a threat to his power. If anything, it reinforces his power, for even in drag the King is still the King and everybody knows it. By performing in a ludicrous outfit Louis XIII is daring the court to laugh or to mock him. That is why the spectacle of the transvestite King is still a spectacle of power. ${ }^{91}$ The cross-dressing reinforces the King's power because it shows (in the literal sense of putting on a show as a spectacle for an audience) that the King's power is still there even when it seems to be absent because he looks effeminate and ridiculous. By dancing in drag the King is offering the court a gentle reminder of his very real power by showing that his power is so big that he can retain it even when he seems to have lost it in preposterous burlesque. If the court can use burlesque to criticise the King, the King can camp it up right back at them. Such is the theatre of power. This is probably also the reason why it is the King, disguised as the Duc (a grotesque sodomitical disguise), who sabotages the exorcism with the empty relic box. By exposing Laubardemont and Barré as frauds the King, even while incognito, is keeping them in control: by staging his own masque he briefly takes over the direction of the spectacle to put his own revelatory twist on the proceedings. But these machinations of the King are only visible to $u s$, the spectators of the film who know about the impersonation (as opposed

\footnotetext{
${ }^{91}$ Franko (1994: 79) makes the point of the duality of the King both risking and asserting his power through burlesque.
} 
to Laubardemont and Barré). In fact, when the King-as-Duc has entered the church, he removes his mask in a gesture that is deliberately aimed at the camera, inviting us, the film's viewers, to become aware of the masquerade (ill. 9). The King's mask/masque is therefore aimed at us. It acknowledges the mise-en-abyme and thus helps Russell to achieve his allegory.

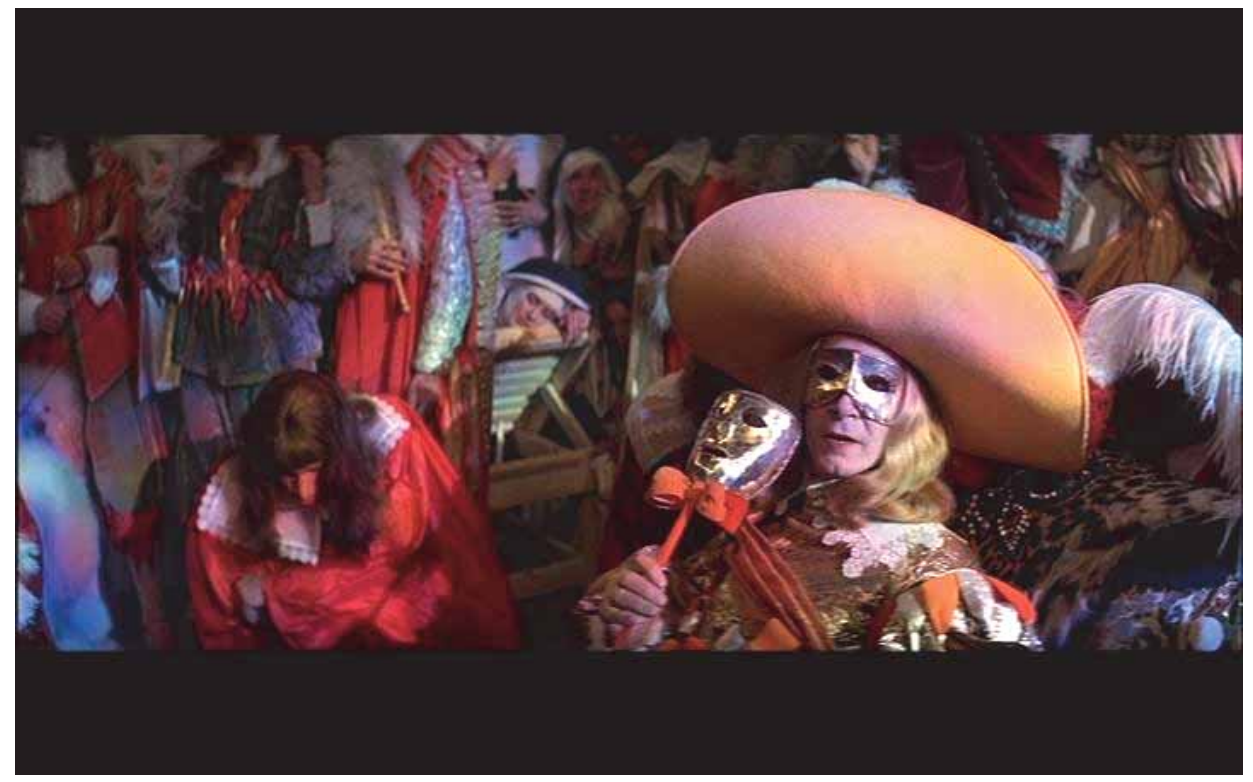

Illustration 9 Masque: the King as the Duc

\subsection{THE DEVILS GO TO TRIAL}

The third embedded stage of The Devils is the trial against Grandier. Huxley comments that in 1634 'most educated people were doubtful of the nuns' possession, were convinced of Grandier's innocence and were shocked and disgusted by the iniquitous conduct of his trial' (1971: 135). ${ }^{92}$ That is why the trial against Grandier was literally a show trial: a performance that was meant to show Loudun, but by extension every dissident in France, what the powers that be can do to those who dissent. ${ }^{93}$ This takes us into the

\footnotetext{
${ }^{92}$ In fact, a considerable number of the citizens of Loudun were so outraged by the proceedings that they called a general assembly that dispatched the town bailli to Paris to ask the King to intervene. They were not received and Laubardemont declared the assembly illegal: see Carmona (1988: 235-237).

${ }^{93}$ Muchembled (1978: 287-340) provides a discussion of witchcraft trials as part of a campaign to root out traditional cultural superstitions and impose a centralised culture (both religious and political) upon the
} 
heart of the issues at stake in The Devils. If the film is a theatrum mundi reflecting the way that reality is created, then the trial is the place where the fabrication of the real, or the fabrication of truth, takes place. In Loudun it is those with political and legal power who determine the truth. And as Huxley points out, 'for minds trained in the law, legal truth is the same thing as truth without qualification' (1971: 45). In other words, it is the law that determines what reality is like. So whoever has the power of law has the power to determine reality. This is why the trial against Grandier is so important. Trials are not about finding truth, they are about determining truth. The ruling of a judge or a jury is binding in the sense that how they find is how things will be. To be found guilty or innocent is to be made guilty or innocent by decree. The rhetoric of retrieval is misleading because a person's guilt or innocence are never "found" in a trial as something that was already there before or outside the trial. Rather, the trial establishes that a person is guilty or innocent in the very literal sense that guilt or innocence are created. That people who are actually innocent are sometimes "found" guilty, as in the case of Grandier, underlines this fact. The fact that many people who actually are guilty (in the sense that they did perform the acts of which they are accused) are also "found" guilty does not change this fact, for only the ruling of the court turns their guilt into a "real" fact.

That Richelieu and Laubardemont wield the power to determine reality in this way is nowhere more clear than in their opportunistic use of the nuns' testimony. Since the devil is the Father of Lies he cannot be trusted to ever tell the truth. In practice this should have meant that accusations uttered or evidence offered by the devil during exorcism could not be taken in evidence. In the film, however, as in historical fact, Laubardemont and Barré operate according to the principle that "if duly constrained by an exorcist, the devil is bound to tell the truth", which Laubardemont explicitly invokes during Grandier's trial to legitimate his fabricated evidence. This principle simply leaves Laubardemont and Barré free to accept or reject anything said by the nuns during the exorcisms as they see fit. ${ }^{94}$ This was necessary because, as the case against Grandier became more serious and its

French peasantry. In Muchembled's view so-called witches 'sont les victimes d'un processus d'acculturation des campagnes. Ils symbolisent la culture populaire que les élites dirigeantes et les juges cherchent à détruire, aidés en cela par une minorité de ruraux qui rompent avec leur vision du monde traditionelle' (o.c. 318). Muchembled outlines the way in which centralisation, the threat of Protestantism, changing economic circumstances, but also petty fears and hostilities contributed to an atmosphere in which a witch craze became possible.

${ }^{94}$ Such an approach was not uncommon in actual witchcraft trials, where confessions under torture were readily admitted as truthful while maintaining one's innocence under torture was simply taken to be another sign that one was in league with the devil: an obvious catch-22 for the poor victims of witch-hunters (Carmona 1988: 23-24 and 37 on confession under torture; 259-260 and 263-264 for the principle of due constraint). See Spierenburg (1984: 8-9) on the inquisitorial procedure. Grandier himself is reported as having said that ' $i l$ ne faut point prêter croyance aux paroles du Diable, qui est le père du mensonge' (quoted in Carmona 1988: 239). 
implications more obvious, several of the nuns, including Jeanne, were overcome by remorse at having wronged an innocent man. Such remorse could now be rejected as the devil's work on Grandier's behalf, forcing the nuns to persist in the possession. Once the accusations had been made there was simply no way back. In the film this remarkable piece of psychological terror is realised in a bizarre scene in which the nuns are gathered together in the woods, where Laubardemont has staged a mass execution because they are "guilty" of obstructing justice and therefore of treason. The mock execution is halted by Barré who shows the nuns a way to salvation: they must reassert the lies of the exorcism and duly keep on performing their possession. When Barré shouts at the nuns that 'You will scream?! You will blaspheme?! You will no longer be responsible for your actions?!' he is showing them the only way to save themselves: to persist in the lie, persist in the hysteria, and to trust that the Church will make it all right by sanctifying their lies as truths. If they scream and blaspheme, and if they are not responsible for their actions, they must be possessed and therefore innocent. And both Barré and Laubardemont need the nuns to be possessed and innocent in order for Grandier to be guilty. During his trial Grandier is aware of all this. He argues that Laubardemont and Barré have perverted the truth and theology. 'Satan had spoken and to doubt his word would be sacrilege' (Huxley 1971: 155): the phrase is taken from Huxley's authorial comment in the book but in the film it is given as dialogue to Grandier who uses it to argue that Laubardemont and Barré have perverted theology. But to no avail, for the judge preposterously cuts him short by saying that 'this is not a political trial'. During the investigation Laubardemont had taken good care that all the testimonies from "possessed" nuns, but also from citizens who had been bribed into giving false testimony against Grandier, had been put on record. 'Conscientiously Laubardemont and his clerks made notes of everything that was said. The minutes were duly signed, countersigned, and filed in duplicate at the record-office. Factually, theologically, and now legally, it was all true' (o.c. 156).

It was a magisterial coup on reality: people who really believed in the possession would submit to Laubardemont's political will out of piety, but those who saw through it and did not believe might feel even more compelled to submit to his will because beyond the mock possession they perceived something even more terrifying: ruthless power. The allegorical message for us, spectators of Huxley's and Russell's distant mirrors, is that all truth is always the temporary outcome of the never-ending struggle for power. And power is simply the ability to determine truth or reality. As Panajotis Kondylis points out, he who rules society is he who is able (for the present time) to determine 
binding interpretations of the world. ${ }^{95}$ That is what the show trial against Grandier is about: Laubardemont and Richelieu are showing all dissidents that, despite what we all know and see, they can determine what the world will officially be like. By staging the trial of Grandier as a series of embedded stages, Russell exposes the machinery of power. He shows that power carries the force of its own conviction only to the extent that it can make itself real in its consequences: one has the power to determine reality to the extent that one can enforce one's reality upon others by making them behave as if reality were like that. One critic, writing about the use of art and court spectacle in the propaganda around Louis XIV, writes that 'power resides in its representation; the representation of power is only an artifice void of substance; consequently, power only enchants when the artifice seduces' (Hochner 2014: 343). In this sense, the trial sequence serves the same formal function in the film as the masque with the Duc de Condé during the orgy. Both scenes are keys to understanding how power determines the world of The Devils. In the trial sequence, however, power is made real. Even while the machinations of power are exposed, both to us and to many of the participants in the events, we see them becoming real in their implications because, ultimately, Grandier does die and the walls of Loudun are blown to pieces. Richelieu and Laubardemont are flaunting their power: they do not simply want to dupe the good people of Loudun, they want them to enter into the trap with their eyes and minds open. It is only then that the terrible force of their power, which is the emergence of absolute power in France, will be as clear as possible. In showing how power operates, power is exercised and made real. Even as its mechanisms are revealed power is (still) made real. The circle closes.

\footnotetext{
${ }^{95}$ See Kondylis's observation that 'Herrscher ist, wer verbindlich $z u$ interpretieren vermag' (2002: 156). My understanding of the power dynamic in The Devils is deeply indebted to Kondylis's analysis of power and society in Macht und Entscheidung (1984) and Das Politische und der Mensch (1999). Kondylis argues that to understand a culture or an epoch one needs to see how it marks itself off from others by opposing them: the dominance of one world-view is always achieved by the defeat of another. He concludes that 'es gibt keinen anderen methodischen Zugang zur Erfassung des Charakters einer Epoche oder einer Gesellschaftsformation als ihre Abgrenzung gegen eine frühere oder eine andere' (1991: 287). On this view, what we see happening in Loudun is a battle between rival descriptions of the world. A similar understanding of the events is reached if one looks at Loudun through the work of Quentin Skinner, who has also focused on the importance of descriptions of the world in social processes and stresses the importance of the analysis of rhetoric for the historian. For Skinner, rhetoric is the art of 'exploiting the power of words to underpin or undermine the construction of our social world' (2002: 5). This struggle to construct the social world is all-pervasive, so that 'no one is above the battle, because the battle is all there is' (o.c. 7). Both Kondylis and Skinner's work is deeply informed by their reading of Machiavelli (see Kondylis's [2007; orig. 1971] monograph on Machiavelli with Cser [2007] and Skinner [2000] on Machiavelli), although Kondylis's outlook was also informed by his reading of Clausewitz (Kondylis 1988: 9-102).
} 


\subsection{THE DEVILS GO TO MARKET}

But the circle immediately expands again as we reach the final embedded stage of the film: the central square of Loudun where Grandier is to be burned. This stage in itself again contains two embedded stages. First, there is the scaffolding on which Grandier's body is burned. Second, there is also a hell's mouth theatre stage on which a mummers' play is performed that parodies Grandier's sexual exploits (ill. 10). These two stages, and the massive crowds of celebrating townspeople and onlookers that fill the market place, open up several avenues for interpretation that make it possible to unravel the theatrical complexity of The Devils even further. First, I will discuss the mummers' play in the context of early modern popular culture and the carnivalesque. Next, I will look at the scaffolding of Grandier's execution and explore its implications as a scene for political theatre. Both are key to understanding The Devils and its intended message for the present. It is here, then, as Grandier burns, that all the strands of The Devils come together in an emblematic conflagration.

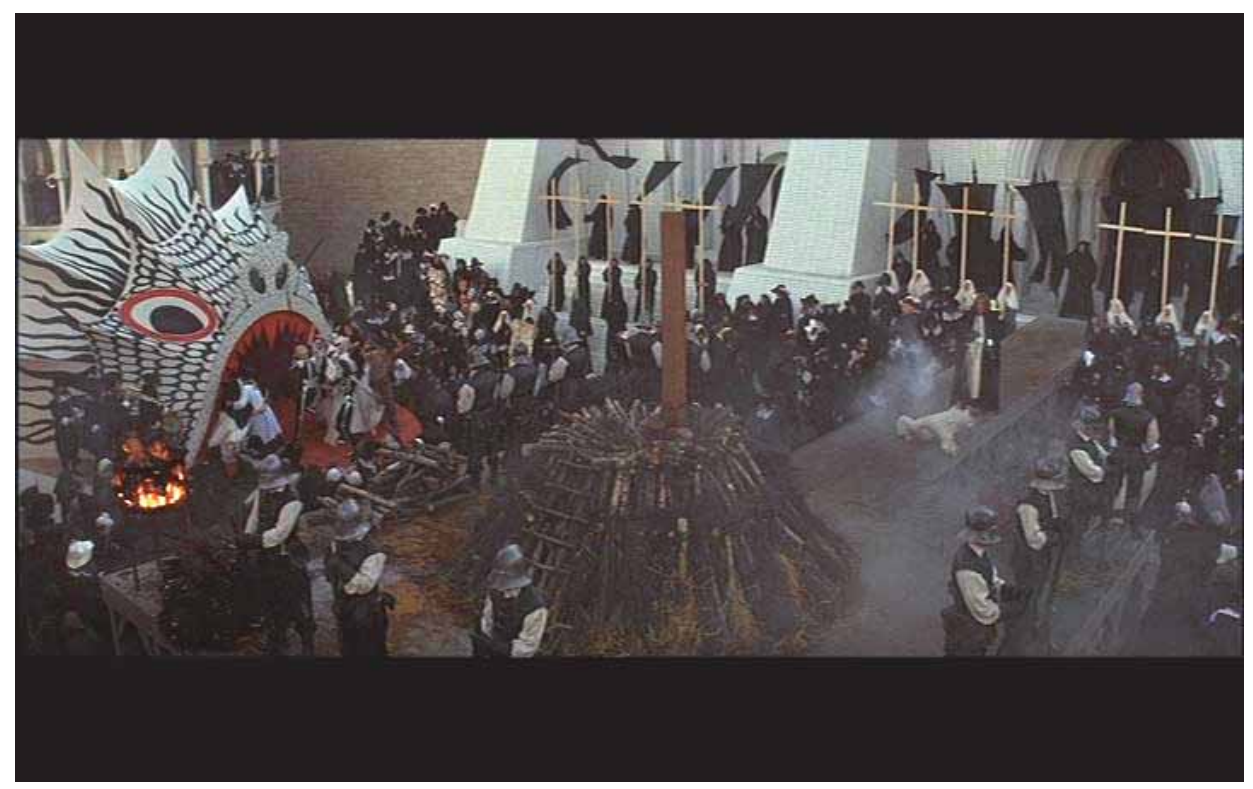

Illustration 10 Stages within stages: the hell's mouth stage and the scaffolding for Grandier's execution in the central square of Loudun 


\subsubsection{Carnival in Loudun}

The execution of Grandier is treated by the people of Loudun as a carnival. As he burns, they cheer and sing and dance. ${ }^{96}$ We see much of this from Grandier's point of view: grossly distorted faces, laughing obscenely, lurk behind the flames that consume him. In the middle of the chaos a mummers' play is performed. It shows actors on a hell's mouth stage dressed as nuns and a priest enacting Grandier's fornications. Despite the fact that their genitalia were obviously made of cloth and sewn onto the clerical costumes the British censor demanded the removal of the sequence. ${ }^{97}$ As part of the carnivalesque staging of Grandier's execution, however, it is worthwhile discussing this short sequence because it will open yet another perspective on the theme of power and theatre in The Devils. The obvious point of entry is Bakhtin's study of the work of Rabelais in relation to early modern popular culture and the carnival. ${ }^{98}$ In his introductory remarks about carnival Bakhtin notes that carnival 'belongs to the borderline between art and life' because 'carnival does not know footlights, in the sense that it does not acknowledge any distinction between actors and spectators. [...] Carnival is not a spectacle seen by the people; they live in it [...]. While carnival lasts, there is no other life outside it. During carnival time life is subject only to [...] the laws of its own freedom. It has a universal spirit; it is a special condition of the entire world, of the world's revival and renewal' (1984: 7). ${ }^{99}$ This description contains two elements. The first describes the theatrical structure of carnival as an event with no footlights. The second explains the meaning of

\footnotetext{
${ }^{96}$ Spierenburg (1984) is excellent on the spectacle of public executions in early modern Europe (his focus is on The Netherlands, but with copious material on France, England, and Germany), including a discussion of the reactions of the spectators, which tended to be more muted that in Russell's film, although sometimes riots broke out.

${ }^{97}$ On the audio-commentary for The Devils Russell and editor Michael Bradsell explain that they did not reinstate the mummers' play in the restored director's cut of the film because they now feel that it unnecessarily slows down the flow of the execution scene. It can now be seen under the end credits of the documentary Hell on Earth.

${ }^{98}$ Bakhtin's work has added relevance if we consider that in 1973 Russell was actually preparing to film Gargantua for the Italian producer Carlo Grimaldi, who had also produced Pasolini's Trilogy of Life based on the Decameron, the Canterbury Tales, and the Arabian Nights. Derek Jarman was once again enlisted as production designer, and although pre-production had begun, the film was never made. Apparently Pasolini had pulled out of the project as director, after which Russell was called in. Derek Jarman remembers that in the room next to mine [at the film studios in Rome] Pasolini was putting the finishing touches to the Arabian Nights' (2001: 158). There was a screenplay by Alberto Moravia which Russell did not like. Russell's own treatment was to have been in two parts: first a play about Gargantua, and then a second part about Gargantua himself (AT 228-330; Lanza 2007: 148-150; Yacowar 1980). I want to thank Paul Sutton for making a copy of the typescript of Russell's 1973 treatment for Gargantua available to me.

${ }^{99}$ See Muchembled (1978: 57-79) for a discussion of carnival as part of the cycle of the festive year and Cornette (2012: 36-39) for a schematic overview of the religious feasts that punctuated the annual cycle of early modern life.
} 
carnival, which it connects to a universal revival of the world. Let us first look at the meaning. Because he sees it as an extension of a pre-modern (medieval) popular culture that integrated birth and decay, the high and the low, in one grand continuum, Bakhtin understands carnival as an event that encompasses the whole world. It is 'a boundless world of humorous forms and manifestations opposed to the official and serious tone of medieval ecclesiastical and feudal culture' (o.c. 4). ${ }^{100}$ Within this boundless world the established order is inverted: all that official culture considers lowly and vulgar, namely everything that is connected to the material and the bodily, is celebrated as part of the chain of being. This is most clearly expressed in the imagery of the grotesque body. This is the body in its materiality, or what Bakhtin calls the material bodily lower stratum. It is the body as an organism that eats, defecates, and reproduces. Its basic principle is degradation or 'contact with the earth as an element that swallows up and gives birth at the same time' (o.c. 21). The grotesque body exists in complete opposition to the 'artistic canon of antiquity, which formed the basis of Renaissance aesthetics' (o.c. 28-29). It reduces everything to the material. For this reason Bakhtin argues that the grotesque body functions according to a topographical symbolism: it pulls everything downwards, inverting high and low. The most emblematic representation of this topographical principle is the body of the acrobat doing cartwheels, with the head and the ass constantly switching places. ${ }^{101}$ However, according to Bakhtin this process of degradation and inversion has a positive meaning in folk culture because the earth also brings forth new life. In the chain of being the earth is the locus of both death and resurrection. Death is not fearful in the popular world-view because death leads to rebirth (which connects to the myths of Jesus Christ and Dionysos, both of whom died and rose from the dead). In this world-view death 'is a more or less funny monstrosity' (o.c. 51). ${ }^{102}$

The most important feature of the grotesque body is the mouth because that is the part through which the body most intimately communes with (partakes of) the world. ${ }^{103}$ In the cycle of life and death (the material continuum) 'the body swallows the world and

\footnotetext{
${ }^{100}$ Modern scholarship now acknowledges that Bakhtin drew too firm a line between popular and elite culture. Throughout much of the Middle Ages and the early modern period the privileged classes actively participated in popular culture. Burke (2009: 259-286) surveys more recent insights into carnival, its structure, and its themes, although these do not affect the present analysis.

101 See Bakhtin (1984: 397).

${ }^{102}$ Russell told John Baxter that 'rotting away worries me much more than the thought of death itself and that 'corpses - the awful, tangible remains - ought to be treated as jokes, or as extravagance or smoke or dust. But whatever you do with them they're certainly not worth preserving in a box under the ground. I don't agree with cemeteries. [...] We've all come out of something enormous and we're surrounded by this unthinkable universe which we're all part of. One should be exploded back into it when one has died' (AT 199-200).

${ }^{103}$ Muchembled (1978: 92-101) discusses the bodily lower stratum as a microcosm connected to the surrounding universe.
} 
is itself swallowed by the world' (o.c. 317). The mouth is the organ that accomplishes this interaction. This is why the motif of the banquet and of excessive eating is central to popular culture and especially to carnival (Shrovetide, after all, is the three days of excessive feasting preceding Lent). The mouth is also connected to the gueule d'enfer, the gaping devil's mouth that signifies the entrance to the underworld in popular imagery (suggesting a parallel between the body's and the earth's bowels). But this hell's mouth is also well-know as a stage set in medieval mystery plays. As such, it is the stage of the mummers' play in The Devils, which involves men impersonating five nuns, one Grandier, and four devils. ${ }^{104}$ It begins with a nun lifting her habit to show a giant red vagina (sewn onto a body-stocking ${ }^{105}$ ) to the camera. As an explosion of the fourth wall this is a radical demolition job. After all, we are looking at a play within the play within the play: the mummers' play is performed on the central square, but I have argued that the square itself is an embedded stage within the larger stage of Loudun as a metaphorical theatrum mundi. So in terms of sex-crazed nuns doing the splits this is an especially elastic vagina bridging an abyme of considerable theatrical proportions. But it should also be understood in terms of the film's overall message. Because it is a wink and a nudge at us, the film's audience, the gesture re-establishes the connection between what we are watching and the film's message for our own time. If we next consider that, as Bakhtin explains, carnival erases the dividing line between performers and spectators it is clear that the suggested reading is even more enforced: by treating us, the film's viewers, as people who can be addressed by an actor on a stage several times embedded, a co-extensive space is created between the deepest abyme of the fictional world and the everyday reality of the film's spectators' world. After this remarkable clin d'oeil on Russell's part the scene develops in a relatively straightforward manner. Four nuns dance in a circle around the exhibitionist nun as the Grandier figure appears from the hell's mouth. He gleefully blesses the audience in the square. Behind him four devils in several guises

\footnotetext{
${ }^{104}$ In a strict sense the mummers' play in the film is not a mummers' play at all, although Russell consistently refers to it as such (for example on the audio-commentary for the film). The mummers' play is a folk ritual that is found throughout Europe in an infinite number of local varieties that are tied together by two universal features: they are seasonal, in the sense that they were originally performed to mark the return of spring after winter, 'and they all contain a death and resurrection somewhere in the course of their action' (Brody 1970: 3), which is obviously connected to the seasonal element of the return to life of the natural world. But the term "mummers' play" remains confusing because throughout history several often very different forms of dramatic performance, both in folk culture and at court, have been called "mummings". Confusion also arises "because of the connotation of silence the word "mummer" carries' (o.c. 4). Yet in the case of The Devils the element of a mute performance would seem to be the main justification for identifying the performance as a mummers' play. See Brody (1970) for a survey of the mummers' play (with special focus on the British mummers) and its several types. Vandenbroeck (1997: 47-59; also 2002: 294-298) puts the mummers' play in the context of the moresca or morris dance and other folk rituals.

${ }^{105}$ See Tydeman (1978: 213) for the early modern use of body-stockings to imitate nudity on stage.
} 
appear dancing. Then the Grandier figure turns to the exhibitionist nun and lifts his own habit to reveal a huge sausage-like penis which he thrusts at her as she kneels to mimic both masturbation and fellatio on it. While this little tryst takes place the other nuns and devils dance. But the iconographic elements are clear. The over-sized genitals are obviously Rabelaisian grotesques while the hell's mouth, as the entry to the underworld, connects the whole display to the cycle of the material bodily lower stratum in which the entrails of the body are connected to the entrails of the earth. ${ }^{106}$

If we now turn to the theatrical structure of carnival, its all-encompassing nature is expressed in the fact that, in Bakhtin's description, it knows no footlights. There is no distinction between actors and spectators. In other words, all the world is a stage and all the men and women are its actors. Nobody is a spectator in the pageant of life, everybody is a player. This is also relevant for the carnival in Loudun, for as I argued above, the city of Loudun is treated in The Devils as a huis clos that is a theatrum mundi. This also means that we should not simply look at the carnivalesque execution scene as a sequence in which there is an audience (the unruly crowd) looking at stages (the execution, the mummers' play). Rather, the audience itself is also already on a stage. It is on the stage of the city of Loudun, which is the stage on which an allegorical play about power is performed: the rigged show-trial against Grandier. That is why the carnival mood in Russell's film is not a straightforward representation of popular culture such as Bakhtin describes it. For one thing, the possessions and the trial came at the heels of the plague, which took a third of the city's population. In the short documentary Director of Devils (1971) Russell says about this that 'there was a terrible feeling of death in the air and death not mattering and people were totally indifferent to death'107. Furthermore, the show-trial against Grandier had made it abundantly clear that truth was something that could be made and unmade on a stage. Combined with the terrible shock of the plague this lead, in Russell's vision, to a sense of relativism and cynicism. Fully aware of

\footnotetext{
${ }^{106}$ In this context it is also worth pointing out that a popular kind of grotesque play performed at carnival were 'mock weddings, in which the bride might be a man, or the groom a bear' (Burke 2009: 264). Obviously, the mummers' play in The Devils is such a mock wedding, but an even clearer example can be seen earlier in the film: after the nuns in the convent have heard about Grandier's clandestine marriage to Madeleine (which, from an orthodox religious point of view, is also a "grotesque" union) they perform a parody of the ceremony with one of the nuns in male drag. Since the mummers' play features men in drag it functions as an inverted mirror to that previous mock wedding.

${ }^{107}$ Robert Muchembled points out that the omnipresence of death often led to a sense of contempt for life: ' $\mathrm{L} a$ mort est partout, dans les villes et dans les villages, qui perdent soudainement, en cas d'épidémie, des dizaines, des centaines d'habitants, pour se gonfler rapidement ensuite, dans l'attente d'une nouvelle crise ou mortalité. Quoi d'étonnant, dès lors, si règne sur ce monde un certain mépris de la vie, ou du moins une grande indifférence à la mort des proches' (1978: 28). This contempt for life also helps explain the (to our minds) shocking everyday violence in early modern communities, where fights and brawls, often ending in murder, were quite common and functioned as a kind of release for the constant sense of dread that permeated life (o.c. 40-43).
} 
the mechanisms of power the crowd at Loudun probably realised that power must be and were ready to cheer power triumphant, whatever side it was on. This is a very dark reading of the finale, but the film bears it out. As Canon Mignon gives Grandier the kiss of death the crowd first cheers 'Kiss! Kiss!' and next mocks Mignon with a chorus of 'Judas! Judas!' The most remarkable thing about this chorus is its implication that the crowd knows that it is seeing a farce. By identifying Mignon as a Judas, who betrayed the saviour of mankind, it seems that the crowd is making a self-reflexive statement about the execution: they know that Grandier is innocent and that he was trying to save them, but they cheer nevertheless. Now that he is defeated, Grandier is no longer important. Power triumphant is throwing a party.

A final element of early modern popular culture that could clarify some elements in Russell's treatment of the carnival is the charivari, an often frighteningly violent and socially disruptive shaming ritual, documented in countless local variants throughout Europe, in which bands of young men expressed their disapprobation of couples who violated the community's sexual code of conduct (for instance, when an older man took a much younger wife, thus removing a young woman from the young men's pool of eligible brides). The group would show up in front of their victims' house and create a raucous noise (so-called "kettle music" or "rough music") and perform a shaming ritual that involved either the victims themselves or their effigy. While such rituals could be relatively innocuous, functioning as a warning (and an incentive to mend one's ways to prevent worse from happening), they often involved grim violence and psychological terror ending in serious injury for the victims, who might be paraded through town seated backwards on an ass (typical punishment for a cuckolded husband), pelted with debris, chased through town by townspeople hitting them with sticks, or dunked in a pond. The ritual sometimes occurred at night, and the young men might be masked as they read out a mock poem listing the couple's transgressions, which was usually followed by a physical invasion of the victims' house, which could be ransacked. ${ }^{108}$ Although The Devils does not contain a fully developed charivari as a narrative element, we

\footnotetext{
${ }^{108}$ See Rey-Flaud (1985) for a general discussion of many regional variants of the charivari throughout Europe and the important collection edited by Le Goff and Schmitt (1981). As a rule, a charivari was 'a summary form of censure that made life in the village quite impossible' (Brown 1979: 19) for the victims, who often moved away the next morning. Among the variants in England we find the "stag hunt" in Devon (Brown 1952 and 1979), a symbolic slaughtering of the victim in the proxy of a person disguised as a stag and which was often directed against adulterers or homosexuals, and the "skimmington", which was commonly used against a wife who had beaten her husband (Ingram 1984). The charivari was often accompanied by "rough music", which was 'a rude cacophony, with or without more elaborate ritual, which usually directed mockery or hostility against individuals who offended against certain community norms' (Thompson 1992: 3). The German form of the charivari is the Haberfeldtreiben (Kaltenstadler 2011). The many regional variants across the continent are considered 'a family of ritual forms' (Thompson 1992: 3) with many similarities between them.
} 
can find traces of it. For example, when Laubardemont is ransacking Grandier's house, a male voice can be heard from the street singing a mocking ballad. The combination of such ribald verse with a literal "invasion" of the sexual transgressor's home could certainly be interpreted as a form of charivari. More importantly, it could also be argued that Peter Maxwell Davies's dissonant music for the film, with its scraping and arhythmic soundscapes, is an evocation of the literal "kettle music" of a charivari. This would mean that the structure of the charivari has been inscribed into the film's form, where the frantic editing and dissonant music of the execution scene create a formal equivalent for the claustrophobic dissociation of an actual charivari. The powers that be want to cleanse Loudun of Grandier, whom they consider its moral stain. If their means are outwardly catholic and legal (exorcism and trial), their internal logic has all the brutality of the charivari: drive out the socially undesirable. By using fractured editing and aural dissonance in depicting these events Russell achieves a unity of meaning and form.

The fact that Laubardemont and his cohorts are deliberately exploiting the carnivalesque spectacle of the exorcisms and the trial has a broader historical resonance that we can use to elucidate yet another aspect of Russell's film. The way the burlesque court ballet and (elements of) the charivari are used in The Devils reflects a slow process of cultural appropriation that has been traced through the sixteenth century and into the seventeenth. Throughout this period elements of popular culture, and especially such elements as could be considered subversive of the established order, were appropriated both by the ruling elite and by the emerging new class of the bourgeoisie. In both cases, however, the appropriation served different purposes, and it is this that is interesting in relation to The Devils. The way that burlesque theatre was used at court, and which was discussed earlier in this chapter, is an example of how popular culture was appropriated by the ruling elite to disarm criticism. ${ }^{109}$ The appropriations of popular culture by the bourgeoisie are slightly more complicated because, as a new class that was developing mainly in expanding urban centres, the bourgeoisie needed to articulate its own identity in contradistinction to the three classes identified within the traditional social ordo: the aristocracy, the clergy, and the peasantry. As an upwardly mobile person the bourgeois especially wanted to distinguish himself from the lower class. This occasioned a process of 'negative self-definition' (Vandenbroeck 2002: 209) that can very clearly be seen in the arts, where the unruly behaviour and excesses of their social inferiors became the butt of satire or violent repudiation. In this sense the grotesque work of Hieronymus Bosch should be read as moralistic criticism of the lower classes. Similarly, a large literature emerged, of which Erasmus's Praise of Folly (1511) is only the most famous exam-

${ }^{109}$ See above, section 2.3.2. 
ple, in which a topsy-turvy world is created where common vices are ironically presented as virtues. ${ }^{110}$ At the same time, however, the ritual of the charivari, which originated in rural communities, was adapted to the urban context, where it emerged in the form of raucous carnival societies. The members of such societies were mainly young males from the middle class, and much of their satiric activity was no longer aimed at forms of sexual misconduct (because cities were larger and more anonymous communities with a less tribal social fabric) but at forms of political misrule. This means that their ritual rioting, which culminated in the annual carnival festivities (which are still today an occasion for lampooning politicians and the clergy), took aim at the governing elite that constituted the social layer above the bourgeoisie. The elite in turn responded by legally curtailing the freedoms of such societies. ${ }^{111}$ The interesting thing, however, is that in such cultural practices (Bosch's work, carnival societies) we can see the middle class attacking both the class below and the classes above them.

\footnotetext{
${ }^{110}$ The literature on this topic is vast. Vandenbroeck (2002) is the authority on Bosch. Vandenbroeck (1987: 132-151) also provides copious visual evidence for the way such art took critical aim at "outsider" groups such as wild men (also from the colonies), fools, peasants, and beggars. On the representation of the fool, see also Pleij (2007) in general and Thomson (2004) on fools and clowns on the Elizabethan and Jacobean stage. Representations of utopian topsy-turvy worlds are discussed by Pleij (1979; also 2003 on the Land of Cockaigne). Such trends continued into the next century, perhaps most clearly in Dutch genre painting, which iconologists have connected to the moralities expressed in emblem books but also to other sources of popular morality, such as proverbs. See the discussions by De Jongh (1967 and 1976) and De Vries (2005).

${ }^{111}$ The history, role, and destiny of the carnival societies has found its classic discussion in Davis (1975: $97-$ 123; a deeply influential contribution that triggered much subsequent research that is surveyed in Davis [2012]). Dylan Reid has shown that the Abbaye des Conards, a carnival society in Rouen, was run primarily by people from the middle classes and that such 'festive societies [...] generally developed sometime during the fifteenth century, flourished in the early sixteenth century, and for the most part, had disappeared by the beginning of the seventeenth century' (2001: 1030). Bakhtin, too, was aware of this shift, for he points out that 'we observe a process of gradual narrowing down of the ritual, spectacle, and carnival forms of folk culture' and that 'the state encroached upon festive life and turned it into a parade' (1984: 33) that is perhaps not dissimilar to the series of quasi-subversive entrées in burlesque court ballet mentioned earlier in the discussion (see section 2.3.2. with the references there). Beam (2007) outlines a similar evolution in the cultural function of farce, a form of grotesque popular theatre that was often very critical of the dominant classes but which was tolerated because it could also be made to function as a form of disciplining. See also Muchembled (1978: 189215) for a discussion of the changing attitudes towards popular culture in France since the late sixteenth century that also addresses the role of the urban youth societies. Ingram (1984) sorts through the English evidence for the period and suggests that a narrative of official oppression of the charivari simplifies the historical record, which shows much more complicated attitudes, while Pettitt (1984) highlights elements of festive ritual in social revolt.
} 


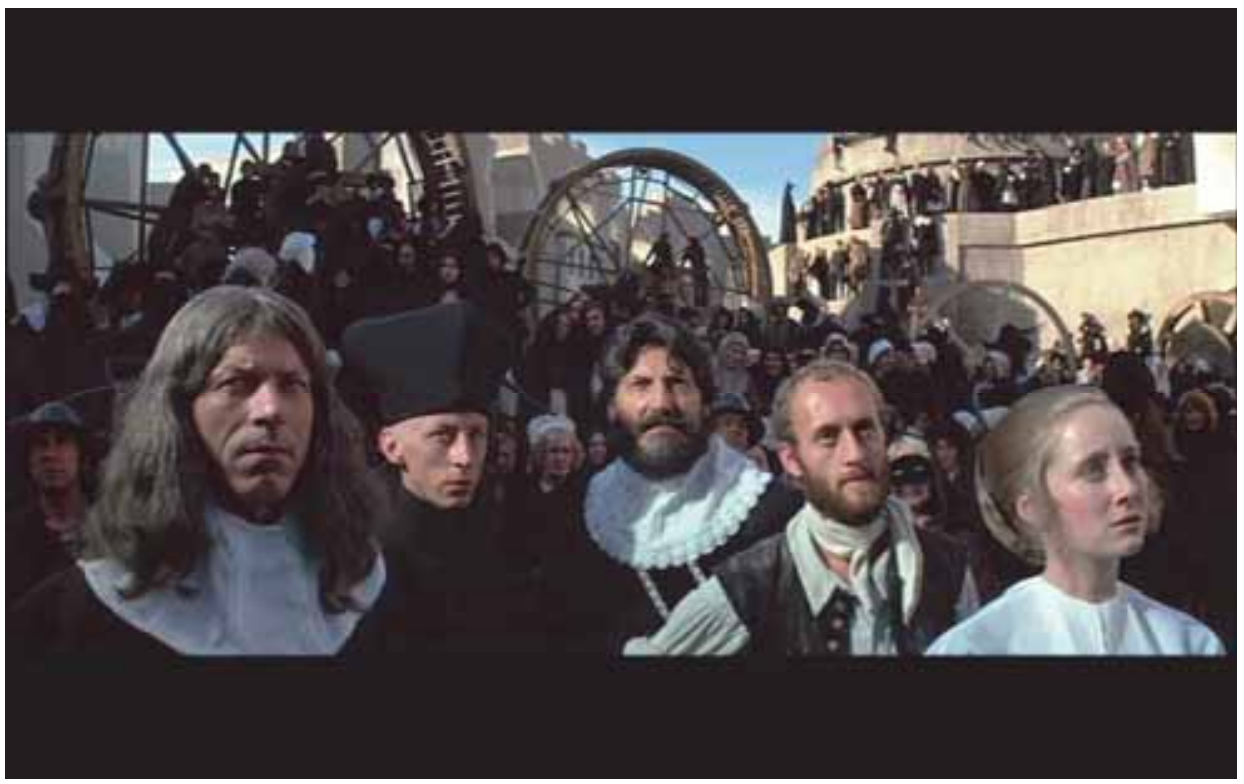

Illustration 11 Citizens of Loudun (left to right): Trincant, Mignon, Rangier, Legrand, and Madeleine

These complex tensions have found their way into the fabric of The Devils, and specifically into its portrayal of the bourgeoisie, who are represented in the film by Rangier (Andrew Faulds), who owns a hotel, and Legrand (Kenneth Colley), the baker. Both characters are often present as observers in the middle distance, occasionally speaking out against the iniquitous proceedings orchestrated by Laubardemont (ill. 11). When they object to the preposterous exorcism of Jeanne in the convent Laubardemont dismisses them as dissenters and smirks to Trincant that the two of them might soon acquire an interest in the catering trade, suggesting that these opposing voices will have to be disciplined by less than legal means. Later, Rangier and Legrand physically try to prevent Grandier's arrest in the church, loudly proclaiming the priest's innocence. At that point they are also arrested and not seen again until Grandier's trial, where they are exhibited, pale and drawn, after fabricated testimonies have been tortured out of them. The proud and virile demeanour of both men in the first part of the film forms a striking contrast to two other professional men in Loudun, Ibert (Max Adrian) and Adam (Brian Murphy), the surgeon and the chemist who are the local quacks. It is they who do most of the footwork for Jeanne's purging, assaulting her with huge syringes for colonic irrigation and examining her vomit for evidence of a witches' sabbath, human sacrifice, and the occasional carrot. This is grand guignol, but it does reflect how the investigation actually took place. Ibert and Adam are portrayed as human amphibians, and they are 
still part of the pre-modern world lampooned by Bosch, while Rangier and Legrand are men of sceptical and inquiring mind. But the constellation is clear: the members of the bourgeoisie are standing up against the joint forces of the aristocracy and the clergy who are whipping up hysteria among the lower classes. To be sure, in the historical Loudun the lines were never so neatly drawn and many of the middle classes sided with those who wanted to see both Grandier and the walls destroyed (in fact, the line between the regionalists and the centralists ran right through and divided all classes and social and religious groups in Loudun, tearing the city apart). But Russell is not making a historical documentary. His film is an allegory, and within this allegory even members of the bourgeoisie play their exemplary part.

\subsubsection{The Spectacle of Power: Grandier's Two Bodies}

At the beginning of my discussion I suggested that the possessed nuns' bodies were in a sense signs of a demonic cosmos or microcosm, and therefore also a miniature theatrum mundi. The same can now be said of Grandier for, as Ken Hanke argues, 'it is [Grandier's] pride and his difference as an individual that causes his downfall. Grandier is an independent man. Loudun is an independent city because of the unique feature of its walls. [...] It is significant that when Grandier dies the walls will be torn down, and equally significant that his destruction must be brought about before this can happen' (1984: 123). In a real sense the walls of Loudun die with Grandier, which suggests that Grandier almost literally represents the body politick of Loudun: the city will live or die with him. So if, as I suggested at the beginning, the whole city of Loudun is a stage, a theatrum mundi on which the larger political and religious conflicts tormenting France are represented in the struggle between Grandier and Laubardemont, then Grandier's body comes to function as another theatrum mundi in the sense that the scene itself, the very world which the actors (the good citizens of Loudun) inhabit, is represented in his body. Grandier's body relates to Loudun as microcosm to macrocosm. This physical inscription even seems to go beyond a mere sign, for if his body dies, so does the signified body. In fact, the world is so deeply inscribed in Grandier's body that the world itself, the stage of Loudun, cannot be destroyed if Grandier's body is not destroyed first: Grandier must die for the city to die, too. Or, to put it differently, during the trial and the execution Grandier has two bodies. On the one hand, he is a physical being, a material man with a mortal body. But on the other hand this body also symbolically represents several things that extend beyond its material qualities. First, it is on this symbolic body of Grandier that the reality of the possessions depends. The nuns can only really be possessed if Grandier is really a devil, which can only be proved with a real and really 
legal execution following a real trial with real evidence. But second, it is also on this body that the reality of Loudun depends, because the same execution that will make the possessions real will also create and make real Loudun as a city without walls. Whether Loudun will or will not have walls depends on Grandier's body living or dying.

Of course, as Ernst H. Kantorowicz has demonstrated, in late medieval and early modern theology it was the King who was understood to have two bodies, not fornicating priests. The King's first body was the material mortal body of the King as a private person. But in his quality of monarch the King also embodied the idea of monarchy. In other words, the person who was the King embodied for a limited period of time the role or theological function of the King. He embodied the monarchy. This idea of the monarchy did not die with the material King, for although the two bodies depend upon each other (the mystical body needs the physical body to be represented, but the physical body needs the mystical body to become an exceptional body) they are not intrinsically connected because the individual properties and qualities of the King as a private person have no causal or other determining relation to the mystical body. Take the example of Louis XIII. The role of the King had earlier been filled by Henry IV, the father of Louis XIII, and would subsequently be filled by Louis XIV, son of Louis XIII. The role persisted. But while he was King Louis XIII fully embodied and represented this idea of the King. It is also for this reason that, when a King died, it could be announced that 'Le roi est mort! Vive le roi!': the King is dead, long live the King! This simply meant that while this individual person who was King had died, the monarchy persisted. ${ }^{112}$ It is

\footnotetext{
112 Kantorowicz (1997; orig. 1957) is still the classic study of the doctrine of the King's two bodies and its theological roots. Louis XIV certainly believed that he had been given his powers and function by God and that he partook of the godhead. In his Mémoires pour l'instruction du Dauphin he spoke of God as 'une puissance supérieure, dont la nôtre est une partie' (quoted in Canova-Green 2014: 35n17). To fulfil this high office the King had to learn to be master of his passions and be in constant control of everything he said and did: the King as private and physical person disappeared behind the persona or role of the King. In this sense Louis XIV was certainly 'l'artiste supérieur du métier de roi' (Fumaroli 1986: 107): being King was his craft. It is the role he plays. The King himself was acutely aware of all this. Jean-Baptiste Primi Visconti (1648-1713), an important memorialist of the period, captured the King's awareness of his role-playing when he observed that 'en public, il est plein de gravité et très différent de ce qu'il est en son particulier. Me trouvant dans sa chambre avec d'autres courtisans, j'ai remarqué plusieurs fois que, si la porte vient par hasard à être ouverte, ou s'il sort, il compose aussitôt son attitude et prend une autre expression de figure, comme s'il devait paraître sur un théatre; en somme il sait bien faire le roi en tout' (quoted in Da Vinha 2014: 7). This shows that the King himself was acutely aware of the fact that, as was suggested in the main text, there is no intrinsic connection between the King's physical and mystical bodies. Of course, the dual nature of kingship was ritualised at court, and the daily lever $d u$ roi, the ritualised rising and dressing of the King, played an important role in this drama. It was connected to the symbolism of the Sun King, with Louis rising like Apollo at dawn. Kantorowicz (1963) has traced the ancient sun symbolism that informs the lever, while more recently Richard has elaborated on the ceremonial importance of the King's bed, arguing that the Chambre $d u$ Roi, where the King rose, took prece-
} 
for this reason that the King's mystical body is an imaginary body. But my discussion of Grandier's trial as a struggle for power can now help to understand how such an imaginary could take hold of the collective imagination. If we consider that the struggle for power is the struggle to determine what reality will be like then it becomes clear that the imaginary is simply a widely accepted ideology or belief system that tells people what reality is like. The best way to get people to accept such an ideology (which is the best way to obtain and maintain power in society) is to show the ideology to be real in its consequences. The story of The Devils is a tug of war over the reality of Loudun, and by extension over the reality of France, for we are witnessing the struggle between centralising powers (Richelieu, Laubardemont) and regionalist powers (Grandier and his supporters). Ultimately, reality is determined by the party that can enforce its vision upon the other, which means that one should try to force one's opponents to act in such a way that displays that they have accepted one's world-view, or to force one's opponents to submit to one's world-view. This is what happens when Grandier is burned: the worldview or ideology of Laubardemont and Richelieu is made real because its reality is inscribed in the very body of their most formidable opponent: it has destroyed Grandier. And in destroying Grandier, Grandier's world-view is also destroyed or rendered illegitimate. This is what makes the trial against Grandier a political trial.

The only thing the authorities did not get from Grandier, however, was a confession: he did not die a penitent man. Although the stage for his execution was carefully set, in this ultimate respect Grandier 'does not deliver [the] expected performance' (Hanke 1984: 145) because he dies protesting his innocence. This spoils the performance for the authorities. As Spierenburg explains, 'in the eyes of the authorities the staging of executions achieved its most beautiful form of ultimate success when it came to a kind of overall victory of the criminal. For this his co-operation was required. He had to be convinced of the righteousness of his punishment. [...] Notably those who were going to die were expected to be penitent and convinced of the wrongness of their own acts and the righteousness of their death. They had to die repenting their sins, in order to save their souls at the last moment. The execution of a disbeliever was not a perfect one' (1984: 59). Except, of course, for those who shared the world-view of the executed. From the perspective of those who shared Grandier's views his execution is the point at which the priest becomes a martyr for his faith. And this opens an interesting perspective on the way Russell has staged, or rather: filmed, the execution. Critics took offence at the immense and intense detail with which Grandier's torture and burning were shown in

dence even over the Throne Room because the King's bed 'est le meilleur symbole de la puissance monarchique et de la continuité dynastique' (2011: 276). 
the film, forming an oppressively protracted climax. Robin Wood delivered a snidely backhanded compliment when he remarked that, 'above all, Russell hates the human body: its degradation might almost be regarded as his central theme, as it seems to provide many of his films with their creative élan. This explains why The Devils [...] is probably the most successful of his feature films: here, the human body is deformed, contorted, flung into heaped plague-pits, tortured, has its legs broken and its tongue pierced, and is finally burned at the stake: it is the film in which Russell goes all the way' (1980: 909-910). Such lingering on gruesome detail, however, was already an important convention of seventeenth-century plays dramatising the suffering of martyrs. Such plays depicted martyrs' serenity under torture, which was meant to evoke two things for the spectator: first, it showed the deep conviction of their beliefs, which was in itself a "proof" of their truth; second, it suggested that the martyr was spiritually strengthened by God in his or her suffering. The spectacle of the suffering martyr was displayed at length so that the viewer might have sufficient time to contemplate its terrible implications. To be sure, in Russell's film there are precious few spectators who stand in mute admiration or contemplation of Grandier's death. But the citizens of Loudun are not watching a play on the life of a martyr: they are witnessing the actual execution of Grandier. As a film, however, The Devils is a representation of Grandier's martyrdom, and the audience in Loudun is with him on the stage, like the mockers of Christ are part of the performance of a Passion play. In the extended finale, showing Grandier's suffering in detail, Russell's intended audience is not the people of Loudun. His audience is us, the spectators of the film, and we are very much expected to sympathise with Grandier. It is we who must be overwhelmed and awed by the spectacle. What some critics condemn as sensational cynicism is in reality a rhetorical trope borrowed from popular seventeenth-century religious theatre. ${ }^{113}$

We can now draw together the threads of interpretation circling around Grandier's suffering body. The events in The Devils (but also in the historical case) are a form of ideological warfare. He who wins the war will be able to impose his world-view upon society. In this struggle the two bodies of the opponents become important. For the best way to destroy the mystical body of one's opponent is to eliminate the physical body that functions as its vehicle. Here, at least, there is a crucial difference with the monarch. The dead monarch can continue to embody the mystical body because the monarchy is already the ruling ideology of society. He dies as the King, so the legitimacy of his mysti-

\footnotetext{
${ }^{113}$ Biet and Fragonard (2012) provide detailed historical background and analysis for the saint plays and their representation of violence in early modern France. Davidson (2001: 301-303 and 308-313) discusses the situation in Elizabethan England. It is instructive to compare this form of theatrical contemplation with the discussions of vividly realistic Baroque sculptures of suffering martyrs in Bray (2009).
} 
cal body is not in question. In Loudun, on the other hand, neither mystical body has so far established itself as legitimate: centralists and regionalists are still engaged in a battle for power. ${ }^{114}$ It is interesting to see how this battle is in a sense a battle to represent the King. Laubardemont represents Richelieu who rules the King. But we should remember that Grandier only becomes the representative of Loudun's body politick when he reminds Laubardemont that the King had promised Loudun's late governor SainteMarthe that he would spare Loudun's walls. So the question is not simply about whether the King can change his mind (of course he can) but more significantly about who can make up the King's mind (and thus rule the mystical body) for him. Discussing Loudun, Louis XIII needlingly asks Richelieu whether he would really expect the monarch to go back upon his given word. But this is exactly what Richelieu wants. And it is exactly what Grandier and the regionalists do not want. That is why the battle over Loudun's walls must be a battle to the death and why Grandier can become such a powerful symbol of the battle: by pitting two claimants to the King's will against each other the dispute effectively suspends the King's will. What the King really wants, and what reality will therefore be like, must be decided anew because it is clear that the King is temporarily of two minds. His mind must be made up. But by whom? Who will embody the King's mind (which is the same as asking who will govern) or who will represent, in physical form, the will of the King in Loudun: Laubardemont or Grandier? Because only one body can represent the King's will (otherwise the King would remain divided within himself) the other claimant's body should die and, most importantly, be seen to die. ${ }^{115}$ This, again, is the coup on reality that takes place in Loudun. ${ }^{116}$ The risk involved in

\footnotetext{
${ }^{114}$ In this respect Carmona (1988: 47-58 and 82-97) provides a survey of the crucial and constantly shifting role that the Poitou region and especially Loudun, one of the strongholds of Protestantism in an overwhelmingly Catholic France, played in an endless series of religious wars, provocations, and painfully slow negotiations and political manoeuvring. As ideological terra infirma, Loudun had no match. De Certeau (2005: 21-22) argues that precisely this instability made Loudun fertile soil for such a remarkable series of possessions, which functioned as a relief for the social, political, and religious tensions seething within the community.

${ }^{115}$ Regarding the ideological need for publicity in executions, Spierenburg explains that 'late medieval and early modern executions served especially to underline the power of the state. They were meant to be an exemplary manifestation of this power, precisely because it was not yet entirely taken for granted. [...] The authorities held a monopoly of violence and showed this by actually using it' (1984: 201).

116 That is, in fact, what war is all about. As Elaine Scarry explains in her classic study of war (which deeply informs my analysis), 'the dispute that leads to the war involves a process by which each side calls into question the legitimacy and thereby erodes the reality of the other country's issues, beliefs, ideas, self-conception' (1985: 128). War is 'a huge structure for the derealisation of cultural constructs and, simultaneously, for their eventual reconstitution. The purpose of the war is to designate as an outcome which of the two competing cultural constructs will by both sides be allowed to become real, which of the two will (after the war) hold sway in the shared place where the two (prior to war) collided. Thus, the declaration of war is the declaration that "reality" is now officially "up for grabs," is now officially not only to be suspended but systematically deconstructed' (o.c. 137). The injuring of bodies is central to the practice of war because it is in the bodies of the
} 
such ideological butchery, however, is that the dying man becomes a martyr for his cause. Especially if he is seen to die (as he must be), and if he dies without giving the required performance of a good death.

A historical footnote is in place here. The case of Loudun is situated in a time when absolutism was consolidating itself in France. Richelieu had embarked on his politics of centralisation, and razing the walls of self-governing cities was part of that project. ${ }^{117} \mathrm{On}$ a symbolic level the death of Grandier, to the extent that it was perceived to be a political death and hence a display of power, made central power real in Loudun (and in historical reality Loudun was obviously only one element in a much larger cultural movement). There is considerable irony, but now certainly no surprise, in the fact that the end of absolutism eventually also took a theatrical form. For monarchical absolutism, or what is now commonly referred to as the Ancien Régime, was effectively killed on a scaffold when Louis XVI and Marie-Antoinette were beheaded before the eyes of le tout Paris. ${ }^{118}$ Just like it took a theatrical (in the sense of publicly displayed) real death to make power real in Loudun, so, too, it would take another theatrical real death to undo this power again. This also means that the beheading of the King was actually a double beheading, for with the King's mortal body the revolutionaries at once also beheaded his mystical body. That is to say that the symbolic effect of the King's execution was to create and make real a new power or a new world order (a new imaginary). The execution of the King signified the end of absolutism as a legitimate way of describing reality. Nobody was bound by it anymore because it had been killed off for all to see. ${ }^{119}$ That is why a modern historian can write, without irony or hyperbole, that 'L'Ancien Régime est né au moment où il disparaissait' (Bély 2010: xi): when it was killed, the Ancien Régime became a circumscribed and closed entity within history, something that could be signified by those two words because, as something belonging to the past and therefore no

casualties that the cultural constructs, and especially the cultural construct that emerges as winner from the war, is materialised and substantiated. The claim that one has won the war is just a set of words and 'in most instances the verbal assertion has no source of substantiation other than the body.' That is why 'the injuring not only provides a means of choosing between disputants but also provides, by its massive opening of human bodies, a way of reconnecting the derealised and disembodied beliefs with the force and power of the material world' (o.c. 127-128). This, too, is why Grandier's body must be tortured, broken, and burnt, and most importantly: must be seen by all as tortured, broken, and burnt.

${ }^{117}$ See Carmona (1988: 153-154).

${ }^{118}$ In this respect, Biet (2006: xxix) points to the semantic continuity between scaffold, theatre stage, and altar in early modern France. All three are elevations with the purpose of making a spectacle more visible to an audience. All three accommodate spectacles around the representation of bodies in their physicality: the executed body (on the scaffold), the actor's body as representation of a character (on the theatre stage), and the transubstantiated body of Christ in the host (on the altar).

${ }^{119}$ Here Arasse (2010) is the classic discussion. 
longer legitimate in the present, it had become an object available for observation from a distance.

\subsection{THE WORLD MADE FLESH: A MYSTERY PLAY IN SECULAR} TIME

Now that all the embedded stages of The Devils have been discussed it is time to step back and see the framing stage anew. I have argued that Loudun is a theatrum mundi on which the history of the world is performed. The undercurrent of the events in Loudun is a struggle for power. But it is not simply a specific or historically situated struggle for power: in Russell's film the events have universal import. The struggle for power in Loudun is staged in an emblematic way, which is to say that it carries a timeless message about the role of power in the history of the world anytime and anywhere. That is the reason why Russell wanted the film to be staged on a modern-looking and therefore timeless set. Loudun is a distant mirror. The trials of Grandier are a prefiguration of the many show trials that were to come in modern history. ${ }^{120}$ And this aspect of the film, its use of historical events as figures or types for later events, makes it possible to bring all the stages of Loudun together in one final vision. To achieve this I want to suggest that The Devils is structured as a Corpus Christi play. Russell himself has said that 'I think of my films as sort of modern medieval mystery plays. In the days of mystery plays, they took religion, bashed it over the head, cocked a snook at it, blasphemed it, sent it up, treated it melodramatically, comically... all in one act' (quoted in Gomez 1976: 39). ${ }^{121}$ But although it is clear throughout the film that Russell is aiming for a parallel between the suffering of Grandier and the Passion of Christ (an interpretation that is underlined by Jeanne's hallucinations about the priest, which show Grandier crucified and walking on water), a mere analogy to the Passion cannot fully account for the film's political import for the present. Through its presentation of Grandier's passion the film also intends to reveal something about the structure and dynamics of history itself. This meta-level of the film finds its dramatic counterpart in the highly specific form of the Corpus Christi play which, in the words of its greatest critic, 'sought to pattern human experience, to give to the history of men an order that would reveal its meaning' (Kolve

\footnotetext{
${ }^{120}$ In this respect Davis (2012: 11-13) retrospectively points out how her own research into the popular violence of the charivari and religious riots in early modern Europe was developed against the background of the protests against the Vietnam war, the civil rights movement, and the memory of the holocaust.

${ }^{121}$ For the broad expressive spectrum of mystery plays, and especially their use of humour, see Kolve (1966: 145-174).
} 
1966: 20). This is exactly what The Devils also aims to do: like the Corpus Christi play it reveals to its spectators the meaning and deep structure of the whole order of the world. And this deep structure, as I have argued, is (the struggle for) power.

The play called Corpus Christi was performed on the occasion of the feast of Corpus Christi, a moveable feast that could occur between 21 May and 24 June and which was celebrated 'in honour of the Real Presence of Christ in the Eucharist, celebrating God's gift of the Holy Sacrament to mankind' (Tydeman 1978: 97). ${ }^{122}$ This means quite simply that the feast was created to celebrate the fact that Christ was sacrificed for the salvation of mankind. Christ has died to relieve us of Original Sin incurred at the Fall (the unfortunate event with Adam and Eve and some fruit) and so ensure our salvation come the Last Judgement. This is why the Eucharist is the central sacrament of the Catholic faith: every time the believer takes communion they commemorate Christ's sacrifice in a rehearsal of the sacrament that Christ himself instated at the Last Supper when, with terrible foresight, He invited His disciples to partake of His flesh and His blood. In the Eucharist, which is performed in Mass, we find a theatrical act (priests are said to perform Mass, and the choice of words is very accurate, for by performing the ritual they are, performatively, making the transubstantiation of the Host real for those who believe in it) that covers a number of "embedded" layers of meaning, each of which both reflects its meaning and expands its circumference until we reach the most basic and transcendent level, which is the level that rehearses world history. The Corpus Christi play also stages these interconnected levels, and this is what provides the parallel to the structure of The Devils. But the Corpus Christi play was not really a single play. Rather, it was a cycle of individual short plays that could take a full day (but sometimes even several days) to perform at several stations along a processional itinerary. ${ }^{123}$ Several such cycles

\footnotetext{
${ }^{122}$ For the history of the sacrament of the Eucharist and the creation and early dissemination of the feast of Corpus Christi in the late medieval context, see Rubin (1991).

${ }^{123}$ The question whether it was practically possible for the Corpus Christi cycles to have actually been staged in a processional manner (meaning that each play in the cycle would be performed in full at each of several stations along a processional trajectory through a town) was forcefully put, with a wide-ranging discussion of the evidence, by Nelson, who argues that the most common practice would have been to ride the pageant along the several stations in a non-dramatic procession (possibly with some mime performance or brief narration) followed by a full dramatic staging on one location: 'Processional pageants were the rule, acted drama the exception' (1974: 180). Nelson acknowledged that there is indisputable evidence that several processional stagings of full cycles did take place (1972: 123-125, and esp. 128), but remained sceptical nevertheless about the common practice. Summaries of the arguments for and against can be found in Nagler (1976: 55-73) and Tydeman (1978: 95-120). Over the last few decades the discussion has been greatly enriched by the practical experience of modern productions of full processional stagings of entire cycles which have shown, among other things, that several of the practical objections to their feasability tend to resolve themselves in practice and are therefore rather theoretical (see Marshall [1994: 302-305] for a response to Nelson; McKinnell [2008] for a survey of modern productions; and Beadle [2008] for the York cycle plays specifically). Twycross (2008:
} 
have come down to us, in greater or lesser states of completeness. The York cycle is generally regarded as the greatest. Each cycle, however, is different, and not all cycles dramatise the same stories, although there are a number of key stories that are common to all cycles for the very simple reason that the logic of the cycle would fall apart without them. These are the stories related to the key moments in the history of mankind: the Creation, the Fall, the Nativity, the Passion, and the Last Judgement. As a whole the cycle encompassed the whole history of the world 'from its beginning to the end of time' (Kolve 1966: 42) or 'from Creation to Judgement' (o.c. 48). But since the Bible contains many great stories a principle of selection had to be imposed to decide which stories would be included and which would not. In his classic study of the plays Kolve argues that the main principle of selection was based on the figura or type. The Corpus Christi play was based on what is commonly called a typological reading of the Bible. This is a principle of interpretation that sees stories from the Old Testament (but also sometimes from the New Testament) as signs or prefigurations (which are called "types") of events in the New Testament, and most specifically in the life and Passion of Christ. ${ }^{124}$ In a

27-45) offers a splendidly lucid discussion of processional staging of full cycles that takes into consideration much of the new material.

${ }^{124}$ See Kolve's distillation of what he calls 'a kind of proto Corpus Christi play, the generic thing-in-itself, the irreducible core' (1966: 50-56, here 50-51). However, the idea of such an "irreducible core" has been challenged and revised in view of the very diverse practices in producing cycles, parts of cycles, and even individual plays (Rubin 1991: 271-287). Although Kolve's magisterial study is still a canonical text in the study of early modern drama (Happé 1994: 319-321) it was taken to task by Alan H. Nelson (1974) for a number of other points relating especially to the genealogy of the plays. For my own purposes the crux of Kolve's argument is the suggested typological connection between the Eucharist, the Passion, and world history. This is one of the points that come up for criticism in Nelson, who points out that 'the sacred history of the world provides the ultimate context of significance for every historical event, liturgical rite, or doctrinal statement' (1974: 3), suggesting that Kolve's argument is simply stating the obvious. Nelson's own hypothesis, based on a survey of previously unknown archival sources, argues 'that the fifteenth-century English dramatic cycles developed out of fourteenth-century festival processions. A corollary of this argument is that the doctrinal relationship of the Corpus Christi dramatic play to the feast of Corpus Christi is almost entirely incidental' (o.c. 9). But surely such coincidence should beg the question. Nelson also points out that Kolve himself acknowledges that the authors of the cycles did not choose typology as a principle of selection but that it was simply a standard part of traditional exegesis. 'In conceding this point, Kolve, to my mind, concedes all,' argues Nelson. 'The cycles are not eucharistic plays or Passion plays set in a context encouraging joy. Rather, they are plays of sacred history, or Heilsgeschichte. Their form is determined by historical more than typological principles' which were 'already centuries old' (o.c. 6). But even if Nelson is correct in his criticism, the practical effect of the long historical tradition would still be typological if traditional theology already established typological connections between the Old and New Testament parts of sacred history, so the typological interpretation of the cycles still stands even as its historical explanation is called in question. For typology in relation to Corpus Christi, see also several discussions in Rubin (1991: 129-131 on typological correlations in the medieval Biblia pauperum and Bible moralisée; and 229-232 for the use of types in a poem by John Lydgate that is actually a report on a Corpus Christi procession in London in the mid-fifteenth century). It is interesting to put Kolve's typological interpretation alongside a similar interpretation in Taylor (1972; originally published in 1964, which possibly accounts for its absence in Kolve's bibliography, coming too late for inclusion). 
typological reading the Eucharist symbolises the Passion, but the Passion was itself already "prefigured" in stories of the Old Testament. By connecting the dots between these different temporal levels one expands the vision from the focal point of the sacrament of the Eucharist, which is itself focused on the Host that (through transubstantiation) embodies Christ, to the all-encompassing view of the whole of history. ${ }^{125}$

A few examples can make clear how such connecting of dots is achieved. Both the story of Jonah and the whale (in which a man emerges unscathed though, one imagines, not unsoiled from the stomach of a whale) and the raising of Lazarus are seen as types of Christ's resurrection. Jonah is an Old Testament story, the raising of Lazarus is an act of Christ (New Testament), and the resurrection is part of the Passion. What connects these stories is the theme of a man magically rising from (real or symbolic) death. Similarly, Noah's ark, which saves a selected few animals and humans from death by water, was read as a figure of baptism: both the ark and baptism are aquatic events that are connected to the salvation of those who are "chosen". One of the most complex types, but also one of the most central, is the story of Abraham and Isaac. This is an Old Testament story in which God commands Abraham to prove his love for God by sacrificing his beloved son Isaac. When Abraham complies with this terrible request God intervenes and Isaac is replaced by a lamb. This story of a father sacrificing his son is an obvious type for the Crucifixion, when God sacrificed His own son. ${ }^{126}$ But as we know, Christ is also called the Lamb of God during the sacrament of the Eucharist. This is in reference to this type (and explains why, of all things, a sheep should be at the centre of the famous Ghent alter piece by the Van Eyck brothers). So the Host in the Eucharist represents (and is referred to by the priest as) the Lamb of God, which is Christ crucified. And this entire ritual or sacrament was first performed by Christ himself at the Last Supper (which is the type of the Eucharist). This means that in the Host the entire history of everything is focalised. To understand the sacrament of the Eucharist is to understand not just a number of typologically connected narratives: it is to understand the meaning of the whole of history, its sense and purpose, which is the salvation of mankind through the sacrifice of Christ. As such, in the Corpus Christi play, which rehearses all of the above, 'form and meaning become one' (Kolve 1966: 84).

\footnotetext{
${ }^{125}$ This expansive fecundity of the Eucharist was also remarked upon by Alexander Parker, who observes (in his classic study of Calderón's autos sacramentales) that, 'of all Catholic dogmas the doctrine of the Eucharist is the one that can offer the widest scope to the theological dramatist. So all-embracing is it, so central to the whole theological system, that there is hardly a single dogma that cannot, in a sense, be included in it' (1943: $60)$.

${ }^{126}$ See Rubin (1991: 135-137) for a discussion of the Sacrifice of Isaac as a type and Murray and Murray (1998: 267-268) for the rich Christian symbolism attached to the lamb.
} 
In a similar way, form and meaning become one in The Devils, too. In close analogy to the Corpus Christi play the form of the film is a Passion (Grandier's), but its meaning is transcendent: it reveals the meaning of history like the Corpus Christi play reveals the meaning of history. Grandier is the saviour who would save Loudun, and like Christ's sacrificial body, which carries the burden of history since the Fall, Grandier's body carries the symbolic burden of Loudun and its walls. These are Grandier's two bodies. Furthermore, like the Corpus Christi play the structure of The Devils is processional. Just like the many plays of the Corpus Christi cycle would be performed at different stations throughout a town so, too, Grandier's passion makes its way processionally through Loudun. The main stations are Grandier's home (which is invaded and ransacked in a kind of charivari), the trial, and the town square (where he is executed). On his way to execution Grandier is even dragged through the streets of Loudun on a stretcher pulled by a donkey in a humiliating parody of a procession (or Christ's entry into Jerusalem on a donkey on Palm Sunday). But there is a difference and the difference is crucial. The Devils is a Passion play in non-eschatological time. It is set in a universe that knows no salvation. This makes its story a modern story, suitably staged on a modern set. But modern time is no longer eschatological, it is scientific. It has no purpose: it just goes on. In modern time nobody is ever saved: people and world-views are born and then they die, that is all. This is what makes Grandier a tragic hero. He begins the story as a proud man, selfish and sexist, but he humbles himself for what he must know to be a lost cause. As he sees the good people of Loudun cheer his death he must surely wonder whether this rabble was even worthy of salvation and if the sacrifice he has made was worth it. To be sure, Grandier still believes in God and in personal salvation. But the film probably doesn't. ${ }^{127}$ The meaning of history that The Devils reveals is a profound and shattering sense of arbitrariness: history is only a struggle for power, a Passion play that endlessly repeats itself, showing how the creation of one world-view necessarily implies another's doom. And just like a Passion play or a Corpus Christi cycle could and would be staged again and again to reveal again and again the meaning of history, so, too, the struggle for power will repeat itself again and again and essentially innocent people will continue to be sacrificed to its logic again and again. Only in this sense, but especially in this sense, could and should The Devils be read as a typological narrative: the events at Loudun are a type for everything that comes after and everything that came before. It is the type of history itself, which is the process of brute power.

${ }^{127}$ Russell's changing attitude to Catholicism in the late 1960s, when he fell from the faith, is discussed in Chapter Four: see section 4.2.2. 
It is on this note, despairing of meaning, that the film ends. The last shot, which offers us a view of the world beyond Loudun, is even drained of all colour. And yet something remains. For it should not be forgotten that Madeleine, and only Madeleine, escapes. But why? I believe that this escape should be read, like everything else in the film, on two levels: as a narrative event and as a symbol. On the narrative level Madeleine is the only character in the film who is truly of pure heart. Her love for Grandier is real and she inspires in him a similar pure love in return. Where Grandier's attitude to Philippe is callous in the extreme, counselling her to carry the burden of pregnancy out of wedlock with Christian fortitude, he finds that he truly loves Madeleine (and upon the finding immediately implores God to help him). In this sense Madeleine's escape from Loudun could be read, on a narrative level, as the best one could expect in terms of a happy end to a very dark film. Perhaps, now that the pustule of Loudun has burst, she at least will be able to escape to something better. But the symbolic import of the final scene puts the lie to such a reading. I would argue that Madeleine not so much escapes from Loudun as she is set adrift. As she steps out of the bell jar of Loudun she steps into the cosmos of the modern world that surrounds it: a desert void of meaning. Stumbling along the road that stretches away from Loudun, Madeleine is not going anywhere. She is walking away from something terrible rather than walking towards something better. And to judge by the expansive horizon she still has quite a bit of walk ahead of her. Visually, the view of the road away from Loudun looks like a perverse parody of the yellow brick road in The Wizard of $\mathrm{Oz}$ (Victor Fleming, 1939), where scene after scene is played on studio-bound sets with painted backdrops on which the yellow road just stretches on and on and on. But there is no Emerald City waiting for Madeleine at the end of her dusty road. Before she leaves Loudun, Madeleine emerges from the church with her dress torn and covered in soot. She has a look of shock and dissociation on her face. Her escape from Loudun is neither a purposeful act nor a happy release. She is just putting one foot in front of the other in the dazed manner of people who are mechanically walking away from the site of some appalling disaster. She is literally shell-shocked, for the walls of Loudun were blown up. And it is as a shell-shocked ghost of a person that she embarks upon a road that, by the evidence of the film's final image, leads nowhere. Russell later claimed that it was 'my favourite shot ever - a prophetic image of the horrors yet in store for mankind' (quoted in Sutton 2002b: 13). 


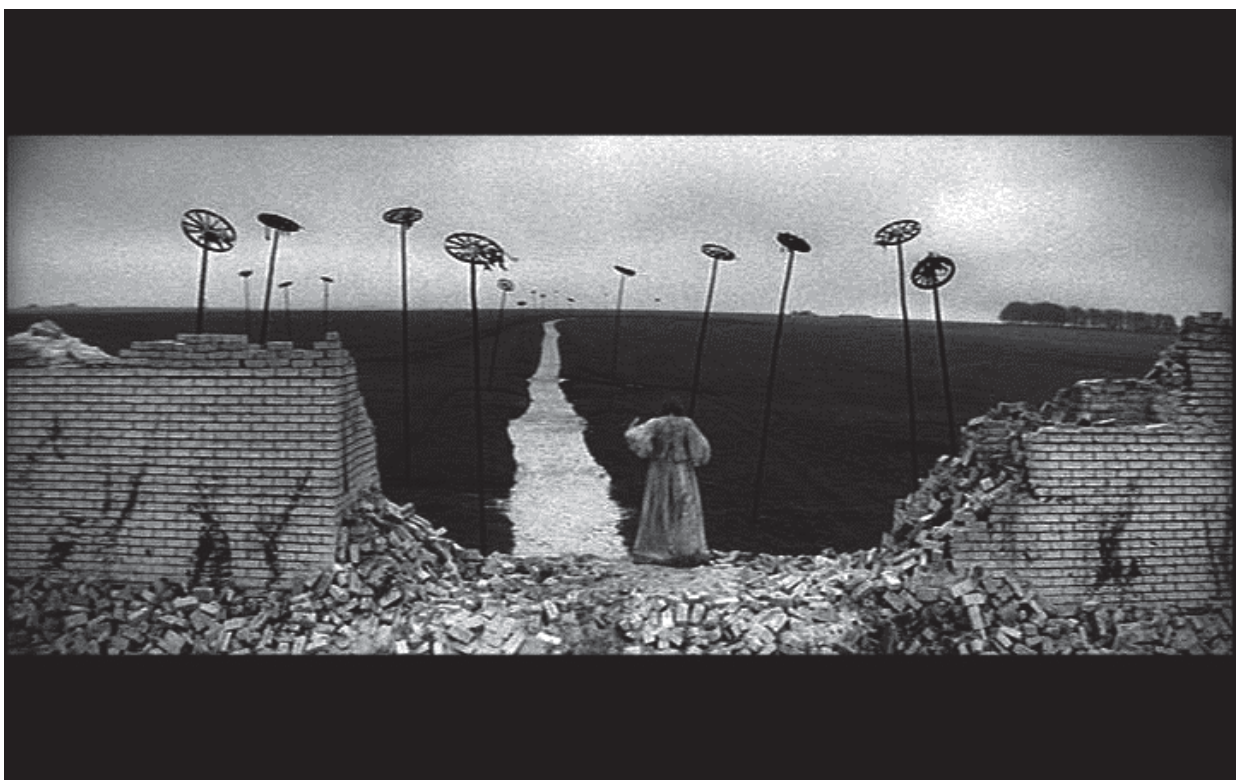

Illustration 12 Madeleine steps into the void

Let us leave the film by looking down that road one more time, for it is the film's ultimate symbol and its parting stage (ill. 12). It differs from the other stages in the film because it is not embedded in the framing stage of the world that is Loudun. It is, so to speak, hors-scène or obscene in the literal sense of that which could and should not be seen. But that is exactly what The Devils reveals when it reveals the meaningless meaning of history: it reveals something that we do not usually want to see or even acknowledge. The road that stretches away from Loudun is obscene because it stages the arbitrariness of all (socially constructed and therefore utterly relative) meaning. By blowing a hole in the walls of Loudun the film suddenly offers us a view of what we should and could not see as long as we were part of that world: the ultimate futility of all meaning. Madeleine has seen (as we, the viewers of the film, have seen) that which one should never see and which cannot be seen without shattering those who see it: the brutal nullity of life on a planet that is but a cosmic scrap of dust. Now that she has seen it, she is swallowed up by nothingness, walking along the ghost road towards nothing, like the undead walking the barren earth of Purgatory. Whether one walks in circles or along an endless road to nowhere makes little difference: one will walk eternally and never arrive anywhere. Marking the barren landscape around the ghost road are breaking wheels on stakes with dead bodies on them. They are like petrified flowers of death modelled on similar break- 
ing wheels in Pieter Bruegel the Elder's The Triumph of Death (ca. 1562). ${ }^{128}$ On the narrative level these men are dead Protestants, casualties of the religious wars; but on the symbolic level they are the death of man in a meaningless universe. As she leaves Loudun, Madeleine steps into the void. We, the viewers, looking out at her from the rubble of Loudun, are balanced (with Russell's camera) on the verge of oblivion. Which way shall we fall? Backwards into the world (of Loudun) or forwards out of it? And is either of these options less hellish than the other? I say that The Devils is a film that blows up the world and leaves us sans meaning, sans world, sans everything.

\subsection{THE MAGIC CIRCLE}

With Grandier dead, Loudun destroyed, and Madeleine adrift I have completed my analysis of The Devils. It is time to return once more to the metaphor of the theatrum mundi. I have argued that the smallest stage representing the world in The Devils was the individual body. Two cases are exemplary: the possessed body of Sister Jeanne inscribed with the demonic cosmology of a retinue of devils and Grandier's body inscribed with the new world order of the powers that condemn him. Let us revisit this primary (and intimate) site of signification with Michel de Certeau, who points out the particular role of smell in the Loudun possessions. Although this aspect of the historical case is not dramatised in Russell's film, it is interesting to note that it was said that the vehicle of the possession had been a bunch of roses which Sister Jeanne had found in the convent. Immediately after smelling these flowers Jeanne and her fellow sisters became possessed. Obviously, Grandier was accused of having introduced the flowers into the convent to work his diabolic magic. This was an acceptable argument to explain the possession because it was widely believed at the time that smells were material phenomena and that by smelling something one was in fact ingesting into one's body (surely a grotesque body that swallows up the world by smelling it) the material reality of the smelled object. The scent of the diabolic roses therefore constituted a real material invasion of the nuns' bodies, carrying the demons with it. Similarly, people would carry scents around with them during the plague to avoid the disease's infectious smell from entering their bodies. ${ }^{129}$ As such, the aura of scent became a material area or field that

\footnotetext{
${ }^{128}$ Breaking on the wheel was a common form of execution in early modern Europe. See Spierenburg (1984: 71-72) for details.

${ }^{129}$ Such scents also appear in The Devils: when he is visiting the exorcism in the church the King-as-Duc advises his favourite boy to smell one to avoid the infectious stink of the naked nuns rolling about. See De Certeau (2005: 66-71) for the roses and their role in the Loudun possession and Carmona (1988: 163-165) for the belief that the plague was carried through the air.
} 
functioned as a protective enclosure. However, if a noxious smell did enter the body, the body itself became a site of infection. This is how the individual body first became a signifying theatrum mundi in the Ursuline convent of Loudun: with the scent of the roses the devil gained entrance to the body, which could then become a microcosm of demonology. The primary scene was set. And as the infection spread (like the plague sneaking into the innards of a town despite its fortifications) and the crowds of onlookers increased, so, too, the circle of infection widened to take in the convent, the central square, and ultimately the walled circumference of Loudun itself.

The magic circle is of course a well-known image in discussions of, among other things, medieval theatre and primitive religion. Susanne K. Langer has applied it to the arts, and most specifically to the art of dance. In any dance, she argues, 'a virtual realm of Power' (FF 175) or 'a realm of virtual Powers' (FF 187) is created. All art, Langer argues, creates an illusion. It is fiction, a representation of something else. ${ }^{130}$ In dance the illusion of a field of power or a force-field is generated. 'In watching a collective dance,' Langer explains, 'one does not see people running around; one sees the dance driving this way, drawn that way, gathering here, spreading there [...]; and all the motion seems to spring from powers beyond the performers. In a pas de deux the two dancers appear to magnetise each other; the relation between them is more than a spatial one, it is a relation of forces; but the forces [...] really do not exist physically at all. They are dance forces, virtual powers' (FF 175-176). The crux of Langer's argument, for our present purposes, lies in the observation that the powers created by the dance are virtual powers. They are 'illusions' (FF 188), they are the work of art that the dancers create on the stage. This means that the magnetic force-field of the dance creates 'a complete, autonomous realm, a "world"' (FF 190) that functions as a 'magic circle' (FF 191). But as 'the image of a world of vital powers' (FF 193) the dance is also an image, namely something that is 'essentially addressed to sight' (FF 196). As a virtual realm of power the dance is a work of art, cut off from the real world (the realm of the spectator who is looking at it) and circumscribed by the force-field that it creates for itself, or rather: that the dancers create by performing the dance. Obviously, the magic circle thus described does not have to be, and in reality rarely is, actually circular in shape. It is a metaphor to describe the fact that any work of art is "cut off" from the world of everyday pursuits. Similarly, in his discussion of the Corpus Christi plays, Kolve explains that 'the duration

\footnotetext{
${ }^{130}$ Langer's theory of art, which deeply informs my own understanding of art, is systematically presented in Feeling and Form (orig. 1953; see Langer 1973, here FF), which developed ideas first articulated in Philosophy in a New Key (orig. 1942; see Langer 1957a). Langer's final synthetic statement on art was in the first volume of Mind: An Essay on Human Feeling (1967: 71-244). For an introduction to Langer's philosophy of art, see Innis (2009: 79-146) and Van Eecke (2011: 56-74).
} 
of the play is a momentary interval in, and abstention from, the real concerns of life' $(1966,21) .{ }^{131}$ This is what we mean when we speak of a magic circle: it is an enclosure, which need not be material, that isolates the work or performance from the common pursuits of everyday life. ${ }^{132}$ And thus "framed" within a magic circle, Langer argues, every work of art is 'a prime symbol' or 'a total form' (FF 369) or 'a single metaphorical image' (1957b: 53). ${ }^{133}$

The Devils is such a prime symbol or single metaphor and, as I hope to have shown in this chapter, an exceptionally successful symbol. Nevertheless it may seem counterintuitive to speak of a film as a single unified symbol. It is easier to accept the idea of a work of art as a prime symbol in the case of the visual arts, such as a painting or a sculpture or a work of architecture, where we can usually capture the entire work within our field of vision. The idea of a prime symbol may seem less appropriate in relation to the narrative arts such as the novel, drama, and the cinema, or even poetry or a ballet or a piece of music, all of which take time to unfold and can therefore not be captured in a single moment. Yet the description of art as a prime symbol holds in these cases, too. After all, the full import of a piece of music, a novel, a poem, a ballet, or, indeed, a film is only completely clear to us when the unfolding of the work has run its course and its entire structure, from beginning to end, has been presented to us. It is then that all the pieces truly come together to form a whole symbol, albeit a symbol that exists in our mind's eye or in our memory of it, which is a memory informed by hindsight (we now remember the beginning of the film in view of what its ending revealed and not just as it was initially perceived). That is why it can be so rewarding, but also disconcerting, to watch a film a second time or re-read a novel. It is also why such renewed engagement

\footnotetext{
${ }^{131}$ Kolve discusses the Expositor figure in the Corpus Christi plays, who fulfils the role of narrator, as a figure used 'to enclose the action' (1966: 27). This rehearses the fact that the narrator in literature functions as a frame. This even holds when the narrator function is merely the authorial voice. This is something that Langer also points to when she argues that right from the first word or line a novel draws us into its fictional world (FF 213-214). Obviously, this connects back to the discussion of the impossibility of breaking the fourth wall between fiction and reality at the end of Chapter One: see section 1.4.

${ }^{132}$ Creating a circle in which to play is also the first thing that happens in the mummers' play. Since mummers' plays are performed in private homes or impromptu on the street the circle is usually drawn by one or several actors walking around in a broadening circle that pushes back the accumulating crowd, thus clearing space for the performers while also generating the configuration (a circle) that is most beneficial for all spectators to perceive the action. As such 'the action is set apart from the spectators yet made accessible to all of them by the drawing of the circle' (Brody 1970: 17). In her discussion of indoor theatre performed in the great hall of an Inn or a household Meg Twycross matter-of-factly points out that 'clearing the magic circle for the players [...] is also a physical necessity, as anyone who has performed with an unstructured audience will tell you' (2008: 61).

${ }^{133}$ Reminiscing about The Devils in the documentary Hell on Earth Vanessa Redgrave is therefore quite correct to point out that the success of the film, and in fact of any film, is due to the fact that all elements and all people involved in it came together in 'making a single whole'.
} 
with a work of art can be a profoundly different experience from the first. It is also why works of art can grow on us, allowing us to discover new subtleties at every encounter, or to find deeper pleasure in the forms that have become familiar to us. This is simply because, after the first experience of the work, we know its whole structure and can recall, anticipate, and connect elements. We can see how one thing emerges from (rather than follows) what came before and anticipates (rather than comes before) what is yet to come. To say that forms of art that require an unfolding in time, such as cinema, achieve a single metaphorical symbol is therefore not fanciful: it is simply to acknowledge that to know the import of a work of art one needs to know it as a whole.

I have argued that what holds The Devils together as a work of art (as a unified symbol) is its structure as an allegorical theatrum mundi. This is the structure of its magic circle as a work of art. And it is this allegorical structure that allows us to return once more to the Corpus Christi plays, to make one final point about The Devils. At the beginning of this chapter I briefly discussed Calderón's El gran teatro del mundo as one of the main examples of the theatrum mundi in seventeenth-century theatre. But this is only one in a very large collection of sacramental plays, the so-called autos sacramentales, that the playwright created for the feast of Corpus Christi. And one of the most significant features of these autos was their structure as allegorical drama. This means that these plays are not concerned with creating life-like characters or recognisable situations. Their primary aim was to represent, in a vivid way, abstract ideas related to the dogma of the Eucharist which, as was mentioned before, encompasses the entire history of everything, albeit from a theological perspective. The allegorical nature of $E l$ gran teatro del mundo is made clear by the fact that its main characters are themselves allegorical figures: they are not individual people but personifications of the World, of Beauty, of the Peasant, or the King, and so on. The play in which they perform, is meant to clarify, for the audience, the importance of charity in the world. In this sense the entire play is an allegorical presentation of a theological principle. To be sure, Russell does not go quite that far in The Devils, which has well-developed characters that are real or, at least, based on real historical personages. But the film, which (upon my interpretation of it) is structured throughout as a Corpus Christi play, certainly aims at a similar allegorical effect, evoking not a theological dogma but (what the film presents as) the ontological truth about the world and all of human society. This truth (which is the film's truth and possibly also Huxley's and Russell's truth) is the fact that there is no truth beyond that which we create and which we can make others believe in (by persuasion or by force: whatever makes it real in its consequences).

It is this conclusion that allows us to connect The Devils to the questions raised at the end of the previous chapter. It will be remembered that I there suggested that Forestier's 
claim that embedding a narrative makes the framing narrative more real is misguided: when a play-within-the-play begins, we do not suddenly perceive what is happening on the stage as part of the actual everyday world we live in. What does happen, I argued, is that we become acutely aware of the fact that the everyday world we live in is structured in the same way as a performance on a stage. ${ }^{134}$ In other words, we acknowledge, in a moment of lucidity that the work of art allows us, that what we call the real world is also a play upon a stage, except that the stage upon which we play, happens to be the world itself, or what we call reality. The import of this awareness, however, lies in the fact that it forces us to acknowledge that, no matter how we act upon this world-stage, and no matter how we organise the scenery, the plot, and its governing rules, everything could always also be different. We have the gift of what Hannah Arendt called natality: 'the capacity of beginning something anew' (1998: 9). If the ontological foundation of the world has been cancelled, then nothing (except that which is the consequence of biological or physical forces beyond our control, such as ageing or the climate) has necessity. All that is made by humans can and could be changed if we so willed it (although, again, the more of us will it the easier it will be to change it). Like Prospero, we can invent and invent again at the wielding of the wand. But we must will it and, most importantly, we must get others to will it, too, or to at least believe in what we will. This is the struggle that The Devils dramatises: who will get to determine reality? Whose will shall be imposed upon the world and made real? At the beginning of this chapter I said that, if you blow up the world, you have to build it again. We can now rephrase this and say that, if you want to, you can blow up the world and build it again. The only problem is that we are not the only builders on the site.

\subsection{OUTLOOK: RUSSELL ENTERS THE STAGE}

With my analysis of The Devils the philosophical foundations are laid for a discussion of Russell's own performance of self in and through his work. In Chapter One I looked particularly at the baroque structural devices used in Russell's narratives. In the present chapter I have explored the ontological issues that are at play in such baroque devices. The result is a stage of the world upon which we perform ourselves for others and struggle with them over what the shared world (the stage upon which we all engage with each other in our personal histrionics) will be like. This is a world-view that does not allow of any metaphysical foundation: like the Heraclitean stream, it is constantly changing,

\footnotetext{
${ }^{134}$ See Chapter One, section 1.4 .
} 
subject to human action. In the following chapter I want to make this analysis more concrete by looking at Russell himself as an artist working in a specific context and show how he developed and articulated his ideas on art and artists, on how to make films on the lives of artists, and, most importantly, on what kind of artist he himself ought to be (perceived as being). I have argued that the import of The Devils is ontological because the allegory of its theatrum mundi reveals something about human society in general, everywhere and at all times. Although Russell was never in danger of burning at the stake for what he believed or performed (although he was on many occasions flagellated in effigy by critics lashing out at his films) he has nevertheless developed his own performance as an artist, and the way he performs himself through his art, in an elaborate and complex struggle with and negotiation of the institutional context of the BBC at a time when ideas about truth in relation to the arts were an important concern. If all the world is a stage, how does Russell's artist perform on that stage, and how did Russell conceive of that artist? How did his image of the artist develop in relation to the context in which he worked? These are the questions to which the following chapter turns in an attempt to capture Russell's growth as an artist in flagrante, or at least in the texture of his $\mathrm{BBC}$ films. This means that at this point, midway through the book, the perspective shifts. In the first two chapters I looked at what makes Russell baroque: his narrative structures (Chapter One) and the specific philosophical outlook that underlies those structures (Chapter Two). In the following two chapters I will look at Russell's own performance of self. First I will reconstruct the context in which this performance developed (Chapter Three) and then I will analyse the specific way in which Russell used his films to perform his self (Chapter Four). 


\title{
Chapter Three
}

\section{WITH BIG STROKES, BOLDLY}

Fashioning the Artist as a Savage Messiah

\author{
(1972)
}

'If a man could say nothing against a character but what he can prove, history could not be written.'

Dr Johnson (quoted in Wittkower and Wittkower 2007: xxix) 

The artist is sitting on top of a huge Easter Island head. The museum guards try to coax him down, one of them sarcastically suggesting that 'we don't want to disturb the taxpayers enjoying the benefits of cultural democracy, do we sir?' But Henri Gaudier (Scott Antony), the artist in question, is having none of it, and as he throws leaflets around he shouts back that 'of course they should be disturbed! Shocked into life! This isn't a morgue! Art is alive! Enjoy it! Laugh at it! Love it or hate it! But don't worship it! We're not in church!' Shortly after that he is captured and Gaudier and his companion, the Polish writer Sophie Brzeska (Dorothy Tutin), are unceremoniously dumped outside the Louvre. Henri Gaudier's behaviour in this scene from Ken Russell's Savage Messiah (1972), a film about the artist's life, displays the same kind of irreverence towards art that has been associated with Russell. This is hardly surprising if we consider that Savage Messiah was an intensely personal project for Russell, who 'second-mortgaged [my] house to get money for the film. Everything I have is in it' (AT 74). The portrait of the artist on offer in Savage Messiah is a spiritual self-portrait of Russell, and I will show that it is key to an understanding of his own development as an artist. The film is therefore perfectly suited as a point of reference for the next stage of my analysis of Russell's performance of self. In the previous two chapters it became clear that Russell was attracted to Baroque narrative strategies because these allow the artist to reflect back upon reality. This was keyed to a concept of the self as a performance (upon the stage of the world). In this chapter I will investigate how Russell performed his own identity as an artist. I will show that the way Russell thought about being an artist, and how he performed himself as an artist, was something that developed over a period of ten years when he was working for the BBC. Throughout this period we can see that the way Russell made films reflected his changing ideas about what it means to be an artist.

As Russell developed his views on art (and the way he made his films) he also developed his own public performance as an artist. The most familiar public image of Russell is that of the "wild man of the BBC" who behaved (or was at least reported to behave) like a madman, both on the set and off. In the course of the 1960s, we can see this public persona of Russell begin to emerge. The aim of this chapter is to connect these developments (the ideas on art, the performance of self, and the way of making films) in a description of Russell's evolution as an artist that also explains how he came to hold the ideas he held, perform the way he performed, and make films the way he did. It will emerge that at the heart of Russell's development as an artist there is an important conflict about the status and nature of truth. As a film-maker employed in a documentary capacity (for it was documentaries on artists that Russell was required to make at the $\mathrm{BBC}$ ) questions of truth, objectivity, and fairness were obviously important to Russell and to his employer: how can one present a filmed (documentary) account that is truth- 
ful and objective? Does it mean presenting all the known and reported facts of an artist's life? Or should one pursue the "spirit" of the artist or the "spirit" of their work? And however one defines truth and objectivity, how does one access them? How does one communicate them? As will become clear in the course of this chapter, Russell's work at the $\mathrm{BBC}$ is situated at the crossroads of several conflicting approaches to truth and truthfulness. In fact, Russell's views on art and artists can only be properly understood as at least partial answers to the challenges of navigating an institutional context (the BBC) with a strong tradition of fact-based truth (but also, I will show, a tradition whose idea of "facts" tended to be highly tendentious) while at the same time harbouring, especially in the early 1960s, several new and rival approaches to what could be called truthful, objective, and neutral broadcasting. I will describe how several parties in the debate proposed different approaches to truthfulness and objectivity, how these different approaches were translated into different artistic practices (specifically in the making of films, both documentary and fiction, for television), and how this context helps us understand Russell's approach to truth and his attitudes to art as articulated in his film Savage Messiah. This also means that I will not engage the question of truth itself. Which of the proposed approaches to truth is the best, or the most objective, or the most correct, or the most truthful, is and must remain a moot question. My approach is descriptive and explanatory: I want to map out the several views on truth that circulated in the context in which Russell worked and how they informed Russell's own ideas on the subject.

As we delve into the history of the BBC and Russell's work there, it might seem as if the baroque is receding into the distance as a central concern of this book. But it is not. In the previous chapter I have argued that the culture of the Baroque saw the world as a stage, and that one of the central dramas played out on this stage is the struggle to determine reality. This is also the struggle at the heart of the present chapter. As notions about truth and art clash at the BBC, we can see Russell developing his own position within this debate. If baroque, as a state of mind rather than a formal matrix, is about the questioning and representation of reality, then the story of Russell's self-creation through art during his years at the $\mathrm{BBC}$ is very much a baroque story. Not only because it shows us the performance of an artist as it emerges through his work (for that is the process that the present chapter seeks to reconstruct), but also because the reality of who Russell is, was created through his work, and because (to complicate matters further) this work itself (his films) was engaged in an institutional struggle (within the BBC) about the relationship between art and truth. And that, I have argued, is a central concern of the baroque. If the heart of the baroque is the problem of representation (of the world, of the self), then this is the central concern of Russell's years at the BBC. How 
does one represent artists on film? How does one represent oneself as an artist? How can one represent oneself through one's art? What, in other words, is the relation between art and reality, fact and fiction? These were the questions that we addressed in the previous chapters, but they are still the central questions of the present chapter. Now, however, they are read out of the micro-history of a very specific case-study: Ken Russell's formative years as a documentary film-maker at the BBC. If Russell is a baroque artist, then this chapter tells the story of how he became baroque.

\subsection{PORTRAIT OF THE ARTIST AS A WORKER}

Before he became a film director for the BBC Russell spent a decade drifting from one inadequate job to another. After graduating from Pangbourne Nautical College he spent several months at sea in the Merchant Navy. After demob he moved to London, where he set out on a three-year career as a professional dancer. He joined the Hampstead Ballet Club to learn the dancer's craft, supporting himself with a job at the Lefevre art gallery in Bond Street, where he worked for half a year. For the next three years Russell danced in several professional companies, and according to his own account these tended to go bankrupt shortly after his arrival. He then shifted his attention to a career as stage actor, with equal lack of success. At that point, Russell explains, 'I gave up the stage - or rather the stage gave me up' (quoted in Phillips 1979: 25) and he started a much more successful career as a commercial photographer. ${ }^{135}$ It was during this early period of his career ${ }^{136}$ that Russell says he discovered Savage Messiah (1931), H.S. Ede's biography of the French sculptor Henri Gaudier who spent most of his creative life in England, where he lived with the Polish writer Sophie Brzeska in a possibly platonic but intense relationship. Russell said he strongly identified with the story of Gaudier, who was 'totally down and out but struggling onward nevertheless,' and that the fact that he was about the same age (his early twenties) as Gaudier at the time 'gave me the courage to keep going, if not as a dancer or actor, then in some other art form. I was impressed by Gaudier's conviction that somehow or other there was a spark in the core of him that was personal to him, which was worth turning into something that could be appreciated by others. I wanted to find that spark in myself and exploit it for that reason' (quoted in Phillips 1979: 25). Some two decades later Russell returned to Ede's book and made a

\footnotetext{
${ }^{135}$ For the early years in Russell's creative life, see the director's own account (AT 82-89) and Sutton (2012: 4049).

${ }^{136}$ Sutton (2012: 41) narrows it down to the second month of his period at the Lefevre gallery, but he gives no source for the claim, which is possibly based on Russell's recollections.
} 
film of it. But Savage Messiah is an unusual film in the Russell canon because it breaks the mould of most of his other artist biographies, which seek to understand the life and person through the work. The film does not contain great flights of fancy, interpretative fugues, or allegorical interpretations of the work. On the contrary, Russell felt that 'Gaudier's life was a good example to show that art, which is simply exploiting to the full one's own natural gift, is really bloody hard work, misery, momentary defeat and taking a lot of bloody stick' (AT 220). In an interview for the film Russell explained that he wanted to show 'an artist as a worker, not someone who lives up there in an ivory tower. [...] The artist's work is 90 per cent hard slog and sweat and 10 per cent inspiration' (quoted in Buckley 1972, 14). ${ }^{137}$

With this approach Russell sought to position himself in relation to both his own earlier work for the $\mathrm{BBC}$ and the conventional Hollywood approach to biographical films on the lives of artists. As I will show in this chapter, an important turning-point in Russell's career was his BBC film on Elgar (1962), which was highly romanticised and idealised. In his later films Russell reacted violently against the Romantic myth of the artist as a pristine genius, struggling and misunderstood, living on the fringes of society, or being celebrated as a child prodigy. Savage Messiah is part of Russell's project of undermining this conventional representation of artists in film. Previously, he had already attempted to shatter the myth with Dance of the Seven Veils (1970), his BBC film on Richard Strauss, which was entirely conceived as an irreverent and provocative comic strip, and The Music Lovers (1970), a biopic on Tchaikovsky that was organised around the destructive effects of Tchaikovsky's fear of disclosure of his homosexuality, which causes him to flee into a fantasy marriage with a woman who turns out to be a mentally troubled nymphomaniac. By displaying the "ugly" facts of Tchaikovsky's sexual life and connecting them to his creativity, Russell turns his film into 'a bitter, satirical rebuttal of the romanticism of the Elgar film' (Gomez 1976: 98). This makes his film an alternative to the Hollywood version of artists' lives, where the facts of the life are generously sanitised and embellished to the point that the films become completely divorced from the historical record. Russell himself observed that 'I think the Hollywood films are all boring $[. .$.$] because they all follow the same path. They're totally interchangeable. The Liszt$

\footnotetext{
${ }^{137}$ Ede (1931) and Pound (1970; orig. 1916) were the main sources for Russell's film, which was scripted by Christopher Logue (who had played Richelieu in The Devils). See now O'Keeffe (2004) for a modern critical biography of Gaudier-Brzeska and the essays collected in Antliff and Greene (2010), and especially Antliff (2010), for discussions of Gaudier-Brzeska in the artistic context of Vorticism. Cole (1978) is still the best catalogue of the artist's sculptural work and also provides a good biography. See also Olson (1974) for the artist's graphic work.
} 
and Chopin films were almost identical' (quoted in Gow 1970: 10). ${ }^{138}$ But if the earlier films had criticised the "Hollywood version" of artists' lives, in Savage Messiah Russell elaborated on his alternative model of the artist as a worker. In this respect, however, it is interesting that Gaudier-Brzeska stands somewhat apart from the usual subjects of Russell's films. After all, at the BBC Russell had mainly made films on composers (although Always on Sunday and Dante's Inferno had taken painters as their subject, as had the 1959 short Scottish Painters on Robert MacBryde and Robert Colquhoun) and was used to building his visual sequences around their music. But Gaudier was a sculptor, and while it is possible to set images to a composer's music it is not possible to set images to sculptures, which are themselves images. In Savage Messiah the ideas about art and artists that Russell wants to communicate are therefore conveyed through the characters' actions and dialogue.

This is achieved most impressively in a remarkable scene that is the heart of the film, and also a statement by Russell on the nature of artistic creation. Gaudier has met an important art dealer and has impulsively and unwisely bluffed that he has a marble bust ready in his studio for the dealer to see. When the dealer announces that he will come first thing the following morning Gaudier steals a piece of marble from a churchyard and spends the night chipping away at it to have the bust ready by morning. As he is working Gaudier engages on a long monologue (addressed to Sophie and another art dealer they have befriended) about the mystery of artistic creation. Gaudier explains that 'you can always tell a bad artist like a bad doctor by the fact that he tries to surround his work with some sort of hocus-pocus. Sure, there's a mystery, but then it's as much a mystery to the one who's doing it as to the one who's looking at it.' ${ }^{139}$ Still, he warns that 'you'd be wrong to be taken in by that solitary genius stuff. Of course I do it because it pleases me. There's nothing wrong with that. If it doesn't give me enough doing it, how the hell is it going to give anything to anybody else? That's the mystery.' Here, again, we find the tension between art as hard work (we must stay clear of mystifications of the

\footnotetext{
${ }^{138}$ The characteristics and origins of the myth (or several myths: it is really a conglomerate of interconnected models) of the artist have been elaborated by Kris and Kurz (1995; orig. 1934), Wittkower and Wittkower (2007; orig. 1963) and Kivy (2001). The myth has very smoothly found its way into cinema. Tibbetts (2005) features several chapters detailing how Hollywood has falsified artists' lives to make them fit the mould of the accepted myth of the artist or the dominant moral codes of society (especially in relation to "undesirable" private matter concerning an artist's philandering, whoring, or homosexuality). See also Walker (1993a: 1389), who looks not only at the myths of the artist but also discusses questions about the recreation of history, and Custen (1992) for the conventions of the "Hollywood version" of filmed lives. For discussions of The Music Lovers, whose critique of Romanticism is beyond the scope of the present discussion, see Baxter (AT 183-193), Gomez (1976: 96-113), and Hanke (1984: 75-117).

${ }^{139}$ In an early notebook, dated 1911, Gaudier wrote that 'Mysticisme nuit à la vraie sensation d'art' (quoted in Pound 1970: 42).
} 
solitary genius) and yet a form of mystery (a dynamic between what a work of art means for its creator and what it means for a viewer). In the end, however, art is also about communication, about giving something back to the public. In this, I will argue, we see clear traces of Russell's work at the BBC, with its public service ethos. Or as Russell himself said about Gaudier, 'I was attracted to this material because Gaudier was not what the general public considered an artist to be. He wasn't someone special tucked away at the top of an ivory tower making works which were totally obscure, to be admired by a few friends. He was somebody working for posterity and eternity, somebody who felt that there was something in him which he could transmit to his fellow human beings which might be of use to them' (quoted in Phillips 1979: 112).

As we track the development of Russell's ideas on art and artists through his work for the BBC in the 1960s, the tension between Russell's attack on Romanticism and his strong infatuation with it, resulting in an alternative "myth" of artistic creation, will become increasingly obvious. In the last part of the chapter we will see it culminate in Isadora Duncan, where Russell most explicitly introduces his own subjective approach to the artist biography. This is the theory, expressed in his production notes for Mahler, that one can know an artist through his or her work. But that is itself a deeply Romantic notion, which means that in this chapter we will be exploring the genesis of a paradox: Russell was an artist who used Romanticism against itself. If Russell argues that the artist is a "worker" rather than a mystical genius, then his notion of a "worker" in turn is deeply informed by Romantic ideas on what creative work is like. This is an issue that will be addressed extensively in Chapter Four. In the following pages I will first explore and try to explain how Russell's discontent with the traditional image of the artist came about, how it influenced his approach to artist biographies at the BBC, and how he developed, from film to film, an alternative approach. In the final part of the chapter I will analyse Russell's representation of Isadora Duncan to show exactly what this alternative looks like. I will argue (on the basis of the analysis developed throughout the chapter) that Russell has developed a notion of artistic work that is deeply informed by Romanticism but manages to steer clear of the quasi-mystical hero-worship that so often makes Romanticism unpalatable to post-modern tastes. How this alternative Romantic notion of creative work translates into Russell's own performance of self through his work will then be the subject of Chapter Four, which can be seen as the analytical counterpart to the largely (but not exclusively) historical and biographical approach of the present chapter. 


\subsection{LAYING THE SCREEN: THE CONTEXT OF THE BBC}

When Russell entered the BBC in 1959 television was a profoundly different medium from what it is today. In Great Britain it had existed since 2 November 1936 (with transmissions interrupted during the war, from 1 September 1939 until broadcast was resumed on 7 June 1946), and it had only begun to find a wider audience with the enormous popularity of the broadcast of the Coronation of Queen Elizabeth II on 2 June 1953, which many people watched by flocking to the houses of friends and relatives affluent enough to own a television set. ${ }^{140}$ There were also technical limitations. Broadcasting began from Alexandra Palace in London and the reach of the transmitter was initially limited to the London area. It would take many more years before more or less national coverage was reached. In 1959 all broadcasts were still in black and white and would remain so until BBC 2 started showing colour in 1967, although many viewers would not buy colour sets until sometime in the 1970s. Most importantly, however, the choice of channels was extremely limited. Television in Great Britain began with just one channel, the BBC. In 1955 it received competition from the first commercial channel, ITV, which was authorised by the government out of the explicit consideration that competition was necessary to provide the viewing public with choice. Only in 1964 did BBC 2 emerge as a third channel. This means that whatever programmes were shown would be seen by a much more concentrated audience than today, when we have a wealth of international channels to choose from. One producer later recalled, not without irony, that 'in many ways we had a captive audience' (Shubik 2000: xiv). This is important to understand how certain programmes such as Russell's film on Elgar (1962) could achieve almost iconic status: there were few programmes available and they were therefore often seen by many.

More important, however, for the way Russell made films at the $\mathrm{BBC}$ is the particular public service ethos that lay at the heart of the corporation. The BBC started broadcasting radio in 1922. Its first Managing Director was John Reith. Historians have argued that Reith's control over the Company 'in its early days was massive, totalitarian, and idiosyncratic, and for many decades the traditions of the BBC seemed to flow directly from his personality. The British Broadcasting Company was set up as a business. Reith turned it into a crusade' (Seaton 2003a: 110). He saw broadcasting as a means to

\footnotetext{
${ }^{140}$ See Cooke (2003: 19-20). John Caughie observes that 'up until the sharp increase [in television ownership] in the late 1950s and early 1960s when television truly became a mass entertainment, people went out to see television instead of staying in. It was common to be invited to "come over and watch television". The technology was not yet fully part of the everyday, and, consequently, the characteristic experience was not yet entirely private or exclusive' (2000: 36).
} 
'set a high moral tone for the whole of the nation' (Cooke 2003: 10). In 1926, however, the British Broadcasting Company was closed and replaced (on 1 January 1927) with the British Broadcasting Corporation, which functioned under a Royal Charter that gave it a duty to 'inform, educate and entertain' (ibid.). As such, it was given broadcasting monopoly and it was free to function outside the influence of politics and without commercial considerations. The BBC would function solely for the benefit of the national interest. ${ }^{141}$ Broadcasting was acknowledged as a public service rather than a marketable good. Until his resignation in 1938 Reith put his stamp on the way the BBC would continue to understand its service to the national interest. His ideology has since been termed "Reithianism" and it "dictated that the BBC use the "brute force" of its monopoly to give the public "everything that was best in every department of human knowledge, endeavour and achievement." To give them what they ought to want since "few knew what they wanted and fewer knew what they needed." This dogmatic paternalism was to govern all BBC operations' (Jones 2003: 307). This view obviously implied that broadcasting should be in the hands of a cultural elite. It presupposed 'an intellectual and artistic élite, a nobility of culture rather than of birth' (Bakewell and Garnham 1970: 2). In practice this meant that the $\mathrm{BBC}$ became an 'innately highbrow institution that tended to promote the interests and tastes of the English upper middle class' (Creeber 2003: 24). And as moral guardian to the nation the $\mathrm{BBC}$ was widely perceived as 'a trustworthy national repository for British Christian values and culture' (Brown 2012: 354). The model for this elitist approach was the nineteenth-century Arnoldian idea of a liberal education. ${ }^{142}$ This belief in the power of education was further reflected in the concept of public morale, based on the assumption that "morale" (like "culture") was something 'single and malleable' but also 'peculiarly susceptible to manipulation' both by propaganda and by the new technologies of mass communication (such as radio and television). 'The people, then, were thought to be persuadable' (o.c. 127). And while nominally neutral, the $\mathrm{BBC}$ actively sought to persuade the public in specific directions. ${ }^{143}$

\footnotetext{
${ }^{141}$ In reality, however, the neutrality of the BBC was highly problematic and it was often 'a relationship of independence from and common interest with the State' (Caughie 2000: 25). In this respect the BBC's coverage of the General Strike of 1926, when the radio service remained as the only major national source of news, was a watershed in defining the BBC's "neutrality" as essentially allied to the interests of the state: see Tracey (2000).

${ }^{142}$ See Seaton (2003a: 151).

${ }^{143}$ See Scannell (2000) and Seaton (2003b) for discussions of the origins and context of the public service ethos in British broadcasting and the role Reith played in shaping it. Black (2005) sheds light on the moral and political concerns over television (both BBC and ITV) among Labour and Tories alike, and shows how deeply such concerns were informed by the Reithian ethos. Brown (2012) uses the case of Margaret Knight's humanist broadcasts in 1954 to argue that the BBC actively supported the dominant ideology of Britain as a robust Christian nation, while Morrison (2009) succinctly summarises the way television shifted towards a more
} 
Reithianism infused the $\mathrm{BBC}$ with a kind of benign paternalism aimed at giving the public what it needed and therefore should want. The playwright David Mercer recalled in 1970 that, when he began to work for the BBC, 'I was slightly overawed by the kind of benign, paternalistic civil service temperament, not only of people but the whole atmosphere. What I thought were very posh people, Cambridge and Oxford degrees, being kind of, you know, free and liberal and gentle and all that, rigorously sticking within the meaning of the Charter' (quoted in Bakewell and Garnham 1970: 85). But this attitude did change and develop over time. The way the BBC tried to promote "good design" through its television broadcasts is a good example to track an important shift over the years. After the Second World War, Great Britain had to address the problem of urban devastation caused by air raids. Countless homes had to be rebuilt. Housing estates were developed, town centres were modernised, and even entire New Towns were built from scratch. Much of this urban endeavour would lead to a concrete desert of alienation and ugliness, the so-called "brutalist" style of building. But at the time these projects were undertaken with a sense of great optimism. ${ }^{144}$ It also meant that many people would be faced with the challenge of furnishing their new dwellings. This lead to a series of television programmes promoting and discussing the latest trends in good British interior design. But such programmes were aimed at a very specific, and affluent, audience. This reflected a social reality. Until the early 1950s television sets were an expensive commodity which only the relatively affluent could afford. But in the 1950s prices of sets began to fall and a steady increase in television ownership began. As Michelle Jones explains, 'didactic promotion was acceptable to television's initial, relatively wealthy and educated viewers. By 1953, however, as television ownership increased and the cultural make-up of the audience expanded, the encouragement of "good design" was modified

pluralistic attitude in the 1960s. In an interesting parallel to the "neutral" position of the BBC and its service to the national interest, the films of the GPO (General Post Office) Film Unit, which was also created in the late 1920 s, similarly positioned themselves above party politics and ideological differences, which became 'subsumed into the idea of the benevolent state, above divisive politics (the GPO is simply a public institution)' (Higson 1986: 77). Through the GPO Film Unit a series of remarkable documentaries on topics of general and national interest were produced, often with the aim of informing the public about aspects of 'a common public sphere' (ibid.) such as, perhaps most famously, Night Mail (Basil Wright and Harry Watt, 1936) about the postal services.

${ }^{144}$ Sandbrook (2007: 185-191 and 620-640) offers a vivid discussion of the triumphs and disasters of the New Towns and the brutalist movement. Alexander (2009) is an excellent (and lavishly illustrated) study of the backgrounds, development, and problems of the New Towns. Interestingly, after leaving the BBC Reith was invited to chair a Committee for the New Towns, and he addressed this task with the same sense of public service, writing (in 1946) that it is not enough in our handiwork to avoid the mistakes and omissions of the past. Our responsibility, as we see it, is rather to conduct an essay on civilisation. By seizing an opportunity to design, evolve and carry into execution for the benefit of coming generations the means for a happy and gracious way of life' (quoted in Alexander 2009: 70). 
to make it more accessible. The BBC's attitude towards design promotion moved from the didactic to a more subtle influence, firstly through consumer advice aimed primarily at the "housewife", and secondly subliminally, through positioning objects of "good design" within the studio settings' (2003: 316). In other words, the educational attitude shifted from specific programmes aimed at an affluent elite towards a more general concern with the overall "look" of the BBC. Henceforth 'design should be incorporated within the studio settings rather than remaining merely as a topic for generating debate' (o.c. 316-317). Richard Levin, who became head of design at the BBC in 1953, explained how the educational aspect of television as a "persuader" (subliminally influencing its audience through its "tasteful" studio settings) could be maintained without condescending to the audience. 'People see things on television,' he argued, 'and they seem to generate an instant "want". They ask their suppliers for it and manufacturers, not being stupid, are quick to supply it. It is no part of our job to improve public taste in a "dogooding" kind of way, but trained as we are we are conscious that we have a responsibility here - whether we like it or not' (quoted in Bakewell and Garnham 1970: 40).

Aware of one's responsibility but reluctant to go into "do-gooding" mode: it was into this atmosphere that the arts programme Monitor was launched in 1958. ${ }^{145}$ The programme was created especially as a vehicle for Huw Wheldon, who was already a producer at the $\mathrm{BBC}$ but who was only known to the viewing public as the presenter of a children's programme. Before he joined the BBC Wheldon had been director of the Welsh Arts Council despite the fact that he had neither a background in nor any affinity with the arts. But in view of this previous career, and considering that it would be too delicate for a staff producer to host a political or current affairs programme (because this might cast a shadow of partiality over his work as producer), an arts programme was considered both sufficiently neutral and sufficiently prestigious for Wheldon to helm. Initially Catherine Dove was assigned as producer to Monitor. She would collaborate closely with Wheldon, who would be the programme's public face as presenter. But after several run-ins with Wheldon and an accident involving her knee Dove left the programme (and subsequently the BBC), leaving Wheldon as effectively the producer, editor, and presenter of Monitor. ${ }^{146}$ However, the basic set-up of Monitor was not new: it relied considerably on the "profile" format. This had been a staple of arts programmes since John Read, son of the art critic Herbert Read, made a profile film on Henry Moore

\footnotetext{
${ }^{145}$ Better living through the visual media was not only promoted via television. An interesting feature of British cultural life in the second part of the twentieth century was the so-called Art Film Tour, an itinerant programme of arts documentaries shown throughout the country on $16 \mathrm{~mm}$ prints for the betterment of the populace. The project lasted from 1950 until 1980 and was a tremendously successful venture in mass popular education. See Loukopoulos (2007).

${ }^{146}$ See Ferris (1990: 115-118) for these backgrounds.
} 
in 1951 (and Catherine Dove had actually worked with Read as a trainee before being assigned to Monitor). Within the BBC such programmes were not particularly popular. This was due to the fact that Read had little regard for what has been called the "ontology" of television. This was the idea that the distinguishing characteristic of television as a medium was its "liveness": the fact that it allowed viewers to see events direct over a distance in a live broadcast. Such live broadcasts would usually take place from a studio setting. This ontology extended from current affairs programmes to drama, with teleplays conventionally performed live in the studio for direct broadcast. ${ }^{147}$ For many practitioners of early television broadcasting pre-recorded or filmed programmes was a form of "cheating" the audience. But Read's profiles were necessarily filmed on location and edited into self-contained films. It was precisely this that made broadcasters reluctant to show such programmes on art. ${ }^{148}$

The profile format operated around a basic set of assumptions, including 'an explanatory commentary; a focus on already established artists; and a conception of the artist as a visionary "genius", who is able to transcend the society that encases her or him' (Sexton 2007: 90). ${ }^{149}$ Initially, every episode of Monitor (which was broadcast fortnightly) would contain three items, each of which was introduced by Wheldon, who also wrote and spoke the commentary. Right from the start it was clear that 'Wheldon had a mission to inquire and explain' and that he 'saw himself as the representative of the curious layperson' (Walker 1993b: 47). This was in line with broadcasting's brief to enlighten and educate the public. Wheldon's style of presenting is characterised by his biographer as a form of 'brisk authoritarianism' (Ferris 1990: 119), at once 'affable and conservative. He presided over the place like a stern but kindly uncle' (o.c. 121). Wheldon was often mocked for this. The programme was criticised for being middlebrow and Wheldon himself "was accused of being "melodiously out of his depth"' (o.c. 140). However, Wheldon was acutely aware of the fact that only a small minority of the viewing public had either a university degree or a more than passing acquaintance with

\footnotetext{
${ }^{147}$ See Cooke (2003: 7-9) for a discussion of this ontology in relation to early television drama in the period 1936-54. Barr (1996) is still a key text on liveness and television drama in the 1950s and beyond, but see also McNaughton (2014) for an interesting discussion of experiments with a hybrid form that records a complete live performance on film to edit afterwards.

${ }^{148}$ Other reasons had to do with issues of representation: the impossibility of reproducing works of art in either colour or their actual size on television, where every image has to be reduced to fit the same black and white frame. See Walker (1993b: 27-28) for a discussion of these issues in relation to Read's pioneering films. Wyver (2007: 17-23) provides an assessment of Read's significance for the development of the British arts documentary.

${ }^{149}$ According to Raymond Durgnat, the BBC series of artist profiles suffered from 'hypertrophy of reverence, a feeling that art portrays not so much (or only incidentally) doubts, struggles, contradictions, as some kind of “Third Programme of the soul”, wherein all is lofty and deep' (1967: 82).
} 
the arts. His job was to strike a balance between speaking plainly to the interested layperson and doing justice to his subject. Wheldon later said that the television producer 'serves three masters. The masters are the subject, his craft and the audience. The service required is absolute. The imperatives are categorical' (quoted in Bakewell and Garnham 1970: 115). To serve the audience Wheldon was ready 'to risk looking unclever on television' (Ferris 1990: 141) by asking artists obvious and simplistic questions that would seem stupid to the informed art lover. And this, too, might have been a reason for mockery. As David Frost explained, 'if an élite subject is suddenly made available to a mass the élite has lost something and may resent it' (quoted in Bakewell and Garnham 1970: 72). Possibly, Wheldon's desire to communicate with the audience also helps explain why he was particularly interested in showing the person behind the work. One of his major rows with Catherine Dove had occurred when he told her that 'the public won't care what these people wrote or painted. What they'll want to know is, were they queer or did they have women, and if so, who' (quoted in o.c. 117). A less generous reading might see this (as Dove, who was outraged by the remark, probably did) as a philistine approach and perhaps an expression of Wheldon's own lack of knowledge about the arts.

Russell's desire to work as a film director at the BBC was not a sudden impulse. After all, he had already made a number of amateur films, the most remarkable of which was Amelia and the Angel (1957), a film about a girl who plays an angel in a play, loses her wings, and is given a new pair by an actual angel. The film was awarded the national amateur film prize of the journal Film and was widely distributed at the time. ${ }^{150}$ Wheldon agreed to meet Russell after he had seen Amelia and the Angel, which Russell had submitted to the BBC as a token of his abilities. Wheldon felt that the film 'had all the signs of having been shot on lavatory paper. It was also romantic, eccentric and in many ways not at all my cup of tea, but whatever else it was, it was neither predictable nor cliche-ridden, and so I thought I would see the author' (quoted in AT 118). Russell in turn felt that Monitor was 'one of the most prestigious programmes on television. I thought it was the best; I wanted to be part of it' (BP 15). But he was also aware of the fact that his own amateur films were out of step with the main direction of British cinema at the time, which favoured social realism in "kitchen sink" drama and the experiments of the Free Cinema. It seems that in Russell's perception the BBC, and specifically Monitor, deviated from this trend and that his own work would be at home there. 'If Wheldon didn't like my style of film-making,' Russell wondered in retrospect, 'who

\footnotetext{
${ }^{150}$ See Sutton (2012: 141). See the discussions of Amelia and the Angel by Baxter (AT 104-105), Gomez (1976: 29-30), and Phillips (1976: 14-17; 1979: 29-32).
} 
would? It was hopelessly unfashionable, the very antithesis of the "free cinema" championed by the British Film Institute, which glorified teddy boys at the Elephant and Castle' (BP 16). On their first meeting Wheldon immediately asked Russell for suggestions for a possible film. From Russell's proposals Wheldon selected a short film about John Betjeman. John Betjeman: A Poet in London (1959), also sometimes referred to as Poet's London, shows Betjeman visiting London locations that had been destroyed by brutalist architecture. ${ }^{151}$ Wheldon reflects that upon seeing the finished film 'I recognised the feel that I had hoped for. It felt like Monitor, and like me, as of course it should have done in the circumstances; but as it went on I saw that every frame had a signature, and that signature was "K. Russell"' (quoted in AT 120; emphasis added). This observation clearly shows the iron grip that Wheldon held on Monitor, which had been created entirely 'in his image' (Briggs 1995: 168). Wheldon decided which items would be made and which would not, and he would impose artistic restraints, supervise the editing, and ultimately of course provide the commentary. To get a project started 'Wheldon had to be seized by the art or the life. Otherwise the idea was dropped' (Ferris 1990: 143). But once he was convinced of a project Wheldon was usually very supportive of his directors. Russell also appreciated the fact that 'even if he didn't approve of an idea, if he felt that you were passionate enough, he'd let you do it' (quoted in o.c. 150). Wheldon also provided other kinds of cover for Russell. Grace Wyndham Goldie, who was head of Talks at the BBC and therefore highest in Monitor's chain of command, was not very keen on television directors with artistic aspirations. Wheldon therefore tried to send Russell off on location as often as possible to keep him out of sight. Russell later recalled that 'Grace Wyndham Goldie didn't really want me there. Every producer in talks department was supposed to go to the weekly meeting, but I only went once. Huw always made an excuse, because he knew if she saw me it was like a red rag to a bull. "We don't want film directors manqué here, we want television programme makers." So Huw spirited me into the attic' (quoted in o.c. 149).

Russell was an outsider at the BBC. As Kay Dickinson points out, it is doubtful that a person of Russell's class would have gained a BBC job in previous decades. Russell was, by and large, an autodidact who had not received a university education' (2007: 75). On the other hand, the BBC in the 1950s and 1960s became a breeding ground for maverick

\footnotetext{
${ }^{151}$ Paul Sutton claims that 'Ken Russell was drawn to Betjeman's poetry because Betjeman shared three of Russell's passions - Christianity; the female form; and horror at the post-war destruction of England by brutalist town planners' (2012: 168). Betjeman held 'a sort of totemic position' (Calloway 1994: 190) in English conservationist circles and regularly featured in television documentaries about the British landscape and architectural heritage.
} 
talents like John Schlesinger ${ }^{152}$, Peter Watkins, Ken Loach ${ }^{153}$, and John Boorman ${ }^{154}$. But Russell himself was certainly aware of a class distinction. The most telling sign, for him, seems to have been his weak verbal skills. These were the main obstacle in the learning process that Wheldon, as his editor-mentor, put him through. Russell has famously said that 'Monitor was and still remains the one and only English experimental film school ever, and Huw Wheldon was its guiding genius' (AT 113). Part of the film school was learning to write scripts and commentaries, at which Russell was not good. But Wheldon would force Russell to sit down 'at the Editola and he made me try to say because I really couldn't do it at all - what I felt was needed on the commentary' and 'as the years went by, I falteringly learned, with patient help from Huw, how to put my feelings into words' (ibid.). Later, in his autobiography, Russell again recalls that 'bit by bit he began dragging words, phrases, even sentences out of me which I never thought I possessed.' But this time he adds a remark that is telling in relation to class issues: 'It was painful. All the other directors in the programme had university degrees. [...] But my education proper began at the age of thirty-two with Huw Wheldon' (BP 22). Russell proved an excellent pupil, for already in 1962 Wheldon felt confident to commit to print, in the Foreword to a Monitor anthology, that Russell was 'the most original, unpredictable mind among us' (Wheldon 1962: 13). This is incredibly remarkable. When Russell first met Wheldon there was nothing to suggest that this not-so-young would-be director would amount to anything other than a promising failure. In terms of a cur-

\footnotetext{
${ }^{152}$ Schlesinger was Russell's predecessor as the "star" director of Monitor. Schlesinger had already made a number of amateur films when he submitted his documentary short Sunday in the Park (1956) to the BBC. After several rejections he was finally hired to direct a number of segments for the current affairs programme Tonight. He fell out regularly with producer Ronald Baverstock, but by the time Schlesinger was let go at Tonight his work had attracted favourable attention within the BBC and 'at the time of John's final blow-up with Baverstock, another producer, Huw Wheldon, was already considering him' (Mann 2005: 143) for Monitor, where he made a series of remarkable films between 1958 (he contributed to the very first edition of Monitor) and 1961. Schlesinger's experiences on the programme were in several ways similar to Russell's. His biographer points out, for example, that 'Grace Wyndham Goldie was never a supporter - John recalled having "permanent rows" about various films with her - and, indeed, she criticised [his 1958 film on Benjamin Britten at Aldeburgh] as too "self-indulgent"' (o.c. 147). Again like Russell, Schlesinger later recalled that 'I felt I was making films at the BBC. They were shot on $35 \mathrm{~mm}$, cut the normal way, dubbed the normal way, and still she would say, "You're making television." And I would say, "No, I'm making a film for television." But she insisted, "No, you're making television." I never have been able to understand the difference' (quoted in o.c. 154).

${ }^{153}$ The BBC films of Watkins and Loach are discussed below, in section 3.3.2. of this chapter.

${ }^{154}$ Boorman started his career at ITV, and at a time when many people were abandoning the BBC to work for the commercial broadcasting company, Boorman was 'one of the very first to go the other way' (Boorman 2003: 96) in 1961. He found the BBC and its staff 'remote and snobbish' (o.c. 97) and clashed with Donald Baverstock over his (now classic) documentary series Citizen 63 (1963). According to Boorman, 'the only refuge of imaginative film-making was Huw Wheldon's Monitor, where the work of Ken Russell, John Schlesinger and others [...] seemed to elevate us' (o.c. 98).
} 
riculum vitae he had little more to show than an ill-fated ballet and theatre career ending in multiple bankruptcies, several years' work as a freelance photographer of considerable talent, and a slew of amateur films. The only thing Russell had going for him was his talent. And it is to this talent that Wheldon, to his eternal credit, responded when he had seen Amelia and the Angel and felt he should see its author.

\subsection{REFUSING TO LIE DOWN: FACT AND FICTION AT THE BBC}

Russell's documentaries for Monitor can be seen, in retrospect, as pioneering an era in British television when, as Ian Christie once put it, 'documentaries were refusing to lie down and be documentaries' (quoted in Rees 2007: 150). Throughout the 1960s and 1970s broadcasters would experiment with the documentary form, especially in the field of the arts. ${ }^{155}$ Russell was one of the first television documentary directors to systematically explore and explode the limits of the documentary form. Looking back, his progress seems incredibly swift: one can almost see him expand the format from film to film. However, each step often also entailed a battle with Wheldon over the introduction of yet another innovation or a further freedom with established conventions. But Russell's explorations were not gratuitous. They mirror changes in his conception of art and artists. This is especially relevant because he saw his own documentary films as works of art in their own right, which means that the way he presented artists, and the formal innovations and experiments he introduced in those presentations, are always a reflection of how he felt he himself should work as an artist. Russell's documentaries for Monitor should therefore be understood as intersections of two closely connected strands in his development. On the one hand there is the constant experimenting with form, pushing against the institutional boundaries of arts broadcasting and the documentary format. On the other hand there is the changing attitude towards art and artists, with Russell's increasing belief, articulated through Gaudier-Brzeska in Savage Messiah, that art should not be dealt with too reverently. Although both levels are intrinsically connected there does seem to be a point at which the balance shifts. This point is Russell's immensely successful film Elgar (1962). Before that film the struggle was mainly about changes to the documentary format, changes that were often so small as to seem almost

\footnotetext{
${ }^{155}$ Useful surveys of and backgrounds to arts broadcasting in the 1960 s can be found in Walker (1993b: 4555), Sexton (2007), and Wyver (2007: 10-46), but also in Conlin's (2009) monograph on Kenneth Clark's classic series Civilisation (BBC, 1969). Wyver also illuminates the deeply Arnoldian/Reithian spirit of Clark's work, which was driven by a belief that 'the minority have an absolute obligation to the majority' (2014: 128) to give them, as was discussed above, the best in all areas of human endeavour, including the arts.
} 
insignificant today, although they were a big deal at the time. After Elgar, and in direct response to it, the balance shifted towards Russell's increasing antagonism towards the approach to art and artists that was common at the BBC and on Monitor. I will first look at the early documentary shorts to trace Russell's formal innovations. In a following section I will highlight his changing attitudes to art and artists in the later, and longer, documentaries.

\subsubsection{Televangelising for Truth}

The main issue to cause tension between Russell and Wheldon was the relationship between fact and fiction. Already on Russell's first assignment, his short film on Betjeman, there was an argument when Russell wanted to recreate a brief scene from Betjeman's childhood with (non-speaking) actors in period dress. Wheldon removed the recreated scenes because he considered them 'false - I didn't believe in them' (quoted in AT 123). Several other conflicts would follow. One of the most widely discussed in Russell lore is the issue of Prokofiev's hands and reflection in Portrait of a Soviet Composer (1961), Russell's first biographical film on a composer (Gordon Jacob, made for Monitor in 1959, was a profile of a living composer rather than a biographical film). When Wheldon heard that Russell felt it would be necessary to show Prokofiev in the film he remarked that 'I gather we're planning to get out the dressing-up basket again' (quoted in BP 22). Of the several accounts of what Russell refers to as a 'confrontation' (ibid.) the oldest is also the funniest. It is one of the passages that was deleted from John Baxter's An Appalling Talent but which were subsequently quoted from the book's draft version in Gomez's 1976 monograph. Russell recalls that 'first of all they let us show a pair of hands playing the piano, though they didn't like that too much. "If you say they're Prokofiev's hands you're cheating." Then I said, "There's a scene where we should see him.” "No!" "What about a reflection in a pond?" "Well, if it's a murky pond!" There was great soul-searching about this. It wasn't said lightly. "OK” I said. "I'll shoot the pond. But there's a scene where I should show his back, just going out of the room." "No. Can't possibly do that." "Just let me shoot it," I said. "If you don't like it we can take it out. It's a simple thing." "Well" ... "Then," I said "I also want to shoot him as a child." "A CHILD?!!! You want to shoot him as a what?"' (quoted in Gomez 1976: 31-32). Since then the story has often been told again as a testament to Russell's struggles on Monitor. ${ }^{156}$ But there is another anecdote connected to the Prokofiev film which is much less

\footnotetext{
${ }^{156}$ More than thirty years later Russell gave a very similar account of the story: 'I did say to Huw that it would be wonderful to show Prokofiev walking around in exile, very lonely and very disconsolate. Huw said, "He's dead!" I said, "Yes, I know he's dead!" He asked me if I had any moving pictures of him; and I said no, no
} 
known but which is more revealing about the extent to which Russell wanted to fictionalise his documentaries. In his autobiography Russell recalls that he proposed to integrate his new film material with the archive footage used in the rest of the film 'by degrading the material I shoot myself so that it looks as grainy and as contrasty as the real thing' (BP 22). This chimes with Wheldon's recollection that 'my main objection was not so much to an actor playing Prokofiev as to Ken faking film to look like newsreel footage' because 'when you start mixing reality and reconstruction you're in very tricky circumstances' (quoted in AT 123).

The issue of truthfulness and reconstruction in a documentary was taken to another level on Elgar, a film that Russell made for the hundredth edition of Monitor and which was to fill the programme's entire one-hour slot. At this point Humphrey Burton had taken over as Monitor's producer, but Wheldon, who had been promoted to Head of Documentaries, continued to present the programme and exert his influence over its content. He wrote and recorded the commentary for Elgar. One of Russell's most regularly quoted statements about the film is that "what really appealed to me was the man in the landscape. I'd been to Malvern and knew his environment there had a lot to do with his musical outlook' (AT 114). In his autobiography Russell recalls that Wheldon only warmed to the project after he had been convinced that the Malvern Hills had greatly influenced Elgar's music and that 'they were his inspiration and his solace' (BP 24). Wheldon agreed to let Russell use different actors to play Elgar at different ages in the film on condition that he would 'treat them as figures in a landscape - no dialogue and, above all, no acting. The hills are your stars here, the hills and Elgar's music' (quoted in ibid.). This suggests that Russell's interest in the figure in the landscape was not entirely of his own making but a restriction imposed upon him by Wheldon. And although Russell appreciated that the use of actors 'was a real breakthrough' (AT 114) the problem of truthfulness and objectivity still remained. Both Russell and Wheldon had worries in this department, but they seem to have gone in interestingly different directions: Wheldon was mainly concerned with the reliability of the facts, whereas Russell had increasing concerns about the tone and spirit of the film. To characterise Elgar, Russell had selected a number of anecdotes from the composer's life. One such anecdote was about Elgar flying kites, another saw Elgar sliding down a hill-side on a tea-tray. Wheldon objected to these scenes because 'I wasn't certain (a) that these events had

movies. He said, "It's impossible! We make documentaries here, we want the truth. We can't dress somebody up and pretend he's Prokofiev!" I said, "I don't see why not; but could I just show his reflection in a pond?” He said, "Only if it's a muddy pond, and you stir it up!" So, that was that. He did also let me show hands on the piano, because that was almost an abstract kind of image' (quoted in Tibbetts 2005b: 41). The essentials of the story have remained the same, the differences are in the tone of the telling and the reconstruction of the dialogue. 
taken place at all, and (b) even if they had, whether they weren't giving a false and romanticised picture of Elgar. Well, of course, I shouldn't have queried them, because they had happened, and Ken put me right' (quoted in AT 121). A more fundamental conflict arose, however, over a sequence where Russell used Elgar's Land of Hope and Glory over archive footage of wounded soldiers in the trenches of the first World War. The result was highly ironic and suggested that Elgar was a pacifist who had resented the patriotic appropriation of his music. It was, however, not clear whether this accurately reflected Elgar's actual attitudes. According to Wheldon this sequence triggered a violent clash of wills. He later explained that 'if we were making a programme about Elgar's beliefs it was Elgar's beliefs that counted and the authority of his beliefs, not Ken's or mine. And on this Ken and I, as we frequently did, had what you might call an editorial row. He remembers this as only a small thing but it was actually awful, lasting days on end. There was a time when I didn't want to talk to Ken, who was in the cutting room, and was very anxious to keep out of his way. Humphrey carried the burden of communication. The result of that argument was a compromise: the war sequence, including Land of Hope and Glory, was cut exactly in half (quoted in AT 122).

The completed Elgar was and remains a highly romanticised portrait of the artist. It was also hugely popular with audiences. But Russell soon began to dislike the film. He later claimed to have been surprised by the film's overwhelming success and popularity, 'but then in retrospect I can see why. I think it contains actually some of the worst aspects of popularisation. I mean it's too corny now; it's too romantic. It's schmaltzy and it just shows that the public likes that' (quoted in Bakewell and Garnham 1970: 136). ${ }^{157}$

\footnotetext{
${ }^{157}$ Almost ten years after that comment Russell again argued that 'basically it was a sentimental, romantic film, showing Elgar galloping across the Malvern Hills on horseback in the early morning and so on. The film was all too lovely, like a TV commercial for the Malvern Hills! I was perhaps too much in love with the man's music to see what really produced it. If I were to remake the film, I would be far truer to the man and his struggle than I was the first time. I would show the darker side of his life as well as the lyrical, colourful side' (quoted in Phillips 1979: 39). He had already made a similar claim about a possible new version when he told John Baxter that 'in my research I found a lot of things that didn't square with this [Romantic] conception, so I had to leave them out. There are three main things missing: his relationships with other women around Malvern, his preoccupation with suicide, and his friendship with Jaeger, his music publisher and friend, which is highly romantic. I could have put all these in but it's another story. If I ever did another film on Elgar they'd be complementary, both true in their way but not true without one another' (AT 115). In the event, Russell did return to Elgar several times. Elgar was one of the composers featured in Ken Russell's ABC of British Music (1988). Next, and more extensively, the fortieth anniversary of Elgar was celebrated with a new Russell film, Elgar: Fantasie on a Composer on a Bicycle (2002), commissioned by Melvyn Bragg for the South Bank Show (see Gardiner [2003] for a comparison of the 1962 and 2002 films). Later Russell also published Elgar: The Erotic Variations (2007), one of a series of four highly fantastical biographical novels on composers. In this book Russell does probe the darker side of Elgar to offer the reader 'the private man revealed by half a century's research and, more importantly, by consulting of the magic crystal ball of his music' (Russell 2007b: 8).
} 
Russell's dissatisfaction with Elgar was a turning point. After that film 'I decided to dispel the preconceived idea of what a documentary had to be by presenting the life of a great artist in a way that showed how he transcended his own personal problems and weaknesses in creating great art. Showing the personal struggles out of which an artist's work grew is more of a tribute to him than making believe that he was some sort of saint sitting quietly in his studio creating masterpieces' (quoted in Phillips 1979: 43). Russell's subsequent films for the BBC reflect this new attitude. It was not always appreciated. As John Baxter perceptively observed, 'there is an element of shock in the response to Russell's subsequent Monitor films, which reject Elgar's romanticism for a new sparseness. Seduced by the picture of artistic creation it presents, and in love (as he is) with this image of the likeable composer, audiences cannot accept that Elgar is, for all its assurance, a PR job, skirting the unglamorous and, by careful selection, manipulating even the viewers' response to Elgar's music. When, in later biographies, Russell "plays fair", offering an unvarnished portrait of a great artist, the public, comparing this unflattering image with the apparent accuracy of Elgar, criticise Russell for falsification, and the implication of betrayal figures increasingly in all comment on his work' (AT 19). One such criticism was launched by Pauline Kael, who had a chronic and deep-seated dislike for anything with Russell's name on it. Discussing Savage Messiah she sneers that Russell's films 'are preceded by puffery about the biographical research and the authentic incidents. But he removes those incidents from their human context: the attraction for him and for the audience is the porn of fame' (1976: 50). While one might take issue with the dismissive tone of Kael's observation it is certainly true that the approach and tone of Russell's films changed dramatically after Elgar. His films became more experimental, they were increasingly dramatised with actors, their tone became less reverent, and they rapidly moved away from any traditional concept of the documentary. Of course, this last element had already been achieved by Elgar itself, which is a reenactment of scenes from the composer's life. But subsequent films would push the formal changes even further. At the same time, however, they also increasingly questioned popular assumptions about the artist and his work.

From a formal perspective The Debussy Film is Russell's most radical departure. As was already discussed in Chapter One, the film is structured in embedded narrative layers organised around the conceit of a film crew making a documentary film about Debussy. ${ }^{158}$ This structure allowed Russell to make a number of comments on the documentary format as it was championed at the BBC and particularly on Monitor. Russell

This obviously echoes Russell's argument from Mahler that one can know the person of the artist best through his work.

${ }^{158}$ See above, section 1.3.2.1. 
later explained that the self-reflexive structure of the film 'allowed me to interpret, or "conduct" the subject of Debussy. Any one of a number of interpretations of the subject can be just as valid as another, I suppose' (quoted in Tibbetts 2005a: 84). If documentary orthodoxy argues that the facts are of tantamount importance to the biographer then this film suggests that the only certain claim we can make about Debussy is that, as it is also said in the film, 'it seems he was a musician': all the rest is interpretation, reconstruction, and guess-work. This was a radical statement. Russell later told John Baxter that 'Wheldon didn't dig The Debussy Film. He thought again that I had made up some of the more fantastic details, until I showed him some original photographs to prove my point. Of course the most fantastic things were always accurate, because they were probably the reason for the artist's unique greatness in the first place. Huw insisted on having these photographs as a prologue to the programme "to prove that it's true"' (AT 116). Wheldon confirmed this with the argument that having been deceived, the audience always wonders when seeing anything else whether it is being deceived again. That is why I insisted on the stills being included at the beginning of The Debussy Film and that the commentaries of Ken's films include assurances that certain events actually happened' (quoted in AT 123). Both these accounts suggest that The Debussy Film came about quite easily and that the main issue was about maintaining clarity about the line between fact and fiction. But Melvyn Bragg, who had started working on Monitor in 1964 as Russell's assistant and co-wrote The Debussy Film, remembers it very differently and believes that Wheldon only allowed the film to be made because Elgar had been so successful. But when he saw the finished film in a screening room 'he leaped from the front row, turned round and said, "I will never show this!" You've no idea of the venom. It was barrack-room language. It was actually trench language. We had betrayed the basic idea of truth to the artist' (quoted in Ferris 1990: 161-162). But for Russell The Debussy Film provided a formal solution to the problem of "truth to the artist" through the device of the embedded narrative, which opened the door to a completely dramatised presentation that also allowed him to question the biographical form itself. This happens for example in a scene where the director, who also plays Pierre Louÿs in the film-within-the-film, 'discusses aspects of Debussy's life with the lead actor (Oliver Reed); and he frequently poses problems which any maker of biopics must solve. "I don't know how to work it in. Gide, Oscar Wilde, Mallarmé, Rodin, Manet - all interacting, all so complicated... There is so little evidence of what really happened"' (Gomez 1976-77: 39). The biographer is constantly interpreting and filling in such gaps. Or as Russell advised his own biographer: 'When you are writing a biography and you don't have all the facts - make it up!' (quoted in Sutton 2012: 4). Clearly, for Russell this is not a betrayal of either the artist or truth: it is what he has come to perceive as the essence of 
the art of biography. Every biographer constructs his subject from the scattered traces that we call, as if to reassure ourselves, the evidence.

\subsubsection{Against Naturalism}

In a discussion of Elgar John Tibbetts quotes an internal memo from Humphrey Burton, the film's producer, stating that the BBC would be willing to consider abandoning 'the straightforward documentary approach for something like a feature film' (quoted in Tibbetts 2005c: 162). This is remarkable because it suggests that Russell's relatively swift progression from his early shorts to full-length dramatised films like Elgar and The Debussy Film was not entirely a struggle uphill. Things were changing at the BBC, and not only in the documentary department. This was for a large part due to the influence of Hugh Carleton Greene, the BBC's new Director General who would remain in function until 1969 and who was an outspoken advocate of innovative television. ${ }^{159}$ This was especially obvious in the Drama department, for while Russell was pushing his documentaries towards dramatised documentaries in the shape of what we would now call feature films a new generation of playwrights and directors in the BBC's Drama department were also abandoning the traditional visual language of television drama, which was heavily indebted to theatrical conventions, and pushing towards what was called the "documentary drama". This trend came to a head with Ken Loach's Up the Junction (1965) and Cathy Come Home (1966). The previous year Peter Watkins had already made Culloden (1964), which staged a historical battle in cinéma vérité style. All three of these films, and many others besides, used techniques from the cinema, and especially the French New Wave and American direct cinema, to increase the realism of the narrative. Drama evolved towards the condition of documentary. At the same time Russell took the opposite direction: his documentaries evolved towards the condition of drama. In this section I want to compare developments in Russell's work to the developments in drama to find their common ground and gain a deeper understanding of what was happening. To do this I will briefly sketch the changes in drama at the BBC in the early 1960s and compare the experiments of Ken Loach in drama with those of Peter Watkins and Russell in documentary.

\footnotetext{
159 The 1960s have been described as a "Golden Age" of British television, partly because, 'whatever the contradictions of management, Hugh Carleton Greene's tenure of the Director-Generalship of the BBC from 1960 to 1969 does seem to have been marked by a greater sense of risk-taking - of testing boundaries and giving creativity its head - than any other regime before him and than most regimes which followed' (Caughie 2000: 78).
} 
Although there is no clear-cut line between dramatised documentary and documentary drama (especially if one looks at any practical example) there is nevertheless a subtle difference. ${ }^{160}$ Dramatised documentary 'begins with a documentary base or core and uses dramatisation to overcome certain limitations and to achieve a more broadly popular and imaginatively powerful effect' (Corner 1996: 34). As early as 1946 a Dramatised Documentary Group had been created at the BBC 'to reconstruct, in the studio, stories, events and situations which were difficult or impossible to achieve in the real world because of the limitations of the cumbersome technology in use at the time' (Cooke 2003: 50). ${ }^{161}$ Documentary drama, on the other hand, 'is essentially a form of play, but a form which is seen to develop a documentary character either as a result of its scale of referentiality to specific real events (private or public or both), or because of its manner of depiction' (Corner 1996: 34). The movement towards documentary drama in television was given a creative boost through the influence of a new movement in British theatre, triggered by the premiere of John Osborne's Look Back in Anger in May 1956. Because of its concern with everyday situations that were often taken from working class life this new drama was called "kitchen sink" drama. It galvanised British theatre and quickly made its impact on the cinema. ${ }^{162}$ Television followed suit. The twice-weekly serial Emergency - Ward 10 (ATV, 1957-1967) was perceived as a "documentary drama", as was Granada's hugely successful soap series Coronation Street (first broadcast in 1960), which was initially considered an example of "kitchen sink" drama due to its working-class setting. ${ }^{163}$ It is also interesting that a police series such as $Z$ Cars (19621978) was originally developed within the BBC Documentary Drama Group, which had previously (and significantly) been called the Dramatised Documentary Group, highlighting the overlap between the two genres. ${ }^{164}$ The creative team behind $Z$ Cars were very concerned about getting details of police work and social environment right. Director John McGrath later said that 'the series was going to be a kind of documentary about people's lives' and that the police stories 'were the means of finding out about people's lives' (quoted in Cooke 2003: 57). ${ }^{165}$ Because the series also featured critical and negative

\footnotetext{
${ }^{160}$ Corner (1996: 34-43) discusses the differences and overlaps between the two modes.

${ }^{161}$ Of course, dramatised documentaries were not a new phenomenon: Georges Méliès had created 'reconstructed newsreels' as early as 1897 (Hammond 1974: 34). In fact, with his 1900 film on the coronation of Edward VII Méliès anticipated the news by creating 'a newsreel reconstructed before the event' (o.c. 53).

${ }^{162}$ Hill (1986) is the classic discussion of British realist cinema in the late 1950s and early 1960s, focusing on the social problem film and the New Wave of "kitchen sink" realism. He also shows that many of the social problem films of the period had a much less progressive outlook (on class, race, or gender issues) than is often assumed and interestingly highlights the repeated representation of Teddy Boys as a kind of "folk devils".

${ }^{163}$ See the discussion in Cooke (2003: 32-37).

${ }^{164}$ See Corner (1996: 38).

${ }^{165}$ See Cooke's (2013) interview with McGrath, where Z Cars is also discussed.
} 
portrayals of the police it has been seen as marking the beginning of 'the era in which the $\mathrm{BBC}$ was to gain a reputation for controversial, anti-establishment, socially conscious drama' (o.c. 58) made from 'liberal or left-wing perspectives that involve a critique of the status quo' (Hill 2013a: 107).

The programme most directly associated with "kitchen sink" drama at this stage was ABC's Armchair Theatre. This was due to the influence of its producer, Sydney Newman, a Canadian who championed the work of playwrights such as Alun Owen, Clive Exton, and Harold Pinter on the programme. ${ }^{166}$ Eventually Newman was lured to the BBC, where he was made Head of Drama in 1963. It was during this period that "kitchen sink" drama made its most lasting impression on television through the plays staged on The Wednesday Play, which was broadcast from October 1964 until October 1970 (when it was changed to Play for Today). Newman was a great supporter of The Wednesday Play, which became very successful both in the ratings and with critics. Nevertheless, because of its cost and its often controversial content its position within the $\mathrm{BBC}$ was always embattled at best. ${ }^{167}$ But despite these internal struggles The Wednesday Play has become ingrained in public consciousness as the flagship of the BBC's "radical" attitude in the 1960s. ${ }^{168}$ Several plays featured on the series were highly controversial because they tackled topics that were at the front of the news at the time. But not just the choice of topics was controversial, the way they were dramatised was equally unorthodox. It should be remembered that in the early 1960s most drama was still either broadcast live from the studio or pre-recorded in the studio. This was due to the technical limitations imposed by the electronic studio and the use of videotape, which was very difficult to edit with precision. As Ken Loach later said, 'cutting tape in 1965 was like building Stonehenge' (quoted in o.c. 73). ${ }^{169}$ And because the electronic studios represented a huge financial investment producers and directors were discouraged from abandoning them in favour of location work on film. The usual procedure for

\footnotetext{
${ }^{166}$ Cooke (2003: 37-48) discusses Armchair Theatre and its innovations. Wheatley (2007) examines its relation to "kitchen sink" drama while Shubik (2000: 3-40) offers an often candid look behind the scenes at her work with Newman (she was story editor on the show). Lamb (2014: 362-366) surveys the production practices of the Armchair Theatre single plays, especially their use of camera movement.

${ }^{167}$ MacMurraugh-Kavanagh (1997a) discusses the tenuous position of The Wednesday Play at the BBC. Philip Purser, writing in the Sunday Telegraph in 1967, expressed his concern over 'the Red Wing of the Wednesday drama department' (quoted in Hill 2013b: 130).

${ }^{168}$ Caughie (2000: 57-87) provides an illuminating discussion of the various factors that went into producing the "Golden Age" of British television and its radicalism. Drawing on converging movements in literature, the theatre, and cinema, but also American social-realist television drama of the 1950s (an important precedent for Armchair Theatre) and the influential 1960 Pilkington Report (which was instrumental in the decision to grant a third channel to the BBC rather than to ITV, thus creating BBC2) his discussion offers a rich context for Newman's work on Armchair Theatre and later The Wednesday Play.

${ }^{169}$ See Barr (1996: 64-65) on the difficulties of editing videotape.
} 
drama would be that several video-cameras filmed the performance in the studio from different angles and that the vision mixer, controlling all these images, would switch from camera to camera during broadcast. This required a tightly rehearsed choreography of actors and cameras. It was possible, however, to mix in pre-recorded sequences that had been shot on location and on film. Such pre-recorded sections would often allow the actors in the studio some time to change costume or move to another set during the live broadcast. ${ }^{170}$

All of this would change in the 1960s. The main catalyst was the publication of an article by Troy Kennedy Martin, the writer who had developed $Z$ Cars, in the March 1964 issue of the theatre magazine Encore. In 'Nats Go Home: First Statement of a New Drama for Television' Kennedy Martin attacked what he called the dominant naturalism in television (hence Nats in the title). ${ }^{171}$ In retrospect this may seem bizarre because the innovations in television drama of the 1960s are usually described as a movement towards increased realism. But in 1964 the term "naturalism" had a very specific meaning in the context of television and it had nothing to do with the naturalistic movement in the arts and literature of the nineteenth century. In television naturalism referred to studio-bound drama that operated according to conventions that were modelled on the theatre. These included a reliance on dialogue, resulting in drama filmed as a succession of talking heads, and a drama that unfolded in natural time and where, according to Kennedy Martin, 'studio-time equals drama-time equals Greenwich Mean Time' (quoted in Hill 2007b: 52). Kennedy Martin urged television drama to free itself from these restrictions. It should instead be filmed on film and on location; it should abandon the reliance on the close-up for filming dialogue; and it should pursue subjective identification with the characters. In terms of plotting this meant that the unity of time and place should be abandoned "in favour of "non-Aristotelian" forms of episodic narration simi-

\footnotetext{
${ }^{170}$ Jacobs (2000) is definitive on the methods and aesthetics of early British television drama, reconstructing lost material from written documents and other archive material. See also Cooke (2003: 6-55) for a discussion of early television drama. Caughie (2000: 37-56) provides some fascinating backgrounds and highlights (o.c. 44-45) the centrality of the actor/performer in live television drama (as opposed to the director's centrality in pre-recorded drama). More recently, Bignell (2014) provides a wide-ranging discussion of the cultural position of The Wednesday Play that takes in production restraints, the combined use of the electronic studio and location filming, institutional pressures, and social response to the plays. Byard (2014) expands the discussion on the hybrid combination of studio performance with filmed inserts and stock footage to children's television of the early 1950s while McNaughton (2014) comments on a short-lived but interesting experiment that combined multi-camera as-live studio production with output direct to film (which could then be edited), following a process introduced in the United States of America by Lucille Ball. In the context of "radical" drama, Smart (2013) discusses the case of the BBC production of Brecht's The Life of Galileo (1964; directed by Charles Jarrott), which made the apparatus of the electronic studio visible as part of its distancing strategies. See also Hill (2007a) for the role of the Langham Group in the exploration of new forms of drama.

${ }^{171}$ See Hill (2007b) for a full discussion of Kennedy Martin's seminal article.
} 
lar to the eighteenth-century picaresque novel' (o.c. 53). Kennedy Martin especially recommended the use of a narrator as a means of both eliminating dialogue and increasing the flow of the action. Such methods of film-making would take television into the realm of cinéma vérité and direct cinema. In cinéma vérité the presence of the camera and the intervention of the camera crew and director are acknowledged, which means that the presence of the film crew becomes part of the "evidence" or vérité that the film reveals. Because the presence of the camera and film crew necessarily influences the "reality" that is being shown ${ }^{172}$ such an acknowledgement of their presence in the film itself contributes to its truthfulness. Direct cinema, on the other hand, 'tries to render the film-making itself invisible and to give viewers the sense of unmediated access to the contingencies of an actuality uncompromised by the camera' (Corner 1996: 44). Direct cinema approaches were especially typified in the work of American directors such as Frederick Wiseman and Don Pennebaker. It is the so-called "fly on the wall" approach. But in practice it is often difficult to distinguish clearly between cinéma vérité and direct cinema because it is not always easy to determine what counts as acknowledging the camera or the presence of the film crew. Most critics agree, however, that the less selfreflexive direct cinema method was 'the primary model' (o.c. 45) for the new British television drama.

It was this new kind of drama that The Wednesday Play would come to represent. And its most important director would be Kenneth (only later abbreviated to Ken) Loach, whose directing credits for the programme included three of its most controversial pieces: James O’Connor's Three Clear Sundays (7 April 1965), Nell Dunn's Up the Junction (3 November 1965), and Jeremy Sandford's Cathy Come Home (16 November 1966). ${ }^{173}$ The first was a piece against capital punishment and was widely perceived as partisan in its attitude, supporting new legislation to abolish capital punishment which was then being discussed in Parliament. More controversially, Up the Junction contained a harrowing representation of a backstreet abortion and was again widely perceived as a play designed to gain public support for liberal changes to abortion legislation that were being debated at the time. Finally, Cathy Come Home would become the

\footnotetext{
${ }^{172}$ In fact, the entire question of "reality" is moot. In his discussion of the 'Drama-documentary' on television Raymond Williams already pointed out that 'some of the complaint about "confusion between reality and fiction" is naive or disingenuous. This attempt to hold a hard line between absolutely separated categories seems to depend on a fiction about reality itself. It depends also on the convention that "factual" television simply shows, neutrally, what is happening' (2003: 71).

${ }^{173}$ Hill (2011) includes a broadly contextualising analysis of Loach's work for The Wednesday Play. See also Hill (2007b) for a detailed discussion of the six-part Diary of a Young Man (1964), which introduced some of the plays' innovations in an earlier programme. See also Cooke (2003: 64-75) for a discussion that focuses especially on Up the Junction.
} 
most famous of all the Wednesday Plays. It was a play about homelessness and the dramatic failure of the social services to address the problem adequately and humanely. The play was 'instrumental in developing public awarenes of the problem of homelessness' (Corner 1996: 90). ${ }^{174}$ But it was precisely the plays' social engagement that made them a source of concern within the BBC. The Wednesday Play was regularly accused of interfering with politics and public policy, and this was obviously in conflict with the BBC's commitment to neutrality. Loach later explained that 'we were very anxious for our plays not to be considered dramas but as continuations of the news' (quoted in Cooke 2003: 73). The fact that The Wednesday Play was broadcast immediately after the news and before the current-affairs programme Twenty-Four Hours 'offered the opportunity to exploit the "flow" 175 of television to set up a kind of internal dialogue between purportedly "factual” and "fictional” programming' (Hill 2011: 67). The Wednesday Play was in fact a concerted attempt to convert "drama" into "news". ${ }^{176}$ This was also the reason why the directors preferred to work on $16 \mathrm{~mm}$ film stock: $35 \mathrm{~mm}$ was used for fiction, $16 \mathrm{~mm}$ was used for news (because $16 \mathrm{~mm}$ equipment was much easier to handle on location). ${ }^{177}$ Working on $16 \mathrm{~mm}$ would allow Loach, but also other directors, to achieve a visual immediacy that was 'an important part of the strategy of convincing viewers that what they were seeing was authentic' (Cooke 2003: 73).

But it was not the only strategy. Not content to simply shoot on location, Loach would mix his actors with real people. These could either be non-actors hired to more or less play themselves, but just as often it meant that the actors would perform in a public place amid unsuspecting passers-by. Sometimes an actor's actions would be edited together with 'semi-documentary footage of real people apparently engaged in their normal activities' (Hill 2011: 32) and in the case of Three Clear Sundays a woman who had been filmed without her knowledge while buying from a stall wrote to the BBC after the

\footnotetext{
${ }^{174}$ The intentions behind these socially engaged plays sometimes backfired as viewers tended to interpret the events within their own moral frame of reference. The distressing abortion scene in Up the Junction was interpreted by some conservative viewers as just deserts for the girl's promiscuous lifestyle. Similarly, John Hopkins's play Fable (27 January 1965; directed by Christopher Morahan) was an indictment of apartheid and racial intolerance which used the ingenious strategy of showing a hypothetical Britain in which black oppresses white. Incredible as it may seem, some viewers interpreted the play as a warning about the dangers of immigration. MacMurraugh-Kavanagh (1997b) provides a very perceptive analysis of the way The Wednesday Play tried to intervene in public debates and how these strategies sometimes produced unexpected (and counterproductive) results.

${ }^{175}$ The reference here is obviously to Williams (2003: 86-96).

${ }^{176}$ See the discussion by MacMurraugh-Kavanagh (1997b). The concern within the BBC over the plays' social engagement could even lead to programmes being cancelled or directors not being called back for further work. John Hill (2013b) has discussed left-wing director Roy Battersby's struggles with the BBC in this respect. ${ }^{177}$ See Sexton (2003) on the introduction of $16 \mathrm{~mm}$ equipment in broadcasting and its effect on the ontology of liveness, which shifted to a concern with "immediacy".
} 
broadcast to claim payment for her participation in the film. ${ }^{178}$ During conversations filmed in the street, with traffic and pedestrians passing by in front of the actors and obscuring our view, 'the position of the camera and its vantage-point suggest that the action has been "captured" on film in the manner of documentary even though the conversation (if not the traffic) has been specifically "staged" for the camera. A similar effect is achieved [...] when - apparently real - people walk across the screen and momentarily look at the camera as if only just realising that filming is occurring. Whereas such occurrences (or apparent "mistakes") would normally be edited out of a work of fiction, they are here preserved as a means not only of suggesting a kinship with documentary shooting but also as a way of reinforcing the verisimilitude to which the “staged" images lay claim' (o.c. 33). The result is 'an unpolished style of camerawork that gives the impression that events might actually be "happening" rather than being specifically "staged" for the camera' (o.c. 39), with the camera 'struggling, as in observational documentary, to capture what is happening' (o.c. 57). Another way to achieve verisimilitude, and especially to pull the viewer into the characters' subjective experience of the world, was to fracture the narrative thread and present an impressionistic series of loosely connected scenes. Discussing the use of this technique in Up the Junction Loach explained that 'it was meant as a kaleidoscope of fragmented images. The idea of a story that is complete and resolved and too well worked never feels right to me because it doesn't have any loose ends. It's just phony; life is full of loose ends' (quoted in Cooke 2003: 70).

Perhaps the most radical use of vérité and direct cinema techniques on television could be found in the documentary work of Peter Watkins. Like Russell, Watkins was brought in at the BBC by Wheldon on the strength of his early shorts. But where The Wednesday Play focused on contemporary issues, Watkins's two signature films for the $\mathrm{BBC}$ addressed contemporary concerns through the past and the (hypothetical) future. In Culloden (1964) he used both cinéma vérité and direct cinema techniques to reconstruct the 1746 battle at Culloden as if a camera had actually been present. One of the film's most startling devices is to let the participants in the battle address the camera and an (unseen) interviewer directly as if a film crew were actually on the scene in 1746 . Combined with shaky hand-held camerawork that takes us into the heart of the action the effect of this direct cinema approach is (still today) staggeringly persuasive. ${ }^{179}$ In The

\footnotetext{
${ }^{178}$ This anecdote is reported by Hill (2011: 32-33).

${ }^{179}$ Jamie Sexton has suggested that Culloden's direct cinema approach of a historical battlefield might have influenced Loach's films because 'this was a "documentary" that smuggled in elements of "drama", a process that Loach and [story editor Tony] Garnett would reverse with Up the Junction' (2003: 443). See Cull (2001) for the production history and reception of Culloden.
} 
War Game (1965) Watkins looked at the future and presented a hypothesis about the possible impact of nuclear warfare on Britain's population. Of course, both films were meant as comments on the present: they were pacifist tracts. This was especially obvious in the case of The War Game. Based on broad research into the effects of nuclear warfare this hypothetical documentary shows what could and probably would happen if enemy forces struck at Great Britain with nuclear arms. It shows the effects of impact and of radiation, the long-term devastation of the country, the physical degeneration of people exposed to radiation, and the complete social disintegration that ultimately follows. To achieve this Watkins again took his $16 \mathrm{~mm}$ camera into the action, creating shaky hand-held images. As in Culloden he uses amateur performers to great effect, especially in their direct address of the camera in staged interviews. These are juxtaposed with authentic street interviews showing that the British public of 1965 was indeed completely ignorant about the dangers of nuclear radiation. This was Watkins's initial reason for making the film: he wanted to shock the public into awareness and believed the public would support a ban on nuclear weapons if it were properly informed about the nuclear threat. This partisan agenda, combined with the callous way in which government officials and representatives of the Church are represented in the film, made The War Game highly controversial within the Corporation and the film was banned, which in itself also caused controversy. ${ }^{180}$

\footnotetext{
${ }^{180}$ Many conspiracy theories have circulated about the War Game ban. The main reason for the ban that was communicated to the public was that the film was simply too horrific for broadcasting and that it might frighten (and even literally scare to death) the elderly or the feeble-minded. It is clear that such arguments are 'flimsy in the extreme' (Chapman 2008: 111). John Corner has suggested that, in the unease that such diverse films as Cathy Come Home and The War Game generated, 'anxiety over the substance of what was "said" became displaced into claims about deceit in the "saying"' (Corner 1996: 41). Troubled by the political implications of the films, but unwilling to appear to be censoring the films for such reasons, the films' "style" (their horrific realism or their mixing of fictional and factual methods) was given as the reason for dismissing them. This would mean that 'behind some of the apparent concern expressed about hybrid forms lies the straightforward objection to views being aired which run counter to dominant dispositions and politics' (o.c. 43) and that the objections are therefore 'made from a position of strategic bad faith' (o.c. 41). John Hill (2013b: 133134) shows that a similar bad faith was suspected behind decisions not to broadcast work by left-wing director Roy Battersby. Since the 1990s written BBC archives have become available and research there has shown that, although the BBC conferred extensively with Government, the ultimate decision to ban The War Game was the Corporation's. Briggs (1995: 531-536) incorporated some of this material in his official history of the BBC, but Chapman (2006) now provides a balanced and persuasive argument against an organised coup on the film while at the same time presenting a wealth of unsettling evidence on the negotiations and machinations that lead to the ban. Wayne (2007) offered a strong rebuke and revived the conspiracy theory by putting the ban on the film in a longer history of BBC censorship. But Chapman (2008) provides a thoughtful rejoinder that undermines several of Wayne's arguments. Shaw (2006) covers some of the same ground (leaning towards conspiracy), including the film's pre- and post-production troubles, but adds an extensive discussion of its subsequent role as an iconic document and cause célèbre in the movement for nuclear disarmament. See Gomez (1979) for a general assessment of the first two decades of Watkins's troubled career.
} 
If we now situate Russell's work in relation to the experiments of Loach (in drama) and Watkins (in documentary) an interesting dynamic emerges. What connects both movements (of documentary towards drama and the reverse) is the rejection of an established form of naturalism. In Russell's case the established norm is the truthfulness of verifiable facts as an expression of the BBC's adherence to objectivity. As we saw earlier, Russell opposed this factual approach to truth with a form of experiential truthfulness that found its fullest formulation in his notes on Mahler, where he argues that the only way to know the artist is through one's personal response to his work. ${ }^{181}$ In the case of drama, however, the established naturalistic convention was not about the presentation of facts but about an established visual code based on the conventions of the theatre. According to its proponents the direct cinema approach, including elliptical editing and fragmented narratives, was much more true to the actual felt experience of life. Hence, this approach was more naturalistic (in the sense of "reflecting the way things actually are") than the established convention. Discussing his methods in a 1982 interview Watkins said that 'I feel that the basic Hollywood narrative structure is totally antithetical to the way we experience life. We don't experience things in sync; we don't think in sync. Our bodies may go through a basic rhythm during the day, but we certainly don't do so inside, particularly inside our feelings. We can look at someone and be thinking about something else. You can be hearing something, but seeing something else, etcetera, etcetera. Your thoughts can be a mixture of past, present, and future, all in a highly complex individual pattern' (quoted in MacDonald 1982: 51). It would seem, then, that the opposite movements of drama towards documentary and of documentary towards drama are different ways of asking similar questions about the representation of the world. Rather than an outright attack on naturalism, as the title of Kennedy Martin's article suggests, the real stake would seem to be a conflict about what "naturalism" or "realism" or "truth" or "objectivity" (can) actually mean and how such possible meanings can (and should) be translated into a (tele)visual language.

\footnotetext{
${ }^{181}$ Interestingly, around the same time Watkins made a highly celebrated biographical film on Edvard Munch (1974), and he also said that a primary level of his film came from 'my own feelings, twisting in and out of what I perceived to be Munch's feelings. Or rather, let me say, I never tried to make decisions about what Edvard Munch "felt" - at a very early stage, I realised the utter futility (and arrogance) of this - instead, I tried to fuse my feelings about my childhood, my own sexual experiences, my own work, into a recreation of various events that occurred to Munch' (quoted in Gomez 1976-77: 43). Behind this approach lies the conviction that no truly "objective" presentation of facts is ever possible. It is worth recalling Russell's claim, already quoted above, that 'any one of a number of interpretations of the subject can be just as valid as another, I suppose' (quoted in Tibbetts 2005a: 84). Or, as one critic points out in a profile of Watkins, the presence of bias or perspective is not in itself the problem, 'the trick is to not disguise the nature or articulation of bias' (Arthur 2004: 63).
} 
For the new generation of television directors of the 1960s realism, to feel real, required a subjective slant, whether it was Loach's socially conscious drama, which Sydney Newman championed as a form of 'agitational contemporaneity' (quoted in MacMurraughKavanagh 1997a: 376), Watkins's 'purposely inconvenient cinema' (Arthur 2004: 58), or Russell's subjectively felt experiences of the artist's life in the work. What is at stake in each is the status of reality, and especially the (tele)visual language that will allow the filmmaker to convey "his" (view of) reality to the spectator. At this point it is good to remember the influence that the Free Cinema, a documentary movement in British film of the 1950s, had upon these developments. In its statement of intent (drafted, among others, by Lindsay Anderson) the Free Cinema claimed that 'an attitude means a style. A style means an attitude' (quoted in Sinker 2004: 82). This holds no less for Russell (who saw himself as completely opposed to the Free Cinema) than it holds for "engaged" filmmakers such as Loach and Watkins. Loach wants to convince people that what they see is, if not factual, then at least authentic and truthful. That is why drama must be made to resemble the news. Russell, on the other hand, wants to make his documentaries look less like the news because he has come to believe that a subjective interpretation is more truthful, especially in view of the fact that any kind of objectivity is always merely one perspective on the world. And Watkins needs to be openly partisan in his dramatised reporting on past or possible future events because he feels that this is the most efficient way to deconstruct official accounts of "reality" and give the public the information (about nuclear or other warfare) that it needs for considered judgement but which the government is withholding. Although these three highly individual approaches to truthfulness may be mutually incompatible they do share a resistance to established visual codes and narrative practices. All three would argue that there is no single "objective" truth because any supposedly "objective" account only offers one facet of a complicated whole. That is why "official" truth always needs a subjective corrective. This corrective can be as radically free as Russell "feeling" his way through an artist's biography or as militantly agitational as a tract on nuclear warfare, homelessness, or abortion. This means that Russell's work occupies a key position to discuss the intersections and ultimately the blurring of the borders between documentary and drama. His work (but certainly also that of Peter Watkins) should therefore be at the heart of discussions both of documentary and of drama at the BBC. ${ }^{182}$

\footnotetext{
182 This is rarely done, although Sexton (2003: 443) and now Hill (2015) are exceptions and, interestingly, Roy Armes had already brought Russell, Loach, and Watkins together in a perceptive chapter on 'An Art of the Real' in his Critical History of British Cinema (1978: 300-314). Nevertheless, histories and discussions of BBC drama (Caughie 2000; Cooke 2003; but also Hill 2011 on Loach) either do not mention Russell at all or only in passing, while histories and discussions of the arts documentary (Walker 1993b; Wyver 2007) tend to discuss
} 


\subsubsection{A Poetics of Fact and Fantasy}

It is very instructive to take a fresh look at some of Russell's early Monitor shorts with this background in mind. Elements of the new direct cinema approach to the documentary are clearly in evidence. In this respect it is interesting to recall Russell's feeling that his amateur films were 'hopelessly unfashionable' (BP 16) in comparison with the new "kitchen sink" realism in British cinema at the time. Russell explained in retrospect that 'whereas their approach was rooted in the wartime documentaries of Humphrey Jennings, I was inspired by the bold imagery of Fritz Lang and the surreal world of Jean Cocteau' (1993: 81). ${ }^{183}$ These influences are relevant because Russell's work has always been tinged with elements of fantasy that seem to discount it as a form of realism. But the evidence of the early Monitor films tells a more complex story in which an unmistakable sense for stylised fantasy is constantly wedded to a resolute eye for social realism. Furthermore, if looked at in view of the emergence of the direct cinema style in television drama, it is possible to see similar tensions between bold imagery and "direct cinema" approaches, sometimes even within one Russell film. A good example is Pop Goes the Easel (1962), a forty-five minute Monitor profile film on Peter Blake, Derek Boshier, Pauline Boty, and Peter Phillips, four young British Pop artists who were only just emerging on the scene, and which has since assumed historical importance as an early visual document of Pop Art in Britain. ${ }^{184}$ In this film Russell moves back and forth between dramatised documentary sequences, direct cinema sequences, and sequences that hover poetically in-between. For example, a section of the film follows the artists as

\footnotetext{
Russell without reference to developments in drama. I believe that keeping the lines of communication open enriches our view of Russell and suggests that the distinction between documentary and drama may be up for grabs because, ultimately, everything in television is dramatised to some extent. It is interesting to see, however, that this territorial (or disciplinary) approach to documentary and drama, treating them as two essentially different things, reflects an attitude that was also typical of the BBC itself. When Russell entered the BBC in 1959 the Corporation was divided into so-called "baronies". This meant, in the words of director Tony Palmer, that 'different departments actually assume that different subject matter is their property. You find this consideration dominant inside the BBC' (quoted in Bakewell and Garnham 1970: 139). Drama was drama and not documentary or current affairs, and vice versa. John Hill (2011: 66) points out, for example, that one of the reasons Cathy Come Home was criticised was because the film was made by the drama department rather than as a documentary. In a quaint (but perhaps revealing) way scholarship on British television history seems to mirror such baronial considerations. Russell's work, balanced on the edge between documentary and drama, suggests that we should cross the dividing line, and perhaps even give it up.

${ }^{183}$ Russell has written and talked extensively about the influence on his work of German silent cinema, and especially Lang's Siegfried films, which he would project for neighbours in his parents' garage during the war (see AT 60-62; BP 16-17; but also Sutton 2012: 23-24).

${ }^{184}$ See Brauer (2001: 65-67). Flanagan (2009b) puts the film in the educational context of television's Reithian mission. There is now an excellent detailed analysis of the film by John Wyver (2015) which addresses, among many other things, the film's innovative challenge to explanatory voice-over narration in arts documentaries.
} 
they visit a fairground. There is an unmistakable direct cinema feel in the way the camera tries to keep track of the artists, dodges other visitors, and captures the glare of available light. But this is intercut with highly stylised shots of a Ferris wheel and other attractions that sometimes move towards abstract composition. There is also a direct cinema sequence of the four artists in a shooting gallery. Later Russell contrives a similar vérité-looking set-up with the four of them sitting in a row at slot machines. He then makes the viewer aware of the camera's presence by having each of the artists pull back as the camera makes its way forward between them and the slot machines. It is a nice impromptu invention that looks spontaneous and playful, but at the same time it acknowledges the influence of, for example, Busby Berkeley-like choreography where the camera pushes forward between rows of legs that fan out to let it through. The film's most memorable sequence visualises one of Boty's nightmares in an embedded minidrama in which the artist is chased down a hallway by an evil-looking woman in a wheelchair. ${ }^{185}$ This again stands in counterpoint to other sequences where the artists are observed talking casually amongst themselves. But by combining contrived scenes with direct cinema elements Russell makes us aware that everything in a documentary, including the direct cinema observations, is contrived and staged. ${ }^{186}$

Two other early Russell shorts are of particular interest in this context. One is Shelagh Delaney's Salford (25 September 1960), the other is A House in Bayswater (14 December 1960). Both have complex ties to all the issues raised in the previous discussion of changing attitudes in broadcasting in the 1960s. Let us look first at the profile of Shelagh Delaney, a young playwright who had made a splash with her play A Taste of Honey (1958), which was made into a key film in the new "kitchen sink" drama in 1961, directed by Tony Richardson. In Russell's short film, Delaney is both seen on screen talking and heard talking over a montage of images shot at Salford, where she lived at

\footnotetext{
${ }^{185}$ Wheelchairs are a remarkable recurrent motif in Russell's work. Of an old man in a wheelchair in his earliest extant film, the fragment Knights on Bikes (1956), Russell observes that 'I was on my wheel-chair kick again. Still am, in fact. Even if I don't have a wheelchair in my films there's usually one around the set in which I am pushed about with the camera at some point' (AT 100). A more or less random sampling of wheelchairs in Russell's films would certainly include the 'wheelchair ballet' that was apparently cut from The Boy Friend (AT 34; also Fox 1973: 106), Max Adrian's appearance in a wheelchair in that same film (the chair was required because 'he was simply too ill to dance his way through it'; AT 219), and Russell's own cameo appearance as a paraplegic in a wheelchair in Tommy. Wheelchairs also appear in his autobiography, where Russell connects a visit to the Guggenheim, where he and Viv make a nuisance of themselves by rushing about in a wheelchair, to a wheelchair ride down a street with upcoming traffic during his time at Pangbourne Nautical College (BP 100-101; also AT 70). There are also memories of pushing his grandmother in a wheelchair (BP 263-264).

${ }^{186}$ The following year Russell again enlisted Boty as an actress in an embedded narrative for his film on Bela Bartok (1963), playing the part of a prostitute in Russell's visualisation of a scene from The Miraculous Mandarin in a contemporary setting.
} 
the time. ${ }^{187}$ The film opens with Delaney walking her dog, coming home, and asking whether there is anything to eat. She is then seen talking about her work at the kitchen table. This sequence is obviously staged for the camera, but the kitchen setting clearly connects it to the new realism in which Delaney herself is an important figure. Her statements in the film's commentary, entirely spoken by her, were edited together from several interviews and conversations 'recorded during the course of some days we spent with her in Salford' (Wheldon 1962: 126). ${ }^{188}$ The film's tone connects back to Russell's very first BBC film with John Betjeman as both Delaney's commentary and Russell's imagery combine a focus on the social problems of poverty and housing in Salford with a genuine affection for its working-class milieu, which is now threatened with obliteration through the development of housing estates and tower flats. On the one hand there is dirt, poverty, and a severely polluted river in which children have even drowned because it is not properly fenced off. But at the same time Delaney tells us that the city has 'a terrific life force' and 'it's like a terrible drug', 'it's virile, it lives and it breathes' (quoted in Wheldon 1962: 126-127). Delaney talks about the way parts of Salford are being torn down and their inhabitants forced to move and becoming uprooted. 'They're taken from one spot and put into another spot, into these new housing estates; and these places - they don't look nice to me. I don't think they look at all pleasant. But they're put there. And they're sterile places. Nobody knows anybody' (quoted in o.c. 128). Here we once again see the indictment of the new (brutalist) architecture destroying the soul of a community. This is underscored by the cinematography: magnificently composed shots of rooftops, candid street scenes, river banks, but also the new high-rise. ${ }^{189}$ The film takes social realist themes but presents them in a stylised and aesthetic manner, as a series of images infused with nostalgia for a disappearing world.

\footnotetext{
${ }^{187}$ There is a transcript of the film in Wheldon (1962: 126-130), but it is slightly edited from the film version.

${ }^{188}$ The film has several connections to Russell's other work. First of all, A Taste of Honey was first performed by Joan Littlewood's Theatre Workshop. The film version co-starred Murray Melvin, an actor in Littlewood's company who also became a regular Russell performer, most notably as Canon Mignon in The Devils. Many of the actors in Littlewood's company, who were often non-professional actors, would also become regular performers in Loach's BBC films (see Hill 2011: 31-32). Melvin now fulfils the role of the Theatre Workshop's unofficial (meaning unpaid) archivalist: see the handsome photographic memoir in Melvin (2006).

${ }^{189}$ Russell could indeed find poetry in a high-rise. In his film on Bela Bartok (1963) Russell included two embedded dramatisations of sequences from Bartok's operas. His dramatisation of The Miraculous Mandarin was mentioned in a previous note, but it is interesting to see that he filmed the interiors for his dramatisation of Bluebeard's Castle in New Zealand House, a modern, fourteen-storey high-rise in London, designed by Robert Matthew, the construction of which had just been completed in 1963 (Wright 2006: 61). It housed the New Zealand Embassy. The smooth and (at the time) ultra-modern interiors of the building are used to great effect in Russell's film to suggest a cool, alienating, and frightening world with a futuristic edge. Russell's aestheticised and "poetic" representation of Salford is in line with similar aestheticised approaches to "social realism" in the Free Cinema: compare Hill (1986: 127-129) on the latter.
} 
In comparison A House in Bayswater has both interesting similarities and differences. The film opens and closes with a shot of a building site. A new tower-block is being constructed. It then cuts to an Edwardian boarding house in the Bayswater area of London. Russell himself used to live in that boarding house, and one of the tenants profiled in the film is the photographer David Hurn, a personal friend who would later become the subject of a separate Russell short, Watch the Birdie (1963). The film focuses on several tenants: apart from Hurn there is also a painter, a working class husband and wife, a retired dancer, and a retired maid. Russell moves back and forth between these tenants' flats and stories and uses the narration of the retired woman who runs the boarding house as a framing device. The most interesting part of the film for our present concerns is the last section, when Russell takes us into a fantasy sequence, filmed entirely in slow motion, in which the tenants' fantasies and dreams are presented in a Cocteau-like flow of images that ultimately melt back into shots of a similar old boarding house that is being demolished to clear space for a tower-block. Russell uses a fantasy sequence to comment on the human stories attached to the building, and how tearing down the building also obliterates its memories. This tendency to introduce fantasy into documentary contexts goes back to Russell's photo-essays of the mid-1950s, several of which were constructed around friends dressing up for Russell's camera. ${ }^{190}$ But despite his penchant for fantasy, Russell's most impressive photo-essays already tended to have a social-realist and documentary theme. His most famous photo-essay, for example, was devoted to the Teddy Girls, the female equivalent of the Teddy Boys. 'As far as I know,' Russell later commented, 'I was the only photographer who chronicled the Teddy Girl phenomenon' (quoted in Sutton 2012: 59). It is especially this series of photographs that has earned Russell recognition as 'a transitional figure whose work anticipated elements of the new photojournalism, although his most original photographs involved elaborate, theatrical scenarios' (Harrison 1998: 115). Such photo-essays show that Russell was not as estranged from the new realism that was emerging in the late 1950s as he would have us believe when he claims that his early shorts were simply "old-fashioned". If Russell's own assessment of Free Cinema's glorification of 'Teddy Boys at the Elephant and Castle' (BP 16) is to be taken at face value, his involvement with the Teddy Girls suggests that his own work was not old-fashioned but very much in step with contemporary developments in British film and popular culture. What did set him apart from the main

\footnotetext{
190 The fullest account of Russell's years as a professional photographer is in Sutton (2012: 50-70, 78-97, and 111-118), but see also Rees's (2011) interview with Russell. The director's photography was "re-discovered" in 2005 and the subject of several exhibitions. See Aylot (2005) and Arnold (2006), both with handsome reproductions of a selection of photographs. Nevertheless, Russell's position as a forerunner of the new photojournalism was already acknowledged in Harrison (1998), which is a lavishly illustrated survey of British photojournalism between 1957 and 1965.
} 
line of social realism, however, was his inclination to infuse his documentary work with elements of fantasy and explicit stylisation. This is sustained through many of the early Monitor shorts. But even this does not set Russell dramatically apart from the main line of British documentary. After all, John Grierson, Alberto Cavalcanti, Harry Watt, and Humphrey Jennings, the key figures in the British documentary movement, already made elaborate use of the dramatised documentary form. ${ }^{191}$ Jennings even introduced elements of fantasy in his work. ${ }^{192}$

\subsection{SEE ME, FEEL ME: TRUTH, VULGARITY, AND ART}

Now that we have mapped the context of Russell's formal innovations we can take a closer look at content, and more specifically at the way Russell's ideas on art and artists developed during his time at the BBC. The best way to do this is to show how changes in Russell's ideas were in part a response to contextual challenges: a way of looking for solutions to practical problems. And one of the most startling and perplexing problems

\footnotetext{
${ }^{191}$ Drazin (2011) and Sargeant (2011) discuss the use of dramatisation and studio recreation of documentary sequences in the work of leading GPO Film Unit directors Cavalcanti and Watt respectively.

${ }^{192}$ In fact, the very idea of a "main line" of British social-realist documentary is problematic in ways that suggest how Russell could be considered a part of it. The British documentary tradition is primarily associated with the long legacy of John Grierson, who founded it in the late 1920s. An immediate impetus was the need to address the overwhelming presence of Hollywood-produced films on British screens with 'a responsible and artistically respectable cinema' (Higson 1986: 74). Since Hollywood provided escapist entertainment British cinema would have to respond with an engaged realist cinema (see Street [2009] for a discussion of the 1927 Cinematograph Films Act and its imposition of quota for British films on British screens in this context). Grierson saw documentary films as a means of communication between the State and the (mass) audience. To accomplish this communication he started a film unit that made its best work after it moved to the General Post Office in 1933, since when it has been known as the GPO Film Unit. Although Jennings (along with Cavalcanti) is the most famous director associated with the GPO Film Unit his background before joining it was in modernist art. Geoffrey Nowell-Smith has argued that Jennings 'was disparaging of realism' (1986: 323) and that modernist aesthetics (especially the use of montage) is key to understanding his films. Similarly, although influenced by Grierson, the Free Cinema was not a simple continuation of the GPO approach. Lindsay Anderson embraced elements of the Griersonian doctrine but also stressed the importance of 'personal style and leftist politics,' paving the way for 'a British art cinema based upon radicalism in form as well as in substance' (Hedling 2009: 40). As John Hill points out, 'for Anderson, the key term in Grierson's definition of documentary ("the creative treatment of actuality") was "creative" rather than "actuality"; it was only through "creative interpretation" that documentary was to be distinguished from mere journalism' (1986: 128). All of this means that "realism" was not a clear-cut category by any means in the British documentary tradition and that Russell's imaginative approach was not foreign to several of its key tendencies. The fullest account of the GPO Film Unit is now the volume edited by Anthony and Mansell (2011), but Aitken (2009) is an excellent presentation of Griersonian principles while Higson (1986) is a clearly argued survey of the tradition from Grierson to the Angry Young Men of the 1950s. Nowell-Smith (1986) and McClusky (2011) discuss the modernist strain in Jennings while Hedling (2010) details the subtly shifting attitudes to Griersonianism in Anderson's early work.
} 
that a maker of biopics could confront is if the facts of the life are unavailable to him not because they are unknown but because he is not allowed to use them. This is the problem that Russell faced when he made Isadora Duncan: The Biggest Dancer in the World (1966) for the $\mathrm{BBC}$ (at this point Monitor no longer existed: the film was commissioned for the arts programme Omnibus). Parallel to Russell's film on Duncan the Hakim brothers were producing Karel Reisz's feature film on the dancer, starring Vanessa Redgrave. The Hakims had bought the rights to virtually every book ever written about Duncan, which meant that Russell could not use anecdotes or events that were mentioned in them. Only information that was in the public domain would be available. One ingenious way of dealing with this problem was to engage Sewell Stokes, who had known Duncan towards the end of her life. Stokes had written a book about her, the rights to which were also bought by the Hakims, but since they did not buy Stokes's memory he was still allowed to reminisce on camera. Therefore the film begins (after a newsreel prologue) with Stokes introducing the dancer and her life. But for some of the events in Duncan's life Russell still had to invent fictional alternatives. For example, when Duncan became the lover of sewing machine magnate Paris Singer the latter brought an entire orchestra on his yacht to accompany Duncan's dancing on deck. Unable to use this story, Russell devised the alternative that when she arrived at Singer's mansion Duncan found an enormous golden box which, upon opening, contained six harpists to accompany her. Russell considered this a good example 'of finding a parallel incident which, although it cannot be as good as the truth, has some sort of flavour of the original' (quoted in Gomez 1976: 46).

Although clearly a nuisance, the need to devise alternatives turned out to be a watershed in Russell's work. It forced Russell to create a truthful account of the artist as a person without access to all or most of the elements that make up factual truth. The result in Isadora Duncan was extremely successful, and as Ken Hanke points out, 'with Isadora it becomes clear that fiction firmly rooted in fact can be more persuasive than the fact' (1984: 18). It is here, partly out of necessity, that Russell's signature style of metaphorical hyperbole was born. Unable to show the facts, Russell had to rely on scenes that evoked the facts metaphorically. The solution Russell devised to deal with the challenges of making Isadora Duncan is therefore instrumental to an understanding of the further development of his biographical films after he had already cleared the problem of dramatic re-enactment with The Debussy Film. For the use of metaphor in lieu of a factual account entailed a completely new conception of art and the artist. It is in Isadora Duncan that Russell's own views on art such as we found them expressed in Savage Messiah first come to the fore. Isadora Duncan sketches the dancer's life in bold strokes, focusing on a number of key episodes and emblematic scenes, while devoting much of its running time to an expression of Duncan's artistic ideas through dramatised re- 
enactments of her dance performances. Like Duncan, the film communicates primarily through dance, which takes up a considerable part of its running time. Narrative exposition is therefore sketchy and broad, leaping from key event to key event, using the commentary track to maintain unity and facilitate temporal and spatial leaps. The main goal of the film is therefore not to give us an accurate factual account of Duncan's life and career: it is to make us understand who she was, what she stood for, and to make us enthusiastic for her (ideas on) art. More than just a biography the film is also a celebration of Duncan and her principles. And the celebration is achieved by assimilating some of her ideas into the way the film itself is created. Russell has commented extensively on his intentions in making Isadora Duncan. He later explained that Duncan 'had genuine talent, some mystical insight, but she was a bit bogus as well. She had a touch of vulgarity which I think art and people connected with it could well profit by. [...] She was just a great person and that was her art' (AT 129-130).

Partly out of necessity, yet in line with Russell's developing ideas on art, Isadora Duncan moves towards a connection between art, passion, and (a specific form of) vulgarity. 'God knows what her dancing was like,' Russell told John Baxter. 'Pretty terrible, I imagine. But that doesn't matter. She affected and moved and meant a great deal to a lot of people. Everyone who saw or came into contact with her came away a bit different' (AT 130). In fact, he said, 'she was the art' (quoted in Gomez 1976: 36). Duncan's greatest performance was not her dance but her life. But its meaning was conveyed partly through the passion with which she danced. Duncan performed her life with an exuberance that bordered on the vulgar: she drank too much, had a string of unsuitable lovers and destructive affairs, and organised her dancing lessons around pseudo-mystical invocations of the cosmos. In the film she is shown several times raising her hands to salute the earth, friendship, and the universe. Although much of this could indeed be called 'bogus' Russell nevertheless concludes his observations with a programmatic statement of his sympathy with Duncan and her passion. 'It's strange that people can't reconcile vulgarity and artistry,' he says. 'They're the same thing to me. But don't get vulgarity mixed up with commercialism. By vulgarity I mean an exuberant over-the-top largerthan-life slightly bad taste red-blooded thing. And if that's not anything to do with Art let's have nothing to do with Art. Let's have more of that' (AT 131). This connects back to Savage Messiah. In one of his letters Gaudier wrote that in art one must exaggerate; as the sculptor deepens a depression, or accentuates a relief, so the writer accentuates a vice, diminishes some quality, according to his needs; and it is only here that the imagination comes into play. Grandiosity, sublimity and luxury [...] goes with that necessary exaggeration of the facts which helps to secure greater truth' (quoted in Ede 1931: 89). Grandiosity, exaggeration, and truth are placed in a continuum here. And the way to 
achieve them is made clear in Gaudier's eminently quotable advice to his sister who has taken up drawing: 'Thus - with big strokes, boldly. Don't be frightened, make mistakes, as many as you like, but all the time draw very very strongly' (quoted in o.c. 109). But this is clearly what Russell started doing with Isadora Duncan: taking liberties with the facts, trusting rather upon his instinctive sensing of the person through the work, he drew his artists strongly and boldly, in big strokes and with no fear of mistakes. As Gaudier says, these big strokes imply a form of simplification, the accentuating of one element at the expense of others. But such exaggeration only helps to 'secure greater truth'. ${ }^{193}$

From all the elements that have been introduced so far we can now reconstruct a kind of Russellian practice. Factual truth can only carry us so far. There is, however, another form of truth which can be sensed in and through works of art. The person of the artist does not reside in the external facts of the life but in the form of his or her works. Works of art should therefore be seen as vehicles: they transport intimate knowledge of the artist to the viewer. Art is a medium for communicating intimate knowledge of the self. Art is an emanation of the self, and the receiver can re-activate the person encapsulated in the emanation by immersing himself in it. As the following chapter will show, this takes us into the terrain of Romantic poetics. But at present my main concern is to show where this poetics came from and how one can see Russell move into it in the course of the 1960s. Intriguing-

\footnotetext{
${ }^{193}$ The approach sketched in this section, and especially in relation to Isadora Duncan, almost reads like a textbook case of some of the main issues surrounding historical reconstruction in film. In his classic study of the historical film Robert A. Rosenstone takes the argument even further and claims that 'on the screen, history must be fictional in order to be true' because 'filmic "literalism" is impossible' (1995: 70; emphasis added). After all, a film 'can never provide a literal rendition of events that took place in the past. Can never be an exact replica of what happened (as if we knew exactly what happened). Of course, historical recounting has to be based on what literally happened, but the recounting itself can never be literal. Not on the screen and not, in fact, in the written word' (ibid.). Furthermore, 'film, with its need for a specific image, cannot make general statements [...]. Instead, film must summarise, synthesise, generalise, symbolise - in images. The best we can hope for is that historical data on film will be summarised with inventions and images that are apposite. [...] We must recognise that film will always include images that are at once invented and true; true in that they symbolise, condense, or summarise larger amounts of data; true in that they impart an overall meaning of the past that can be verified, documented, or reasonably argued' (o.c. 71; emphasis added). A film, in this respect not so very different from a written historical reconstruction, must be "true" in its ability to render the meanings rather than the literal reality of past events' (o.c. 133). Recently, Ramirez reiterated this point when he argued that the issue of historical reconstruction on film 'becomes one of plausibility versus ascertained factuality' and that 'the aim of [using] fictional procedures needs not be "to falsify" the past, but rather to exploit the narrative potential of filmic language to the utmost and thus enhance the understanding of the story that is being recounted' (2014: 43). Similarly, Natalie Zemon Davis has come to think of historical film as a "thought experiment" which 'could become both more dramatic and more faithful to the sources of the past' (2000: xi), although she urges every historian who works as a consultant on a film to also subsequently write about the experience to illuminate both the limits and contributions of history on film (2003: 48). In view of such arguments, however, it is baffling that Russell, whose entire output and poetics make these points, is not mentioned by any of these authors. The relevance of Russell's work to Rosenstone's argument was already touched upon in the discussion of the set for The Devils (see section 2.2.).
} 
ly, Russell has demonstrated his poetics. In Russell at Work (Ian Keill, 1965), a half-hour BBC documentary about the making of Isadora Duncan, Russell says that he always begins work on his biopics by listening to the composer's music over and over. We actually see him doing this. Russell draws all the curtains of his living room, extinguishes the main lights, and sits in near-darkness on a chair listening to the music while he gazes intently at an obelisk-shaped lamp whose perforated surface projects patterns of light on the surrounding walls (ill. 13). The documentary is framed at its beginning and end by images of Russell in this position. The whole set-up was of course staged for the camera, and it is irrefutable proof that already in 1965 Russell had become quite aware of his image as a maverick within the BBC, had already developed his ideas about art and what it does, and was already willing and able to perform these ideas for the camera. ${ }^{194}$ Although he looks sober-minded enough when he is on the set (and the candid behind-the-scenes footage of Isadora Duncan shows him as serious and concentrated in his work) Russell is perfectly willing to play the artist as shaman for the documentary.

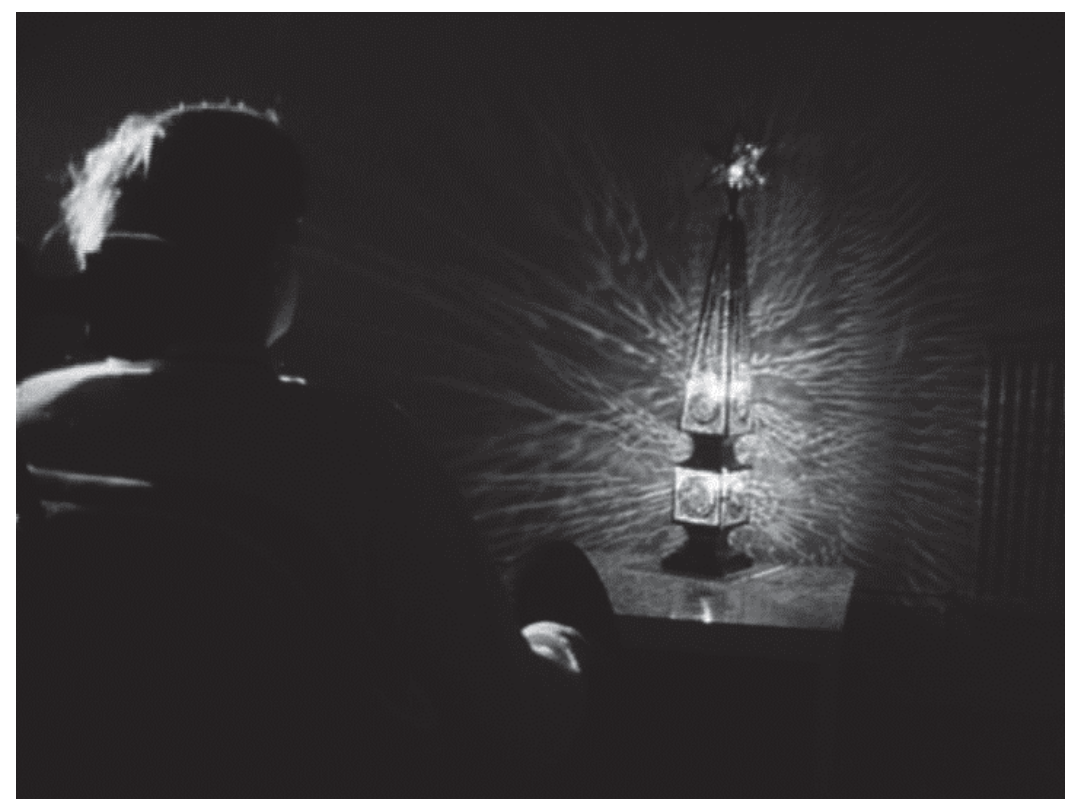

Illustration 13 Russell conjures the muses in Russell at Work

\footnotetext{
${ }^{194}$ Vivian Pickles recalls that Russell consciously changed his behaviour towards the actors when Keill's crew came to film him: 'suddenly it's [...] Ken acting the nice director, going on with this nice dialogue. [...] He must have known that was how he was expected to behave as a director' (quoted in Sutton 2014: 162). This nicely captures an intermediate stage in the evolution of Russell's persona: while he is already performing the role of inspired genius who immerses himself in the work of his precursors he still tries to keep the wilder aspects of his directorial method hidden from the camera.
} 
But the best evidence for Russell's approach is simply to be found in the texture of his films. If we look closely at the way Russell's films are filmed and at the visual grammar they use, it becomes clear that Russell has taken a number of methods from the vérité and direct cinema approaches and welded them seamlessly into a theory of the work of art as the way towards greater truth. According to Russell's approach, the "truth" that documentary seeks to find does not reside in factuality. Real truth lies beyond mere facts: it belongs to the inner self and its experience of the world. In works of art, however, this inner knowledge emerges in an externalised form. As emanations of the self, works of art are also a record of the self. So any documentary that wants to capture truth should not look hard at facts: it should look hard at works of art and try to catch the emanation of truth that they convey. This is exactly what Russell's films attempt: they try to capture in images the elusive insight Russell has felt in the work. But because this elusive something has in turn to be communicated to the viewing audience it must itself again take the shape of a work of art. This means that Russell's films imply a double bridge: first Russell senses the emanation that reaches him from the artist through the work, and then he translates the knowledge thus obtained into a new work of art, in this case a cinematic work of art, that similarly communicates with its audience through expressive form. The goal of this complex structure is to uncover truth, in this case the truth of artistic creation. This is the mystery that Gaudier talks about in Russell's film of Savage Messiah (quoted at the beginning of this chapter). And here Russell's position as a hybrid documentarist comes into play, for one of the central methods he uses to structure his own documentaries is the up-close observational technique of direct cinema. And that is why, ultimately, Russell's dramatised documentaries can still be called documentaries: not because documentaries always use some form of dramatisation, but because Russell's subjective approach reveals a new but for him entirely legitimate form of truth that is an alternative to factual truth. 


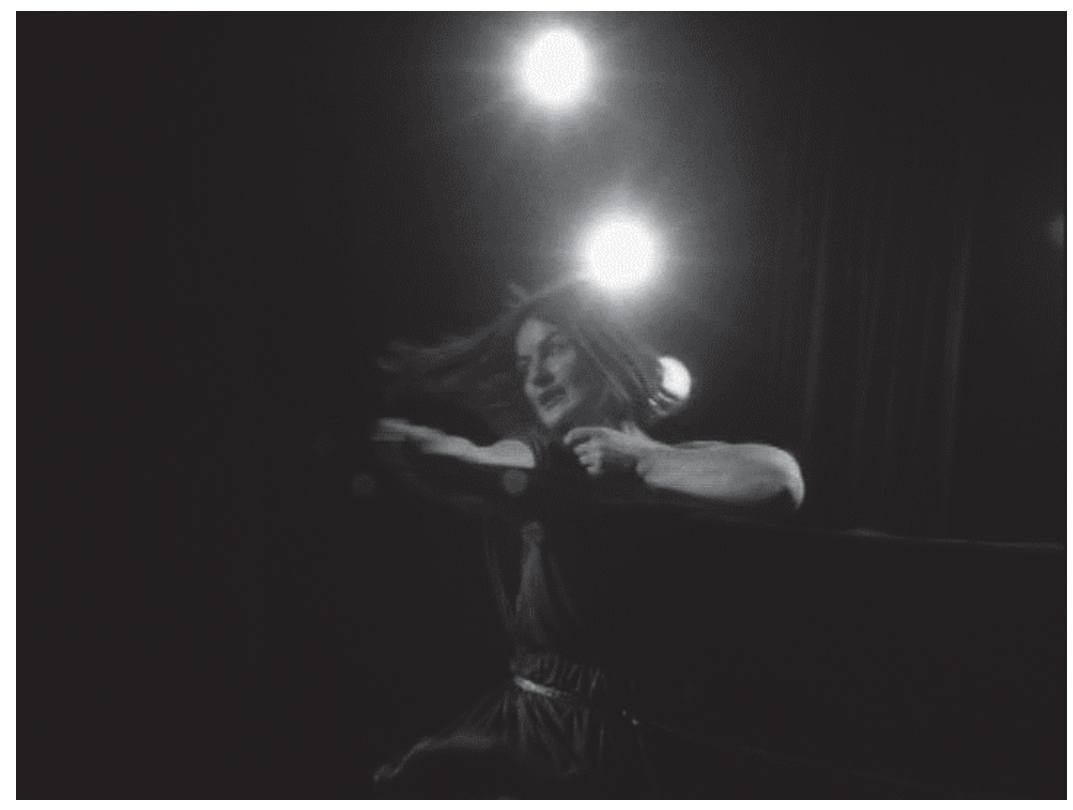

Illustration 14 The sensation of seeing Duncan dance

Let me clarify this with a number of examples. It is appropriate to begin with Isadora Duncan, the film in which these principles are most clearly and in the most straightforward way crystallised. As I pointed out before, much of the film's running time is given to extended re-creations of Duncan's dancing. It now becomes clear that these scenes, while serving no immediate narrative or dramatic purpose, are the heart of the film. First, they represent Duncan's works of art. But as such they also incorporate the essence of Duncan's person. They are the vehicle of the truth that the film Isadora Duncan wants to unveil. But because Duncan's dance died with the artist the success of the film relies entirely on Vivian Pickles's success in replicating something of the thrill of watching Duncan dance. We cannot judge whether Pickles's dancing resembles the way Duncan actually danced. But that is not important: the main thing is that Pickles succeeds in conveying the sensation of seeing Duncan dance (ill. 14). At that point Pickles's artistic creation, which is her work as an actress in this film, becomes a vehicle for Duncan's ideas. So Pickles is not simply required to play the part of Isadora Duncan: her main brief in the film is to capture her spirit by re-creating the experience of Isadora Duncan. It will not do to have Pickles acting in period dress as if Duncan were a character in a costume drama. To really capture Duncan's spirit she must dance. But since her dance cannot imitate Duncan's dance (we don't completely know what it looked like) the only option is for her to dance Duncan's ideas again as if she were Duncan dancing them. 
Pickles literally has to function as the medium for Duncan's ideas through dance. But that is only one side of the story, because this communication of Duncan's ideas through re-created dance next has to reach its audience: the viewers of the film. And here film language plays its part. Entirely in the mode of direct cinema Russell takes his camera right in there with the action. Like Watkins charging into the re-created battle of Culloden with his $16 \mathrm{~mm}$ Arriflex Russell's hand-held camera "follows" the dancing Duncan up-close as she swirls over the stage during several performances. But the purpose of direct cinema is clear: it is to try and get unmediated access to one's subject. And this is what Russell is also doing. As Pickles “channels" Duncan's ideas through dance he takes his camera right in there to try and capture, in as unmediated a way as possible, the emanation of her dance.

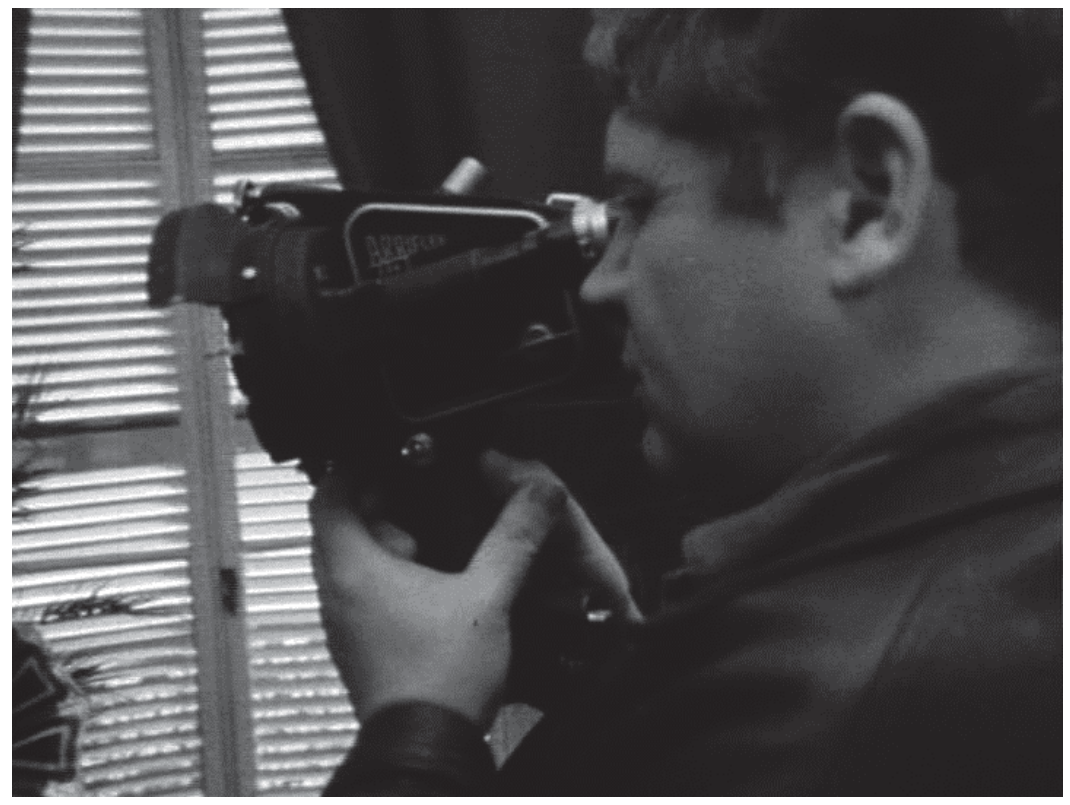

Illustration 15 Getting close to Russell in Russell at Work

It would of course be possible to argue that Pickles could not possibly "channel" Duncan's ideas and that a camera cannot get up-close to a work of art's "emanation": these are just esoteric fabulations, and in elaborating them I have simply been taken in by Russell's own automythography. But this would be to miss the point of my analysis, which is still concerned with Russell's performance of himself. Hence, I am not arguing that Pickles and Russell actually succeed in "channelling" Duncan. Nor am I arguing for a belief in "channelling" or "emanations" or any other more or less esoteric ideas. I am 
simply arguing that this is the way the film's visual language is structured. I am reconstructing Russell's ideas on art as they can be gleaned from the formal characteristics of his films. ${ }^{195}$ This analysis is reinforced by the fact that the direct cinema elements that now emerge as crucial to this film language can be traced (as they were in this chapter) to the immediate institutional and artistic context in which Russell was working. Interestingly, my analysis of Isadora Duncan's visual language is again mirrored in the documentary Russell at Work. Apart from the iconic image of Russell undergoing the influence of music in semi-darkness the film also contains footage shot during the filming of the Duncan biopic. And throughout much of these scenes the camera gets as close to Russell as Russell gets to Pickles in his film's dancing scenes. In Russell at Work Russell is "followed" by the camera in the same way that he "followed" the four artists in Pop Goes the Easel or direct cinema film-makers follow their subjects (ill. 15). Russell at Work is a direct cinema documentary about the making of a film in which direct cinema methods are used as part of the visual grammar of a documentary drama. We may assume that behind Russell at Work there is the same belief that by getting "up close" to Russell the camera will deliver some kind of truth or reality about the wild man of the BBC that simply could not be obtained by keeping a polite distance. Of course, here as in Russell's film, we are dealing with a style of film-making. As I argued above, neither cinéma vérité nor direct cinema nor Russell's shamanistic method is more "objectively" true than the others. It is not a question of which is more true. It is simply a question of having suspended objective truth and offering, through these diverse methods, attempts at capturing at least facets and aspects of what might, perhaps, someday, amount to a prismatic approximation of a reality. It seems Duncan was a dancer. It seems Russell was a film-maker. That much, at least, may be true.

Russell's films want to show what artistic creation is really like. That may explain why many of Russell's biographical films from this period focus on situations and artists who can be presented in such a way that the creative process is explicitly externalised. This becomes clear if we compare Song of Summer to Mahler. They are very different films. Song of Summer is generally considered to be one of Russell's more stylistically conventional films: despite some very vivid moments it is "tasteful" in a way that even hostile critics of Russell's work can appreciate. It is also a film that is deceptively "objective" and neutral in its approach. It has no flights of fancy, no elaborate allegories. Mahler, on the other hand, is constructed entirely out of dreams and memories, many of which (as discussed in Chapter One) are highly imaginatively rendered. And yet, in view

\footnotetext{
${ }^{195}$ And as I will argue in the next chapter, when Russell is scrutinised through the prism of a Romantic poetics, his method is much less esoteric than is perhaps suggested here.
} 
of the arguments just presented, there is a close connection between the two films and it has everything to do with getting up close to the creative process. While it is quite easy to imagine an interesting visualisation of the working processes of a dancer (Isadora Duncan), a sculptor (Gaudier), or a film director and film crew (The Debussy Film or, of course, Russell at Work) it is much more difficult to visualise the creative process of a composer in an exciting way. A film on a novelist or poet would face similar difficulties. Composers and writers tend to sit at pianos or desks, scribbling. In Song of Summer, however, Russell uses Delius's illness as a way out of this problem. In the final years of his life Delius (Max Adrian) was paralysed and slowly going blind. He completed his last works by dictating them to the young composer Eric Fenby (Christopher Gable), who had volunteered his services as amanuensis. This collaboration forces the creative process to be externalised. From an intimate process it becomes a public event: Delius has to dictate his music to Fenby. This means that the internal process becomes available to perception (and therefore to the camera) and is even commented upon, as when Delius corrects Fenby or explains his intentions. To be sure, this is not an exact replica of the creative process in the artist's mind, but it is nevertheless as good an externalisation of the creative process as one is ever likely to see. Russell's entire film is constructed around these scenes between composer and amanuensis, so it could be argued that this film, too, is an attempt to get as close as possible, through documentary means, to a creative process that is normally private. In Mahler, however, there is no such loophole and the only way to visualise the creative process there would be to get inside Mahler's head. That we cannot do. So Russell resorts to an elaboration of the formula developed in Isadora Duncan: allegory, metaphor, and interpretation. As the author of Mahler Ken Russell does what Vivian Pickles had to do in Isadora Duncan and what he demonstrates himself doing in Russell at Work: he immerses himself in Mahler's music to feel the person inside. Next, he translates the insights thus obtained into his own work of art, which is the film. As a visualisation or what John Baxter has called a 'cinematic ectoplasm' (AT 125) of Russell's intensely private experience of the music, which is (or Russell claims to be) the intensely private emanation of Mahler the man, one could argue that Mahler is, in vérité terms, the closest one can get to the real thing (and therefore a documentary accomplishment of the highest order) once one has cancelled the idea of factual truth as a reliable method. Watching Mahler is as close as one could get to being a fly on the inside of Mahler's skull. Or, as Russell himself observed, 'a great challenge in these composer films is visualising moments of creativity. Inspiration comes only in flashes, I suppose; and I've been trying all my life to get that on film' (quoted in Tibbetts 2005c: 216). 


\subsection{PERFORMING INFLUENCE: RUSSELL'S POETICS OF THE SWERVE}

This has been a long journey through BBC history, and perhaps it is best, in conclusion, to step back and take stock of what we have gained by taking a somewhat broader view. To do this, I again want to appeal to the work of Susanne Langer, who has argued that art is a non-discursive symbolism. As Langer explains, everyday language and scientific language are discursive symbolisms. This means, to put it very simply, that they are meant to communicate information as straightforwardly, clearly, and practically as possible. But if "objective" language fails to capture a human experience we turn to other symbolisms, which are expressive. They are non-discursive rather than discursive. Art is such a non-discursive symbolism. It is a language of forms that communicates things (feelings, insights, experiences) that cannot (easily or adequately) be communicated in discursive symbolism. A poem, for example, can move us in a way that a scholar's analysis of what the poem says could not (or, if the analysis also moves us, it will move us in a different way). In fact, the scholar's analysis will need much more time, and many more words, to explain what the poem says in very few words. One could argue that Russell does something similar: he uses a highly subjective "cinematic ectoplasm" to convey ideas on and insights into art that resist expression in discursive models of communication. For Russell the whole point of his biopics lies in the fact that he claims to find in works of art a way into a greater truth than the truth we can find in supposedly "objective" factual accounts. Such factual accounts are, of course, a form of discursive communication. What we learn about Mahler by "tuning in" to his music is obviously the subject of a non-discursive symbolism: it is something we must feel or sense or intuit. This is why it could easily be dismissed as a 'bogus' approach. But it obviously follows that it would be self-defeating if Russell were next to proceed with a straightforward discursive account of what he has discovered while listening intently to Mahler. If objectivity has been suspended as a basis for truth (and this happened in Russell's response to the Elgar film and his subsequent move towards a new form of dramatised documentary in The Debussy Film and Isadora Duncan) then Russell would simply harm his own cause if he would communicate his own insights discursively. He would be doing something senseless and even impossible because he is dealing with a form of truth (Gaudier would call it a greater form of truth) that resists discursive communication (which would necessarily imply a measure of objectification). Therefore he must communicate it non-discursively. When the import of a work of art is translated into discursive language, something is lost in translation; except when the analysis or discussion of the work of art is itself an aesthetic creation. For Russell the implications 
are clear: since what he wants to communicate with us is his personal experience of Mahler through his music he must communicate through the non-discursive symbolism of art.

As should be clear from the previous discussion, the term "cinematic ectoplasms" is a metaphor for the way Russell makes his films and for the way he performs himself through his films. This is perhaps best made clear by returning to the Warburgian approach that was outlined in the Introduction. According to Warburg, artistic motifs travel through time and space on unpredictable and often intricate Wanderstrassen which the iconologist traces in retrospect. But there are many ways in which a motif can travel from one point on a Wanderstrasse to another. One of the most obvious ways is if one artist is struck, for whatever reason, by the expressive power of a motif, or a phrase, or an image, or an idea, or a conceit, or any other element in another artist's work and decides, more or less consciously, to emulate it. By allowing the process to be less than fully conscious I am not courting a psychological or psychoanalytical approach: I merely want to stress that things that strike us at one time might linger in the back of our mind and return to the front again at a later time without a complete awareness of its moment of origin. We forget where we find things, that is all. That is also why motifs sometimes emerge at unexpected times and in unexpected places. It also highlights that the dynamic of the Wanderstrasse is not something mysterious or mystical: it merely encompasses the many vagaries of cultural transmission, which can happen in the silliest of ways as well as through centralised hegemonic imposition of cultural forms. Among this spectrum of forms is also the process of influence, or what we call influence. But "influence" is a problematic concept. The term has the infelicitous connotation of influx: something that enters into us of its own accord. Michael Baxandall calls it 'a curse of art criticism primarily because of [this] wrong-headed grammatical prejudice about who is the agent and who the patient' (1985: 58-59). In reality, the influence never acts upon the influencee of its own accord: it is the influencee who engages with (an element from) the work of a precursor or a colleague who is subsequently called the influence.

Given Russell's intense immersion into the music of his subjects before engaging on a film about them, we may suspect that "influence", understood as a process of creative appropriation, could open up a way of understanding the creative logic underlying the production of his "cinematic ectoplasms". I want to pursue that thought by way of a brief detour via literary theory, which will pay dividends. In The Anxiety of Influence (1973) Harold Bloom argues that it is pointless to try to analyse a poem as a selfcontained unit (he was responding to the New Criticism in literary studies) because in every poem the poet engages the work of a precursor poet. This process typically begins with 'a profound act of reading that is a kind of falling in love with a literary work' 
(1997: xxiii). One could say that the precursor poet is the poet that the later poet feels he should or could or might have been. This is the familiar sensation where someone else has formulated an idea that feels like one's own (and not just the idea itself, but also how it is presented). Bloom describes the experience as 'the shame and splendour of being found by poems' (o.c. 26). The later poet wants to incorporate the splendour of the poem that "found him" into his own work because, to some extent, the precursor poem is the poem that he feels he had wanted to write or should have written. The anxiety of the later poet, however, is the fear that they might be "found out" as merely echoing the strong precursor poet. This is the fear of not being an "original", which is 'each poet's fear that no proper work remains for him to perform' (McFarland 1985: 12), although the point of Bloom's theory is that there is no such thing as absolute originality: there is only the act of holding one's own amid one's influences in an achieved work of art. For this reason, the later poet's work will everywhere show, if one cares to look for it, the evidence of the engagement with the precursor poet. This does not diminish his originality, for if the later poet is also a strong poet he will be able to incorporate what he loves in the precursor into his own voice. Good criticism reads and understands poems not as isolated works but as part of such a concatenation of influences over time: every poem responds to another poem, which responds to another poem, and so on in what amounts to a Wanderstrasse of literary echoes for the critic to map. That is also why, as Bloom famously said, 'the meaning of a poem can only be another poem' (Bloom 1997: 94): the meaning of a poem is its engagement with an earlier poem.

But because the influence of the precursor poet causes anxiety, the influence must be somehow contained. The later poet must not be "found out". To achieve this, poetic influence 'proceeds by a misreading of the prior poet, an act of creative correction that is actually and necessarily a misinterpretation. The history of fruitful poetic influence [...] is a history of anxiety and self-saving caricature, of distortion, of perverse, wilful revisionism' (o.c. 30). The later poet wants to incorporate and assimilate the precursor, not merely copy him. In that sense, every poem is a creative response to a previous poem (which is in turn a creative response to a previous one, and so on). This distortion or revision is what Bloom calls the poem's clinamen or swerve. The term is borrowed from Epicurean physics, an atomist theory which holds that atoms move randomly through space. However, unpredictably and without any external cause, atoms swerve on their course: their trajectory will make a sudden inclination which causes them to collide with others. It is from these collisions, and the composite clusters of atoms that result from them, that the manifold qualities and objects in the world develop. In Epicurean physics, the swerve is the basic dynamic and change-inducing force in the natural universe. In the early fifteenth century this atomism was rediscovered when Poggio Bracciolini hap- 
pened upon a manuscript of Lucretius's De Rerum Natura, which expounds the theory. Its materialist implications (including the argument that creatio ex nihilo, a Christian dogma, was impossible) provided a shock to established theology and physics which would resonate into the seventeenth century, when it influenced the work of Spinoza and the Spinosistes. This made it one of the intellectual and philosophical cornerstones of the upheaval of the Baroque period. ${ }^{196}$ Which means that, with the Bloomian swerve, we have found a practical analytical model that is very useful in the pursuit of a transhistorical sense of the baroque.

If one looks at Russell from Bloom's perspective, one is struck by his fearlessness: he wears his influences on his sleeve. Russell promoted the idea that his work comes about by immersing himself in the work of other artists whose work he admired (the precursors in Bloom's model), which is really to say that he actively invokes and seeks out their influence. In Mahler, the film with which I began my analysis in Chapter One, the title of the film itself announces the influence. Russell takes elements and impressions from his precursors' works to incorporate into his own vision: his work is organised (or perhaps it is better to say: associated) around 'some of the things I feel when I think of Mahler's life and listen to his music' (1974: 6). And if, as Bloom suggests, influence is the outcome of 'a complex act of strong misreading, a creative interpretation' (1997: xxiii), then there seems to be good sense in the claims of the critics who have shouted, at the top of their collective voices, that Russell betrays his subjects, cheapens their work, misrepresents who they are and what they did. But while the critics thought they were exposing fatal flaws in Russell's work they were really showing the strength of Russell's own poetry: to misread, to caricature, and to distort one's influences is the very thing that, according to Bloom, makes a poet a strong poet. ${ }^{197}$ (Of course, some misreading is

\footnotetext{
196 The history of the influence of Epicureanism in early modern culture is beyond the scope of the present discussion, but see Barnes (1979: 40-75), Sedley (1999: 362-382), and Furley (1999: 418-432) for systematic discussions of ancient atomist physics and cosmology (Democritus, Epicurus, Lucretius); Greenblatt (2011) for the remarkable story of the rediscovery of Lucretius in the early fifteenth century; and Israel (2001) for the impact of atomism and its implications on seventeenth-century philosophy, science, theology, and morality.

197 There is a lesson here for the critic, too. Bloom writes that criticism 'is either part of literature or nothing at all' (1997: xix) and that 'all criticism is prose poetry' (o.c. 95). If the meaning of a poem is always another poem it also follows that the critic who wants to provide an understanding of a poem will need to write either a counter-poem or a prose poem about it if his reading of the poem (or the work of art in general) is to be a strong reading. Worthwhile criticism is criticism that engages with its subject in a creative manner, the way an artist would. I take this to also be the meaning intended by Susanne Langer when she wrote that 'a critic who cannot be awe-struck is not equal to his material' (FF 246): unless the critic can address the work on its own terms, like a poet awed into anxiety, the sense he makes of it will inevitably be pedestrian and academic in the worst sense, which is bland and sterile. Bloom writes that 'critics are more or less valuable than other critics only (precisely) as poets are more or less valuable than other poets' (1997: 95). Langer further points out that we should not forget that non-fiction writing is also a 'great literary order' and that, although the critical essay,
} 
just bad reading or bad poetry, but I should hope that nobody will maintain, after the previous discussions, that Russell is a bad artist or a cheap caricaturist) The clinamen or swerve in Russell operates through a double movement: on the one hand he wants to demythologise the artist and show him as a worker rather than a world-weary genius (as was discussed in relation to Savage Messiah), but on the other hand this demythologising happens through the creation of a new myth, which is "Russell's Mahler" or "Russell's Tchaikovsky". After all, Russell did call himself a 'mythographer' (BP 57). Russell first surrenders to the strong precursor (he immerses himself in the music of his subject) but then takes from that experience those elements that he can craft into his own vision of it. He accomplishes the swerve by imposing his own voice on the precursors' influence. That is also why there must be a moment of demythologising in Russell's work: it is Russell's way of clearing space for his own reading of the influence or precursor. ${ }^{198}$

\subsection{OUTLOOK: RUSSELL INSIDE THE TEXT(URE)}

In this chapter I have argued how Russell's views on art and artists developed over his years working at the BBC and have used the example of Isadora Duncan to show how these ideas, once matured, can be seen to articulate themselves in a highly idiosyncratic way of making biographical films on artists. We must now look more closely at the kind of artist that Russell himself performs as, and especially at how he performs himself through the texture of his films. Some of that work was already done in the discussion of Russell's early Monitor shorts and Isadora Duncan in the present chapter, but I will argue that we can increase the detail of the discussion into the most minute aspects of mise-en-scène and montage. That is the project of the following chapter: by analysing the structure of Salome's Last Dance we will get a much clearer picture of the kind of artist Russell wants to perform as, while an analysis of montage in Gothic will show us how this performance is maintained in the texture of Russell's films, shaping the way the whole work is put together. The discussion of montage will therefore be the point where all the strands of the previous discussions converge. It is also at that point that I will be

\footnotetext{
history, philosophy, biography, reports, 'and all kinds of exposition' may not be properly 'poetic' (because they are not fictional), it nevertheless remains true that 'whenever it is done well, it meets a standard which is essentially literary, i.e. an artistic standard' (FF 301). In an essay on Sainte-Beuve, Matthew Arnold once observed that 'first-rate criticism has a permanent value higher than that of any but first-rate poetry and art' (quoted in Monsman 1980: 16).

${ }^{198}$ Monsman argues for such a Bloomian reading of Walter Pater, whose work is full of deliberate misquotations, and that 'such modifications of sources occur because Pater's subjects are Pater himself (1980: 9-28, here 24). Pater will be central to the discussion in Chapter Four.
} 
able to show exactly how Russell performs himself through his films. I will argue that the public role that Russell played was modelled on Romantic genius, pace his claim, explored in the present chapter, that the artist is really a "worker" rather than a genius. But I will also show that the kind of "work" that the artist performs is in fact modelled on Romantic poetics. This means that there is a duality in Russell's work and performance: he uses Romanticism against itself, disavowing the rhetoric of Romantic genius but bringing the poetics of Romantic genius back into his work in the way he constructs his films. This paradoxical complex, however, was developed during his time at the BBC. That is why the present chapter was a necessary step in reconstructing Russell's performance of himself through his work: without insight in his years at the BBC we could not fully understand how he performs himself in his films and why he does it the way he does it. With that task completed, we can now direct all our attention towards the films to find Russell there, performing himself, in their very texture and creative fabric. 


\section{Chapter Four}

\section{WE ARE THE GODS NOW \\ Performing Genius in Salome's Last Dance \\ (1988) and Gothic (1986)}

'Such tricks hath strong imagination'

William Shakespeare,

A Midsummer Night's Dream (5.1.18) 

When he visited Russell during location filming for The Boy Friend critic Rex Reed ominously reported that 'Ken Russell was in town. He was storming up and down the lazy cobblestone streets in knickers, boots, outsize tinted granny glasses, a black Dracula cape and a stone crucifix, brandishing an evil cane with an ivory dog's head handle, and frightening the horses' (1974: 249). When Reed dared to breathe a criticism of The Devils (of which he writes, but probably did not say at the time, that it 'made me throw up'; o.c. 250), Russell 'blanched and grabbed a steak knife. I waited for him to stab me to death. His eyes rolled back and his breathing stopped' (ibid.). By the time Reed left, however, Russell's mood, like a good bipolar tornado, had switched, and 'the last I saw of Ken Russell, he was sitting in a velvet chair, knitting a sweater' (o.c. 254). ${ }^{199}$ Such behavioural excess has become a central part of Russell lore, whether he is portrayed as the "wild man of the BBC" or appears on television to angrily whack Alexander Walker over the head with a copy of his own newspaper. ${ }^{200}$ In 1971, Russell told Time magazine that 'this is not the age of manners' but that 'this is the age of kicking people in the crotch and getting a reaction. I want to shock people into awareness. I don't believe there's any virtue in understatement' (quoted in Lanza 2007: 119). And so in art, as in life, Russell was accused of revelling in excess. Critics have exhausted themselves to complain about Russell's cinematic shock tactics, which they decry as a form of defamation. Pauline Kael spat that Russell's films 'cheapen everything they touch' (1976: 52). In a review of The Boy Friend, Jan Dawson opined that 'Ken Russell consistently approaches his material as a tattered poster upon which to scrawl those outsized and eye-catching graffiti that pass for an auteur's signature among less discerning critics of the Common Market countries' (1972: 111). ${ }^{201}$ And like a metaphor lost on an inter-critical Wanderstrasse the disrespectful scrawls would resurface several years later in (again) Kael's review of Valentino (1976), which she dismisses as 'a five-million-dollar graffito' (1980: 335). But graffiti is the territorial mark of the uncivilised outsider, stalking the streets while polite society sleeps. Graffiti is the signature of the wild man. ${ }^{202}$

Russell was complicit in creating this myth around his persona. He had no qualms about playing the part of Britain's resident mad genius. The persona described by Reed

\footnotetext{
${ }^{199}$ Dorothy Tutin has commented that, when she first met Russell, who wanted to cast her in Savage Messiah, 'here was this huge bear-like creture in a vast cape, with rings on every finger!' (quoted in AT 195)

${ }^{200}$ See Lanza (2007: 122-123) for this anecdote, which regularly pops up in Russell lore.

201 The Common Market gibe is aimed at the auteur theory as developed in Cahiers du cinéma, but it might also be seen in the context of Great Britain's entry into the European Common Market, forced by the Heath administration against much opposition. See Sandbrook (2011: 134-175) for an account of this painful process.

202 At the beginning of The Devils, when Grandier is walking through plague-ridden Loudun at night, he passes a house upon which is scrawled the graffito 'Roussel' in deliberate (mock-archaic?) wrong spelling.
} 
can be seen in photographs of the period, with Russell attired in one or more items from Reed's inventory, sometimes accessorised with a fur coat or other accoutrements that mix the Romantic with the baroque or the simply outrageous. ${ }^{203}$ It is precisely Russell's performance as demented British genius that is under investigation in this chapter. I already suggested that Russell performs as a Romantic genius when, in the previous chapter, he could be seen immersing himself in music to conjure his muses for the documentary Russell at Work. In this chapter, I will look closely at Salome's Last Dance and Gothic, two films that are concerned with the conjuring of artistic visions. I will show how, through the narrative structure and visual language of these films, Russell develops the idea of the artist, and in this case himself as director, as Romantic genius. But this concept of the artist also entails a theory of creation that is very similar to the one expressed in Russell's notes on Mahler, quoted many times before. I will argue that his films, but especially Gothic, also put this theory into action. In other words, Russell's poetics is not just a creative principle underlying his work, it is both thematised and performed in his films.

This point could be made with many of his films (and to an extent the previous chapter has done that with Isadora Duncan), but especially with the two films under review in the present chapter, which are both deeply performative because they are both films about creative processes that we can actually see happening on the screen as the films unfold. This means that I will be continuing the line of argument that closed the previous chapter. We last saw Russell making his poetics visible in the direct cinema tactics of Isadora Duncan. At the same time the director himself also made a public appearance in Russell at Work, where we saw him perform the act of inspiration that (according to his self-description) is the source of all his films. The present chapter will now look in detail at the kind of artist that Russell is performing there. This is the type of the Romantic genius. But my analysis will only occasionally address Russell's actual public performance as himself. It is clear from the examples of Russell's on-set behaviour that I have just listed that Russell's public persona ticks many of the boxes that we

\footnotetext{
${ }^{203}$ Such theatrics had specific British antecedents. One example is the outré environment that Cecil Beaton created at Ashcombe and the infamous Fête Champêtre he organised there in 1937, an elaborate Arcadian costumed ball (one of many indulged in across the continent by an international crew of designers, artists, choreographers, and jetset hangers-on). One of the most remarkable guests was Lord Gerald Berners, who came wearing 'an eighteenth-century braided coat and a pig's head' and who reportedly took 'such a liking to his costume and mask that he often travelled in them, seated in the back of his magnificent chauffeured Rolls Royce, playing the small harpsichord that he had installed there' (Calloway 1994: 92). The example of Berners is suggestive because one of the most memorable images of Russell presented to the public in the early 1970s was the documentary Russell's Progress (1970), 'an interview with Russell filmed in his Rolls Royce cruising through the New Forest' (AT 10). For Beaton and Ashcombe, see Calloway (1994: 90-92). See Zinovieff (2014) for a biography of Berners.
} 
would associate with the image of wild Romantic genius. Discussing them, even in detail, might lead to some quick and obvious conclusions. But the focus of this book is on Russell's performance of self through his art. The main focus of the discussion will therefore once again be on the films and on the way the films perform Russell's genius in the way they are made. The first section of the chapter looks at Salome's Last Dance. This film is almost completely taken up by a performance of Oscar Wilde's play Salomé, which makes it the clearest example of an embedded play in Russell's entire output. But it is also a film in which Russell has cast himself in a supporting role that is clearly meant as a comment on his public image and critical reputation. This means that his presence in the film is similar to Molière's performance as himself in L'Impromptu de Versailles. The most important contribution of Salome's Last Dance to our understanding of Russell, however, is the way the film dramatises the way Russell understands the creative labour of the artist. To make a work of (narrative) art is to create a world. This film shows exactly how this happens (which makes it an interesting companion piece to The Devils).

The largest part of the chapter, however, is taken up by a discussion of Gothic. In this film we can see most clearly how Russell makes his films perform his Romantic genius for him. Gothic is a film about the principles and philosophy of Romantic creation as articulated in the Preface to Wordsworth and Coleridge's Lyrical Ballads and in Mary Shelley's Introduction to Frankenstein, which will be discussed in detail below. In fact, Shelley's Introduction is the text on which the film's narrative is based. But at the same time the film (and this means, of course: Russell) also puts these principles into practice. This is nowhere more clear than in Russell's use of montage to achieve embedded narratives, and especially embedded hallucinatory sequences. Because Gothic does much of its narrative and expressive work through extended streams of images the film leads into a discussion of what is usually considered Russell's trademark: his allegorical hyperboles, or what I have called, in Chapter One, his narrative fugues. Analysing the way Russell creates these 'cascades of vivid, seemingly uncontrolled imagery' (Armes 1978: 305) in Gothic will show that the principles he uses are based on Eisenstein's theory of montage. At the same time, however, they are also completely in line with the Romantic principles of creation that the film is about. This means that form and content of Gothic are deeply entwined. This is always the case in works of art: the way of saying something is always part of what one is saying. Within Russell's oeuvre, however, Gothic is one of the films where this entanglement is most completely realised (The Devils, of course, is another). It is therefore also the film where we are most likely, in the course of an analysis, to reach the essential principles that hold Russell's performance of self through art together. That is why the discussion of montage in Russell's allegorical hyperboles, which ends this chapter, will also complete my analysis: it is the point where everything converges. 


\subsection{MOONSTRUCK FOLLIES: STAGING SALOME'S LAST DANCE}

In Salome's Last Dance Russell stages a complete embedded performance of Oscar Wilde's symbolist play Salomé (1893). ${ }^{204}$ There are two important aspects to this film that have immediate bearing on Russell's performance of himself through his art. The first aspect is the choice of source text and the way it is staged in the film. In Chapter Two I argued that The Devils was structured as a theatrum mundi: it showed that all the world is a stage and that our lives are performances upon that stage. The aim of all the performers, however, was to make the other performers believe their performance. On the most general level, this meant that the drama played out on the stage of the world was a struggle to determine what reality would be like. I will now argue that this is also the dynamic of Wilde's play Salomé, which presents a number of characters locked in a battle of wills to shape the world they inhabit. I will also argue that the text, as Wilde wrote it but also (and especially) as Russell filmed it, stages this struggle as a theatrical event: both play and film display an awareness that to create the world is similar to staging a play. But I will also argue that Wilde's play elaborates a number of key ideas in Walter Pater's philosophy of sensationalism. This will in turn suggest that Pater's work is an important point of passage to clarify Russell's creative methods. The second aspect that pertains to my central project is Russell's own presence in the film in the role of a pornographer. I will argue that this role is a comment on Russell's public reputation as a scandal-monger. Russell here creates a type of self-portrait that Victor Stoichita has called, in his study of self-reflexive painting in the sixteenth and seventeenth centuries, the 'masked self-portrait' (1999: 270): the author of a work represents himself in the work, but "masked" as one of the characters. ${ }^{205}$ In painting it is often difficult to ascertain with absolute certainty whether we are dealing with a self-portrait, and usually we have to rely on circumstantial evidence to come to any conclusions. Famous cases of (supposed) masked self-portraits are Caravaggio's self-portrait as the decapitated head of Goliath (David with the Head of Goliath, ca. 1610) or Michelangelo's self-portrait as

\footnotetext{
${ }^{204}$ In my discussion of Wilde's play (as distinct from Russell's film) I shall be quoting the original French text of Wilde's Salomé from Pascal Aquien's bilingual edition (Wilde 2006; henceforth WS). Although Wilde wrote the play in French critics continue to use English translations, sometimes even Alfred Douglas's flawed translation, which was published in 1894 but rejected by Wilde (for the trouble over Douglas's translation, see Ellmann [1987: 379-381]). Camille Paglia comments that, in any case, 'Salomé sounds better in French, since English prose [...] cannot sustain an incantatory style [and] Salomé is full of hieratic repetitions' (1992: 563). Russell's film uses a new translation by Vivian Jolly (his wife at the time) that takes some liberties with the text. All references to Wilde's other works are to the fifth edition of The Complete Works of Oscar Wilde (Wilde 2003; henceforth CW).

${ }^{205}$ Stoichita (1999: 268-278) discusses the masked self-portrait as one of four types of "contextual selfprojection". The other types are not relevant to the present discussion.
} 
Saint Bartholomew's flayed skin in the fresco of the Last Judgement in the Sistine Chapel. ${ }^{206}$ In film, Stoichita refers to Hitchcock's many cameo appearances in his own films. Russell, too, has often made such appearances in his films, but Salome's Last Dance was the first in a series of films in which Russell would cast himself in more substantial roles. ${ }^{207}$ The special interest of Russell's performance in Salome's Last Dance, however, lies in its self-reflexive comments on Russell's public image, recalling Molière's performance as Molière in L'Impromptu de Versailles.

\subsubsection{Appropriating Salome}

It is 5 November 1892, and Oscar Wilde (Nickolas Grace) is visiting his favourite brothel. He has brought along his lover, Lord Alfred Douglas (Douglas Hodge), for company. Wilde has just learned that his play Salomé has been banned by the Lord Chamberlain because it depicts biblical scenes, which is against the law. What he doesn't know, is that the denizens of the whorehouse, under the direction of its proprietor, Alfred Taylor (Stratford Johns), have mounted a clandestine amateur performance of the play for Wilde's benefit. Alfred Douglas will play Iokanaan, or John the Baptist; Taylor himself will be Herod; and Herodias is impersonated by an extravagant aristocratic woman called Lady Alice Fitzkensington Windsor (Glenda Jackson). ${ }^{208}$ The part of Salome goes to the diminutive chambermaid Rose (Imogen Millais-Scott). The plot of the play is well-known. The young princess Salome becomes enamoured of the imprisoned John the Baptist, who rejects her advances. Herod, the tetrarch, in turn lusts after Salome. This makes him a very wicked tetrarch, for Salome is actually the daughter of his brother and Herodias. Herod had his brother killed so that he could have Herodias to himself. Now he wants the daughter, too. In a moment of drunken abandon he promises Salome

\footnotetext{
${ }^{206}$ See Puglisi (1998: 359-365) and Langdon (2000: 385) on the Caravaggio painting, which is considered a self-portrait on the authority of Bellori, and Partridge (2000: 139) on Michelangelo.

${ }^{207}$ Russell had made small appearances in films such as Song of Summer (as a lusty priest) and Tommy, where he appears as one of a number of paraplegics in a wheelchair. He began to play important roles in many of his television films of the 1980s and 1990s. He also stars in all the Gorsewood films he made in the 2000s, when he returned to amateur film-making, including the feature The Fall of the Louse of Usher (2002). Interestingly, even in his autobiographical film A British Picture Russell remained true to the masked self-portrait, for he appears in this film as a journalist and never as himself: the role of Ken Russell is played by Russell's son Rupert. Russell does appear as himself in In Search of the British Folk Song (1997), but there he is the host of a documentary and does not really play a role.

${ }^{208}$ Lady Alice's name is possibly a reference to the Cleveland Street Scandal, which caused a lot of sensation in 1889 and 1890 because it involved both a homosexual brothel and rumours about the possible involvement of Prince Albert Victor, the elder son of the Prince and Princess of Wales and next in line for succession to the throne after his father. The Cleveland Street brothel may be a model for Alfred's whorehouse in the film. On the scandal, see Hyde (1976, esp. 55-62 for the Prince's alleged but unsubstantiated involvement).
} 
anything she wants if she will only dance for him. Unfortunately, she demands the head of John the Baptist on a silver charger. There is no changing her mind and before he knows it Herod has killed a prophet so that a slinky vixen may kiss his decapitated head. Repulsed, Herod has Salome killed and the curtain falls. However, at the end of this particular performance the police show up to arrest Wilde (for gross indecency) and Taylor (for running a disorderly house) only to find that poor Rose has been killed, too.

The above is a plot summary of Salome's Last Dance, Russell's lush staging of Wilde's Salomé as a very camp embedded play. Despite its minuscule budget the film looks gorgeous. Russell's staging of the play in fact recalls the plans for Salomés abortive first performance, which was supposed to have starred Sarah Bernhardt but was cancelled when the Lord Chamberlain banned the play. ${ }^{209}$ For the planned first performance Wilde had asked his friend, the artist Charles Ricketts, to design the sets and costumes. Ricketts later recalled that he 'proposed a black floor - upon which Salomé's white feet would show; this statement was meant to capture Wilde. The sky was to be a rich turquoise blue, cut across by the perpendicular fall of gilt matting, which should not touch the ground, and so form a sort of aerial tent above the terrace. Did Wilde actually suggest the division of the actors into separate masses of colours, to-day the idea seems mine! His was the scheme, however, that the Jews should be in yellow, the Romans were to be in purple, the soldiery in bronze green and John in white' (1913: 243-244). Although Russell has not rigidly adopted these particular colour patterns, he does create a very similar artificial environment where characters are covered in body-paint or adorned like objets d'art. This is especially true of Glenda Jackson, whose elaborate dress as Herodias recalls Ricketts' later designs for Montezuma (ca. 1925) and for Lady Macbeth (1926). After the performance of the play Lady Alice in fact tells Wilde and Taylor that the dress she wore as Herodias was actually her usual attire as Lady Macbeth (ill. 16). ${ }^{210}$ But the film also takes some liberties with historical fact. For example, Wilde wasn't arrested until 1895. Furthermore, he never saw Salomé performed. The first performance was mounted in 1896, and in Paris, in a gesture of support for the imprisoned

\footnotetext{
${ }^{209}$ See Downey (2004) for a discussion of the ban in its historical context.

${ }^{210}$ For images see Darracott (1980: 167 for Montezuma and 189 for Lady Macbeth). Other influences should perhaps not be excluded. The film's colour patterns, but especially the intricately decorated costumes of Herodias and Salome, could also be seen as originating in Gustave Moreau's famous paintings of Salome. These were described in chapter five of Joris-Karl Huysmans's decadent novel À Rebours (1884; here Huysmans 1977: 141-150). In The Picture of Dorian Gray (1891) Wilde voiced his admiration for this novel's 'curious jewelled style' (Wilde 2007: 104) shortly before he began writing Salomé. Bennett (2010: 297-303) triangulates Moreau, Huysmans, and Wilde and traces their iconographic connections. Finally, Salome's wardrobe in Russell's film, with its explosion of beads, may also be inspired by the beaded breastplates and chains of pearls worn by Salome dancers of the early twentieth century such as Maud Allan: see Bentley (2002: 61-63 with illustrations) and Walkowitz (2003: 357-358 and 361).
} 
Wilde. By pushing all these events back to one night in 1892 (his notorious "telescoping" of events) Russell takes considerable liberties with the historical record for dramatic effect.

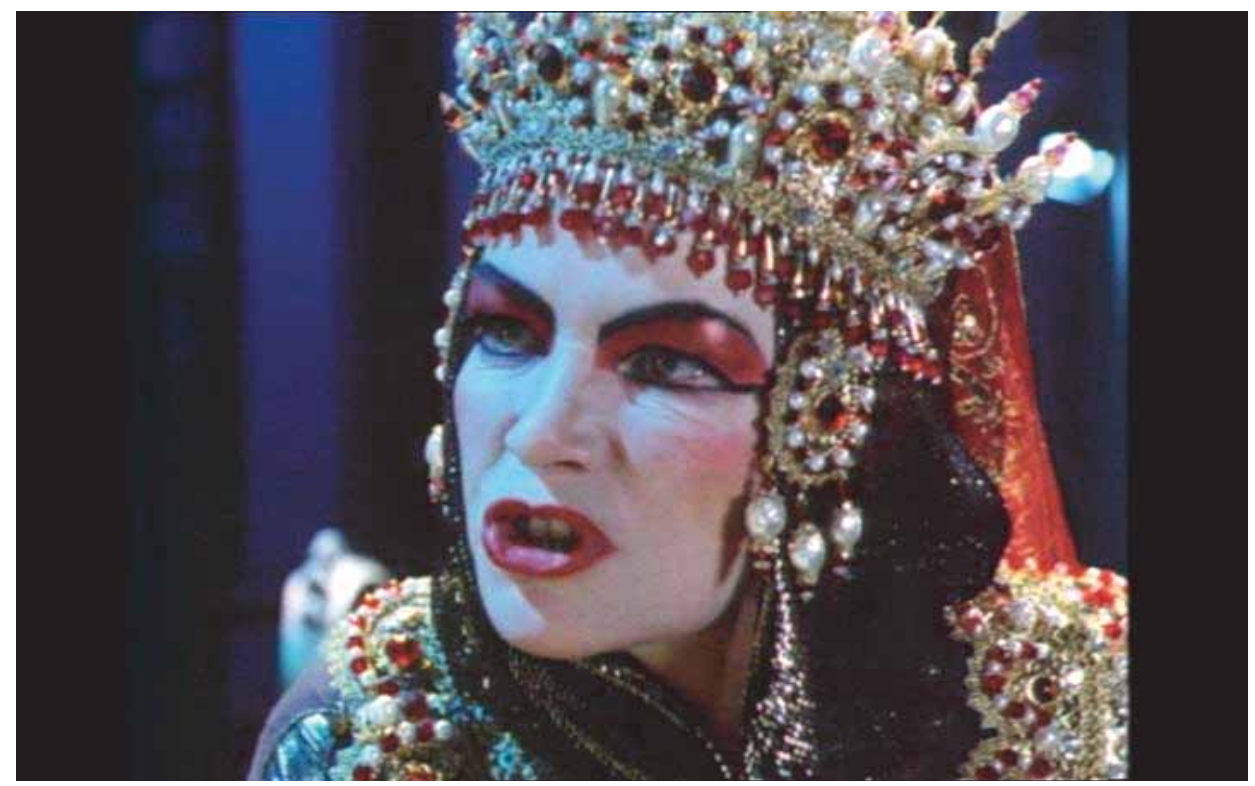

Illustration 16 Objet d'art: Herodias as Lady Macbeth

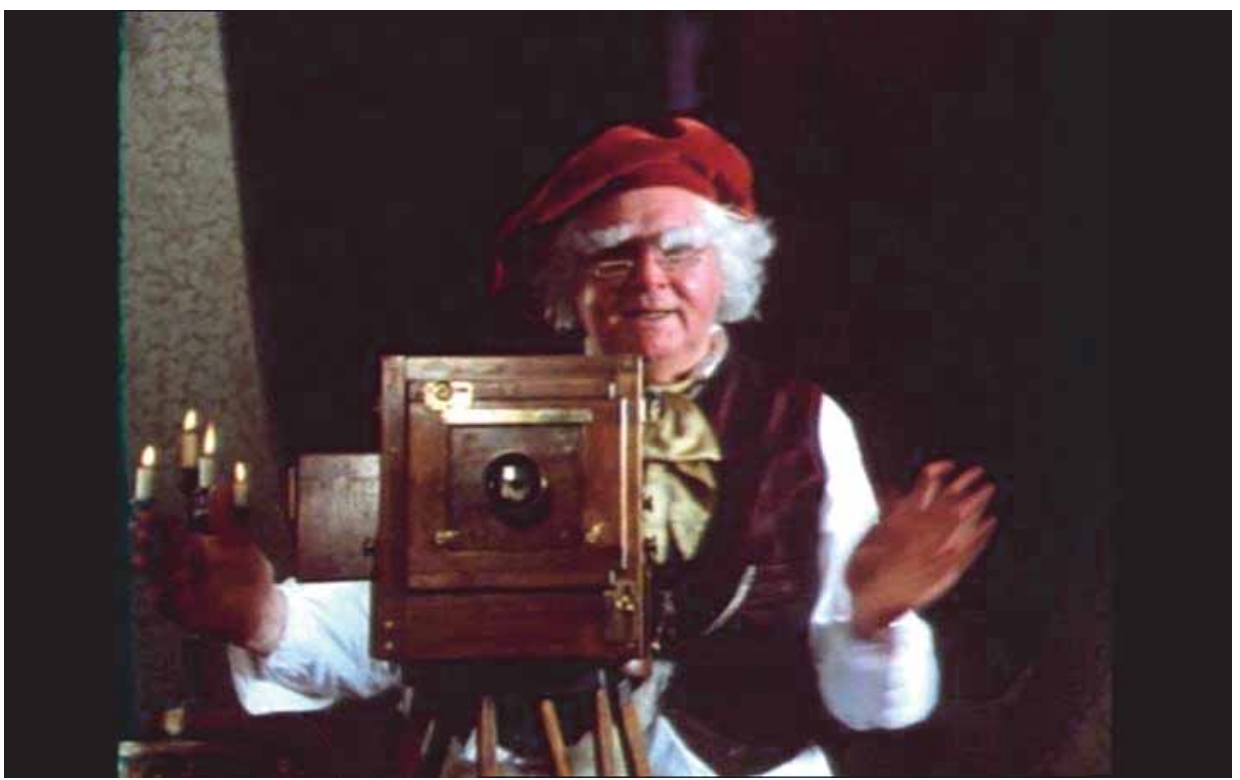

Illustration 17 Kenneth Russell as Kenneth the pornographer 
What makes this film especially interesting within Russell's body of work, is the fact that the director himself plays a supporting role in the film as Kenneth, a pornographic photographer who takes snapshots of all the titillating moments in the play (ill. 17). Russell's role is an obvious wink at his popular (or unpopular) reputation among dismissive critics. Robin Wood famously accused Russell of committing 'a sort of cultural pornography, both degraded and degrading' (1980: 909). Pauline Kael had earlier written in a review of Savage Messiah (1972) that Russell's films indulge in the 'porn of fame' and that they 'cheapen everything they touch' (1976: 50 and 52). Alexander Walker has in turn called Russell 'a master of [...] the porno-biography which is not quite pornography but is far from being biography' (2005: 389). Reviewing Salome's Last Dance in particular, Roger Ebert has remarked that 'Russell demonstrates again that he is most interested in literary figures when their trousers are unbuttoned' (quoted in Prasch 2009: 196). So it is hardly surprising that Russell should cast himself as a photographer of dirty pictures, especially one that shares his first name Kenneth. ${ }^{211}$ But there is a deeper sense in which Russell's presence in the film is made tangible. The structure of the film illustrates Russell's argument that his films are always reflections of his own experience of his source material. It is worth recalling (yet again) Russell's production notes for Mahler (1974), where he conceded that 'most of my films on composers evolve through a stream of consciousness in which the man and the myth, the music and its meaning, time, place, dream and fact all flow and blend into the mainstream of the film itself. [...] My film is simply about some of the things I feel when I think of Mahler's life and listen to his music' (1974: 6). Similarly, of Lisztomania (1975) Russell said that his film 'isn't biography. [...] It comes from things I feel when I listen to the music of Wagner and Liszt, and when I think about their lives' (quoted in Lanza 2007: 182). Critics have repeatedly made similar observations about Russell's films. For example, Richard Eder once wrote in the New York Times that in Russell's films 'it is almost as if Tchaikovsky, Liszt, and Mahler had taken turns making films about Mr. Russell' (quoted in o.c. 165). Russell sees himself as a kind of prism. There is material out there in the world, such as the life of a famous artist, and this material is represented in his work as refracted through the prism of Russell's perception of it. This refraction implies an act of interpretation and hence a distancing from "objective" truth (whatever that may be). This means that Russell's take on his material always implies, to some extent, a fictionalisation and an appropriation: Russell takes his material and swallows it up into his own universe.

\footnotetext{
${ }^{211}$ The accusation of being a conveyor of smut has even haunted Russell into the seemingly chaste terrain of the heritage film, for one critic from the field of Victorian studies has opined that, in his adaptation of The Rainbow, 'Ken Russell works his unique black magic and turns one of the most mysteriously effective novels of this century into motel-room pay-per-view soft-core' (Stewart 1995: 172).
} 
This is the swerve (or creative misreading) he imposes upon it. At the same time, however, he argued that such reading of the artist through the work yielded a deeper kind of truth than an account of mere facts could provide.

This approach, which is by now very familiar from the discussion in previous chapters, returns in Salome's Last Dance. But this time the process of creative refraction is given another layer if we look at it through the work of Walter Pater, who profoundly influenced Wilde. In the infamous conclusion to his Studies in the History of the Renaissance (1873) Pater claimed that all experience is merely 'a swarm of impressions' and that 'we can only conjecture' what the world behind those impressions (what Kant called the thing-in-itself) is really like. 'Every one of those impressions is the impression of the individual in his isolation, each mind keeping as a solitary prisoner its own dream of a world' (Pater 2010: 119). Pater, who was deeply influenced by Heraclitus' theory that all of reality is in constant motion, here formulates a radical form of epistemological scepticism bordering on solipsism ${ }^{212}$ : we are the prisoners of our own impressions, enclosed as if in a constant dream, and nothing can pierce through the walls of that dream because the supposedly "real" world that lies (or is assumed to lie) beyond our perception is forever unattainable. Reality is simply the dream world that our mind assembles out of the impressions that reach it. This radical epistemological scepticism fed deeply into the work of Oscar Wilde, especially in the dialogue 'The Decay of Lying'213, where Wilde argues that all facts are in reality human constructs. It is here that we find Wilde's famous dictum that Nature imitates Art: just like Art, Nature is what or how we make it. Contrary to what we have often been told, it is not art that holds the mirror up to nature, but the other way around. ${ }^{214}$ Since there are no facts and no reality outside of Art, Wilde can claim that 'Art never expresses anything but itself' (CW 1087): since all of Nature is already Art, even the claim that Art mirrors Nature simply means that Art mirrors Art. Wilde explains that 'Nature is no great mother who has borne us. She is our creation. It is in our brain that she quickens to life. Things are because we see them, and

\footnotetext{
${ }^{212}$ In the Conclusion to The Renaissance Pater writes about 'that continual vanishing away, that strange perpetual weaving and unweaving of ourselves' (2010: 119) and poignantly observes of the brevity of human life that 'we have an interval, and then our place knows us no more' (o.c. 120): these are not only very strong articulations of Heraclitean thought, in the context of Pater's work they are also converted from a source of melancholy (as they were in the Baroque) to the foundation of an outlook on life that embraces the sensuality of that fleetingness and elevates it to a positive principle. Beaumont's (2010) Introduction to his edition of The Renaissance is very illuminating on these points.

${ }^{213}$ First published in The Nineteenth Century, January 1889, and subsequently collected in the book Intentions (May 1891). Pater's influence on Wilde's epistemological scepticism is addressed by Danson (1997) and Wright (2009: 99-105).

${ }^{214}$ Wilde reminds us that 'this unfortunate aphorism about Art holding the mirror up to Nature, is deliberately said by Hamlet in order to convince the bystanders of his absolute insanity in all art-matters' (CW 1082).
} 
what we see, and how we see it, depends on the Arts that have influenced us. To look at a thing is very different from seeing a thing. [...] At present, people see fogs, not because there are fogs, but because poets and painters have taught them the mysterious loveliness of such effects. There may have been fogs for centuries in London. I dare say they were. But no one saw them, and so we do not know anything about them. They did not exist till Art had invented them' (CW 1086). Wilde is here simply arguing that we cannot make sense of the sensory data we experience (what Wilde calls "seeing") until some order has been imposed upon them by highlighting (what Wilde calls "looking at") some aspects at the expense of others (which may be seen, but are not noticed as salient to experience). Wilde next famously applied this insight to the Japanese: 'do you really imagine that the Japanese people, as they are presented to us in art, have any existence? [...] The Japanese people are the deliberate self-conscious creation of certain individual artists. [...] The actual people who live in Japan are not unlike the general run of English people; that is to say, they are extremely commonplace, and have nothing curious or extraordinary about them. In fact, the whole of Japan is a pure invention. There is no such country, there are no such people' (CW 1088).

Art as the expression of nothing except itself is an elaboration of Pater's claim that experience is a completely private sensual continuum. Wilde simply develops what was already latent in Pater: we generate our own world and hover in it indefinitely. This further implies that our identities are also part of what we create. To exist is to generate oneself. Identity, or the self, becomes a work of art, a performance. Finally, for Pater the primacy of experience as a self-contained creation of self also implies that one must always maintain the flow of sensual impressions by 'for ever curiously testing new opinions and courting new impressions' (2010: 120). This is the infamous theory of sensual curiosity that scandalised readers because it could be read as an invitation to indulge in homosexual experimentation. ${ }^{215}$ To be a creative self is to indulge every curiosity, however morbid or sensual. These insights were of key strategic importance to Wilde, who was entangled, along with many other prominent homosexuals of his time, in an attempt to generate support for recognition of the homosexual identity. ${ }^{216}$ When Wilde published The Picture of Dorian Gray (first in Lippincott's Monthly Magazine in 1890, and the next year in expanded book form) it caused outrage because it was clearly perceived by critics as an apology for what was considered immoral sexual behaviour. There was also a clear autobiographical link which Wilde himself highlighted when he observed of the novel that it contains much of me in it. Basil Hallward is what I think I

\footnotetext{
${ }^{215}$ See Beaumont (2010: xx-xxvii) on the controversial reception of The Renaissance.

${ }^{216}$ The creation of late-nineteenth-century homosexual identity, and the way Wilde fits into it, is discussed by Dowling (1994).
} 
am: Lord Henry is what the world thinks me: Dorian is what I would like to be - in other ages, perhaps' (2000: 585). By creating a work of art that so clearly and unmistakably reflected on himself as a private person, Wilde was courting legal disaster. I will argue that in Salomé Wilde attempted to create a completely self-contained world that exemplifies the principles of his aesthetic. It puts into artistic practice the principles of the generation of self and world. Unlike Dorian Gray, however, there is no overt attempt at self-portrait in the play. If anything, the play shows us the inside of Wilde's mind, his ideal of what aesthetic experience should be: one long extended and self-contained sensual dream that has no relation to the outside world. I will show how Wilde achieves this encapsulated aesthetic dream in the play and then return to Russell's film, which reproduces this effect.

\subsubsection{Dreaming Salome}

Just like Russell's film initially found few defenders, Wilde's Salomé 'has long been considered thin, pretentious, and unoriginal' (Gilbert 1983: 133). I will try to adjust this view and show that Wilde's play is very tightly constructed. Salomé is structured as a continuous, undulating, but intensifying movement towards its brutal finale, which makes it a paradigmatic example of Paterian sensationalism as an enveloping experience. This structure also gives the play a musical quality. Wilde's friend, the writer Richard Le Gallienne, noted in a review of 22 February 1893 that 'it seems to build to music. Its gradual growth is exactly like the development of a theme in music' (quoted in Wilde 2000: 552n1). After his release from prison Wilde wrote a letter to Alfred Douglas claiming that the play's structure was modelled on the ballad form: 'The recurring phrases of Salomé, that bind it together like a piece of music with recurring motifs, are, and were to me, the artistic equivalent of the refrains of old ballads' (o.c. 874). The engine that drives this movement is Salome's childlike desire to get anything she wants because it has been promised her. For this reason Joseph Donohue has argued that the core theme of Salomé is 'unbridled curiosity and insatiable thirst for new experience' (1997: 126). In her attraction to John the Baptist and her demand for his head on a silver charger, Salome takes Pater's imperative of sensual curiosity to the extreme and has to suffer the penalty of death for her impudence. Curiosity kills the vixen. In this sense, 'the play is about illicit but overwhelming desire and its fateful clash with ultimate authority' and what is represented in Salomé is 'unquenchably strong desire itself (o.c. 121 and 130). ${ }^{217}$ Salome's childlike involvement in her own desire is made clear in her total obliviousness to

${ }^{217}$ Hanson (1997: 263-279) provides an excellent discussion of the theme of desire and seduction in Salomé in the context of Wilde's relation to Catholicism. 
the external world. At a certain point a Syrian guard who is in love with Salome commits suicide because he is jealous of her love for Iokanaan. He falls dead at her feet, but Salome doesn't even blink, let alone acknowledge this alarming intrusion. She is simply too wrapped up in herself to notice anything outside her own desire, which recalls $\mathrm{Pa}$ ter's claim that in the rush of solipsistic sensualism no voice from the outside world can reach us.

But Salome is not the only desiring person in Salomé. Throughout the play, the dynamics of desire unfold along the characters' lustful gazes. Characters constantly remark upon the way other characters look at people. At the beginning of the play Herodias's page repeatedly accuses the Syrian guard (who will kill himself) of looking at Salome too much (the page is in love with the Syrian guard). Later it is Herodias who repeatedly accuses Herod of looking too much at Salome. The way the characters look at each other expresses their desire for each other (the page wants the Syrian, who wants Salome, who wants Iokanaan; Herod wants Salome). Salome's thirst for new experience can also be traced through a narrowing of her desiring gaze as it moves over Iokanaan's body. Once she has laid eyes on him, Salome slowly becomes drunk on her impressions of him. After she has taken in the beauty of his body in its entirety, she focuses on its parts. She is first seduced by his voice ('Parle encore, Iokanaan. Ta voix m'enivre'; WS 81), after which it is his skin, his hair, and his mouth that she lusts for. But the journey of her gaze over his body is dialectical. Every sexual overture Salome makes, is forcefully repudiated by the Baptist. This in turn causes her to repudiate her own previous appreciation of his beauty: she calls ugly what she had first called beautiful. But in praising Iokanaan's beauty and next repudiating him (as he repudiates her) Salome demonstrates Wilde's principle that one can change or create the world of appearances through verbal descriptions of it. If Salome says Iokanaan's body is beautiful, it is beautiful. If she next says it is ugly, it becomes ugly. Nature imitates Art by force of will. Similarly, when she is finally face to face with the Baptist's severed head, Salome repeats several times that she will kiss it, again illustrating Wilde's claim that speech can create reality: she is already savouring the act and making it real through uttering it. And once she has kissed the head, she immediately uses language to extend the experience beyond the moment by repeating like a mantra that 'J'ai baisé ta bouche, Iokanaan, j'ai baisé ta bouche' (WS 165). Salome talks dirty to herself to extend the rush of her necrophiliac reverie. The fetishism of body parts in the play is finally also expressed in a remarkable stage direction that Wilde provides for the appearance of Iokanaan's head, which emerges from a well pushed up by 'Un grand bras noir, le bras du bourreau' (ibid.). The Executioner's 
arm is here objectified as support for the charger with the head. Together, arm and charger form a perverse objet d'art. ${ }^{218}$

Elliot L. Gilbert has argued that 'Salomé is essentially a play about power: about who is to have it, who is to exercise it, how it is to be transmitted' (1983: 148). This brings us to the question of who conjures up this world of intense mutual voyeurism. If Nature imitates Art because Nature is our private invention, then someone must be pulling the strings behind the scenes of Salome's final nocturne. If reality is all in our head, then whose head do these highly charged erotic events inhabit? I suggest, following the model of The Devils, that the world of the play is conjured up in a tug of war. Each character is projecting his or her own desires onto the others and onto the surrounding world. In the case of Salome this happens to the total exclusion of the exterior world. Witness her failing to (deign to) notice the death of the Syrian. But the person who stands most to lose in this war is of course Herod, the tetrarch, who is, nominally, ruler of this realm. Being the tetrarch he has a self-evident claim to being the sole author of the universe in which he exists' (o.c. 146), both in the artistic sense of creating his own fantasy and in the sense that, as ruler, he has absolute power over the external world, including the power to decide on life and death (as Salome will soon find out). But his power is challenged by Salome, who breaks the idyll of his fantasy with her sudden unreasonable demand for the Baptist's head. The fantasy thus disturbed, Herod cancels it altogether. He almost stops the play by literally pulling the plugs on it: he orders the torches to be extinguished, but also, and much more remarkably, to hide the moon and the stars ('Cachez la lune! Cachez les étoiles!'; WS

\footnotetext{
${ }^{218}$ Could it be that this passage in Salomé is connected to Wilde's embellished recollection of an event from his student days? In the Spring of 1877 Wilde made a trip to Greece with J.P. Mahaffy, his teacher from Trinity College, Dublin. The party visited the excavations at Olympia and Wilde later told Charles Ricketts that 'during the excavation I was present when the great Apollo was raised from the swollen river. I saw his white outstretched arm appear above the waters. The spirit of the god still dwelt within the marble' (quoted in Ellmann 1987: 69). Ellmann comments that, in fact, 'the head of Apollo, not his arm, had been found, but on dry land, and some days before Wilde got there' (ibid.). Wilde appears to have used the motif of the emerging arm on more than one occasion. But so has Russell. The objectification of body parts is also in evidence in his contribution to the film Aria (1987), in which his splendid visualisation of the Puccini aria 'Nessun Dorma' fetishises the body of a victim of a traffic accident in an Oriental fantasy that mirrors the over-decorated mood and colour patterns of Salome's Last Dance and culminates in a stunning shot of a white mannequin's dismembered body parts hovering in mid-air. The short film also features a muscular black man in the role of a priest who might be the twin of the equally beefy black Executioner in Salome's Last Dance. The moods, textures, and SM-inspired costumes of both Salome's Last Dance and Aria also show up in Russell's music video for the song 'It's All Coming Back to Me Now' (1989) by the all-girl band Pandora's Box. See Citron (2010: 76-90) for a close examination of Russell's segment in Aria that connects the short to Russell's music video for Sarah Brightman's recording of Andrew Lloyd Webber's 'The Phantom of the Opera' (1987) but does not mention the Pandora's Box video. I find this not very convincing because the Brightman video is actually closer to the style of Gothic (which I discuss later in this chapter). Finally, Russell might have taken some inspiration from the use of SM paraphernalia (especially in the Executioner figure) in Claude D'Anna's film Salomè (1986), an Italian production based on Wilde's play.
} 
165). Wilde's stage instructions at this point direct that the slaves extinguish the fires, but the stars simply 'disappear' ('disparaissent'; ibid.) and a black cloud moves in to cover the moon. Herod clearly fears the moon, who is associated throughout the play with some uncontrollable and threatening force. Herodias's page several times observes that 'la lune a l'air étrange!' (WS 73) and associates this strange air with death. After the Syrian has killed himself the page claims that he had suspected 'que la lune cherchait un mort' (WS 87) and berates himself for not hiding the Syrian from her influence. In the second part of the play it is Herod who remarks on the moon's strange air, which feeds into his many superstitions. For Herod not only fears the moon, but also Iokanaan, who is a prophet who might bring the wrath of his god over Herod's house. He also fears the rumours about Christ moving around the country, performing miracles, and raising the dead. The only person who is immune to all this superstitious moon-gazing is Herodias, who claims that all these people are fools and that 'Ils ont trop regardé la lune' (WS 115). Thus she equates moongazing with lunacy, which is literally moon-induced madness. So if you are a superstitious Herod with a dead Baptist on your hands, extinguishing the moon might seem like a good idea. But the only way Herod could command the moon and the stars in such a way would be if the entire fictional world of the play were his own creation. And it is. All the world's a stage, and the artist who creates the scene (in this case Herod) can manage its props at will. Or, as Wilde puts it in 'The Decay of Lying', Art 'makes and unmakes many worlds, and can draw the moon from heaven with a scarlet thread' (CW 1082). ${ }^{219}$

But once the lights are down Herod also calls the final curtain on Salome by having her killed. In this grisly act of brutal murder Herod restores his power over his own fantasy. We do not learn Herodias's response to this butchery, but we can imagine her lurking in the wings, plotting bloody revenge. At this point, however, it does not matter anymore, for with the darkening of the scene the characters have melted into air. But not entirely, for Art spills over into Life. At the very end of Russell's film something highly dramatic occurs, but it is dealt with in such a cavalier manner that it is easy to miss its importance:

\footnotetext{
${ }^{219}$ In the context of the late nineteenth century the image of the thread is highly suggestive. As Elizabeth K. Menon has pointed out in a discussion of dolls in French consumer culture of the time, the term poupée 'was often used to describe an actress, a use that conflated the meanings of poupée [doll] and pantin [hand puppet] since the theatre suggested actions being manipulated by an unseen force' (2006: 175). Both terms, however, also functioned in a semantic continuum with the term marionette, which is a puppet manipulated with strings (o.c. 167), which is exactly the kind of "unseen force" that Wilde is talking about here. Furthermore, the term poupée also applied to prostitutes (o.c. 176), which in turn connects to Russell's staging of Wilde's play in a brothel. Finally, it is perhaps not without relevance that Russell's mock science fiction novel Mike and Gaby's Space Gospel (1999) revisions the Bible as a story where Jesus is a kind of human puppet whose acts are coordinated by two aliens in a flying saucer. These aliens are also responsible for creating the special effects of Christ's miracles, which are all brought about via their powerful space technology. Here, again, the parallel with creating special effects in the theatre is obvious.
} 
Rose, the chambermaid who played Salome, is actually killed by the spear that pierces Salome. The murder in the play has been used as a foil for the murder of the girl. At the beginning of the film Alfred Taylor briefly threatens he might kill the girl if she does not perform properly. But it seems unlikely that he is behind the murder in some kind of reallife parallel to Herod's murder of Salome because he has no obvious reason for killing her. During the performance of the play, however, we see Herodias/Lady Alice disappear into a trunk behind the scenes to have sex with several actors who play Roman guards. At the end, when she and Wilde and Taylor are bundled into a Black Maria and the body of the girl is carried by, Lady Alice looks straight at the camera and proclaims that it was death through misadventure because the girl slipped on a banana peel. Salome had indeed eaten a banana during the performance and dropped the peel on the stage. But it obviously was not the peel that killed Rose. Lady Alice's triumphant tone suggests that she has used her feminine wiles on one of the actors playing the Roman guards to neutralise a sexual rival.

\subsubsection{Unveiling Salome}

By having Salomé performed in a huis clos situation, and in a brothel at that, Russell achieves something quite similar to the enclosed world of private sensual experience that Wilde generates in the play. However, the choice to limit most of the action in the film to one set was not merely artistic. Russell had to bring the film in on a very small budget and using only one set was a way of drastically cutting costs. ${ }^{220}$ But this necessity was made into a virtue, for by enclosing his entire virtual world in one room Russell could create his spectacle as if it were an exotic world seen under a glass jar. With its anti-naturalistic colours, its conscious use of anachronistic details (Salome licking a lollipop, bare-breasted women and Roman soldiers wearing black leather SM accoutrements) and especially its garish body paints and elaborately ornate costumes, the play-within-the-film looks like a theatrical specimen bred in a Huysmans hothouse ruled by Herodias, the regal orchid. What matters, is not the plot development in itself, which is pretty straightforward, but the overall experience of looking at (and listening to) the gorgeous spectacle. I suggest that this also explains why Wilde wrote the play as a one-act piece: to have no breaks or interruptions that could disturb the flow of experience for the viewer. ${ }^{221}$ Similarly, Russell's highly

\footnotetext{
${ }^{220}$ See Prasch (2009: 201) for the film's production history.

${ }^{221}$ Discussing Pater's style of writing, Monsman similarly observes that 'Pater's art perversely aspires, syntactically, to the atmosphere of a painting or a tapestry: static, pictorial, nonlinear. His complicated syntax, threatening always to break the cognitive sequence, resembles the highly inflected structure of the classical languages, which permits a more arbitrary order of words so that the sentence seems to present to the reader all of its parts simultaneously. [...] The nonlinear pattern of his prose served both as a metaphor of and an instrument in that pursuit and approach to pure synchronic duration' (1980: 37-38).
} 
ornate staging of the play treats the piece like an intricate objet d'art rather than a dramatic event. But Russell departs from Wilde and Pater because he does break the flow of events. His favourite device for doing this is breaking the fourth wall to either allow Wilde to comment on the performance or to show us the goings on behind the scenes (ill. 18). Just like he disrupts the "objective" facts of the lives of the artists about whom he makes his films, Russell disrupts the universe of Wilde's play by sabotaging its flow. By doing this, Russell is again referring to his critical reputation. Some critics have suggested that Russell's films tend to degenerate into a structural vaudeville: a series of only loosely connected sequences that are devised to impress us in their own right. Reviewing Tommy, David Wilson claimed that the film 'remains a series of separate units linked only by a disparate if vigorous style. Which is a fair capsule description of Russell's film-making style' (1975: 192), while Jan Dawson earlier wrote of The Boy Friend that 'Russell's musical numbers succeed one another like entrants in a beauty contest, each soliciting admiration' (1972: 112). But this is exactly the way Russell treats Wilde's Salomé, presenting us with exquisitely performed sections of the play intercut with campy meta-silliness. ${ }^{222}$

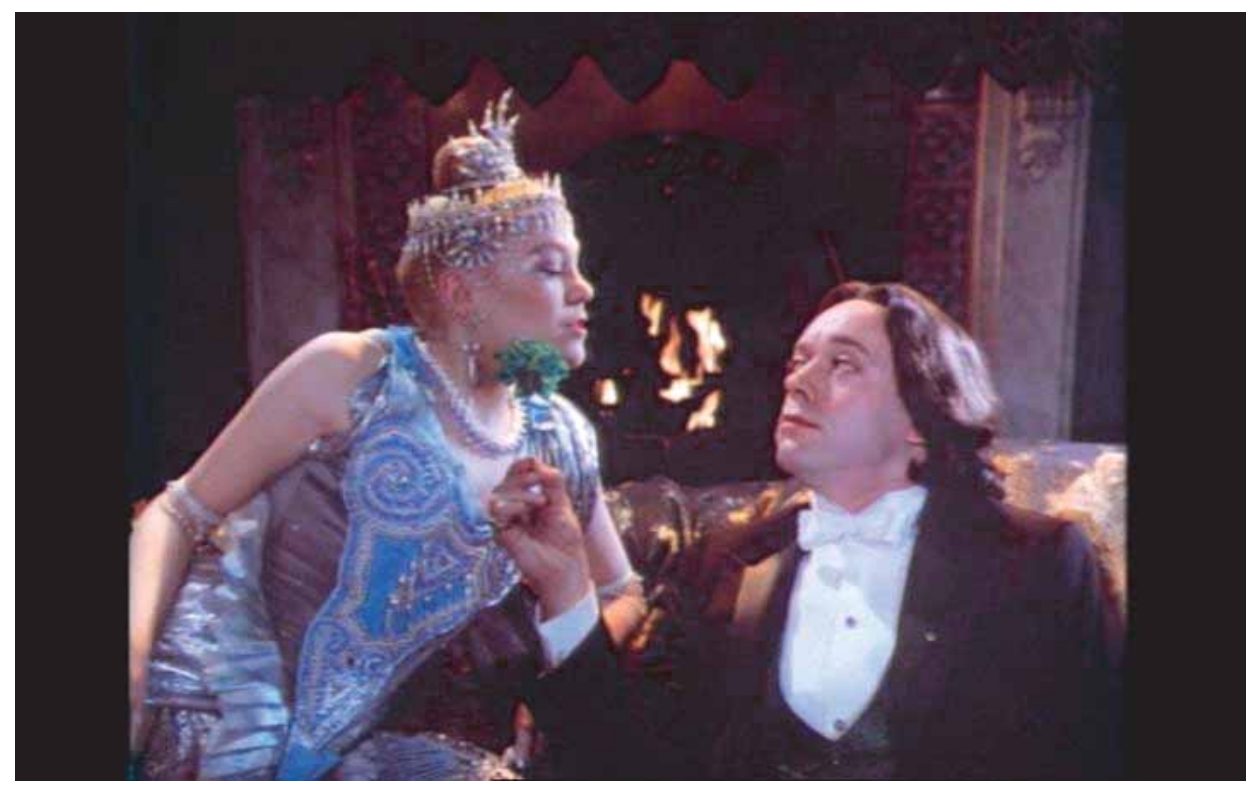

Illustration 18 Fourth wall? Oscar Wilde and Salome exchange a carnation

\footnotetext{
${ }^{222}$ The notion of Russell's films as disconnected sequences in a pageant recalls the discussion of processional stagings of Passion plays in the context of The Devils. One can also see this structure in Tommy, with its sequence of highly achieved segments (the Acid Queen segment, the Cousin Kevin segment, the Uncle Ernie segment, and so on).
} 
The high point of the play is of course the dance of the seven veils. In Russell's treatment there is an added frisson because as the last veil drops (to the tunes of Grieg's 'In the Halls of the Mountain King ${ }^{223}$ ) Salome is briefly shown with a penis. It has been suggested that the gender switch came about because Millais-Scott was weakened through illness and needed a body double for the dance sequence. ${ }^{24}$ Russell found a male dancer of similar physique and included a brief full-frontal shot of the young man flashing his genitals as a kinky visual surprise for Wilde (and us). But Russell also provides a diegetical justification for this flash. Herod is quite drunk by the time Salome starts dancing, and in his inebriated perception (suggested via a number of point of view shots of Salome from Herod's position) there very briefly appear two Salome figures simultaneously just before the climactic revelation. These doubles almost immediately melt back into one. When the reconstituted Salome next flashes her suddenly male physique, this startling sight is immediately drowned in the flash of Kenneth's camera, capturing the saucy moment, after which a proudly full frontal nude Salome has been reconstituted a woman, ready to collect her reward. For the critic, however, this brief moment opens a can of worms. The dance of the seven veils has acquired almost mythical stature in the critical literature. Critics have projected so much onto it that it is rather sobering to find that Wilde's stage directions for it are a mere 'Salomé danse la danse des sept voiles' (WS 141). It is unclear from this how the dance is supposed to be staged. Possibly there was some naughty speculation about it on the part of Wilde himself and Aubrey Beardsley, who created the famous illustrations for the play (some of which are shown during the opening credits of the film). There is a copy of the play with a dedication to Beardsley dated (in Wilde's hand) 'March '93. For Aubrey: for the only artist who, besides myself, knows what the dance of the seven veils is, and can see that invisible dance' (Wilde 2000: $578) .^{225}$

\footnotetext{
${ }^{223}$ It is at first sight surprising that Russell did not use Richard Strauss's dance of the seven veils from his opera based on Wilde's play. However, after the highly controversial Dance of the Seven Veils (1970), which outraged the Strauss heirs with its depiction of the composer as a Nazi, it seemed unlikely that Russell would ever again be able to clear copyrights for the use of Strauss's music on any of his projects. Remarkably, however, he did follow up on Salome's Last Dance with a 1993 staging of Strauss's opera at the Opera House in Bonn (Lanza 2007: 277). Since I have not seen this staging (and know of no video recording of it) I have not included it in my discussion.

${ }^{224}$ See Lanza (2007: 275-276).

${ }^{225}$ Within a decade of Wilde's play all veils of propriety and reticence would be dropped and, encouraged by the success of Richard Strauss's 1905 opera based on Wilde's play, a veritable Salome craze briefly captured the imagination of modern dancers and audiences alike. Perhaps the most famous Salome dancer was Maud Allan, who created a wildly successful routine called "The Vision of Salome" (Koritz 1994; Bentley 2002: 47-84; Walkowitz 2003; Brunotte 2011 and 2012).
} 
However, Wilde's sparse directions have not prevented some critics from finding all manner of coded meanings in the dance. Amanda Fernbach, for instance, argues that the dance 'signifies gender undecidability and subsequently allows for the masked expression of gay erotics, as the body of a potentially male Salome is eroticised through the sexually charged dance. As a fetishistic or male homosexual fantasy, Salome's dance has the power to seduce only while a last veil remains' (2001: 201). This suggests that Fernbach has been looking at Russell's film rather than reading Wilde's text. But she is not alone. In his discussion of the critical reception of Salome's Last Dance Thomas Prasch points out that several critics have been tempted to see Wilde's Salome as an androgynous figure. They usually rely on a combination of sources including Aubrey Beardsley's highly androgynous illustrations for the play, a famous photograph of Wilde himself posing in drag as Salome, and Russell's gender-bending revelation in the film. ${ }^{226} \mathrm{We}$ now know that the person in the photograph is not Wilde but the actress Alice Guszalewicz, who looks uncannily like him. ${ }^{227}$ As for Beardsley's images, they (briefly) postdate the writing of the play and are works of art in their own right. As such they, as much as Russell's film, already constitute an interpretation of the play, which makes it hazardous to infer anything about intended or implicit androgyny in Wilde's play from (androgyny in) Beardsley's images. ${ }^{228}$ There is nothing in the play to suggest that Salome is a character of uncertain sex or gender. ${ }^{229}$ Hence, the flashing of the penis in the film is

\footnotetext{
${ }^{226}$ See Prasch (2009: 203-204). In her similarly problematic discussion of Wilde's play and its diverse artistic progeny, including Beardsley's illustrations, Elaine Showalter asks whether 'Salome's love for Jokanaan [is] a veiled homosexual desire for the male body' (1991: 149-168, here 151). While this is a very sensible suggestion (Wilde has projected his own desire for men into the Salome character) it in no way implies that the sex or gender of Salome herself is somehow unstable or undecidable.

${ }^{227}$ See Holland (1997: 10-12) for a discussion of this remarkable lookalike photograph which was included, without commentary and apparently at deadline editing, in Ellmann's biography of Wilde, giving the attribution the stamp of Ellmann's authority.

${ }^{228}$ Beardsley was commissioned to create illustrations for Salomé after Wilde had seen his drawing J'Ai Baisé Ta Bouche, Iokanaan, which Beardsley had made on his own initiative after reading the play and which Wilde had liked. As Nicholas Frankel points out, 'though inspired by Wilde's play, J'Ai Baisé Ta Bouche, Iokanaan plays no direct role in the textual life of Wilde's play' (2000: 62). He adds that 'discussions of Salome as a work of perverse or androgynous sexuality more accurately owe their point of origin to Beardsley than to Wilde' (o.c. 66).

${ }^{229}$ This is not to deny that, in the context of Victorian ideas about the nature of woman, Salome transgresses gender boundaries: as a sexually aggressive woman she would have been the object of concern and even disgust. But such transgression does not cast doubt upon her sex. On the contrary: it is only because she is so obviously a woman that her sexual behaviour can seem monstrous. Dijkstra (1986) and Menon (2006) have traced how notions of feminine evil, including the association of female sexuality with original sin and degeneracy, inform the iconography of the visual arts and popular culture in the Victorian era. The cultural background to such anxieties about femininity, degeneration, and moral evil is sketched very deftly by Stott (1992: 1-30) and connected to a number of medical texts, such as Nordau's work on degeneracy, by Smith (2004: 1444). But the opposite approach also existed. Richardson outlines how woman was biomedically defined as
} 
Russell's own saucy joke (after all, he could have found a female substitute for MillaisScott). To infer too much about the figure of Salome (or Wilde's intentions) from this brief revelation is to overstep the boundaries of critical caution. The implications of all of this for the mythical dance of the seven veils seem rather minimal. What started as an eloquently minimalist stage direction in Wilde's play has ballooned into a critical fetish for people who mistake other artists' interpretations of a colleague's work for keys to the original artist's intentions (and fictitious characters' nether parts). In fact, Wilde was probably correct not to detail the dance of the seven veils because he must have known that nothing within the bounds of what could legally be represented on a British stage would ever live up to the wild fantasies that the notion of such a dance conjures up in sexually overheated minds. This also explains why critics have felt so free to bring to it what they want. But whatever they bring to it, or read into it, is of their own creation and brings to mind Wilde's famous and ingenious comment on the supposed homosexual content of The Picture of Dorian Gray: 'Each man sees his own sin in Dorian Gray,' Wilde wrote. 'What Dorian Gray's sins are, no one knows. He who finds them has brought them' (2000: 439). ${ }^{230}$ Similarly, what critics find in the unspecified dance of the seven veils is something they bring themselves. For this reason it might sometimes be wise to heed Herod's advise in the play that 'Il ne faut pas trouver des symboles dans chaque chose qu'on voit. Cela rend la vie impossible' (WS 137).

\subsubsection{A Dramatic Case of Death}

Poor Rose. In the process of stripping away the many layers that make up the seductive surface of both Salomé and Salome's Last Dance we seem once again to have lost track of her. But her theatrical death opens up a baroque understanding of Russell's film that connects back to Chapter One, where I argued that Baroque theatre thrived on the thrill of knowing that the audience knew that everything was a performance. This made it

moral and charitable by nature. This way 'morality was biologised as the basis of morality was altered from "duty" or mission to "instinct"' (2003: 33-57, here 45). This view of woman, which was just as repressive as the stereotype of evil, was articulated in the ideal of woman as "angel in the house" (Dijkstra 1986: 3-24; the phrase is taken from an 1854 poem by Coventry Patmore). Specifically in the case of Salome, feminine evil was also connected to widely disseminated anti-Semitic theories about the racial inferiority and moral evil of both women and Jews: see Gilman (1993, esp. 199-203 for a discussion of Oskar Panizza's play Liebeskonzil). Russell returned to the topos of the transgressive/monstrous woman in Victorian culture in The Lair of the White Worm (1988), adapted from Bram Stoker's 1911 novel and in which a bisexual serpent-woman is the central sexual predator.

${ }^{230}$ Hanson (1997: 287-291) provides an excellent commentary on this famous bon mot. Of Wordsworth, whose work will be discussed later in this chapter, Wilde observed, in 'The Decay of Lying', that 'Wordsworth went to the lakes, but he was never a lake poet. He found in stones the sermons he had already hidden there' (CW 1078). 
possible for authors to introduce plays-within-the-play, because they knew that the audience knew how to read such shifts in narrative level. It also means that there was room to play with these conventions, allowing several narrative levels to spill over into each other. Frames seem to become porous, with actors mingling among the spectators, or even spectators sitting on the stage and performing as spectators-in-the-framingplay. In Salome's Last Dance Russell plays with this permeability of the baroque stage. By constantly breaking the fourth wall between the performers on stage and Wilde he allows the parallels between their real-life relationships and the relationships between the characters in the play to come to the fore (as he had previously done in The Debussy Film). By introducing himself into the film and the play, Russell further exploits the interconnectedness of reality and fiction. Apart from performing a parody on his own reputation as a cultural pornographer, Russell can also be seen handling the stage effects, such as lightning and thunder. As such, Kenneth, the character played by the reallife Kenneth Russell, is responsible for the machinerie of the play. In this respect, Russell's self-dramatisation has an interesting historical parallel if we consider that, in L'Impromptu de Versailles, Molière introduced himself as a character in his own play, commenting on how it should be performed, generating a mise-en-abyme. Similarly, in Salome's Last Dance, Russell is the writer of the screenplay (or at least the framing narrative!), the director of the film, and an actor in the film. But as actor in the film he performs a role that is a parody of himself, photographing naughty bits, managing stage effects, and, ultimately, also showing up as a character in the play-within-the-film. Whatever we learn about Russell in this film, we know and learn through the art. His self-portrait as Kenneth is itself a performance. Similarly, Wilde himself is presented, in the film, as an artistic performance, for a large chunk of his dialogue in the film is actually a collage of a number of his famous witticisms and aphorisms. Wilde is constructed almost entirely as a literary work of art.

Now for death. By having Rose killed, a final historical resonance is brought into play, for it brings to mind the legend of Saint Genesius, the patron saint of actors whose story was very popular in the Baroque and was the subject of, among others, Rotrou's play Le Véritable Saint Genest (1645/46). According to legend, Genesius played the role of a Christian martyr for the emperor Diocletian but, through divine intervention, found he had actually been converted by the end of his performance. Outing himself as a Christian he suffered the fate of the character he portrayed: 'a real martyrdom on the very stage on which he had just been prepared to fake it' (Egginton 2003: 1). This in turn conjures up another story, possibly real, possibly an early modern urban legend. It is said that, during a performance of Judith and Holophernes in 1549 in Tournai, the actor playing Holophernes was actually killed during the performance. The actor was in fact a 
convicted murderer who had, according to the legend, been presented with the choice between two modes of execution: either to be skinned alive or to be beheaded on stage in the guise of Holophernes. He chose the latter, possibly because he speculated on the actress playing Judith not having the stomach to actually perform his murder on the stage. He might survive his execution after all. Unluckily for him, his executioners had also thought of this possibility and had the actress replaced by a (cross-dressing) young male convict, promising him a pardon if he would don the dress and do the deed. Needless to say, blood was shed and (the actor playing) Holophernes left the stage feet first. ${ }^{231}$ Whether the story is authentic or not, it clearly illustrates the tension Baroque theatre liked to generate between the appearance of reality and the reality of appearance. In Salome's Last Dance Russell has used these Baroque tropes to the full, generating a wealth of resonances that mirror each other endlessly. Like a Baroque magician, or a Prospero conjuring up the baseless fabric of cardboard palaces peopled with leering tetrarchs and diamond-studded vixens, Russell directs Salome's Last Dance as a luxurious hall of mirrors. The reality lurking behind the screens of this performance, perceived only in flashes, is the man pulling the scarlet threads that keep the film, the play, and the general revelry of these moonstruck follies in check.

\subsection{PHANTASMAGORIANA: GOTHIC AND ROMANTIC GENIUS}

All of life is a dream created by people pulling scarlet threads. Clearly, in the case of performing Salomé, but also in the case of making a film called Salome's Last Dance, pulling the threads of reality is making the work of art. Creating reality is creating an illusion. But can we learn more about how Russell creates his illusions? I have already analysed Russell's narrative structures in detail, but a film is more than a narrative structure. In fact, narrative structure is common to all narrative art (including the novel, the theatre, the opera, and other art forms). It is not at all specific to the film. The question is therefore whether there is something specifically cinematic about Russell's films, something in the way they are constructed as films, which provides further insight into the way Russell creates his performance of himself. These questions invite us to deepen the inquiry into Russell's poetics. An important opening was already created at the end of Chapter Three, in my discussion of Russell's film on Isadora Duncan. But that was

\footnotetext{
231 This legend, which may or may not be (partly) true, is analysed and contextualised in detail by Enders (2002: 182-195) and given a briefer treatment by Biet (2003: 86-87). On the theatrical representation of violence in early modern France, see Biet (2006), Biet and Fragonard (2012, esp. 93-101 on the technologies used to create the effects of torture and execution on stage), and Vanhaesebrouck (2013).
} 
just a first step. Russell's most sustained reflection on the creative process can be found in Gothic (1986), where he develops a swirling sequence of visions and hallucinations around one of the most popular literary legends in modern Western culture: the night at the Villa Diodati in 1816 when Mary Shelley reportedly had the idea that would become Frankenstein. ${ }^{232}$ This film is on the one hand a story about artistic creation. In this it follows Mahler, Isadora Duncan, and Savage Messiah in their attempts to make the creative process explicit. But on the other hand the film does not only develop a poetics that clarifies the creative process, it also puts this poetics into practice. ${ }^{233}$ I want to juxtapose the principles of artistic creation that Gothic is about, and which are drawn from Mary Shelley's Introduction to Frankenstein, with Wordsworth's 1802 Preface to Lyrical Ballads and with the way Gothic is put together as a film. The principles of montage as developed by Sergei Eisenstein, and which cover not just cinema but all the arts, will be the bridge between the film and its literary sources. Through this triangulation of texts (Russell, Shelley, Wordsworth) I will argue that the Romantic philosophy of artistic creation as articulated in the texts by Shelley and Wordsworth is deeply similar to Eisenstein's theory of montage: in each case the creation of art is a process of collage or bricolage, where the genius of an artist is not their capacity for creating something entirely new ex nihilo but a capacity for taking diverse elements and amalgamating them into a new work.

\footnotetext{
${ }^{232}$ In her important reassessment of the heritage film genre Dianne F. Sadoff has called Gothic a 'cheeky film' and a 'faux British heritage film' that should be read as a 'parody of literary production (and, implicitly, filmic adaptation)' (2010: ix, x, xi); but while I agree with Sadoff's claim that 'Russell, often reviled by reviewers as a producer of kitsch, is smarter about history and literary periodisation than his detractors admit' (o.c. xi) I cannot see this film as a parody. While there are certainly a number of grotesque exaggerations and moments of camp in the film, not to mention its self-conscious homage to Hammer horror, I nevertheless read this as a serious film that makes important points about artistic creation.

${ }^{233}$ The screenplay for Gothic was written by Stephen Volk and presented to Russell. Volk must therefore take some of the credit for the ingenious way in which the film is constructed, just like Melvyn Bragg had previously (co-)scripted The Debussy Film and The Music Lovers, in which embedded narratives were also key to the films' structure. Russell said at the time that he had been thinking of filming the topic for a decade when Stephen Volk's script came his way. He said he found the script 'very good: one of the best ever presented to me. I have only made minor modifications to it' (quoted in Pilard 1987: 12). He later changed his mind and claimed that 'I don't much care for [Gothic]. I didn't write the script. I thought it was morbid, a bit mundane. [...] The only thing I like is the headless dummy playing the harpsichord. That was my idea' (quoted in Sutton 2002b: 18). Volk also recalls that 'the original script was bookended by scenes with Mary Shelley on her deathbed, as unreliable narrator. But Ken wasn't interested in Mary Shelley's fantasies, he was interested in Ken Russell's' (Volk 2013: 62).
} 


\subsubsection{It Happened One Night: Myths of Origin}

With Gothic Russell made yet another film that is structured entirely as an embedded narrative that explodes into a vertiginous mise-en-abyme. Like The Debussy Film before it, Gothic lets its several narrative levels flow seamlessly into each other, although Gothic is in this respect Russell's most radical experiment because in this film 'the line between reality and fantasy is not simply blurred but destroyed' (Cook 1996: 581). And as in many of the previous discussions, tracking how Russell embeds his narratives is the best way to understand how the film works. Gothic opens on the shores of Lake Geneva in 1816. A tourist guide is explaining to a group of British tourists that Lord Byron, famously claimed (by Lady Caroline Lamb, one of his mistresses) to be 'mad, bad, and dangerous to know,' is living in exile in the Villa Diodati across the lake. He then helpfully directs a tourist's telescope to the 'bedroom, top right,' where we see the image of Dr Polidori (Timoth Spall), Byron's private physician, gazing out over the lake. Russell then cuts to a shot from inside this room, looking over Polidori's shoulder as three unexpected visitors arrive in a rowing boat. They are the poet Percy Shelley (Julian Sands), his lover Mary Shelley (Natasha Richardson), and Mary's stepsister Claire Clairmont (Myriam Cyr), who is pregnant with Byron's child. With this abrupt cut across the lake we have entered the embedded stage: the Villa Diodati. It is the main stage of the drama, observed by the peering audience across the lake. As such, the goings-on of these Romantic poets débauchés are presented as a performance on the stage of the Villa Diodati. In fact, when the company is seated for dinner Byron (Gabriel Byrne) explicitly tells them that they should blind the peeping tourists with their wickedness to keep up their reputation for scandal and outrage. ${ }^{234}$

Like the city of Loudun in The Devils or the whorehouse of Salome's Last Dance the Villa Diodati becomes a self-enclosed world or stage upon which an intricate psychodrama is played out. As in Salome's Last Dance the action is limited in space and time, spanning just one night. Immediately after their arrival Byron treats his guests to liquid laudanum, which will remain their beverage of choice throughout the proceedings,

\footnotetext{
${ }^{234}$ This is very much in tune with Byron's knack for self-dramatisation. The exiled Byron's risqué letters to his publisher, John Murray, are a great example of how Byron styled his public persona, as he knew very well that Murray would be reading them aloud to a select company of cognoscenti, who would then spread the word of Byron's wickedness through the outraged London upper classes. Byron's letters 'in effect were public bulletins' (MacCarthy 2003: 341) and the poet Leigh Hunt later observed that Byron 'had an incontinence, I believe unique, in talking of his affairs, and showing you other people's letters. He would even make you presents of them; and I have accepted one or two that they might go no further' (quoted in o.c. 400). Besides such epistolary theatrics much of Byron's poetry is of course shot through with autobiography and characters and events drawn from life. On this, see Barton (2010).
} 
although it is important to note that Mary Shelley declines the opiate and seems to drink only water. As a potent hallucinatory drug the liquid laudanum ensures straightaway that the factual status of everything that follows will be in doubt: as soon as the druginduced high sets in, the line between reality and hallucination must necessarily be blurred. ${ }^{235}$ The company then entertain each other by reading ghost stories which they each visualise in their minds. By showing us these fantasies Russell creates a second embedded layer (embedded imagined narratives). After a storm breaks out Byron and Shelley engage in a debate on the possibility of lightning creating life. They decide to take things farther: they will hold a seance to try and wake the dead and bring their fantasies to life. During the seance Claire has a seizure that brings the conjuring to a halt. But as the night progresses and the personal tensions between the protagonists increase it becomes apparent that the seance has actually brought their deepest fears to life. As supernatural occurrences multiply it becomes impossible to determine whether all of this is real, imagined, or hallucinated under the influence of laudanum. It is at this point that the embedded narrative layers collapse into each other: once the line between reality and hallucination is blurred we are left with a stream of images of which it is impossible to determine on which narrative level (or which level of factuality) they are taking place. In a desperate attempt to contain the demons they have unleashed a second seance is organised. But Mary interrupts the seance by crashing the skull around which they are gathered. She goes into hysterics, flees the scene, and descends into a rush of hallucinations brought on by her mental collapse. Finally, the storm subsides and a new day begins. 'There are no ghosts in the daylight,' Byron reassures Mary over breakfast in the garden, while Mary herself announces she has conceived the story that will become Frankenstein. As the natural order is restored we return to the framing

\footnotetext{
${ }^{235}$ Laudanum was an alcoholic tincture of opium, of which morphine and heroin are also derivatives. Although the Romantic opium addicts were referred to as "opium eaters", as in the title of De Quincey's famous book, they actually drank it in the form of laudanum. As Hayter (1971:29-35) explains, laudanaum was widely used for many medicinal purposes in the early nineteenth century because its dangerous properties were not fully understood and it was so cheap that even the poorest of the poor could afford it. It was also completely legal. Even children were given it. Russell himself may not have indulged opium, but he did suffer from a severe snuff addiction (on account of the nicotine) in the 1950s. In one of the most memorable passages in his autobiography he explains how he was "miraculously" cured from his addiction when he could not reach for his snuff box while travelling on a bus clutching a newly bought plaster statue of the Virgin Mary (BP 188-192; AT 101-102). Afterwards, he shunned drugs, except for one experiment in preparation/research for Altered States (BP 175-184). The theme of Romantic drug-taking was previously addressed in Dante's Inferno (1966) on Dante Gabriel Rossetti and in Clouds of Glory: The Rime of the Ancient Mariner (1978) on Coleridge. In Tommy the celebrated 'Acid Queen' sequence (featuring Tina Turner) was a hallucinatory high-point of the movie. Of course, Altered States is the Russell film that more than any other thrives on its impressively achieved hallucination sequences: see the discussion of its production and effects in Clarke (1981) and Yakir (1981).
} 
narrative, but with a temporal difference: we now see late-twentieth-century tourists visiting the Villa Diodati as a guide's voice explains over a loudspeaker what became of the several protagonists of that fateful drug-fuelled night. ${ }^{236}$

As a self-enclosed universe Gothic accomplishes a remarkable unity of time, place, and action: it encompasses the events of just one night in which a foundational Gothic text was born out of an avalanche of supernatural events. This clearly marks the film as an instance of Gothic fiction, which conventionally places a group of people in an old house where they are confronted with supernatural phenomena that suggest that the boundaries between our world and another dimension have been breached. The film's title can in this respect be seen as a declaration of its genre: it is a Gothic fiction about the site of origin of another Gothic fiction. ${ }^{237}$ To enhance this sense of unity Russell again "telescopes" events. On 25 April 1816 Byron had fled England after separating from his wife, hounded by scandalous rumours of incest (with his sister, Augusta Leigh) and sodomy (with several boys and young men during his student years and also during his journeys in the Middle East between 1809 and 1811), the latter a capital offence in Regency England. Byron travelled with his personal servant William Fletcher and his page Robert Rushton, the latter 'my great favourite' (quoted in Crompton 1985: 132) and possibly one of his lovers ${ }^{238}$, and had also invited the young Dr Polidori along as his personal physician, although he would soon find Polidori a disagreeable travel companion. When Byron arrived in Geneva the Shelley party were already there, pursued by their own share of scandal. Percy Shelley, who was married to Harriet Westerbrook, had eloped with nineteen-year-old Mary Godwin, daughter of William Godwin and Mary Wollstonecraft. They already had an infant son, William, born in January 1816 (a previous child, born prematurely in February 1815, had died after several days). They were accompanied by Jane "Claire” Clairmont, Mary's stepsister. In the months before his

\footnotetext{
${ }^{236}$ The modern-day visitors to the Villa Diodati may be taken as a reference to the "heritage" phenomenon in British culture in the 1980s: the conservative politics of Margaret Thatcher which viewed national heritage as an exploitable commodity that could and should become a heritage industry (see footnote 8 ). At the same time the connection to the present may also be seen in view of the New Romantics phenomenon in fashion and popular music of the 1980s, which was in full swing when Gothic was made. Interestingly, in the promo-film for his single 'Blue Jean', which was culled from a twenty-minute short film, Jazzin' for Blue Jean (1984) directed by Julien Temple, David Bowie appears as the pop performer Screaming Lord Byron clad in Oriental dress: see Paglia (2013: 69).

${ }^{237}$ See Hogle (2002: 2-3) for the narrative characteristics of Gothic fiction. It is worth pointing out that the film is also a deliberate homage to Hammer horror films, which would often draw on Gothic texts and conventions, not in the least in extensive Frankenstein and Dracula franchises. Stephen Volk, who wrote the script for Gothic, claims that 'this is a Hammer film, in all but name' (2013: 62). Russell would continue the homage, but this time with tongue firmly in cheek, in The Lair of the White Worm (1988), based on an obscure Bram Stoker novel.

${ }^{238}$ On Byron and Rushton, see Crompton (1985: 130-132) and MacCarthy (2003: 78 and 96-97).
} 
exile Claire had managed to insinuate herself into Byron's attentions, and she now hoped to intercept Byron in Geneva, knowing that she was pregnant with his child (their daughter, Allegra, would die at the age of five). When Byron arrived in Geneva, the Shelley party were staying in the Hôtel d'Angleterre, 'the regular stopping point for all well-to-do English travellers passing by the Lake' (Holmes 2005: 323). Although Russell's film suggests a familiarity between the poets, this was actually the first time Byron and Shelley met. The Shelley party next moved to the chalet of Montalègre across the Lake, while Byron rented the nearby Villa Diodati. They would spend most of that unusually wet and gloomy summer in each other's company while, as Byron later complained, 'I was watched by glasses on the opposite side of the Lake, and by glasses too that must have had very distorted optics' (quoted in MacCarthy 2003: 255). It was, in fact, Mr Dejean, proprietor of the Hôtel d'Angleterre, who rented out telescopes to British guests who wanted to ogle the notorious poet in exile. ${ }^{239}$

By placing Byron already at the Villa Diodati, welcoming his visitors, the stage of the huis clos in Gothic is immediately and effectively achieved. Suggesting (contrary to historical fact) that the poets had met before and were already friends also helps to speed up the characterisation and makes it possible for the film to exploit Byron's reputation for sodomy and develop a strong homo-erotic bond between Byron and Shelley. Once everyone is inside the house, the film telescopes events that happened throughout the summer into one night. The company did begin reading each other ghost stories, and one of the volumes they read from was called (as it is in the film) Phantasmagoriana, a French translation of German ghost stories. One evening, Byron read from Coleridge's Christabel and Polidori recorded in his diary that after reading a passage describing the witch's breast 'Shelley suddenly shrieking and putting his hands to his head, ran out of the room with a candle. He was looking at Ms. S, and suddenly thought of a woman he had heard of who had eyes instead of nipples' (quoted in o.c. 292). This scene has found its way into Russell's film, where Shelley's vision is visualised twice: first, as a drawing in Shelley's sketchbook, and second as one of Shelley's hallucinations when Claire's nipples open up to reveal eyes. Byron next suggested they should write their own ghost stories and read them to each other. Polidori began a story about a skull-faced woman who peeped through key-holes, but it was abandoned. The story is mentioned only at the end of the film. ${ }^{240}$ Byron wrote a fragment about a vampire, which was later published as a

\footnotetext{
239 This brief sketch of the historical circumstances is indebted to MacCarthy (2003: 290-306) and Holmes (2005: 319-334).

${ }^{240}$ The historical Polidori had been an outstanding medical student who had attracted attention with a study of somnambulism. He also had literary ambitions, but these were mocked by Byron and Shelley. During the Diodati summer he and Mary became friends, but he seems not to have recovered from the humiliation at the
} 
postscript to Mazeppa. Notoriously, this story was developed further by Polidori and published anonymously as The Vampyre (1819). It was widely believed to be Byron's work and started the cult of vampirism that would culminate in Bram Stoker's Dracula (1897). ${ }^{241}$ The most lasting document of that summer, however, was Mary Shelley's Frankenstein (1818). In the Introduction to the 1831 re-edition of the book Mary reconstructed the events of that summer and explained that the idea for Frankenstein came to her after an evening listening to Byron and Shelley debating the scientific possibility of bringing dead matter to life through electricity. Clearly, the historical events on which the film is based were not as distraught as the night depicted in the film, but many of the film's narrative and visual details do collapse into one encapsulated event a number of reported historical facts.

But it is of course not the aim of Russell's film to provide a historically accurate account of the events of the summer at Villa Diodati. Gothic is a story about creation. And Mary Shelley is at the heart of that story. She is our point of identification: the film's central and most powerful hallucinations are constructed entirely around her fears and are seen from Mary's point of view. Mary's fears are concerned with death, first and foremost the death of her first child. As she tells Polidori before she joins the seance: 'My fear is, doctor, that I'd give anything to bring that child back to life again'. ${ }^{242}$ Most essentially, however, Russell's film is about artistic creation. Of course, the whole myth of the origin of Frankenstein is itself already a story of artistic creation. But it remains in many ways an external story, connecting a number of recorded facts into a genealogy of an artistic idea. ${ }^{243}$ Underneath this surface layer of narrative reconstruction, however, Russell presents a second story of creation, which is much more difficult to reconstruct

hands of the two great Romantic poets. He committed suicide several years later and in her Introduction to the 1831 edition of Frankenstein Mary Shelley seems to evoke the tone of casual dismissal he must have suffered when she writes that 'poor Polidori had some terrible idea about a skull-headed lady who was so punished for peeping through a keyhole - what to see I forget - something very shocking and wrong of course; but when she was reduced to a worse condition than the renowned Tom of Coventry, he did not know what to do with her' (1992: 7).

${ }^{241}$ On the intricate lines of parentage that stretch from Byron and Polidori's vampires (but reaching back to earlier sources and traditions) to Stoker's Dracula (1897), see Frayling (1991: 3-84).

${ }^{242}$ A few days after the death of her first child, Mary had recorded in her Journal a 'dream that my little baby came to life again; that it had only been cold, and that we rubbed it before the fire, and it lived' (quoted in Hindle 1992: xv).

${ }^{243}$ See Sadoff (2010: 105-109), Butler (2012; orig. 1993), Hindle (1992), and Pollin (1965) for discussions of the many scientific, philosophical, and literary influences that have likely informed Mary Shelley's creation. Since Frankenstein was initially published anonymously and attributed to Percy Shelley, Mary Shelley's authorship of the book has been repeatedly questioned. Careful editing of the surviving manuscripts has now definitively established that the novel is Mary's work with only small additions and insertions by Percy (see Robinson [2008] and Hebron and Denlinger [2010: 79-87]). Shelley (2008) presents an edition of the manuscripts highlighting Percy Shelley's contributions. 
historically. This is the story of the internal creative process. The purpose of the film's extended hallucination scenes is not simply to give us, the film's spectators, an evening's lurid entertainment on the back of well-known stories, myths, and half-truths about the lives of the British Romantics. The hallucinations are also an attempt to visualise the internal processes or, if you will, the work of genius that happened inside Mary Shelley's psyche in the moments she conceived of a work of art. And it is at this point, of course, that the mise-en-abyme does its work because, by presenting us with a stream of images that is an attempt to capture on film something of the structure of the process of artistic creation, the film not only presents the process of artistic creation but also comments upon it. And since both the presentation and the comment are presented in the form of a film directed by Ken Russell all of this necessarily tells us something about Russell himself and about the way he looks at art and artists, and at himself as an artist. So let us start by taking a closer look at the way Russell constructs his stream of images and put his methods alongside some elements of Mary Shelley's own meta-narrative on the creation of Frankenstein.

\subsubsection{A Disposition To Be Affected: Romantic Genius}

In the previous chapter I argued that in Isadora Duncan Russell took us into the performance of Isadora's dancing in an attempt to capture there (in a process similar to direct cinema) something of the spirit of the artist. The aim of the film was to create an illusion of direct knowledge, of being there and feeling something of the excitement that the historical Isadora Duncan created. Gothic does something similar: by taking us into Mary Shelley's hallucinations Russell tries to get as close as possible to the invisible (because internal) processes of the creative mind. The rupture with reality is accomplished when Mary crashes the skull around which the second seance is organised and seeks refuge in her room. ${ }^{244}$ There she hears her son William (who is not actually present at the Villa Diodati) calling for her. She leaves the room to look for him, but she only sees a vision of him lying dead in a coffin on the stairs. She then seems to sleepwalk backwards into her room but instead finds herself in a closed black space surrounded by six doors

\footnotetext{
${ }^{244}$ In the film Byron mentions that the skull was dug up on the ancestral estate of Newstead Abbey. This refers to a particularly ghoulish anecdote from Byron's life. When gardeners dug up a large human skull at Newstead Abbey, Byron 'sent it to London to have it mounted in silver as a drinking cup' and subsequently celebrated it in 'Lines inscribed upon a Cup formed from a Skull' (MacCarthy 2003: 79). During a masquerade party at Newstead, Byron and friends reportedly drank burgundy, claret, and champagne from the skull while dressed up in monk's clothes (o.c. 87). Frayling points out that, when Polidori's The Vampyre was published anonymously, the (false) attribution of the story to Byron was fuelled by 'the rumour that [Byron] had murdered his mistress and "enjoyed drinking her blood, from a cup made of her cranium"' (1991: 7).
} 
(only five of which are visible due to the camera's position above the sixth). Each door opens onto a vision. These visions all deal with real deaths, both past and future. ${ }^{245} \mathrm{We}$ see, in quick succession, the birth and death of Mary's firstborn child, the suicide of Dr Polidori, the death of Claire's and Byron's daughter Allegra (in 1822 at the age of five), two future Shelley children who would be stillborn, Percy Shelley's death by drowning and his funeral pyre on the beach at Viareggio in $1822^{246}$, and the death of Byron (in 1824). The film suggests that this extended hallucination is the source of Mary's story for Frankenstein. In this the film takes up the suggestion of Mary Shelley's own account in her 1831 Introduction to Frankenstein, where she explains that the idea for the novel came to her in a dream after listening to Byron and Shelley talk about galvanism: 'When I placed my head on my pillow, I did not sleep, nor could I be said to think. My imagination, unbidden, possessed and guided me, gifting the successive images that arose in my mind with a vividness far beyond the usual bounds of reverie. I saw - with shut eyes, but acute mental vision - I saw the pale student of unhallowed arts kneeling beside the thing he had put together' (1992: 8-9).

Although Shelley traces the origins of Frankenstein to the vivid mental imagery she experienced on that specific night (and whether such a night and such a dream ever occurred or whether Shelley really experienced a much slower process of creative gestation is now a moot question) she very firmly cuts the creative work off from her mental experience. In fact, Shelley works very hard to eliminate herself as a private person from her creation. This remained a constant concern throughout her later life. As she wrote to Edward Trelawny in 1837, 'for my own private satisfaction all I ask is obscurity' (quoted in Hebron and Denlinger 2010: 128). Already in 1829 she had written, also to Trelawny, who was planning to write his memoirs, that 'I only seek to be forgotten' (quoted in o.c. 132). This deep desire for obscurity also emerges in the 1831 Introduction, where it operates as a kind of framing device. At the beginning of the Introduction she explains that the publisher has asked her to write an Introduction that furnishes her readers with 'some account of the origin of the story' and with 'an answer to the question, so very frequently asked me. "How I, then a young girl, came to think of and to dilate upon so very hideous an idea?"' (1992: 5). But she immediately adds that 'I am very averse to bringing myself forward in print' and that she has only agreed to write the Introduction because, 'as it will be confined to such topics as have connexion with my

\footnotetext{
245 The prophetic quality of dreams or visions, while in itself an ancient theme, was firmly on the agenda in discussions of dreams in the early nineteenth century: see Ford (1998: 131-133).

${ }^{246}$ Remarkably, Russell omits the most famous anecdote about the burning of Shelley's remains, when the poet's heart was snatched from the fire. It was later surrendered to Mary Shelley. See MacCarthy (2003: 428431) and Lee (2008: 10-23) for discussions of this extraordinary relic and its place in Shelley lore.
} 
authorship alone, I can scarcely accuse myself of a personal intrusion' (ibid.). But into what exactly would she be intruding personally? If she is suggesting that it would be immodest to intrude upon her readers with personal reminiscences the observation would not make sense: her readers were extremely eager for her to speak out personally. In fact, what is presented here as a reluctance to intrude is possibly a reluctance to reveal. The second possibility, of course, could be a concern that her personal account might intrude upon the narrative of Frankenstein. Since the book is a work of art it would then not be proper to preface it with personal reminiscences that may seduce the reader into reading the book as something other than what it is, namely a work of fiction. On that interpretation Shelley's fear would be that her Introduction sponsors a symptomatic reading of the book, denying its status as fiction and, therefore, art.

This second interpretation agrees with the argument Shelley makes at the end of the Introduction. She there writes that the book, despite its horrific theme, 'was the offspring of happy days, when death and grief were but words, which found no true echo in my heart. Its several pages speak of many a walk, many a drive, and many a conversation, when I was not alone; and my companion was one who, in this world, I shall never see more. But this is for myself; my readers have nothing to do with these associations' (o.c. 10). This is a masterpiece of equivocation. First, she seems to pro-actively debunk the entire mythology of the Villa Diodati. The summer of 1816 was not the Haunted Summer that future lore would make of it but a period of happy days. She makes a point of saying that it was a period before grief struck at her heart. This means of course that most of the tragic deaths (which were listed above) came only after the book was written. It also suggests (and this is remarkable) that the death of her firstborn child in 1815 may not have cast a dark shadow into the summer of 1816 (perhaps the joy of now having the infant William soothed some of the pain). Next, Shelley suggests that whatever biographical material is in the novel is quite innocuous: it relates to the setting (walks and drives: very pastoral) and conversations (that trigger dreams, one supposes). The master stroke, of course, is the remark that she was not alone. This is very poignant because it refers to the loss of Shelley, the love of her life. The phrase has all the force of sincerity. It gives the quoted passage a tremendous (and tremendously moving) expressiveness. And then, after touching our hearts, she closes her own to us: we, her readers, really have no business with these affairs of her heart and should, if we please, not pry. So we are left hanging in limbo: even as she pours out her heart (the moving reference to Shelley) she tells us that she does not want to reveal it. She writes an Introduction about the circumstances surrounding the creation of Frankenstein simply to argue that these circumstances are really of no consequence whatsoever. As a theatrical performance this 
is exquisite automythography: she meticulously displays for us all the things she does not want to see displayed. The desire for obscurity was rarely so eloquent.

So what is the relation between the nightmare at the Villa Diodati and the novel Frankenstein? How do we get from Mary's mental imagery containing the seed of the narrative to the completed work of fiction? On this, too, Shelley is particularly outspoken. She addresses the issue as a question of invention. She argues that invention, it must be humbly admitted, does not consist in creating out of void, but out of chaos; the materials must, in the first place, be afforded: it can give form to dark, shapeless substances, but cannot bring into being the substance itself. [...] Invention consists in the capacity of seizing on the capabilities of a subject: and in the power of moulding and fashioning ideas suggested to it' $(1992,8)$. The significant thing about this text is that Shelley does not define artistic creation as something that happens ex nihilo but as the ability to assemble previously existing elements into a new whole and develop the germs of ideas that are suggested in the given materials. This was quite a common concept of creative work in Romanticism. In fact, the idea that creative work was a process of assembling disparate parts into new wholes was central to Romantic discourses on genius of the late eighteenth century. Edward Young's Conjectures on Original Composition (1759) argued that 'an original may [be] said to be of a vegetable nature; it rises spontaneously from the vital root of Genius' (quoted in Bate 1989: 89). While this seems to anticipate Wordsworth's view that poetry is the spontaneous overflow of feeling, there is in reality a catch, for William Wordsworth's overflow is not entirely spontaneous. As I will argue below, it contains a moment of reflection in which the creative intelligence gathers its wits and reflects upon how to create a work. This intermediate reflection is implicitly introduced in another key text, Alexander Gerard's Essay on Taste (also 1759), which argues that genius 'is properly the faculty of invention' (quoted o.c. 91): it is a work of the imagination. But for Gerard the imagination works through association. And this is the key, for the idea that genius is a process of associating elements into an organic whole is the idea that found its classic articulation in Wordsworth's Preface to the 1802 edition of Lyrical Ballads, a collection written jointly with Coleridge and first published (without the Preface) in 1798. We can now triangulate Wordsworth, Mary Shelley, and Russell to make sense of Gothic as a film about the creative work of Romantic genius. ${ }^{247}$

\footnotetext{
${ }^{247}$ The history of artistic genius has roots in Antiquity, in Plato's idea of divine inspiration, but also in Aristotle's 'connection between the melancholic humour and outstanding talent in the arts and sciences' (Wittkower and Wittkower 2007: 102; also Murray 1989b and Kemp 1989). In the Renaissance, Ficino brought these two traditions together (Wittkower and Wittkower 2007: 103). Kivy (2001) has explored the dual traditions of genius as divine inspiration and genius as innate gift, while McFarland (1985) investigates the connection
} 
Wordsworth's Preface can be used as a key for both Mary Shelley's 1831 Introduction and Russell's work. We know from Russell's own autobiography that the impact of Wordsworth's The Prelude on him was nothing less than that of a conversion experience. In the 1950s Russell had converted to Catholicism. But in the course of the next decade he gradually lost his faith. As he explains in his autobiography, 'The Devils was the last nail in the coffin of my Catholic faith, a faith that had sustained me for more than ten years and given my life purpose and direction. But my picture of God was hazing over: too much incense, too much stained glass, too much sci-fi in the sky. It was time to come down to earth. My Catholic missile was falling apart. I needed a new prayer book. I found it in Wordsworth's The Prelude and started devotions anew in his church, where the nave was Borrowdale, the transept was Catbells and Grange Fell, the altar [...] was Castle Crag, and the roof was Clouds of Glory. The font, of course, was Derwentwater' (BP 194). But the transition seems to have begun earlier, already during the location scouting for Dante's Inferno in 1965, when he arrived, late at night and in darkness, at a hotel in the Lake District and was blown away the following morning when he opened the curtains and beheld the landscape. 'My heart pounded, my blood raced, I caught my breath, my eyes widened, my hair stood on end, an unseen orchestra played a tremendous chord. Only clichés can describe what no one has ever been able to portray - a vision of God. [...] From my window in the turret, Skiddaw dominated the entire landscape' (BP 130-131). He adds that Coleridge once called Skiddaw 'God made manifest' and that 'from that day of revelation at the Lodore Swiss Hotel, I contrived to spend as much time as possible in the promised land' (BP 131) of the Lake District, a goal attained by buying a house there and doing most of the location shooting for many of his subsequent films in the region. These films included two television films on Wordsworth and Coleridge, Clouds of Glory: William and Dorothy (1978) and Clouds of Glory: The Rime of the Ancient Mariner (1978), the latter of which visualises Coleridge's poem. ${ }^{248}$ But The Rime of the Ancient Mariner was first published as part of the Lyrical Ballads. So Wordsworth, Coleridge, and the Lyrical Ballads must have been at the heart of Russell's creative and spiritual life at least since the middle of the 1960s.

between originality and imagination in Romanticism. On the theories of Young and Gerard, see Bate (1989: 89-93) and Kivy (2001: 32-35 on Young and 100-108 on Gerard). On the history of genius in general, see the several contributions in Murray's (1989a) edited volume.

${ }^{248}$ I would like to thank Dirk Van Extergem for organising a screening of both Clouds of Glory films on the closing night of the Imagining the Past conference. The Coleridge film is especially interesting because it visualises the poet's addiction to laudanum, although it is not possible to base an analysis of the film on a single screening. There are helpful discussions by Hanke (1984: 370-396) and Phillips (1979: 64-72), who also quotes a letter from Russell about a possible third film on Southey. In the event, this latter film was never made (BP 133). See also Hayter (1971: 191-225) for a discussion of Coleridge's poetry in relation to his addiction. 
The impact of the British Romantics on Russell's poetics is tremendous and we can now reconstruct it via Wordsworth's programmatic Preface. Wordsworth's views on the creative process of poetry are so eloquent (and famous) that the poet may speak for himself. ${ }^{249}$ Afterwards, we can connect the relevant dots between Wordsworth, Shelley, and Russell. Wordsworth famously writes that the poet is 'a man [...] endued with a more lively sensibility, more enthusiasm and tenderness, who has a greater knowledge of human nature, and a more comprehensive soul, than are supposed to be common among mankind [...]. To these qualities he has added $a$ disposition to be affected more than other men by absent things as if they were present; an ability of conjuring up in himself passions, which are indeed far from being the same as those produced by real events, yet [...] do more clearly resemble the passions produced by real events'. Because he has this ability 'it will be the wish of the Poet to bring his feelings near to those of the persons whose feelings he describes, nay, for short spaces of time perhaps, to let himself slip into an entire delusion, and even confound and identify his own feelings with theirs'. However, the artist should not forget that his ultimate aim is not to create reality but to create art, a work with 'a particular purpose, that of giving pleasure. Here, then, he will apply the principle [...] of selection; [...] and, the more industriously he applies this principle, the deeper will be his faith that no words, which his fancy or imagination can suggest, will be to be compared with those which are the emanations of reality and truth' (2013: 103-104; all emphases added). So the poet will first immerse himself, in a form of ecstatic surrender, into the feelings of the person he is to portray in his work, but will next have to step back and select from that experience those elements which will help him to make a pleasing work of art. Wordsworth summarises this process in the famous claim that 'poetry is the spontaneous overflow of powerful feelings: it takes its origins from emotion recollected in tranquillity: the emotion is contemplated till by a species of reaction the tranquillity gradually disappears, and an emotion, kindred to that which was before the subject of contemplation, is gradually produced, and does itself actually exist in the mind. In this mood successful composition generally begins' (o.c. 111).

What is interesting about Wordsworth's text in relation to Russell is the tension between a rhetoric of "spontaneous overflow" on the one hand, and the temperance of "contemplation" and "recollection in tranquillity" on the other. This suggests, as I pointed out earlier, that the creative process as described by Wordsworth is less spontaneous than he would have us believe. But it is exactly this same tension that we find in

\footnotetext{
${ }^{249}$ My discussion focuses on only one aspect of Wordsworth's text. For a full discussion of the other themes of the text (such as the nature of poetry, the importance of ordinary language, the function of metre, and the permanence of poetry) see Owen (1957), who provides an edition of the text with systematic commentary and extensive annotations.
} 
Russell's performance and description of his own creative process. Let us bring Wordsworth and Russell together and highlight the similarities. Wordsworth begins by claiming that the artist (whom I shall substitute for the poet) is capable of generating in his mind feelings (Wordsworth calls them passions) associated with a person or an event (we are not straining Wordsworth's meaning by including events) which are just as strong, and sometimes even stronger, as feelings experienced in a real situation. This is a tremendous claim, because it suggests that feelings imagined or remembered (by an artist) can be just as powerful and sometimes even more powerful than feelings lived in the moment. This closely resembles Russell's claim that by "feeling" an artist by listening to his music he can achieve knowledge of that artist's inner life that is more reliable and more "true" than the mere factual knowledge obtained by biographers and historians. For Russell, too, to feel is to know. To obtain intimate knowledge of the persons he wants to portray Russell must "let himself slip into an entire delusion" to the point where his own feelings merge with those of his subject. This is what we saw him doing in Russell at Work. ${ }^{250} \mathrm{He}$ then re-expresses the emotion thus experienced in a work of his own. Finally, Wordsworth concludes with the claim that the poet's words, or the artist's creation in general, should never be checked for accuracy against 'the emanations of reality and truth'. This follows from what went before: if the artist's imagination is just as or even more accurate than the facts themselves, how can the facts be a standard for measuring the accuracy of the artistic creation? That is why all the critics who criticise Russell for distorting the facts of his subjects' lives miss the point: they have not read their Wordsworth. It is for this reason also that it is of such tremendous importance that Russell's name weighs so heavily upon the titles of his films. The full title of The Music Lovers reads Ken Russell's Film on Tchaikovsky and the Music Lovers. Russell's work is full of similar announcements to the effect that we will be enjoying "Russell's film or interpretation of" this or that artist. This is not a matter of bloated ego: it is, already in the title, the first clue we get about how the film should be read.

But we can now also see how Mary Shelley's 1831 Introduction traces similar poetical outlines. The way Shelley reconstructs the invention of Frankenstein follows a remarkably Wordsworthian pattern: under the influence of external stimulants (listening to a discussion about galvanism) she experienced a dream-like vision that suggested the story of a mad inventor who creates life from dead matter. This is the chaos of materials out of which she next fashioned a work of art which then exists independent of its anecdotal sources. In Wordsworth's terms, she has "let herself slip" into a delusion or (in this case) a dream in which she saw an 'acute mental vision' with tremendous 'vividness'

${ }^{250}$ See above, section 3.4 . 
(Shelley 1992: 8-9) and subsequently expressed it in a work of art. She applied the "principle of selection" by taking from the chaos of materials those elements that would give the work a pleasing form. But this is also the way Russell visualises the creative process in Gothic. In fact, the entire structure of embedded narratives in the film is geared towards it. During the night, and under the influence of ghost stories, conversations about creating life, and two botched seances Mary experiences a hallucination about death that provides her with the seeds of the story. When the night is over and calm is restored Byron reassures Mary that there are no ghosts in the daylight. Asked whether she has thought of a story, she is affirmative: 'My story is a story of creation, of a creature who's wracked with pain and sorrow and hunger for revenge. Who haunts his mad creator and his family and his friends... to the grave.' The crucial element, of course, is that this happens in the daylight. The chaos of pain and sorrow that she experienced in her vision have now been ordered and shaped in her mind to form the outlines of a story. But the creative work, the making of art, only begins after the drug-fuelled night is over. Hallucinations are not creation. They can furnish materials to draw upon in creating a work of art, but the creative work itself is a sober-minded process. So invention is not a process that creates something out of nothing. Rather, it assembles elements and motifs into an original work of art that further develops the germs of ideas that they suggest.

\subsection{BUILDING NARRATIVES: RUSSELL'S ART OF MONTAGE}

In Gothic Russell has translated this Romantic theory of creation to the screen, not simply in the sense that the film is about it or depicts some of its processes on a narrative level, but in the actual way in which he has "assembled" the film. This becomes especially evident if one analyses Russell's film in terms of Eisenstein's theory of montage, which is equally a theory of artistic creation that relies on forms of assemblage and bricolage. Russell knew Eisenstein's work well. But although critics have pointed out that Eisenstein is 'a thinker and film practitioner whose ideas have much to offer in the analysis of Russell's films' (Dickinson 2008: 82) the connection has not been systematically pursued and its implications have not been fully thought through. This is odd because Russell has paid explicit homage to Eisenstein in Billion Dollar Brain (1967), a novelty spy thriller with a climax showing a caravan of trucks crashing through the ice as they try to cross a frozen sea, which is a direct quote from the Battle on the Ice from Eisenstein's Alexander Nevsky (1938). Previously, Russell had already used the original Battle on the Ice from Eisenstein's film as archive footage in his film on Prokofiev (1962). Clearly, then, Eisenstein was a reference for Russell already in a very early stage 
of his career. The main aim of my discussion will therefore be to bring Eisenstein and the Romantic theory of creativity to bear on Gothic. This fusion has even further relevance because Eisenstein's work was never limited merely to a study of montage in film. Montage emerges from Eisenstein's writings as a poetics, a general theory and practice of artistic creation. He sees montage as something that is common to all the arts. ${ }^{251}$ His writings on montage often deal only tangentially with film or with the editing process in the narrow sense. Some of Eisenstein's most extensive analyses of montage discuss examples from literature or from the visual arts. ${ }^{252}$ For Eisenstein montage is quite simply the process by which all the arts create a unified work out of many different elements. In my discussion montage will therefore be the last key needed to understand how Russell creates films about artists that are also an extended self-portrait. Russell is created through montage. And since Gothic is the neuralgic point where concepts of montage are directly addressed in Russell, I suggest we pick it up there and dig still deeper into that most fascinating of archaeological sites: Mary Shelley's nightmare at the Villa Diodati.

\footnotetext{
${ }^{251}$ Geoffrey Nowell-Smith put the case quite succinctly when he wrote that 'rather than see the concept of montage limited to that of a special case of film editing, [Eisenstein] argues that montage as he had himself conceived it in his earliest writings on the subject is in fact a special case of montage in general, which is a principle to be found underlying artistic construction of all kinds' (1994: xiv). In his classic study of Eisenstein, David Bordwell also points out that 'most broadly, montage is a formal principle ruling all arts' (2005: 184).

${ }^{252}$ The most famous example is undoubtedly Eisenstein's essay on Valentin Serov's portrait of the actress Yermolova (1994: 82-105), where he argues that the painting is constructed like a sequence of shots that are assembled into an integrated dynamic image. Eisenstein also sees montage in the facial expression of Laocoön, arguing that 'the simultaneous contraction of all the facial muscles of Laocoön is physically impossible' while in an image of 'the head of an anatomically "corrected" Laocoön, i.e. Laocoön with his features distorted in a manner that is anatomically possible [...] there is not a fraction of that dynamic effect of suffering, achieved by the cinematic method' of combining several expressions into one image (o.c. 114). A considerable number of Eisenstein's examples are taken from literature, such as his discussion of Tolstoy's Anna Karenina at the races (o.c. 281-295).
} 


\subsubsection{Of Peacocks and Pigs: Associative Montage}

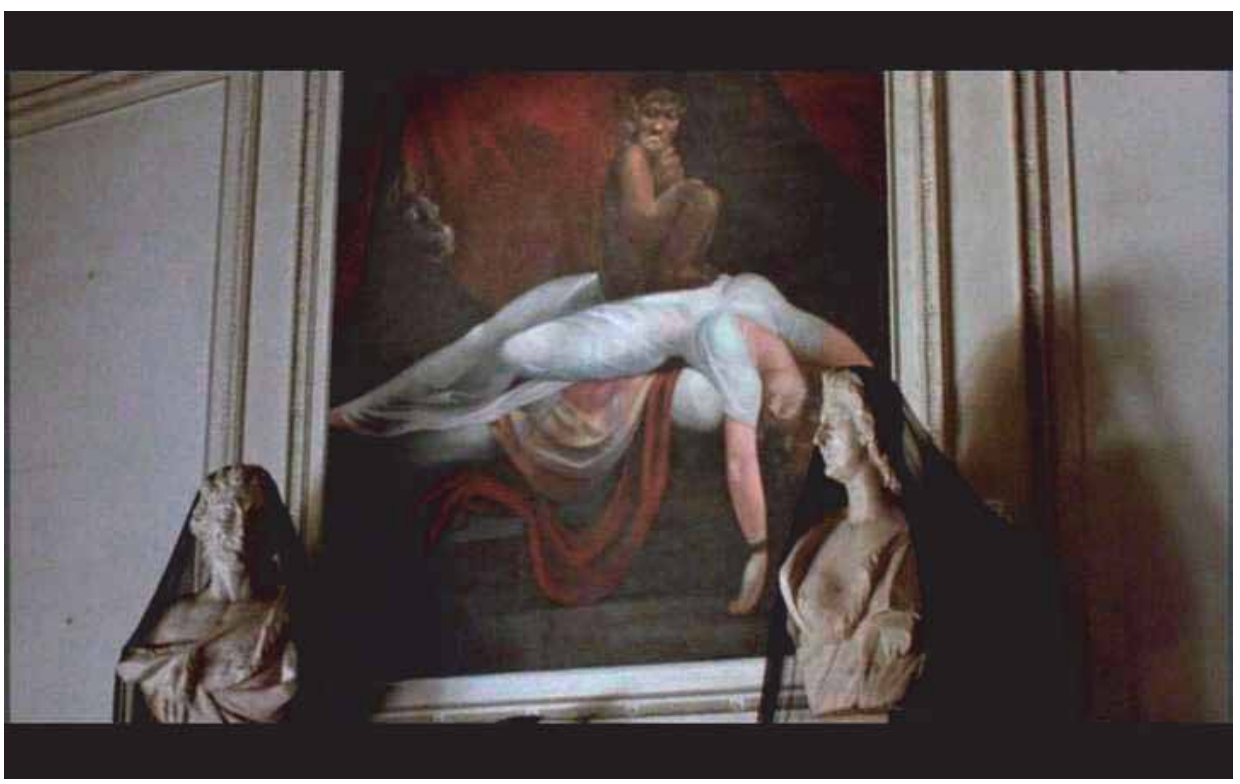

Illustration 19 Fuseli's Nightmare in the Shelleys' bedroom

The entry into Mary's nightmare in the film is provided by one of the finest examples of a mise-en-abyme in Russell's entire oeuvre. It is structured around a reproduction of Fuseli's painting The Nightmare (1780) which hangs in the Shelleys' bedroom (ill. 19). ${ }^{253}$ As Mary goes to bed after Claire's seizure she looks at the painting with visible unease and apprehension. The camera takes up her subjective point of view and then slowly creeps towards the painting until its subject comes alive: the imp sitting on the woman's chest in the painting is suddenly and briefly seen as a real figure sitting on Mary's chest, clawing at her throat. Mary wakes up in a panic to find that Claire is lying across her with her head on her chest. The rapid cutting from (1) a close-up of the imp in the painting to (2) a close-up and (3) long shot of a real imp sitting on Mary's chest to (4) Mary screaming as the imp claws at her throat to (5) Mary waking up with Claire lying across her chest (ill. 20-24), uses visual associations to provide an explanation for this

\footnotetext{
${ }^{253}$ The introduction of the painting has biographical resonance because Mary's mother, the feminist Mary Wollstonecraft, had been infatuated with Fuseli and may have had an affair with him. William Godwin acknowledged the association in his memoir of his wife, so there can be no doubt that Mary Shelley knew about Fuseli and, quite possibly, his most famous painting. For the background to Wollstonecraft and Fuseli, see Tomalin (1977: 117-119). Ward (2000) argues for the extensive influence of Fuseli's painting on Frankenstein.
} 
extraordinary event: after looking intently at the painting Mary fell asleep and when she felt the weight of Claire on her chest she dreamed that it was actually the imp assaulting her. Although this may seem merely a straightforward way of introducing a nightmarish shock-effect into the film, it has a broader relevance for the present discussion. Because this sequence is created entirely by cutting rapidly between a number of shots that are only briefly seen, it is a perfect starting point for a discussion of montage in Russell. I am deliberately using the term montage instead of editing because I want to argue that something more is going on here than a simple effect in cutting film. Montage, as Eisenstein used the term, has a much broader meaning than just the technical aspect of editing. It is this broader notion that will help us, not only to make sense of the sequence with The Nightmare, but of the way Russell constructs his films in general. For this reason it is important to look at the sequence with The Nightmare in detail, analyse its iconography, and connect these elements back to Russell's cinematic grammar.

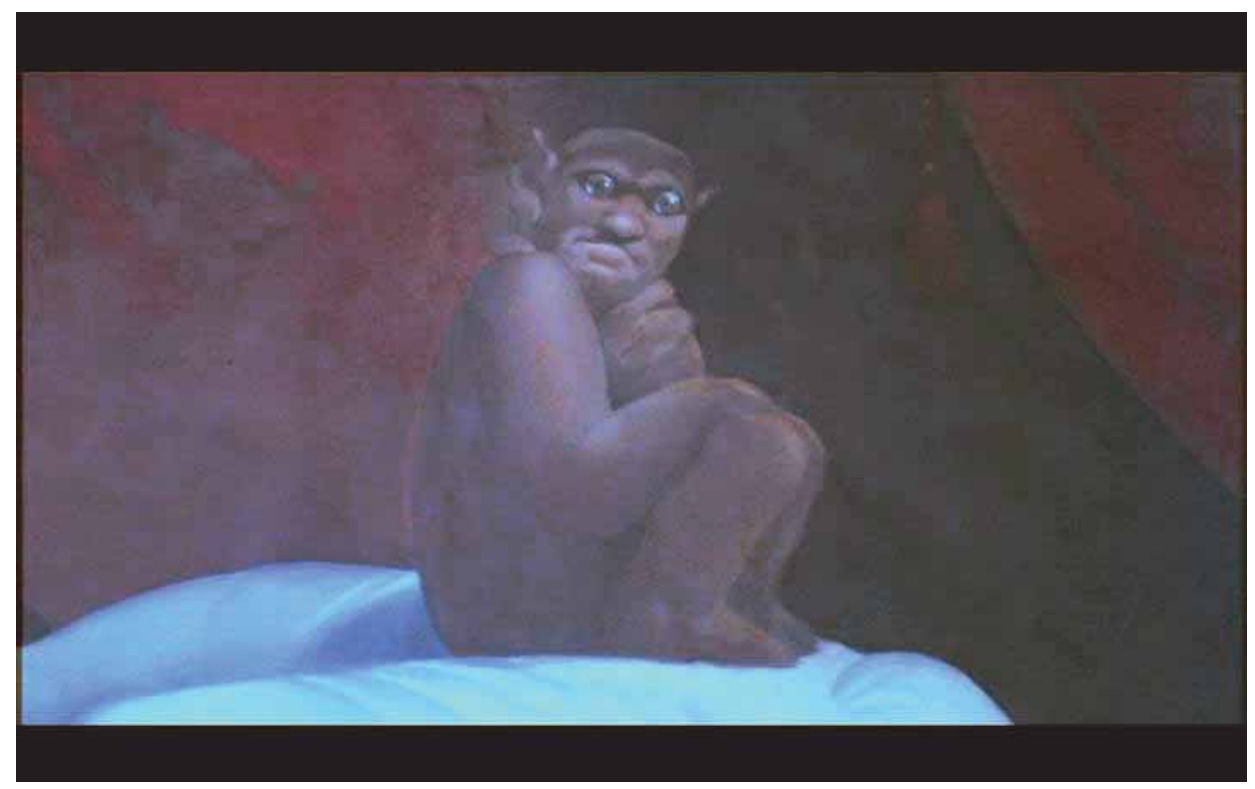

Illustration 20 Associative montage: from a close-up of the imp in the painting... 


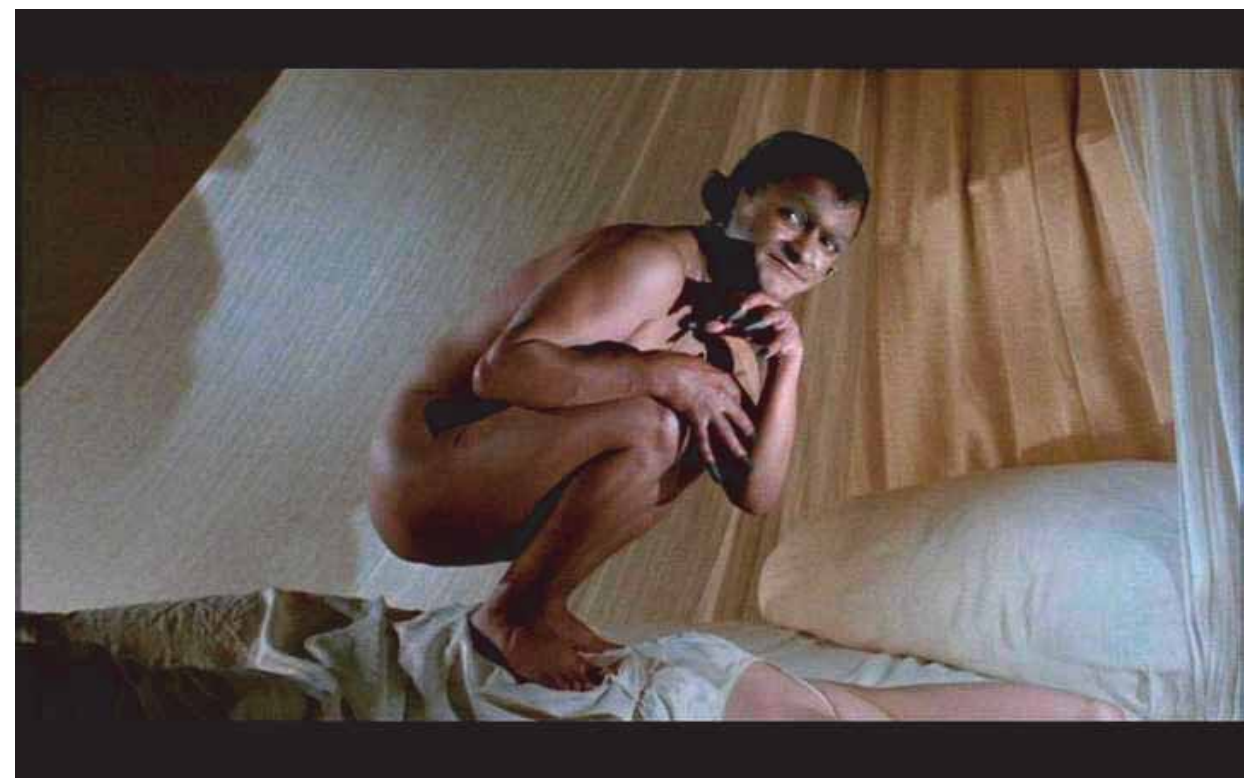

Illustration 21 ...to a close-up of an imp on Mary's chest...

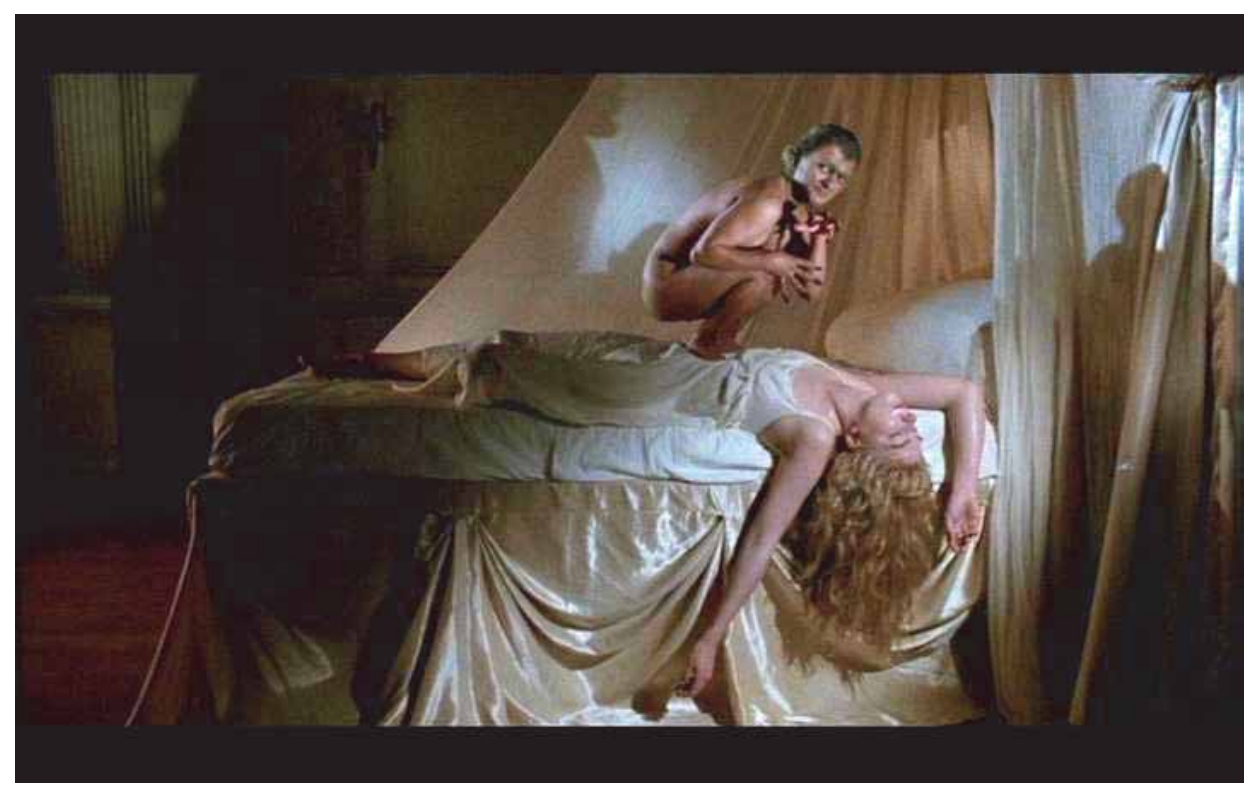

Illustration 22 ...to a long shot of the imp on Mary's chest... 


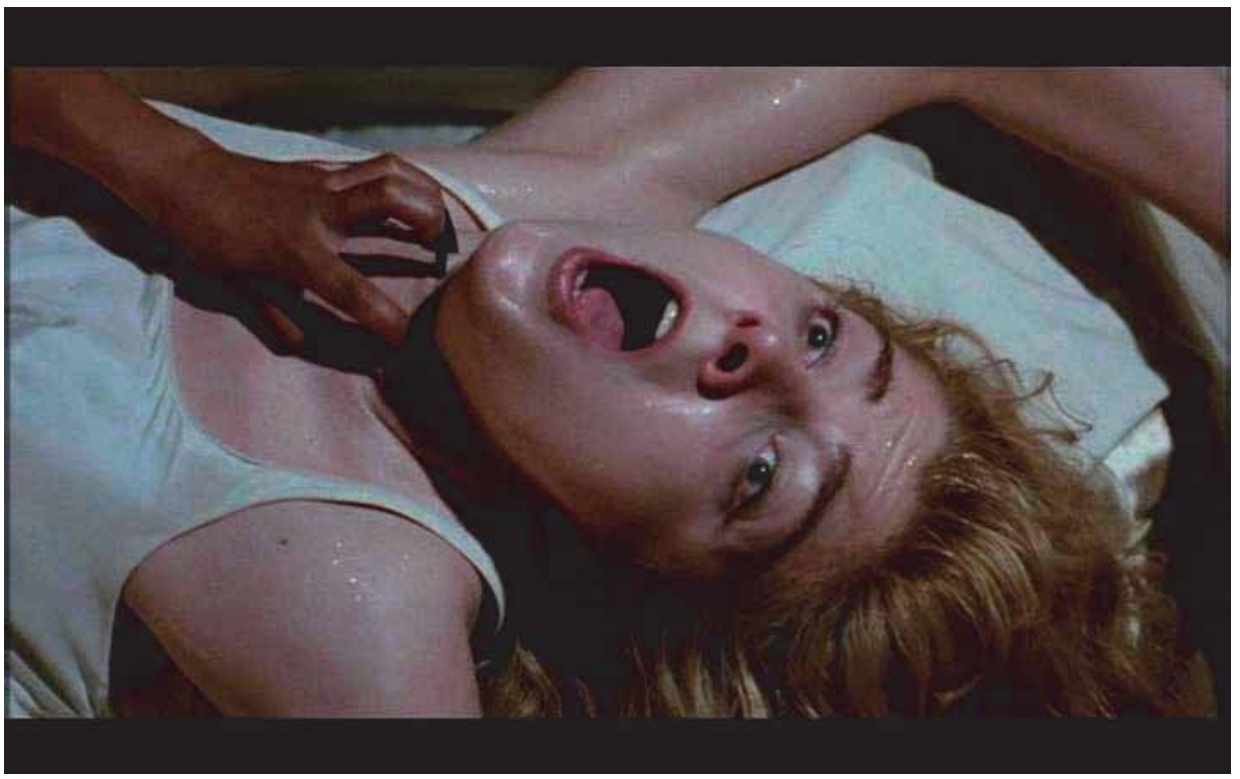

Illustration 23 ...to a shot of the imp clawing at Mary's throat...

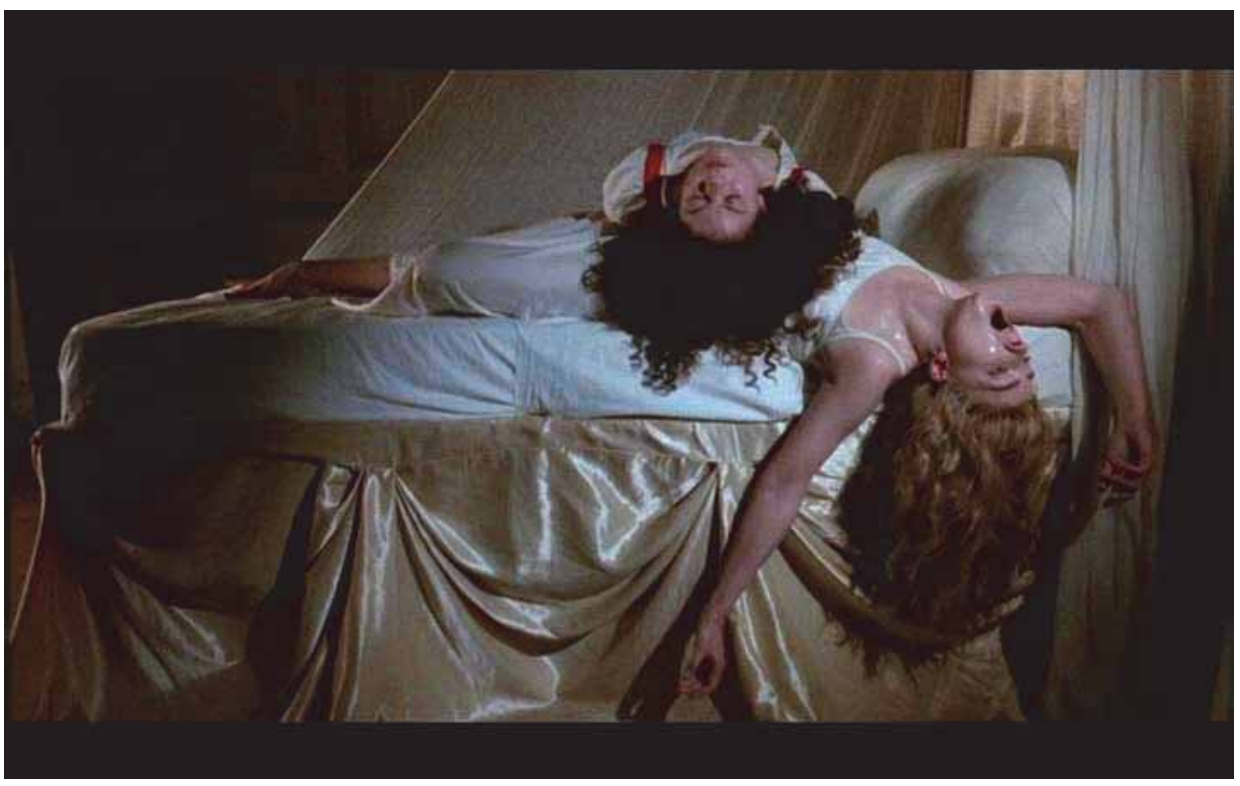

Illustration 24 ...to a shot of Mary with Claire on her chest

The first level of interpretation is simply to see how the theme of the painting connects to the narrative of Gothic. Throughout the events at the Villa Diodati both Byron and 
Mary go to considerable lengths to find rational explanations for the phenomena they perceive. When Percy claims to smell the stench of decay Mary suggests that it is merely the stink of the sewers or leaves rotting while Byron himself is consistently (and sarcastically) dismissive of all superstition. When Polidori goes into increasing religious hysteria and believes that God himself is taking vengeance upon them he is mocked by the others. Mary herself only begins to hallucinate after she goes into hysterics during the second seance. She destroys the skull around which they are gathered and even tries to assault Byron. Percy Shelley not only intervenes but kisses Byron, consolidating a homoerotic tension in the poets' relationship that has occasionally surfaced throughout the film. It is this taking of (romantic) sides on Percy's part that seems to drain all willpower from Mary. So it is only when she is psychologically crushed that Mary (who has not been taking laudanum) loses her rational guard and gives way to a more impressionable condition, allowing hallucinations to take over. This means that the film clearly presents Mary's hallucination not as a supernatural phenomenon but as a symptom of stress: she has reached her breaking point and experiences a physiological response in the form of a hallucination. But on close inspection the entire film is constructed around such physiological explanations. After all, the drug-taking and mounting hysteria are used in the film as a kind of framing device: they ensure that nothing that is seen or experienced during the night has any reliable factual status. That is why, at daybreak, when everyone is sober again, everything also seems to be normal again. Even Polidori, who ran off during the night and tried to hang himself (but did he, or was it imagined?), is sitting at breakfast in a relaxed and jovial mood as if nothing has happened. During the night the company went on a collective trip (with Mary tripping mainly on the others' hysteria), and now they have come down again: narrative closed, reality restored. Which means that the whole embedded spectacle of the night at the Villa Diodati has a perfectly rational explanation: it was all the effect of drug-taking and group hysteria. In this respect it is interesting that the servants at the Villa Diodati neither participate in nor witness the bizarre goings-on. At the beginning of the evening the old butler can be seen wearily shaking his head at the hysterics upstairs, which suggests that the servants are used to these kinds of bacchanals and spend the night peacefully asleep in their quarters while the poets race through the house chasing phantoms. In this respect the servants are also used as a framing device: they are part of the normal world surrounding the stage of Diodati's haunted summer.

The sequence with Fuseli's The Nightmare reinforces this point, not only because it is self-explanatory (the vision of the imp is explained by the weight of Claire on Mary's chest) but because Russell uses it as a mise-en-abyme. The subject of the painting itself can be interpreted as a representation of and commentary on the events in the framing 
narrative. ${ }^{254}$ Fuseli's painting is not a straightforward image of a woman having a nightmare: it represents a combination of elements from eighteenth-century theories about nightmares. ${ }^{255}$ In a lecture 'On Invention' for the Royal Academy Fuseli once asked 'whether it be within the artist's province or not, to find or to combine a subject from himself, without having recourse to tradition or the stories of history and poetry? (quoted in Frayling 2006: 13) This was an attack on the established practice of history painters to base their major tableaux on historical events or passages from literature. Fuseli himself sometimes invented such imagery. For example, his painting Ezzelin Musing over the Body of his Wife Meduna (1780) is titled like a painting based on a historical or literary source, but in reality there is no such source for it whatsoever: it is a sheer figment of Fuseli's imagination. Because he liked to combine elements from different sources or even invent sources Fuseli has sometimes been considered 'a collagist of visual quotations' (ibid.). The Nightmare would seem to be such a collage. ${ }^{256}$ On the one hand it represents modern scientific theories about nightmares, but on the other hand it also incorporates folkloric explanations. In the late eighteenth century nightmares were often given physiological explanations and the woman in the painting exhibits several of them: she is 'sleeping on her back, turned to her left side, with her head below her legs and with a pressure on her stomach' (Frayling 2006: 16). It was believed that each of these elements could trigger nightmares. But the pressure on the woman's stomach in the painting is of course the imp. And this is an element from folklore, where nightmares were said to be caused by the mara, a spirit from Nordic mythology that torments or suffocates sleepers. The presence of a horse in the painting would then be explained by the fact that the mara was believed to ride into a room on horseback or

\footnotetext{
${ }^{254}$ Russell's use of The Nightmare as a mise-en-abyme has an interesting antecedent in seventeenth-century painting, where the use of an embedded painting (a painting-within-the-painting) to comment on the framing narrative was not uncommon. In Dutch genre painting many interior scenes show paintings hanging on the wall (usually actual paintings by colleagues, many of which have been identified) and whose iconography carries a message that reflects on the framing image (the genre scene). A specific sub-set are interior scenes of women reading a letter with a painting of a ship at sea on the wall. Whether the sea is calm or not determines the meaning of the letter in the framing image: if the sea is calm the letter may be assumed to carry good news (perhaps it is a love letter), if the sea is tumultuous the news is bad (the end of the affair, the death of the beloved). See the discussions by De Jongh (1967: 49-52 and especially 1976, cat. 25, 39, and 71), but also Stoichita's (1999: 226-234) remarkable analysis of one such painting by Gabriel Metsu, which he connects to a companion painting of a young man writing a letter, explaining the two panels' iconography by tracing it to contemporary rhetorical conventions for love-letters. See also Bruyn (1987: 89-93) on the meaning of landscapes and seascapes as paintings-within-paintings.

${ }^{255}$ See Ford (1998: 9-32) on theories on dreams in the eighteenth and early nineteenth centuries.

${ }^{256}$ Powell (1973) is still the authoritative monographic study of the painting, but see also Frayling (2006) for an extensive discussion of the painting's iconography and possible sources, and Myrone (2006, esp. 43-51 and 207-212).
} 
would enter through the keyhole in the form of a steed, which also means that nightmares have no etymological connection to female horses and that, in the painting, not the horse but the imp is the nightmare. ${ }^{257}$

This means that Fuseli's The Nightmare is very much the product of eighteenthcentury rationalism: it incorporates both contemporary physiological explanations of nightmares and elements from folklore. 'To regard this picture as a precocious example of nineteenth-century Romanticism,' concludes Nicolas Powell, 'is to misunderstand it' (o.c. 95). If anything, it should be seen as the work of a rational Enlightenment mind displaying a collage of his encyclopedic knowledge. This interpretation of the painting is also very suggestive in relation to Gothic, which contains a similar duality: on the one hand the film presents rational and physiological explanations for the phenomena the poets experience (laudanum and hysteria), but on the other hand it also happily indulges in the outrageous pageantry that the legend of the Haunted Summer occasions. In fact, the whole plot of the film is organised around the fact that the company intentionally work themselves into a frenzy by reading ghost stories and indulging in laudanum and seances. The whole orgy is devised by Byron as a game. Except that the game turns into reality, or at least seems to turn into reality through the prism of their intoxication. This playful duality between reason and irrationality is carried through even in small details. For example, when Polidori runs from the house he tries to hang himself by sitting on a horse, tying a noose around his neck, and then kicking the horse so that it will gallop away. But the suicide attempt is botched, for as he falls off the horse the noose comes undone. But he does see a hairy monster jump onto the back of his horse as it gallops away (in fact, the monster is one of the film's less successful creations, comically resembling the hairy Chewbacca from the Star Wars films). Given that the mara was said to enter a room on horseback it is at least highly suggestive that Russell should have the monster in Gothic leave the premises of the Villa Diodati by the same means of transport. Fuseli himself in any case also produced a watercolour entitled The Incubus Leaving Two Sleeping Women (1810) in which an incubus leaps out of a bedroom window on horseback. ${ }^{258}$ What should be clear, however, is that the use of the painting in the film achieves a mise-en-abyme because the painting's principles of composition mirror the principles of montage used in the framing narrative: if one understands how

\footnotetext{
${ }^{257}$ For the mara on horseback, see Powell (1973: 56). Ford (1998: 110-111) points out that Coleridge's many notebooks on his dreams and nightmares use the unusual spelling "nightmair" to avoid the confusion with a female horse.

${ }^{258}$ See Myrone (2006: 48) for a discussion of this image and its sources. Powell (1973: 84) also reproduced the image.
} 
the painting works this understanding provides a crucial key about how the film should be read.

But the potential of the brief sequence around The Nightmare is not exhausted by showing how it functions as a mise-en-abyme. ${ }^{259}$ It is also the most memorable instance in Gothic of associative montage, a stylistic device that Russell uses several times in this film and many times more in his other films. Of course, associative montage is an important notion in Eisenstein. ${ }^{260}$ Associative montage cuts from one shot to another with the intention of providing a commentary. One of the most famous cases of associative montage in Eisenstein occurs in October (1928), where Eisenstein cuts back and forth between images of Minister Kerensky and images of a mechanical peacock. The peacock functions as a commentary on the personality of the Minister, who is proud and vain. As a visual shorthand it takes the place of narrative exposition. In Russell's film associative montage also functions in such a way. For example, during a game of hide and seek Byron is stalking through the servants' quarters when he happens upon a pig's head lying on the floor. When he touches it with his cane it briefly turns into Polidori's head and then back into a pig's head. The association has narrative import: it says something about the loathing that Byron feels for his physician. In this sense it is the example closest to Eisenstein's use of the peacock in October. But Russell uses associative montage to many effects. Sometimes it is used to propel the narrative or for purposes of characterisation, at other times it is used to achieve a temporal or spatial shift, and in still other cases it combines several of these uses. Many times it is also used simply as a device for creating a visual stream of images. ${ }^{261}$ This is simply but brilliantly achieved during the

\footnotetext{
259 The conceit of the embedded painting that triggers a dream or nightmare must have pleased Russell for he used it again in The Lair of the White Worm, where one of the main characters dreams that he walks into a painting of a dragon's lair that hangs on the wall of his bedroom. While inside this cave he experiences a fantasy vision in which all the main characters of the framing narrative are assembled in a state-of-the-art jetplane and act out a pantomime which provides symbolic clues towards unravelling the film's plot, which involves a dragon-like giant worm lurking in a cave/lair nearby (the dream-as-explanation is the mise-enabyme of the sequence). The painting in the film seems to be modelled on Paolo Uccello's Saint George and the Dragon (ca. 1460) in the National Gallery, although the shape of the entrance to the dragon's lair in it is clearly modelled on the real-life Thor's Cave in Staffordshire which was used as the location for the scenes involving the giant worm's lair.

${ }^{260}$ See Bordwell (2005: 43-50) for a discussion of associative montage in Eisenstein.

${ }^{261}$ In this respect, Russell later remarked of The Lair of the White Worm that 'I played a game with the structure of the film. Because a worm is one long piece I made the film in one long piece. All the scenes are linked. There aren't any cutaways to a scene that is not a continuation of something that happened in the previous scene. There is nothing in the film that is not continuous in one way or another. Perhaps it has some contributory factor to the flow of the film' (quoted in Sutton 2002b: 20). These connecting elements are often visual details or motifs that link two scenes across a cut. In Chapter One we encountered a similar trope in Russell's autobiography, when the sight of his mother mindlessly clapping her hands triggers memories of how she
} 
scene in which the company read ghost stories from the Phantasmagoriana volume. The story that Mary reads, concerns a spectre in medieval armour moving towards a sleeping child. As Mary reads the story, Russell cuts to her internal visualisation of it with her own son William as the child in peril. Mary herself appears in this vision as the petrified mother who looks helplessly on as the spectre bends over the bed to grab the child. Then the spectre lifts its visor to reveal not a face but a jumble of raw meat covered with leeches. We see Mary (as the mother in the story) screaming, but we do not hear her (this is a soundless internal imagining of the story). Instead, we do hear a male voice screaming. The image then cuts abruptly to a shot of Lord Byron screaming, and then to a shot of a plate of rice covered in leeches which Polidori has served Byron by way of a joke. The several narrative levels (the framing narrative of the reading of the story and the embedded narrative of the visualisation of the story) are connected via three steps of associative montage. First, Mary's silent visual scream is associated with the audible but initially invisible scream of Byron. Next, Mary's face screaming in silence is echoed in an image of Byron's face audibly screaming. And finally, the spectre's leech-ridden face is echoed in the plate of rice covered in leeches. This crashing of several narrative layers into each other helps to establish the blurring of lines between reality and illusion. It also helps to inform us about the troubled relationship between Byron and his physician.

There are several other instances of associative montage in Gothic worth noting. The fact that something supernatural might actually be unleashed in the first seance is signalled when Claire goes into convulsions while gazing intently at the eyes of the skull around which the group is gathered. As she goes into a fit there is a stroboscopic crosscutting of Claire's face with close-ups of the skull lit by lightning. By conflating Claire's face with the skull in such a fast pattern of associated images the film suggests that the dark powers of the skull (which is used as a gateway to the beyond) are entering Claire and, via Claire, this world. But perhaps the most disturbing use of associative montage occurs in a scene in which Byron engages in sex with the sleeping Claire. After Mary has informed Byron that Claire is carrying his child he callously replies that surely even Polidori can perform a simple abortion. The subsequent sex scene is almost certainly a wish-fulfilment fantasy on Byron's part. He sneaks up on Claire, who is asleep after her fit, and burries his head between her legs. The increasing rhythm of Claire's breathing suggests oral sex, but when Byron re-emerges from between her legs his lips are dripping blood. This suggests that, like a vampire (to which he has been likened and about which he said he would invent his own ghost story), he has sucked out the foetus. Of

applauded his acting performances at the beginning of his career: the association of the visual/narrative motif carries us from framing narrative into embedded memory (see above, section 1.2.2.). 
course, this is another event of dubious factual status since we know that Claire gave birth to Allegra. But while Byron ravages Claire, Polidori is hysterical with fear and frustration in the next room. He crashes the palm of his hand into a nail in the wall in rhythm with Claire's breathing. As the breathing becomes quicker, so the rhythm of Polidori's self-torture increases as Russell cuts back and forth between the two. The associative montage of the hand hitting the nail and the unconscious excitement of Claire reinforces the sense of the sexual encounter as a violent assault upon her womb by a physical and emotional vampire. After climax Byron's bloody lips are juxtaposed with a shot of Polidori licking his bloodied hand.

\subsubsection{Peepshow: Gothic as Montage of Attractions}

With this discussion of associative montage we have not exhausted the Eisensteinian elements in Russell. But before we can investigate Russell's art of montage deeper it is important to also take the context in which Eisenstein articulated his theories into account. The theory of associative montage was developed out of reflections on the theatre as a montage of attractions. Eisenstein started his career working in the theatre and developing techniques to achieve audience engagement. The idea of a montage of attractions arose from the discovery that theatre could use strong visual or dramatic shocks to engage the audience. This led Eisenstein to think of the theatre, and later of film, as a medium with which the audience could be "moulded": by carefully calculating shocks and surprises the performance (or film) could trigger certain moods or attitudes, and ultimately even insights and beliefs, in the spectator. In this view, as David Bordwell explains, 'the stage apparatus, including the actors, becomes a set of tools for "processing" the spectator' (2005: 115). ${ }^{262}$ In Eisenstein's theory shocks, or scenes that captivate the audience and which are strung together for ideological or emotional effect, are called the attractions. An attraction could be 'any aggressive moment in theatre, i.e. any element of it that subjects the audience to emotional or psychological influence, verified by experience and mathematically calculated to produce specific emotional shocks in the spectator in their proper order within the whole' (Eisenstein 1988: 34). But the tech-

\footnotetext{
${ }^{262}$ See Bordwell (2005: 3-7) for the Proletkult theatre productions that Eisenstein worked on, including The Mexican (1921), which included a boxing match, and The Wiseman (1923), which featured a set resembling a circus arena and included clowns, acrobats, and a finale during which firecrackers were set off under the spectators' seats. More importantly, Bordwell (o.c. 115-123) also discusses the theoretical principles underlying Constructivist theatre and Eisenstein's application of them to film. In her excellent monograph on Eisenstein's unfinished film Que Viva Mexico! (1931), Salazkina argues that 'Eisenstein's theory of montage of attractions [...] can be seen as a perfect baroque tool' (2009: 92-97, here 93) because it aims to turn the spectator into an (ideological) extension of the film/work.
} 
nique worked differently in the theatre than in film. In the theatre attractions are live and immediate, operating directly on the spectator through 'physiological perception' (o.c. 41). In the cinema, which works with photographic representation, the operation is indirect. In other words, a certain shock effect, such as the introduction of spurting blood, will have a much more immediate effect if it happens live on stage than if it is seen in a projected film image. In both cases, however, anything can be included in the montage to achieve the desired effect because, as Eisenstein points out, 'art admits all methods except those that fail to achieve their end. It was Voltaire who said, "Au théâtre il faut mieux frapper fort que frapper juste!"' (o.c. 69). For Eisenstein the montage of attractions was a battle with the spectator and even an assault on the audience. 'In our conception,' Eisenstein writes, 'a work of art (at least in the two spheres in which I work: theatre and cinema) is first and foremost a tractor ploughing over the audience's psyche' (o.c. 62). The aim is to mould the audience into certain beliefs and responses. Montage thus emerges as a series of 'methods of processing the audience' (o.c. 56) and influencing its ideas and world-view 'through a series of calculated pressures on its psyche' (o.c. 39).

Montage of attractions and its potential for shocking the audience into awareness are not foreign to Russell's work. Discussing The Music Lovers Russell explained that 'there are certain points in every film I do, where I deliberately want to shock people into awareness. If you treat a situation in unexpected terms, by suddenly doing something in an extraordinary way, or even a very funny way, I think it makes them doubly aware' (quoted in Gow 1970: 8). ${ }^{263}$ Of course, Eisenstein's montage of attractions was based on psychological and social theories that Russell does not necessarily share. The main thing, however, is the formal similarity: like Eisenstein, Russell strongly believed in the use of visual shocks to make a point, and he did this extensively throughout his career and in virtually every film. In a 1973 interview Russell made an interesting comparison (quoted already in Chapter Two) between his own work and medieval theatre, explaining that 'I think of my films as sort of modern medieval mystery plays. In the days of mystery plays, they took religion, bashed it over the head, cocked a snook at it, blasphemed it, sent it up, treated it melodramatically, comically... all in one act. And people liked it' (quoted in Gomez 1976: 39). Critics have taken Russell to task for this approach. In a

\footnotetext{
${ }^{263}$ In a 1973 interview Russell used almost the exact same phrase again when he explained that television had desensitised people to such an extent with news footage of war and violence that 'they don't stop eating while it's going on. I do want to shock people into a sense of awareness' (Fox 1973: 105). A few years later, however, he claimed to have changed his mind, arguing that 'I got tired of Eisenstein, I don't like him any more. I used to think he was the best, but now I don't like him at all. Very operatic, pretentious, obvious propaganda. I'm a great propagandist myself, in things I believe in, but I don't believe in necessarily ramming it down people's throats in such an obvious way. I think more subtlety is required and I don't think his films are subtle enough' (quoted in Litchfield 1977: 96).
} 
review of The Boy Friend quoted earlier in this chapter, Jan Dawson deplored the film as 'an infuriatingly discordant mosaic' in which 'Russell's musical numbers succeed one another like entrants in a beauty contest, each soliciting admiration' (1972: 112). But if we take away the critic's bias this observation simply highlights the way Russell's films are sometimes structured as a pageant of set-pieces that, on a superficial reading, may seem to only seek to stun or astound. Or, as a more sympathetic critic pointed out, 'seeing one of his films can be likened to a ride through a carnival funhouse - a controlled journey which jerks us back and forth and sideways as we catch glimpses of comic reproductions and grotesque or horrible images' (Gomez 1976: 39). But as the discussion of associative montage in Russell has shown, this is indeed a very controlled journey in which every detail has a deliberate meaning and function. Russell himself has explained that his use of shock montage and high-impact (or sensational) imagery was actually triggered by his work at the BBC. In the same 1973 interview quoted above, he talked about his schooling at the hands of Huw Wheldon, who urged him to reduce his films to their essentials: 'He said, "We don't want length, we want brilliance - cut it." That's been my credo ever since. I cut them down - all my ideas - to the bare minimum before anyone gets a chance to be bored' (quoted in Fox 1973: 64). The threat of boredom was real, because the underlying pragmatic reason for condensation was the need to keep audiences from switching channels or switching off. As Russell explains, 'when you're making films for television, you've really got to grab the audience. Our programme came on every other Sunday, after the feature film, and people who would watch a feature film wouldn't necessarily watch an arts programme. So before they could get up and turn us off, we had to grab them. A lot of my early films had terrific impact starts' (ibid.).

Tom Gunning has argued that the montage of attractions in film creates 'an exhibitionist cinema' (2006: 382). This means that it is a cinema that reveals itself as cinema. Gunning further argues that the earliest period of the cinema was in many ways such a cinema of attractions because many of the actions in early shorts were performed explicitly for the camera. This is chiefly indicated by 'the recurring look at the camera by actors. [...] From comedians smirking at the camera, to the constant bowing and gesturing of conjurors in magic films, this is a cinema that displays its visibility' (o.c. 382). But this is also a kind of cinema that has left considerable traces in Russell's work. The obvious example is the moment in The Devils when Louis XIII, for no obvious diegetic reason, addresses the camera directly after shooting a Huguenot, smirking 'Bye Bye Blackbird', an intentionally anachronistic reference to a song by The Beatles. I also mentioned, in Chapter Two, the moment in The Devils when the Duc de Condé removes his mask to show the camera (and that means: the spectators of the film) that he is actually Louis XIII. Throughout The Boy Friend the actors, both in the framing narrative and in the 
embedded narratives (such as the imagined versions of the musical-within-the-film), explicitly talk to or wink at the camera. ${ }^{264}$ But such references to early cinema were there right from the start. Consider Peepshow (1956), Russell's first completed (and remarkably accomplished) amateur film. It shows a magician whose act, performed on a stage, consists in bringing a doll (actually his daughter) to life. A group of petty criminals peer at his performance through holes in a fence and then rob him. A wild pursuit follows, ending with the robbers, divested of their loot, paddling down the river in a coffin (the coffin from which the magic doll emerges in the magician's act). This remarkable film displays all the features of early cinema of attractions: a magician performing both for the diegetic audience and for the camera, the use of intertitles, and actors looking directly at the camera.

Another salient connection lies in the origins of the montage of attractions in popular culture. Eisenstein derived the concept not only from the theatre, but also from music-hall and the circus, two forms of performance that are entirely a montage of attractions performed by singers, dancers, actors, clowns, acrobats, and trained animals. But the late eighteenth and early nineteenth century also saw the introduction of the phantasmagoria, a popular fairground attraction that is relevant to Russell's work. Phantasmagoria were a species of ghost-shows or 'illusionistic exhibitions and public entertainments in which "spectres" were produced through the use of a magic lantern' (Castle 1988: 27): images painted on glass would be projected (like slides) onto a surface in a darkened room. Of course, magic lantern shows had been known for a long time. ${ }^{265}$ What made the phantasmagoria different, and what makes them relevant to the study of early cinema, is the fact that they included movement. Through an ingenious mechanism it was possible to move the projector back and forth, causing the projected image

\footnotetext{
${ }^{264}$ In early cinema theatrical performances would sometimes be filmed with a fixed camera, reproducing the effect of sitting in a theatre and watching a performance framed by a proscenium arch. Russell deliberately evokes this "primitive" look at several points in Salome's Last Dance and The Boy Friend. One of the musical numbers in the latter is filmed entirely in such extended static long shot, perversely reducing the visual impact of its lush set. See also Jacobs (2000: 16-17) for the influence of this aesthetic on the "photographed stage play" approach to early television drama.

${ }^{265}$ Magic lanterns had first been illustrated in Athanasius Kircher's Ars Magna Lucis et Umbrae (1671): see Robinson (1993: 8 and 14). The Belgian Etienne-Gaspard Robertson presented the first "fantasmagorie" in Paris in 1798, but the process was soon widely copied. The early shows often claimed to 'serve the cause of public enlightenment' because they supposedly intended to reveal 'that so-called apparitions were in fact only optical illusions,' but in reality 'everything was done, quite shamelessly, to intensify the supernatural effect' (Castle 1988: 30). Besides Castle (1988), which triggered several subsequent investigations, Mannoni (1996) is very good on the technical aspects of the ghost shows. Barber (1989) traces the dissemination of the phantasmagoria in America in the early decades of the nineteenth century. The phantasmagoria are now seen as part of the prehistory of cinema and trick films. Mannoni (2000) is the classic study, but see also Mannoni (1995) and especially Mannoni and Campagnoni (2009), which offers an overwhelming amount of stunning colour reproductions.
} 
to grow and decrease at great speed, as if it were moving towards or away from the spectator. Furthermore, the projected images where painted on glass slides, and by superimposing several slides it was possible to make images move. For example, by superimposing a slide with pupils over a slide with a face it was possible to make the figure roll its eyes. ${ }^{266}$ To increase the illusion that the images were hovering in the air (as real spectres would) the open space around the images would often be painted black, so that only the image itself, painted in translucent paint, was projected. This effect is used literally by Russell in the opening credits for Gothic, where an isolated image of a skull slowly floats towards us against a black background, beginning as a small dot in the distance and ending as a large image in the centre of the frame (ill. 25). Intriguingly, however, by the second decade of the nineteenth century it had become a commonplace that, rather than such sensational trick shows, 'the true "Phantasmagoria" is the human brain itself (o.c. 46). Many contemporary texts simply use the term to refer to any kind of frightening mental phenomena, such as nightmares or hallucinations. In this sense, too, the entire embedded narrative at the Villa Diodati is a phantasmagoria: a sequence of frightening mental phenomena conjured by the mind that tricks itself. ${ }^{267}$

\footnotetext{
${ }^{266}$ For this procedure, see Barber (1989, esp. 76-77), Mannoni (1995: 97-110, with colour plates 118-167), and Mannoni (1996).

${ }^{267}$ The Music Lovers contains a memorable sequence which, although not a ghost show, refers to similar sensational use of the camera obscura as entertainment when, on their honeymoon, Tchaikovsky and Nina visit a building where a mirror is used to project images from the surrounding landscape onto a horizontal surface. Interestingly, during the experiment the mirror catches two lovers in the shrubbery, exposing their tryst to the very interested eyes of the tourists. This sequence is almost certainly a direct quote from Michael Powell's A Matter of Life and Death (1946), which features a doctor who observes life in his village through a camera obscura that projects its image on a table-top. In Tommy, the sequence where Tommy's father (Robert Powell) crashes in a burning airplance equally seems to be a direct quote from the beginning of the same Powell film, where it is David Niven who plunges, with great eloquence, not towards his death but to a suspended intermediate state between life and death that brings about much ado, including a heavenly convention on whether he should be allowed to live or not.
} 


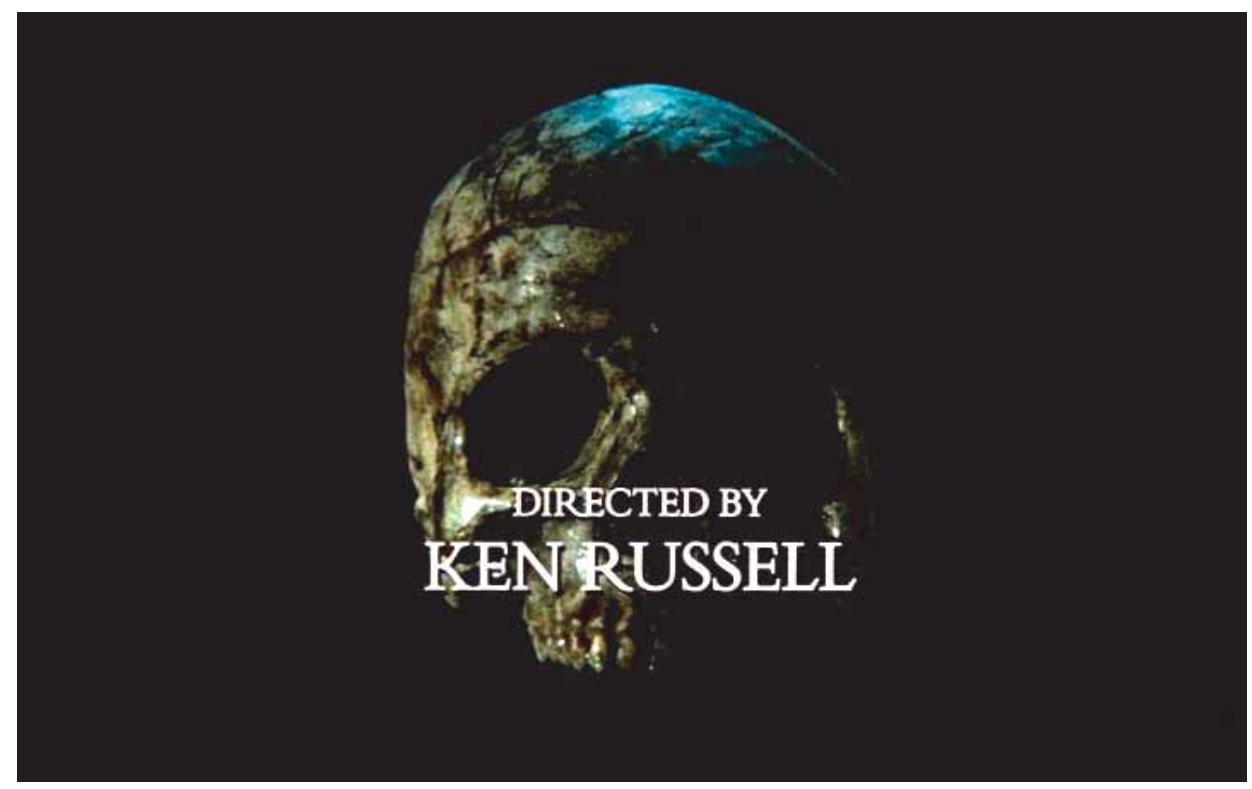

Illustration 25 Phantasmagoria

This context now also invites us to take a fresh look at Salome's Last Dance, which is steeped in references to early cinema, and especially to the work of Georges Méliès. Before he became a film-maker Méliès ran the Théâtre Robert-Houdin in Paris, which he had bought in 1887 and where he staged elaborate magic shows. Many of his later films would derive their themes and, more importantly, their trick effects from this previous career as a prestidigitator. ${ }^{268}$ Russell reproduces several of the characteristics of Méliès's work in Salome's Last Dance. As was pointed out before, in this film Russell himself performs the part of Kenneth the pornographer. He does this in an exaggerated acting style that recalls the way Méliès himself liked to play the part of the magician in many of his own films. ${ }^{269}$ The luridly coloured cardboard sets and backdrops used in the

\footnotetext{
${ }^{268}$ The origins of the early trick film in magic shows is discussed in Solomon (2006 and 2010: 60-79), Gunning (1995: 61-64), Mannoni (2002), and Le Forestier (2002). On Méliès and the Théâtre Robert-Houdin, see Fechner (2002) and Solomon (2010: 40-59).

${ }^{269}$ It is worth pointing out that Méliès himself was aware of the way his role as magician reinforced a reading of his films as a series of attractions. As Paul Hammond explains, 'Méliès thought of his films as connected fragments, and he compared his rôle to the compère of a revue who "is there to link the acts that have nothing to do with each other"' (1974: 8). Méliès confirmed that the scenarios of his films were often 'simply a thread intended to link the "effects", in themselves without much relation to each other' (quoted in o.c. 57). He also said that 'quant au scénario, à la "fable", au "conte", je m'en occupais en dernier. Je puis affirmer que le scénario ainsi fait n'avait aucune importance, puisque je n'avais pour but que de l'utiliser comme "prétexte" à "mise en scène", à "trucs", ou à tableaux d'un joli effet' (quoted in Le Forestier 2002: 228). Of course, all of this also reflects back on Corneille's L'Illusion comique, which is all about a magician's conjuring tricks. One could read
} 
performance of Wilde's Salomé in Russell's film could now also be seen as modelled on similar cardboard sets in Méliès's films. They also bring to mind the moveable cardboard sets used in the performance of the Birth of Venus which opens The Devils and in the many musical numbers in The Boy Friend. The connection to Méliès also extends to film technique. Among the cinematic tricks that Méliès especially loved was the socalled substitution splice, where the camera is briefly stopped while the actors hold their poses to substitute one object or person for another, creating a magical appearance, disappearance, or transfiguration. ${ }^{270}$ Salome's Last Dance explicitly refers to the substitution splice and its magical effect of making objects disappear or change shape. Russell uses it in association with the flash of Kenneth's camera, which seems to "mark" the substitution splice with a self-referential flash. A first instance occurs at the beginning of the performance, when Kenneth shouts "Now!" to take a photograph of the Executioner and the flash of his camera seems to startle Salome into awareness. She then begins her performance. Like a doll brought to life by a magician (the subject of Russell's early short Peepshow) Salome is brought to life and set into motion by Kenneth's magic flash. A second instance was already discussed earlier in this chapter: it is the brief substitution of a naked male dancer and his flashing genitals for Salome in the dance of the seven veils. This is literally a substitution, and it again occurs as Kenneth's camera works its magical flash to make a dirty picture. ${ }^{271}$

\subsubsection{Altered States of Narrative: Allegorical Hyperbole}

Eisenstein's theory of montage can now also be used to illuminate some of the most complicated sequences in Russell's films. Russell's art of montage achieves its greatest

\footnotetext{
that play as a theatre of attractions in which each of the embedded visions is just one in a series of trucs, or entrées, or phantasmagoria. This is certainly the implication of Robert J. Nelson's observation that 'the magician is an artist [...]. Like the playwright-author, he selects events and arranges them in a pattern calculated to interest and please his spectator. [...] And Alcandre is a very Cornelian playwright: he cares little about the unities of time and place. He reverses the natural course of events so that we witness the present and the past in a single moment. By sleight of hand the magician shifts his scene from grotto to public square to prison to stage. As the magician is beyond physical laws of cause and effect, so the playwright is beyond their aesthetic counterpart of vraisemblance. [...] His coups de théâtre are so many tricks to delight and surprise the spectator' (1958: 50).

${ }^{270}$ On Méliès's use of the substitution splice, see Solomon (2006: 604 and 2010: 33-36). Solomon (2000) puts the substitution splice in the context of "quick change" tricks in magic shows of the 1890s and makes an interesting connection to Eisenstein's notion of the plasmatic: organic figures that are capable of effortless mutability. For Eisenstein's notion of "plasmaticness", see Eisenstein (2006: 85-175) on Disney.

${ }^{271}$ See the discussion in section 4.1.3. The connection between Russell and Méliès is also made explicit in The Lair of the White Worm, where one of the main characters can be seen watching a clip from a Méliès film on television. The fact that the clip is shown on television obviously also establishes an embedded screen.
} 
sophistication in two tropes that are closely intertwined: the fugue and the allegorical hyperbole. In Chapter One I argued that the fugue was one of Russell's favoured means of developing a narrative because it allows him to telescope events and develop both plot and character at great speed through visual and narrative shortcuts. For example, the "fell-walking fugue" of Russell and his wife climbing the mountains in the Lake District was in reality a montage of events that took place on different occasions but which were telescoped, for dramatic purposes, into one scene of Russell's autobiography. ${ }^{272}$ Fugues are always climactic events in Russell's films, and they usually have great narrative of dramatic import. Sometimes a film will even be structured almost entirely as a series of such fugues. This was the case in Mahler, where the train journey is the narrative base from which we descend into a series of interwoven imbedded memories. ${ }^{273}$ Mary's final hallucination in Gothic is also a fugue. With its fluid sequence of visions it resembles a stream of consciousness. Its structuring motif of several doors opening to reveal the visions links together the vignettes in a symbolic representation of her subconscious. But Russell also introduces symbolism and metaphors into his fugues. A clear example is the moving sequence in Mahler where Alma buries her own music as a symbolic expression of her stifled creativity. In fact, the film begins with an allegorical image of Alma's frustration: she is pictured as a chrysalis struggling to break free next to a rock sculpted to resemble Mahler's head. When such symbolism dominates a fugue it turns into allegorical hyperbole: an imaginative sequence in which narrative elements are infused with metaphorical motifs that express Russell's commentary on the events. Mahler contains several other such fugues. First, there is the sequence where Mahler imagines his own death. In this fugue Alma is seen dancing on his coffin and provocatively straddling a gramophone. Clearly, such events are allegorical representations of feelings, thoughts, and fears. A second example is the infamous fugue on Mahler's conversion. It shows Mahler jumping through burning hoops while Cosima Wagner, whip in hand, spurs him on like the ringmaster in a circus. This entire sequence is Russell's authorial commentary on a biographical fact from Mahler's life. ${ }^{274}$

In such complex sequences Russell moves far beyond associative montage or montage of attractions. He is using an allegorical visual language. But for this, too, Eisenstein provides the theoretical blueprint. In his later writings Eisenstein moved towards a more organic view of the film which takes its cue from musical language, analysing film in terms of polyphonic or vertical montage. The principle of polyphonic montage holds

\footnotetext{
${ }^{272}$ See above, section 1.2.

${ }^{273}$ See above, section 1.1.

${ }^{274}$ The Cosima Wagner sequence was previously discussed at the end of section 1.2.1. Gomez (1976: 183-193) focuses especially on Russell's use of metaphor in Mahler.
} 
that all elements that go into a film must be orchestrated to form a unified whole, from the editing and the acting to the symbolic use of colour and the introduction of music. It means that 'a film's texture must [...] be through-composed; every stylistic choice is governed by the evolving expressive context. By interlacing motivic "voices," the artwork achieves a dynamic organic unity' (Bordwell 2005: 184). The two most important strands that must be interwoven are the film's visual and aural tracks. This is where Eisenstein's notion of vertical montage comes in. It pertains to the relation between image and sound. As Eisenstein himself explained, it was designed to solve the problem of 'finding what makes picture and sound compatible [...]. This will be primarily a matter of finding an inner synchronicity between picture and music [...] in which the visual principle merges wholly with the tonal' (1994: 334). ${ }^{275}$ This form of montage is vertical in the metaphorical sense that a film's soundtrack could be said to "float" above its visual track. The effects that can be achieved by matching (or intentionally mismatching) sound and vision are the creative work of vertical montage. And it is everywhere in Russell, who already approached his earliest films for Monitor as Eisensteinian audiovisual symphonies. It is important to remember that, when dealing with dead artists, Russell was initially not allowed to recreate scenes and had to rely on archive or stock footage to tell his story. This means that, in such films, Russell would actually be constructing (parts of) a new work from existing footage, which we would now call "found footage" and consider a radical avant-garde practice. At the BBC it was called Reithianism. Both Prokofiev and Bela Bartok contain sequences that clearly show Russell editing vision (archive footage) to sound. In both films he is especially concerned to illustrate longer musical excerpts with footage of nature and animals that is cut very accurately to follow the music. In Bela Bartok there is an extended sequence focusing on the composer's habit of stalking through the woods at night with a flashlight to observe the fauna. This sequence contains brief shots of animals that are edited into the visual flow for expressionistic effect, matching movements in the music. ${ }^{276}$

\footnotetext{
${ }^{275}$ It is interesting to consider Eisenstein's vertical montage, described as a form of "symphonic" art, in relation to Walter Pater's observation in The Renaissance that 'all art constantly aspires towards the condition of music' (2010: 124): both are inroads into Russell's work, from his use of the rondo structure in Mahler to the importance of allegorical hyperbole in his construction of cinematic fugues. As for Eisenstein, the relationship between image and sound was one of his main theoretical preoccupations in key texts such as the 1928 'Statement on Sound', co-authored with Vsevolod Pudovkin en Grigori Alexandrov (Eisenstein 1988: 113-114), his text on rhythm (Eisenstein 1994: 227-248) and, of course, the long essay on 'Vertical Montage' (o.c. 327-399). The musical analogy for montage is developed in Eisenstein's 1929 essay on 'The Fourth Dimension in Cinema' (Eisenstein 1988: 181-194). See Bordwell (2005: 131-134) for a discussion of the principles involved.

${ }^{276}$ In a celebrated scene in Mahler where Alma has to silence the environment so that Mahler may have peace and quiet to work, Russell takes vertical montage a step further in the sense that the musical soundtrack itself
} 
The best example of an allegorical hyperbole using vertical montage in Russell's work is the stunning fugue on Tchaikovsky's Ouverture 1812 in The Music Lovers. As I pointed out above, the title of the film is its programme: it is Ken Russell's Film on Tchaikovsky and the Music Lovers. But it is quite justified that the film is usually referred to (also by Russell) as The Music Lovers, not only because these three words are given in a separate title card, and are therefore the film's main title, but also because they provide the key to the film's content: the "music lovers" in the film are the people who cling to Tchaikovsky in the hope that some of his genius and his success will rub off on them. His nymphomaniac wife Nina (Glenda Jackson) is obsessed with his fame. His brother Modeste (Kenneth Colley) is mainly concerned with the money Tchaikovsky can make for both of them by becoming a concert conductor. Madame von Meck (Isa Teller), who is Tchaikovsky's benefactress, projects her own frustrated desires onto Tchaikovsky's music and likes to think of herself as the only person who can truly see and feel the genius of his music. Count Chiluvsky (Christopher Gable), who is Tchaikovsky's homosexual lover, only cares about himself and has little concern for Tchaikovsky's own feelings: when Tchaikovsky dismisses him, Chiluvsky reveals the secret of his homosexuality to Madame von Meck, who withdraws her financial support for the composer, leaving Modeste to step in and take charge of Tchaikovsky's career. By this time Nina, who has gone mad with sexual obsession, is already safely tucked away in an insane asylum. And it is at this point that Russell introduces his magnificent visualisation of the Ouverture 1812. The entire sequence is really a statement about sincerity in art. As such, it connects back to the previous chapter, where I discussed the way Gaudier inspired Russell with his belief that an artist should always follow the spark or fire within himself. ${ }^{277}$ In The Music Lovers Tchaikovsky is destroyed because he allows the music lovers to distract him from the purity of his art. But rather than explain these ideas in a discursive way, Russell presents them in a fugue that is constructed as an allegorical hyperbole, using a highly imaginative stream of images, set to Tchaikovksy's music, to convey the film's central message. It is a spectacular visual shortcut to make a point without the interference of narrative or dialogue. The hyperbole on the Ouverture 1812 is triggered by Tchaikovsky's dramatic departure from Madame von Meck's estate after she has banished him from her life. As Tchaikovsky and Modeste drive away in a carriage Modeste urges Tchaikovsky that 'you could be famous now, Peter, really. It's like a bonfire. It's all laid, it's set. It just needs a final touch and - whoosh!'

is a collage of pieces taken from different Mahler symphonies: see Hanke (1984: 229-231) and Tibbetts (2005c: 191).

${ }^{277}$ See above, section 3.1 . 


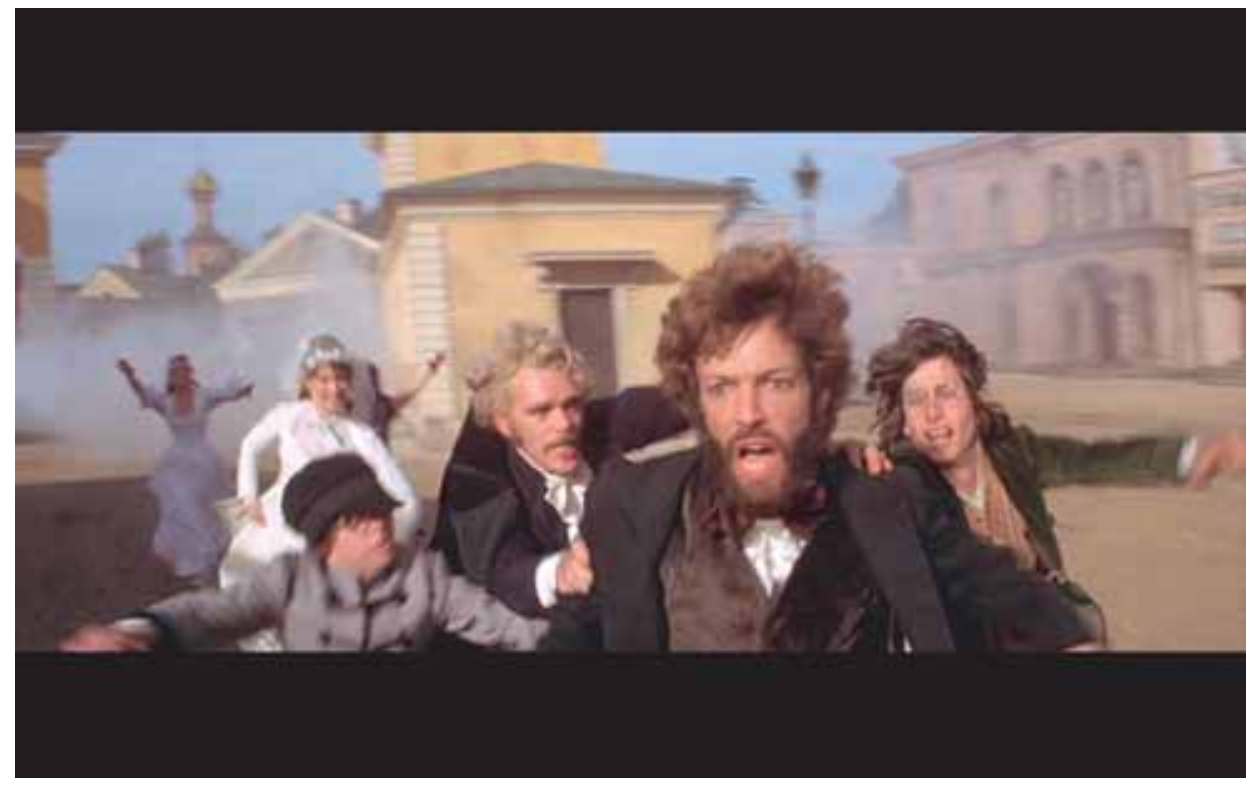

Illustration 26 Tchaikovsky is chased by the "music lovers"

This last exclamation, which vocalises the sound of a fire flaring up, covers an abrupt cut from Modeste's face in the carriage to a close-up of a cannon with Nina next to it. The cannon fires at Tchaikovsky, who ducks the assault. Chiluvsky, Madame von Meck, Tchaikovsky's amanuensis Alexei, and Tchaikovsky's sister Sasha next also each take a shot at the composer, who runs away and suddenly finds himself in the streets of Moscow running around in a dense fog, chased by the music lovers, who are seen pulling at him from moving carriages and from windows as he runs around seeking refuge (ill. 26). As Tchaikovsky turns a corner, believing himself safe, Russell cuts to Modeste on a rooftop, pointing Tchaikovsky out to a mob of admirers (Moscow's music lovers) as if he were an emcee. At this point the sound of church bells is for the first time introduced in the music of the Ouverture 1812 and the crowd carries Tchaikovsky along as coloured ribbons rain down on him. He is next driven around in a carriage while the crowd applauds him. Modeste, who is with him, shows Tchaikovsky's conductor's baton to the crowd and hands it to Tchaikovsky, who starts making conducting gestures. This image makes a lot of narrative exposition redundant: it represents the way Modeste has taken charge of Tchaikovsky's career and made him a star in Moscow. We next see Modeste amid a swirl of money, trying to grab as much as he can. The vulgarity of Tchaikovsky's fame at this point is represented in a shot of him conducting music for the Follies Bergères, while in a later image Modeste uses the canon that we have earlier seen to blast the 
heads off all the music lovers who stand in the way of even more success and even more money. The Ouverture 1812 sequence ends on an allegorical image that encapsulates the central message of the film. As the music swells to climax Tchaikovsky, sitting on a chair, is carried out of a church by the crowd and placed on a pedestal where, covered in flying ribbons, he seems to conduct music for the masses. But at one point Tchaikovsky holds his pose and Russell cuts to a bronze statue of Tchaikovsky on the same pedestal in the same conducting posture. Except that now it is winter, the ribbons and the crowds are gone, and snow is covering Moscow. The world has literally grown cold. Success has destroyed Tchaikovsky's artistic soul. In a classic substitution splice (which is also an instance of commentary through associative montage) Tchaikovsky is literally petrified (ill. 27-28).

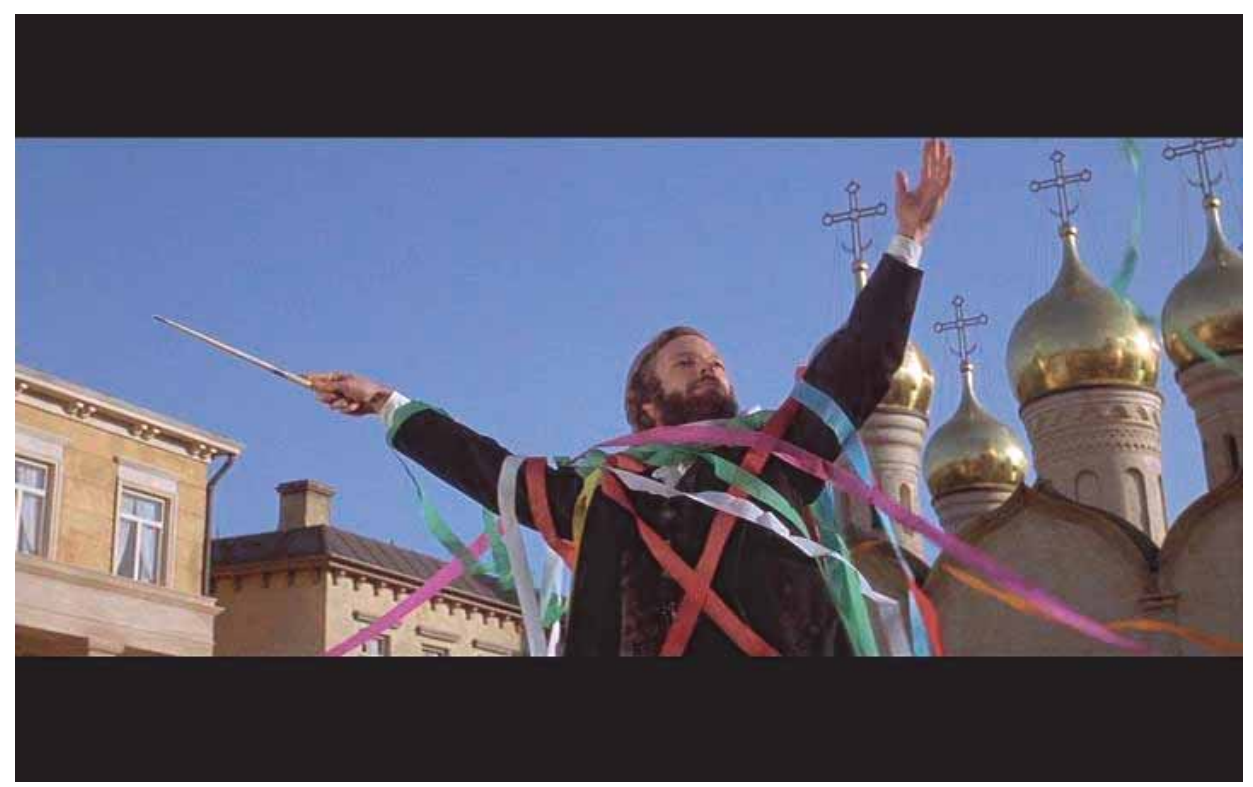

Illustration 27 Tchaikovsky celebrated 


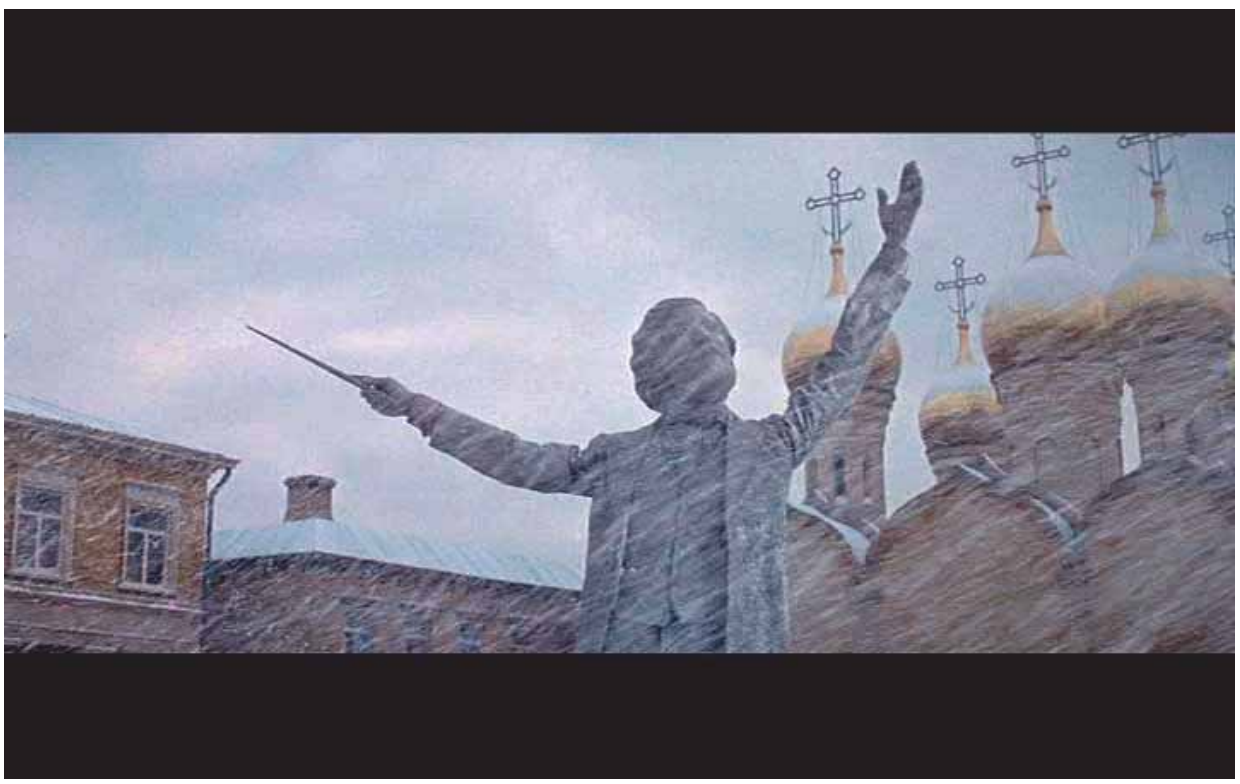

Illustration 28 Tchaikovsky petrified

\subsection{PERCHANCE TO DREAM: PORTRAIT OF THE ARTIST AS GENIUS}

With this image, one of the most powerful in Russell's work, I have completed my analysis of Russell's films. It is now time to draw together the scarlet threads of the argument in some concluding remarks about Russell's performance of himself through his art and the important role of montage in this process. As with the discussion of Harold Bloom at the end of the previous chapter, however, we will benefit from a brief detour through a more general point about film as an art form. My point of entry is once again provided by Susanne Langer, who has argued, in a very pregnant (and critically neglected) 'Note on the Film' at the end of Feeling and Form (1953), that films are like dreams because dreams and films share a capacity for jumping through time and space. That is why she calls the film an art form that establishes a "dream mode". She argues that the nature of space in dreams is similar to the nature of space in films. As Langer explains, 'dream events are spatial - often intensely concerned with space - intervals, endless roads, bottomless canyons, things too high, things too near, too far - but they are not oriented in any total space. The same is true of the moving picture, and distinguishes it - despite its visual character - from plastic art: its space comes and goes [...]. The "dreamed reality" 
on the screen can move forward and backward because it is really an eternal and ubiquitous virtual present. The [...] dream mode is an endless Now' (FF 415). The logical conclusion to infer from this, of course, is to say that spatial mobility in dreams and films is always also temporal mobility: like the mind's eye in imagination, daydreaming, or dreaming ${ }^{278}$, films are free to roam both space and time at will because to roam space is to roam time, and vice versa. Montage is the tool that allows film to roam in this way because in its crudest form, which is simple editing, it makes it possible to juxtapose (images of) any place at any time with (images of) any other place at any other time. But Langer points towards a second similarity which helps to make clear what she means when she says that both in dreams and in films we experience an eternal present (or 'endless Now'). She argues that 'the most noteworthy formal characteristic of dream is that the dreamer is always at the centre of it' (FF 413). The dreamer is the perceptual centre of the dream: everything that is seen in the dream appears to the dreamer who moves through the dream. That is why the dream is an endless present: unable to control or predict what will happen in the dream, the dreamer undergoes the dream despite himself. The images just keep coming, a flood that is especially distressing in the case of a nightmare. This constant unpredictable newness makes of the dream an eternal present: everything in the dream is happening here and now. This is what one could call the emergent nature of dreams, and it is shared by films. ${ }^{279}$ After all, part of the excitement

\footnotetext{
${ }^{278}$ Elaine Scarry has offered a beautiful reading of the mind as the inner space of imagining, arguing, among other things, that objects imagined are perceived mentally as if they were projected onto the inside of the forehead, which is 'the habitual space for interior imagining' (2001: 47). It would be interesting, but beyond the scope of the present analysis, to elaborate the analogy between the dark space of a cinema and the dark inside of one's head, both with their own form of projection. In this respect, it is interesting to note that Coleridge's writings on dreams often address the mind as a dream space, and he sometimes writes of dreams as if they were plays performed in the head. On this, see the second chapter in Ford (1998, esp. 33 and 37-39). Hayter argues that, for the Romantic poets, 'the dream process is a parallel and model for the process of poetic creation' because in dreams images and words are freely (and often eccentrically) associated. 'In their dreams poets could thus watch how imagery was formed,' which was in turn a stimulus to experiment with laudanum, which was believed to trigger intense dreams. For the Romantic poets, then, 'dreams were part of one's professional equipment as a writer' (1971: 67-76, here 70, 71, and 73).

${ }^{279}$ The few commentaries on Langer's ideas on film tend to misinterpret the "virtual present" of film. Curran (1980) is the only monograph on the topic but is disappointing in part because the author seems uninterested in the philosophical and formal questions raised by Langer and seems to not fully grasp Langer's meaning, as when she associates the virtual present of film with the physicality of bodies and faces filmed in close-up (o.c. 49). Of the shorter discussions, Beinhorn (1974) provides a thoughtful commentary that takes issue with Parker Tyler's (1971: 120-127) attack on Langer, which is based on a misreading. In the last section of his discussion, however, Beinhorn deduces normative criteria from Langer's argument that are completely at odds with the philosopher's intentions. Sparshott's discussion of the analogy between film and dream only mentions Langer in passing (1971: 20) but provides interesting elaborations of ideas that are expressed in the Note. Innis (2009) is mute on the subject of Langer's ideas on film. There are interesting similarities between Langer's treatment of space and time in the cinema and the observations in Morin (1956: 63-72).
} 
of watching a film, especially in the cinema, is the thrill of subjecting oneself to the emergence of the stream of sound and vision. Once the film starts, sound and image just keep on coming as the reels unwind. ${ }^{280}$

Throughout his work Russell has made very self-conscious use of the spatial and temporal mobility of the film. The several embedded narrative layers of Mahler, for example, could only be accomplished because in film the move from one narrative, spatial, or temporal level to another is always only a cut away. In my discussion of The Debussy Film I pointed out an example where the journey through the several narrative layers is accomplished with a few simple cuts from Debussy's fantasy to Debussy on the beach with Madame Bardac to the director stepping in. ${ }^{281}$ But the analogy with the dream extends beyond the use of editing. Equally significant is the fact that Russell's films are constructed as a self-contained universe. This is something that was clearly visible in The Devils, Salome's Last Dance, and Gothic with their huis clos structure, but it is in fact achieved every time Russell uses a framing device to encapsulate his narrative, whether it is a train ride (in Mahler), the making of a film (in The Debussy Film), or tourists peeping at outrageous poets camping out in exclusive villas on the shores of even more exclusive Swiss lakes (in Gothic). Once he has established this self-contained universe Russell can move freely from one narrative, spatial, or temporal level to another. Of course, any film can do that. But I have been arguing in this chapter that in Russell's films these movements take on a very specific significance because they are used to construct a mise-en-abyme that reflects back upon the creative process itself. In other words, any and every film uses the spatio-temporal mobility of film. It is part of the basic grammar of film (this was part of Langer's point). But in Russell's work this grammar also becomes part of what the films are about. Most films don't want us to

\footnotetext{
${ }^{280}$ Raymond Bellour has argued that 'the dispositif of the cinema is much closer to that of hypnosis than to that of the dream' because in hypnosis determination 'comes from the outside' while in dreams the determination (of what is dreamed) 'remains purely internal' (2009: 62). The suggestion is that films, because they are made by other people and shown to us in a context that we do not control, are imposed upon us from outside like a hypnotic state rather than a dream (which emerges from within ourselves). He further suggests that 'the filmic state seems like [...] a superposition between the two times of the hypnosis, the process of induction and the state. [...] And it is in this pre-sleep that the film is continually suggested to [the viewer]; forbidding him to fall asleep, but propelling him into an intermediate state between waking and sleeping' (o.c. 63). The film, like the hypnotist, lets us hover between waking and sleeping/dreaming or "being under" hypnosis. However, I find the analogy with hypnosis unsatisfactory and would argue that in order to appreciate a film well we cannot afford to be either semi-conscious, hovering between mental states, or under hypnosis: we need to be wholly alert to the representation. This is also the point of Langer's analogy between film and dream, which is about their formal language and structure. Morin also points out that "la "relaxation" du spectateur n'est pas hypnose: l'impuissance du rêveur est affreuse et celle du spectateur heureuse: celui-ci sait qu'il assiste à un spectacle inoffensif (1956: 157).

${ }^{281}$ See above, section 1.3.2.1.
} 
notice how they are edited. The typical twist of Russell's films is that Russell uses montage, in the Eisensteinian sense, to edit his films in such a way that, while the editing process itself may not be noticed (because the physical splices dissolve into the stream of imagery), its effects on the narrative are such that the films do become a commentary on montage. This is because Russell's films are essentially concerned with the process of artistic creation. They are essentially and deeply performative: they exemplify their poetics.

It is through this self-reflexive performativity that Russell can use his films to perform himself. With the exception of A British Picture (1989) none of Russell's films takes his autobiographical self as its subject. And yet, because the films are about the nature of the creative process in general and because they always also exemplify the poetical views on the creative process that they present, Russell's films do double back on themselves and become an exemplification of Russell's own creative processes. By doing what he is saying, Russell himself, as the director of these films, becomes the clearest example of the creative processes that the films investigate. Russell's films are their own poetics put into action. So whatever they say about art and artists, they say about Russell. This is how Russell can suggest, as he did in his notes on Mahler, that all of his films are ultimately about himself. This claim goes much deeper than the obvious fact that he is simply giving us "his interpretation" of the artist concerned. The fact that, like a Wordsworthian poet, he positions himself as the medium who "feels" the artist in his music and gives us a portrait of the artist as refracted through his own experience of their work simply means that the film itself is a completely original work of art, a montage of influences, suggestions, and numerous other elements that are assembled by Russell into a montage that is his own invention. But as we saw, in Romanticism invention is not the creation of something out of nothing: it is the process of shaping a mass of given material into a new work that speaks with what Harold Bloom has called, as a definition of genius, 'fierce originality' (2002: 11). Mahler, Isadora Duncan, and Gothic are films about the creative process. They try to show how creation works by "getting in there" with the artist (in a direct cinema way). But Gothic illustrates that, in order to show us the process of creation, Russell has to apply it: otherwise he could not make his film. Russell must perform what he says because he can only say it by performing it. And because the thing that is being performed is artistic creation, the act of performing it is the act of creating Russell the artist. Russell is an artist because he creates. And because he creates according to the principles of Romantic genius, his films certify his own Romantic genius, despite the fact that he opposes (as was seen in the discussion of Savage Messiah) the Romantic myth of the artist. Russell argues that the artist is not an inspired genius but a worker. But when it next turns out that the nature of the artist's work neatly fits the model of the poetics of Romantic genius, the logic doubles back upon itself. 
There is a moment in Gothic when Dr Polidori is on the verge of a nervous breakdown and expresses his fear that God is about to punish the revellers at the Villa Diodati for their Promethean arrogance in trying to create life. Byron scoffs at him and shouts sarcastically that 'we are the gods now!' God is dead. Modern man has become the measure of everything. This connects back to my discussion of Salome's Last Dance in the first part of this chapter. That film was structured entirely as a tug of war over who would get to determine the nature of reality in the world of the embedded play. This is one of the themes, I argued, of Oscar Wilde's work, not just in Salomé but also in his philosophical dialogues. By staging these philosophical questions as a play-within-the-film Russell dramatises the implication that follows from such an understanding of the world: all the world is indeed a stage, and it is we who decide which roles we play, and how, and why. All of reality is a construct, a work of art. This, I argued, is the deeper significance of Russell's casting of himself as a stage hand in charge of several of the visual and sonic effects of the performance of Salomé: as a technician behind the scenes (and what is a film director if not the god in charge of the technicians behind the scenes of a film?) his character reflects the fact that creating reality is a matter of pulling the scarlet threads of one's own performance. At the same time, however, Russell's self-dramatisation as a technician also highlights the fact that the reality that emerges from this trickery is always also a fiction. It is the dream of ourselves that we impose upon others. If the others accept the imposition, we are made real. Our performance of self becomes real in its consequences when others accept it to such an extent that their own behaviour suggests that we are what we perform. Our self-made truth is reflected back at us. But the best way, of course, to impose one's dream of oneself upon others is to provide those others with irrefutable proof of it. In the case of the artist, this proof is his body of work. Every artist is an artist by virtue of making works of art. But Russell takes this logic a step further: he performs himself through his art because the very texture of his films exemplifies the principles of creation that they are about. In that sense Russell becomes Russell through his films. And once his films are made, the traces of the creative process are self-reflexively there for all to see. Gothic is the clearest example: the film's narrative is all about the very creative processes that Russell has put into practice making the film. This is the performative twist in Russell's film which makes it possible for the film to perform Russell. Just like the reality of Loudun's new world order is inscribed into the body of the dead Grandier, so, too, Russell, and who he is as an artist, is inscribed into the texture of his films. That is why the films can perform Russell again and again, despite the fact that they never change: they exemplify him, as if his very identity as an artist has been captured there like a fly in amber. 
This is a remarkable process, and one that raises many questions about the nature of self and reality, about their connections to a baroque world-view, and about the possibilities of making lives and making selves beyond (and despite) the constraints of social, cultural, or ideological context. I have portrayed Russell as an artist who belongs to the $\mathrm{Na}$ chleben of ideas that crystallised in the Baroque but whose Wanderstrasse winds through time and space to take in Oscar Wilde and Walter Pater, Wordsworth and Lord Byron, Harold Bloom and Lucretius, and many others besides whose names have not been mentioned in these pages. It is now time, however, to gather our wits and take stock of what we have found. This is the business of the essay that concludes this book. 



\section{Conclusion}

\section{MOY QUI ME VOY}

An Essay on the Self in a Time of Baroque

'Nought may endure but Mutability' 

This has been a study of representation. The subject of my analysis was the film-maker Ken Russell who, I argued, created an oblique self-portrait through his work, and especially (though not exclusively) through his biographical films on the lives of other artists. In the course of my analysis, and specifically in the discussion of Isadora Duncan in Chapter Three and in the extended analysis of Russell's use of montage in Gothic in Chapter Four, it became clear that this performance of self is not something that happens exclusively, or even primarily, on the narrative or thematic level of Russell's films: Russell performs himself first and foremost in the way he makes his films. As I explained, the image of himself that he projects, is that of a Romantic genius. But Russell demystifies genius: to speak of genius in his work is not to invoke pseudo-mystical theories about divine or other transcendent inspiration. Genius, in Russell, is a way of doing things (a way of making art). It is the ability to make startling new wholes out of disparate elements that are brought together in a way that allows one to look at the world and understand it in a new way. That is what Russell does in making his films. In that sense Russell's films are deeply performative. If speech acts can bring a reality about simply by uttering words (as when an appropriate official declares one husband and wife) it is perhaps possible to see Russell's films as "art acts" or "film acts" declaring his genius: works of cinematic art (but we should remember that Russell's art also includes his autobiography and several novels) that are intrinsically involved in (the production of) the identity of their author, not simply because Russell is the man who made them (because that relationship exists between every work of art and its creator), but because who he is, as a creator, and what kind of creator he is, is performed in and through the texture of the films. There is an intrinsic co-dependence between the person and his work that goes much deeper than the conventional authorial claim that any artist has on their work. One cannot separate Russell from his films the way one can separate most other artists from their creations: Russell's films “do” Russell.

If Russell performs himself as a Romantic (or as a Romantic genius even) in his work, then I have argued that the way he achieves this is baroque. It is important to keep these two strands separate, at least for analytical purposes: the self that Russell has created through his work is a Romantic self, but the tools that he uses to achieve this are baroque. That is why I have called Russell's performance of self a baroque performance of (Romantic) self. As I showed in Chapter One, the technique of embedded narratives, including the mise-en-abyme, is the bedrock of Russell's narrative art. It is his most consistently used dramatic device. The other central device, and the one with which Russell's style is most readily associated, is that of the allegorical hyperbole. It is through the combined use of embedded narratives (including the mise-en-abyme) and allegorical hyperboles (which rely, in Russell's films, on principles of Eisensteinian montage) that 
Russell puts his films to work in the performative way mentioned before: because they exemplify the Romantic theory of genius these films "do" Russell's genius for him. In Chapter Three I reconstructed Russell's development as a film-maker in the first decade of his career to show how his particular (and performative) approach to film-making emerged out of a continuous and continuously developing negotiation of a number of contextual factors, including the institutional framework of documentary film-making at the $\mathrm{BBC}$ and the creative innovations introduced by direct cinema and cinéma vérité. Russell's own discontent with the established conventions of the $\mathrm{BBC}$ motivated a search for new forms which was articulated, with increasing explicitness, in the films following Elgar and culminating in Isadora Duncan. Within this process The Debussy Film may stand as Russell's most radical experiment with baroque narrative structures and therefore perhaps also the film in which his personal artistic signature most firmly announced itself. But while the play-within-the-play, the mise-en-abyme, and allegory are central to the poetics of the Baroque, their overwhelming presence as formal conceits in Russell's work is not in itself sufficient to proclaim Russell a baroque artist (although, as I pointed out in the Introduction, this is exactly what is often done, both in relation to Russell and in relation to the neo-baroque: the reduction of the baroque to a formal matrix). The real justification, and the more interesting interpretation, is to say that Russell is baroque because he uses these conceits in ways that are similar to their uses in the historical Baroque, when they were involved in a fundamental questioning of the nature of reality in a changing world, and of the place and identity of the self within that world. A central trope in this respect was the world as a stage upon which we perform our selves as characters in a play. It is this cultural sense of the baroque that Russell engages when he performs himself through his films. And that is what truly makes Russell baroque.

It is because of the performative quality of Russell's films that the tools of life writing studies by themselves were never going to be sufficient to grasp the complexity of his work. In the Introduction I mentioned a number of concepts that life writing scholars have introduced to address the inevitable contamination between biography and autobiography that takes place whenever one person takes on the task of writing a life, their own or someone else's. It is clear that Russell's films are indeed what we might call "auto/biografictions": they are films in which autobiography (Russell's) and biography (the artists') become intertwined because Russell so obviously offers us personal interpretations of the lives rather than a dry factual account. The double "impurity" of, first, the highly subjective interpretation of the life and, second, the highly imaginative rendering of this interpretation further suggests that his films may perhaps even be read as straight fiction. This impurity clearly marks Russell's films as highly convoluted examples of 
auto/biografiction: texts in which biography and autobiography become entangled on an intersection between fact and fiction. It's a four-way crossroads with no way out (for none of the four individual roads can in itself carry the burden of clarifying what is going on). That has everything to do with the fact that Russell's work really operates beyond biography and autobiography: it is a performance of self. To treat it as (auto)biography is to get ahead of ourselves: the work is still constituting its subject. And, I have argued, it never stops constituting its subject because the subject's identity has been inscribed into the films to be performed and performed again every time the films are shown. As I argued, this even takes Russell beyond performativity, for his particular form of performance of self lacks the (re)iterativity that is so typical of performative practices: while one could argue that Russell reiterated his performance with every new film he made (and that means: in the act of making them, which then becomes a performative as well as a creative act), the vocabulary of performativity cannot fully account for what the films (continue to) perform once they are completed and publicly exhibited. In the four chapters that make up the body of this book I have tried to clarify this process and show how exactly Russell achieves this extremely peculiar form of performance of self. ${ }^{282}$ We should now consider some of the implications of this analysis and stake out the terrain for future research.

\subsection{BAROQUE STYLE}

Russell's style is baroque. On that we can agree even with Russell's critics. But what does it mean? A style is much more than a way of saying or showing things. It is more than a formal matrix. Susanne Langer, to whose work I want to appeal one last time in these pages, has argued that 'art is the creation of forms symbolic of human feeling' (FF 40). By this she does not mean that works of art are the unmediated expression of some private personal emotion (which would be the vulgar Romantic concept of art as expression). As Langer herself puts it, 'what art expresses is not actual feeling, but ideas of feeling' (FF 59): we must be wary of 'the confusions between feeling shown and feeling represented, symptom and symbol' (FF 184). What she does mean, then, is that every work of art is the articulation, in an objectified form, of the artist's felt experience of life. Works of art encompass and express a whole world of experience, an attitude to that

\footnotetext{
${ }^{282}$ Peculiar, but not unique: I have taken the liberty of suggesting, in a number of footnotes, that artists such as Andy Warhol, Grace Jones, and Siouxsie Sioux might be considered similar cases of performance of self through art. Walter Pater in many ways seems to fit the model. It would also be interesting to look at the life and work of Gilbert and George from this perspective. Doubtless, there are many others. But I do hope to have shown that Russell's case is paradigmatic of this particular type of performance of self.
} 
experience, a world-view. They are formally shaped responses to subjective experience. And as I already pointed out at the end of Chapter One, they are virtual or fictional responses to the felt experience of life. If they were not fictional, they would not be symbolic but symptomatic. This does imply, however, that the style of a work of art is always much more than simply "how" it is made: a subject and its attitudes are involved and expressed in it. A work of art is not simply the presentation of a subject (a story, a theme, an image) in a specific formal language (suggesting that the subject could also be translated into another style-as-formal-language). As Nelson Goodman points out, we must resist the temptation of the 'misleading opposition of style and subject, of form and content, of what and how' (1978: 33). In good art, the subject and the way the subject is presented, are deeply entwined: 'what is said, how it is said, what is expressed, and how it is expressed are all intimately related and involved in style' (o.c. 27). ${ }^{283}$ This means that 'style consists of those features of the symbolic functioning of a work that are characteristic of author, period, place, or school' (o.c. 35). The operative word here is "symbolic" because it stresses that the formal features in themselves are only half the style: the other, and much more important, half are the expressive uses to which those formal elements are put. ${ }^{284}$

All of this is not meant to engage us in a philosophical discussion of the notoriously slippery concept of style. ${ }^{285}$ It is meant to make a point about Russell in relation to the baroque. As I pointed out in the Introduction, there is a tendency in some of the literature on the neo-baroque to identify baroque with a way of doing things: it relies (echo-

\footnotetext{
${ }^{283}$ In a discussion of literary criticism Langer points out that 'the significance of any piece of literature must lie, supposedly, in what the author says; yet every critic who is worth his salt has enough literary intuition to know that the way of saying things is somehow all-important. This is especially obvious in poetry. [...] Isn't the wording everything? And yet, must not the wording itself be judged by its adequacy to state the author's ideas?' (FF 208) One might at this point also recall Lindsay Anderson's observation, quoted in Chapter Three, that 'an attitude means a style. A style means an attitude' (quoted in Sinker 2004: 82).

${ }^{284}$ René Wellek made the same point in his discussion of the limitations of a purely formal concept of the baroque. According to him, 'if we say that baroque literature uses conceits or is written in an ornate prose style, we cannot draw any kind of line which shall rule out the predecessors of the baroque and even styles which historically arose without any connection with the baroque. [...] If an ornate mannered prose is baroque, then many church fathers were baroque' (1963: 97-98). He therefore concludes that 'it is probably necessary to abandon attempts to define baroque in purely stylistic terms. One must acknowledge that all stylistic devices may occur at almost all times. Their presence is only important if it can be considered as symptomatic of a specific state of mind' (o.c. 102-103). For Wellek, a style is defined not by formal characteristics but by how formal features symbolise a state of mind. However, although he makes this point he here still uses the word style in the sense of a formal matrix, probably because there is no ready alternative for the word "style" in this context.

${ }^{285}$ See Elkins (1996) and Lang (1998) for surveys of the changing concepts of "style" in the history of aesthetics. The notion of style as the fusion of what is said and how it is said is also central to Gibbs's (2005) handbook on mise-en-scène in cinema.
} 
ing Wölfflin) on style as a formal matrix. But to point out the formal analogies between some Baroque art from the seventeenth century and elements in contemporary art and popular culture explains very little: formal conceits re-appear everywhere all the time and for all kinds of reasons. My analysis of Russell's performance of self as baroque suggested an alternative approach by returning to the historical context in which baroque forms were first articulated. As such, Russell's work has become a hermeneutic bridge connecting the past to the present in a way that illuminates both. As I suggested in my discussion of The Devils in Chapter Two, the concern with questions of representation and theatricality that pervades the historical Baroque was in an important (but certainly not an exclusive way) connected to the upheavals of the times. In a fundamentally changing world, where former certainties (such as geocentrism) were revealed as new impossibilities, people experienced a paradoxical mixture of abandonment and freedom (at some times leading to a certain kind of Baroque zestfulness, at others to an equally Baroque melancholy). If the world is in upheaval, if certainties are abandoned, if forms of life are changing, then how does one represent the world, and how does one think about one's own place in the world? I have argued that the Baroque is the period when modern man finds himself on the stage of a world whose meaning is embattled. This is the process that The Devils, Russell's only film that is actually set in the seventeenth century, dramatises: a battle of wills between representatives of conflicting worldviews, where the winner will inevitably be the side that performs best on the stage of the world. Approaching the Baroque as a cultural struggle with problems of representation makes it possible to conceive of the Baroque as a multiform phenomenon that encompasses much more than spectacular art or "the art of the Counter-Reformation" (as if there was nothing more to the Baroque than popish propaganda, or as if only religious art was made in the Baroque).

Because Ken Russell used baroque forms to engage on a tremendous project of selfrepresentation he re-invigorated both the Baroque (as a world-view) and the baroque (as a formal matrix) at once. He uses baroque forms of art (especially those of Baroque theatre), but the purpose of this use (the performance of self) is intriguingly akin to the concerns of the historical Baroque. It is this remarkable coincidence of form and meaning that makes Russell an exemplary figure to discuss the baroque in the present. It is also this remarkable coincidence of form and meaning that gives Russell a style. It is his style. The coincidence is what style means. Only in this sense, but especially in this sense, can one say with absolute conviction that Russell is a baroque artist. This also means that a really significant discussion of "neo-baroque" would look, not for a reprise of a formal matrix in the present, but for the use of baroque tropes in aspects of our culture that address issues of representation (of the world, the self, or the self in the 
world). It is one thing to identify rollercoaster rides, blockbuster movies, post-dramatic theatre, or "immersive" virtual environments as baroque on account of their visual rhetoric. Such formal identifications will usually amount to simple truisms with little explanatory power. It is another thing, however, to ask whether certain baroque tropes concerning problems of representation and the performance of self are being re-used in contexts that function as sites for identity formation or for making sense of the world. From such a perspective one could argue that the creation of avatars or profiles on a wide array of social media are more telling signs of a re-engagement with baroque concerns in the present than theme park rides modelled on blockbuster movies. One could even argue that the present obsession with biography, but also the surge in academic concern with life writing and the awareness of how forms of life writing are always also ways of shaping and moulding lives, should be of great interest to anyone inquiring about a neo-baroque. The intimate life narrative of a transgender person who has to remould and re-write themselves for their new incarnation may then be more significantly baroque than the latest cinematic extravaganza featuring digitally created contraptions crashing into each other in 3D IMAX widescreen.

\subsection{BAROQUE LIVES: THE ART OF PERFORMING}

Russell is inseparable from his work: he created his mirror image in his films, which perform him. Jean Rousset once observed that 'a baroque work is at the same time the work itself and the creation of the work' (1953: 232). By this he meant that baroque works tend to retain traces of the process of creation, whether it is the insistent visibility of the brushstroke that reveals a painting as a painting or the self-reflexiveness of theatre about the theatre. This has the effect of turning the work itself into a process: 'the creation is still visible in the achieved work, which doesn't present itself as a real achievement, but as an intermediate phase at the heart of a development' (ibid.). While this principle (like most artistic principles) cannot be absolutely generalised, it nevertheless points towards an important feature of Baroque art, and whenever we find it there, it is always significant because it touches upon the problem of representation. In Russell's work, Gothic is the film for which the principle holds most literally: as I have shown in Chapter Four, this is a film all about its own process of creation. In fact, it not only creates itself through the process, it also creates Russell in the process, for the film reveals the creative principles that have made Russell into Russell via (the process of making) his films. I have also shown how the BBC films of the 1960s track the development of Russell's process of creation from its first stirrings (culminating in the displeasure over 
Elgar) to its full-blown articulation (in Isadora Duncan and Russell's own performance in Russell at Work). In the course of this remarkably swift development we see Russell shaping himself through (his shaping of) his films. Even The Devils, the Russell film that would seem, on the surface, to have the least to do with the performance of self, performs the basic principles of the conception of the self, and of the self within the world, that make Russell's performance of self through art not only possible but, once one embraces this world-view, inevitable and necessary. In this way Russell's films carry the traces of their own creation: they perform the principles that made them possible, and in doing so they create the artist who created them. To watch Russell's films is to see, at the same time, how the films are made. By showing us how his mind works (how he "assembles" his films) Russell articulates the workings of his mind as he creates, exactly in the way that he tried to represent the internal creative processes of Mahler in Mahler or of any other artist in his biopics. That is why one can say that each of Russell's biopics documents, as in an intellectual biography, the life of the mind of the artist: both the artist depicted and Russell's.

In that sense, too, this book, besides the other things it hopes to achieve, must ultimately also be a kind of biography of Russell, albeit not an account of the external events in his life (although I did address a number of these) but an account of the life of the mind of the artist, of its workings and its development. This spiritual or creative biography was compiled from the evidence of the external manifestation of the artist's creative mind in his work. There are many written sources upon which I have drawn, first and foremost Russell's own autobiography, but also Baxter's remarkably hybrid book on Russell (which is really a thinly veiled autobiography) and a number of extensive interviews and accounts of Russell's life and work. However, memories, public statements, and interviews being what they are (and that means: constructs, usually after the fact, in retrospect, embellished, shaped, moulded to swerve in the direction of a desired representation of the self) I have tried to mainly let the works themselves speak for the life of the mind of their author. It has become clear that the works speak very eloquently in this respect and that Russell is very much there in the films, in the way they are made, in the kinds of stories they tell about the kinds of people that are portrayed in them. This is the co-dependency between Russell and his work, or the tautology of man and oeuvre, which I signalled at the outset of this book. Russell is everywhere in his work. It is very common for artists to be present in their work in the sense that the world-view, the outlook, the sentiments, or the ideas expressed in the work inevitably reveal something about the person who made them. An artist's moral and intellectual temperament crucially shapes their work. But in Russell's case the work also shapes the person, who seems connected to it like identical twins joined at the hip (or, more appropriately, at 
the head): Russell and his work are the two halves of an elaborate Rorschach test, in constant mutual reflection. That is why, as Maaike Meijer says, 'the biographer of an artist has to write two biographies: one of the person and one of their art and how these two are connected' (2014: 8). These two biographies are really one. It is in the "how the two are connected" that the real work of the biographer begins. As the case of Ken Russell suggests, understanding either the work or the art in separation is futile: both parts are of a piece. ${ }^{286}$

Russell's progress was swift. In a remarkably short period of time, concentrated between Elgar and Isadora Duncan, he seems to have found out what it was that he wanted to do and what kind of artist he should (like to) be (perceived as). After that, his performance was remarkably consistent. This consistency, however, should not blind us to the fact that, underneath the performance, there is an awareness, not of a consistent self, but of a fleeting, elusive self. The baroque artist knows that any attempt to grasp, articulate, and communicate (anything about) his self is a performance, and already an interpretation (of that self by the self). He knows that by articulating the self he has already altered it. But it seems, however, to never be more real, more alive, than when it is being performed. The self is the process of its performance. Its constant change, its mutability, is all that endures. The Baroque model for such self-reflexive awareness of oneself is, of course, Montaigne, who composed, and repeatedly self-reflexively recomposed, contradicted, second-guessed, and re-evaluated his Essais, which are attempts at capturing the human self in its profound inconstancy. Deeply influenced (via his reading of Sextus Empiricus) by Pyrrhonism, the ancient philosophical school of scepticism, Montaigne doubted not simply the reliability of the senses but the very foundations of knowledge and the self. That is why his Essais always turn back (in several layers of later additions) to comment on themselves: since the world is constantly changing and the self, as both part and observer of that world, is changing with it, so, too, the way the self perceives and thinks about the world and itself must constantly evolve. 'Montaigne was the first to recognise the gap that existed between reflections already recorded and his present response to them which adds, and inevitably modifies, the original text. Far from hiding such adjustments, he parades the ways his writing comments on itself and shows the process of imitating, digesting and transforming the older texts in action' (McGowan 1989: 12). Or, as Montaigne himself observed, 'je ne peints pas l'estre. Je peints le passage' (III.2): he records change, almost as if trying to hold running water in one's hand, and the layering of text over text is an attempt to

\footnotetext{
${ }^{286}$ In a posthumous tribute to Walter Pater, published in 1894, William Sharp observed that Pater was 'one of those authors of whom there can never be any biography away from his writings' (quoted in Monsman 1980: 9).
} 
capture this passage in prose and let it stand as an existential palimpsest. Montaigne thus became the author of an extended self-portrait in which he looks at himself looking at himself. He is a 'moy, qui me voy' (III.5) in an endless self-reflexive spiral. Montaigne discovered, however, that an unstable and principally incoherent self that reflects back upon itself to capture its ever-fleeting existence necessarily ends up constructing, reconstructing, and (therefore) fabricating itself. Not in the sense that it falsely creates a retrospective wholeness or essence, but in the sense that, as he explained himself, 'in modelling this figure upon myself, I have had to fashion and compose myself so often to bring myself out, that the model itself has to some extent grown firm and taken shape. Painting myself for others, I have painted my inward self with colours clearer than my original ones. I have no more made my book than my book has made me - a book consubstantial with its author' (II.18; quoted in Larmore 1998: 1151). In writing his book about himself, Montaigne discovered that the book wrote its author. ${ }^{287}$

In a film such as Gothic we can see Russell looking at himself: it is a film about Romantic genius, made according to the principles of Romantic genius, and which therefore establishes the Romantic genius of the artist who made the film according to those principles. In Gothic (but also in many of his other films) we see Russell making himself. This self-reflexive creation of self is baroque. If all is mutability, then all is changeable and can be made and remade. As we flow, we can swerve. Like the poet who internalises his precursor and makes him his own by imposing a clinamen on him, so, too, Montaigne imposes a clinamen on his previous self to re-write his present self. And so, too, Russell has imposed a clinamen upon Debussy, Isadora Duncan, Tchaikovsky, Mahler, Mary Shelley, and many others to re-write, re-perform, shape, and mould his self. ${ }^{288} \mathrm{His}$ autobiography, as part of his work, is his clinamen upon his own former selves. The tautology between artist and work that this engenders could be compared to the bizarre tension between private self and social role, where both always end up contaminating each other (for we often end up being what we perform, sometimes even to our own displeasurable surprise), or the tension between sex and gender, where one's gender-role is assigned on the basis of the sex one is determined to have, but where definitions of sex are entirely moulded by cultural concepts of gender. This constant to and fro between role and self, body and mind, flesh and culture, is the site of the swerve. It is in the

\footnotetext{
${ }^{287}$ See Larmore (1998: 1147-1155) on these aspects of Montaigne's work. See also Greenblatt (2011: 243-249) for the influence of Lucretius on Montaigne.

${ }^{288}$ Of course, Harold Bloom has argued that Shakespeare 'invented the human as we continue to know it' and that 'our ideas as to what makes the self authentically human owe more to Shakespeare than ought to be possible' (1998: xx and 17). The argument has proved controversial, and I feel inadequate to stage an intervention in the debate, although I do find Bloom's case deeply persuasive and have been thrilled to find that I have been living Shakespeare all my life.
} 
movement between the two poles that change occurs. As roles, principles, and models are re-performed and reiterated, things go wrong, things swerve, and people take control of the process. It is at those moments that we can re-write the script, change the scene, or cancel the play altogether. It is because life is like a play, and like a work of art, that art can mirror life. But neither can be the other. ${ }^{289}$ If one turns art into life one impoverishes the latter by cancelling the former: it would shatter our mirror and leave us without a reflection that helps us to know ourselves. We can put the world on a stage, and know it. But on the stage of the real world we play for life.

\subsection{BAROQUE WORLDS}

I have argued that Russell's performance of self through art is a chapter in the Nachleben of the Baroque. I have shown that he uses a number of representational conceits (embedded narrative, the mise-en-abyme, allegory, the theatrum mundi) which are typically, though by no means exclusively, Baroque. What marks them as baroque in Russell, however, is the uses to which he has put them: as in the historical Baroque these conceits are put to work in a representation of the world and of the self within the world that is deeply self-reflexive. At first sight, this would seem to make Russell post-modern. In fact, as I showed already in the Introduction, the recurrence of baroque forms and tropes in the present has been explicitly connected to an aesthetics of the post-modern. I would suggest, however, that rather than "post" the modern, this resurfacing of the baroque in the present is part of the Nachleben of the Baroque and in that sense "still" modern. As explained in the Introduction, a Warburgian approach to the history of cultural forms allows one to see history not as a sequence of neatly packaged periods (let alone that they would be separated from each other by coupûres épistémologiques) but as an accumulative river in which the debris of history is carried along down the centuries. Which objects, forms, motifs, or ideas rise to the surface at any given time is as much a matter of chance as it is a matter of deliberate intervention by human agents. Alive today, we are the beachcombers of history, collecting from the jetsam and flotsam of the ruins of the past those elements that we can use to build our world and our selves today. ${ }^{290}$ As Walter Pater once wrote, 'the composite experience of all the ages is part of

\footnotetext{
${ }^{289}$ This is what I argued at the end of Chapter One: the fourth wall can never really be broken. Artists offer us a representation of the breaking of the fourth wall. This invites us to reflect upon the nature of reality, but it does not affect or change or invade reality. See above, section 1.4.

${ }^{290}$ In a riveting book on the slow shift of cultural forms from the modern to the post-modern, Panajotis Kondylis characterises the post-modern as an 'analytical-combinatory' way of living and thinking in which there are 'keine Substanzen und keine festen Dinge, nur letzte Bestandteile, die durch konsequente Analyse ermittelt
} 
each one of us' (quoted in Monsman 1980: 28). Thus, the ruins of the past become the building-blocks of the present. They are a repertoire upon which we can draw, although many a motif may linger in obscurity for centuries until, as with the theatrum mundi in the Renaissance, someone picks it up and finds it will do them a service. It is also for this reason that Russell is a baroque artist before he is a Romantic. Romanticism, after all, was already part of the Nachleben of the Baroque, which was itself part of the Nachleben of other, older ideas and cultural forms. ${ }^{291}$ One of the ideas that re-emerged in Italy in the fifteenth century was 'the phenomenon that practitioners of the visual arts were elevated from the rank of mere craftsmen to the level of inspired artists' (Wittkower and Wittkower 2007: 1). The long shadow of that rekindled idea falls into the present and includes the history of Romantic genius. But Russell belongs neither to the Baroque nor to Romanticism: he belongs to the history of the twentieth century. Russell took elements from the Romantic tradition and tailored them to suit his own purposes in the context in which he was working. The structure of this performance, however, was peculiar, for Russell did much of his performing through his art, which exemplified him.

The idea that the world and the self are made through artifice, at least in its modern form, crystallised most clearly in the Baroque. That makes Russell's performance of self through art a moment in the Nachleben of Baroque culture. But like any moment on a

werden, Punkte oder Atome, deren Wesen und Existenz, eigentlich nur in ihrer Funktion besteht, d.h. in ihrer Fähigkeit, zusammen mit anderen Punkten oder Atomen immer neue Kombinationen einzugehen' (1991: 16). It should be clear that people are also such atoms and that the roles they devise for themselves are combinations of elements picked up from a world where, because of the loss of any fundamental truths, everything has fallen apart (has been analysed) into constituent parts that can be re-assembled as we see fit. This is identity and culture as bricolage.

291 There is a strong connection between Romanticism and Baroque. René Wellek observes that when the term "romantic" was first used in the early nineteenth century, it was opposed to the term "classical" and covered 'all poetry written in a tradition differing from classical antiquity' (1963: 133). August Wilhelm Schlegel considered Don Quichote the 'perfect masterwork of higher romantic art' (quoted in o.c. 135) and counted Shakespeare and Calderón as Romantic dramatists. He and Ludwig Tieck translated Shakespeare (see Paulin [1985: 239-270] on Tieck; Roger and Paulin [2010] on Schlegel; but also Frank [1989: 373-376] on Tieck's important essay on the fantastical in Shakespeare). In France, Stendhal wrote, in an 1818 letter, that 'je suis un romantique furieux c'est-à-dire, je suis pour Shakespeare contre Racine et pour Lord Byron, contre Boileau' (quoted in Wellek 1963: 141). It is also striking how Baroque self-reflexiveness and melancholy seem to find a Nachleben in Romantic irony, which for Friedrich Schlegel was an attitude born from 'the discovery of the manylayeredness, the uprootedness, the inconsistency, the contradictoriness of human character' (Frank 1997: 936). Laurence Sterne was an important author for Schlegel (Beus 2007: 19-21), who saw Tristram Shandy as a key example of transcendental or self-reflexive poetry, which was 'zugleich Poesie und Poesie der Poesie' (quoted in Frank 1989: 364). For Tieck, irony was an 'Äthergeist' or ethereal spirit that suffuses an entire work of poetry: a style of writing that expresses, in its mercurial insubstantiality, the elusiveness of the nature of things (Frank 1989: 370-372 and 377-378). The Wanderstrasse that connects all of this, however, stretches back earlier: it was when remains of Antique sculpture began to emerge from the soil of Italy in the Renaissance that a fragment began to be considered beautiful in its own right: see Barkan (1999: 119-136). This could be explored further, but this book is running out of pages. 
Wanderstrasse, Russell's has both a past and a future. There is no reason to assume that the cultural dynamic of the Nachleben of the Baroque would somehow end with Russell, or that Russell's work would have been the only form it took in the present. This, of course, is the subject of future research: to inquire whether the model I have identified in Russell (an artist performing himself through his art) can be found in other artists, but also to inquire whether elements of the Baroque Nachleben inform other cultural forms, especially those that we tend to call post-modern, or whose identification as postmodern or (neo-)baroque has relied, perhaps too readily, on strictly formal criteria without sufficient probing into the underlying ideas about identity, selfhood, and the self s relation to the world. In that sense this book has been exploratory: it cannot do everything, and there are many aspects of the Baroque and the baroque, of Russell and Romanticism, that are left unexplored, not because I am not aware of them, but because there are limits to the number of detours any argument can suffer without losing its footing. If I may quote an embedded quote (and how appropriate is that!), in the Introduction to Feeling and Form Susanne Langer quotes Whitehead's observation of William James's pragmatism that it 'chiefly starts a lot of hares for people to chase' (FF viii). While I hope to have provided at least a number of answers, I am certain to also have raised as many questions, several of which I hope to address myself on a future occasion. For the present, however, I will restrict myself to pointing out a recent film that not only touches upon the theme of the theatrum mundi and life as a stage, but does so in a way that includes a number of telling motifs that suggest that the film may belong as much to the Nachleben of Russell as to that of the Baroque. I will then connect it back to a Baroque text, and both of these again to Russell. If this sounds like a serpentine baroque trajectory, it is chiefly meant as an attempt to open the discussion and set loose a number of hares for future chasers. It will also bring us back to the central topic of this book: Russell's performance of self through art.

Peter Weir's The Truman Show (1998) is an allegorical fable in which a young man called Truman (Jim Carrey) discovers that his entire life has been lived on a stage. For the sake of an elaborate experiment in reality television he has been raised and kept an unwitting prisoner in an artificial town called Seahaven, which was built in a huge domed television studio (a self-enclosed world) and peopled with hundreds of actors and extras who perform their roles day after day, for years on end. Hundreds of hidden cameras broadcast every second of Truman's life live as “The Truman Show” to millions of addicted viewers across the globe. Truman himself is the only person in Seahaven who is not aware of the illusion: for him, this is simply real life. In reality, however, Truman's mother, his best friend, and even his wife are all actors playing a role. Furthermore, everything in Seahaven is stage-managed by Christof (Ed Harris), the god-like 
creator and director of the programme who, like a Wildean stage manager pulling the moon from the sky with a scarlet thread, has the power (which means: the computers and machinery) to let the sun rise and set whenever he wants or cause rain to fall in a specific spot at any time. When Truman finally does become wise to the fraud, he decides to escape the self-enclosed world of Seahaven and takes to sea in a sailboat until he crashes into the painted backdrop that represents the sky. And it is here that our Wanderstrasse surfaces again. Just like The Devils ends with an image of a hole blown into the wall of its self-enclosed theatre of the world, so, too, The Truman Show ends with the walls of its stage of the world being punctured. Walking along the painted backdrop, Truman next discovers a door, camouflaged with a trompe-l'oeil painting of the sky, which reads 'exit'. When he opens it, we only see darkness: the real world is still a void, for to Truman it is terra incognita. The film ends with Truman taking a bow for his audience and stepping out of Seahaven into reality.

While this film raises many questions about the ethics of reality television, but also about the extent to which we live in a fabricated world managed by multinational superpowers beyond our control, perhaps the most telling element in relation to Russell is the fact that hundreds of extras and a number of important cast members have dedicated their entire lives to creating a fictional world around Truman. The actor playing his best friend or the actress playing his wife (and who is even planning to get pregnant by Truman!) can hardly expect to have a "real" life outside the role they are playing. If the set of Seahaven is a stage of the world that is offered to us, the film's viewers, as an allegory about our mediated lives, then the actors upon that stage face the problem that the roles they perform are in danger of swallowing up their entire backstage identity: while they may still know that they are playing a part, and the audience may know this as well, they may also find that they have little life left outside the part. Interestingly, there is a text from the historical Baroque that similarly touches upon the disquieting fact that masks become reality, and vice versa. In 1659 the French writer Charles Sorel published a short novel called Description de l'île de portraiture et de la ville des portraits. It describes a city where everyone is engaged in the practice of portraiture. There is a street in which heroic portraits are painted, in another satiric portraits are painted, in yet another portraits of lovers and mistresses. There is even a street for painters of indifferent and mediocre portraits. This is in itself not remarkable: in early modern Europe (as, indeed, still today in major cities), it was not uncommon for certain crafts to congregate in specific neighbourhoods or areas. But then there is a twist. Since the clientele of these painters are mainly drawn from the court, there are observations on people who have their portraits made but who are themselves already paintings. These are the women whose faces are encrusted with a layer of paint to hide their natural features. In some, the mask has 
become indistinguishable from their real face. ${ }^{292}$ Of course, Sorel's novel was a moral satire taking aim at court life at Versailles, where the front of one's face and dress were the armour with which one engaged in social warfare over the favour of the King. As such the novel commented, disapprovingly, on the nature of the real world as a stage on which social roles were performed in a way that both jeopardised the moral integrity of the actors and threatened to obliterate the identity behind the public mask. ${ }^{293}$

There is more than a passing similarity between the actors in Seahaven, the courtiers in Versailles, and Sorel's ladies with the encrusted faces. In each case, a person is someone wearing a persona: a mask through which they speak on the stage of the world. The artifice of their public performance will become especially clear if we connect them back to the three forms of performance presented in the Introduction: theatrical performance, social role-playing, and the performance of self through art. Despite the exotic strangeness (from our vantage point several centuries down the historical river) of the courtiers at Versailles or Sorel's painted ladies, it is clear that they are both instances of what Erving Goffman called the presentation of self in everyday life. They are playing a social role that they will probably shed in the privacy of their home. Even the painted ladies at court have ways of peeling off the paint at their dressing tables. The actors on the stage of Seahaven are engaged in a theatrical performance: they are playing a part on a stage, in this case the set of a television programme. They know that they are playing a role, and so does the audience that watches the embedded narrative of "The Truman Show": there is really no confusion about who is who in which context. Only Truman himself is duped, but because he does not know he is living on a stage he can in no way be accused of playing a part (except, of course, the usual social roles that are required in everyday social situations: but these are not dramatic parts such as those played by everyone around him). However, the special twist for us, as viewers of the film The Truman Show, is that we are seeing a representation of actors playing the part of people enacting everyday social roles. This gives The Truman Show an interesting embedded approach to acting: we see "real" actors playing the part of fictional actors who have to perform, in a play, as people performing ordinary social roles. It is a theatrical performance that is about and comments on social role-playing. Like The Devils, this is a film that shows us a theatrum mundi that comments allegorically on the nature of reality. Like Salome's

\footnotetext{
${ }^{292}$ Debaisieux' (2006) Introduction to her edition of the novel connects it to the vogue for portraiture, both in painting and in literature, that characterised the first half of the seventeenth century and to which Sorel's novel was a critical response. Jeanneret (2006) further elaborates on the novel as part of the moralist literature of the seventeenth century.

${ }^{293}$ In a remarkable conflation of images and real people, there is even a chapter describing the fate of paintings convicted of being defamatory or deceptive and which are taken to the town square to be publicly hanged and burned like any common criminal in the real world.
} 
Last Dance, however, and unlike The Devils, the film also reveals what goes on behind the scenes of Seahaven and "The Truman Show". But what sets both examples apart from Russell's artifice in the performance of self, is that they do not resort to the performance of self through art. They are art about the performance of self, which lacks the special kind of performativity which I have identified in Russell. And it is to the latter that we must now, in conclusion, turn.

\subsection{NO EXITS AND NO ENTRANCES: LIFE BEYOND PERFORMANCE AND PERFORMATIVITY}

Of course, Russell also played a social role: he was the enfant terrible of British cinema, the wild man of the BBC, the Romantic genius who stalked the streets in a cape and tinted granny glasses. This is how Russell presented himself to the public eye. But I have argued that Russell's performance of himself does not end with his social role or, in the few cases where he performed in films in a masked self-portrait, with the performance of a dramatic part: Russell complements his social role with a performance of himself through art. I have suggested in the Introduction that this kind of performance hovers somewhere between performance and performativity, except that it lacks reiteration. We can now elaborate in more detail exactly how Russell achieves this performance of self through art or, to put it differently, how he achieves performative effects through works of art that are performatively inert in the sense that they can only be repeatedly viewed, not reiterated. The key, I have argued, lies in the texture of the films. The social role that Russell plays is modelled on the type of the Romantic genius, with a generous selection of the auto-mythology, eccentricities, and wild behaviours that this entails. But since an artist is mainly an artist by virtue of the work he creates, the credibility of any artist's performance of self is always connected to his work. In most circumstances, an artist is recognised as an artist because of the creative act in itself: one is an artist if one creates works that are recognised by others as works of art. Russell takes things a step further: he has inscribed this performance of self into his work, which carries on the performance even in his absence. One could argue that, in Russell's case, his performance is made real by the work because it is indeed an "ectoplasm" of himself.

But as I suggested at the end of Chapter Three, this "ectoplasm" is really just a metaphor, and a pernicious one if taken literally. We now know that Russell achieved his performance entirely through the way he composed his work. In Chapter Four I argued that montage is the central key to Russell's practice: there is a deliberate structural similarity (which is more than a parallel or fortuitous coincidence) between the way Russell 
assembles his films and the way Romantic theories of artistic creation describe the creative process. In that sense, Russell's films are the evidence of the role of genius he performs: just like the reality of Loudun is inscribed in Grandier's defeated body, so, too, the reality of Russell's performance as an artist is inscribed in the very texture and structure of his films (his "body of work"), which display in their form that they were made following the principles of Romantic genius. There is a performative element here: once one defines the way Romantic genius creates in a concrete and practical way (as Mary Shelley and Wordsworth allowed us to do), one can claim to be such a genius if one is perceived (and repeatedly perceived) to be creating in the manner of genius. The resulting work is the visible trace of the act. This is a thoroughly circular argument, to be sure, but none the less effective for that. Similarly, I argued in Chapter Two that power is real if it is made real in its consequences: it then carries the force of its own conviction. In Russell's performance of self the films are the consequences that make his genius real. In that sense, the detour through Wordsworth and Mary Shelley made it possible to make the much-maligned term "genius" operational again for practical criticism. Not only does it describe a poetics (a way of making things that we could apply ourselves), it also offers an identity to those who apply the poetics (if we apply the poetics successfully, we might be perceived as, and could certainly present ourselves as, genius). This is Russell's coup on the reality of Romantic genius. As I argued in Chapter Three, Russell undermines the myth of the artist as a pristine, ivory-tower creator. He rejects, in other words, much of the traditional image of artistic genius as described by Kris and Kurz and by the Wittkowers. In its stead, he offers a portrait of the artist as worker. But as I argued in Chapter Four, the work of the artist, which we may now (for the sake of brevity) rubric as a broadly understood form of montage, is in remarkable agreement, not with myths of Romantic genius, but with the practical poetics of Romanticism as articulated by Wordsworth and Mary Shelley. So Romantic genius is no Schwärmerei: it is something you can analyse and evaluate in practical terms, which is what I have been doing, it now appears, throughout this book.

I might at this point be expected to put "genius" between scare quotes to indicate that Russell is not "really" a genius (because we have become uncomfortable with that term) but only "performing" as one. But that would beg the question. Such scare quotes would put us in a situation not dissimilar to the situation of a person who, when encountering a transvestite, observes that they are seeing a man dressed as (performing as) a woman, but who is not "really" a woman. This response assumes that the person is "really" a man trying to "pass" as a woman. And because we notice the impersonation, the performance in some sense fails: the person "is" a man, regardless of the female "put-on". Putting scare quotes around "genius" would similarly suggest that Russell is 
merely trying to "pass" as a genius, where the very use of the verb "to pass" implies that this is merely a front, a masquerade "put on" by someone who is "really" something else. In this sense Russell's performance is testing the extent to which we have the courage of our convictions. If we have abandoned the idea of "essence" (and we certainly claim to have done that, at least since Nietzsche, Pater, and Wilde), then surely the "front" is the only reliable level of reality. The problem with this is, of course, that there must always be a person who is the vehicle of the front: and what is the relation between the front and the "real" person behind it? To return to the example of the transvestite: many of us will readily assume that we are seeing a man (the "real" sex or gender of that person) trying to look like a woman (the "performed" sex or gender); others, more politically sensitive, might see a woman (the "real" sex or gender of that person) struggling to triumph over the physical burden of her body, the male traits of which are difficult to erase completely; but how many of us would ponder the possibility that the intermediate state of "a man who tries to look like a woman" or "a woman with male traits" is itself the as yet uncategorised and floating gender identity that this person "really" feels like? Perhaps this person is not trying to "pass" as a woman at all. Perhaps they are trying to "pass" as a man who dresses like a woman or as another hybrid form in-between-thegenders. In which case, paradoxically, there is no "passing": one is simply oneself. Performance and "essence" coincide because the essence is right there on the surface: the hybridity is not only the intended performance, it is also the intimately experienced sense of self. ${ }^{294}$

At this point we are crashing, with full force, into the spectre of the thing-in-itself. It has in many ways, which are only now becoming clear, haunted this book. But Russell,

\footnotetext{
${ }^{294}$ Pfeffer (2014), discussing the shifting gender identities of women who are in relationships with (female-tomale) transsexuals, begins to give an idea of the infinite shades of gender identity that are available to us. In general, the term "passing" has not only been used in the study of gender (and especially in the quest of transsexuals to assume the opposite sex), but also in the study of race (to discuss the problems of light-skinned black people who are sometimes taken for white people: see Piper [1996] for a mesmerising account of what is at stake). Snorton points out that, for "transsexuals who are not able to "pass" all the time, passing is not simply a question of how one is read but includes an agential power of affirming one's own reading of self [and] brings one's [psychological] "self" into view. [...] Therefore passing is not simply the essence of transsexualism; it is the way we make identity' (2009: 87) in general. The problem is, however, that "passing" is often a process of trying to fit into ("pass as") a pre-established social category, whether it is a gender category or any other. What I am arguing for, and what Butler (2001) argues for in her discussion of the brutalisation of a young boy at the hands of psychiatrists and surgeons who all want to transform his body to fit some kind of essentialist gender model, is a situation where we may be free to pass as whatever we may experience ourselves to be, irrespective of this self's categorical indeterminacy. To the extent that such a view moves beyond all normative categorisation it suggests a real atomisation of selves, an absolute individuality beyond convention. A person would then no longer belong to any sex or gender, or to any other category of identity whatsoever, but simply be an individual who might, if the occasion arises, move through many shades of sexual experience as they move through the times of the day or the moons of the year.
} 
in these last pages, is forcing us to exorcise it. The spectre has been there all along in the theatrical rhetoric of the analysis; a rhetoric, by the way, which has always been part and parcel of more or less all discussions that engage the Baroque or the baroque, which is conceived as theatrical by "nature". I have talked about embedded plays, about the performance of self and the performance of social and theatrical roles, about mise-enabyme, about the theatrum mundi, about stage-managing the moon (and the sun!) with scarlet threads, and so on. We have even discussed burlesque performances, as when Louis XIII, masked (life is a masquerade!) as the Duc de Condé, visited Loudun. The mere fact, however, that we describe such scenes in terms of "burlesque" performance and "grotesque" performance suggests that we automatically assume that they are a departure from the real. In The Devils such performances are used to reveal reality, and are therefore easily read as the opposite of the real. But perhaps, in a number of cases, such a performance simply is reality, with nothing hiding behind it (but no less subversive of the established order for that fact). For example, an outrageous drag queen may also dress the way she dresses in the privacy of her home, not because she wants to subvert her home (what a spectacle that might be!), but because the dress is who she is. In other words, the spectre of the thing-in-itself haunts the theatrical rhetoric for the very simple reason that any theatrical performance, or any discourse that engages a theatrical vocabulary, presupposes, implicitly and perhaps often more explicitly than we suspect, that there is also an hors-scène, the backstage area (the place where the performers of The Boy Friend battle out their petty rivalries), and that this is where the masks come off. With his over-the-top performance as enfant terrible, and with his over-the-top films that shatter all the canons of good taste and proper art, however, Russell is daring us not to look for the reality behind the performance because the performance is all there is. The co-dependency of his social role and his self as performed by his work is so tight that they seem to be welded together without suture marks: they effectively block any gaze that would look behind the scenes. If you want to know Russell, you have no choice but to look at the surface: of his movies, of his montage, of his capes and tinted granny glasses. It is all there, and there is nothing behind it. Or, as Andy Warhol famously said in a 1966 interview: 'if you want to know all about Andy Warhol, just look at the surface: of my paintings and films and me, and there I am. There is nothing behind it' (quoted in Berg 2004: 90).

Of course, there is. There always is. The private self is the thing-in-itself that will always elude us. Even our own private self at times eludes us (try, for a moment, to characterise your own personality: how difficult it is to make any kind of definite statement about oneself, and how little we often recognise ourselves in the statements others make about us, and how violated we feel by the diagnoses that "expert" psychologists would 
impose upon us). We may assume, however, that in Russell's case, as in many others (such as our transvestites), the performance we get to see is performed because the private self, for reasons best known to itself, wills it so. And there is no basis in reality to doubt the reality of the baseless fabric of this vision. By performing himself through art Russell's life and work point towards a greater freedom for the self than most of us have ever dared imagine, or would have deemed conceivable. The world may be stubbornly out there in its brute materiality, but we may shape our own material to our will as best we can. For ours is a will in the world, acting upon it. What Russell shows us, and what makes him baroque (and what makes the Baroque baroque), is the fundamental inconstancy of the world and the self, and the tremendous open space this clears up for acts of human invention. History always happens in the present moment, and as beachcombers of the ruins of the past we may re-fit that historical repertoire to the needs of our moment and the flights of our fancy. Adrift in the dream of life, which comes and goes like the images on a cinema screen (or like a landscape that rushes up, unfolds, and slips through the corners of our eyes as we drive by in a car), we may assemble our selves in the colours and fabrics of our choosing and burn, like a flaming gem, in the eyes of our beholders. Beyond the walls of our world, as much as beyond the walls of Loudun, there is nothing. The real is what you see and what you do and what you feel in the moment: 'we have an interval, and then our place knows us no more. Some spend this interval in listlessness, some in high passions, the wisest in art and song. For our one chance is in expanding that interval, in getting as many pulsations as possible into the given time' (Pater 2010: 120). In his time, Russell inhabited the lives of countless artists and made them his own. And there is much to be said, despite Huw Wheldon's shudders of horror, for getting out the dressing-up basket and filling one's interval in fancy dress. But however you play, and whichever parts you assemble into your performance, one's cue is always now. You are playing for life. 

BIBLIOGRAPHY 

This is not a comprehensive bibliography: only books and articles that are quoted or referred to in the text and footnotes are listed. More extensive bibliographical data on Russell can be found in Rosenfeldt (1978) and Flanagan (2009a).

Aitken (Ian)

(2009) 'The British Documentary Film Movement', in: Robert Murphy (ed.), The British Cinema Book, third edition, London: British Film Institute/Palgrave Macmillan, pp. 177-184.

Alexander (Anthony)

(2009) Britain's New Towns: Garden Cities to Sustainable Communities, London/New York: Routledge.

Allen (Dave)

(2012) 'Moving Images and the Visual Arts in 1970s Britain', in: Sue Harper and Justin Smith, British Film Culture in the 1970s: The Boundaries of Pleasure, Edinburgh: Edinburgh University Press, pp. 34-49.

Anthony (Scott) and Mansell (James G.)

(2011) (eds.) The Projection of Britain: A History of the GPO Film Unit, London: British Film Institute/Palgrave.

Antliff (Mark)

(2010) 'Sculptural Nominalism/Anarchist Vortex: Henri Gaudier-Brzeska, Dora Marsden, and Ezra Pound', in: Mark Antliff and Vivien Greene (eds.), The Vorticists: Manifesto for a Modern World, London: Tate, pp. 47-57.

Antliff (Mark) and Greene (Vivien)

(2010) (eds.) The Vorticists: Manifesto for a Modern World, London: Tate.

Apostolidès (Jean-Marie)

(1981) Le roi-machine: Spectacle et politique au temps de Louis XIV, Paris: Minuit. Arendt (Hannah)

(1998) The Human Condition [orig. 1958], second edition with an Introduction by

Margaret Canovan, Chicago/London: The University of Chicago Press.

Arias (Ricardo)

(1980) The Spanish Sacramental Plays, Boston: Twayne.

Armes (Roy)

(1978) A Critical History of British Cinema, New York: Oxford University Press. Arnold (Ben)

(2006) 'Alive and Swinging: Ken Russell Talks About Teddy Girls and Home Movies', in: ZOO Magazine, No. 9, pp. 28-31. 


\section{Arthur (Paul)}

(2004) 'The Troublemaker', in: Film Comment, Vol. 40, No. 3, pp. 58-65.

Atkins (Thomas R.)

(1976) (ed.) Ken Russell, New York: Monarch Press/Simon and Schuster.

Aylot (Bob)

(2005) 'The director's cut', in: Amateur Photographer, June 11, pp. 49-56.

Bakewell (Joan) and Garnham (Nicholas)

(1970) The New Priesthood: British Television Today, London: Allen Lane/Penguin.

Bakhtin (Mikhail)

(1984) Rabelais and His World, translated by Hélène Iswolsky, Bloomington/Indianapolis: Indiana University Press.

\section{Barber (Sian)}

(2012) 'British Film Censorship and the BBFC in the 1970s', in: Sue Harper and Justin Smith, British Film Culture in the 1970s: The Boundaries of Pleasure, Edinburgh: Edinburgh University Press, pp. 22-33.

Barber (X. Theodore)

(1989) 'Phantasmagorical Wonders: The Magic Lantern Ghost Show in Nineteenth-Century America', in: Film History, Vol. 3, No. 2, pp. 73-86.

Barkan (Leonard)

(1999) Unearthing the Past: Archaeology and Aesthetics in the Making of Renaissance Culture, New Haven/London: Yale University Press.

Barnes (Jonathan)

(1979) The Presocratic Philosophers. Volume 2: Empedocles to Democritus, London/Henley/Boston: Routledge \& Kegan Paul.

Barnes (Richard)

(1977) (ed.) The Story of Tommy, Twickenham: Eel Pie.

\section{Barr (Charles)}

(1986) (ed.) All Our Yesterdays: 90 Years of British Cinema, London: British Film Institute.

(1996) “"They Think It's All Over”: The Dramatic Legacy of Live Television', in: John Hill and Martin McLoone (eds.), Big Picture, Small Screen: The Relations Between Film and Television, Luton: John Libbey Media/University of Luton, pp. 47-75. 
Barton (Anne)

(2010) 'Byron and the Mythology of Fact' [orig. 1968], in: Alice Levine (ed.), Byron's Poetry and Prose: Authoritative Texts, Criticism, New York: Norton, pp. 812-828.

Bate (Jonathan)

(1989) 'Shakespeare and Original Genius', in: Penelope Murray (ed.), Genius: The History of an Idea, Oxford: Basil Blackwell, pp. 76-97.

Baxandall (Michael)

(1985) Patterns of Intention: On the Historical Explanation of Pictures, New Haven/London: Yale University Press.

\section{Baxter (John)}

(1973) An Appalling Talent: Ken Russell, London: Michael Joseph.

Beadle (Richard)

(2008) 'The York Corpus Christi Play', in: Richard Beadle and Alan J. Fletcher (eds.), The Cambridge Companion to Medieval English Theatre, second edition, Cambridge: Cambridge University Press, pp. 99-124.

\section{Beam (Sara)}

(2007) Laughing Matters: Farce and the Making of Absolutism in France, Ithaca/ London: Cornell University Press.

Beaumont (Matthew)

(2010) 'Introduction', in: Walter Pater, Studies in the History of the Renaissance, edited with an Introduction and Notes by Matthew Beaumont, Oxford: Oxford University Press, pp. vii-xxix.

Beinhorn (Courtenay Wyche)

(1974) 'Susanne Langer's Film Theory: Elaboration and Implications', in: Cinema Journal, Vol. 13, No. 2, pp. 41-54.

\section{Bellour (Raymond)}

(2009) Le corps du cinéma: hypnoses, émotions, animalités, Paris: P.O.L.

Bély (Lucien)

(2010) (ed.) Dictionnaire de l'Ancien Régime: Royaume de France, XVIe-XVIIIe siècle [orig. 1996], Paris: Quadrige/PUF.

Benjamin (Walter)

(1978) Ursprung des deutschen Trauerspiels [orig. 1928], Frankfurt am Main: Suhrkamp. 


\section{BIBLIOGRAPHY}

\section{Bennett (Chad)}

(2010) 'Oscar Wilde’s Salome: décor, des corps, desire', in: ELH, Vol. 77, No. 2, pp. 297-323.

\section{Bentley (Toni)}

(2002) Sisters of Salome, New Haven/London: Yale University Press.

\section{Berg (Gretchen)}

(2004) 'Andy Warhol: My True Story’ [orig. 1966], in: Kenneth Goldschmidt (ed.),

I'll Be Your Mirror: The Selected Andy Warhol Interviews, 1962-1987, New York: Carroll \& Graff, pp. 85-96.

\section{Bernheimer (Richard)}

(1956) 'Theatrum Mundi', in: The Art Bulletin, Vol. 38, No. 4, pp. 225-247.

(1958) 'Another Globe Theatre', in: Shakespeare Quarterly, Vol. 9, No. 1 (Winter), pp. 19-29.

\section{Beus (Yifen)}

(2007) 'Self-reflexivity in the Play within the Play and its Cross-Genre Manifestation', in: Gerhard Fischer and Bernhard Greiner (eds.), The Play within the Play: The Performance of Meta-Theatre and Self-Reflection, Amsterdam/New York: Rodopi, pp. 15-26.

\section{Bialostocki (Jan)}

(1981) Stil und Ikonographie: Studien zur Kunstwissenschaft, Cologne: DuMont.

\section{Biet (Christian)}

(2002) 'L'avenir des illusions, ou le théâtre et l'illusion perdue', in: littératures classiques, No. 4: l'illusion au XVIIe siècle (Patrick Dandrey and George Forestier, eds.), Paris: Honoré Champion, pp. 175-214.

(2003) 'Naissance sur l'échafaud ou la tragédie du début du XVIIe siècle', in: Intermédiales: histoire et théorie des arts, des lettres et des techniques, No. 1, pp. 75-105.

(2006) 'Introduction', in: Christian Biet (ed.), Théâtre de la cruauté et récits sanglants en France (XVIe-XVIIe siècle), Paris: Robert Laffont, pp. v-xlvii.

Biet (Christian) and Fragonard (Marie-Madeleine)

(2012) 'Introduction', in: Christian Biet and Marie-Madeleine Fragonard (eds.), Tragédies et récits de martyres en France (fin XVIe - début XVIIe siècle), Paris: Classiques Garnier, pp. 9-116. 
Bignell (Jonathan)

(2014) 'The Spaces of The Wednesday Play (BBC TV 1964-1970): Production, Technology and Style', in: Historical Journal of Film, Radio and Television, Vol. 34, No. 3, pp. 369-389.

Bingham (Dennis)

(2010) Whose Lives Are They Anyway? The Biopic as Contemporary Film Genre, New Brunswick/London: Rutgers University Press.

Black (Lawrence)

(2005) 'Whose Fingers on the Button? British Television and the Politics of Cultural Control', in: Historical Journal of Film, Radio and Television, Vol. 25, No. 4, pp. 547-575.

Bland (Alexander)

(1977) The Nureyev Valentino: Portrait of a Film, London: Studio Vista.

Bloom (Harold)

(1997) The Anxiety of Influence: A Theory of Poetry, second edition with a new

Preface [first, 1973], New York/Oxford: Oxford University Press.

(1998) Shakespeare: The Invention of the Human, New York: Riverhead Books.

(2002) Genius: A Mosaic of One Hundred Exemplary Creative Minds, New York: Warner Books.

Bluche (François)

(2005) (ed.) Dictionnaire du Grand Siècle, second, revised edition [first, 1990], Paris: Fayard.

Boorman (John)

(2003) Adventures of a Suburban Boy, London: Faber and Faber.

\section{Bordwell (David)}

(2005) The Cinema of Eisenstein, second edition with a New Preface, New York/London: Routledge.

Bouchenot-Déchin (Patricia) and Farhat (Georges)

(2013) (eds.) André Le Nôtre en perspectives, Versailles/Paris: Établissement public du château, du musée et du domaine national de Versailles/Hazan.

Brauer (David E.)

(2001) 'British Pop Art: 1956-1966. A Documentary Essay', in: David E. Brauer and Jim Edwards, Pop Art: U.S./U.K. Connections, 1956-1966, OstfildernRuit/Houston: Hatje Cantz/ Menil Foundation, pp. 55-87. 


\section{BIBLIOGRAPHY}

\section{Bray (Xavier)}

(2009) The Sacred Made Real: Spanish Painting and Sculpture 1600-1700, London: National Gallery Company.

\section{Briggs (Asa)}

(1995) The History of Broadcasting in the United Kingdom. Volume V: Competition, 1955-1974, Oxford/New York: Oxford University Press.

\section{Brody (Alan)}

(1970) The English Mummers and Their Plays: Traces of Ancient Mystery, Philadelphia: University of Pennsylvania Press.

\section{Brown (Callum G.)}

(2012) “"The Unholy Mrs Knight” and the BBC: Secular Humanism and the Threat to the "Christian Nation", c.1945-60', in: English Historical Review, Vol. CXXVII, No. 525, pp. 346-376.

\section{Brown (Geoff)}

(2009) 'Paradise Found and Lost: The Course of British Realism', in: Robert Murphy (ed.), The British Cinema Book, third edition, London: British Film Institute/Palgrave Macmillan, pp. 28-38.

\section{Brown (Theo)}

(1952) 'The "Stag-Hunt" in Devon', in: Folklore, Vol. 63, No. 2, pp. 104-109.

(1979) 'A Further Note on the 'Stag Hunt' in Devon', in: Folklore, Vol. 90, No. 1, pp. 18-21.

\section{Brunotte (Ulrike)}

(2011) “'The Cult of the Clitoris”. Der englische Salome-Skandal um 1900', in: Ulrike Auga, Claudia Bruns, Dorothea Dornhof, and Gabriele Jähnert (eds.), Dämonen, Vamps und Hysterikerinnen: Geschlechter- und Rassenfigurationen in Wissen, Medien und Alltag um 1900, Bielefeld: transcript, pp. 233-249.

(2012) 'Unveiling Salome 1900 - Entschleierungen zwischen Sexualität, Pathosformel und Oriental Dance', in: Bettina Dennerlein, Elke Frietsch, and Therese Steffen (eds.), Verschleierter Orient - Entschleierter Okzident? (Un-)Sichtbarkeit in Politik, Recht, Kunst und Kultur seit dem 19. Jahrhundert, Munich: Wilhelm Fink, pp. 93-115.

\section{Bruyn (Josua)}

(1987) 'Toward a Scriptural Reading of Seventeenth-Century Dutch Landscape Paintings', in: Peter C. Sutton, Masters of $17^{\text {th }}$-Century Dutch Landscape Painting, Boston: Museum of Fine Arts, pp. 84-103. 


\section{Buci-Glucksman (Christine)}

(1984) La raison baroque: De Baudelaire à Benjamin, Paris: Galilée.

(1986) La folie du voir: De l'esthétique baroque, Paris: Galilée.

Buckley (Peter)

(1972) 'Savage Saviour', in: Films and Filming, Vol. 19, No. 1 (October), pp. 13-21.

Burke (Peter)

(1992) The Fabrication of Louis XIV, New Haven/London: Yale University Press.

(2009) Popular Culture in Early Modern Europe, third edition [first, 1978], Farnham: Ashgate.

Burningham (Bruce R.)

(2008) Tilting Cervantes: Baroque Reflections on Postmodern Culture, Nashville: Vanderbilt University Press.

Burns (Elizabeth)

(1973) Theatricality: A Study of Convention in the Theatre and in Social Life [orig. 1972], New York: Harper \& Row.

Butler (Judith)

(2001) 'Doing Justice to Someone: Sex Reassignment and Allegories of Transsexuality', in: GLQ: A Journal of Lesbian and Gay Studies, Vol. 7, No. 4, pp. 621-636.

(2006) Gender Trouble: Feminism and the Subversion of Identity, second edition [orig. 1999; first, 1990], New York/London: Routledge.

(2011) Bodies That Matter: On the discursive limits of "sex" [orig. 1993], London/New York: Routledge.

Butler (Marilyn)

(2012) 'Frankenstein and Radical Science' [orig. 1993], in: Mary Shelley, Frankenstein: The 1818 Text, Contexts, Criticism, edited by J. Paul Hunter, second edition (first, 1996), New York/London: Norton, pp. 404-416.

\section{Byard (Victoria)}

(2014) 'Style, Space and Seriality in Early Children's Television Drama: Puck of Pook's Hill, Five Children and It (BBC, 1951) and Man in Armour (1951-1954)', in: Historical Journal of Film, Radio and Television, Vol. 34, No. 3, pp. 345-356.

Calabrese (Omar)

(1992) Neo-Baroque: A Sign of the Times [orig. Italian, 1987], with a Foreword by Umberto Eco, translated by Charles Lambert, Princeton: Princeton University Press. 


\section{BIBLIOGRAPHY}

\section{Calderón}

(2003) Le grand théâtre du monde. El gran teatro del mundo, bilingual edition edited with an Introduction, Notes and Commentaries by François Bonfils, Paris: Flammarion.

Calloway (Stephen)

(1994) Baroque Baroque: The Culture of Excess, London: Phaidon.

Canova-Green (Marie-Claude)

(2014) 'On ne naît pas roi, on le devient: Louis XIV au miroir de ses Mémoires', in:

Mathieu Da Vinha, Alexandre Maral and Nicolas Milovanovic (eds.), Louis $X I V$ : l'image et le mythe, Rennes/Versailles: Presses Universitaires de Rennes/Centre de recherche du château de Versailles, pp. 33-43.

Carmona (Michel)

(1988) Les diables de Loudun: Sorcellerie et politique sous Richelieu, Paris: Fayard.

Cassirer (Ernst)

(1942) 'Giovanni Pico della Mirandola: A Study in the History of Renaissance Ideas (Part II)', in: Journal of the History of Ideas, Vol. 3, No. 3, pp. 319-346.

Castle (Terry)

(1988) 'Phantasmagoria: Spectral Technology and the Metaphorics of Modern Reverie', in: Critical Inquiry, Vol. 15, No. 1, pp. 26-61.

Caughie (John)

(2000) Television Drama: Realism, Modernism, and British Culture, Oxford/New York: Oxford University Press.

Certeau (Michel de)

(2005) La possession de Loudun [orig. 1970], revised edition, Paris: Gallimard.

Chapman (James)

(2006) 'The BBC and the Censorship of The War Game (1965)', in: Journal of Contemporary History, Vol. 41, No. 1, pp. 75-94.

(2008) 'The War Game Controversy - Again', in: Journal of Contemporary History, Vol. 43, No. 1, pp. 105-112.

Charcot (J.-M.) and Richer (Paul)

(1887) Les Démoniaques dans l'art, Paris [photomechanical reprint; Amsterdam:

B.M. Israël, 1972].

Christian (Lynda G.)

(1987) Theatrum Mundi: The History of an Idea [orig. 1969], New York/London: Garland. 
Christout (Marie-Françoise)

(2005) Le ballet de cour de Louis XIV, 1643-1672: Mises en scène, new edition with a Preface by André Chastel [first, 1967], Paris: Picard.

Citron (Marcia J.)

(2010) When Opera Meets Film, Cambridge: Cambridge University Press.

Clair (Jean)

(2005) (ed.) Mélancolie: génie et folie en Occident, Paris: Gallimard/Réunion des musées nationaux.

Clarke (Frederick S.)

(1981) (ed.) 'The Filming of Altered States', in: Cinefantastique, Vol. 11, No. 2, pp. 16-36.

Coldewey (John C.)

(2004) 'From Roman to Renaissance in drama and theatre', in: Jane Milling and Peter Thomson (eds.), The Cambridge History of British Theatre. Volume I: Origins to 1660, Cambridge: Cambridge University Press, pp. 3-69.

Cole (Roger)

(1978) Burning to speak: The life and art of Henri Gaudier Brzeska, Oxford: Phaidon.

Coleridge (Samuel Taylor)

(2000) The Major Works, edited with an Introduction and Notes by H.J. Jackson, Oxford: Oxford University Press.

Conlin (Jonathan)

(2009) Civilisation, London: British Film Institute/Palgrave Macmillan.

Cook (David A.)

(1996) A History of Narrative Film, third edition [first, 1981], New York/London: Norton.

Cooke (Lez)

(2003) British Television Drama: A History, London: British Film Institute.

(2013) 'It was political': John McGrath and Radical Television Drama', in: Journal of British Cinema and Television, Vol. 10, No. 1, pp. 241-255.

Copenhaver (Brian)

(1998) 'The Occultist Tradition and Its Critics', in: Daniel Garber and Michael Ayers (eds.), The Cambridge History of Seventeenth-Century Philosophy, Cambridge: Cambridge University Press, pp. 454-512. 


\section{BIBLIOGRAPHY}

\section{Corneille}

(1980) Ouevres complètes I, edited with an Introduction and Notes by Georges Couton, Paris: Gallimard/Pléiade.

(2008) L'Illusion comique, edited with a Presentation and Dossier by Jean-Yves Huet, Paris: Flammarion.

Corner (John)

(1996) The art of record: A critical introduction to documentary, Manchester/New York: Manchester University Press.

(1999) Critical Ideas in Television Studies, Oxford: Oxford University Press.

Cornette (Joël)

(2009) Louis XIV [orig. 2007], s.l.: Éditions du Chêne.

(2012) L'affirmation de l'État absolu, 1492-1652, seventh edition, Paris: Hachette.

Cowan (Bainard)

(2005) 'Walter Benjamin's Theory of Allegory' [orig. 1981], in: Peter Osborne (ed.), Walter Benjamin: Critical Evaluations in Cultural Theory. Volume II: Modernity, London/New York: Routledge, pp. 56-69.

Cowart (Georgia J.)

(2008) The Triumph of Pleasure: Louis XIV \& the Politics of Spectacle, Chicago/London: The University of Chicago Press.

Creeber (Glen)

(2003) 'The Origins of Public Service Broadcasting (British Television before the War)', in: Michele Hilmes (ed.), The Television History Book, London: British Film Institute, pp. 22-26.

Crompton (Louis)

(1985) Byron and Greek Love: Homophobia in $19^{\text {th }}$-Century England, Berkeley/Los Angeles: University of California Press.

Crouse (Richard)

(2012) Raising Hell: Ken Russell and the Unmaking of "The Devils", Toronto: ECW Press.

Cser (Andreas)

(2007) 'Die Machiavellistudie von 1971: Zum Erstlingswerk von Kondylis', in: Falk Horst (ed.), Panajotis Kondylis: Aufklärer ohne Mission. Aufsätze und Essays, Berlin: Akademie Verlag, pp. 15-42.

Cull (Nicholas J.)

(2001) 'Peter Watkins's Culloden and the Alternative Form in Historical Filmmaking', in: Deborah Cartmell, I.Q. Hunter, and Imelda Whelehan (eds.), Retrovi- 
sions: Reinventing the Past in Film and Fiction, London/Sterling: Pluto Press, pp. 87-101.

Curran (Trisha)

(1980) A New Note on the Film: A Theory of Film Criticism Derived from Susanne K. Langer's Philosophy of Art, New York: Arno Press.

Custen (George F.)

(1992) Bio/Pics: How Hollywood Constructed Public History, New Brunswick: Rutgers University Press.

Dällenbach (Lucien)

(1989) The Mirror in the Text [orig. French: Le récit spéculaire: essai sur la mise en abyme, 1977], translated by Jeremy Whiteley and Emma Hughes, Chicago: The University of Chicago Press.

Dandrey (Patrick)

(2003) Les Tréteaux de Saturne: Scènes de la mélancolie à l'époque baroque, Paris: Klincksieck.

Danson (Lawrence)

(1997) 'Wilde as critic and theorist', in: Peter Raby (ed.), The Cambridge Companion to Oscar Wilde, Cambridge: Cambridge University Press, pp. 80-95.

Darracott (Joseph)

(1980) The World of Charles Ricketts, New York/Toronto: Methuen.

Daston (Lorraine) and Galison (Peter)

(1992) 'The Image of Objectivity', in: Representations, No. 40, pp. 81-128.

Davidson (Clifford)

(2001) 'Violence and the Saint Play', in: Studies in Philology, Vol. 98, No. 3, pp. 292-314.

Da Vinha (Mathieu)

(2014) 'Louis XIV: l'image et le mythe', in: Mathieu Da Vinha, Alexandre Maral, and Nicolas Milovanovic (eds.), Louis XIV: l'image et le mythe, Rennes/Versailles: Presses Universitaires de Rennes/Centre de recherche du château de Versailles, pp. 7-18.

Da Vinha (Mathieu), Maral (Alexandre), and Milovanovic (Nicolas)

(2014) (eds.) Louis XIV: l'image et le mythe, Rennes/Versailles: Presses Universitaires de Rennes/Centre de recherche du château de Versailles.

Davis (Natalie Zemon)

(1975) Society and Culture in Early Modern France, Stanford: Stanford University Press. 


\section{BIBLIOGRAPHY}

(1983) The Return of Martin Guerre, Cambridge/London: Harvard University Press.

(1987) Fiction in the Archives: Pardon Tales and Their Tellers in Sixteenth-Century France, Stanford: Stanford University Press.

(2000) Slaves on Screen: Film and Historical Vision, Cambridge: Harvard University Press.

(2003) 'Movie or Monograph? A Historian/Filmmaker's Perspective', in: The Public Historian, Vol. 25, No. 3, pp. 45-48.

(2012) 'Writing 'The Rites of Violence' and Afterward', in: Graeme Murdoch, Penny Roberts, and Andrew Spicer (eds.), Ritual and Violence: Natalie Zemon Davis and Early Modern France, Oxford: Oxford University Press, pp. 8-29.

Dawson (Jan)

(1972) review of The Boy Friend, in: Sight and Sound, Vol. 41, Nr. 2 (Spring), pp. 111-112.

Debaisieux (Martine)

(2006) 'Introduction', in: Charles Sorel, Description de l'île de portraiture et de la ville des portraits (1659), edited by Martine Debaisieux with a Preface by Michel Jeanneret, Geneva: Droz, pp. 29-62.

\section{Degli-Esposti (Cristina)}

(1996a) 'Federico Fellini's Intervista or the Neo-Baroque Creativity of the Analysand on Screen', in: Italica, Vol. 73, No. 2 (Summer), pp. 157-172.

(1996b) 'Sally Potter's Orlando and the Neo-Baroque Scopic Regime', in: Cinema Journal, Vol. 36, No. 1 (Autumn), pp. 75-93.

(2008) 'Neo-Baroque Imaging in Peter Greenaway's Cinema', in: Paula WilloquetMaricondi and Mary Alemany-Galway (eds.), Peter Greenaway's Postmodern/Poststructuralist Cinema, revised edition, Lanham/Toronto/Plymouth: Scarecrow Press, pp. 51-78.

Deleuze (Gilles)

(1988) Le pli: Leibniz et le baroque, Paris: Minuit.

Demont (Paul)

(2005) 'La mélancolie dans l'Antiquité: de la maladie au tempérament', in: Jean Clair (ed.), Mélancolie: génie et folie en Occident, Paris: Gallimard/Réunion des musées nationaux, pp. 34-37.

Dickinson (Kay)

(2007) “"The very new can only come from the very old”: Ken Russell, national culture and the possibility of experimental television at the BBC in the 1960s', in: 
Laura Mulvey and Jamie Sexton (eds.), Experimental British Television, Manchester: Manchester University Press, pp. 70-88.

(2008) Off Key: When Film and Music Won't Work Together, New York: Oxford University Press.

Didi-Huberman (Georges)

(2002) L'Image survivante: Histoire de l'art et temps des fantômes selon Aby Warburg, Paris: Minuit.

(2012) Invention de l'hystérie: Charcot et l'iconographie photographique de la Salpêtrière, fifth, revised and enlarged edition [first, 1982], Paris: Macula.

Dijkstra (Bram)

(1986) Idols of Perversity: Fantasies of Feminine Evil in Fin-de-Siècle Culture, New York/Oxford: Oxford University Press.

Doebler (John)

(1972) 'The Play Within the Play: the Muscipula Diaboli in Hamlet', in: Shakespeare Quarterly, Vol. 23, No. 2 (Spring), pp. 161-169.

Donohue (Joseph)

(1997) 'Distance, death and desire in Salome', in: Peter Raby (ed.), The Cambridge Companion to Oscar Wilde, Cambridge: Cambridge University Press, pp. 118142.

D’Ors (Eugenio)

(2000) Du Baroque [orig. Spanish: Lo Barroco 1935], translated by Agathe Rouart-

Valéry and with an Introduction by Frédéric Dassas, Paris: Gallimard.

Dowling (Linda)

(1994) Hellenism and Homosexuality in Victorian Oxford, Ithaca/London: Cornell University Press.

Downey (Katherine Brown)

(2004) Perverse Midrash: Oscar Wilde, André Gide, and Censorship of Biblical Drama, New York/London: Continuum.

Drazin (Charles)

(2011) 'Alberto Cavalcanti: Lessons in Fusion at the GPO Film Unit', in: Scott Anthony and James G. Mansell (eds.), The Projection of Britain: A History of the GPO Film Unit, London: British Film Institute/Palgrave, pp. 45-52.

Durgnat (Raymond)

(1967) 'The Cinema as Art Gallery', in: The Burlington Magazine, Vol. 109, No. 767, pp. 81-86. 


\section{BIBLIOGRAPHY}

(2011) A Mirror for England: British Movies from Austerity to Affluence, second edition [first, 1970] with a Foreword by Kevin Gough-Yates, London: British Film Institute/Palgrave Macmillan.

Eakin (Paul John)

(2008) Living Autobiographically: How We Create Identity in Narrative, Ithaca/London: Cornell University Press.

Eco (Umberto)

(1985) 'Innovation and Repetition: Between Modern and Post-Modern Aesthetics', in: Daedalus, Vol. 114, No. 4, pp. 161-184.

Ede (H.S.)

(1931) Savage Messiah: Gaudier-Brzeska, New York: The Literary Guild.

Ede (Laurie N.)

(2012) 'British Film Design in the 1970s', in: Sue Harper and Justin Smith, British Film Culture in the 1970s: The Boundaries of Pleasure, Edinburgh: Edinburgh University Press, pp. 50-61.

Egginton (William)

(2003) How the World Became a Stage: Presence, Theatricality, and the Question of Modernity, Albany: State University of New York Press.

(2010) The Theater of Truth: The Ideology of (Neo)Baroque Aesthetics, Stanford: Stanford University Press.

Eisenstein (S.M.)

(1988) Selected Works, Volume I: Writings, 1922-34, edited and translated by Richard Taylor, London/Bloomington: British Film Institute/Indiana University Press.

(1994) Selected Works, Volume II: Towards a Theory of Montage, edited by Michael Glenny and Richard Taylor and translated by Michael Glenny, London: British Film Institute.

(2006) The Eisenstein Collection, edited by Richard Taylor, Oxford/New York/ Calcutta: Seagull Books.

Elkins (James)

(1996) 'Style', in: Jane Turner (ed.), The Dictionary of Art, Vol. 29, London/New York: Macmillan/Grove, pp. 876-883.

Ellmann (Richard)

(1987) Oscar Wilde, London: Hamish Hamilton. 
Enders (Jody)

(2002) Death by Drama and Other Medieval Urban Legends, Chicago/London: The University of Chicago Press.

Fechner (Christian)

(2002) 'Le Théâtre Robert-Houdin, de Jean Eugène Robert-Houdin à Georges Méliès', in: Jacques Malthête and Laurent Mannoni (eds.), Méliès, magie et cinéma, Paris: Paris-Musées, pp.73-113.

Fentone (Steve)

(2000) AntiCristo: The Bible of Nasty Nun Sinema \& Culture, Guildford: FAB Press.

Fernbach (Amanda)

(2001) 'Wilde's Salomé and the Ambiguous Fetish', in: Victorian Literature and Culture, Vol. 29, No. 1, pp. 195-218.

Ferris (Paul)

(1990) Sir Huge: The Life of Huw Wheldon, London: Michael Joseph.

Flanagan (Kevin M.)

(2009a) (ed.) Ken Russell: Re-Viewing England's Last Mannerist, Lanham/Plymouth: The Scarecrow Press.

(2009b) 'Television, Contested Culture, and Social Control: Cultural Studies and

Pop Goes the Easel', in: Kevin M. Flanagan (ed.), Ken Russell: Re-Viewing England's Last Mannerist, Lanham/Plymouth: The Scarecrow Press, pp. 65-84.

(2009c) 'Complicating the Costume Drama: Lady Chatterly, Ken Russell, and the Conceits of Heritage', in: Kevin M. Flanagan (ed.), Ken Russell: Re-Viewing England's Last Mannerist, Lanham/Plymouth: The Scarecrow Press, pp. 211-226.

Ford (Jennifer)

(1998) Coleridge on Dreaming: Romanticism, Dreams and the Medical Imagination,

Cambridge: Cambridge University Press.

Forestier (Georges)

(1996) Le théâtre dans le théâtre sur la scène française du XVIIe siècle, second edition [first, 1981] with a new Preface, Geneva: Droz.

Fox (Terry Curtis)

(1973) 'Conversation with Ken Russell', in: Oui, Vol. 2, No. 6 (June), pp. 63-64, cont. 102-108.

Frank (Manfred)

(1989) Einführung in die frühromantische Ästhetik: Vorlesungen, Frankfurt am Main: Suhrkamp. 


\section{BIBLIOGRAPHY}

(1997) "Unendliche Annäherung": Die Anfänge der philosophischen Frühromantik, Frankfurt am Main: Suhrkamp.

(2007) Auswege aus dem Deutschen Idealismus, Frankfurt am Main: Suhrkamp.

Frankel (Nicholas)

(2000) Oscar Wilde's Decorated Books, Ann Arbor: The University of Michigan Press.

Franko (Mark)

(1993) Dance as Text: Ideologies of the Baroque Body, Cambridge: Cambridge University Press.

(1994) 'Double Bodies: Androgyny and Power in the Performances of Louis XIV', in: The Drama Review, Vol. 38, No. 4, pp. 71-82.

Frayling (Christopher)

(1991) Vampyres: Lord Byron to Count Dracula, London/Boston: Faber and Faber.

(2006) 'Fuseli's The Nightmare: Somewhere between the Sublime and the Ridiculous', in: Martin Myrone, Gothic Nightmares: Fuseli, Blake and the Romantic Imagination, London: Tate, pp. 9-20.

Freeman (Louise Gilbert)

(2005) 'Vision, Metamorphosis, and the Poetics of Allegory in the Mutabilitie Cantos', in: Studies in English Literature, 1500-1900, Vol. 45, No. 1, pp. 65-93.

Friedman (Lester D.)

(2006) (ed.) Fires Were Started: British Cinema and Thatcherism, second edition, London/New York: Wallflower Press.

Fumaroli (Marc)

(1986) 'Sacerdoce et office civil: la monarchie selon Louis XIV', in: Emmanuel Le Roy Ladurie (ed.), Les Monarchies, Paris: Presses Universitaires de France, pp. 101-114.

(1997) Le poète et le roi: Jean de la Fontaine en son siècle, Paris: Fallois.

Furley (David)

(1999) 'Cosmology', in: Keimpe Algra, Jonathan Barnes, Jaap Mansfeld, and Malcolm Schofield (eds.), The Cambridge History of Hellenistic Philosophy, Cambridge: Cambridge University Press, pp. 412-451.

Garber (Daniel) and Ayers (Michael)

(1998) (eds.) The Cambridge History of Seventeenth-Century Philosophy, Cambridge: Cambridge University Press. 
Garber (Daniel), Henry (John), Joy (Lynn), and Gabbey (Alan)

(1998) 'New Doctrines of Body and Its Powers, Place, and Space', in: Daniel Garber and Michael Ayers (eds.), The Cambridge History of Seventeenth-Century Philosophy, Cambridge: Cambridge University Press, pp. 553-623.

Gardiner (John)

(2003) 'Variations on a Theme of Elgar: Ken Russell, the Great War, and the television "life" of a composer', in: Historical Journal of Film, Radio and Television, Vol. 23, No. 3, pp. 195-209.

Genette (Gérard)

(1969) Figures II, Paris: Seuil.

(2007) Discours du récit, Paris: Seuil.

Gibbs (John)

(2002) Mise-en-scène: Film Style and Interpretation, New York/Chichester: Wallflower/Columbia University Press.

Gibson (Pamela Church)

(2000) 'Fewer Weddings and More Funerals: Changes in the Heritage Film', in: Robert Murphy (ed.), British Cinema of the 90s, London: British Film Institute, pp. 115-124.

Gibson (Pamela Church) and Hill (Andrew)

(2009) “Tutte e Macchio!”: Excess, Masquerade and Performativity in 70s Cinema', in: Robert Murphy (ed.), The British Cinema Book, third edition, London: British Film Institute/Palgrave Macmillan, pp. 333-340.

Gilbert (Elliot L.)

(1983) “Tumult of Images”: Wilde, Beardsley, and Salome’, in: Victorian Studies, Vol. 26, No. 2 (Winter), pp. 133-159.

\section{Gilloch (Graeme)}

(2002) Walter Benjamin: Critical Constellations, Cambridge: Polity.

Gilman (Sander L.)

(1993) 'Salome, Syphilis, Sarah Bernhardt and the "Modern Jewess", in: The German Quarterly, Vol. 66, No. 2, pp. 195-211.

Goffman (Erving)

(1990) The Presentation of Self in Everyday Life [orig. 1959], London: Penguin.

Golder (John)

(2007) 'Holding a Mirror up to Theatre: Baro, Gougenot, Scudéry and Corneille as Self-Referentialists in Paris, 1628-35/36', in: Gerhard Fischer and Bernhard 


\section{BIBLIOGRAPHY}

Greiner (eds.), The Play within the Play: The Performance of Meta-Theatre and

Self-Reflection, Amsterdam/New York: Rodopi, pp. 77-99.

Gomez (Joseph)

(1976) Ken Russell: The Adaptor as Creator, London: Frederick Muller.

(1976-77) 'Peter Watkins's Edvard Munch', in: Film Quarterly, Vol. 30, No. 2, pp.

38-46.

(1979) Peter Watkins, Boston: Twayne.

Goodman (Nelson)

(1978) Ways of Worldmaking, Indianapolis: Hackett.

Gow (Gordon)

(1970) 'Shock Treatment', in: Films and Filming, Vol. 16, No. 10 (July), pp. 8-16.

Gowland (Angus)

(2006) 'The Problem of Early Modern Melancholy', in: Past \& Present, No. 191, pp.

77-120.

Gracián (Baltasar)

(2011) The Pocket Oracle and Art of Prudence [orig. 1647], translated with an Introduction and Notes by Jeremy Robbins, London: Penguin.

Grant (Barry Keith)

(2009) 'The Body Politic: Ken Russell in the 1980s', in: Kevin M. Flanagan (ed.), Ken Russell. Re-Viewing England's Last Mannerist, Lanham/Plymouth: The Scarecrow Press, pp. 24-39.

Green (Andrew J.)

(1953) 'The Cunning of the Scene', in: Shakespeare Quarterly, Vol. 4, No. 4 (October), pp. 395-404.

Greenblatt (Stephen)

(2011) The Swerve: How the World Became Modern, New York/London: Norton.

Gruber (Alain)

(1994) 'The Ballet Royal de la Nuict: A masque at the court of Louis XIV', in: Apollo: a journal of the arts, Vol. 139, No. 386, pp. 34-40.

\section{Gunning (Tom)}

(1995) 'Phantom Images and Modern Manifestations: Spirit Photography, Magic Theater, Trick Films, and Photography's Uncanny', in: Patrice Petro (ed.), Fugitive Images: From Photography to Video, Bloomington/Indianapolis: Indiana University Press, pp. 42-71. 
(2006) 'The Cinema of Attraction[s]: Early Film, Its Spectator and the AvantGarde' in: Wanda Strauven (ed.), The Cinema of Attractions Reloaded, Amsterdam: Amsterdam University Press, pp. 381-388.

Hacker (Jonathan) and Price (David)

(1991) Take 10: Contemporary British Film Directors, Oxford: Oxford University Press.

Hammond (Paul)

(1974) Marvellous Méliès, London: Gordon Fraser.

\section{Hanke (Ken)}

(1984) Ken Russell's Films, Metuchen/London: Scarecrow Press.

Hanson (Ellis)

(1997) Decadence and Catholicism, Cambridge/London: Harvard University Press.

Happé (Peter)

(1994) 'A guide to criticism of medieval English theatre', in: Richard Beadle (ed.),

The Cambridge Companion to Medieval English Theatre, Cambridge: Cambridge University Press, pp. 312-343.

Harper (Sue) and Smith (Justin)

(2012) British Film Culture in the 1970s: The Boundaries of Pleasure, Edinburgh: Edinburgh University Press.

\section{Harrison (Martin)}

(1998) Young Meteors. British Photojournalism: 1957-1965, London: Jonathan Cape.

Hayter (Alethea)

(1971) Opium and the Romantic Imagination [orig. 1968], London: Faber and Faber.

Hebron (Stephen) and Denlinger (Elizabeth C.)

(2010) Shelley's Ghost: Reshaping the Image of a Literary Family, Oxford: Bodleian Library.

Hecht (Peter)

(1986) 'The debate on symbol and meaning in Dutch seventeenth-century art: an appeal to common sense', in: Simiolus, Vol. 16, No. 2/3, pp. 173-187.

Hedin (Thomas F.)

(1997) 'Le Nostre to Mansart: Transition in the Gardens of Versailles', in: Gazette des Beaux-Arts, Vol. 130, No. 1547, pp. 191-343. 


\section{Hedling (Erik)}

(2009) 'Lindsay Anderson and the Development of British Art Cinema', in: Robert Murphy (ed.), The British Cinema Book, third edition, London: British Film Institute/Palgrave Macmillan, pp. 39-45.

(2010) 'Meet the Pioneers: Early Lindsay Anderson', in: Patrick Russell and James Piers Taylor (eds.), Shadows of Progress: Documentary Film in Post-War Britain, London: British Film Institute/Palgrave, pp. 313-327.

Henkel (Arthur) and Schöne (Albrecht)

(2013) (eds.) Emblemata: Handbuch zur Sinnbildkunst des XVI. und XVII. Jahrhunderts, second edition [orig. 1978; first, 1967], Stuttgart: J.B. Metzler.

Hersant (Yves)

(2005) 'L'acédie et ses enfants', in: Jean Clair (ed.), Mélancolie: génie et folie en Occident, Paris: Gallimard/Réunion des musées nationaux, pp. 54-59.

Higson (Andrew)

(1986) “"Britain's Outstanding Contribution to the Film”: The documentary-realist tradition', in: Charles Barr (ed.), All Our Yesterdays: 90 Years of British Cinema, London: British Film Institute, pp. 72-97.

(2003) English Heritage, English Cinema: Costume Drama since 1980, Oxford/New York: Oxford University Press.

(2006) 'Re-Presenting the National Past: Nostalgia and Pastiche in the Heritage Film', in: Lester D. Friedman (ed.), Fires Were Started: British Cinema and Thatcherism, second edition, London/New York: Wallflower Press, pp. 91-109.

Hill (John)

(1986) Sex, Class and Realism: British Cinema 1956-1963, London: British Film Institute/Palgrave Macmillan.

(1999) British Cinema in the 1980s: issues and themes, Oxford/New York: Oxford University Press.

(2007a) "Creative in its own right": the Langham Group and the search for a new television drama', in: Laura Mulvey and Jamie Sexton (eds.), Experimental British Television, Manchester: Manchester University Press, pp. 17-30.

(2007b) 'A “new drama for television"?: Diary of a Young Man', in: Laura Mulvey and Jamie Sexton (eds.), Experimental British Television, Manchester: Manchester University Press, pp. 48-69.

(2011) Ken Loach: The Politics of Film and Television, London/Hampshire: British Film Institute/Palgrave.

(2013a) 'Radical Television Drama: Introduction', in: Journal of British Cinema and Television, Vol. 10, No. 1, pp. 106-111. 
(2013b) 'From Five Women to Leeds United!: Roy Batttersby and the Politics of 'Radical' Television Drama', in: Journal of British Cinema and Television, Vol. 10, No. 1, pp. 130-150.

(2015) “Blurring the lines between fact and fiction': Ken Russell, the BBC and 'television biography”, in: Journal of British Cinema and Television, Vol. 12, No. 4.

Hills (Helen)

(2011) 'The Baroque: The Grit in the Oyster of Art History', in: Helen Hills (ed.), Rethinking the Baroque, Farnham/Burlington: Ashgate, pp. 11-36.

Hindle (Maurice)

(1992) 'Introduction', in: Mary Shelley, Frankenstein or The Modern Prometheus, edited with an Introduction and Notes by Maurice Hindle, Harmondsworth: Penguin, pp. vii-xliii.

Hogle (Jerrold E.)

(2002) 'Introduction: the Gothic in western culture', in: Jerrold E. Hogle (ed.), The

Cambridge Companion to Gothic Fiction, Cambridge: Cambridge University Press, pp. 1-20.

Holland (Merlin)

(1997) 'Biography and the art of lying', in: Peter Raby (ed.), The Cambridge Companion to Oscar Wilde, Cambridge: Cambridge University Press, pp. 3-17.

Holmes (Richard)

(2005) Shelley: The Pursuit [orig. 1974 and 1994], London: Harper Perennial. Hoyle (Brian)

(2009) 'In Defense of the Amateur', in: Kevin M. Flanagan (ed.), Ken Russell: ReViewing England's Last Mannerist, Lanham/Plymouth: The Scarecrow Press, pp. 40-62.

(2013) '“Start as you mean to go on": Ken Russell's Early Amateur Films', in: Ryan Shand and Ian Craven (eds.), Small-Gauge Storytelling: Discovering the Amateur Fiction Film, Edinburgh: Edinburgh University Press, pp. 201-220.

\section{Hunter (I.Q.)}

(2013) British Trash Cinema, London: British Film Institute/Palgrave.

\section{Huxley (Aldous)}

(1971) The Devils of Loudun [orig. 1952], Harmondsworth: Penguin.

\section{Huysmans (Joris-Karl)}

(1977) A Rebours [orig. 1884], edited with a Preface by Marc Fumaroli, second edition, Paris: Gallimard. 
Hyde (H. Montgomery)

(1976) The Cleveland Street Scandal, London: W.H. Allen.

Ingram (Martin)

(1984) 'Ridings, Rough Music and the "Reform of Popular Culture" in Early Modern England', in: Past \& Present, No. 105, pp. 79-113.

Innis (Robert E.)

(2009) Susanne Langer in Focus: The Symbolic Mind, Bloomington/Indianapolis: Indiana University Press.

Israel (Jonathan I.)

(2001) Radical Enlightenment: Philosophy and the Making of Modernity 1650-1750, Oxford: Oxford University Press.

Jackson (Shannon)

(2004) Professing Performance: Theatre in the Academy from Philology to Performativity, Cambridge: Cambridge University Press.

Jacobs (Jason)

(2000) The Intimate Screen: Early British Television Drama, Oxford/New York: Oxford University Press.

Jarman (Derek)

(1991) Dancing Ledge [orig. 1984], edited by Shaun Allen, London: Quartet Books.

(2001) Smiling in Slow Motion [orig. 2000], edited by Keith Collins, London: Vintage.

Jeanneret (Michel)

(1997) Perpetuum mobile: Métamorphoses de corps et des oeuvres de Vinci à Montaigne, Paris: Macula.

(2006) 'La tyrannie du visuel', in: Charles Sorel, Description de l'île de portraiture et de la ville des portraits (1659), edited by Martine Debaisieux with a Preface by Michel Jeanneret, Geneva: Droz, pp. 7-27.

(2012) Versailles, ordre et chaos, Paris: Gallimard.

Jones (Amelia)

(1997) 'Tracing the Subject with Cindy Sherman', in: Cindy Sherman: Retrospective, New York/London: Thames \& Hudson, pp. 33-53.

(2002) 'Performing the Other as Self: Cindy Sherman and Laura Aguilar Pose the Subject', in: Sidonie Smith and Julia Watson (eds.), Interfaces: Women, Autobiography, Image, Performance, Ann Arbor: The University of Michigan Press, pp. 69-102. 


\section{Jones (Michelle)}

(2003) 'Design and the Domestic Persuader: Television and the British Broadcasting Corporation's Promotion of Post-War “Good Design”", in: Journal of Design History, Vol. 16, No. 4, pp. 307-318.

Jongh (Eddy de)

(1967) Zinne- en minnebeelden in de schilderkunst van de zeventiende eeuw, s.l.: Nederlandse Stichting Openbaar Kunstbezit/Openbaar Kunstbezit in Vlaanderen/Prins Bernhard Fonds.

(1976) tot Lering en Vermaak: Betekenissen van Hollandse genrevoorstellingen uit de zeventiende eeuw, Amsterdam: Rijksmuseum.

(1991) 'Some Notes on Interpretation', in: David Freedberg and Jan de Vries (eds.), Art in history. History in art: Studies in Seventeenth-Century Dutch Culture, Santa Monica: The Getty Center for the History of Art and the Humanities, pp.119-136.

(1999) Kwesties van betekenis: Thema en motief in de Nederlandse schilderkunst van de zeventiende eeuw, second, corrected printing [first, 1995], Leiden: Primavera Pers.

Kael (Pauline)

(1973) Deeper Into Movies, Boston/Toronto: Little, Brown and Company.

(1976) Reeling, Boston/Toronto: Little, Brown and Company.

(1980) When The Lights Go Down, New York: Holt, Rinehart and Winston.

Kaltenstadler (Wilhelm)

(2011) Das Haberfeldtreiben: Geschichte und Mythos eines Sittenrituals, Greiz: König.

Kant (Immanuel)

(2006) Kritik der Urteilskraf [orig. 1790], edited with Introductions and Bibliography by Heiner F. Klemme and with Notes by Piero Giordanetti, Hamburg: Meiner.

Kantorowicz (Ernst H.)

(1963) 'Oriens Augusti - Lever du Roi', in: Dumbarton Oaks Papers, Vol. 17, pp. 117-177.

(1997) The King's Two Bodies: A Study in Mediaeval Political Theology [orig. 1957], with a new Preface by William Chester Jordan, Princeton: Princeton University Press.

Kemp (Martin)

(1989) 'The "Super-artist" as Genius: The Sixteenth-Century View', in: Penelope Murray (ed.), Genius: The History of an Idea, Oxford: Basil Blackwell, pp. 32-53. 


\section{BIBLIOGRAPHY}

\section{Kermode (Mark)}

(2002) 'Raising Hell', in: Sight and Sound, NS Vol. 12, No. 12 (December), pp. 28-31. Kivy (Peter)

(2001) The Possessor and the Possessed: Handel, Mozart, Beethoven, and the Idea of Musical Genius, New Haven/London: Yale University Press.

Kolve (A.E.)

(1966) The Play Called Corpus Christi, Stanford: Stanford University Press.

Kondylis (Panajotis)

(1984) Macht und Entscheidung: Die Herausbildung der Weltbilder und die Wertfrage, Stuttgart: Klett-Cotta.

(1988) Theorie des Krieges: Clausewitz - Marx - Engels - Lenin, Stuttgart: Klett-Cotta.

(1991) Der Niedergang der bürgerlichen Denk- und Lebensform: Die liberale Moderne und die massendemokratische Postmoderne, Weinheim: VCH/Acta humaniora.

(1999) Das Politische und der Mensch. Grundzüge der Sozialontologie I: Soziale Beziehung, Verstehen, Rationalität, edited by Falk Horst, Berlin: Akademie Verlag.

(2002) Die Aufklärung im Rahmen des neuzeitlichen Rationalismus [orig. 1981], Hamburg: Meiner.

(2007) Machiavelli [orig. Greek, 1971], translated by Gaby Wurster and with a Foreword by Günter Maschke, Berlin: Akademie Verlag, 2007.

\section{Koritz (Amy)}

(1994) 'Dancing the Orient for England: Maud Allan's “The Vision of Salome”, in:

Theatre Journal, Vol. 46, No. 1, pp. 63-78.

\section{Kraye (Jill)}

(2007) 'The revival of Hellenistic philosophies', in: James Hankins (ed.), The Cambridge Companion to Renaissance Philosophy, Cambridge: Cambridge University Press, pp. 97-112.

Kris (Ernst) and Kurz (Otto)

(1995) Die Legende vom Künstler: Ein geschichtlicher Versuch, second edition with a Foreword by Ernst H. Gombrich [orig. 1980; first, 1934], Frankfurt am Main: Suhrkamp.

Lafayette (Madame de)

(2014) Oeuvres complètes, edited with an Introduction and Notes by Camille Esmein-Sarrazin, Paris: Gallimard/Pléiade. 
Lamb (Ben)

(2014) 'Narrative Form and the British Television Studio 1955-1963', in: Historical Journal of Film, Radio and Television, Vol. 34, No. 3, pp. 357-368.

Lamberti (Edward)

(2012) (ed.) Behind the Scenes at the BBFC: Film Classification from the Silver Screen to the Digital Age, London: British Film Institute/Palgrave.

Lang (Berel)

(1998) 'Style', in: Michael Kelly (ed.), Encyclopedia of Aesthetics, New York/Oxford: Oxford University Press, pp. 318-322.

Langdon (Helen)

(2000) Caravaggio: A Life [orig. 1998], Boulder/Oxford: Westview Press.

Langer (Susanne K.)

(1957a) Philosophy in a New Key: A Study in the Symbolism of Reason, Rite, and Art [orig. 1942], Cambridge/London: Harvard University Press.

(1957b) Problems of Art: Ten Philosophical Lectures, New York: Charles Scribner's Sons.

(1967) Mind: An Essay on Human Feeling. Volume I, Baltimore/London: The Johns Hopkins University Press.

(1973) Feeling and Form: A Theory of Art Developed From 'Philosophy in a New Key’ [orig. 1953], London: Routledge \& Kegan Paul Limited.

Lanza (Joseph)

(2007) Phallic Frenzy: Ken Russell and His Films, Chicago: Chicago Review Press.

\section{Lapper (Craig)}

(2012) 'The censors, the studio and 'cutting the orgy in two", in the booklet accompanying the BFI dvd of The Devils (BFIDV940), pp. 7-13.

Larmore (Charles)

(1998) 'Scepticism', in: Daniel Garber and Michael Ayers (eds.), The Cambridge History of Seventeenth-Century Philosophy, Cambridge: Cambridge University Press, pp. 1145-1192.

Larue (Anne)

(1992) 'Le "théâtre du monde": variations sur un thème', in: L'information littéraire, Vol. 44, No. 2, pp. 11-18.

\section{Lawrenson (T.E.)}

(1986) The French Stage and Playhouse in the XVIIth Century: A Study in the Advent of the Italian Order, second, revised and enlarged edition [first, 1957], New York: AMS Press. 


\section{BIBLIOGRAPHY}

\section{Leach (Jim)}

(2004) British Film, Cambridge: Cambridge University Press.

Lee (Hermione)

(2008) Body Parts: Essays on Life-Writing [orig. 2005], London: Pimlico.

(2009) Biography: A Very Short Introduction, Oxford: Oxford University Press.

Le Forestier (Laurent)

(2002) 'L'enregistrement fantastique ou quelques réflexions sur la nature et l'utilisation des trucages méliésiennes', in: Jacques Malthête and Laurent Mannoni (eds.), Méliès, magie et cinéma, Paris: Paris-Musées, pp. 211-236.

Le Goff (Jacques) and Schmitt (Jean-Claude)

(1981) (eds.) Le Charivari, Paris/The Hague: École des Hautes Études en Sciences Sociales/Mouton.

Lejeune (Philippe)

(1996) Le Pacte autobiographique, second, augmented edition [first, 1975], Paris: Seuil.

Le Roy Ladurie (Emmanuel)

(1978) 'Système de la cour (Versailles, vers 1709)', in: Emmanuel Le Roy Ladurie, Le territoire de l'historien II, Paris: Gallimard, pp. 275-299.

(1986) 'Auprès du roi, la cour', in: Emmanuel Le Roy Ladurie (ed.), Les Monarchies, Paris: Presses Universitaires de France, pp. 209-233.

\section{Levillain (Henriette)}

(2003) Qu'est-ce que le baroque?, Paris: Klincksieck.

Lindner (Burkhardt)

(2000) 'Allegorie', in: Michael Opitz and Erdmut Wizisla (eds.), Benjamins Begriffe. Erster Band, Frankfurt am Main: Suhrkamp, pp. 50-94.

\section{Litchfield (Patrick)}

(1977) 'Ken Russell', in: Richard Barnes (ed.), The Story of Tommy, Twickenham: Eel Pie, pp. 87-97.

Loukopoulous (Katerina)

(2007) '“Films Bring Art to the People”: The Art Film Tour in Britain (1950-1980)', in: Film History, Vol. 19, No. 4, pp. 414-422.

\section{Lucas (Tim)}

(1996) 'Cutting the Hell out of The Devils', in: Video Watchdog, No. 35, pp. 37-51. MacCarthy (Fiona)

(2003) Byron: Life and Legend [orig. 2002], London: Faber and Faber. 


\section{MacDonald (Scott)}

(1982) 'An Interview with Peter Watkins', in: Journal of the University Film and Video Association, Vol. 34, No. 3, pp. 47-55.

\section{MacMurraugh-Kavanagh (M.K.)}

(1997a) 'The BBC and the Birth of The Wednesday Play, 1962-66: institutional containment versus "agitational contemporaneity", in: Historical Journal of Film, Radio and Television, Vol. 17, No. 3, pp. 367-381.

(1997b) “'Drama" into "news": strategies of intervention in The Wednesday Play', in: Screen, Vol. 38, No. 3, pp. 247-259.

\section{Malcuzynski (Marie-Pierrette)}

(2009) 'The (Neo) Baroque Effect: A Critical Inquiry into the Transformation and Application of a Conceptual Field to Comparative American Studies', in: Comparatative Literature, Vol. 61, No. 3, pp. 295-315.

Malthête (Jacques) and Mannoni (Laurent)

(2002) (eds.) Méliès, magie et cinéma, Paris: Paris-Musées.

Mann (William J.)

(2005) Edge of Midnight: The Life of John Schlesinger [orig. 2004], London: Arrow.

Mannoni (Laurent)

(1995) Trois siècles de cinéma de la lanterne magique au Cinématographe: Collections de la Cinémathèque française, Paris: Éditions de la Réunion.

(1996) 'The Phantasmagoria', in: Film History, Vol. 8, No. 4, pp. 390-415.

(2000) The Great Art of Light and Shadow: Archaeology of the Cinema [orig. French: Le grand art de la lumière et de l'ombre: archéologie du cinéma, 1995], translated and edited by Richard Crangle with an Introduction by Tom Gunning and a Preface by David Robinson, Exeter: University of Exeter Press.

(2002) 'Méliès, magie et cinéma', in: Jacques Malthête and Laurent Mannoni (eds.), Méliès, magie et cinéma, Paris: Paris-Musées, pp. 37-70.

Mannoni (Laurent) and Campagnoni (Donata Pesenti)

(2009) Lanterne magique et film paint: 400 ans de cinéma, Paris: Éditions de La Martinière/La Cinémathèque française.

Maral (Alexandre)

(2012) Achille, Apollon, Diane, Jupiter, Vénus... Parcours mythologique dans les jardins de Versailles, Paris: Artlys.

(2013a) Le roi, la cour et Versailles 1682-1789: Le coup d'éclat permanent, Paris: Perrin. 


\section{BIBLIOGRAPHY}

(2013b) La Grande Commande de 1674: Chefs-d'oeuvre sculptés des jardins de Versailles sous Louis XIV, Montreuil: Gourcuff Gradenigo.

Marshall (John)

(1994) 'Modern productions of medieval English plays', in: Richard Beadle (ed.), The Cambridge Companion to Medieval English Theatre, Cambridge: Cambridge University Press, pp. 290-311.

Martin (John Rupert)

(1991) Baroque [orig. 1977], Harmondsworth: Penguin.

McCluskey (Michael)

(2011) 'Humphrey Jennings: The Customs of the Country', in: Scott Anthony and James G. Mansell (eds.), The Projection of Britain: A History of the GPO Film Unit, London: British Film Institute/Palgrave, pp. 62-71.

McEwan (Dorothea)

(2006) 'Aby Warburg's (1866-1929) Dots and Lines. Mapping the Diffusion of Astrological Motifs in Art History', in: German Studies Review, Vol. 29, No. 2, pp. 243-268.

McFarland (Thomas)

(1985) Originality \& Imagination, Baltimore/London: The Johns Hopkins University Press.

(1987) Shapes of Culture, Iowa City: University of Iowa Press.

McFarlane (Brian)

(1997) An Autobiography of British Cinema, London: Methuen.

McGowan (Margaret M.)

(1963) L'Art du ballet de cour en France, 1581-1643, Paris: Éditions du Centre National de la Recherche Scientifique.

(s.d. [1986]) The Court Ballet of Louis XIII: A collection of working designs for costumes 1615-33, London: Victoria and Albert Museum/Hobhouse/Mortom Morris.

(1989) 'Montaigne: the Self Discovered - au rebours', in: George Craig and Margaret McGowan (eds.), Moy Qui Me Voy: The Writer and the Self from Montaigne to Leiris, Oxford: Oxford University Press, pp. 1-18.

(2001) 'Ballets for the Bourgeois', in: Dance Research: The Journal of the Society for Dance Research, Vol. 19, No. 2 (Winter), pp. 106-126. 


\section{McKinnell (John)}

(2008) 'Modern productions of medieval English drama', in: Richard Beadle and Alan J. Fletcher (eds.), The Cambridge Companion to Medieval English Theatre, second edition, Cambridge: Cambridge University Press, pp. 287-325.

McNaughton (Douglas)

(2014) 'Video Film Recording: A New Production Paradigm For 1960s BBC Drama', in: Historical Journal of Film, Radio and Television, Vol. 34, No. 3, pp. 390-404.

Medhurst (Andy)

(1996) 'Dressing the Part', in: Sight and Sound, NS Vol. 10, No. 5, pp. 28-30.

Meijer (Maaike)

(2014) 'M'n hart stond van stocht bijna stil!' (F. Harmsen van Beek): Dichters en hun biografen, Maastricht: Universiteit Maastricht/Faculteit der Cultuur- en Maatschappijwetenschappen/Centrum voor Gender en Diversiteit.

Melvin (Murray)

(2006) The Art of the Theatre Workshop, London: Oberon Books.

Menon (Elizabeth K.)

(2006) Evil by Design: The Creation and Marketing of the Femme Fatale, Urbana/Chicago: University of Illinois Press.

Mérot (Alain)

(2007) Généalogies du baroque, Paris: Gallimard/Le Promeneur.

Metz (Christian)

(1991) L'énonciation impersonelle, ou le site du film, Paris: Méridiens Klincksieck.

Milovanovic (Nicolas)

(2005) Les Grands Appartements de Versailles sous Louis XIV: Catalogue des décors peints, Paris: Réunion des musées nationaux.

(2012a) 'Le palais du soleil: les quatre saisons et les sept planètes', in: Alexandre Maral and Nicolas Milovanovic (eds.), Versailles et l'antique, Versailles/Paris: Établissement public du château, du musée et du domaine national de Versailles/Artlys, pp. 227-236.

(2012b) 'Grands hommes et femmes fortes dans les Grands Appartements', in: Alexandre Maral and Nicolas Milovanovic (eds.), Versailles et l'antique, Versailles/Paris: Établissement public du château, du musée et du domaine national de Versailles/Artlys, pp. 265-275.

\section{Molière}

(2010) Oeuvres complètes, edited by Georges Forestier, two volumes, Paris: Gallimard/Pléiade. 


\section{Monk (Claire)}

(1995) 'Sexuality and the Heritage', in: Sight and Sound, NS Vol. 5, No. 10, pp. 32-34.

(2002) 'The British heritage-film debate revisited', in: Claire Monk and Amy Sargeant (eds.), British Historical Cinema: The History, Heritage and Costume Film, London/New York: Routledge, pp. 176-198.

Monsman (Gerald)

(1980) Walter Pater's Art of Autobiography, New Haven/London: Yale University Press.

\section{Montaigne}

(2007) Les Essais [orig. 1595], edited by Jean Balsamo, Michel Magnien, Catherine Magnien-Simonin, and Alain Legros, Paris: Gallimard/Pléiade.

Morin (Edgar)

(1956) Le Cinéma ou L'Homme Imaginaire: Essai d'Anthropologie Sociologique, Paris: Minuit.

Morrison (David E.)

(2009) 'Cultural and Moral Authority: The Presumption of Television', in: Annals of the American Academy of Political and Social Sciences, No. 625, pp. 116-127.

\section{Most (Glenn)}

(1989) 'The Second Homeric Renaissance: Allegoresis and Genius in Early Modern

Poetics', in: Penelope Murray (ed.), Genius: The History of an Idea, Oxford: Basil Blackwell, pp. 54-75.

Muchembled (Robert)

(1978) Culture populaire et culture des élites dans la France moderne (XVe-XVIIIe siècle), Paris: Flammarion.

Mulvey (Laura) and Sexton (Jamie)

(2007) (eds.) Experimental British Television, Manchester: Manchester University Press.

Murray (Penelope)

(1989a) (ed.) Genius: The History of an Idea, Oxford: Basil Blackwell.

(1989b) 'Poetic Genius and its Classical Origins', in: Penelope Murray (ed.), Genius: The History of an Idea, Oxford: Basil Blackwell, pp. 9-31.

Murray (Peter) and Murray (Linda)

(1998) The Oxford Companion to Christian Art and Architecture [orig. 1996], Oxford/New York: Oxford University Press. 
Myrone (Martin)

(2006) Gothic Nightmares: Fuseli, Blake and the Romantic Imagination, London: Tate.

(2007) 'Henry Fuseli and Gothic Spectacle', in: Huntington Library Quarterly, Vol. 70, No. 2, pp. 289-310.

Nagler (A.M.)

(1976) The Medieval Religious Stage: Shapes and Phantoms, translated by George

C. Schoolfield, New Haven/London: Yale University Press.

Ndalianis (Angela)

(2004) Neo-Baroque Aesthetics and Contemporary Entertainment, Cambridge/ London: The MIT Press.

(2009) 'The Frenzy of the Visible in Comic Book Worlds', in: animation: an interdisciplinary journal, Vol. 3, No. 4, pp. 237-248.

Nelson (Alan H.)

(1972) 'Some Configurations of Staging in Medieval English Drama', in: Jerome Taylor and Alan H. Nelson (eds.), Medieval English Drama: Essays Critical and Contextual, Chicago/London: The University of Chicago Press, pp. 116-147.

(1974) The Medieval English Stage: Corpus Christi Pageants and Plays, Chicago/London: The University of Chicago Press.

Nelson (Robert J.)

(1958) Play within a Play. The Dramatist's Conception of His Art: Shakespeare to Anouilh, New Haven: Yale University Press.

Nowell-Smith (Geoffrey)

(1986) 'Humphrey Jennings: Surrealist observer', in: Charles Barr (ed.), All Our Yesterdays: 90 Years of British Cinema, London: British Film Institute, pp. 321-333.

(1994) 'Eisenstein on Montage', in: S.M. Eisenstein, Selected Works, Volume II: Towards a Theory of Montage, edited by Michael Glenny and Richard Taylor and translated by Michael Glenny, London: British Film Institute, pp. xiii-xvi.

Nussbaum (Martha C.)

(1995) Poetic Justice: The Literary Imagination and Public Life, Boston: Beacon Press.

O’Keeffe (Paul)

(2004) Gaudier-Brzeska: An Absolute Case of Genius, London: Allen Lane/Penguin. Olson (Roberta Jeanne Marie)

(1974) 'Graphic Gaudier-Brzeska', in: Record of the Art Museum, Princeton University, Vol. 33, No. 1, pp. 1-36. 
O’Pray (Michael)

(2009) “New Romanticism” and British Avant-Garde Film in the Early 80s', in: Robert Murphy (ed.), The British Cinema Book, third edition, London: British Film Institute/Palgrave Macmillan, pp.343-349.

Owen (W.J.B.)

(1957) Wordsworth's Preface to Lyrical Ballads, edited with an Introduction and Commentary, Copenhagen: Rosenkilde and Bagger.

\section{Paglia (Camille)}

(1992) Sexual Personae: Art and Decadence from Nefertiti to Emily Dickinson [orig. 1990], Harmondsworth: Penguin.

(1993) Sex, Art and American Culture: Essays [orig. 1992], Harmondsworth: Penguin.

(2013) 'Theatre of Gender: David Bowie at the Climax of the Sexual Revolution', in: David Bowie Is, London: V\&A Publishing, pp. 68-92.

\section{Panofsky (Erwin)}

(1962) Studies in Iconology: Humanistic Themes in the Art of the Renaissance [orig. 1939], New York: Harper \& Row.

(1970) Meaning in the Visual Arts [orig. 1955], Harmondsworth: Penguin/Peregrine.

(1971) Early Netherlandish Painting: Its Origins and Character. Volume One [1953], New York/Evanston/San Francisco/London: Icon Editions.

(1972) Renaissance and Renascences in Western Art [orig. 1969], New York: Icon Editions/Harper \& Row.

(1995) Three Essays on Style, edited by Irving Lavin, Cambridge/London: The MIT Press.

Parker (Alexander A.)

(1943) The Allegorical Drama of Calderon: An Introduction to the Autos Sacramentales, Oxford/London: The Dolphin Book Co.

Partridge (Loren)

(2000) 'Michelangelo's Last Judgment: An Interpretation', in: Michelangelo: A Glorious Restauration [orig. 1997], New York: Abradale, pp. 8-154.

Pater (Walter)

(2010) Studies in the History of the Renaissance [orig. 1873 ], edited by Matthew Beaumont, Oxford: Oxford University Press.

Paulin (Roger)

(1985) Ludwig Tieck: A Literary Biography, Oxford: Oxford University Press. 
Payne (Alina)

(2011) 'On Sculptural Relief: Malerisch, the Autonomy of Artistic Media and the Beginnings of Baroque Studies', in: Helen Hills (ed.), Rethinking the Baroque, Farnham/Burlington: Ashgate, pp. 39-64.

Peake (Tony)

(2001) Derek Jarman [orig. 1999], London: Abacus.

Petitfils (Jean-Christian)

(2014) Louis XIII [orig. 2008], two volumes, Paris: Perrin.

Petley (Julian)

(1986) 'The Lost Continent', in: Charles Barr (ed.), All Our Yesterdays: 90 Years of

British Cinema, London: British Film Institute, pp. 98-119.

(2015) 'Witch-hunt: The Word, the Press and The Devils', in: Journal of British Cinema and Television, Vol. 12, No. 4.

Pettitt (Thomas)

(1984) 'Here Comes I, Jack Straw': English Folk Drama and Social Revolt', in: Folklore, Vol. 95, No. 1, pp. 3-20.

Pfeffer (Carla A.)

(2014) “"I Don't Like Passing as a Straight Woman”: Queer Negotiations of Identity and Social Group Membership', in: American Journal of Sociology, Vol. 120, No. 1, pp. 1-44.

Phillips (Gene D.)

(1976) 'The Early Films: Peepshow and Amelia and the Angel', in: Thomas R. Atkins

(ed.), Ken Russell, New York: Monarch Press/Simon and Schuster, pp. 11-18.

(1979) Ken Russell, Boston: Twayne.

Pilard (Philippe)

(1987) 'Propos de Ken Russell', in: La Revue du Cinéma, No. 424 (February), pp. 12-14.

Piper (Adrian)

(1996) 'Passing for White, Passing for Black', in: Elaine K. Ginsberg (ed.), Passing and the Fictions of Identity, Durham/London: Duke University Press, pp. 234269.

Plasseraud (Emmanuel)

(2007) Cinéma et imaginaire baroque, Villeneuve d'Ascq: Presses Universitaires du Septentrion. 


\section{BIBLIOGRAPHY}

Plate (S. Brent)

(2005) Walter Benjamin, Religion, and Aesthetics: Rethinking Religion Through the Arts, New York/London: Routledge.

Pleij (Herman)

(1979) Het gilde van de Blauwe Schuit: Literatuur, volksfeest en burgermoraal in de late middeleeuwen, Amsterdam: Meulenhoff.

(2003) Dromen van Cocagne: Middeleeuwse fantasieën over het volmaakte leven [orig. 1997], s.l.: Aula.

(2007) De eeuw van de zotheid: Over de nar als maatschappelijk houvast in de vroegmoderne tijd, Amsterdam: Bert Bakker.

Polanyi (Michael) and Prosch (Harry)

(1975) Meaning, Chicago/London: The University of Chicago Press.

Pollin (Burton R.)

(1965) 'Philosophical and Literary Sources of Frankenstein', in: Comparative Literature, Vol. 17, No. 2, pp. 97-108.

Post (Jack)

(2012) 'The Ambiguity of Weeping. Baroque and Mannerist Discourses in Haynes' Far from Heaven and Sirk's All That Heaven Allows', in: Image and Narrative, Vol. 13, No. 2, pp. 26-52.

(2015) 'From Altered States to Altered Titles: A close analysis of the title sequence

to Ken Russell's Altered States', in: Journal of British Cinema and Television, Vol. 12, No. 4.

Pound (Ezra)

(1970) Gaudier-Brzeska: A Memoir [orig. 1916], New York: New Directions.

Powell (Nicolas)

(1973) Fuseli: The Nightmare, London: Allen Lane/Penguin.

Powrie (Sarah)

(2013) 'Spenser's Mutabilitie and the Indeterminate Universe', in: Studies in English Literature, 1500-1900, Vol. 53, No. 1, pp. 73-89.

Prasch (Thomas)

(2009) 'Behind the Last Veil: Forms of Transgression in Ken Russell's Salome's Last

Dance', in: Kevin M. Flanagan (ed.), Ken Russell. Re-Viewing England's Last Mannerist, Lanham/Plymouth: The Scarecrow Press, pp. 195-210.

Puglisi (Catherine)

(1998) Caravaggio, London: Phaidon. 
Pulleine (Tim)

(1986) 'Russell's Romantics', in: Sight and Sound, Vol. 55, No. 4, p. 222.

Pym (John)

(2005) (ed.) Time Out Film Guide, fourteenth edition, London: Ebury.

Ramirez (Bruno)

(2014) Inside the Historical Film, Montreal \& Kingston/London/Ithaca: McGillQueen's University Press.

Rampley (Matthew)

(1997) 'From Symbol to Allegory: Aby Warburg's Theory of Art', in: The Art Bulletin, Vol. 79, No. 1, pp. 41-55.

Ranum (Orest)

(1980) Artisans of Glory: Writers and Historical Thought in Seventeenth-Century France, Chapel Hill: The University of North Carolina Press.

Rapley (Robert)

(1998) A Case of Witchcraft: The Trial of Urbain Grandier, Montreal/Kingston:

McGill-Queen's University Press, 1998.

Reed (Rex)

(1974) People Are Crazy Here, New York: Delacorte.

Rees (A.L.)

(2007) 'Experimenting on air: UK artists' film on television', in: Laura Mulvey and Jamie Sexton (eds.), Experimental British Television, Manchester: Manchester University Press, pp. 146-165.

Rees (Jasper)

(2011) 'theartsdesk Q\&A: Director Ken Russell, 1927-2011', on: theartsdesk.com, November 28 (URL: www.theartsdesk.com/film/theartsdesk-qa-director-kenrussell-1927-2011; accessed 2 December 2011).

Reid (Dylan)

(2001) 'Carnival in Rouen: A History of the Abbaye des Conards', in: Sixteenth

Century Journal, Vol. 34, No. 4, pp. 1027-1055.

Rey-Flaud (Henri)

(1985) Le charivari: Les rituels fondamentaux de la sexualité, Paris: Payot.

\section{Richard (Vivien)}

(2011) 'Un théâtre de la diplomatie: La chambre du roi et les réceptions d'ambassadeurs à Versailles sous le règne de Louis XIV', in: Revue d'histoire diplomatique, Vol. 125, No. 3, pp. 269-281. 


\section{BIBLIOGRAPHY}

Richardson (Angelique)

(2003) Love and Eugenics in the Late Nineteenth Century: Rational Reproduction and the New Woman, Oxford: Oxford University Press.

Ricketts (Charles)

(1913) Pages on Art, London: Constable.

Robinson (Charles E.)

(2008) 'Introduction', in: Mary Shelley, Frankenstein or The Modern Prometheus:

The Original Two-Volume Novel of 1816-1817 from the Bodleian Library Manuscripts, edited by Charles E. Robinson, New York: Vintage, pp. 16-37.

Robinson (David)

(1993) The Lantern Image: Iconography of the Magic Lantern, 1420-1880, Nutley: The Magic Lantern Society.

Roger (Christine) and Paulin (Roger)

(2010) 'August Wilhelm Schlegel', in: Roger Paulin (ed.), Voltaire, Goethe, Schlegel, Coleridge: Great Shakespeareans, Volume III, London/New York: Continuum, pp. 92-127.

Rosenfeldt (Diane)

(1978) Ken Russell: a guide to references and resources, Boston: G.K. Hall.

Rosenstone (Robert A.)

(1995) Visions of the Past: The Challenge of Film to Our Idea of History, Cambridge/London: Harvard University Press.

Rotrou (Jean)

(1999) Le Véritable Saint Genest, edited with a Presentation and Dossier by Emmanuelle Hénin and François Bonfils, Paris: Flammarion.

Rousset (Jean)

(1953) La littérature de l'âge baroque en France: Circé et le paon, Paris: José Corti.

Rubin (Miri)

(1991) Corpus Christi: The Eucharist in Late Medieval Culture, Cambridge: Cambridge University Press.

Russell (Ken)

(1973) Gargantua by Rabelais, unpublished typescript treatment dated 3 January 1973.

(1974) 'What Mahler Tells Me', in: Ken Russell's "Mahler": Production Notes, London: Visual Programme Systems, unpaginated [pp. 4-6].

(1991) Altered States: The Autobiography of Ken Russell, New York: Bantam Books. 
(1993) Fire Over England: The British Cinema Comes Under Friendly Fire, London: Hutchinson.

(1999) Mike and Gaby's Space Gospel, London: Little, Brown and Company.

(2000) Directing Film: From Pitch to Premiere, London: Batsford.

(2007a) Beethoven Confidential and Brahms Gets Laid, London/Chester Springs: Peter Owen.

(2007b) Elgar: The Erotic Variations and Delius: A Moment with Venus, London/Chester Springs: Peter Owen.

(2008) A British Picture: An Autobiography, second edition [first, 1989], London: Southbank.

(2012) Ken Russell's Dracula, with an Introduction by Paul Sutton, Cambridge: Bear Claw.

Ryan (Marie-Laure)

(2001) Narrative as Virtual Reality: Immersion and Interactivity in Literature and

Electronic Media, Baltimore/London: The Johns Hopkins University Press.

Sadoff (Dianne F.)

(2010) Victorian Vogue: British Novels on Screen, Minneapolis/London: University of Minnesota Press.

Salazkina (Masha)

(2009) In Excess: Sergei Eisenstein's Mexico, Chicago/London: The University of Chicago Press.

Sandbrook (Dominic)

(2007) White Heat: A History of Britain in the Swinging Sixties [2006], London: Abacus.

(2011) State of Emergency. The Way We Were: Britain, 1970-1974, London: Penguin.

Sarduy (Severo)

(1975) Barroco, translated by Jacques Henric and the author, Paris: Seuil.

\section{Sargeant (Ay)}

(2005) British Cinema: A Critical History, London: British Film Institute.

(2011) 'Harry Watt: On land, at Sea and in the Air', in: Scott Anthony and James

G. Mansell (eds.), The Projection of Britain: A History of the GPO Film Unit, London: British Film Institute/Palgrave, pp. 53-61.

Saule (Bearix)

(2007) 'La galerie au temps de Louis XIV, de l'ordinaire à l'extraordinaire', in: La galerie des glaces, histoire et restauration, Dijon: Faton, pp. 54-73. 


\section{BIBLIOGRAPHY}

\section{Saunders (Max)}

(2010) Self Impression: Life-Writing, Autobiografiction, and the Forms of Modern Literature, Oxford: Oxford University Press.

\section{Scannell (Paddy)}

(2000) 'Public Service Broadcasting: The History of a Concept', in: Edward Buscombe (ed.), British Television: A Reader, Oxford: Oxford University Press, pp. $45-62$.

Scarry (Elaine)

(1985) The Body in Pain: The Making and Unmaking of the World, New York/Oxford: Oxford University Press.

(2001) Dreaming by the Book [orig. 1999], Princeton: Princeton University Press.

Schöne (Albrecht)

(1993) Emblematik und Drama im Zeitalter des Barock, third, enlarged edition [first, 1964], Munich: Beck.

\section{Seaton (Jean)}

(2003a) 'Broadcasting history', in: James Curran and Jean Seaton, Power Without Responsibility: The press, broadcasting, and new media in Britain, sixth edition, London/New York: Routledge, pp. 107-234.

(2003b) 'Broadcasting and the theory of public service', in: James Curran and Jean

Seaton, Power Without Responsibility: The press, broadcasting, and new media in Britain, sixth edition, London/New York: Routledge, pp. 363-376.

Sedley (David)

(1999) 'Hellenistic physics and metaphysics', in: Keimpe Algra, Jonathan Barnes, Jaap Mansfeld, and Malcolm Schofield (eds.), The Cambridge History of Hellenistic Philosophy, Cambridge: Cambridge University Press, pp. 355-411.

\section{Sennett (Richard)}

(1992) The Fall of Public Man [orig. 1977], New York/London: Norton.

\section{Sexton (Jamie)}

(2003) “"Televerite" hits Britain: documentary, drama and the growth of $16 \mathrm{~mm}$ filmmaking in British television', in: Screen, Vol. 44, No. 4 (Winter), pp. 429-444. (2007) 'From art to avant-garde? Television, formalism and the arts documentary in 1960s Britain', in: Laura Mulvey and Jamie Sexton (eds.), Experimental British Television, Manchester: Manchester University Press, pp. 89-105.

Shakespeare (William)

(1987) Hamlet, edited with an Introduction and Notes by G.R. Hibbard, Oxford: Oxford University Press. 
(1994) A Midsummer Night's Dream, edited with and Introduction and Notes by Peter Holland, Oxford: Oxford University Press.

\section{Shaw (Tony)}

(2006) 'The BBC, the State and Cold War Culture: The Case of Television's The War Game (1965)', in: English Historical Review, Vol. CXXI, No. 494, pp. 13511384.

Shelley (Mary)

(1992) Frankenstein or The Modern Prometheus, edited with an Introduction and Notes by Maurice Hindle, Harmondsworth: Penguin.

(2008) Frankenstein or The Modern Prometheus: The Original Two-Volume Novel of 1816-1817 from the Bodleian Library Manuscripts, edited by Charles E. Robinson, New York: Vintage.

Shelley (Percy Bysshe)

(2003) The Major Works, edited with an Introduction and Notes by Zachary Leader and Michael O’Neill, Oxford: Oxford University Press.

Showalter (Elaine)

(1991) Sexual Anarchy: Gender and Culture at the Fin de Siècle [orig. 1990], Harmondsworth: Penguin.

Shubik (Irene)

(2000) Play for Today: The evolution of television drama, second edition [first, 1975], Manchester/New York: Manchester University Press.

Simkin (Stevie)

(2012) 'Wake of the Flood: Key Issues in UK Censorship, 1970-5', in: Lamberti Edward (ed.), Behind the Scenes at the BBFC: Film Classification from the Silver Screen to the Digital Age, London: British Film Institute/Palgrave, pp. 72-86.

\section{Sinker (Mark)}

(2004) IF...., London: British Film Institute.

\section{Skinner (Quentin)}

(2000) Machiavelli: A Very Short Introduction, Oxford: Oxford University Press.

(2002) Visions of Politics. Volume I: Regarding Method, Cambridge: Cambridge University Press.

\section{Sluijter (Eric J.)}

(1991) 'Didactic and Disguised Meanings? Several Seventeenth-Century Texts on Painting and the Iconological Approach to Northern Dutch Paintings of This Period', in: David Freedberg and Jan de Vries (eds.), Art in history. History in 


\section{BIBLIOGRAPHY}

art. Studies in Seventeenth-Century Dutch Culture, Santa Monica: The Getty Center for the History of Art and the Humanities, pp. 175-207.

Smart (Billy)

(2013) 'The Life of Galileo and Brechtian Television Drama', in: Journal of British

Cinema and Television, Vol. 10, No. 1, pp. 112-129.

Smith (Andrew)

(2004) Victorian demons: Medicine, masculinity and the Gothic at the fin-de-siècle,

Manchester/New York: Manchester University Press.

Snorton (C. Riley)

(2009) “'A New Hope”: The Psychic Life of Passing', in: Hypatia, Vol. 24, No. 3, pp. 77-92.

Snow (Peter)

(1996) 'Designing for the Theatre and Cinema', in: Roger Wollen (ed.), Derek Jarman: A Portrait, London: Thames and Hudson, pp. 81-88.

Solomon (Matthew)

(2000) “'Twenty-five Heads under One Hat”: Quick-Change in the 1890s', in: Vivian Sobchack (ed.), Meta-Morphing: Visual Transformation and the Culture of Quick-Change, Minneapolis/London: University of Minnesota Press, pp. 3-20.

(2006) 'Up-to-Date Magic: Theatrical Conjuring and the Trick Film', in: Theatre Journal, Vol. 58, No. 4, pp. 595-615.

(2010) Disappearing Tricks: Silent Film, Houdini, and the New Magic of the Twentieth Century, Urbana/Chicago: University of Illinois Press.

Sorel (Charles)

(2006) Description de l'île de portraiture et de la ville des portraits (1659), edited by

Martine Debaisieux with a Preface by Michel Jeanneret, Geneva: Droz.

\section{Souiller (Didier)}

(1992) Calderón de la Barca et le grand théâtre du monde, Paris: PUF.

Sparshott (F.E.)

(1971) 'Basic Film Aesthetics', in: Journal of Aesthetic Education, Vol. 5, No. 2, pp. 11-34.

Spierenburg (Pieter)

(1984) The Spectacle of Suffering. Executions and the evolution of repression: from a preindustrial metropolis to the European experience, Cambridge: Cambridge University Press.

Starobinski (Jean)

(2012) L'Encre de la mélancolie, with a Postscript by Fernando Vidal, Paris: Seuil. 
Stevens (Martin)

(1973) 'The Theatre of the World: A Study in Medieval Dramatic Form', in: The Chaucer Review, Vol. 7, No. 4, pp. 234-249.

Stewart (Garrett)

(1995) 'Film's Victorian Retrofit', in: Victorian Studies, Vol. 38, No. 2 (Winter), pp. 153-198.

Stoichita (Victor I.)

(1999) L'Instauration du tableau: Métapeinture à l'aube des temps modernes, second, revised edition, Geneva: Droz.

Stoker (Bram)

(2006) Dracula's Guest and Other Weird Stories with The Lair of the White Worm [orig. 1914 and 1911], edited by Kate Hebblethwaite, Harmondsworth: Penguin.

Stott (Rebecca)

(1992) The Fabrication of the Late-Victorian Femme Fatale: The Kiss of Death, Basingstoke/London: Macmillan.

Strauven (Wanda)

(2006) (ed.) The Cinema of Attractions Reloaded, Amsterdam: Amsterdam University Press.

Street (Sarah)

(2009) 'British Film and the National Interest, 1927-39', in: Robert Murphy (ed.), The British Cinema Book, third edition, London: British Film Institute/Palgrave Macmillan, pp. 185-191.

Sutton (Paul)

(2002a) 'Melvyn Bragg', in: Camera: Cambridge University Film Quarterly, No. 2 (Summer), pp. 6-7.

(2002b) 'Ken Russell', in: Camera: Cambridge University Film Quarterly, No. 2 (Summer), pp. 8-21.

(2012) Becoming Ken Russell: The Authorised Biography of Ken Russell, Volume One, Cambridge: Bear Claw.

(2014) Six English Filmmakers, Cambridge: Buffalo Books.

\section{Taylor (Jerome)}

(1972) 'The Dramatic Structure of the Middle English Corpus Christi, or Cycle, Plays' [orig. 1964], in: Jerome Taylor and Alan H. Nelson (eds.), Medieval English Drama: Essays Critical and Contextual, Chicago/London, The University of Chicago Press, pp. 148-156. 


\section{Thompson (E.P.)}

(1992) 'Rough Music Reconsidered', in: Folklore, Vol. 103, No. 1, pp. 3-26.

\section{Thomson (Peter)}

(2004) 'Clowns, fools and knaves: stages in the evolution of acting', in: Jane Milling and Peter Thomson (eds.), The Cambridge History of British Theatre. Volume I: Origins to 1660, Cambridge: Cambridge University Press, pp. 407-423.

\section{Tibbetts (John C.)}

(2005a) 'Ken Russell's The Debussy Film (1966)', in: Historical Journal of Film, Radio and Television, Vol. 25, No. 1, pp. 81-99.

(2005b) 'Elgar's Ear: A Conversation with Ken Russell', in: Quarterly Review of Film and Video, Vol. 22, No. 1, pp. 37-49.

(2005c) Composers in the Movies: Studies in Musical Biography, New Haven/London: Yale University Press.

\section{Tomalin (Claire)}

(1977) The Life and Death of Mary Wollstonecraft [orig. 1974], Harmondsworth:

\section{Penguin.}

Tracey (Michael)

(2000) 'The BBC and the General Strike: May 1926', in: Edward Buscombe (ed.), British Television: A Reader, Oxford: Oxford University Press, pp. 25-44.

\section{Twycross (Meg)}

(2008) 'The theatricality of medieval English plays', in: Richard Beadle and Alan J.

Fletcher (eds.), The Cambridge Companion to Medieval English Theatre, second edition, Cambridge: Cambridge University Press, pp. 26-74.

\section{Tydeman (William)}

(1978) The Theatre in the Middle Ages: Western European Stage Conditions, c.800-

1576, Cambridge: Cambridge University Press.

\section{Tyler (Parker)}

(1971) Sex Psyche Etcetera in the Film [orig. 1969], Harmondsworth: Penguin.

\section{Vandenbroeck (Paul)}

(1987) Beeld van de andere, vertoog over het zelf: Over wilden en narren, boeren en

bedelaars, Antwerp: Koninklijk Museum voor Schone Kunsten.

(1997) De Kleuren van de Geest: Dans en Trance in Afro-Europese Tradities, Ghent:

Snoeck-Ducaju \& Zoon.

(2002) Jheronimus Bosch: De Verlossing van de Wereld, Ghent/Amsterdam: Ludion.

Van Eecke (Christophe)

(2011) Only Connect: Five Exercises in Aesthetics, Breda: Lokaal 01. 
(2012) 'Moonstruck Follies: Ken Russell's Salome's Last Dance as Baroque Performance', in: Image and Narrative, Vol. 13, No. 2, pp. 5-25.

(2013) 'Refusing to Lie Down: Truth, Fiction, and Ken Russell's Early Television Documentaries', in: Photogénie, No. 1 (URL: http://www.photogenie.be/photogenie_blog/article/d-refusing-lie-down)

(2015) 'Staging the World: The Devils as Theatrum Mundi', in: Journal of British Cinema and Television, Vol. 12, No. 4, pp. 496-514.

Van Eecke (Christophe), Hill (John), and Vanhaesebrouck (Karel)

(2015) 'Introduction', in: Journal of British Cinema and Television, Vol. 12, No. 4, pp. 427-437.

Vanhaesebrouck (Karel)

(2013) 'Lichamelijkheid en emoties op het vroeg-moderne podium: De martelaar als theatraal effect', in: Tijdschrift voor Geschiedenis, Vol. 126, No. 4, pp. 516-529.

Vidal (Belén)

(2012a) Heritage Film: Nation, Genre and Representation, London/New York: Wallflower/Columbia University Press.

(2012b) Figuring the Past: Period Film and the Mannerist Aesthetic, Amsterdam: Amsterdam University Press.

Vincendeau (Ginette)

(2001) (ed.) Film/Literature/Heritage: A Sight and Sound Reader, London: British Film Institute.

Volk (Stephen)

(2013) 'Villa Diodati', in: James Bell (ed.), Gothic: The Dark Side of Film, with a Foreword by Sir Christopher Frayling, London: BFI, p. 62.

Vries (Lyckle de)

(2005) Verhalen uit Kamer, Keuken en Kroeg: Het Hollandse Genre van de Zeventiende Eeuw als Vertellende Schilderkunst, Amsterdam: Salomé - Amsterdam University Press.

Wakeman (John)

(1988) (ed.) World Film Directors. Volume II: 1945-1985, New York: H.W. Wilson, s.v. 'Ken Russell', pp. 943-951.

Walker (Alexander)

(2005) Hollywood, England: The British Film Industry in the Sixties [orig. 1974], London: Orion. 


\section{BIBLIOGRAPHY}

\section{Walker (John A.)}

(1993a) Art and Artists on Screen, Manchester/New York: Manchester University Press.

(1993b) Arts TV: A History of Arts Television in Britain, London: John Libbey.

Walkowitz (Judith R.)

(2003) 'The "Vision of Salome": Cosmopolitanism and Erotic Dancing in Central London, 1908-1918', in: The American Historical Review, Vol. 108, No. 2, pp. 337-376.

Wallis (Tom)

(2009) 'Smashing Our Guitars, Deconstructing Our Idols: The Pop Art Aesthetic in Tommy', in: Kevin M. Flanagan (ed.), Ken Russell: Re-Viewing England's Last Mannerist, Lanham/Plymouth: The Scarecrow Press, pp. 85-106.

Walsh (John)

(1991) 'Skies and Reality in Dutch Landscape', in: David Freedberg and Jan de Vries (eds.), Art in history. History in art. Studies in Seventeenth-Century Dutch Culture, Santa Monica, The Getty Center for the History of Art and the Humanities, pp. 95-117.

Warburg (Aby)

(2010) Werke in einem Band, edited with commentaries by Martin Treml, Sigrid Weigel, and Perdita Ladwig, Frankfurt am Main: Suhrkamp.

Ward (Maryanne C.)

(2000) 'A Painting of the Unspeakable: Henry Fuseli's The Nightmare and the Creation of Mary Shelley's Frankenstein', in: The Journal of the Midwest Modern Language Association, Vol. 33, No. 1, pp. 20-31.

Wayne (Mike)

(2007) 'Failing the Public: The BBC, The War Game and Revisionist History. A Reply to James Chapman', in: Journal of Contemporary History, Vol. 42, No. 4, pp. 627-637.

Wellek (René)

(1963) Concepts of Criticism, edited with an Introduction by Stephen G. Nichols, Jr., New Haven/London: Yale University Press.

Werner (Gerlind)

(1977) Ripa’s “Iconologia”: Quellen - Methode - Ziele, Utrecht: Haentjens Dekker \& Gumbert.

West (Candace) and Zimmerman (Don H.)

(1987) 'Doing Gender', in: Gender and Society, Vol. 1, No. 2, pp. 125-151. 
Westfall (Richard S.)

(1977) The Construction of Modern Science: Mechanisms and Mechanics [orig. 1971], Cambridge: Cambridge University Press.

Wheatley (Helen)

(2007) “'And now for your Sunday night experimental drama...”: experimentation and Armchair Theatre', in: Laura Mulvey and Jamie Sexton (eds.), Experimental British Television, Manchester: Manchester University Press, pp. 31-47.

Wheldon (Huw)

(1962) (ed.) Monitor: An Anthology, London: MacDonald.

Whiting (John)

(1961) The Devils, London/Melbourne/Toronto: Heinemann.

Wilde (Oscar)

(2000) The Complete Letters of Oscar Wilde, edited by Merlin Holland and Rupert Hart-Davis, London: Fourth Estate.

(2003) The Complete Works of Oscar Wilde, fifth edition, London: HarperCollins.

(2006) Salomé, edited with an Introduction, Notes, and Documents by Pascal Aquien, revised edition, Paris: Gallimard.

(2007) The Picture of Dorian Gray, edited by Michael Patrick Gillespie, second edition, New York/London: Norton.

Williams (Linda)

(1999) Hard Core: Power, Pleasure, and the "Frenzy of the Visible", second, expanded edition [first, 1989], Berkeley/Los Angeles/London: University of California Press.

Williams (Linda Ruth)

(2007) 'Ken Russell: Sweet swell of excess', in: Sight and Sound, NS Vol. 17, No. 7 (July), pp. 28-32.

Williams (Linda Ruth) and Kermode (Mark)

(2012) 'Mythomania: Ken Russell 1927-2011', in: Sight and Sound, NS Vol. 22, No.

2 (February), pp. 23-24.

Williams (Raymond)

(2003) Television: Technology and cultural form [orig. 1974], edited by Ederyn Williams with a new Preface by Roger Silverstone, London/New York: Routledge.

Williamson (George)

(1935) 'Mutability, Decay, and Seveneenth-Century Melancholy', in: ELH: A Journal of English Literary History, Vol. 2, No. 2, pp. 121-150. 


\section{Wilson (Colin)}

(1974) Ken Russell: A Director in Search of a Hero, London: Intergroup.

\section{Wilson (David)}

(1975) review of Tommy, in: Sight and Sound, Vol. 44, No. 3, pp. 192-193.

\section{Wilson (Sandy)}

(1972) The Boy Friend: A Play in Three Acts [orig. 1955], with a Preface by Vida Hope, Harmondsworth: Penguin.

\section{Wittkower (Margot) and Wittkower (Rudolf)}

(2007) Born Under Saturn: The Character and Conduct of Artists. A Documented

History from Antiquity to the French Revolution [orig. 1963], with an Introduction by Joseph Connors, New York: New York Review Books.

\section{Wollen (Roger)}

(1996) (ed.) Derek Jarman: A Portrait, London: Thames and Hudson.

Wood (Robin)

(1980) 'Ken Russell', in: Richard Roud (ed.), Cinema: A Critical Dictionary. The Major Film-Makers, two volumes, s.l.: Nationwide Book Services, pp. 909-910.

\section{Wordsworth (William)}

(1995) The Prelude: The Four Texts (1798, 1799, 1805, 1850), edited by Jonathan Wordsworth, London: Penguin.

(2013) 'Preface' [1802], in: William Wordsworth and Samuel Taylor Coleridge, Lyrical Ballads, 1798 and 1802, edited with an Introduction and Notes by Fiona Stafford, Oxford: Oxford University Press, pp. 95-115.

\section{Wright (Herbert)}

(2006) London High, London: Frances Lincoln.

\section{Wright (Thomas)}

(2009), Oscar's Books [orig. 2008], London: Vintage.

\section{Wyver (John)}

(2007) Vision On: Film, Television and the Arts in Britain, London/New York: Wallflower Press.

(2014) 'Television', in: Chris Stephens and John-Paul Stonard (eds.), Kenneth Clark: Looking for Civilisation, London: Tate, pp. 123-131.

(2015) 'The filmic fugue of Ken Russell's Pop Goes the Easel', in: Journal of British Cinema and Television, Vol. 12, No. 4.

Yacowar (Maurice)

(1980) 'Ken Russell's Rabelais', in: Literature/Film Quarterly, Vol. 8, No. 1, pp. 41-51. 
Yakir (Dan)

(1981) 'Altering “States”, in: Film Comment, Vol. 17, No. 1 (January-February), pp. 52-55.

Yates (Frances A.)

(1969a) The Art of Memory [orig. 1966], Harmondsworth: Penguin.

(1969b) Theatre of the World, Chicago: The University of Chicago Press.

Zamora (Lois Parkinson) and Kaup (Monica)

(2010) (eds.) Baroque New Worlds: Representation, Transculturation, Counterconquest, Durham/London: Duke University Press.

\section{Zinovieff (Sofka)}

(2014) The Mad Boy, Lord Berners, My Grandmother and Me, London: Jonathan Cape. 

FILMOGRAPHY 

Only commercial dvd releases that have been used in the course of my research are listed here. Some of Russell's early BBC shorts are available online. In view of the ephemeral quality of weblinks I have not included such internet resources here.

I am indebted to Kevin Flanagan and Paul Sutton for providing me with dvd copies of rare Russell films from their own collections. Lisi Tribble has very generously provided me with copies of Russell's late video films.

\section{Brook (Peter)}

(2013) Marat Sade, Cinema International Media (Spain).

Clark (Kenneth)

(2005) Civilisation: A Personal View by Lord Clark [4-disc set], BBC Worldwide.

D'Anna (Claude)

(s.d.) Salomè, 01 Distribution (Italy).

\section{Loach (Ken)}

(2011) Ken Loach at the BBC [6-disc set; includes Cathy Come Home and Up the Junction], BBC Worldwide.

Méliès (Georges)

(2010) Georges Méliès: Le Premier Magicien du Cinéma (1896-1913) (6-disc set), Lobster Films (France).

Powell (Michael) and Pressburger (Emeric)

(2005) The Powell and Pressburger Collection, Granada.

\section{Russell (Ken)}

(1998) L'Ultima Salomè [= Salome's Last Dance], Eagle Pictures (Italy).

(2001) Delius: Song of Summer, London: British Film Institute.

(2002) Elgar, London: British Film Institute.

(2003) Ken Russell's Der Biss der Schlangenfrau [= The Lair of the White Worm, cut version], Concorde (Germany).

(2004a) Tommy: 2-Disc Collector's Edition, Quest.

(2004b) Billion Dollar Brain, MGM.

(2005a) Altered States, Warner.

(2005b) Gothic, MGM.

(2006a) The Rainbow, Lionsgate.

(2006b) Lady Chatterley, H.O.M. Vision (The Netherlands).

(2007) In Search of the English Folk Song, Warner. 
(2008a) Ken Russell at the BBC [contains Elgar, The Debussy Film, Always on Sunday, Isadora Duncan: The Biggest Dancer in the World, Dante's Inferno, Song of Summer, and Russell at Work], BBC Worldwide.

(2008b) Crimes of Passion, Optimum.

(2009) Lisztomania, Digital Classics.

(2011a) The Boy Friend, Warner.

(2011b) The Music Lovers, Final Cut Entertainment.

(2011c) Savage Messiah, Warner.

(2012a) The Devils [2-disc set, includes Amelia and the Angel, Hell on Earth, and Director of Devils], London: British Film Institute.

(2012b) Mahler, Odeon.

(s.d.) Aria: Special Edition, Second Sight.

(s.d.) The Fall of the Louse of Usher, London: Salvation Films.

(s.d.) Whore, Pulp Video (Italy).

\section{Various Directors}

(2006) Free Cinema (3-disc set), London: British Film Institute.

\section{Watkins (Peter)}

(2011) Edvard Munch, Eureka!

(s.d.) La bombe - Culloden [contains The War Game and Culloden], Doriane Films (France).

Weir (Peter)

(2006) The Truman Show: Special Collector's Edition, Paramount. 
APPENDIX 



\section{HOW TO DO THINGS WITH A BOOK}

A Note on Valorisation

'All art is quite useless'

Oscar Wilde, The Picture of Dorian Gray

(1891 [2007: 4]) 

As I write this Europe is in the middle of a refugee crisis to which its only answer seems to be a form of collective cynicism with a veneer of liberal callousness. One might well ask how one could justify spending several years of one's life studying the work of a baroque film-maker, and from an avowedly aestheticist point of view at that, when such pressing social and political emergencies are upon us. Apart from the fact that such questions are based on false assumptions (for abstaining from activities that do not contribute to a solution for the emergency almost never means that those energies are then redirected towards such a solution), they are also guilty of a prejudice that has become especially widespread in these supposedly enlightened neo-liberal times: that the arts, philosophy, and the traditional humanities are little more than a leftist hobby, something that one indulges in when all the really significant aspects of life (and that means: economic productivity) have been safeguarded, - and even then preferably only at one's own expense, unless the appeal of one's humanist endeavours is broadly populist and therefore deserving of public money. This state of mind is the social context in which scholars of the humanities have to work today, and I would like to think of this book, among the other things it does, as a tool-box for fighting one's way out of a number of the cultural constraints that have been imposed upon the pursuit of the growth of mind. When dumbing down has become the norm in the globalised race to the cultural bottom it is time for all of us who care for the mind of man, its pursuits and achievements, its triumphs and interesting failures, to stand up and be counted.

It is in times of crisis that the traditional humanities are more needed than ever. Not because they solve the practical problems of the day, which are too terribly wicked to be resolved so easily, and certainly not because the pursuits of the mind provide some kind of relief for the harsh realities of the everyday. It is not the business of great art to provide succour. If anything, great art tends to trouble and provoke, and to leave its mark upon our sense of self. But it is exactly because they disrupt our complacency and challenge our mind that the arts and the humanities can be a force of change in society. When economics and politics divide and oppress, the achievements of culture past and present are the last remaining reminders of our better self: they are the near-ruins of an image of man that is more than a $\operatorname{cog}$ in the economic machine. Our true nature is not that of a labouring animal. Man is not made to live in a world where persons are marketable (and where, conversely, to not be marketable is to not be a person). As Susanne Langer argued, man is a symbolic creature: what makes us human is our ability to create meaning in the world and shape our surroundings into an environment, an ethnic domain, in which we can be at home. In times when freedom is overwhelmingly defined as joyful bondage to the constraints of labour we would therefore do well to recall Schiller's observation that man is most himself, and most free, when he is at play. Both play and 
art are serious business, and the study of them is not and should not be considered a frivolous afterthought. If we lose a sense of the past we are doomed to repeat its worst excesses. To know history and to understand art is to address the most vital questions that pertain to our humanity.

A crucial aspect of this book is its contribution to our understanding of life writing, which is perhaps our most vital symbolic activity. The specific form of life writing it identifies, namely the performance of self through art, is not simply meant as an addition to the many other forms of life writing that have already been recognised (and many of which are listed in the Introduction). Rather, it is a form of life writing that questions the very epistemological foundations that are central to our concepts of self. The subject of this book is a form of artistic endeavour that connects art to life. It shows how the pursuits of artists can be intricately linked to the way we think of and create our selves in the world. To make sense of this link, I have attempted to develop a notion of the baroque that is operational for practical criticism. What makes it useful, or should make it useful, is exactly the way it straddles the gap between art and life. By connecting baroque tropes to the performance of self, Russell's work can show us how works of art are not something that stands apart from "real life" but are intrinsically involved in it. I have highlighted how the baroque, as more than just a formal matrix, allows us both to understand the complexity of the performance of self in the post-modern world and to connect that sense of self to the past. I have also suggested that a baroque sensibility can provide an effective framework for understanding our present concerns with identity politics. It opens up perspectives for thinking about the self that are non-essentialist while clearing space for manifold forms of identity-formation. The notion of baroque that I develop in this book makes it possible to situate contemporary works of art, and especially works of art that engage with issues of identity, in their social and cultural context while at the same time respecting their integrity as works of art. This may sound paradoxical, but it is not. After all, Oscar Wilde, who is one of the central philosophical references in this book, also combined a radical aestheticist outlook with equally radical socialist ideas. The notion that the aestheticist movement (l'art-pour-l'art) is divorced from social concerns has always been misguided: as a principled rejection of liberal ideologies of utility it was always already an act of resistance against oppressive social and cultural models.

But in connecting our present cultural moment to the historical Baroque and its Nachleben I try to do more than merely show the continuing usefulness of the traditional humanities for understanding the world in which we live. I also want to show that baroque is difference. Historically, the Baroque was a period when world-views were in upheaval and reservoirs of potential for newness were activated. This makes the period 
similar to our own, which is nothing if not globalised and differentiated. In our struggle to deal with difference (and the lack of humane response to the current refugee crisis shows how difficult the struggle is) the baroque is an unexpected hermeneutic tool - not to resolve the struggle (for that is also a political and moral project) but to make sense of its complexity and of what is at stake. As I have shown in the chapters of this book, the complex interconnections of formal conceits and ontological concerns that structure the concept of baroque can be applied to gain insight not merely into the performance of self through art or into the theatre of everyday life, but also into the tensions between competing world-views and the politics of power. As a concept the baroque opens perspectives for finding inroads into debates about multiculturalism, globalisation, and diversity, and especially about the creative solutions that will be needed to structure those aspects of post-moden life into a shared world that is made fit for people to live in, - many different kinds of people who sometimes share little more than their sense of difference. The baroque, whose Nachleben includes the epistemologies of Pater and Wilde and the montage practices of the Romantics and Eisenstein, is more than an exotic relic from an over-decorated past besotted with absolutist theatrics. The baroque and the many manifestations of its Nachleben are a toolbox for dealing with the challenges that face us today. They are a diverse repertoire of ideas, concepts, and creative strategies for understanding and living with difference. The concluding essay of the book has tried to map a number of the ways in which ideas developed in the course of my analyses can help to tackle contemporary questions of gender identity, the experience of self in a mediated world, and the many ways in which people now craft a sense of self. The discussion of the performance of self through art developed in these pages opens perspectives on ways for moving beyond established categories for doing identity. And it is this aspect of the baroque outlook on life that perhaps holds the greatest promise for strategic interventions in the way we live now.

Clearly, the implication of my closing observations on gender must be that all categories of sex and/or gender should be abolished. In the end, the notion of gender can become just as oppressive as the binary sex system because categories of gender are often simply grafted onto the materiality of sex. The fact that we now allow for several intermediate sexes or genders can in the long run only be cold comfort, as even a smorgasbord of intermediate sexes or genders will inevitably result in difficulties for people who still fall somehow in-between the several intermediate forms. The problem was never merely that there were only two sexes, although that certainly was a huge issue in itself. The real problem is the very existence of categories itself because this implies that within any given individual at least some gender or sex must be; and that means: some defined sex or gender that fits an established category, even an intermediate one. In 
other words, giving up on the sexual binaries (male/female, gay/straight, human/nonhuman) may be liberating up to a point, allowing for a number of shades in-between the polar opposites (such as intersex, transsexual, and transgender), but in the end it does sponsor the production of new categories, which will inevitably have new exclusionary effects (such as transphobia). These may then perhaps be remedied with the introduction of yet another category or categories, but surely at some point we should realise that the sensible thing to do is simply to give up on categories altogether. Anyone who takes the long view can see that expanding the repertoire of "male" and "female" boxes to tick on official forms with a new box for a third or intermediate sex simply begs the question. Why should people be sexed or gendered or sexually oriented at all if they could also just be sensual, or erotic, and respond to the moment? This would be the Paterian ideal of human life as a constant flow of ever-changing impressions and our responses to them.

Who we are, should not be our gender, our sex, our race, or any other feature or combination of features. We are a constantly changing cluster of experiences that cannot be defined in any way at any moment except as change. This logic also extends to race, which has de facto ceased to exist. As individuals from different races amalgamate and their mixed offspring in turn amalgamates with other mixed offspring, race goes out the window. All human blood is mixed, and it has been so for many a century. In the United States the one-drop rule says that anyone who has one drop of black blood in their family tree is, in the final reckoning, black. But if you turn the logic around and call anyone with at least one drop of white blood in their lineage white, you would probably find that there is no such thing as a black American. As the races continue to mingle in the globalised world they will simply cease to exist because the gene-pool gradually becomes a global ocean of absolute difference. And that, again, is why all categories must go. In the real world there are only individual people with absolutely individual identities that no category can grasp except by doing deep and cruel violence to the person. Accepting individuality and giving up on categories will not lead to conceptual or practical chaos, nor will it render critical reflection impossible. It will simply make us human. It is such a world, where humans meet humans in whatever guise they desire, that is held out as the promise of the baroque, of aestheticism, and of the philosophy of montage as a way of life. As ideologies fall into disrepute (none too soon) it is to bricolage that we will need to turn if we want to re-build a human world on a small but beautiful scale. We cannot know where the mighty river of history will take us, but we can map its past trajectories and learn from its record. The future can be made. To embrace possibility and change is to take the baroque approach to life. 
A PERSONAL NOTE 

Ken Russell's film Gothic (1986) changed my life. It is the earliest memory I have of watching a film that seemed to have been made especially for me. I was a young teenager at the time. I had videotaped the film from television and I watched it very regularly. I know it almost by heart now. For better or worse, Gothic in many ways determined what I thought film could be. Other films that I saw at the time and which also helped form my idea of cinema were John Boorman's Excalibur (1981), Peter Greenaway's The Cook, the Thief, His Wife, and Her Lover (1989), Rainer Werner Fassbinder's Martha (1973), and Paul Schrader's The Comfort of Strangers (1990), a film that really gave me the feeling I was watching something I shouldn't be watching. But Gothic is the film that marked the beginning of my conscious engagement with cinema as an art form and as something that would take a central place in my life. When I began to trawl the shelves of a second-hand bookshop in Bruges on weekly expeditions I was very excited to find a copy of Alexander Bland's book on Valentino and also a set of John Wakeman's World Film Directors. The discussions of Russell in those two books for a long time were my main sources of information on the director. Later, in the last two years of high school, we had a weekly one-hour aesthetics course for which we were required to write a final essay rather than make an exam. In the first year I wrote on Tchaikovsky's ballets, in the second year I produced a rather large paper on Ken Russell. That was twenty years ago, and since then I have never stopped thinking that, one day, I should write a book on Ken Russell. And now I have.

I want to thank my wonderful supervisors for their enthusiasm, their open minds, and their steadfast forbearance in the face of avalanches of chapters being thrown at them at what must have seemed, at times, an alarming rate. Maaike Meijer is the best promotor one could hope for: she intuitively felt where I wanted to go with this really strange idea about a crazy film-maker who, I alleged (following some of his own statements), made his self-portrait, and even created himself, by making films about other artists. Her boundless enthusiasm and welcoming attitude towards anything that breaks the mould of the safely predictable was very stimulating and deeply encouraging. I was once introduced, at a conference, as 'someone from the school of Maaike Meijer'. When I told her about that in an e-mail Maaike wrote back, amused, that she wasn't aware of having founded any schools. But if she had, I would be proud to enroll. I already knew Karel Vanhaesebrouck from the days of working together on the journal rekto:verso (that's how long he's been having to read what I write) and it was really great to be teaming up again, especially because he knows how to deal with gung-ho baroque theatricality. Jack 
Post always catches you in the detail and has constantly urged me to be precise where I was inclined to be sweeping. He also has a knack for knowing what book you will need to read two months from now and finds things on the internet you never even knew existed (and not in a naughty way). Together, they made valiant attempts to curb my most baroque excesses. They also demanded that I be rigorous and meticulous in every detail. They also gently but firmly pointed out, when necessary, that what I mistook for a sub-chapter was actually another book. As was that other sub-chapter over there. And that one, too.

There is much talk these days of thinking "out of the box". Everybody's doing it. Which probably means that it has ceased to mean anything. But with Maaike, Karel, and Jack it is really possible to do so in a significant way, and we had a lot of fun, but also a lot of hard intellectual work, tearing that box to pieces. It was a pleasure and a privilege to have three supervisors who were willing to help me write the book that I needed to write.

Now the terrifying part begins, which is the part where, despite all your best intentions in expressing gratitude, you might overlook someone significant. First and foremost, then, I want to thank my colleagues of the AMC (Arts Media and Culture) research group and the Literature and Arts cap-group at the Faculty of Arts and Social Sciences at Maastricht University, and especially Renée van de Vall for sharing my enthusiasm for Susanne Langer. A very big hug to Ana Menéndez for a meeting of the minds and for being a very cool person. I also learned a lot from the seminars of the Media and Aesthetics group. But I especially want to thank (in an alphabetical manner) my wonderful colleagues from the Centre for Gender and Diversity, which has become a real intellectual home for me over these past four years. The group has had its transient members over the years, but I want to mention Agnes Andeweg, Annette de Bruijn, Ulrike Brunotte (who shares my fascination with Salomé and has generously shared her knowledge about that mythical princess of ill repute), Louis van den Hengel, Codruta Pohrib, Eliza Steinbock, and Aagje Swinnen (the only person ever to acknowledge my scholarly smurf!). I especially want to thank Lies Wesseling, the Centre's director, for her unstinting support, her interest in and enthusiasm for my work (far beyond what is in these pages), and, not the least of virtues, her wonderful sense of humour. A big thanks also to the boys and girls of the office: Melissa Van Drie (good times, great talks, fond memories), Anna Harris (more of the above), Stefan Krebs (who once, in the parking lot of the Faculty, very cleverly connected the battery of my car to that of his own, which had gone 
flat, and revived it!), Ties van de Werff, and especially Lotte Thissen, who is my exact contemporary: we started on the same day and even had our intake moment at Human Resources together. I vividly remember that sweltering hot and brilliantly sunny late August day in 2011 when we sweated it out on the Berg, not quite knowing what exactly we were in for. Turned out we shared an office, many a worry, and many a joke. Beyond the office I should not forget to mention Tim van der Heijden, who also provided me with an important article, and Rafael Bienia.

Many people have helped me by reading and commenting on my work or in other small and less small ways. I want to thank Mel Kohlke and Christian Gutleben for their helpful comments and for their interest in my work (and many thanks to Lies Wesseling for introducing me to them during a very pleasurable seminar and lunch). Very special thanks are due to all the participants of the Imagining the Past conference (Brussels, 1920 March 2014) that I co-organised with Karel Vanhaesebrouck and Muriel Andrin: Roger Crittenden, Kevin M. Flanagan, John Hill, Sandra Kisters, Maaike Meijer, Matt Melia, Jack Post, Jamie Sexton, Paul Sutton, Lisi Tribble, Pascal Vandelanoitte, and John Wyver. They have helped to deepen my understanding of Russell's work. Dirk Van Extergem very generously took our conference under the wing of his OffScreen Film Festival and organised a big Russell retrospective around it. He also made it possible to show the reconstructed director's cut of The Devils on opening night, which was a tremendous treat in itself. I also want to express my gratitude to John Hill for his generosity in suggesting that we create a special issue of the Journal of British Cinema and Television from the conference (and thanks to chief editor Julian Petley for welcoming that idea) and for commenting on several pieces of my writing. Special thanks also to Paul Sutton and Kevin Flanagan for sharing difficult-to-find recordings of Russell's television work. Paul also provided me with a copy of Russell's treatment for Gargantua. Lisi Tribble generously entrusted me with copies of Russell's late Gorsewood films and gave our conference Russell's blessing.

Sometimes you need a break, and taking long walks in nature is a great escape. I have taken much comfort from the beauty and quiet of our garden, which Kris has created over the four years that he suffered the presence of this book in our new home. I can sit and stare at foraging bees endlessly and am seriously contemplating becoming an entomologist. I like bees, butterflies, and beetles best (and dragonflies, of course). Living next to expansive orchards also means you get to see kestrels swooping down into the garden and get visits from fantastically coloured birds, although there is one particular multi- 


\section{A PERSONAL NOTE}

coloured woodpecker that had better keep away from my saxifraga! For much-needed spiritual sustenance and regeneration I would also like to thank Shirley Bassey, Madonna, Miranda, Karen Walker, "ons Nancy", dark red wine, the cast of Dynasty, Samantha Jones, Grace Jones, Doris Day, Nigella, Will and Grace, more dark red wine (and more Shirley Bassey, louder this time), Justin Timberlake, Judy Garland, Coil, Kate Bush, Current93, Rufus Wainwright, Siouxsie Sioux, Boudewijn de Groot, The Great British Bake-Off, Ramses Shaffy, Mary Servaes, and Ann Christy. And the supreme baroque of Army of Lovers, of course. When I need an adrenaline shot rather than sustenance, I turn to Camille Paglia. I have always admired Paglia for her pointed and incisive literary criticism and as a prominent (and loud) voice speaking up against the usurpation of the humanities by trendy theory and the neo-liberal corporate ideology of bureaucratic professionalisation. When in doubt, I read Paglia.

I also want to thank my battered and time-worn PC for not crashing or breaking down in the course of the long process of writing this book, which was composed in Word95 (it does not recognise 'internet' as an English word) and, to a considerable extent, in longhand. You remember longhand, don't you?

Last, but not least, I want to thank Andreas Fickers for believing that we also need crazy projects. I hope he will like my misreading of Russell.

This book is for Kris, who was at Versailles with me. 
REFERENCES AND

ACKNOWLEDGEMENTS 

I have introduced a limited number of abbreviations for works that are referred to throughout the book or extensively within one section of it (see the Bibliography for full references):

AT John Baxter, An Appalling Talent (Baxter 1973)

BP $\quad$ Ken Russell, A British Picture (Russell 2008)

CW Oscar Wilde, The Complete Works of Oscar Wilde (Wilde 2003)

FF Susanne K. Langer, Feeling and Form (Langer 1973)

WS Oscar Wilde, Salomé (Wilde 2006)

I use single inverted commas (') for direct quotes from other texts and double inverted commas ("') for quotes-within-quotes and all other uses (including the use of quotation marks as a shorthand for "what-so-and-so-means-with").

All images from Russell's films are the author's own screen-shots and are used here in the spirit of fair dealing.

Inevitably, some of the content of this book has found its way into other publications and I would like to acknowledge these here. Part of the argument of Chapter Two will be published as 'Staging the World: The Devils as theatrum mundi' (Van Eecke 2015) in a special Russell issue of the Journal of British Cinema and Television (Volume 12, Issue 4) that I co-edited with John Hill and Karel Vanhaesebrouck. Some of the material from my Introduction has also found its way into the co-authored Introduction to that special issue (Van Eecke, Hill, and Vanhaesebrouck 2015). Part of Chapter Three was previously published, in somewhat different form, as 'Refusing to Lie Down: Truth, Fiction, and Ken Russell's Early Television Documentaries' in the first issue of Photogénie (Van Eecke 2013). The section of Chapter Four dealing with Salome's Last Dance was previously published, in considerably different form, as 'Moonstruck Follies: Ken Russell's Salome's Last Dance as Baroque Performance' in Image and Narrative (Vol. 13, No. 2; Van Eecke 2012). 

SAMENVATTING

(Dutch summary) 

Dit boek is een onderzoek naar een bijzondere vorm van zelfrepresentatie: het creëren van een (publiek) zelf doorheen kunstwerken. Het onderwerp van het onderzoek is de Britse filmmaker Ken Russell (1927-2011), die vooral bekend is voor een uitgebreide reeks biografische films over het leven van kunstenaars, hoofdzakelijk componisten. Russell beweerde echter dat die films eigenlijk een soort zelfportret waren. Bovendien waren zijn films bijzonder eigenzinnig opgebouwd: Russell geloofde niet in de traditionele, feitelijke biografie maar probeerde de kunstenaar weer te geven zoals die in zijn muziek naar voor kwam. Volgens Russell kan je de persoon van de kunstenaar namelijk het best leren kennen doorheen zijn werk, en niet via conventionele biografische feiten. Dat betekent dat Russell een subjectieve interpretatie geeft van het leven van de kunstenaar op basis van zijn eigen beleving van diens werk. De conclusie die hieruit volgt, is dat Russells films toch vooral over Russell zelf gaan. Maar als we zijn eigen logica doortrekken, namelijk dat je een kunstenaar best leert kennen doorheen zijn werk, dan zijn die films uiteraard meteen ook een vorm van zelf-representatie van Russell. In dit boek onderzoek ik hoe Russell er precies toe komt om zichzelf te creëren doorheen zijn kunst.

De hypothese die ten grondslag ligt aan het onderzoek is dat Russell een barok kunstenaar is en dat zijn benadering van biografie en zelfcreatie, namelijk het creëren van een zelf doorheen kunst, een typisch barok fenomeen is. Daarmee begeeft dit onderzoek zich in het domein van de neo-barok, een academisch discours in de humane wetenschappen dat eigentijdse cultuuruitingen, met name in de populaire cultuur zoals de film, begrijpt als een terugkeer van of een teruggrijpen naar de barok, de cultuurperiode die grotendeels samenvalt met de zeventiende eeuw. Daarvoor wordt vaak verwezen naar de spektakel-elementen in de huidige cultuurproductie. Het interessante is dat Russell zelf ook vaak een barok filmmaker is genoemd op basis van zijn extravagante stijl. Ik argumenteer echter dat de narratieve structuur van zijn films eveneens ontleend is aan de historische barok en dat die structuur op zich een veel interessanter barok element is dan zijn extravagante signatuur. Ik toon dit aan door na te gaan welke mentaliteit in die barokke narratieve structuren tot uiting kwam (in de zeventiende eeuw) en vervolgens te tonen dat gelijkaardige bekommernissen Russells gebruik van die structuren motiveren. Wat de historische barok en Russell delen, is een gebruik van theatraliteit en kunst om een zelf en een gedeelde wereld te creëren. Vanuit die invalshoek wordt het veel interessanter en onthullender om zowel naar Russell als naar onze eigentijdse cultuur te kijken als barok. Bovendien wordt het onderzoek op die manier ook een bijdrage aan de discipline van life writing (het bestudeert een weinig bekende en weinig onderzochte manier om het zelf te creëren, namelijk doorheen kunst) en aan de studie van performativiteit (het creëren van identiteit door herhaalde handeling). 
Het eerste hoofdstuk biedt een nauwgezette analyse van Russells narratieve structuren en argumenteert dat zijn hele oeuvre gekenmerkt is door een systematisch gebruik van het theater-in-het-theater (of de film-in-de-film en andere varianten), en vooral ook van de mise-en-abyme, een theater-in-het-theater dat terugreflecteert op het kaderverhaal. Ik toon dit aan door een analyse van de structuur van Russells autobiografie naast een analyse van zijn film Mahler (1974) te plaatsen. Vervolgens analyseer ik ook een aantal zeventiende-eeuwse theaterteksten, met name van Molière en Corneille, om aan te tonen dat dezelfde structuren daar ook al werden gebruikt en, wat belangrijker is, voor dezelfde doeleinden, namelijk een reflectie over wat het zelf is. Het hoofdstuk eindigt met een bespreking van de barokke trope van het theater van de wereld, die de idee vertolkt dat het gehele menselijke samenleven een vorm van theater is. Die gedacht wordt verder ontwikkeld in hoofdstuk twee, waarin ik een close reading bied van Russells film The Devils (1971), die volledig als een theatrum mundi is opgebouwd en in die zin duidelijk maakt hoe de wereld precies als een theater kan worden opgevat. Op die manier bieden hoofdstukken één en twee samen een overzicht van de basis van Russells creatie van zichzelf doorheen kunst: de structurele elementen van zijn werk worden geanalyseerd op een manier die duidelijk maakt hoe ze verbonden zijn met de idee van kunst als een medium om het zelf (en de wereld) vorm te geven.

In het derde en vierde hoofdstuk worden deze inzichten toegepast op Russells eigen performance van zichzelf doorheen zijn werk. Het derde hoofdstuk gaat na hoe Russells ideeën over het zelf en de kunst vorm kregen binnen de context van de BBC in de jaren 1960, toen hij daar werkte als regisseur van documentaires over kunstenaars. Ik toon aan dat we een geleidelijke verschuiving kunnen zien naar een steeds subjectievere methode in Russells werk, en dat zijn eigen ideeën over hoe kunst werkt steeds meer gestalte krijgen in de manier waarop hij zijn eigen films maakt. Dat is het performatieve element in Russell: hij doet wat hij zegt. In het vierde hoofdstuk wordt dit inzicht verder uitgespit door heel precies te gaan kijken naar het soort kunstenaar dat Russell wil zijn. Ik toon aan dat hij zichzelf presenteert als een romantisch genie. Met een uitgebreide analyse van de film Gothic (1986) wordt tenslotte aangetoond dat die performance van zichzelf als genie zich vooral articuleert in de manier waarop de film in elkaar is gezet. Met name de rol van montage (in de zin van Eisenstein) is cruciaal om aan te tonen hoe Russells films zijn rol als romantisch kunstenaar verpersoonlijken door te doen wat hij zegt. Ik toon namelijk aan dat de principes van montage parallel lopen aan de principes van de romantische poetica zoals we die vinden bij Wordsworth, die een zeer belangrijke inspiratiebron was voor Russell.

Het boek sluit af met een essay over het zelf in barokke tijden en brengt de draden van het onderzoek samen. Het herneemt hoe Russell zichzelf doorheen kunst represen- 
teert en bekijkt een aantal implicaties van dat inzicht voor de studie van het barokke, life writing, en performance en performativiteit. 

CURRICULUM VITAE 

Christophe Van Eecke $\left({ }^{\circ} 1977\right)$ is a philosopher and writer. He obtained his Master in Philosophy from the Katholieke Universiteit Leuven (Belgium) with a thesis on the place of the body in Schillers aesthetic theory (2000). Subsequently he also obtained a Bachelor in Art History (2001) from the same university.

For the past ten years Christophe has worked as a critic and has published numerous essays on film, art, and philosophy in the journals rekto:verso, Cinemagie, Metropolis $M$, and Streven. He has also contributed catalogue texts for exhibitions and monographs. From 2009 until 2011 he was "philosopher in residence" at the exhibition space Lokaal 01 in Breda (The Netherlands). One of the outcomes of his work there was the publication of his book Only Connect: Five Exercises in Aesthetics (2011), in which he engages the work of Susanne K. Langer in the philosophy of art.

Christophe has worked for several years as a teacher and was also a lecturer for Amarant (Ghent, Belgium), an adult education programme for which he developed courses in philosophy and art for interested lay audiences. In this capacity he has lectured widely. Since September 2011 he has been employed by Maastricht University, first as a doctoral candidate working on the performance of self of Ken Russell and now as a Teaching Assistant.

Email contact: christophe.vaneecke@maastrichtuniversity.nl

Personal website: www.christophevaneecke.be 
Ken Russell (1927-2011) was a renegade talent and the self-styled enfant terrible of British cinema. His legacy as a film-maker consists of a large number of films on the lives of artists, mainly composers. But Russell's approach to artist biography was highly unorthodox: rather than reconstruct a factual account he offered a deeply personal interpretation of artists' lives based on his own understanding of their work. In a programmatic text for his film on Mahler (1974), Russell explained that his films 'evolve through a stream of consciousness in which the man and the myth, the music and its meaning, time, place, dream and fact all flow and blend into the mainstream of the film itself' and that 'my film is simply about some of the things I feel when I think of Mahler's life and listen to his music'.

This book is an attempt to explain what that statement means and to unpack its implications for the practice of life writing. It takes a baroque approach to performance and performativity to show how Russell not simply made highly inventive films on other artists, but also constructed those films as a kind of self-portrait. Russell's work then becomes a performance of self through art. In four chapters of detailed analysis this book reconstructs Russell's method, from the very first films he made for the BBC in the early 1960s through his major feature films of the 1970s and 1980s. 